\title{
Key Contributors to Business Insolvencies and the Effects of Business Insolvencies to the Entrepreneurs
}

\author{
An Analysis of 12 Insolvency Cases in Bavaria, Germany
}

Christina Margit Wermescher

The thesis was submitted to the University of Gloucestershire in accordance with the requirements of the degree of Doctor of Philosophy $(\mathrm{PhD})$ in the Business School.

March 2019

Word Count: 58,878 
Abstract

Based on the existing management literature, this study aims to fill the identified gaps within the current knowledge in the field of insolvencies. The research aims to contribute to this current knowledge by gaining deeper understanding of the key contributors to insolvencies considering a broad time frame and the entrepreneurs' personality. Furthermore, the study aims to evaluate the effects that the entrepreneurs experience through an insolvency in a comprehensive way.

The participants were 12 former CEOs and owners of small and medium-sized enterprises (SMEs) that became insolvent. With those 12 participants, narrative interviews were conducted. Additionally, the 12 participants administered the NEOFFI questionnaire to examine the possible influence of their personality traits on the key contributors identified in the narrative interviews.

The research identified a number of key contributors to their insolvencies. These were poor leadership, lack of knowledge and experience, overconfidence, inappropriate or risky contract design, and insufficient funds. These key contributors were the responsibility of the CEOs. Other key contributors, like influences of market dynamics and the loss of customers, in the reviewed cases predominantly lay outside the CEOs' control, but their handling of these situations was based on their experience, knowledge, skills and personality.

The following outcomes of the insolvency processes were predominantly experienced in a similar way by the participants: they had to deal with the experience of failing and its stigmatisation, suffered the loss of image and influence, faced poverty and daily life problems and had to undergo the poor perspective of the future due to unemployment and the long good conduct phase. However, the reactions of the environment, the effects on their own person and health as well as positive aspects were experienced in very different ways.

In reactions of the environment there seemed to be the tendency that the close environment (family) was supportive, but going further outside to friends, acquaintances and others, more and more negative reactions were reported. For all participants the insolvency was a time of personal trauma and three participants even had to face serious illnesses. 
Asking the participants if they feel like they have changed through the insolvency, their responses varied. While some felt discouraged, with less energy or more mistrust, others saw their change more positively and felt calmer and as a more likeable person. The analysis of the average NEO-FFI values of the participants was conducted by a ttest using IBM SPSS Statistics 23.0. This t-test showed high significance $(<0,05)$ for neuroticism with $\mathrm{p}(\mathrm{N})=0,000$, extroversion with $\mathrm{p}(\mathrm{E})=0,007$ and conscientiousness $\mathrm{p}(\mathrm{C})=0,000$.

Examining the values of the single cases, just two of the twelve NEO-FFI profiles showed the values of all five dimensions: neuroticism, extroversion, openness, agreeableness and conscientiousness, within the standard range. Within the analysis of the single cases, the test values, that were differing more than two standard deviations from the values of the normative comparison groups, were triangulated with the interview data of the same participants. This showed significantly high values of extroversion as a possible supporter of the key contributors, especially of risky decisions and insufficient funds. 
Author's Declaration

I declare that the work in this thesis was carried out in accordance with the regulations of the University of Gloucestershire and is original except where indicated by specific reference in the text.

No part of the thesis has been submitted as part of any other academic award. The thesis has not been presented to any other education institution in the United Kingdom or overseas.

Any views expressed in the thesis are those of the author and in no way represent those of the University.

Signed

Date 15 March 2019

DOI:10.46289/WERM2793 


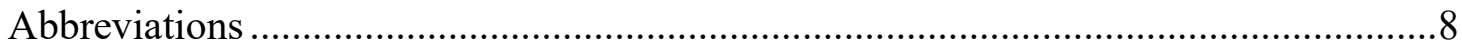

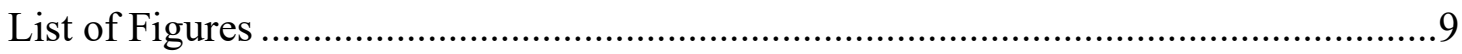

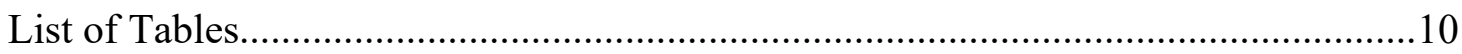

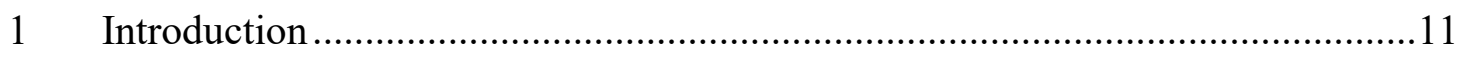

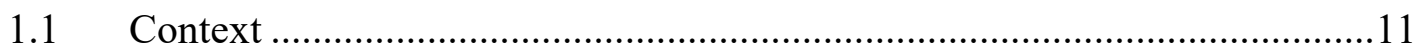

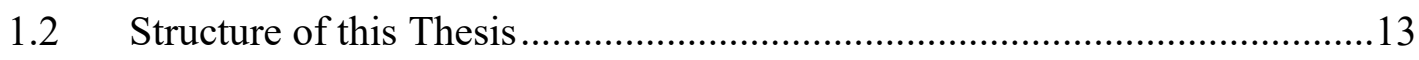

2 Legal Background: German Insolvency Law ..................................................15

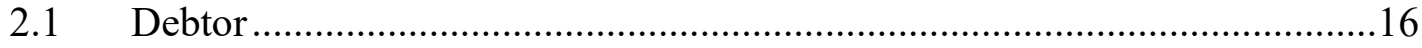

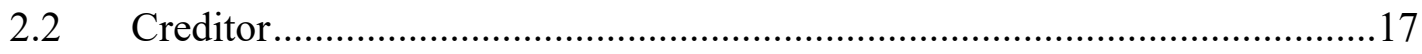

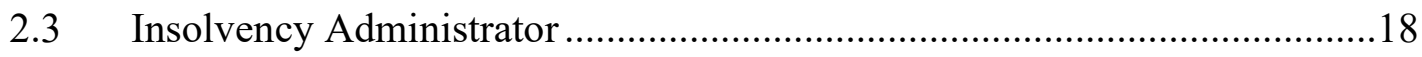

$2.4 \quad$ Objectives and Personal Activators ........................................................... 19

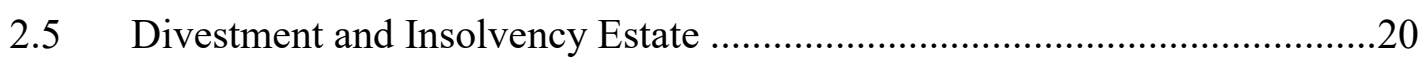

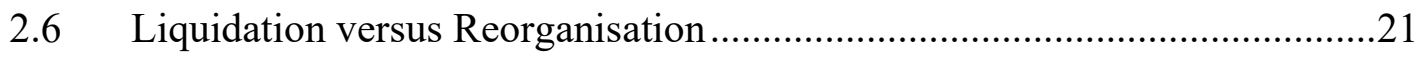

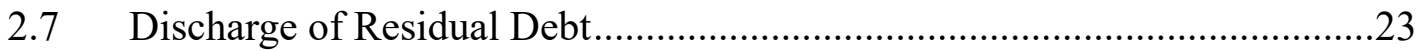

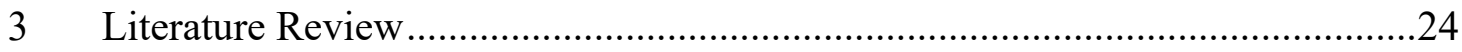

3.1 Narrative versus Systematic Literature Review ........................................24

3.2 Literature Review on Key Contributors to Insolvencies and the Effects of

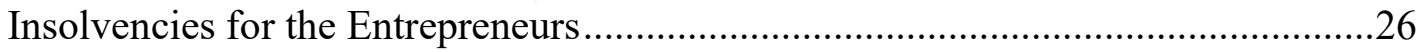

3.2.1 Literature Review on Key Contributors to Insolvencies.......................26

3.2.2 Literature Review on Effects of Insolvencies for the Entrepreneurs .....41

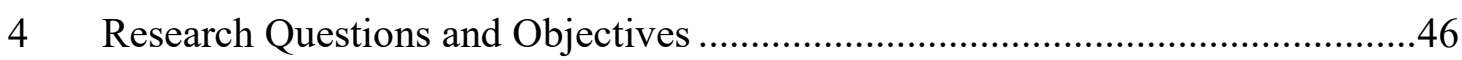

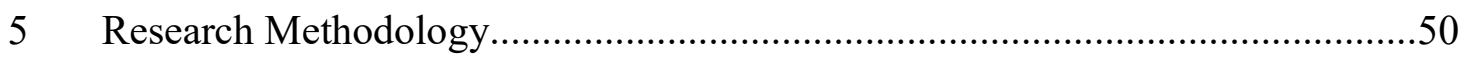

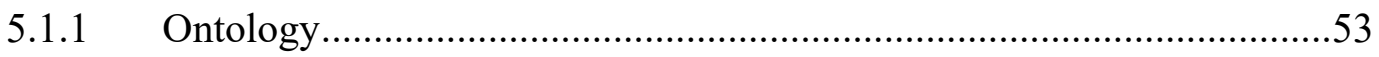

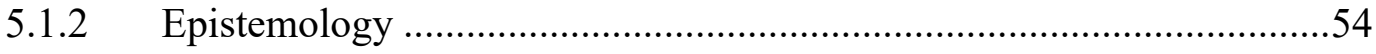

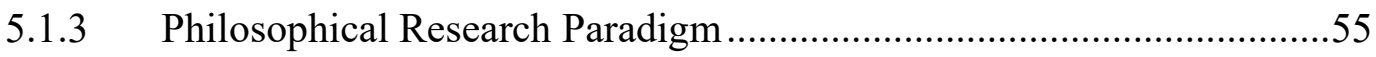

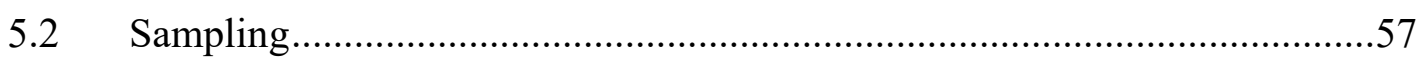

5.3 Qualitative Research.......................................................................63

5.3.1 Choice of Qualitative Research Method .............................................64

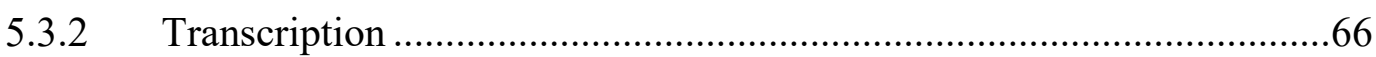

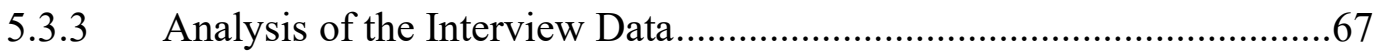

5.3.4 Quality of Qualitative Research ..........................................................

5.3.5. Quantitative Aspects in Qualitative Research......................................75

5.4 Quantitative Approach as Additional Method...............................................77

5.4.1 Choice of Quantitative Research Method .............................................77 
5.4.2 Quality of the NEO-FFI questionnaire ...............................................79

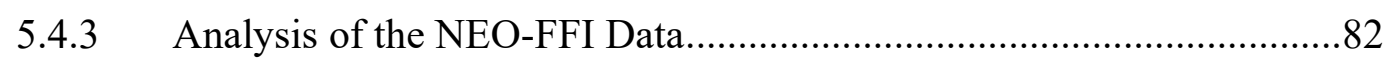

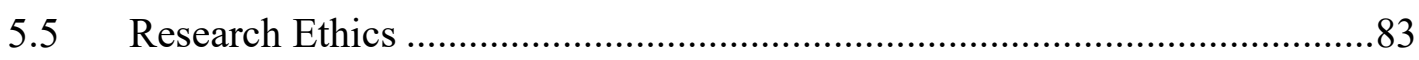

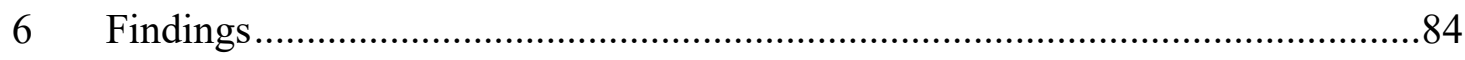

6.1 Key Contributors to the Insolvencies in the Reviewed Cases ......................8 84

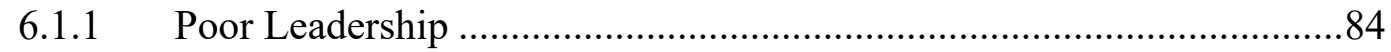

6.1.2 Lack of Knowledge and Experience ................................................92

6.1.3 Overconfidence and Overestimation of own Capabilities .....................96

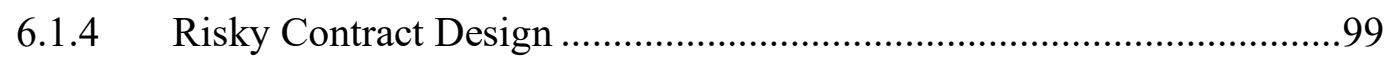

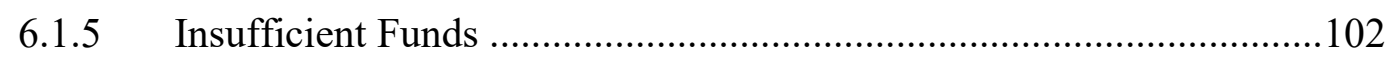

6.1.6 Market Crisis/ Loss of Customers....................................................110

6.2 Personality Traits of the Participants (NEO-FFI) ......................................113

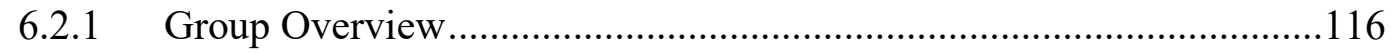

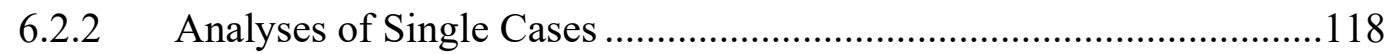

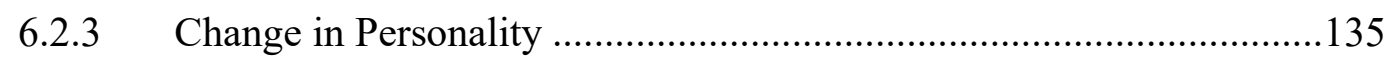

6.3 Effects of the Insolvencies experienced by the Participants ......................137

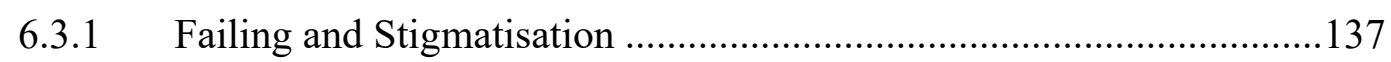

6.3.2 Loss of Social Status and Influence .................................................... 141

6.3.3 Reactions of Family, Friends and Others ............................................145

6.3.4 Poverty and Daily Life Problems .......................................................149

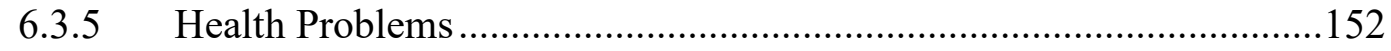

6.3.6 Poor Perspective for the Future ....................................................... 156

6.3.7 Change of the Person ......................................................................164

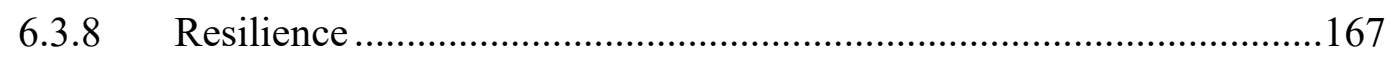

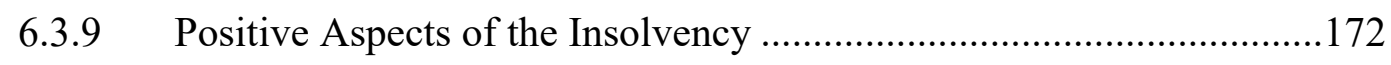

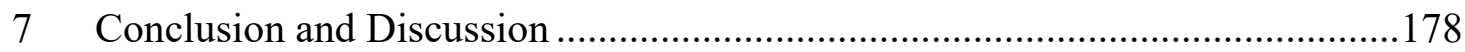

7.1 Conclusion and Discussion of the Identified Key Contributors....................179

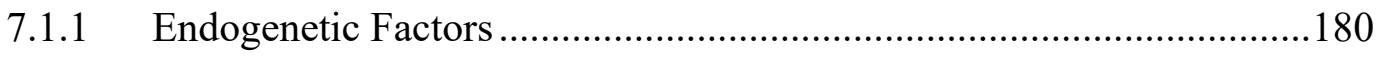

7.1.2. Exogenetic Factors Uncovered Internal Risks ...................................180

7.1.3 Overconfidence as Supporter of Identified Key Contributors ...............182

7.2 Conclusion and Discussion of the NEO-FFI Findings ................................ 184

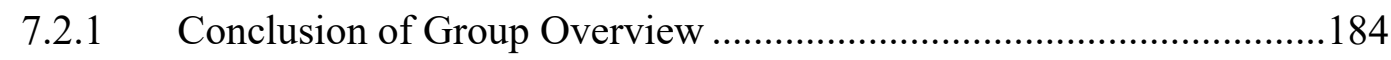

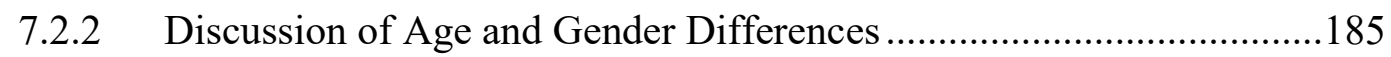

7.2.3 High Level of Extroversion............................................................. 186

7.2.4 High Level of Conscientiousness ................................................... 188

7.3 Conclusion and Discussion of the Insolvencies' Effects............................189 


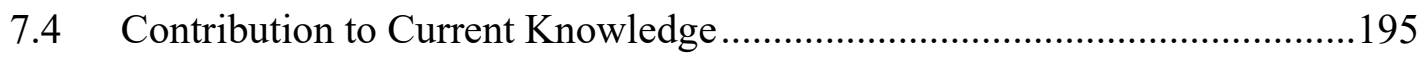

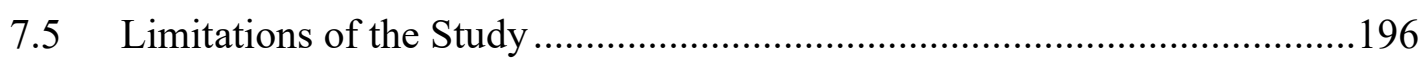

7.6 Suggestions for Further Research.........................................................198

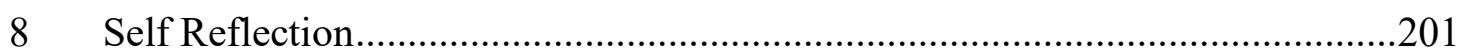

8.1 Why I Wanted to do a Doctorate ..............................................................202

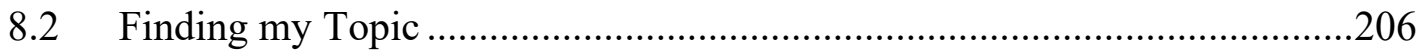

8.3 The Fear of not Finding (enough) Participants ............................................208

8.4 The Role of the Interviewer....................................................................209

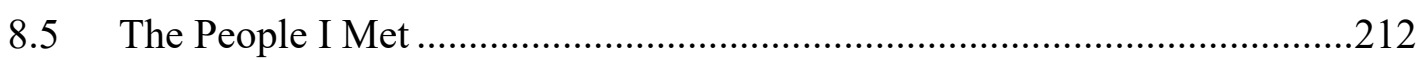

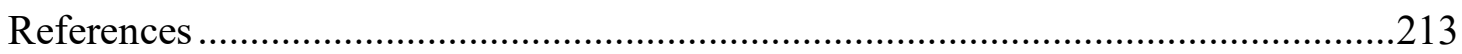

Appendix I: Further Information about Approach and Quality of the NEO-FFI........227

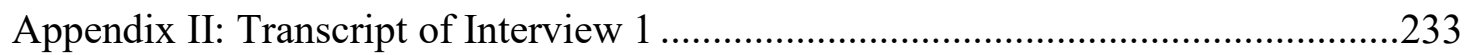

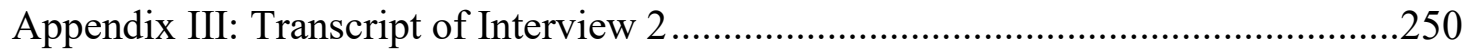

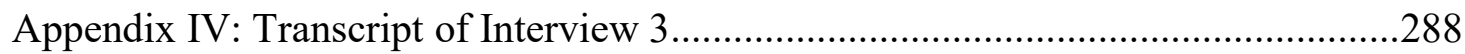

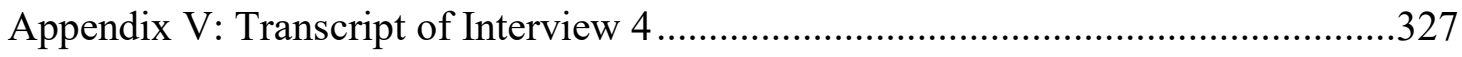

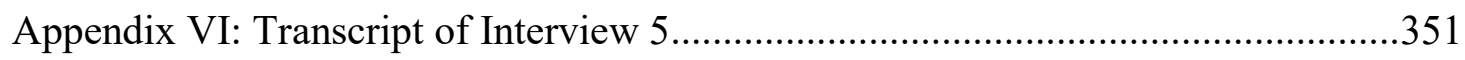

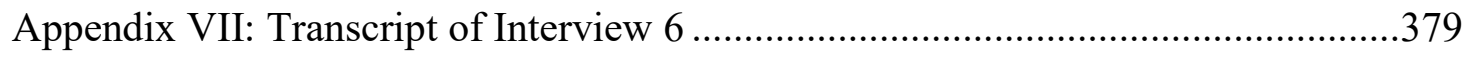

Appendix VIII: Transcript of Interview 7 .........................................................4 415

Appendix IX: Transcript of Interview 8 ..............................................................434

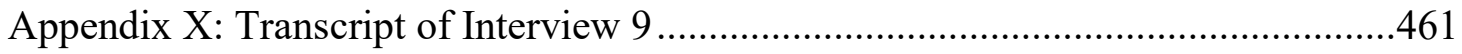

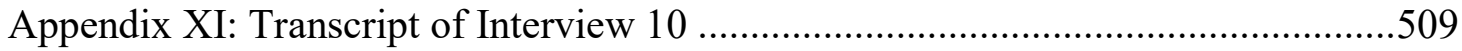

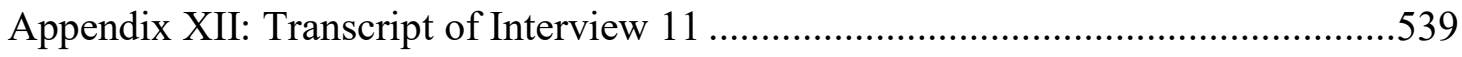

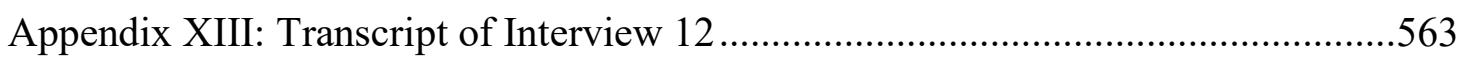


Abbreviations

\begin{tabular}{|c|c|}
\hline BGB & German Civil Code (Bundesgesetzbuch) \\
\hline $\mathrm{CEO}$ & Chief Executive Officer \\
\hline DBA & Doctor of Business Administration \\
\hline EI & emotional intelligence \\
\hline \multirow[t]{2}{*}{ ESUG } & Law to Faciliate the Reorganisation of Enterprises \\
\hline & (Gesetz zur weiteren Erleichterung zur Sanierung von Unternehmen) \\
\hline $\mathrm{GmbH}$ & Private Limited Company (Gesellschaften mit beschränkter Haftung) \\
\hline \multirow[t]{2}{*}{$\mathrm{GmbHG}$} & Law for Private Limited Companies \\
\hline & (Gesetz betreffend die Gesellschaften mit beschränkter Haftung) \\
\hline InsO & Insolvency Code (Insolvenzordnung) \\
\hline NEO-FFI & Neuroticism Extroversion Openness-Five Factor Inventory \\
\hline NEO-PI-R & Revised NEO Personality Inventory \\
\hline NLSY & National Longitudinal Survey of Youth \\
\hline $\mathrm{PhD}$ & Doctor of Philosophy \\
\hline QPM & Quality and Process Management \\
\hline RQ & Research Question \\
\hline \multirow[t]{2}{*}{ SGB II } & Second Germain Code of Social Law \\
\hline & (Sozialgesetzbuch, zweites Buch) \\
\hline SMEs & Small and Medium-Sized Enterprises \\
\hline StGB & Penal Code (Strafgesetzbuch) \\
\hline WHO & World Health Organization \\
\hline $\mathrm{ZPO}$ & Civil Process Order (Zivilprozessordnung) \\
\hline
\end{tabular}


List of Figures

Figure 1: Development of research questions based on literature review 48

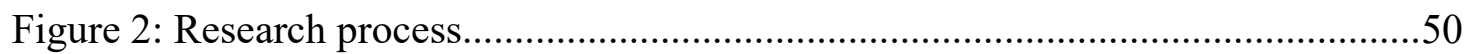

Figure 3: Code tree of key contributors to the reviewed insolvencies .........................70

Figure 4: Code tree of effects of the insolvencies experienced by the participants ......71

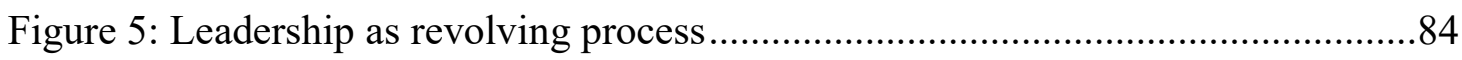

Figure 6: Management of employees as essential part of the steering task ..................85

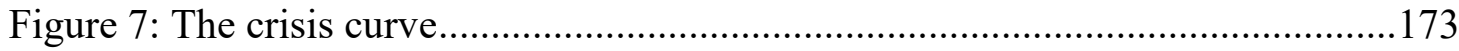

Figure 8: Identified key contributors and their frequency of occurrence in the reviewed

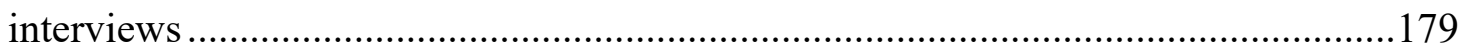

Figure 9: Overconfidence as supporter of identified key contributors .......................182

Figure 10: Extroversion as supporter of identified key contributors ..........................187

Figure 9: Balance of education and professional experience....................................203

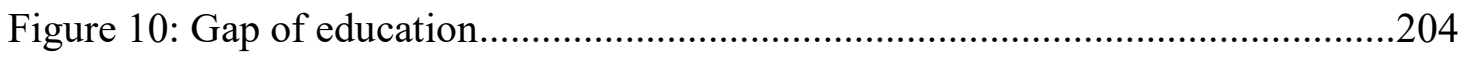

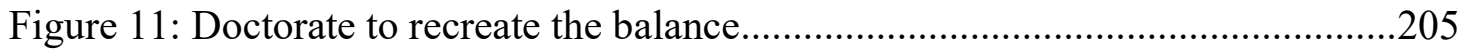


List of Tables

Table 1: Average NEO-FFI values of group of participants compared to the average

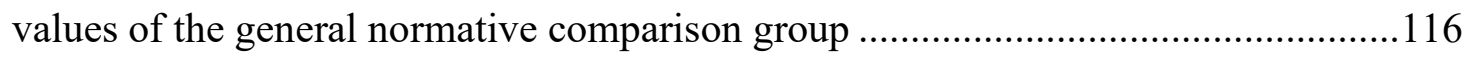

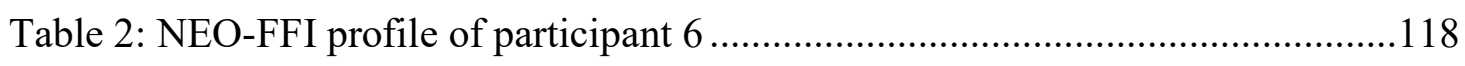

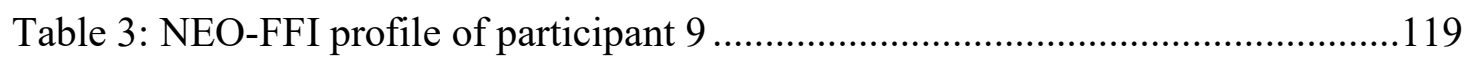

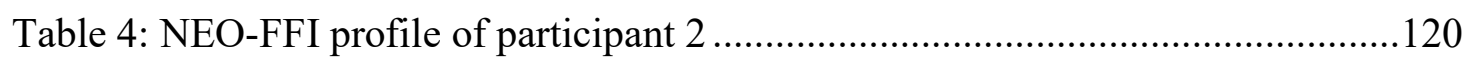

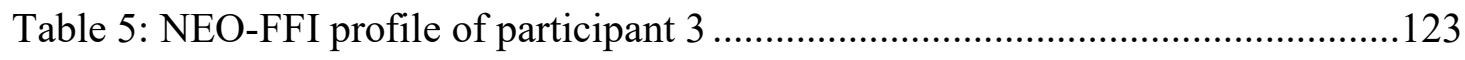

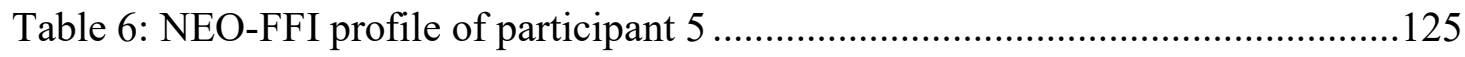

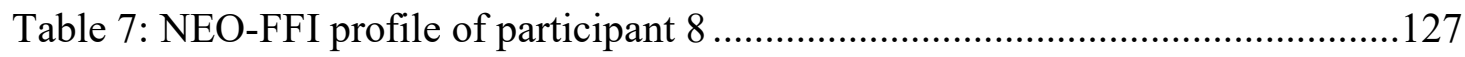

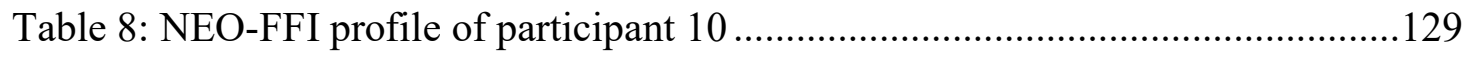

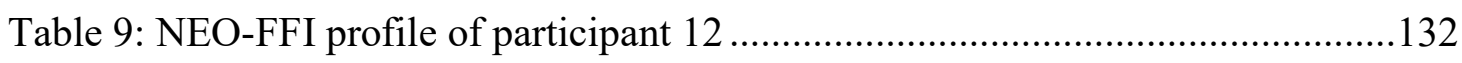




\subsection{Context}

Insolvencies of big German companies have always aroused the public interest. In the year 2012 the chemist's shop chain, Schlecker, had to file for insolvency and about 36.000 people lost their jobs (Koenen, 2017). The case was reported extensively in the media as well as other big company bankruptcies for example the do-it-yourself store chain, Praktiker, one year later (Mielke \& Matern, 2013).

The latest media attraction within this field was the insolvency of Air Berlin in the year 2017. Air Berlin was the second largest German airline, although the number of concerned employees here at about 8.000 was much lower than it was in the Schlecker case (Koenen, 2017).

However, the financial damage was immense. When Air Berlin shut down its usual air traffic in October 2017, it became public that since the stock market launch in 2006 the company had incured a loss of about 25 million euros per month. Over time this made a deficit of about three billion euros and there were further outstanding debts. Although already half a year before filing for insolvency the end was obvious there was just enough money left for the insolvency proceedings, but the creditors had to go away empty-handed (Hegmann, 2018).

In addition to such famous and spectacular cases there happen many little company bankruptcies every year that are not highlighted in the media. Luckily the number of insolvencies is decreasing. The reasons for this decrease are seen in the continuous economic growth. The gross domestic product is growing and especially the domestic demand shows an ongoing positive development (Creditreform, 2017).

In the year 2017 the number of insolvencies reached its minimum since 2003. In total, there were $5.4 \%$ insolvencies fewer than in the year before. The number of business bankruptcies decreased by $6.3 \%$, customer insolvencies by $6.7 \%$ and bankruptcy of deceaseds' estates stayed on a more or less constant level with a decline of $0.3 \%$ (Creditreform, 2017).

This is a positive development, but reviewing the real figures, there were still 116,000 insolvencies in Germany in 2017, 20,200 of which were business insolvencies. 
While the number of business insolvencies went down, their financial damage stayed similar to the previous year's level with 26.6 billion Euros (Creditreform, 2017).

Furthermore, there are also parts of the economy, such as older enterprises for example, where the number of insolvencies was increasing against the total trend. In addition, $82.7 \%$ of the business insolvencies affected small enterprises with five employees or fewer (Creditreform, 2017).

Importantly, the insolvencies of small companies and their importance for the area of small and medium- sized enterprises (SMEs) are still of special interest in Germany. SMEs are often highlighted as "the engine of the German economy" (KfW-Research a, 2017).

Especially as employers, the SMEs play an important role. In their annual analysis of structure and development of German SMEs the KfW-Research highlighted that in the year 2016, 30.9 million people were employed in SMEs. That means an increase of 1.46 million people compared to the year before, while big companies and the public sector reduced employment by about 432.000 people. Never before were so many people employed in German SMEs (KfW-Research b, 2017). 
This overview of the structure belongs to the introduction chapters that further include the context within which the topic of this thesis is embedded and that give a brief overview of the economical relevance of insolvencies in Germany.

Chapter two contains the relevant legal background. The topic of the thesis touches different disciplines. Although the overall focus is a social one, it is necessary to have basic knowledge about the German Insolvency Law to understand the peoples' situation during and after the insolvency procedure. Key terms like debtor, creditor or insolvency administrator for example will be explained in these chapters, to be clear about the actors and their tasks, rights and interrelations defined and determined by legal regulations.

After the discussion of systematic and narrative literature review approaches chapter three contains a narrative literature review about key contributors to and effects of insolvencies.

In chapter four, research gaps with regard to the literature review of the previous chapter will be identified, from which the research questions and objectives are derived.

Research methodology is the content of chapter five. After clarifying the research philosophy of the author, the sampling process is explained. It was identical for both the use of qualitative and quantitative methods, as all twelve participants took part in the interview as well as in the questionnaire. In-depth narrative interviews provided deep insights about the insolvencies of the participants and the psychometric inventory (NEO-FFI) enriched the findings, and further aimed to cross-validate them.

After the explanations about the sampling process, the qualitative and quantitative methods are considered separately including statements about their choice and quality criteria. 
After ethical considerations at the end of chapter five, the next chapter contains the

findings of this research. In line with the three research questions, this sixth chapter is divided into three parts.

In chapter seven, the findings will be discussed and limitations will be addressed. 
This research does not have a legal focus but the insolvency regulations build the framework for the insolvency procedures and influence the participants' situation significantly. A better understanding of this legal framework is essential background knowledge for this study. The following chapters include a brief introduction to the German insolvency law.

The term insolvency derives from the Latin word "solver" which means "to pay" and describes a situation where a debtor is no longer able to meet his/ her creditors' claims (Burk, 2014).

The regulations about insolvencies that apply in Germany are stated in the $\S \S 1-334$ of the insolvency code (InsO, 2018). Although there are also influencing aspects of other statutes, like the corporation law or the labour law for example, the insolvency code is compressed and clearly arranged. "By contrast there are countries with up to five laws instead of one" (Paulus, 2017, p. 7). The structure of the insolvency code basically follows the sequence of the insolvency procedure (Häring, 2010).

The following explanations about the German insolvency code provide several aspects that are important to understand this research project. This includes the introduction of the main players and essential definitions of the insolvency procedure. Parts of the insolvency code that are not relevant for this research, such as regulations concerning consumer insolvencies, company groups, estate insolvencies, special processes or judicial subtleties would reach beyond this research's boundaries in terms of scope and available resources. 
The two possible debtors that play a role in this research are natural persons and legal entities of private law. The legal term "natural person" means a human being in his/ her role as a subject of rights and duties. It is definded in $\S \S 1 \mathrm{ff}$. BGB (2019). $\S 11$ I InsO (2018) submits all natural persons to its scope of application. The decision about whether the concerned natural person is subjected to the regulations of the consumer insolvency or the general insolvency proceedings is covered by $\S 304 \mathrm{InsO}$ (2018): In cases where the natural person executes or has executed a self-reliant employment, has a minimum of 20 creditors when opening the insolvency procedure and/ or there are outstanding debts out of labour contracts, not the regulations concerning a consumer insolvency but the general insolvency proceedings are applicable.

To restrict the risk of the business failure for the entrepreneur as a natural person, it is possible to create an artificial legal person. The legal person is a legal entity with an insolvency risk limited to its bounded property (Paulus, 2017). All such legal entities are eligible for insolvency according to $\S 11 \mathrm{I}$ InsO (2018). So the personal liability can be reduced considerably by choosing the legal form of organisation.

However, this does not mean that the entrepreneur is free of responsibility and can fully hide behind his legal entity. In this context it is necessary to mention the law for private limited companies (GmbHG, 2017). It includes regulations that have been the basis for various legal disputes. According to the GmbHG (2017), the managing director has the duty to reimburse payments that were effected after the occurrence of illiquidity or excessive indebtedness. This responsibility is not enforced if the payments are compatible with the accuracy of a decent businessman (Burk, 2014). 
$2.2 \quad$ Creditor

According to $\S 1 \mathrm{InsO}$ (2018), it is the goal of the legal insolvency proceedings to satisfy the creditors' claims collaboratively. This implies that this satisfaction follows the principle of equal treatment. However, this is not completely true as the principle of equal treatment just applies to creditors that share the same tier group. The tier group decides whether the creditor gets preferential or quotal satisfaction of his/ her claims for example. Not just because of the different tiers do the creditors have various interests. Some want to get at least their quote as soon as possible, others wish the continuity of the business relationship with the debtor. All creditors with their different interests come together in the creditors' meeting (Paulus, 2017).

The first creditors' meeting influences the further proceeding significantly as they decide about closing, continuation or the presentation of an insolvency plan for example. If there is no conflict with the decisions of the meeting, the insolvency administrator starts with the liquidation of the insolvency assets (Krüger, 2014). 
The insolvency administrator is commissioned by the court. He becomes the "temporary boss" of the tilted business and is the main person of every insolvency procedure (Burk, 2014, p. 91). The insolvency administrator has the task to achieve the maximum price for the liability estate on behalf of the creditors. However, his responsibilities also include the well-being of the employees and tax topics for example (Burk, 2014).

The insolvency administrator has several accounting duties. Within an insolvency procedure, there are commercial, fiscal and insolvency-related accounting duties. The insolvency-related ones are regulated in $\S \S 151 \mathrm{ff}$ InsO (2018). According to the insolvency code, the administrator has to prepare the lists of tangible objects and creditors, and the inventory of assets. The commercial and fiscal accounting duties are also the responsibility of the insolvency administrator as long as they concern the insolvency assets. If the insolvency administrator breaches his/ her commercial accounting duties, he/ she is criminally liable according to $\S \S 283$ I 5, II, 283b I of the penal code (StGB, 2018). In this context it is worth mentioning that every breach of commercial accounting duties is automatically a breach of fiscal accounting duties, too, as the one is the base for the other (Hillebrand, 2015).

The compensation of the insolvency administrator is regulated by a separate compensation regulation and is taken out of the insolvency estate. So on the one hand the amount that is paid to the insolvency administrator is missing for satisfying the creditors (Paulus, 2017). On the other hand the administrator does have a good motivation to use his/ her economical expertise and experience to realise a huge profit through the liquidation of the enterprises' property, because his fees are closely connected to the achieved insolvency estate (Burk, 2014).

The insolvency administrator holds a lot of power during the insolvency procedure. Of course, it is necessary to control a person with such an amount of power to avoid misuse. There are two ways of supervision implemented in the German law. On the one hand there is the supervision by the court, which is stated in $\S 58 \mathrm{InsO}$ (2018). On the other hand also the creditors' meeting supervises the administrator's performance. An additional control as in other countries like a supervision chamber is not implemented in Germany (Paulus, 2017). 
The opening of the insolvency procedure needs an objective activator. According to $\S \S$ $16 \mathrm{ff}$ InsO (2018), the insolvency code includes three possible objective activators: excessive indebtedness, current illiquidity and imminent illiquidity (Krüger, 2014). Excessive indebtedness is given if the business' property no longer covers its existing commitments (§ 19 II 1 InsO, 2018).

The debtor is illiquid if he/ she is not able to pay the outstanding debts (§ $17 \mathrm{II} 1 \mathrm{InsO}$, 2018).

If the debtor is the opener of the insolvency procedure, imminent illiquidity can also

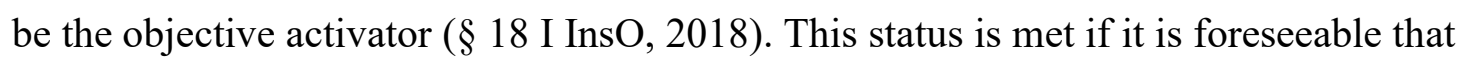
he/ she will not be able to pay the existing demands at their due date ( $§ 18$ II InsO, 2018). With this possibility, the debtor gets the chance to open the insolvency procedure early enough that reorganisation can also be an option in addition to the liquidation of the enterprise (Häring, 2010).

The wording of $\S 18 \mathrm{InsO}$ also leads to the question of personal activators. It states that while the debtor can initiate the insolvency procedure, a creditor can also do so ( $\S$ 13 I 2 InsO, 2018).

The application by a creditor is allowed if he/ she has a legal interest in the opening of the insolvency procedure, and he/ she can make the claim and the objective activator credible (14 I 1 InsO, 2018). In practice, applications by a creditor are very rare as in most cases the creditor does not have the needed documentation to prove if the debtor is illiquid or over-indebted (Krüger, 2014).

In this research, there was one case where a creditor made the application to open the insolvency procedure. It was the fiscal authorities who took that step, after the participant could not pay their existing demands. In advance, they had sent several reminders and finally had even blocked his bank account before filing for his insolvency. At this time, his two legal entities of private law were already within insolvency procedures, and the fiscal authorities then brought him as a natural person into insolvency procedure as well. 
The insolvency estate is defined in $\S 35 \mathrm{I}$ InsO (2018) as "the whole property that belongs to the debtor at the point in time of opening the insolvency procedure or that he/ she earns during the insolvency procedure". In the past, the insolvency estate was limited to the current status of the debtor's property at the opening of the insolvency procedure and everything he/ she acquired after that point in time was not part of the insolvency estate but his/ her personal capital gain. § 35 I InsO (2018) now enlarges the definition of the insolvency estate by the capital gain during the procedure. This delays the fresh start of the debtor from the opening of the insolvency procedure to the time of the discharge of residual debt (for more information about this point please see chapter 6.3.6.2) and weakens the position of new creditors as the property is reserved for the old ones (Paulus, 2017).

All physical and intangible assets are to realise and be included in the insolvency estate, as the satisfaction of the creditors has to be conducted with cash only (Burk, 2014). 
In former times during the validity of the bankruptcy act of the year 1877, it was all about the remaining debtor's property. The only goal of the bankruptcy procedure at that time was the realisation of the debtor's liability through liquidation and satisfaction of the creditors. "The business itself and its fate were not of note in this context" (Häring, 2010, p. 110).

"It was the "New World" that joggled that basic pattern. In the 19th century there came from the USA the finding that it is more helpful for the creditors if the debtor's property does not get liquidated, but the debtor him-/ herself gets reorganised" (Paulus, 2017, p. 3).

An important milestone was the Act for the Further Facilitation of the Restructuring of Companies (ESUG, 2011) that came into effect on March 1, 2012. Its integration into national law led to important changes of the German insolvency code. The main changes were the implementation of the possibility of an early and successful restructuring of distressed companies and the improvement of particular insolvency plan proceedings to make the process more reliable and predictable (van Kann, 2012). Meanwhile, this new option has generally been accepted and can be found in the law of nearly every country in the world. In Germany, it was established with the implementation of the so called plan procedure (Paulus, 2017). It is regulated in the $\S \S 217 \mathrm{ff}$ InsO (2018).

Although the course for reorganisation and continuation of businesses is legally set, asset stripping seems still to be the predominant principle in most people's minds when it comes to insolvencies. The insolvency code still gives the impression that the creditors are the ones who deserve protection but not so much the enterprises or even the concerned leaders. As explained, there have been amendments in the regulations to enable reorganisation instead of liquidation but an extensive and clear change did not take place. The insolvency administrators still have the focus on satisfaction of the creditors through liquidation. This may be because the former insolvency law had this focus, too. Or maybe it is because an insolvency administrator is just not an entrepreneur, even if he/ she should act like one for the period of the insolvency procedure (Häring, 2010). 
In the interviews, this topic was raised. Some participants feared getting an insolvency administrator, who did not consider the chances to reorganise the enterprise accordingly but started his/ her routine of liquidation. Participant 3 summed it up by stating:

"There are two types of insolvency administrators: the liquidator and the reorganiser. Meanwhile, the legal regulations changed. Apparently, it seems more sensible to reduce the protection of the creditors a little bit. Of course, it is always that balance between protecting the creditors on the one hand and preserving the enterprise on the other hand. (...) I was very worried to get to a liquidator prematurely, who maybe does not understand what we are doing, or who maybe does not see the enterprise as something worth preserving."

The participant's company found an investor, and is still alive and successful. 
If the debtor is a natural person and it was not possible to conduct a plan procedure, there remains the question of how to treat the residual debt that is left over after the insolvency procedure (Burk, 2014). Following the basic principle "pacta sunt servanda" (principle of contract compliance: “contracts are to fulfil”) the debtor's liability would persist until all creditors are satisfied or at least until the statutory limitation. The specifications to be applied in such a case are stated in $\S 197$ I 5 BGB (2019) and apply for 30 years (Paulus, 2017).

The perspective to have to pay the creditors for such a long period is not just horrible for the debtors. Also, for social state and economy this cannot be a preferable solution, as this procedure would destroy the debtors' motivation to get involved with new employment and chase the concerned persons into the shadow economy (Burk, 2014). Following the practice from the USA, where an insolvent person has the possibility for a fresh start right after the closing of the insolvency procedure, the concept of the discharge of residual debt was implemented in Germany with § 1 II InsO (2018). However, in this country the debtor does not leave the insolvency procedure clear of debt. In fact, he/ she has to absolve a so-called good conduct phase of generally six years. In this time the debtor has to give his/ her earnings from employment or other income to a trustee (Paulus, 2017). To have an adequate income, the debtor has the duty to seek a full-time job, but is just allowed to keep a small basic income for him-/ herself and his/ her family (Burk, 2014).

There are some good reasons that can lead to the denial of the discharge of residual debt if the debtor gambled his/ her trustworthiness for example by committing an insolvency crime (Burk, 2014). As all concerned participants of this study achieved their discharge of residual debt, there is no need to go into detail concerning these reasons of denial within this excursus. 
The starting point of this research builds the review of the existing literature in the field. After a brief discussion of the different ways to conduct a literature review, this literature review includes studies about key contrubutors to insolvencies as well as studies about the effects insolvencies have on their entrepreneurs.

3.1 Narrative versus Systematic Literature Review

A literature review can be seen as a comprehensive overview about the current knowledge of a topic. The author has to search through the literature and review the diverse sources of information critically (Green, 2006).

There are different ways to conduct a literaure review. So some time was spent to decide if a narrative or a systematic literature review was the appropriate way for this research. Both approaches of reviewing the existing literature in the specific field of interest have their advantages and disadvantages that will be discussed in the following paragraphs to make clear the methodology choice that was made for this review.

The narrative literature review is the traditional approach. Its strength is to present a broad perspective in an accurate and readable format (Green, 2006). On the other hand, narrative literature reviews may be criticised for lacking thoroughness and rigour (Tranfield, Denyer \& Smart, 2003). Also, the subjectivity and missing critics of the reviewed literature lead to negative positions toward the traditional approach. Concerning the negative aspects of narrative literature reviews, it is necessary to point out that the critics cannot be seen in absolute terms. Furthermore, systematic literature reviews can also show a lack of objectivity and critical assessment. When the academic researcher is aware of the possible pitfalls of the traditional review, he/ she can also produce an appropriate and valuable paper by doing a narrative literature review (Green, 2006).

As the narrative literature review nevertheless can be seen as a rather unsystematic approach concerning the search and selection of the literature the systematic literature review was developed (Mullen, 2006). With a clear and transparent process this new 
approach seeks to improve the quality of the research by minimising bias and subjectivity (Tranfield, Denyer \& Smart, 2003). The documented search and selection of the reviewed studies are made transparent. So the process of the systematic literature review is clear and potentially replicable (Bryman, 2007). This is a very important point as replication is one of the most prominent criteria for the evaluation of business and management research (Bryman, 2007). For the systematic literature review a focused research question is needed (Green, 2006). If that precondition is given, the systematic literature review can be seen as "an efficient scientific technique" (Mulrow, 1994, p. 597) to reduce the almost unlimited amount of available information through critical exploration, evaluation and assessment of the relationships and magnitudes within the specific field of interest (Mulrow, 1994).

On the one hand, the systematic literature review seems to be more manageable for the researcher as it is a well-structured procedure and has some kind of limitation while the narrative literature review can grow more and more as the researcher digs deeper into the topic. On the other hand, this growing character that reminds of a tree, whose branches are the different aspects and facets of the topic, is something very valuable. Within this research, a systematic literature review did not seem to be the appropriate approach due to the multidisciplinarity of the topic. Making the search criteria too wide caused a literature overflow including many texts not relevant for this study as for example specific accounting topics or articles about customer insolvencies. Making the search criteria too narrow, too specific, held the danger of missing interesting literature. These reasons lead to the use of the narrative literature review for this research. 
As this study researches key contributors to insolvencies as well as the effects of insolvencies on the entrepreneurs, the literature review is divided into these two parts, too.

Literature Review on Key Contributors to Insolvencies

The research of corporate crises includes causal research, crisis management and prevention (Kraus, Schlepphorst, \& Tyshkun, 2012). These three areas can be seen as connected as for the prevention of crises the understanding of their key contributors seems to be crucial, and also effective crisis management benefits from this understanding to not just stay on the surface of its possibilities as pure reaction and troubleshooting.

Meanwhile, there are several theoretical assumptions about corporate crises and its nature which lead to many definition approaches of the word "crisis". A comprehensive and often cited definition can be found in Krystek (1987): "Corporate crises are undesigned and undesired processes with limitation in time and interference and ambivalent outcomes. They can harm the survival of the whole company substantially and enduringly" (Krystek, 1987, p. 6).

Concerning the key contributors to such crises, their multi-causality is commonly accepted as corporate crises emerge from clusters of different root causes (Kraus, Schlepphorst, \& Tyshkun, 2012).

An insolvency can be seen as the extreme end of the financial problems of a company, as the peak of a corporate crisis (Ramsey et al., 2016).

Research in organisational ecology also gives hints why some enterprises are more or less successful than others. In this context, there exist several studies that support the current numbers of insolvencies including the high percentage of very small bankrupt enterprises. The stated advantages of large companies are manifold. They are able to produce at lower costs per piece and can realize synergetic effects through diversification for example (Dawley, 2003). 
Anheier (1996) makes clear how broad the field of organisational failure can be interpreted when he divides the topic into the following four subareas: political aspects, cognitive aspects, organisational aspects, and structural aspects.

Within the perspective emphasising political aspects, organisations are understood as political entities that are embedded in a larger political economy (Anheier, 1996). Studies focusing on the cognitive aspects deal with the question of why some failures appear obvious and expected while others are difficult to identify. This perspective seeks to gain deeper understanding concerning perception, identification and declaration of failures and to "highlight the importance of routines and blueprints for interpretation and organization" (Anheier, 1996, p. 952).

Within this context, Kets de Vries and Miller (1984) found that there are some personality-related or behavioural characteristics of CEOs that make their failure more likely. Examples are paranoid elements like speculative mistrust and hypersensitivity towards possible risks or threats, or carefree elements like overconfidence and the feeling of being invincible towards any challenge. Both extreme cultural directions can be seen as enablers of failure (Kets de Vries \& Miller, 1984).

Focussing on the organisational aspects of failure, authors use the organisational life cycle with its phases of establishment, growth, maturity and decline (e.g. Whetten, 1987). Every phase of this organisational life cycle includes specific crises potential such as leadership-driven problems, coordination difficulties or environmental aspects (Anheier, 1996).

The structural approach sees the topic as a network of different actors and organisations. "The failures occur in the social fabric of organizations and groups, and such failures may not necessarily coincide with situations of economic distress" (Anheier, 1996, p. 952). This perspective goes back to Simmel, who focused on the relationships between organisations and there supportive as well as conflict-burdened character (Simmel, 1968).

In his conclusion, Anheier (1996) states that it is important to understand that the reasons why organisations fail may be different from the mechanisms and events that can trigger the failure. Here he sees the need for further research and calls among others for gaining deeper understanding concerning failure reasons and outcomes (Anheier, 1996). 
"By doing so, we may be in a better position to understand how some failures, such as bankruptcies and social policies, become successes and how some initial successes, such as nuclear energy and technological advances, turn into failures" (Anheier, 1996, p. 957).

Ooghe and De Prijcker (2004) developed a theoretical framework of enabling factors of organisational bankruptcy. Also, according to their model, bankruptcy is the result of a combination of factors. They differentiate influences of the general environment, the immediate environment, management/ entrepreneur, the corporate policy and company characteristics. These factors interact, affect the company and finally lead either to its success or its failure in the form of an insolvency (Ooghe \& De Prijcker, 2004).

Park (2004) suggests a model of causal factors of municipal bankruptcy with three dimensions: long-term and short-term factors, internal and external factors and economic and political factors (Park, 2004).

Of special interest for this research are studies with a more practical orientation that go further into detail such as projects like the Munich Founder Research for example. The Munich Founder Research is a project conducted by the Institute of Sociology of the University of Munich about risks and chances of newly-created small enterprises. Input of this study was a survey with 1849 participants that had founded a business in upper Bavaria in the years 1985 or 1986. It shows that more than a quarter of the researched businesses were deleted from the Professional Register again within three years after their creation. More than half of the participants stated as the reason for the closure that the business was not profitable in the long term. With a five-scale-rating the participants evaluated the sources of their problems. The main sources in descending order were too strong competition, bad conditions of the industrial sector, insufficient support from outside, lack of experience within the industrial sector, not enough equity capital, inappropriate location, bad macroeconomical conditions, lack of mercantile knowledge, not enough depenture capital and problems of recruiting appropriate staff (Kiefl, 1998).

The Munich Founder Research shows how difficult it is to establish a new enterprise and that success is not something God-given. Despite the huge number of participants, 
the survey stays on the surface concerning the sources of the missing success. The main problem here I see in the survey design. The participants were given a list of possible reasons for their business closure. Using a Likert response format, the participants rated to what extent they agreed that the mentioned sources were relevant for their own case. Firstly, this leads to a limitation in variety of the given answers, and secondly, this way of research is missing explanations. I want to make my criticism clearer with the possible source "insufficient support from outside". What does this tell us? Who were the stakeholders? What is support, is it money, consulting etc.? Or is this item probably just an easy way for the participant to shirk some responsibility?

Yarbrough Landry researched 42 hospitals that registered for insolvency under federal law in the USA between the years 2000 and 2006. She found three differences between the researched insolvent hospitals and their successful competitors. Her study implies that the insolvent hospitals were smaller than their competitors. Furthermore, fewer of them were members of a hospital or health system and more of them were investor-owned in comparison to their competitors. To research the reasons that led to the insolvencies, Yarbrough Landry reviewed the relevant articles about the researched hospital insolvencies published in the trade press. The reasons that were mentioned most frequently were poor management in general and poor financial management in particular. Furthermore, there had been problems with the payer mix and reimbursement changes, such as slowdowns and reductions in Medicare and Medicaid payments, and cases of fraud (Yarbrough Landry, 2009).

Having stated thosa insolvency reasons, the study does not go into further detail. This might be caused by the kind of data the researcher uses as her assumptions are controlled by the attention to detail of the reviewed press articles.

Accordig to Gösche (1987), who conducted an interrogation including 300 bankrupt enterprises, the economic situation is seen as the main influence on insolvencies. Also Gösche highlighted that corporate crises often do not have just one single root cause but clusters of influencing factors (Gösche, 1987).

Bellinger (1962) divided the causes according to their importance in causes of first order, second order and third order. He reviewed 214 cases and brought the found 
causes into a ranking. As the most important factors, the first order causes, he sees goals that could not get reached in the reviewed companies, such as low sales quantities, low productivity or illiquidity. For him losses of capital are especially to be highlighted as the main root cause of corporate crises (Bellinger, 1962).

Capello (2002) conducted a research about entrepreneurship and spatial externalities. In her empirical analysis, she investigated how the productivity of enterprises is influenced by urbanisation on the one hand and localisation on the other hand. Therefore, she analysed 60 enterprises within thehigh-tech sector, which demonstrates a high spatial concentration in particular areas in the region of Milan through the estimation of a production function, taking spatial economies into account (Capello, 2002).

Her result was that (at least for enterprises of the high-tech sector) productivity is greater in those firms appreciating localisation economies more. Furthermore, the research implies that localisation economies are more appreciated by small firms, while large firms seem to appreciate urbanisation economies more (Capello, 2002). The data Capello used were employment figures from Census of Employment records for 1981 and 1991 and the enterprises' balance sheets. This implies that the data might be biased as company accounts are the basis for company taxation in Italy. So enterprises might try to underestimate sales and over report expenses in order to reduce their taxes. For Capello's study, this means that there is the risk that productivity and profits rates might be biased downwards (Capello, 2002).

Following the idea of Brüderl \& Schüssler (1990) who postulate that business survival is a constitutive indicator of business success, Korunka et. al. (2010) researched predictors of business survival within a longitudinal study of 354 small business owners observed over a timeframe of eight years. $283(79.9 \%)$ still had active businesses at the end of that observation period. The researchers point out that concerning the indicators line of business, startup size/financial capital, gender and age of the small business owners, their sample was representative of Austrian small businesses (Korunka, Kessler, Frank, \& Lueger, 2010).

Korunka et. al. (2010) found that personal characteristics, resources and environmental aspects at the start of the business activities explain only a small part of 
the variance in business survival. According to their study, the most important predictor of long-term business survival is the amount of financial capital at the start of the business activities (Korunka, Kessler, Frank, \& Lueger, 2010). This again is in line with Brüderl \& Schüssler (1990), who also stated that larger businesses have a substantially higher longterm survival (Brüderl \& Schüssler, 1990).

Concerning the effect of personality, Korunka et. al. only found a weak influence on midterm survival. They see high risk-taking as especially problematic in the early business development as customer relationships are not stabilised yet (Korunka, Kessler, Frank, \& Lueger, 2010).

Korunka et. al. point out that their lifecycle approach has its weaknesses as "businesses probably do not encounter similar generic problems but have specific problems which differ from business to business. It is therefore not age of business but the firm specific learning experiences with problems encountered that should be addressed in more detail in future research" (Korunka, Kessler, Frank, \& Lueger, 2010).

Lee, Peng \& Song (2013) discuss how government policies can faciliate entrepreneurship initiatives and development by policies with special focus on generating positive externalities and the avoiding of failure for individual firms. Therefore, they propose the following six policy domains: tax policies, industry structure and entry barriers, foreign direct investment, opening foreign markets, bankruptcy legislations, and moving away from traditional industrial protection (Lee, Peng, \& Song, 2013).

The paper seems to have the aim of engouraging government to intervene in the markets by influencing the entrepreneurs' political framework with positive externalities. Lee, Peng and Song (2013) see it as a task of governmental institutions to stimulate entrepreneurship development (Lee, Peng, \& Song, 2013). However, the focus here seems to be the founding of new enterprises, while the continuity and growth of existing enterprises could be taken into consideration more.

Tavassoli \& Jienwatcharamongkhol (2016) studied the role of agglomeration externalities for business survival. Therefore, they looked at newly-established and selfemployed businesses in the "Knowledge-Intensive Business Service sector" and 
their location within the 72 functional regions of Sweden from 1997 to 2012. For the survival of these enterprises they investigated the role of Marshallian and Jacobian externalities (Tavassoli \& Jienwatcharamongkhol, 2016).

Marshallian externalities are based on the specialisation of an area on a specific industry sector. Here the idea is that the valuable knowledge for businesses is predominantely industry-specific (Marshall, 1920). Following this idea, it would be favourable to concentrate on a particular industry in a region as enterprises in such an area then could benefit from intraindustry knowledge spillovers (Tavassoli \& Jienwatcharamongkhol, 2016).

Jacobs' externalities occur in cities and congested areas, where a lot of enterprises of different industry sectors are located. Here the focus lies on benefits through interindustry knowledge spillovers (Jacobs, 1969).

Tavassoli \& Jienwatcharamongkhol (2016) found that only Jacobian externalities influence the survival of entrepreneurial enterprises positively, especially the related variety matters, while unrelated variety barely has any significant correlation (Tavassoli \& Jienwatcharamongkhol, 2016).

Related variety measures the intersection of knowledge and skills of two industry sectors. Unrelated variety measures the diversity in a particular region (Frenken, van Oort, \& Verburg, 2007).

All in all, about $61 \%$ of the analysed enterprises survived up to five years after their establishment and about $42 \%$ survived up to 10 years. At the end of the research period, after fifteen years, $27 \%$ of the enterprises were still alive.

Tavassoli \& Jienwatcharamongkhol (2016) point out the uniqueness of the Swedish economy in terms of entrepreneurship, and advise caution concerning the generalisability of their results (Tavassoli \& Jienwatcharamongkhol, 2016).

Fleege-Althoff (1930) had already researched bankruptcy records and business reports of public limited companies and divided the found reasons for bankruptcy in endogenetic and exogenetic root causes. The endogenetic factors can be influenced by the companies while the exogenetic ones are outside their area of influence. The endogenetic factors he saw as the main causes, especially he pointed out the lack of qualification of the leaders (Fleege-Althoff, 1930). 
Hahn (1958) adopted Fleege-Althoff's differentiation in exogenetic and endogenetic root causes. By reviewing 200 court files he also came to the conclusion that predominantly endogenetic factors were responsible for the bankruptcies. The main cause he saw in poor management (Hahn, 1958).

Rinklin (1960) supported these findings with his research. In the fortification of Fleege-Althoff's and Hahn's researches, he saw weaknesses in the leaders' qualification and/ or personality as the main root causes of the reviewed insolvencies (Rinklin, 1960).

Keiser (1966) reviewed court files and conducted interrogations with entrepreneurs who went bankrupt. In $86.4 \%$ of the reviewed cases, the entrepreneur him-/ herself was the root cause of the insolvency due to their mistakes (Keiser, 1966).

Bennedsen, Pérez-Gonzáles and Wolfenzon (2006) conducted a research about the importance of the leader for the company's success. From 1992 until 2003, they analysed Danish enterprises to research how the death of the CEO influences the business profits. They were able to show that the profit declined with the leader's death. Even the death of a family member of the CEO caused a loss of profits. According to Bennedsen, Pérez-Gonzáles and Wolfenzon (2006), the reason might be that the leader was distracted from his/ her professional tasks because of the bereavement. The study showed the connection between CEO and company, and the importance of the leader for the business profits (Bennedsen, Pérez-Gonzáles \& Wolfenzon, 2006).

Also Hinterhuber (2010) had the opinion that the "man or the woman in front is essential for the company's success" (p.181). In this context, he distinguished charismatic leadership from narcissistic leadership. In charismatic leadership he generally saw positive influence on the performance of the employees. According to Hinterhuber (2010), every leader is narcissistic to some degree, but to an increasing extent there are two versions occurring: Leaders with productive or destructive narcissistic personality. The first category can be visionary and sees their employees as a resource for the company's success. Leaders of this first category need conscientious partners aside. The second category is a big risk for the company and can significantly influence the company's performance in a negative way. There might be truth within 
these arguments but unfortunately Hinterhuber leaves with his statements without any foundation. Furthermore, the leadership personalities that are the core of his statements are weakly defined. There are psychological methods to identify narcissism, but Hinterhuber uses examples and general descriptions instead (Hinterhuber, 2010).

Pechlaner (2010) clearly stated that "all enterprises that failed did this because of entrepreneurial or management mistakes" (p. 207). To cover possible reasons for business failures, he also challenged the life cycle of companies with its phases of establishment, growth, maturity and regression. All these phases require amendments in systems, processes and logic and can lead to crises because of the leaders' missing knowledge, competences or actions (Pechlaner, 2010). Pechlaner's thoughts seem to be comprehensible, but he fails to present substantiation for his statement that all business failures are based on leaders' input.

Lynn (1969) built a research on the base of Eysencks study about the personality characteristics of businessmen (Eysenck, 1967). He had found out that businessmen scored lower in the dimension of neuroticism and were more introverted than the normal population. His participants had been employees. Lynn (1969) used his personality system of neuroticism and introversion-extraversion, and conducted a research with entrepreneurs to compare the results with his. The entrepreneurs scored higher in the dimension of neuroticism than Eysenck's businessmen. Furthermore the entrepreneurs scored higher in the dimension of extroversion than the general managers (a subgroup of all tested businessmen), but this difference is not statistically significant $(\mathrm{t}=0.95)$ (Lynn, 1969).

For Brandstätter (2011), entrepreneurship is "highly important for socio-economic prosperity" (p. 222). In his article, he reports the main results of five meta-analyses. Concerning the Big Five factor model, he points out that entrepreneurs showed differences in personality traits compared to managers: entrepreneurs scored higher in the dimensions of conscientiousness, openness and extroversion, but scored lower in the dimensions of neuroticism and agreeableness (Brandstätter, 2011). 
Kets de Vries (1985) researched the personality of entrepreneurs in depth conducting observations of and interviews with 38 entrepreneurs from a clinical point of view. He admits that his sample is biased as he "dealt with "dramatic" cases" (Kets de Vries, 1985, p. 162). However, he obtained deep insights during the therapeutic contact with his clients.

For Kets de Vries, entrepreneurs seem to be achievement-oriented and like to take responsibility for decisions. They tend to dislike repetitive, routine work. Furthermore, he points out that they "can have personality quirks that make them hard people to work with" (p. 161). Some of his clients for example had serious difficulty addressing issues of dominance and were suspicious about authority. Here Kets de Vries (1985) sees an essential difference between entrepreneurs and managers, as managers tend to identify with authority figures in a positive and constructive way.

The entrepreneurs that he studied did not just have their issues against authority, they also showed a proclivity toward suspicion of others. They had a strong distrust for the world around them and were afraid of being victimised. Connected to this attitude, the researched entrepreneurs had a strong desire for applause and being in full control (Kets de Vries, 1985).

About ten years later, Kets de Vries (1996) conducted a case study about an entrepreneur whom he met for five 50-minutes sessions per week over a timeframe of five years as his therapist. He points out that this continuity gave him the opportunity for in-depth observations of mood states and behaviours, and that this case study was enhanced by knowledge from interviews and questionnaires. The researched case highlights some themes of the entrepreneur's personality that also had emerged in previous studies:

Entrepreneurs tend to hold on to archaic representations that have influence throughout life and are not easily modified or even given up. They furthermore show narcisisstic behaviour that often is reactive as they fear failure and their behaviour is not based on a secure sense of self. For them, their enterprise is a highly emotionally charged entity, that is even sometimes experiened as an extension of the self. Furthermore the researcher comes to the conclusion that running a business is often not a rational process, quite the contrary. Additionally the entrepreneur builds the centre of the enterprise and often there is no other staff member to counterbalance the leader. Kets de Vries (1996) calls this constellation a "dramatic organisation" (p. 876). Leaders of dramatic organisations 
often lack self-discipline, tend to overreact and to centralise power while iniative of staff members gets restricted (Kets de Vries, 1996).

Hornaday and Aboud (1971) researched characteristics of successful entrepreneurs. In their study, they found significant differences between entrepreneurs and "men in general" (p. 147): entrepreneurs scored significantly higher on scales reflecting need for achievement, independence and effectiveness of their leadership, while they scored lower on scales refiecting need for support. This follows the experiences of Kets de Vries $(1985$, 1996) reported earlier, but the study of Hornaday and Aboud has its weaknesses. A problem here might be the definition of what is a successful entrepreneur. Hornaday and Aboud (1971) defined the successful entrepreneur as "a man or woman who started a business where there was none before, who had at least eight employees and who had been established for at least five years" (p. 143). This definition can be seen as questionable as it does not include any information about the market. In times of economic growth, it is easier to keep an enterprise alive, while in times of depression, internal weaknesses or risky decisions can become serious problems.

Researching a sample of 806 insolvent enterprises, Hotchkiss (1995) found that only $24 \%$ were able to reorganise and proceed, and just $49 \%$ of those reorganised enterprises survived for five years. Her study furthermore includes an aspect concerning the influence of management on the business success, as she found that the retention of the leaders led to a weaker post-bankruptcy performance (Hotchkiss, 1995).

According to Antoniakis, Cianciolo, \& Sternberg (2004) within the research field of leadership, the focus lay on the personality of the leaders in its beginnings. From about 1900 until the 1950s, trait theories of leadership dominated the academic interest (Antoniakis, Cianciolo, \& Sternberg, 2004). These early approaches aimed to understand charismatic individuals that influenced history significantly supported by their leader personality. Besides personality traits, this Great Man Theory also included other traits like physical or social ones (Carlyle, 1907). Over the years, a large number of studies were conducted and their results were quite contrary. Bird (1940) tried to consolidate the different findings of the field. Using 20 different studies 
about the trait based approach of leadership he developed a list of 79 relevant personality traits, but a clear identification of just a few key traits was not possible (Bird, 1940).

The trait theories of leadership were replaced by other approaches in the following years and no longer played a significant role probably due to the inconsistent results of that research field (Antoniakis, Cianciolo, \& Sternberg, 2004).

With the New Leadership approaches, the trait theories of leadership became reanimated especially in the context of the transformational leadership style (Fraude, 2015).

According to Bass (1985), transformational leadership contains four components: idealised influence, inspirational motivation, intellectual stimulation and individualised consideration (Bass, 1985).

Idealised influence here can be seen as charisma. Transformational leaders can be seen as role models that set high standards for emulation. Inspirational motivation here means to create committment through challenges and engagement in shared goals. The intellectual stimulation as a component of transformational leadership contains transparency and openness. Such openness can help the employees to question assumptions and to generate more creative solutions to problems (Bass \& Steidlmeier, 1999). Individualised consideration here claims for altruism to avoid authoritarian control. The leader should treat every employee as an individual and provide mentoring, coaching and opportunities for development (Bass, 1985).

According to Bass \& Steidlmeier (1999), an authentic transformational leadership style "must be grounded in moral foundations". This includes "the moral character of the leaders (...), the ethical values embedded in the leaders' vision, articulation, and program (...) and the morality of the processes of social ethical choices and action in which the leaders and followers engage and collectively pursue" (Bass \& Steidlmeier, 1999, p. 181).

The transformational leadership style can be seen as a combination of trait, behavioural, situative and relationship theories of leadership. So the leader's personality again is seen as an essential element but no longer as the only one (Fraude, 2015). 
Bass \& Steidlmeier (1999) state that on the one hand "in leadership character matters" (p.193), but on the other hand "there is no one best way to lead in all situations" (p. 206).

Fraude (2015) states that the relationship between the personality traits of a leader and the transformational or transactional leadership style could not be clarified yet (Fraude, 2015). Therefore, he researched the relationship between specific social competences and the transactional as well as transformational leadership style. His research implied that assertiveness can be seen as an obstruction for the transformational leadership style, while enthusiasm and sensitivity can be seen as supportive for the transformational leadership style. A statistically significant relationship concerning the transactional leadership style was not found in his research (Fraude, 2015).

Palmer et al. (2001) conducted a study to examine the relationship between emotional intelligence (EI) and leadership. For EI they used the definition of Salovey and Mayer (1990) who described EI as a set of abilities that refer to how effectively one deals with emotions within oneself and others. According to their framework, EI can be seen as intelligence consisting of a conceptually related set of mental abilities to do with emotions and the processing of emotional information (Salovey \& Mayer, 1990). Palmer et al. (2001) worked with a sample of 43 participants. The leadership style was assessed with the multifactor leadership questionnaire by Avolio et al. (1995). The ability to monitor and manage emotions in oneself and others was assessed by items taken directly and adapted from the Trait Meta Mood Scale by Salovey et al. (1995). Palmer et al. (2001) had predicted that transformational leaders would score higher in EI than transactional leaders. This hypothesis was not supported, but there were significant relationships between single components of transformational leadership and EI sub-scales: Inspirational motivation and individualised consideration are components of transformational leadership. These two components correlated significantly with the ability to monitor and manage emotions in oneself and others. Here further research is suggested to validate these results with a larger, more diverse leadership sample (Palmer, Walls, Burgess, \& Stough, 2001). 
To find personality differences between successful businessmen and businesswomen and leaders who had to face an insolvency, Neß (2013) conducted a study with 21 insolvent CEOs in northern Germany. Neß showed that successful businessmen and insolvent leaders differ in risk taking, risk aversion and inequality aversion ( $\mathrm{Ne} \beta$, 2013).

According to her study, insolvent leaders are much more risk taking concerning loss and have a higher risk aversion than the successful businessmen. The insolvent leaders fear the possibility of loss that much that they close their eyes to those risks. There were hints in her interviews that these characteristics did not just appear through the insolvency but were obvious before. So when the leaders struggled with their enterprises, some of them simply stopped opening mail to avoid the confrontation with invoices or demand notes $(\mathrm{Ne} \beta, 2013)$.

Another difference was found in the inequality aversion. The insolvent leaders showed a strong inequality aversion comparing their own business success with other companies. Loss is justifiable and can be higher if they see that others in the same industrial sector also had to face a loss. Profit also does not have to be that high if they see that comparable companies also did not gain too much profit. By contrast successful businessmen always strove for profit maximisation (Neß, 2013).

For Imgrund (2009), an insolvency is not necessarily the end of the company. He researched the role of the entrepreneurs of small and medium-sized enterprises (SMEs) before and during their insolvencies. Entrepreneurs of SMEs in particular transfer their moral concept to the company and influence it by their qualifications and personality. So SMEs can be seen as systems that reflect the leaders in aspects of organisation and culture. This aspect gets intensified by the double role of the entrepreneur, as in SMEs the leader and the owner are often the same person (Imgrund, 2009).

He pointed out the early filing of insolvency as an essential aspect as a late filing often reduces the financial resources significantly and decreases the probability of a successful reorganisation. However, often the concerned entrepreneurs wait too long to file the insolvency, as they fear social stigmatisation and have a high emotional connection to their enterprises. Imgrund saw further problems in the lack of managerial knowledge and missing information about the insolvency proceedings on 
the side of the entrepreneurs and just a small number of support offers on the public side, like crisis consulting of banks and associations for example (Imgrund, 2009). Concerning the lack of managerial knowledge, the controlling in particular was a deficit. Often no adequate or even no controlling systems were implemented in the reviewed SMEs. So everything seemed to be fine as long as profit was made and the business environment was working, but when the conditions changed, the crisis was not realised in time as there was no early-warning system. The crisis then only became obvious at the point when liquidity became a problem (Imgrund, 2009).

Missing controlling systems were also identified by Hilmer (2006) as one of the main issues that lead to insolvencies. By asking 125 insolvency administrators Hilmer found that failures in management were the main causes of insolvencies. In addition to the above-mentioned lack of controlling systems, the missing identification of funding gaps, a weak receivable management, and dictatorial and non-innovative leadership were also identified as common pitfalls (Hilmer, 2006).

Hauschildt, Grape \& Schindler (2005) pointed out that corporate crisis research predominantly focused on the end of the crisis, on the financial crisis that then quickly leads to the insolvency. However, there are also root causes that exist before that apparent period of the crisis. They call this early stage "latent crisis" (p. 4; see also Röthing, 1976) and even before that early stage, critical events or failures can happen that influence the later insolvency (Hauschildt, Grape, \& Schindler, 2005).

There has been plenty of research concerning influences on insolvencies in the past decades. The reviewed studies widely agree that an insolvency in most cases cannot get traced back to one critical event but there are clusters of key contributors. Furthermore, it is commonly accepted that the entrepreneurs play a crucial role in success or failure of their enterprises. They influence their companies significantly through their behaviours and decisions especially in small and medium-sized companies. 
The words "crisis" and "failing" are frequently and deeply discussed expressions. Rohrhirsch (2010) for example connected this discussion with the question of being. Failing for him was a holistic experience that shows us that we cannot ensure the ability of our own existence. According to him it also shows that "we are not the master, nor can we rule" as there is no security how the world, other people or oneself behave. "Failing throws us back into the basic sensitivities of human being" (Rohrhirsch, 2010, p. 131).

Failing in the context of corporate crises and insolvencies can be seen as the personal dimension of the entrepreneur's risk. As the business he/ she founded, established and/ or lead reflects his/ her attitudes and experiences, the failing of this business hurts the entrepreneur inside. It shakes his/ her opinions and expectations. So the insolvency is not just a crisis for the business but also for its leader personally (Pechlaner, Stechhammer, \& Hinterhuber, 2010).

In general, the word "crises" labels percussions of balance or turning points that can lead into good or bad development. A classical example therefore is the fever crisis in medieval times that interrupted a period of health and could lead into regeneration or death (Ulich, 1987).

Compared to other forms of change, crises differ by their discontinuity, their interruptive character, their limited time frame and the central and emotional personal areas they affect (Ulich, 1987).

Compared to other forms of stress they differ because of their "specific quality of threat, excessive demands, strong strain, insecurity, helplessness, 'crack' in the socialemotional continuity of the own life in terms of time and the relationship to the environment" (Ulich, 1987, p. 51).

In Germany, insolvencies are still frowned upon. Either the insolvent people are seen as losers, who simply were not able to handle the business challenges accordingly, or they might be chisellers, who trifled with their business or probably even ruined it on purpose (Häring, 2010). However, failing is important not just for people in general, but especially for entrepreneurs. For Stechhammer, failing is "the shadow of success" (Stechhammer, 2010, p. 194). It is just natural that with success there belongs the 
possibility of failing. However, this does not have to be seen as something negative, it is just an immanent part of success that hides in the darkness (Stechhammer, 2010). In this context, Stechhammer (2010) applied to adapt the view of research that is not polluted by the postmarks of failing and success. In research, we are talking about falsification and verification instead, and this world view would also be preferable for society and culture to accept failings as a possibility that is necessary for development and innovation (Stechhammer, 2010).

The Munich Founder Research that was mentioned earlier within the context of the key contributors to business closures also includes the question about the further career after the entrepreneurship. Their result was that $44 \%$ of the participants became full-time employees, $29 \%$ stayed freelancer and $6 \%$ were registered officially unemployed. The remaining percentages were people that fit in none of these three main groups like mini-jobbers for example. Kiefl (1998) highlighted that stranded entrepreneurs have to face difficulties to find a new job as many employers have prejudices. Furthermore, he speculated that certainly not all the people who stayed self-employed or started to work part-time did this of their own will (Kiefl, 1998). Here we come to reflections about what a business closure can mean for the concerned entrepreneur and his/ her further career. However, Kiefl only speculated about the real meaning of the researched figures as in-depth investigation of the background was not part of the research.

Maroto (2012) conducted a research about negative effects of insolvencies for the people concerned. Her study is based on the data of the National Longitudinal Survey of Youth (NLSY). The NLSY started in the year 1979 as a sample of 6,111 respondents between 14 and 22 years old. By 2008, this sample had declined to 4,723 remaining respondents, who then were between 42 and 50 years old. In 2004 and 2008 information about bankruptcies was also collected. The participants were asked if they had declared bankruptcy in the past, and if yes when. According to Maroto, the cumulative number of bankruptcies from 1979 until 2008 was 589, which means that $12.4 \%$ of the respondents had declared bankruptcy at least once (Maroto, 2012). Maroto (2012) recognised the contribution of the credit market to more inequality in the United States. Bankruptcy is such an example, where circumstances of the credit 
market have extensive influences. She mentioned the positive effect of bankruptcy that enables the debtor to lose his/ her debts, but she also found very negative effects. As the bankruptcy leads to a formal statement on a person's credit history, she saw this as a formalized stigmatisation. "When lenders, landlords and employers access this information through credit reports, it contributes to a system that can exacerbate disadvantage for delinquent debtors, leading to further hardships instead of a new beginning" (Maroto, 2012, p. 100).

Typically, sociologists use the term "cumulative advantage" when talking about increasing inequality. Derived from that wording, Maroto used the term "cumulative disadvantage" for the "relative loss of assets, resources and opportunities for bankrupters" (Maroto, 2012, p. 100). Her research implies that this cumulative disadvantage also contained negative influences of bankruptcies on the labour market. Her research showed that the bankruptcies affected the participants' employment situations. On average, the people, who declared bankruptcy had to face earnings penalties and spent less time working than persons who had not declared bankruptcy in that time period. The effects were more significant for bankrupters with higher education and earnings. Maroto (2012) gave the explanation for her results by the assumption "that employers may statistically discriminate against bankrupters when this information is made available to them" (p. 124).

Her analysis showed connections between bankruptcy and negative labour market outcomes, but she admitted that it could not fully explain this effect and its mechanisms as multiple factors can be involved here (Maroto, 2012).

Unemployment can be a highly destructive experience and probably entails several undesirable effects. There are studies that imply that unemployment undermines the future employment opportunities and earnings and even raises the risk of divorce and early death of the people concerned (Røed, 2014).

"Being unemployed can lead to crises and serious psychological strain at any time" (Ulich, 1987, p. 195). Becoming unemployed has to be considered as a critical event that causes drastic changes in people's life situation (Ulich, 1987).

The loss of security of the means of existence appears as a priority problem of unemployment. However, a full-time job also has other qualities that can have extensive influence on people's well-being. Work supports the ability to follow daily routines, involves social contacts, allows the participation in collective goals and tasks, 
causes a feeling of affiliation and is connected to a lot of activities (Weig, 2009). This implies that people who become unemployed do not just lose their salary, they also lose values like conversations, commitment, affiliation, responsibility and action. According to a study with 104 participants these fundamental changes of becoming unemployed, which can be seen as a turning point in life, have several effects. The people concerned reduce their life goals or shorten their goals' time frames. They for example tend to capitulate, tend to become passive and to lose hope concerning their own situation and escape into the intellectual world, trying to solve problems not through action but theoretically (Ulich, 1985).

On the other hand, the researchers found attitudes and values that influence how the unemployed person experiences his/ her situation. They have a supportive impact and can be seen as the reverse image of the outlined negative effects. Such protective factors are for example having life goals, a differentiated and wide perspective of the future, self-esteem and fulfilling the required actions (Ulich, 1985).

Psychosomatic medicine is based on the idea that our body is influenced by our mind (Friedmann, 2004). This implies a holistic perception of human health understanding body and soul as integrated halves of the whole individual. The use of placebos for example supports the idea that the mind is able to influence the body (Martens, 2016). In India, an experiment showed this influence in a dramatic way. A convict was told that he would be executed by a new method. Then the researchers blindfolded him, scratched his skin slightly and let water drop into a bowl to make the convict believe he would bleed to death. The result was that he really died without losing one drop of blood (Bartens, 2013).

According to Friedmann (2004) the role of a sick person and the expectations that are connected to this sickness are also to be considered. Sometimes people stay within that role even when they are fine again to be treated with care and avoid stress or work (Friedmann, 2004).

There is a high number of documented cases that show a connection between stress and a variety of illnesses, like heart- and vascular diseases (Baum, 1998) and also impacts on the immune system (Themoshok, 1998). 
Ulich (1987) pointed out that aversive life conditions, critical events or wrong decisions can lead to crises that block a person's possibilities to develop and can harm the mental and physical health (Ulich, 1987).

In addition, the health consciousness of a person plays an important role, and this health consciousness seems to be strongly related to his/ her personality. It is for example known that there is a correlation between attitudes like smoking or drinking and personality facets like aggressivity or weak self-esteem (Friedmann, 2004). Well known examples of psychosomatic illnesses are gastric ulcers, hypertension, cardiac arrhythmia, skin diseases and asthma. Especially in combination with the consumption of nicotine, being overweight and a lack of physical activity stress has to be seen as an activator of vascular calcification and its implications like circulatory disorders, heart attacks and strokes (Prager \& Hlous, 2006).

Concerning possible negative effects of insolvencies on the health of the entrepreneurs concerned, Ramsey et al. (2016) researched the influence of financial distress on cancer patients. According to the research team, severe financial distress and insolvencies after a cancer diagnosis appear to be a risk factor for mortality. Their study, which researched 7,682 patients, of whom half were filing for insolvency, gives hints that there might be a connection. However, due to the research design, the question of whether insolvencies have a negative influence on the health of cancer patients could not fully be answered. So it remained unclear for example if a possible explanation for the found relation could also be that cancer patients, who had to face an insolvency, were less likely to complete or have access to follow-up treatment. Whether mortality really increases with the financial distress or with other side effects needs further research (Ramsey et al., 2016).

The reviewed literature about the effects of insolvencies on the entrepreneurs concerned contained studies about failing and its stigmatisation as well as the insolvency as personal crisis for the former leader. Furthermore, researches about the job opportunities of entrepreneurs after an insolvency and health risk through stress and strain were reviewed. 
The literature review suggests that there may be two recurrent patterns about major contributors to insolvencies.

The first theme is, that in most cases the insolvency cannot be traced back to one critical event that led to the crisis, but in general there are clusters of influencing factors.

The second is that it is already generally accepted that the entrepreneurs influence their companies significantly through their behaviours and decisions, and that they also play a crucial role in crises and insolvencies of their enterprises. Although there is this broad acceptance that the entrepreneurs influence the success or failure of their companies, the most reviewed researches do not explain the management-made mistakes or the management weaknesses in detail. Because of the major role that the entrepreneur plays in crisis and insolvency in his/ her company, there is further need for research. As for the prevention of insolvencies, it is not enough simply to know that it is the entrepreneurs' fault or joint guilt and have rough headlines that name the area of his/ her failure. In fact an in-depth understanding of possible pitfalls in daily business life is needed. This leads to the first research question:

RQ1: What key contributors to the insolvencies can be found in the researched cases?

The first objective of this research is to identify the insolvencies' key contributors of the reviewed cases. Here the focus is not just the identification of these key contributors but also their explanation for a deeper understanding. Furthermore, this first research question aims to meet the demand of Hauschildt et al. (2005), who pointed out that corporate crisis research predominantly focused on the end of the crisis (Hauschildt, Grape, \& Schindler, 2005). In order to also explore key contributors in earlier stages, a broad time frame was chosen for the data collection.

The literature further shows that the bankrupt entrepreneur as a person including his/ her character was identified as a key contributor to the insolvency and not just his/ her lack of knowledge or management skills for example. Furthermore, with the New 
Leadership approaches, the trait theories of leadership became reanimated. So the leader's personality again is seen as an essential element (Fraude, 2015).

This led to the second research question of this research:

RQ2: Are there patterns within the personalities of the participants that can be seen as key contributors or their supporters?

The second objective of this study is to analyse the participants' personalities to find out if patterns occur that could belong to the clusters of insolvencies' key contributors. Here the triangulation of the quantitative trait values with the qualitative interview data aims to gain deeper understanding of the leaders' personalities as potential key contributors.

Within the field of the effects of insolvencies for the entrepreneurs concerned, the literature review contained studies about their job opportunities and health risk for example. The reviewed studies deal with narrow fields within this broad topic and concentrate on specific aspects within the effects concerned entrepreneurs have to face during or after their insolvencies. However, the effects of insolvencies on the former leaders do not seem to have been comprehensively researched so far. This led to the third research question of this study:

RQ3: What effects of their insolvencies did the participants experience?

The third objective of this study is to research the effects the participants had to face through and after their insolvencies and how they experienced these effects. 


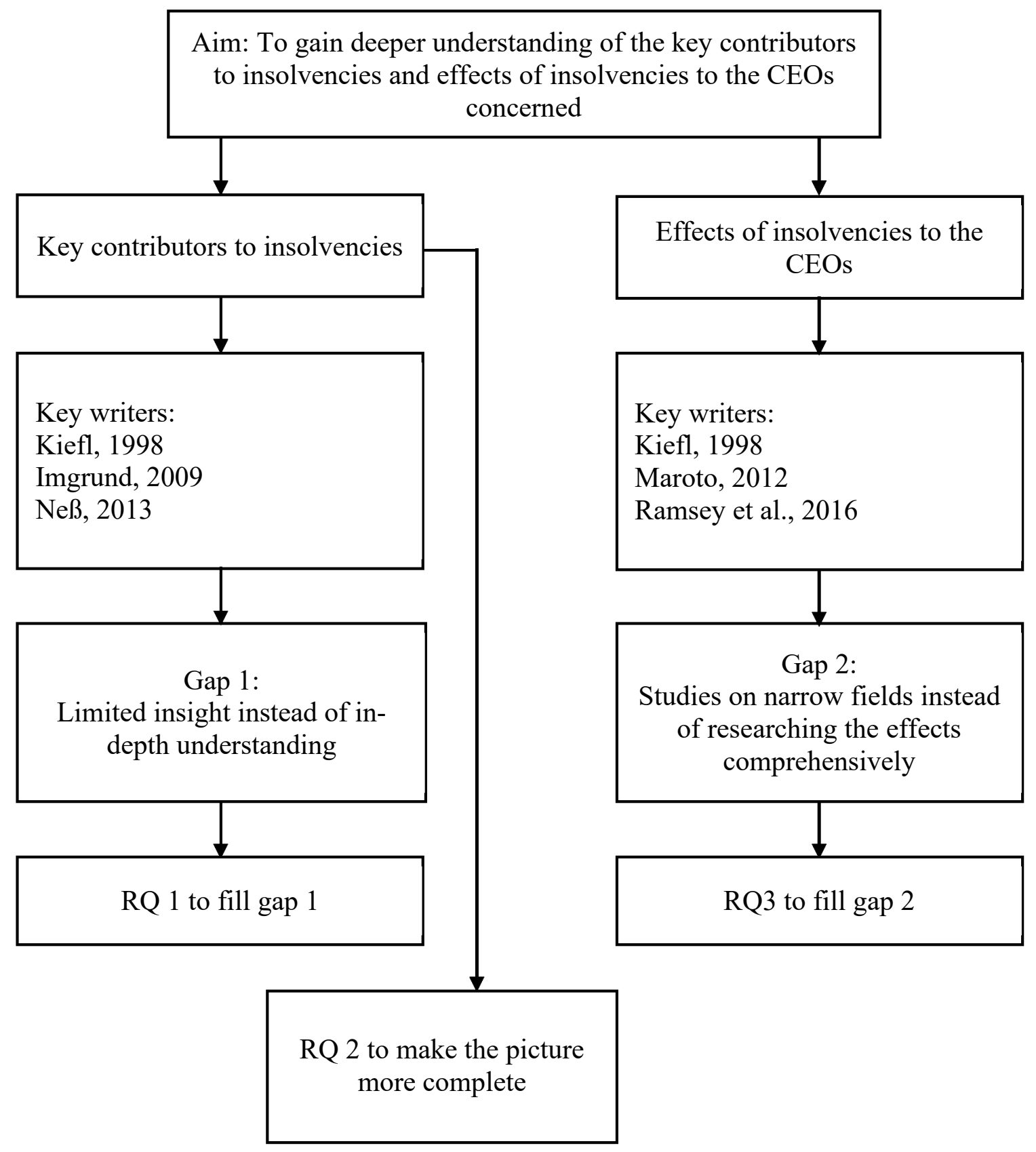

Figure 1: Development of research questions based on literature review

Own presentation

Figure 1 gives an overview about how the research questions of this study were developed.

This study with its three research questions aims to fill the identified gaps within the current knowledge in the field of insolvencies. The research aims to contribute to this current knowledge by gaining deeper understanding of the key contributors to 
insolvencies considering a broad time frame and the entrepreneurs' personality.

Furthermore, the study aims to research the effects that the entrepreneurs experience through an insolvency comprehensively. 
The part research methodology explains the research philosophy of the author and deals with qualitative and quantitative research methods to show the chosen research strategy in line with the research questions.

The following figure shows the research process to explain how this study was conducted step by step.

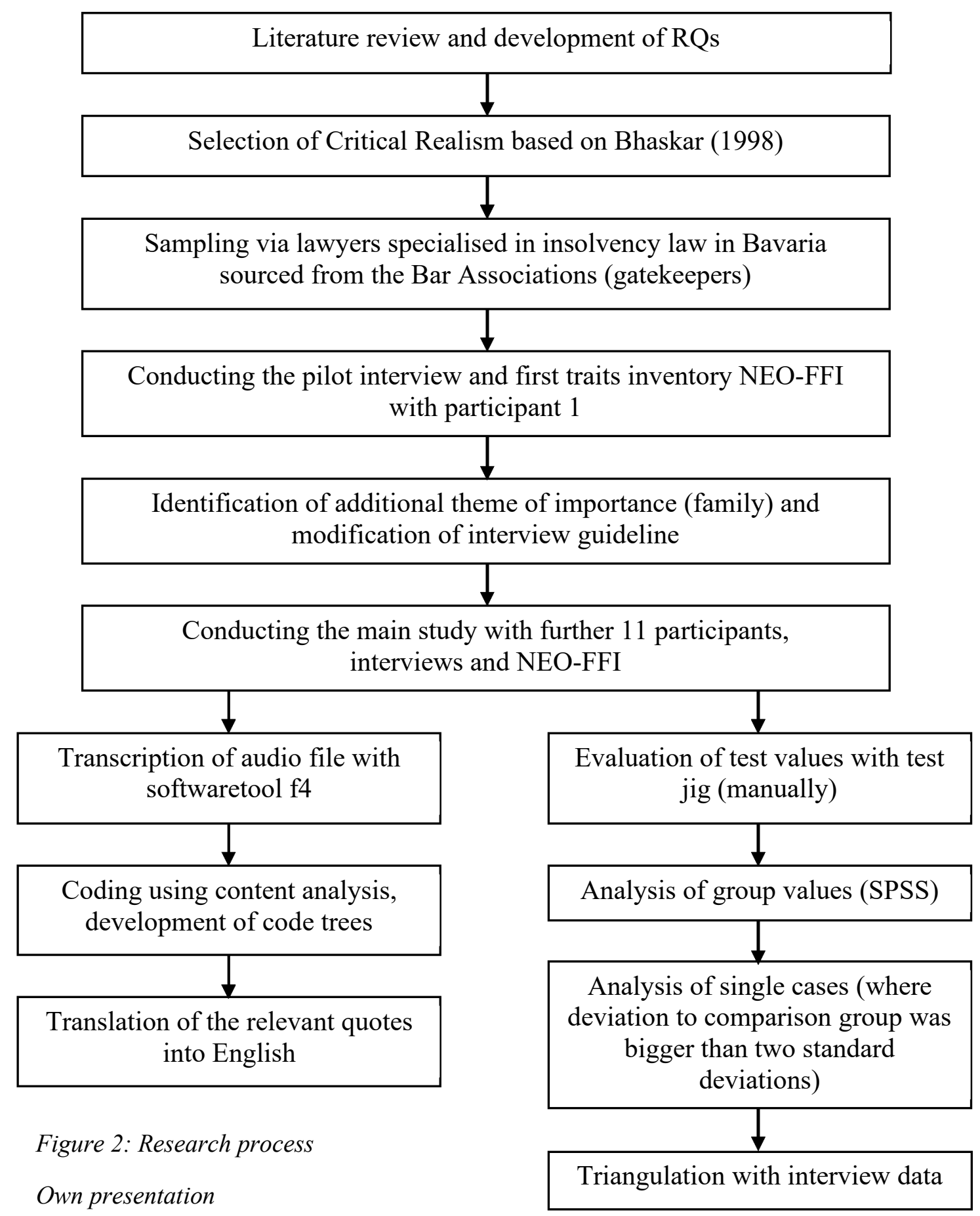


Figure 2 shows that the starting point of this research was a literature review about key contributors to insolvencies and effects of insolvencies for the concerned CEOs. The literature review identified gaps within the current literature that led to the three research questions to fill those gaps as contribution to the current knowledge in the field of insolvencies. The study follows the aim to seek deeper understanding by exploring different layers of reality with their relationships and underlying meachanism. So the paradigm of critical realism according to Bhaskar (1998) was identified as philosophical background. To obtain access to participants who had to face an insolvency as CEOs, lawyers with specialisation in insolvency law were contacted to forward my research request to possible volunteers. This procedure led to 12 participants. With all these 12 participants there was conducted a NEO-FFI questionnaire to capture their personality traits and in-depth interviews about their insolvencies. After participant 1 as the pilot of the study, the rough interview guideline was slightly amended and the topic family was added. The transcription of the 12 interviews was conducted by the researcher herself by using the software $\mathrm{f} 4 \mathrm{as}$ a supportive tool. This software, which provides a consequent link between sound and text file, enables the researcher to work with the interview data very closely. Content analysis of the 12 interviews led to several codes and categories. As a result, two code trees were developed, one about the key contributors to insolvencies and one about the effects of insolvencies for the participants. The relevant quotations then were translated into English to be presented within the findings chapters to show the empirical anchoring of the findings. As there was a small number of participants, the evatuation of the personality traits inventory could be done manually. So the NEO-FFI questionnaires were evaluated with a test jig that is part of the manual package. As a first step the group values of the participants were analysed by a t-test using IBM SPSS Statistics 23.0. In a second step, the single cases were analysed that had a deviation bigger than two standard deviations from the specific normative comparison group. This was done manually by using the comparison tables provided by the test pubisher. Here also gender and age of the participants could be taken into consideration. The results were triangulated with the interview data of the participants.

In the following chapters detailed information about all those steps of the research process will be provided. 
"Questions of method are secondary to questions of paradigm, which we define as the basic belief system or worldview that guides the investigator, not only in choices of method but in ontologically and epistemologically fundamental ways" (Guba, 1994, p.105). That implies that every research also represents the researcher him-/ herself through the choices the study contains. So it is essential to be completely aware of one's own standpoint within the diverse philosophical positions to create a consistent piece of work.

The research philosophy can be seen as the frame of the study. Or, as Saunders (2009) explains in a figurative way, as the outside layer of the research onion, that encloses, supports and protects all the other questions and choices of the research project. "This over-arching term relates to the development of knowledge and the nature of that knowledge" (Saunders, 2009, p. 107). So the researcher's own research philosophy contains assumptions how he/ she defines terms like knowledge or truth. This has an essential impact on the study as research aims to create new understanding. The personal way the researcher sees the world leads to his/ her choice of strategies and methods and finally to the statement which is seen as valuable knowledge (Saunders, 2009).

This implies that the researcher him-/ herself is a source of potential bias. Within the research process he/ she makes assumptions and decisions that go in line with his/ her picture of the world. However, it should be remembered that this is always just one picture out of various possible pictures.

Ontology and Epistemology contain primal philosophical assumptions about the view of reality and knowledge. The following chapters will clarify the philosophical background of this research. 
Ontological questions deal with the way people see the world and the nature of reality. This includes assumptions about the character of operations within that world. The two poles that can be found here are objectivism and subjectivism (Bryman, 2007). An objectivist believes that the world with its social entities exists in reality. The social entities are external to social actors. The idea of the existence of social phenomena as external facts contains the assumption that these phenomena are independent of social interaction and beyond the researcher's influence. Because of that independence, those phenomena can be measured and described (Bryman, 2007). Subjectivism on the other hand does not see social entities as independent and external to social actors, but created though social interaction. The subjectivist believes that the social actors are the origin of all social phenomena. So "it is necessary to explore the subjective meanings motivating the actions" (Saunders, 2009, p. 111).

Critical realists stand between the mentioned positions of objectivism and subjectivism. In this context, some writers speak about critical realism as the third way (Robson, 2002). The critical realist ontology follows a differentiated and stratified approach and divides the social and natural world into three different domains: the real, the actual and the empirical (Bhaskar, 1998).

According to Sayer (2000), the real domain contains all objects that exist naturally and socially including their structures and powers and is independent of people's experience. The actual domain then is about what happens when the powers of the real domain are activated and producing events and experiences. The third domain, the empirical one, consists of what people experience directly and indirectly (Collier, 1994).

These different domains can be seen as strata or layers of the natural and social reality. Each of these strata has its own mechanisms (Collier, 1994).

Sayer (2000) describes that stratified aspect by using the example of water, because water does not behave like its components hydrogen and oxygen, which are highly flammable (Sayer, 2000).

This research follows the ontology of critical realism. The world is seen as a conglomerate of different levels and facets. To stay with Bhaskar's (1998) divison of the social and the natural world, the study researches within real, actual and empirical 
domains (Bhaskar, 1998). Here the real domain can be seen as the participants of this research as naturally and socially existing objects. Their insolvencies build the actual domain as an outcome of the activated powers of the real domain, an outcome of actions and decisions of the participants. The third domain, the empirical one, contains the experiences that the participants had before, during and after the insolvency. Of special interest for this research are not just the mechanisms within one layer but also how the different aspects influence each other. The researcher of this study is seeking deeper understanding of these influences and mechanisms.

\subsubsection{Epistemology}

Epistemology contains the perception what is valuable knowledge in a discipline. In analogy to ontology also this field can be understood as a continuum of different positions with two opposite poles. On the one side there is the researcher who prefers the collection and analysis of measurable "hard facts". This researcher stands in line with the natural scientists and is called positivist. On the other side, there is the researcher who is interested in feelings and motivations of social actors - what could be named as "soft facts" - the interpretivist (Saunders, 2009).

The controversy between these two poles can be seen as a discussion "between an emphasis on the explanation of human behaviour that is the chief ingredient of the positivist approach to the social sciences and the understanding of human behaviour. The latter is concerned with the empathic understanding of human action" (Bryman, 2007, p. 18).

This research follows the idea that neither hard nor soft facts can be seen as generally more or less valuable than the other - it always depends on the question that they want to answer. As a critical realist, the researcher is seeking deeper understanding of the world by obtaining "knowledge about underlying casual mechanisms" (McEvoy, 2003, p. 412), in this case deeper understanding of key contributors to and effects of insolvencies for the concerned entrepreneurs and the underlying (e.g. psychological) mechanisms. These generative mechanisms deal with the individual's structures, 
powers and relations, and seek to explain what really happens under the observable surface (Harré, 1970).

Critical realism can be seen as a paradigm that shows the possibility of a shared ontology and epistemology for the natural and the social sciences (Sayer, 2000). On the one hand, it criticises the positivist view that neglects the importance and perspective of social actors (Blaikie, 1993), and on the other hand, it points out that social conditions and actions can have real consequences, whether or not they can be observed (Sayer, 2000).

Going in line with this idea that a critical realist stands between the two poles of positivism and interpretivism, qualitative as well as quantitative methods were chosen for this reserch. Bryman (1988) in this context pointed out that it is appropriate to use a different method to investigate another layer of reality. Following this idea, the NEO-FFI as a quantitative method was added to this qualitative research to investigate the possible influence of the participants' personality on the identified key contributors.

\subsubsection{Philosophical Research Paradigm}

The sum of the above discussed philosophical assumptions builds the philosophical paradigm of the researcher. Guba (1994) explains this with the following words: "A paradigm may be viewed as a set of basic beliefs (...) that deals with ultimate or first principles. It presents a worldview that defines (...) the nature of the "world", the individual's place in it, and the range of possible relationships to that world" (Guba, 1994, p. 107).

A philosophical paradigm, like here in this study the critical realism, can be seen as the basis of the research consisting of epistemological and ontological pillars. In line with that idea, Filstead sees these assumptions about the social world as the needed philosophical and conceptual framework for every study (Filstead, 1979).

Guba (1994) states that, "both qualitative and quantitative methods may be used appropriately with any research paradigm" (p. 105). Every method, whether quantitative or qualitative, is one way of drawing a picture of the social world. One 
method may not be generally better or worse than another one - they just draw different pictures (Denzin, 1994).

This qualitative research also contains the use of a quantitative method: A personality traits inventory was conducted to gain deeper understanding of the participants personality and its potential influence on the insolvencies. This was done in addition to the narrative interviews that were conducted to explore different aspects of key contributors to and effects of the insolvencies for the participants. This mixed method approach was chosen as it appeared an appropriate way to gain in-depth understanding of the reseach field which is the aim of a critical realist researcher. 
A sample is the segment of the entire population that is selected for the research project. It can be seen as a subset of the population (Bryman, 2007). In some studies, it might be possible to collect data from the entire population, but for all research projects where that would be not practicable a sample has to be selected (Saunders, 2009).

For this research, the entire population were all those who that had to face an insolvency in Germany. In fact there is a website where all bankruptcy courts present their insolvency cases. However, according to $\$ 2$ of the regulation about official declarations within insolvency procedures on the internet, an unlimited research is just possible for the previous two weeks. However, for this study especially cases that date back some time were of interest to be able to research the effects of the insolvencies for the participants. This and the limited feasibility of the available research tool for older cases led to the following sampling procedure:

On 19 December 2013 an online research about the bar associations of Bamberg, Munich and Nuremberg was conducted to identify the Bavarian lawyers specialised in insolvency law. This resulted in a list of 231 people (43 listed in Bamberg, 135 listed in Munich and 53 listed in Nuremberg).

In a second step, letters were sent to them all on 07 January 2014. In those letters, the research project was introduced to those lawyers including the appeal to forward the letter to possible participants. On 28 January 2014, an email was sent to the 231 lawyers as a reminder with a scan of the letter as attachment.

Through this procedure, twelve participants from all over Bavaria were acquired for this research. They all took part in the interview as well as in the personality questionnaire.

Participant 1 was male and 60 years old when he took part in this research. He studied business administration, and after getting his diploma he worked for two years in a large company in strategic planning. At the age of 28, he took over his father's enterprise. It was an engineering company with 50 employees that was producing stamping parts and tools. He led and developed this company. About twenty years later, it had a branch office in the Czech Republic and about 700 employees in total. 
Then he sold that company and invested the money in a company in Poland. He bought $50.1 \%$ of this Polish company, which was also in the engineering sector. However, participant 1 was betrayed by his companions. He transferred money again and again without realising that his companions did not use it to improve the company. They established and built a second company instead without the participant's awareness but with his money. His company was insolvent about 4 years after he had bought it.

At about that time, when he invested in Poland, he got divorced from his first wife, and legal proceedings were started because of his corporate sale that he had not paid taxes on, as he thought he would have been a Czech resident at that time. The fiscal authorities were the biggest creditor in his insolvency because of those tax debts, and lead to an insolvency as a natural person additionally to the business insolvency.

Participant 2 was female and 66 years old when she took part in this research. After school, she studied psychology and economics, but after four semesters she became pregnant and dropped out of university. She then completed a traineeship in a market research institution. At the same time, she got divorced from her husband.

After her traineeship, she worked at a specialist printer and by the age of 32 she got first managerial responsibility. She stayed at that printer for a further 18 years and rose to become the publishing house manager.

Then the CEO changed and the new one suggested that participant 2 should work selfemployed. She followed that suggestion and offered communication services. She went insolvent after 10 years of entrepreneurship at the age of 60 .

Participant 3 was male and 46 years old when he took part in this research. He studied chemistry and pharmacy. During his time at university, he met his wife, and they are still together.

Participant 3 started his business right after his doctoral studies in chemistry. In the course of his doctorate he had applied for a patent and because of this a pharma company contacted him and asked for these specific patent-protected chemical research intermediates. This was the headstone of his business.

He went insolvent after 7 years of entrepreneurship. 
Participant 4 was male and 59 years old when he took part in this research.

He started his career as retail salesman. When he started a family, he went to an automotive factory as an unskilled worker as he could work more there and so also could earn more money. The CEO and founder of that company kept an eye on him, and so he soon was working there in the purchasing department and finally became his successor as director and (partial) owner. He had led the company for more than 20 years when it went insolvent.

Participant 5 was male and 63 years old when he took part in this research. He did an apprenticeship as an export merchant. He married at the age of 19, and they are still together.

Participant 5 worked in a small company that created processes and IT support for bank security. Soon he became partner, and they developed the company, and established offices in different German cities. In the eighties, they sold their enterprise to a larger one. Then he realised that working within this new, lerger company did not satisfy him, and he established a new company with the same services and customers again.

He was leading this new, self-established company for about 20 years before it went insolvent.

Participant 6 was male and 65 years old when he took part in this research. He did an apprenticeship as engine builder and studied engineering. After his studies, he worked in a company as employee, where he was supposed to take the lead of the construction design department. However, he lost that job after two years.

Because of problems of getting a new job, he founded his own construction design office together with a companion. After about ten years, this companion left the company, he got divorced from his first wife and had to go to hospital because of prostate cancer. After that time of changes, he bought an engineering company. He was leading this engineering company for 13 years until it went insolvent. At that time, he was living in a new relationship.

Participant 7 was male and 49 years old when he took part in this research. 
He grew up with his aunt, who was living abroad, as his mother was a single parent and unable to cope with participant 7 and his brother. He originally came from Belgium.

Abroad he did an apprenticeship as a toolmaker at a large company. After serving in the army for two years, he returned to that company and worked there in the logistics department. In rotation of two to three years there followed different positions in different sectors and companies.

His wife originally came from Germany. When she got a job offer from a large German company, they decided to move to Germany.

Participant 7 started working as a process manager in a company producing toys here in Germany. Soon he became the director there as the former one retired. Three years later participant 7 had to face the insolvency.

Participant 8 was male and 67 years old when he took part in this research. He did an apprenticeship as an insurance broker. Immediately after this apprenticeship, he married and worked self-employed as an insurance broker for 18 years.

Then he started a new business as consultant with a focus on insolvencies and reconstruction. In this position, he made contact with a struggling tooling company. He bought shares in that company and became their CEO. Five years later he had to file for insolvency.

Participant 9 was male and 57 years old when he took part in this research. He studied business administration. Already as s student he had started dealing with tapes and floppy disks and later software. So actually, he was self-employed his whole professional life.

He described his entrepreneurship with many ups and downs and struggles. At the age of 55 he went insolvent.

Participant 10 was male and 74 years old when he took part in this research. He studied architecture and construction engineering. Already during his studies, he had started working in his father's construction company. He married his wife at the age of 25 , and they are still together. 
He developed the company, established different locations and had 1800 employees at peak. However, he went insolvent in the year 2000 because he had given a high debt guarantee to a customer who went insolvent himself.

Participant 11 was male and 63 years old when he took part in this research.

He studied forestry and worked as a public officer in the forestry district for ten After that period, he became self-employed within that sector with a timber harvesting and trading company.

He described his entrepreneurship with many ups and downs and struggles and went insolvent after 23 years of self-employment.

He and his wife broke up during his entrepreneurship and lived apart. However, she stayed with him in the company as an employee in the office. After the insolvency, they got divorced.

Participant 12 was male and 54 years old when he took part in this research. He was born in the German Democratic Republic (GDR). He did an apprenticeship as a fitter and was working as fitter in a large bakery. After an accident on the job, he did not work until the end of the GDR. He married, and they are still a couple.

After the German reunification, he worked as a sales man and rose to become the sales director there. When the company was sold, he lost his job. After some other jobs, he worked as a self-employed sales representative for a company selling bibles and atlas facsimiles.

One day he saw an advertisement in the newspaper that a supermarket chain was looking for a self-employed shop manager. He became that shop manager but after 4 years he was insolvent.

The group of participants consisted of one woman and eleven men. The participants were between 46 and 74 years old at the time of data collection. They had been the directors and (at least) partially owners of the enterprises that went bankrupt. The enterprises were small and medium-sized. The smallest was a sole trader, the biggest had 1800 employees at peak. The SMEs were operating in different industries and market sectors. One was offering marketing services, one did enterprise resource planning for SMEs, one created processes and IT support for bank security, one was 
an engineering company, two were supplying the automotive industry, one was producing and trading timber, one was operating in the wooden toy industry, one was synthesising chemical research intermediates for the pharma industry, one was operating in the construction sector, one was a supermarket, and one company was producing tools.

Due to this sampling process and the small number of participants compared to the Population, this is not a representative sample. Especially the aspects of gender and age will be addressed within the discussion of the NEO-FFI findings (second research question). 
In the literature many different definitions of qualitative research can be found. According to Denzin and Lincoln (1994), "Qualitative research is a situated activity that locates the observer in the world. It consists of a set of interpretive material practices that make the world visible. These practices transform the world. They turn the world into a series of representations (...). At this level, qualitative research involves an interpretive, naturalistic approach to the world. This means that qualitative researchers study things in their natural settings, attempting to make sense of (...) phenomena in terms of the meanings people bring to them" (p. 3).

The interviews with the participants followed that approach. The applicants explained their point of view, their feelings and motivations. It was their choice where the interview should take place as it was much appreciated that they should feel comfortable while getting interviewed. Most of the participants wanted to be visited at home. That they could choose the location freely seemed to be one of the success factors of these interviews, as at least in terms of location they could stay within their comfort zone. The researcher was welcomed in their homes and although meeting for the first time, private information was shared within a positive atmosphere.

According to Kvale (1996), not only are the insights the researcher obtains through the interviews essential, but also the personal contact is an important experience. "It is a specific form of human interaction (...) neither as anonymous and neutral as (...) a survey questionnaire, nor as personal and emotional as a therapeutic interview" (Kvale, 1996, p. 125). The interviewer obtains emphatic access to the participants' world (Kvale, 1996).

In addition, in the case of this research, the personal contact seemed to be very valuable - not just for the researcher to obtain deep and personal insights, but also for the participants. It seemed to be a positive experience for them to meet a person interested in their story and to whom they can talk personally but also to a certain extent anonymously as a confidentiality agreement was signed, and they did not meet the researcher beforehand or afterwards. In some cases, it even seemed as if they had the need to talk about their insolvency, a topic that is tabooed and probably not too much talked about in daily life. 
An interview is a direct colloquy with a person about their experiences and behaviours (Jäger, 2013). There is no method that can capture every facet and variation in human experience, but what an interview can capture is an account about what the participants have done and why (Denzin \& Lincoln, 1994). This implies that interviews can be seen as an appropriate method to get access to people's minds, to their feelings, motives and attitudes. Also, according to Byrne, "qualitative interviewing is particularly useful as a research method for accessing individuals' attitudes and values - things that cannot necessarily be observed or accommodated in a formal questionnaire” (Byrne, 2004, p. 182).

Within an interview, knowledge is created through the combination of the interviewer and the interviewee (Kvale, 1996). To achieve this, the interviewer on the one hand has to be able to retrace and understand the participant's experiences, and on the other hand has to objectify the participant's experiences to a certain extent to be able to follow his/ her own conclusions instead of just adopting the participant's ones (Bohnsack, 2014).

There are plenty of different interviewing approaches known in the qualitative social research, such as thematic, problem-oriented and biographical approaches for example. Often the differences between the various approaches are not really strict or concise. However, what they have in common is clear. All those interviews support an open communication as they include no limitations of the participants' answers. This can be seen as the contrast to the standardised interviews used in statistically oriented social research (Nohl, 2017).

The interviews in this research were conducted without any limitation on time. All participants could talk as long as they wanted and needed. The shortest interview took 31 minutes, the longest interview took 1 hour and 53 minutes.

The conducted interviews followed the biographical interview approach according to Schütz (1983). The fundamental idea of a narrative interview is that it aims to capture information within subjective meanings and structures and that might not become obvious through a systematic interrogation (Mayring, 2002). 
This approach was chosen to get a good amount of unbiased information not influenced by the researcher's ideas about what could be relevant points. Furthermore, the narrative interview approach allowed data to be collected over a broad time frame and not just about the end of the corporate crisis. Additionally, a rough guideline was prepared to make sure that all areas of interest would be covered and nothing could be forgotton during the interview situation.

Schütz' approach seemed to be an appropriate one for this research as with the insolvency the participants should describe a period of their life, a part of their biography. To facilitate communication and to enable an easy start for the participants to narrate, all the interviews began with the same request: "I would like to get to know you a bit better, so to start with, could you please tell me your professional and personal life history along general lines?"

So the participants started to talk freely and in a non-biased way, and often most of the points of the interview guideline had been covered without having to ask explicitly. Of course, with this procedure data was also presented that was not of interest for answering the research questions. However, this was accepted for a positive conversation atmosphere. In interviews, the contact between interviewer and participant is an important success factor that also requires the buidling of a conversation relationship (Froschauer \& Lueger, 2003). So this extra time that was spent listening to the participants when talking about topics that were less relevant for the research can be seen as contribution to a well-working conversation relationship. Typically, after asking such an opening question, the researcher listens to the participant's narration for a longer time. In this first part of the narrative interview the interviewer is asked to hold off to give the narration time and space. This is necessary as the narration as a communication scheme knows three compulsions that challenge the participant in this situation: the compulsions of design development, condensation, and detailing (Froschauer \& Lueger, 2003).

The compulsion of design development here means that the participant has to find a comprehensive and adequate form of presentation in a limited time. On the one hand, the narration has to contain all points that are relevant for the participant, and on the other hand, the narrator has to make his/ her story clear and comprehensible. The narrator is subject to a compulsion of condensation as he/ she cannot tell the whole information in detail but has to select and point out the topics and points that are 
relevant for the specific conversation situation. However, as the narration is addressed to the interviewer, the participant also has to pay enough attention to details that are important to understand the different aspects of the narrator's story. This compulsion of detailing makes the narration feasible for the interviewer (Froschauer \& Lueger, 2003).

In the second part of the narrative interview, the researcher enquires about previously mentioned topics to gain deeper insights (Nohl, 2017). To do this, so-called immanent questions are chosen that do not seek to interrupt or disturb the participant's flow of words but which "support the narrative creativity" (Schütze, 1978, p. 34).

As a third part of the interview, the researcher also asks questions about topics that were not previously mentioned to cover all areas he/ she needs for the study. In this last part, the researcher can also ask the participant to give reasons or further explanations about his/ her motives and behaviours (Nohl, 2017). For this last part, the mentioned rough interview guide was used to make sure that all areas of interest were covered and no field was missing.

\subsubsection{Transcription}

All interviews were recorded by a dictation machine with the agreement of the participants. The transcriptions of the interviews were completed by the researcher. Within this process, names of persons, places and companies were anonymised. No transcript can fully present the sound file as well as no sound file can fully present the real interview. Every medium highlights some aspects but also neglects some. In this context, the method of transcription is also important as it has to fit the research and the questions this research wants to answer (Knoblauch, 2011). In contrast to a complete or selective protocol, the transcription stays with the original structure of the narration and reproduces the text word by word. Depending on the research questions, there are different methods of transcriptions. It is possible to use the international phonetic alphabet to capture the accent and dialect of the speaker, the literary translation into the conventional alphabet to express the dialect of the speaker, or the transformation into literary language if the dialect is not of interest for the research. Furthermore, comments about laughing, emphasises or pauses can be useful 
to capture relevant information (Mayring, 2002). This study concentrates on the content of the interviews. Because of that focus, the transformation into literary language was used, and language and punctuation was slightly polished.

The software tool $\mathrm{f} 4$ was experienced as useful support for the researcher to transcribe the interviews. The change of speaker was made obvious by starting a new line within the transcript. The interviewer is betokened by an I and the participant by a B (for German "Befragter", which means respondent). With the $\mathrm{f} 4$ software it is also possible to regulate the sound reproduction by mouse click, hot key or foot switch. With the return button, the change of speaker is executed automatically. Furthermore, the time mark of the interview is saved in the text file with every paragraph. This provides a consistent link between sound and text file. After transcription, the interviews were saved as rich text files for further proceeding.

As a general rule, the time that is needed for transcription varies between four- to eightfold of the real interview length (Rädiker \& Stefer, 2007). Within this research, the sixfold time for the transcription of the interviews was needed in the best cases. There were also interviews where the transcription process was much slower as the participants often stopped in the middle of a sentence or spoke unclearly. In one interview, furthermore, some side noises were recorded that slowed transcription speed down significantly. In the worst cases, the twelvefold length of the real interview time was needed for the transcription.

\subsubsection{Analysis of the Interview Data}

For analysing the data of the transcribed interviews, content analysis was seen as an appropriate method. According to Früh (2004), the sense of this method is to reduce complexity in huge amounts of data with regard to specific research questions (Früh, 2004).

For this analysis, an inductive approach was used. While within the deductive approach, the researcher starts with an existing theory to evaluate the qualitative data, here the starting point was the data collection, to then explore it and see which topics occur that are worth concentrating on. In such an inductive themes' analysis, the subprocesses of data collection, analysis, development and verification of propositions go 
hand in hand as interrelated segments of an interactive overall process (Saunders, 2009). This can be seen as a sensitive process that requires active construction, fluency and methodological competence as the categories do not just appear automatically (Kuckartz, 2016).

So the analysis in this case does not just follow the data collection (and data transcription), but it also occurs already during the collection of data (Kvale, 1996). As a result of this interactive nature of data collection and analysis, the researcher recognises important patterns and relationships already as he/ she collects the data (Saunders, 2009). As propositions appear out of the data, the researcher tests these by comparing them against the further cases of the study (Erlandson, 1993).

The third aspect of this process is the re-categorisation of the existing data according to new aspects. Strauss and Corbin also suggest adjusting the future data collection according to the findings of the first interviews (Strauss \& Corbin, 2008). This adjustment of data collection, for example the amendment of the researcher's interview guideline or the addition of special questions was rejected by the researcher of this study. Doing this, the interviewer has to take care not to influence the participants by bringing up topics that they would not have mentioned. Otherwise, the researcher is in danger that in his/ her study the hypotheses become self-fulfilling prophecies. Furthermore, the conducted interviews lack comparability with each other when changing parameters of the data collection during the process. Because of these dangers, the interviews of this research were not amended during the data collection process.

According to Froschauer \& Lueger (2003), such themes-analytical approaches are an appropriate method for researches that have to handle large amounts of data, concentrate on the apparent content of words, such as opinions or experiences, and include a recapitulatory preparation of different aspects (Froschauer \& Lueger, 2003) as this research does.

The first step of data analysis was the coding with regard to the research questions one and three. So all interviews were scanned concerning key contributors to the insolvency as well as concerning the consequences for the CEOs.

Coding is a central step within the process of data analysis. Berelson (1952) points out the importance of these categories by stating that every content analysis is only as 
good as their coding. The developed categories can be seen as the quintessence of the investigation that contain their substance (Berelson, 1952).

According to Wenzler-Cremer (2007), there are three approaches to developing codes out of the text: Codes can appear out of the data by asking questions and comparing different interviews (Wenzler-Cremer, 2007). This is the approach that predominantly was used to answer the research questions of this study. The second approach is the use of so-called in-vivo codes. These are concise terms that the participants use in their interviews (Wenzler-Cremer, 2007). With this approach for example, the topic resilience found its way into this research. The third approach of coding is the use of previous knowledge to include concepts that might be relevant for the research questions (Wenzler-Cremer, 2007). This approch is seen critically as it stands in contrast to the common postulation to meet the data unprejudiced. So this third approach of coding was not used for this research. One can argue that previous knowledge was already used to formulate the research questions and so indirectly also was used for coding. However, the theories about reasons of insolvencies are extremely universal and basically just agree that there are normally clusters of reasons for companies to go bankrupt. This vague theoretical view was actually one of the reasons to dig deeper into the topic to gain better understanding but did not seem to bias the analysis as previous knowledge.

The coding was done manually. The transcription software $\mathrm{f} 4$ supported the manual process, as the time marks in the text files enabled the researcher to easily jump into the connected positions in the sound files. So the researcher could listen to the applicable sequences of the interviews again and dive deeply into the data. After this coding process, the codes were organised into categories. Also, this was done manually.

With regard to the research questions, two code trees were built, one for key contributors to the reviewed insolvencies and one for effects of the reviewed insolvencies for the entrepreneurs.

The two code trees were growing fast in the beginning. However, their growing slowed down during the process as codes that were already noted appeared again. Finally, the codes were structured and categorised as presented in the following figures. On the left there are the categories, which can be seen as headlines containing 
a connected bundle of codes. On the right there are the single codes marked with bullet points.

\section{key contributors to the reviewed cases}

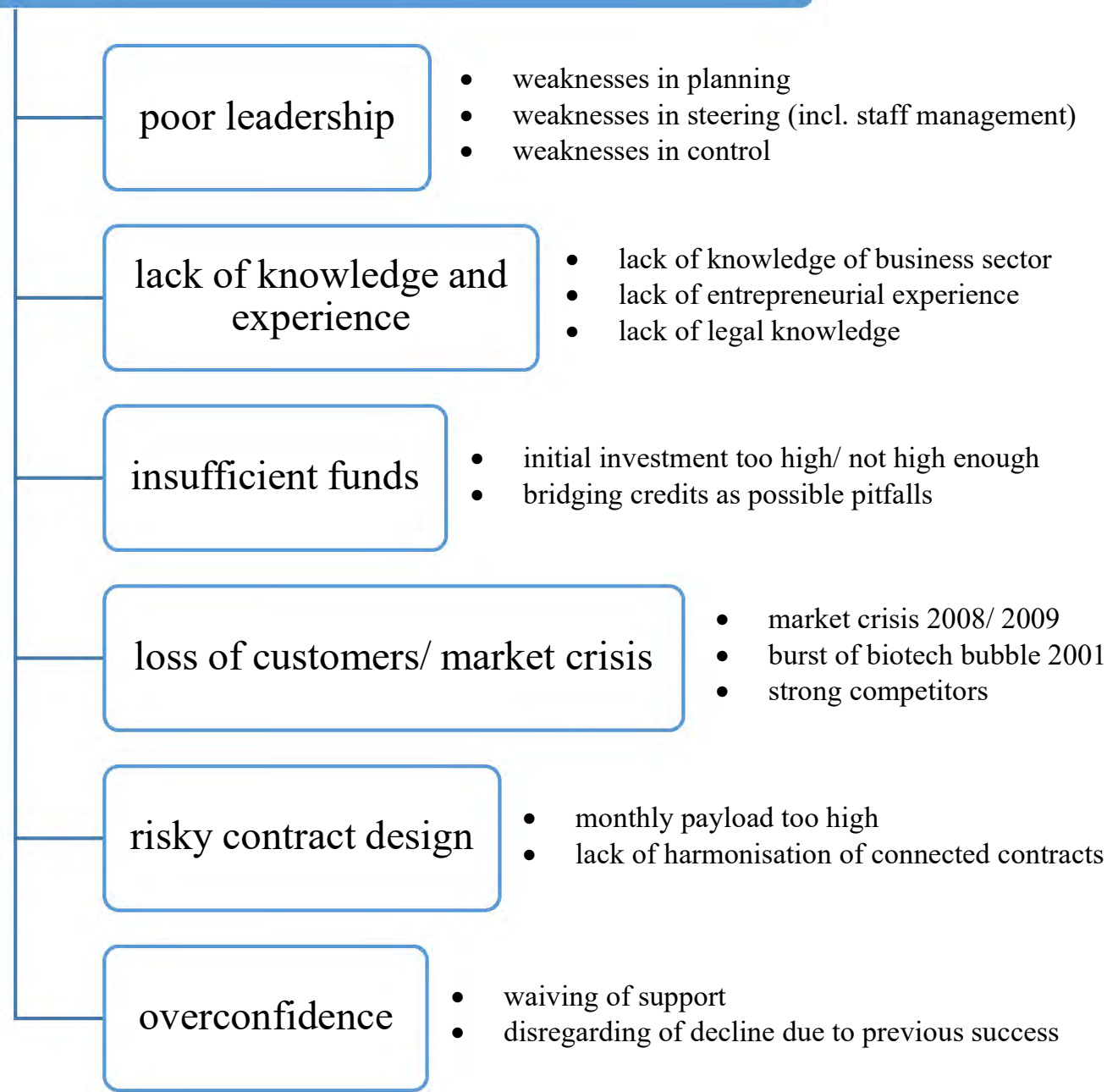

Figure 3: Code tree of key contributors to the reviewed insolvencies

Own presentation 


\section{effects experienced by the participants}

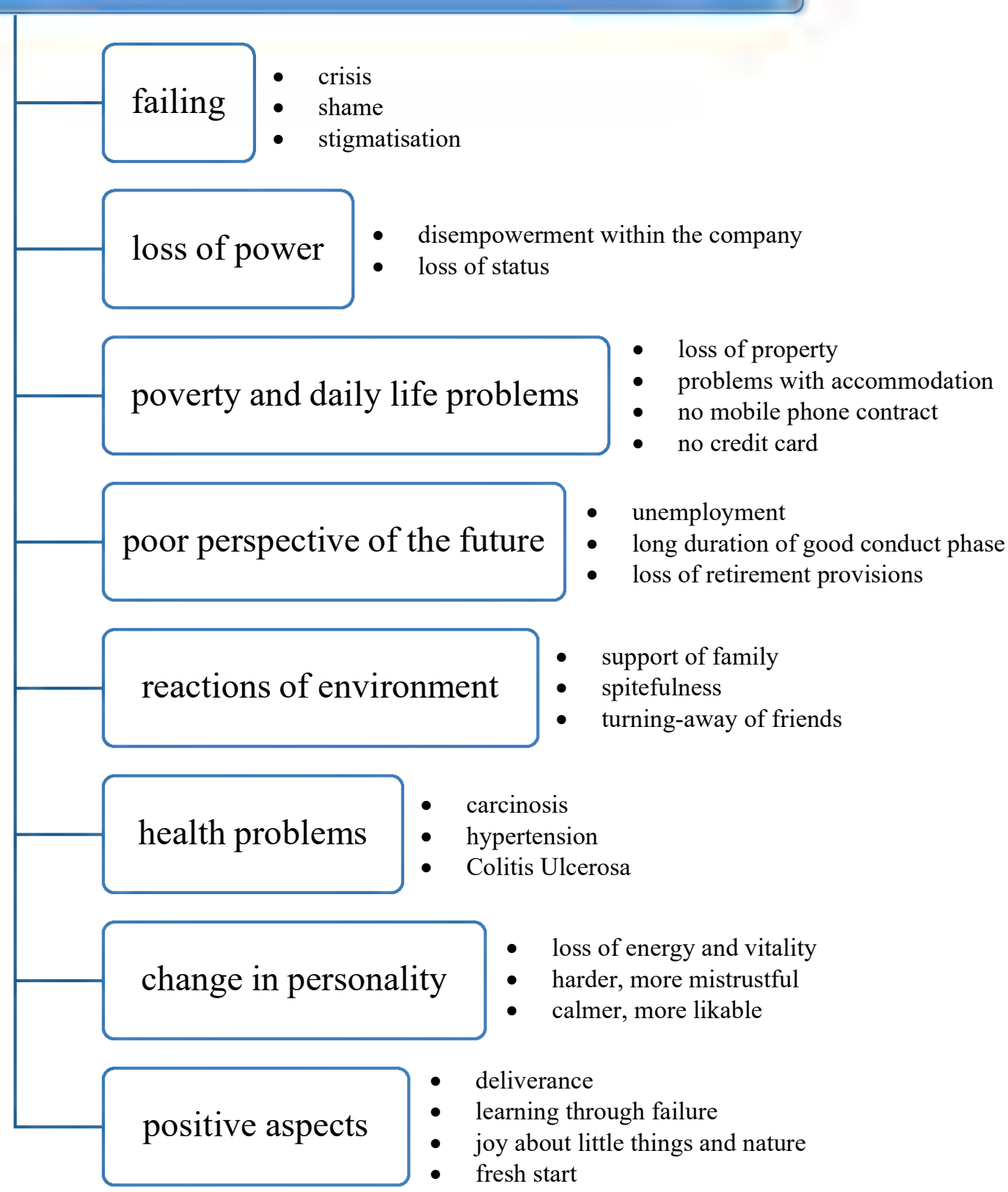

Figure 4: Code tree of effects of the insolvencies experienced by the participants

Own presentation

These categories will be discussed in detail in chapter 6.1 about the key contributors of the insolvencies in the reviewed cases and in chapter 6.3 about the effects of the insolvencies for the participants. 
The researcher is aware of the limitations of the chosen method. Of course, a content analysis can always only be as good as the documents that it is analysing (Scott, 1990). This is why special focus was given to the interviewing and transcription processes as explained in the previous chapters.

Furthermore, it is hard to avoid the fact that the researcher, with his/ her cultural and personal background, influences the codes and cathegories unconsciously (Garfinkel, 1967).

The study is located in southern Germany. The German Law builds the background and framework of this research as explained in chapter 2. So the whole research is based on a specific regional, legal and cultural area.

Sometimes content analysis is accused of being an atheoretical approach as the emphasis can be placed on what is measurable instead of on what is theoretically significant or important (Bryman \& Bell, 2007). This research aims to gain deeper understanding of insolvencies with focus on the entrepreneurs' experiences before, during and after the insolvency. It contributes to academic knowledge as well as being applicable to give advice to practitioners. This double function was enabled by a huge amount of data illuminating the field from different angles.

Strengths of content analysis are the handling of large amounts of data (Froschauer \& Lueger, 2003) and the generation of information of social groups that are difficult to gain access to (Bryman \& Bell, 2007).

Furthermore, content analysis is a transparent method (Bryman \& Bell, 2007). As will be pointed out in the following chapter about the quality of qualitative research more explicitly, this study follows the criterion of intersubjective traceability (WenzlerCremer, 2007). Transparency about methods and processes is highly appreciated. Another reason that led to the choice of content analysis for this research is the flexibility of the approach. "It can be applied to a wide variety of kinds of unstructured information" (Bryman \& Bell, 2007, p. 320).

Although content analysis has its limitations, it was seen and chosen consciously as a valuable and appropriate method for this research. 


\subsubsection{Quality of Qualitative Research}

In quantitative research, the quality criteria of objectivity, reliability and validity have been well-established for decades. However qualitative research is lacking such a consensus concerning its quality criteria. Compared to quantitative research the topic here is younger and approaches seem to be emerging instead of being fully developed and accepted (Lüders, 2004).

In the UK, the discussion about quality criteria of qualitative research is further advanced than in Germany. So the British Psychological Society for example postulated a certain contingent of qualitative methodology for the approval of degree programmes. Also the rising number of academic publications within this field show the importance and up-to-dateness of the topic (Flick, 2007).

Within the disagreement of approaches, there are three possible methods emerging: The use of the well-established quality criteria of quantitative research, the refusal of the criteria objectivity and reliability while concentrating on validity, and the use of other appropriate criteria for evaluating the quality of qualitative research (Steinke, 2007).

At first sight, it might seem possible to use the established criteria of objectivity, reliability and validity also for qualitative research. However, the researcher has to be aware that qualitative research then will look inferior to quantitative research, as these criteria were developed for quantitative methods and cannot fully cope with qualitative methods too. The criteria are simply not transferable into qualitative research (Steinke, 2007).

Objectivity in quantitative research is defined as independence from the researcher in procedure, evaluation and interpretation (Laux, 2008). Of course, also in qualitative research and especially in interviewing the researcher has to take care not to bias the data by his/ her actions and behaviours. Nevertheless, the data collection through interviews can be understood as a process created by both the interviewer and the participant. Through the face-to-face-situation, there will always be a stronger influence of the researcher just because of his/ her presence than in an anonymous questionnaire. Because of this, the criterion objectivity as we know it from quantitative research cannot play the same role for qualitative research without amendments (Flick, 2007). 
Reliability in its original sense has to be seen as stability of data and results within several data collections. For the evaluation of qualitative data, this is also not suitable as the identical revision of a narration in repeated narrative interviews suggests an arranged version rather than a high reliability (Flick, 2007).

Some qualitative researchers refused the criteria objectivity and reliability and concentrated on the use of a modified criterion of validity. Here especially the communicative validity, where the researcher discusses his/ her results with the research partner (Kvale, 1995), and the triangulation, where the combined use of different methods, researchers or theories is required (Denzin, 1989), are discussed approaches.

The third possibility to deal with the subject is to neglect the established criteria as not appropriate for qualitative research. Many qualitative researchers distance themselves from the criteria of objectivity, reliability and validity for qualitative research and ask for other adequate approaches (Steinke, 2007).

Meanwhile, several authors developed approaches to secure the quality of qualitative research, but these approaches are manifold and there is no consensus (Lüders, 2011). As in qualitative research unvaried measurements are not possible, some authors ask for the transformation of reliability into the quality criterion of intersubjective traceability (e.g. Wenzler-Cremer, 2007). Like others of this new qualitative criteria, it is also important and valuable for quantitative research. The documentation of the research process enables the receiver of the study to retrace the proceeding and assess the quality of the study. Besides this documentation, the alternative criteria are for example the benefit of the study, suitability of the chosen methods, the empirical anchoring of the research results and ethical aspects (Steinke, 2007). These criteria are closely connected to the research process. This is why it was decided not to list them in a separate chapter within this thesis. Going in line with the research process, the compliance of these quality criteria was documented within the several process stages: The benefit of the study was derived from the literature review in chapters 3 and 4 . Showing the suitability of the chosen methods is important not only for qualitative but also for quantitative research. Statements concerning the choice of the NEO-FFI can be found in chapter 5.4.1 about the quantitative part of this research. Information concerning why narrative interviews in combination with a rough interview guide were chosen are included in chapter 5.3.1 about the qualitative part of this research. 
The empirical anchoring of the findings is shown by diverse citations of the interview participants in chapter 6.1 about the found key contributors to the reviewed insolvencies and chapter 6.3 about the experienced effects of the insolvencies for the participants.

In addition, the intersubjective traceability is integrated in the different steps of the research procedure. So the reader can retrace how this study was conducted by detailed statements about sampling as well as preparing, transcribing and analysing the interviews within the following chapters starting with 5.2 sampling. Information about ethical considerations can be found in chapter 5.5. The opinions differ concerning the criterion generalisability. Some authors see generalisability as an essential quality criterion and a goal also for qualitative research (Lüders, 2011). For Steinke (1999), the generalisability also is appreciated in qualitative research within the borders of the contextual and historical ligation of the results (Steinke, 1999). Lincoln \& Guba (1985) suggested describing the researched cases in depth to enable the reader to draw their own conclusions to what extent the results may be conferable to other contexts (Lincoln \& Guba, 1985).

\subsubsection{Quantitative Aspects in Qualitative Research}

A question that regularly arises within the analysis of qualitative data is whether the frequency of occurrence is to mentioned.

According to Seale (1999), who postulates the phrase "count the countable" (p. 121), quantitative information will be part of qualitative research (Seale, 1999). This generally can include information about frequency and percentages but also statistical calculations like chi-square-tests or cluster analyses (Kuckartz, 2016).

This research supports authors like Rädiker \& Stefer (2007), who see quantifying information as a valuable addition within qualitative research. "Whether an aspect was mentioned by just one person or by three quarters of the participants makes (...) a remarkable difference" (Rädiker \& Stefer, 2007, p. 90).

Especially with regard to Lincoln \& Guba's request to give the reader enough information to evaluate the possibility of transferring the results to other contexts (see previous chapter), quantitative aspects of qualitative data are seen as valuable 
information. So within the single chapters of the findings of the qualitative content analysis there will also be information concerning how many participants mentioned the several topics. Furthermore, the discussion will contain an overview of the quantitative allocation of the qualitative categories. 
Quantitative research can be seen as a "research strategy that emphasizes quantification in the collection and analysis of data" (Bryman \& Bell, 2007, p. 28). Quantitative research methods have the reputation of being objective and go in line with the research in natural sciences. The idea of measurement plays a central role within quantitative research. The reasons for that Bryman and Bell (2007) see among others especially in the fact that measurement allows showing fine differences between the participants concerning the questioned item (Bryman \& Bell, 2007).

\subsubsection{Choice of Quantitative Research Method}

The personality traits inventory that was chosen to answer the second research question of this study supports Brymann and Bell's statements about measurement and qualitative research approaches. It is a tool that shows how people differ within their personality traits. According to Costa and McCrae (2008), "traits point to more-orless consistent and recurrent patterns of acting and reacting that simultaneously characterize individuals and differentiate them from others" (Costa \& McCrae, 2008, p. 160).

Personality can be described by a range of traits that determine the behaviour of people in specific situations. There is a great deal of literature about the traits term. Most of the definitions agree on the following aspects: Traits are hypothetical constructs that include a relatively time stable range of reactions to situations (aspect of stability and aspect of behaviour-situation-combination). People differ within these traits from each other (aspect of differentiation) and react with similar behaviours not just in the same but also in similar situations (aspect of generalisation) (Kleiter, 2005). The personality characteristics of the participants were evaluated by using a personality traits inventory. Those questionnaires are a standardised way to measure a person's self-perception within that specific field (Westhoff, 2004).

For the purpose of this research, a list of 41 personality structure tests that are available in German (Brähler, 2002) was reviewed by the following criteria:

- The test has to be designed for adult participants. 
- The test should not take more than half an hour to prevent the participants from being discouraged.

- The test has to have a good reputation concerning objectivity, reliability and validity.

- To analyse the results, the test should include a key or template (not necessarily computer based).

- As this research was conducted with an English university and to enable a broader audience to use the results for further studies, the test should be international in use.

These criteria lead to the NEO-FFI (Borkenau \& Ostendorf, 2008). It is a shorter version of the NEO-PI-R and concentrates on the so called "BIG five" (McCrae \& Costa, 1990; John, 1990). It can be seen as the dominant personality theory in modern academic psychology and includes the following five trait domains: neuroticism, extroversion, openness, agreeableness and conscientiousness (Egan, 2009).

As one of the most widely used measures of these five factors, the NEO-FFI has been translated into different languages (Pytlik Zillig, 2002).

Costa and McCrae (1997) compared data from studies using six translations of the Revised NEO Personality Inventory with the American original. German, Portuguese, Hebrew, Chinese, Korean, and Japanese samples $(\mathrm{N}=7,134)$ showed the crosscultural generalisability of the model (Costa \& McCrae, 1997).

Between the German version of the personality traits inventory that was used in this research and its English original, there is a high equivalence. The congruence between the English and German factors lies between 0.96 and 0.98 (Sarges, 2001). With its high level of abstraction, its well-established theoretical foundation and its transparency, the NEO-FFI is good to capture rough but comprehensive personality structures and their individual differences (Ziegler, 2002).

The NEO-FFI was not developed to provide definitive measurement but will be an instrument to produce reasonable estimates of the factors. Its frequent use over many years showed its usefulness in various contexts (McCrae \& Costa, 2004).

So the NEO-FFI should not be used, if the researcher is interested in specific personality constructs, as there are other specialised tests that lead to better results in these cases. However, the NEO-FFI is the appropriate tool to capture differences in 
personality traits of participants in a broad and comprehensive way (Borkenau \& Ostendorf, 2008), as it is the goal in this study.

\subsubsection{Quality of the NEO-FFI questionnaire}

Using a globally accepted and well-developed personality traits inventory like the NEO-FFI has its benefits and can support creating new knowledge. Costa and McCrae (1993) even see the five factor model as "the Christmas tree on which findings of stability, heritability, consensual validation, cross-cultural invariance, and predictive utility are hung like ornaments" (Costa \& McCrae, 1993, p. 302). However, the researcher always has to reflect the chosen tools thoroughly to really gain understanding. One of the criteria that led to the choice of the NEO-FFI was that the test should have a good reputation concerning objectivity, reliability and validity (Brähler, 2002). To substantiate these requirements, the quality criteria of the NEOFFI were reviewed. In addition to the following paragraphs, please see Appendix 1 for further information.

The criterion reliability contains the internal consistency reliability as well as the testretest-reliabiliy (Friedmann, 2004). Friedmann (2004) recommended an internal consistency reliability of 0.80 and more. The NEO-FFI meets this requirement according to several studies, and also a high test-retest-reliability of this personality traits inventory could be confirmed (e.g. Borkenau \& Ostendorf, 2008 and Ziegler, 2002).

"When the internal consistency reliability and the test-retest-reliabilty are high, we know that we are measuring something real - we have a solid personality traits inventory" (Friedmann, 2004, p. 49).

The validity of the NEO-PI-R was verified in comparison with other five factors inventories and important German and international personality tests (Sarges, 2001). A test is objective if its results are independent of the researcher who uses it (Lienert, 1998). According to Laux (2008), this includes all three steps, the procedure, the evaluation and the interpretation of the test (Laux, 2008). 
The NEO-FFI has a high objectivity in procedure as long as the researcher follows the test instructions consequently. Borkenau and Ostendorf (2008) give instructions about the topics: researcher, participants, test situation, test instruction and the behaviour of the researcher if the participants have questions (Borkenau \& Ostendorf, 2008). All those instructions were followed thoroughly. Traceability of evaluation and interpretation is supported by the explanations about the analysis in the next chapter 5.4.3.

The participants carried out the personality tests as a self rating. The information received from the traits inventory is how the participants see and feel about their own reactions and behaviours in several situations. A study of Costa \& McCrae (1992) about 250 peer-self-comparisons of the English NEO-PI-R showed that some facets can get experienced completely differently by an observer than by the person him/herself (Costa \& McCrae, 1992). In this context, it should be mentioned that Ostendorf \& Angleitner (2004) found a significantly higher peer-self-correlation for the German Version of the NEO-PI-R in their comparative study with $\mathrm{N}=750$ accounts (Ostendorf \& Angleitner, 2004). The reasons for that difference between the language versions are not clear (Wagner-Menghin, 2008).

In spite of the NEO-FFI showing good results in its quality criteria, there are some phenomena that have to be reviewed in this context to be fullymaware of the validity of the NEO-FFI as they could bias the results for all accuracy.

If the participants do not have the motivation to answer the questions truthfully, the NEO-FFI generally is able to be distorted (Pauls, 2005).

A differing motivation that can lead to such a distortion is the social desirability for example. So the researcher has to expect distorted results if the participant wants to appear in a very positive way or if the participant knows what results are most desired in the specific research situation (Borkenau \& Ostendorf, 2008).

The often discussed social desirability can obviously have an influence on the test results. The participants can have different motives that might find their expression in emphasising one of the five dimensions of the NEO-FFI depending on their self presentation strategy. If the participant wants to appear very competent for example, he/ she has the goal to highlight performance and skills. The facet competence finds its counterpart in the NEO-FFI- dimension conscientiousness. Another strategy of self 
presentation can have the goal to appear as exemplary. This facet also leads to an emphasis of conscientiousness. If the participant wants to ingratiate him-/ herself, we have the link to the test dimension agreeableness (Laux, 2008).

However, the participants do not have to distort the inventory results because they are following a special strategy of self presentation. People can have response tendencies that also might have an influence on the participants' answers.

The NEO-FFI uses a five point Likert response format to answer each item. On the one hand, this response format is "well researched, academically accepted and flexible" (Lohff, 2008, p.237). On the other hand, Likert response formats often abet response tendencies that lead to profiles with little differences (Lohff, 2008).

There are people who tend to avoid extreme values when answering questionnaires, but choose the more neutral values. The opposite type also exists. Some people prefer to answer questions with a clear "Yes" or "No" (Rammsayer, 2016).

Hinz et al. (2003) researched the answers of 853 men and 1055 women who answered the NEO-FFI concerning tendencies of agreement or negation. People with a very high tendency of agreement affirm every item no matter if it is positive or negative. In a similar way, a person with a high tendency of negation denies all (positive and negative) items. So the answers of such persons are formally consistent but inconsistent with regard to contents (Hinz, 2003).

Hinz et al. (2003) found that people with a high tendency of agreement have higher values in the NEO-FFI-dimension extroversion and surprisingly lower values in the NEO-FFI-dimension agreeableness. Although it might sound inconsistent, Houtkooper (2001) also found a negative correlation between the tendency to agree and the dimension agreeableness. However, his study does not support Hinz's second finding, the higher values of extroversion. Instead Houtkooper's study implies a positive correlation between the tendency of agreeableness and the dimension neuroticism (Houtkooper, 2001).

It may sound very feasible that a response tendency as a specific behaviour goes in line with correlations of the NEO-FFI-dimensions. However, there seems to be room for further research. 
Being aware of these possible problems, the NEO-FFI was accepted as a useful tool to add depth and understanding to this research, and cross validation of the qualitative data.

\subsubsection{Analysis of the NEO-FFI Data}

The test manual of the used second edition of the NEO-FFI (Borkenau \& Ostendorf, 2008) contains several standard tables of representative samples for comparison of the test results. With these tables, the researcher can find out how the participants' values behave in comparison with these norm values.

In a first step, the average values of the group of participants were compared with the standard normative comparison group of the test publisher. This is the comparison group that has no limitations of gender and age, as not all of the participants fitted into the same more specific comparison group as two participants were younger than 50 years old and one was female.

The comparison was conducted by a t-test using the software tool SPSS to show if the test values of the participants differed significantly within the trait domains neuroticism, extroversion, openness, agreeableness and conscientiousness from the values of the comparison group of the test publisher.

In a second step, the single cases that showed values with a deviation more than two standard deviations compared to the age- and genderspecific comparison group were reviewed. For the interpretation the NEO-FFI data was triangulated with the data of the interviews to gain deeper understanding about possible influences of distinctive personality traits on the participants' insolvencies.

Therefore, the interviews were scanned manually to identify actions or behaviours that support the NEO-FFI profiles. So for example if a participant had a value higher than two standard deviations compared to the age- and genderspecific comparison group in the dimension of conscientiousness, the researcher reviewed the textfile of the interview of that participant concerning signs of conscientiousness and their influence on the insolvency case. The results of this analysis will be discussed in chapter 6.2. 
The research is in line with the principles and procedures of the University of Gloucestershire's handbook of research ethics. Its principles emphasise "the personal responsibility of researchers to act ethically and to promote ethical behaviour in all aspects of research activities" (University of Gloucestershire, 2008, p. 3).

The participants are seen as vulnerable and deserving protection. Here the researcher has the responsibility to take care that the well-being of the participants is not harmed by the research and their participation physically, socially or psychologically (University of Gloucestershire, 2008). This begins with the data collection itself. While interviewing and testing the participants, the researcher ensured a comfortable atmosphere in privacy without interruption.

The participants stayed anonymous. The research includes personal information about the participants. To share their thoughts, it was important for them that they could be sure that their data would be treated with respect and discreetness. Confidentially agreements were prepared and signed to show the participants officially that their data is protected. The agreements included on the one hand the acceptance of the participants that the researcher is allowed to use their data for this research. On the other hand, they were assured that the data would only be used for this research. With professional experience of working in the purchasing department dealing with a lot of suppliers, it is clear for the author that a confidentially agreement is an important document. However, unfortunately also the experience made it clear that some suppliers tend to sign everything without really caring. That was one of the two main reasons why the sound files of the interviews were not given to a transcription service. The participants had the promise that their data would be safe. By giving them away to a supplier, the researcher would no longer have been able to guarantee that safety. 
This chapter includes the finding of the analyses of this research. Following the structure of the research questions, it is devided in three sections: the key contributors to insolvencies, additional insights through the NEO-FFI questionnaire, and the effects of the insolvencies on the participants.

6.1 Key Contributors to the Insolvencies in the Reviewed Cases

There were six fields of key contributors to insolvencies occurring in the interviews: poor leadership, lack of knowledge and experience, overconfidence and overestimation of their own capabilities, risky contract design, insuficient funds, and the loss of customers for example through market crises.

\subsubsection{Poor Leadership}

In a company, everyone has his/ her function, and the function of the senior management is to lead the company (Hungenberg \& Wulf, 2004).

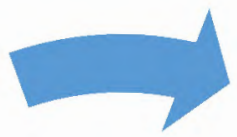

\section{Planning Steering}

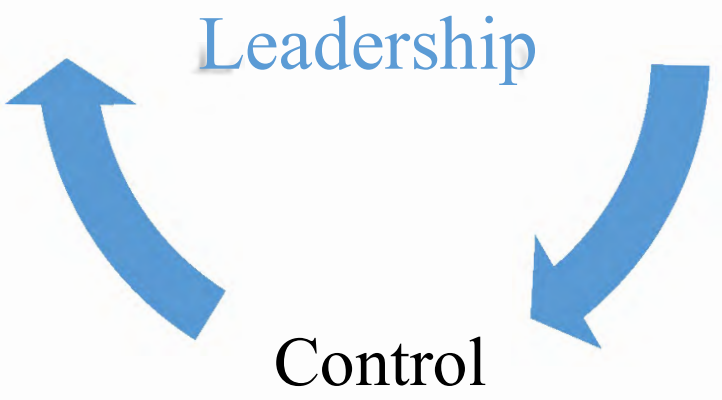

Figure 5: Leadership as revolving process

Own figure in dependence on Hungenberg, H., \& Wulf, T. (2004). Grundlagen der Unternehmensführung. Heidelberg: Springer-Verlag, p. 25. 
Leadership can be seen as a revolving process with the activities of planning, steering and control (Hungenberg \& Wulf, 2004).

Planning is the starting point of any leadership. Goals have to be defined and also the actions to reach these goals. Steering is the link between planning and realisation. Plans have to get transferred into packages of measures. Those packages have to be allocated to the suitable employees. This also contains the staff management with clear communication, motivation, development and evaluation as well as guidance of the employees. The control identifies the results of the planned actions. It is to evaluate if goals were met or if there are deviations. In case of deviations the leader has to take care of corrective actions. This is an ideal structure. In reality there often are loops within that process (Hungenberg \& Wulf, 2004).

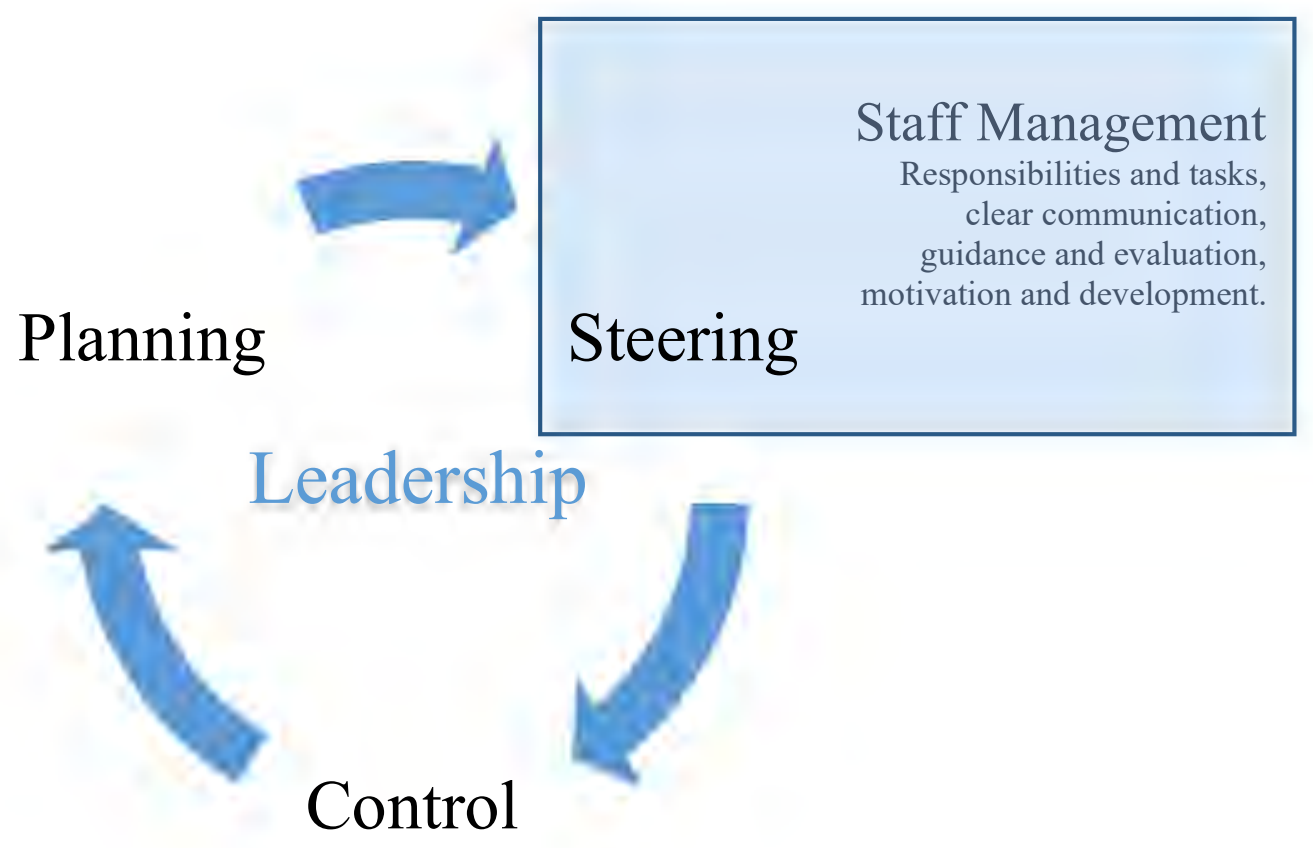

Figure 6: Management of employees as essential part of the steering task Own figure in dependence on Hungenberg, H., \& Wulf, T. (2004). Grundlagen der Unternehmensführung. Heidelberg: Springer-Verlag, p. 25.

Steering the company including guiding and developing its own employees appropriately gains particular importance within the growing competition of today's 
markets and can be seen as an essential contributor for a company's success (Avolio, 2004 and Cascio, 1995).

Reviewing the narrations of the participants, hints of weaknesses or omissions in all of the leadership tasks of planning, steering and control could be identified.

Participant 7 explained in the interview that he did not fulfil these leadership functions as he never worked as a CEO although it was his job title. When he had his job interview, he explained that he would love to do the technical part of the job, but he admitted not being qualified to do the commercial part. So he in fact was working as a plant manager, making improvements in production and leading the plant staff. As agreed (orally!), he never cared about the figures or the strategic orientation of the company. When he got suspicious about the actions of his partner, he hired an accountant to check the figures and was shocked by the results.

The figures brought him two essential insights. The first one was that an insolvency was unavoidable. The second one was that the trouble already had started when the owner of the company unexpectedly died. That was three years before participant 7 joined the enterprise. He pointed out:

"For me, the starting point of the tilt of the company really was the change from family owner to an external owner."

Identified problems with the leadership task planning:

Participant 3 had serious problems with planning. His company was in the biotechh sector. He saw a big issue in the limited retention periods of financial resources. In his opinion, banks and other investors think in short term investments while the development cycles in the pharma- or biotechh industry are much longer than the investors' expectations.

"(Chemical) research is an area of high risk that you cannot prophesy. (...) Of course, you can project: I have this number of chemists and so on. But the question is, how long it takes to synthesise a chemical combination. 
You can be lucky, and something complicated is ready within two weeks. Other things are not ready within six months. This is very hard to forecast. That means you have to revise all the time. That makes the investor nervous. And we had the unpleasant situation that some projects took much longer because the time (...) was calculated wrongly."

This problem was intensified by the participant's dependence on his investor. His company was always short of money as the initial investment when he started the business was also quite tight. This dilemma also led to handicaps in performance. There were situations for example where further research would have been required but short of time and money he decided to take the risk of leaving some research aspects unclear. Often such decisions took revenge and caused even more need for time and money and above all they increased the investors' mistrust. Participant 9 also had his issues with his planning task. He was a CEO of an ITcompany that implemented material management systems in other companies. The strategic orientation of his company is embossed by reaction instead of action. All new developments or applications were always driven by the ideas and suggestions of others, such as business partners or employees. The only thing that he did in this context was to agree and pay apprentice's due by going through a heteronomous trialand-error-process without a clear and planned business strategy. Also with the project planning, he had his issues. Being a business man, he did not have the needed ITknowledge to forecast the resources that were needed for the projects accordingly. Although he worked in the IT sector all his life, he never adopted the relevant knowledge.

The problems participants 3 and 9 had with their leadership task planning were both rooted in unforeseeable timelines of their development processes. Both calculated in tight time schedules to satisfy their stakeholders, more precisely their customers and investors. However, in the end the absence of financial buffers in their planning caused exactly the opposite effect, and they dissatisfied them by not being able to fulfil their plans and promises. 
Problems with the leadership task steering:

Participant 9 also had problems with steering the company. In particular, the staff management did not work at all in his company according to his narration. In the interview, he reported problems with his employees again and again.

Among others, there were ongoing conflicts with his employees about their roles, responsibilities and work performance. According to Kelloway et al. (2005), poor leadership may result in role conflicts and role ambiguity (Kelloway, Sivanathan, Francis \& Barling, 2005).

There were ongoing conflicts with employees, but he just went on without solving these problems. His lack of decision-making and guidance seemed to have the result that several employees left their jobs as he admitted that the ongoing conflicts poisoned the atmosphere in the company. Two people he had conflicts with finally left the company and took along several other employees. Once, even the whole sales department left.

He called his way of leadership a cooperative style. However, his employees for example accused him of being "resistant to feedback and suggestions". In this and other contexts, it seemed that his so-called "cooperative style of leadership" was much more the reluctance of making decisions. He said:

"Well, some people said, I am resistant to feedback and all suggestions.

(...) But I think it of course makes a difference how people say something, with what emphasis."

For him, it was not enough to get risks presented in an objective way. In his narration, he said that employees highlighted risks, but he did not take that into consideration concerning his decisions as they didn't highlight the risks strenuously and/ or explicitly enough to influence him.

He also was unable to resolve the problems concerning customers' payment issues:

"We had 4-500,000 euros outstanding (from the customers), but they just did not pay us although they had payment obligations." 
The problems with the customers went hand in hand with his problems steering his employees as the customer service also did not work effectively.

"We would have had to change the contracts earlier to bill everything on a time base. But this would have required a clear discipline within the customer service to book the services accordingly, and it is always difficult to discipline people."

Participant 9 seems to be a clear example of leadership failure as the loss of employees in combination with project planning issues and customers that did not pay their bills were too much for the company to survive. In all those problems, his lack of decisionmaking and assertiveness played the essential role.

He underlines his problems with his employees by admitting that he did not enjoy dealing with his people at all:

"This whole charade with the employees (...) waah! It jangles my nerves!"

When describing weak leaders "the focus has mainly been on active and manifest destructive behaviours as compared to passive and indirect forms" (Skogstad et al., 2007 , p. 80). However, the leader's lack of action and initiative can have negative effects on the satisfaction and motivation of his/ her employees, too (Frischer \& Larsson, 2000).

Also for participant 3, the responsibility for his employees was a big challenge. Meanwhile, he withdrew from the daily business of his biotech company and started working as a consultant. One of the reasons for that step was that he did not want to have responsibility for staff any more. Especially when it came to problems or even to the necessity to fire somebody, he did not cope with those leadership tasks very well.

"I am missing the needed hardness for that", participant 3 explained, "but this is something that I do not want to get for myself. Because of that, I do not have employees any more." 
Concerning his leadership style, participant 6 explained that he had a laissez-faire style but also was very dictatorial. His narration implies that he did not guide his staff at all but when problems occurred, he suddenly tended to give harsh orders.

Before he became an entrepreneur, he lost his job as an employee because of dissatisfaction about his leadership style and the cooperation with his colleagues. According to Bass (1990), laissez-faire leadership is "the absence of leadership, the avoidance of intervention, or both. (...) Decisions are often delayed; feedback, rewards, and involvement are absent; and there is no attempt to motivate followers or to recognize and satisfy their needs" (Bass, 1990, p. 20).

Kelloway et al. (2005) describe two types of poor leadership: The passive laissez-faire style, which was previously discussed, and the active one, which is aggressive and involves shouting at employees. Participant 6 seems to combine those two kinds of poor leadership. He did not guide his staff until problems occurred, and then he seemed to treat them harshly and in a very authoritarian way.

What the participants 6 and 9 have in common is that they did not seem to see their employees as valuable or even partners. The interviews imply that they accepted their staff as necessary to run their business but no more. In contrast to that attitude, participant 3, for example, mentioned his staff in a lauding way, and participant 11 also pointed out the importance and value of his employees several times.

Problems with the leadership task control:

To complete the picture of participant 9 concerning his leadership issues, it should be mentioned that he also failed in the leadership tasks control and corrective actions. He never consequently tried to solve the issues presented here although there were clear deviations in the target-performance comparison.

He admitted that the company would have had enough existing clients to earn good money and thrive if they had focused on keeping them and billing them accordingly. However, the participant's focus was always the acquisition of new customers. Participant 1 was betrayed by his companions. This case is also included here into the chapter of poor leadership as he would have noticed the fraud much earlier if he had 
taken care of controlling and control of the agreed measures. He transferred money again and again without realizing that his partners did not use it to improve the company. They established and built a second company instead without the participant's awareness but with his money.

"It turned out that it was very much in disorder, what they had kept secret in my own company. Well, suddenly I was confronted with titles of creditors that I didn't even know. And then they finally stashed away the controlling (...) Suddenly I discovered a black hole within my own company."

Participants 1 and 9 both were focused on their daily business, the many little tasks that need to be done to keep the business running every day. However, in addition to daily troubleshooting, the strategic orientation of an enterprise also requires attention and this includes control. Both participants failed to evaluate the development of their businesses by thorough and systematic target-performance-comparisons.

The literature review showed that concerning success and failure of companies, the achievements and faults are often seen in the leaders. The saying "a fish rots from the head down" is mentioned frequently in this context. The interviews of this research revealed weak leadership skills and the omision of leadership tasks. 
The relevant knowledge of leaders can be divided into knowledge about the specific industry sector in which the company is acting, managerial knowledge, and also knowledge about the management of crises (Imgrund, 2009).

When it came to the insolvency, the participants admitted that they didn't know what an insolvency according to German law really is and had to get informed about their tasks within these proceedings. Only participant 8 had knowledge about crisis management and insolvencies as he was working as a consultant within that field before his entrepreneurship.

Participant 1 was in trouble with the fiscal authorities because he did not have the appropriate information. He had a company in the Czech Republic and was paying taxes there as long as the business was running. When he sold that company, no taxes would have been incurred according to Czech tax law. He had a flat in the Czech Republic, but he also had kept his accommodation in Germany. So he would have had to pay the taxes for his company sale in Germany but did not know or realise that. When buying his new company in Poland, he transferred the money. So he was no longer able to pay his tax debts.

The German fiscal authorities were the main creditor. His tax debts did not just cause his insolvency; he also had to go to jail as the amount was more than one million Euros. He was one year in investigative custody and another 18 months in jail after the court decision.

Participant 3 started his business right after his doctoral studies. In the course of his doctorate, he had applied for a patent and because of this a large pharma company contacted him and asked for these specific patent-protected chemical research intermediates. So he established his company right after university without having experience of the daily business in industry in general and entrepreneurship in particular. He furthermore was not aware of the specific challenges within the pharma industry with its long and unforeseeable development periods that collide with the interests of the investors who want to have short term returns.

"Of course, I was not aware of that. (...) If I had known all that, I probably would never have done that. Then I never would have founded a company. 
If I had been aware of all that, I would never have got into debt that high. (...) It was a real fight, really a life-or-dead struggle somehow. And I was very, very lucky at the right time."

Participant 3 found an investor during the insolvency procedure and is still co-owner of the company that meanwhile is successful and growing. On the one hand, his youth and optimism enabled the establishment of his company. On the other hand, he then had to learn everything about challenges by taking them.

Participant 11 studied forestry and was working as a public officer in the forestry district for ten years. He had knowledge about the timber sector including the current potential volume of orders, the contracts and the prices. So he felt well-prepared and informed when he decided to become self-employed within that sector with a timber harvesting and trading company. However, then he had to realize that he was not prepared at all due to his lack of management and economic knowledge:

"Well, I was not aware of anything. Although I had been a well assessed public officer, I have to say I was in another world there. As a public officer you are in another world, no clue of the free economy. And especially there were a lot of simple things in the daily economic activities (...) that I did not know, although I should have known them of course."

Similar to participant 3 he described his period of entrepreneurship as a struggle:

"Surely that (experience) contributed to my further education as a human being in general, but it was painful. And if I had known what difficulties I would have to face, I do not know, if I would have left (the public office), because it was a very hard period of training."

Good and bad years alternated and, when he finally had to file for insolvency, some people said that they had expected this earlier. Also participant 11 himself said he wished that the insolvency had come earlier, as it was also a deliverance for him. This aspect will be discussed in detail in chapter 6.3.9.2. 
Participant 6 presented in his interview narration a clear lack of knowledge that caused him a large number of problems. The legal form of his company was a general partnership (OHG). In capital companies, the liability is limited, but a general partnership belongs to the non-incorporated firms and means that the partner is fully liable (Paulus, 2017).

Furthermore, he gave his son a share of one percent when he was celebrating his 18th birthday without realizing that with this engagement he involved him in the liability of the company, too. Participant 6 was sorry when he recognised that in case of an insolvency his son was liable as well. He managed to get his son out of the company in time. However, participant 6 himself had to go through the general insolvency proceedings as a natural person.

"If you are small and you want to buy a machine and you want to finance this machine, then the private limited company $(\mathrm{GmbH})$ gets no cent (from the bank). Then you also have to be liable as the partner."

In fact, it is right that a bank in such a case would ask for securities. As participant 6 had a high initial investment for his company, he knew that from his experiences. However, even after the sorrows he had as the insolvency was threatening his son, and after having to go through an insolvency as a natural person, he still seemed not to understand the advantages of a capital company with limited liability. He did not know what forms of organisations exist in Germany and what they are called or abbreviated correctly:

"It is absolutely non-relevant, if I am an e.K. (=registered merchant) or a BGB or whatever."

The abbreviation BGB stands for the German Civil Code and not for any form of company organisation.

The participants showed lack of knowledge about the specific industry sector in which their company was acting, about managerial knowledge, and also about the management of crises. Furthermore, some of them just had a theoretical idea about the 
daily business and tasks of an entrepreneur. The lack of knowledge created problems and struggles during their entrepreneurship. 


\subsubsection{Overconfidence and Overestimation of own Capabilities}

Neß (2013) researched overconfidence of entrepreneurs in general and insolvent leaders in particular. She found that even after going through an insolvency procedure, the business people still were unbowedly convinced of their entrepreneurial competences and skills. They still believed they were more suitable to lead a company in the industrial sector within which they had gone insolvent before as other entrepreneurs (Neß, 2013).

$\mathrm{Ne} ß$ (2013) also analysed a group of students concerning the item overconfidence. One part of the students group planned to become entrepreneurs in the future and the other part of the group was not interested in an entrepreneurial career. The first group showed overconfidence while the second group did not. According to Neß (2013), this indicates that there could be a relationship between overconfidence and entrepreneurship in general no matter if the entrepreneur is successful or not $(\mathrm{Ne} \beta$, 2013).

Also, the participants seemed to be self-reliant people who did not doubt their competences, and they were not able to reflect on the mistakes they might have made in the past. Particularly when they spoke about the time right before the insolvency, there were signs of overconfidence.

Participant 1: "Well, I in fact always worked like a sole proprietor, who does not have to listen to anybody and also did not want to. And for a long time I was blessed with success. In this respect I did not question anything, but I thought "never change a working system" and just went on."

Participant 2: "Maybe my biggest mistake was that I thought the way will always go upwards, because of my career and more and more money and so on."

Participant 4: "And there came one success story after the other. (...) I said, I am invulnerable. Everything I start will become a success. I was obsessed by this idea, because it had always been going better and better." 
Participant 5: "Maybe I made the mistake that I did not ask for professional support half a year earlier. But (...) I thought I would make it. I'll make it alone."

Participant 6 presents the thoughts he had in the past concerning the possibility of a threatening insolvency with the following words:

"Well, this will never happen to me! (...) Never ever! This is complete rubbish, this cannot happen to me, to me? (...) Never ever!"

When he was talking like this, he was smiling and it seemed like he wanted to show that then he was wrong but now he knows better. However, that he did not lose his overconfidence meanwhile he showed at the end of the interview. When talking about his current situation and that he now has to be flexible to be able to seize any chances, he said:

"I am very lucky, (...) because I know how to do everything."

Participant 10 also admits that considered in hindsight it was a "big mistake" that he tried to lead the company alone although he had two adult sons who were also working there in responsible positions. Meanwile, one of his sons is the CEO and his way of leading is different to the leadership of participant 10 :

"Today I know that my son delegates a lot of responsibility. Thereby the company works better."

Participant 11 explains his way of decision-making with the following words:

"Again and again I took decisions of great importance or big financial commitment much too fast, (...) I did not think about it enough, did not challenge or review enough. (...) Or in other words: I stumbled into many things being too naive. And that also wasted a lot of money." 
As mentioned before, Neß (2013) found that overconfidence might not necessarily just be an attitude of unsuccessful leaders, but of entrepreneurs in general. This is in line with the narrations of the participants. They thought they can make it, that it will be alright as they had also had success before. Also they did not just think they would make it, they thought they could make it alone and did not ask for support in time. 
In the following, the participants were bound by contracts that were designed very optimistically. When problems occurred, they could no longer hold on to those agreements.

For participant 4 it was a leasing contract that turned out to be one of the key contributors to his insolvency.

Leasing exists in a variety of different versions. They all have in common that the lease provider enables and finances the lessee to use the lease object, while the lessee pays a fee for that use. There are special cases, like the finance lease, where the lessee can become the proprietary of the lease object at the end of the contract. However, during the contract period, the property of the lease object stays with the lease provider (Krüger, 2014).

As his company was successful and going well, participant 4 chose a leasing contract with a short period and a high monthly fee. When the financial crisis of 2008/ 2009 came and additionally a large customer backed out of the branch that the participant's company was supporting, he was suddenly no longer able to pay the fees.

"We had a very short-term leasing (...) That would not have been a problem, they (=the leasing provider) just should have elongated it to six years, then we would have had the needed air to breath, because we still were chalking up profits. However, as they did not elongate the leasing contract, we had to pay 2.7 million euros leasing fees at a time when we were earning hardly any money. (...) I had chosen a very short time frame. I should have taken six instead of three years. Then the financial burden would not have been that high. Maybe then I would not have had to file for insolvency."

Additionally, participant 4 had invested in a new production hall for 15.7 million Euros in 2006 that was not amortised yet.

Participant 9 had the problem that his IT-service contracts were not clear and up to date. He had a mixture there combining a monthly fee and additional costs for some services. However, this combination did not recognise the real costs and were also 
never updated. This inappropriate contract design was intensified by his employees who preferred to go the easy way and book as much as possible in the service category that was covered by the monthly fee. So they could reduce workload and avoid discussions with the customers.

Participant 11 had the situation that he could not discharge his monthly payment obligations. In his case, it was not a leasing contract but the financing of new machines. Participant 11 had also chosen a short period and a high monthly payment.

"In the year 2007, when I had large jobs, I had bought three new machines. That was a volume of more than a million euros. (...) I was in the middle of the debt retirement with a relatively high (monthly) clearance. We paid 70,000 euros per month, I think. (...) Then the financial crisis came with a crash. Then I just had 5-10\% of the jobs any more. (...) And I had machines, that of course could not get sold. (...) Nobody had jobs, so nobody needed the machines."

Another case of inappropriate contract design can be found in the insolvency of participant 5. He lost a large customer (The detailed circumstances of this loss are part of chapter 6.1.5.2). When this customer contracted out of their agreement, participant 5 wanted to withdraw his contract with a supporting sub-company, too. However, then he had to realise that he had missed matching the cancellation periods of these two agreements. So he was trapped in the contract with his service supplier although he no longer had enough workload to need that service.

"I had a mismatch (in the contracts), that means, I could not withdraw from the agreement (with the service supplier) any more. And in the discussion that company then showed, that they wanted to have a recourse claim.”

Together with the damage caused by his main customer, the amount of loss then was about 600,000 euros - too high for participant 5 and his company to handle. 
The reviewed cases here have in common that the contract was designed to match to the current situation. However, the participants did not bear in mind that things can change, that profit can go down or alliances can break. Those are the risks that they did not consider in their contract design. 
As explained in chapter 2.4 about the German insolvency law, possible reasons for opening the insolvency procedure are current or imminent illiquidity and excessive indebtedness (Paulus, 2017). In consideration of these opening reasons, it might not be surprising that insufficient funds have to be mentioned as enablers for insolvencies. Already the initial investment at the beginning of the business establishment can lead to problems. However, also later, when the business is running, it can always happen that the business leader needs fresh money, whether it is to handle large investments or to bridge a financial gap because of other problems. It is in the nature of things that banks and credits play an important role here.

\subsubsection{Initial Investment}

In some of the reviewed cases, the trouble already began with the initial investment to establish or buy the company.

One example therefore is participant 6 who considered in hindsight that his initial investment was much too high. Participant 6 bought his engineering company for a price of two million D-Mark then. The original plan was to make this investment together with a business partner. When it came to the price negotiations, the business partner was omitted because of a heart attack, and participant 6 negotiated alone. When the business parter heard the agreed price of two million D-Mark, he was shocked and backed out of that deal. Nevertheless, participant 6 wanted to hold on to his acquisition of that company and tried to find a bank willing to fund this transaction. He found only one institute that was willing to give him the money, and the conditions were "not good". In the interview he admitted that he paid an excessive price then:

"Well, I would never buy the company under such circumstances again. Half of the price still would have been too much. And you have to keep out emotions. I mean, emotions make such a purchase difficult. I simply was in love with that company. And that should never happen." 
The high initial investment blocked participant 6 in the development of the company, as all profit had to be used to support that credit, and there were no possibilities left for further investment like modernisation or expansion. So in the end he had an engineering company trapped in a location without free capacity for expansion, without innovation potential and with over-aged machinery.

\subsubsection{Bridging Credits and Their Perils}

When a company gets into financial trouble, it is often the banks that are the first point of contact for the CEOs. In phases of crisis and reorganisation, outside creditors become one of the most important stakeholders for the struggling enterprise.

Especially when the company finds itself within a liquidity crisis, the influence of the established outside creditors grows as then fresh money is needed quickly and most of the time it is very difficult then to find a third party who is willing to provide liquidity (Tyroller \& Nienstedt, 2012).

Also, for most of the participants, their bank was the first place to go when they realised that their enterprise was heading towards financial trouble. In such a situation, the bank has to think in two categories. On the one hand, it has to minimise risk and maximise recovery. On the other hand, it may not harm the company and its other creditors (Ringelspacher, 2012).

There are cases where the bank is not willing to provide fresh money as the risk is evaluated as too high. However, more interesting in this context seem to be the cases where the bank agreed to provide liquidity. Participant 8 and participant 5 were supported by their banks with bridging credits. They got fresh money, but considering the bridging credits in hindsight, they just delayed the insolvency and added bad debts.

When participant 8 joined into the company as the new CEO and a partial owner, there were already existing bad debts. Nevertheless, he was willing to take the challenge to reorganise the company. $15 \%$ of the turnover went into clearance and interest. According to participant 8 , "those two rucksacks devoured everything completely" no 
matter how they tried to improve the situation. Nevertheless, the banks agreed to give another three million euros. Participant 8 then thought with this fresh money the company would be safe, but the insolvency was no longer to be averted:

"I said now we should be able to get through this. (...) They had a socalled success fee (in the contract). That means at first sight the banks take low rates, that were somewhere between four and six percent. But then when you add in the success fee that you have to give the banks as soon as you reach certain stages of liquidity again (...) it is very, very quickly another million in addition."

So in the end the fresh money that should have rescued the company led to further increase of the bad debts.

According to Ringelspacher (2012), if banks provide a credit to a company that is in a serious crisis, it should not be a so called self-serving credit that just delays the insolvency and improves the position of the banks compared to the other creditors (Ringelspacher, 2012). However, the CEO is in charge of finding solutions for the company's problems. It is also his responsibility to evaluate and choose such offers.

Another case to be mentioned within this context is the insolvency of participant 5. Leading a specialised security service provider, the banks in the first instance were not his creditors but his customers. When one of his main customers took over another company, they explained to him that they would need approximately one year to sort everything out. After that time period, he and his company should get the new locations running but for one year there would be no orders. Participant 5 made clear, that he could not hold all needed employees in readiness without turnover for one year. The bank reassured him that they would need him and even supported him financially with a bridging credit to endure this year more easily. Everything looked good, but when the year ended, they cancelled the contract, gave the business to another supplier and called in the loan. So instead of cooperation, participant 5 got outstanding debts and a broken bond of trust. 


\subsubsection{The Bank as Conqueror - An Extreme Example}

Participant 10 reported the following experiences with his bank. Although his business went very well, he got into financial trouble because of a loan guarantee that he had bailed for customers who then went bankrupt. As all this took place within the construction sector, we are talking about large values here as participant 10 demonstrated with the following narration:

\footnotetext{
"We went bankrupt because I lost 276 million D-Mark because of my good-naturedness. (...) (In one case) alone I lost 138 million D-Mark, because the building project organiser went bankrupt and I had bailed for him. (...) This caused costs of nearly one million per month (...) and we also had made enormous investments. When you are once on such a difficult path, you can't get out any more, because the banks also take their part."
}

Participant 10 directly accused his bank, and as he continues with his narration, it becomes clear, why he was so upset with them. The relationship between participant 10 as the CEO and the bank as main creditor during the insolvency was conflict-ridden right from the start. According to participant 10, they had a problem with his forthright and powerful appearance, and he also highlighted several omissions and faults they had made. He seemed to be an inconvenient partner for them. To solve this problem, the bank contacted the participant's son and successor in the company with the following suggestion:

"Your father should go into a psychiatric clinic. We know doctors, we can take him in quickly. (...) With that father, you will never get the lead of the company, he will not let you work your way up. (...) Just sign here, your father surely has slapped you in the face some time or was violent, wasn't he?"

When his son refused to cooperate, the bank contacted the participant's wife. 
"They said, they would give her a monthly payment of 9,500 D-Mark until her death (...) if she signed that I was violent to her.

(...)

"Thank God! Just imagine I would have had a bad relationship with my wife (...) and she would have said: 'Yes, then the wrinkly is gone, and I am financially safe.' then I would have been gone."

Here the bank is not responsible for the participant's insolvency. Furthermore, the conflict between the participant and his bank escalated after filing for insolvency. However, the case supports the questions about the ethical standards of banks' behaviours, that it was seen worth presenting within this context as additional information.

\subsubsection{Excursus: Banks and Ethics}

For Ringelspacher (2012), transparency and trust are essential for the collaboration between a struggling enterprise and a bank. However, she seems to see this mainly from the point of view of the bank, as she argues for transparency on the part of the debtor to enable a faithful collaboration within which the bank can provide support to master the crisis (Ringelspacher, 2012). Also, in some of the described cases, this socalled team work appeared one-sided in favour of the banks. However, collaboration means team work between enterprises with the goal of improving the position of both players (Weerth \& Mecke, 2017).

In the face of the economic crisis of the years 2008/2009, the topic of business ethics had a revival in the public media and the academic world. The German Academic Association stated that a large number of economic players "lost their ethical and moral compass" (Horstkotte, 2009, p. 20). The rising interest in business ethics could also be seen in the development and implementation of codes. The graduates of the Harvard Business School for example in 2009 for the first time swore a voluntary oath to do their future job in an ethical manner (Horstkotte, 2009). 
Banks operate in a market environment of growing pressure with challenging circumstances such as long-term low-level interests, growing regulation- and control requirements and changing customer requirements (Praeg, 2017).

In addition to these difficulties, banks and their employees have to face serious damage to their reputation in recent years. So for example the Swiss banking secrecy, which was an important unique selling proposition, is factually broken. The newspapers regularly report about high administrative penalties that large banks have to pay because of their misbehaviours. Also, a decade after the large financial and economic crisis with its bursting bubble and the decline of leading financial service providers, the sector seems to be in bad shape with losses of workplaces and financial penalties on the one hand and the ongoing damage of image and trust on the other hand (Stüttgen, 2017).

"The historical crisis also has to be understood as a moral crisis of the financial sector and its actors" (Schaefers, 2017, p. 205). The banks are criticised because they would not serve the customers' requirements but themselves and lived a culture of "morally blind profit maximisation" (Schaefers, 2017, p. 205).

For large parts of the public, the job of the banker meanwhile is connected to immorality. They are seen as "corrupt, greedy, criminal, completely unmoral" (Koller, 2017, p. 335).

Looking at the highest administrative penalties for corruption, the companies of large pharmas top the list, closely followed by large banks (Stüttgen, 2017).

As the potential for financial damage in the bank sector is much higher than in most other industries, ethical behaviour and action here is of special interest (Karkowski, 2012).

Alain Cohn and his colleagues of the university of Zurich carried out an experiment with 128 employees of a large international operating bank to research the honesty of bankers. In a first step, the participants had to answer an online-questionnaire with seven questions. Half of the bankers got questions about job-related topics, and the other half had to answer a questionnaire about other areas of life such as their TV consumption for example. This was made to inspire some of the participants with the point of view they have in their professional life, as former studies already showed that ethical standards can be context-related, and it is possible that people act differently under private and professional circumstances. After that preparation, all 
participants were asked to toss a coin at home ten times and insert the results into an online-form. In advance, they were informed that for every toss of tails they would get 20 US dollars, to give them a stimulus to cheat. The results were compared with the average distribution of such coin tosses.

Alain Cohn and his team found that the participants, who had the questionnaire with private topics, told the truth, as their results corresponded with the average. However, $26 \%$ of the bankers who had been influenced by the job-related questions cheated. Some of them even stated that they tossed the tails ten times (Podbregar, 2014). Other studies showed that bankers are not less moral persons per se, and the percentage with personality disorders such as narcissism or even psychopathy are not significantly higher than in other professional categories (Karkowski, 2012).

Alain Cohn saw the reasons for his results in the direct working environment of the bankers. According to Cohn, the study showed that the business culture within the financial sector stimulated dishonest behaviour. So the business culture of the banks seemed to be the field that needed adjustment. An idea to improve this business culture for Prodbregar (2014) could be an oath for bankers similar to the Hippocratic one for doctors (Podbregar, 2014).

In the Netherlands, for example, there was established such an ethical oath for bankers in the year 2013. While it was only relevant for top managers of the financial sector at first, since April 2015, it has been obligatory for all bank employees (Koller, 2017). Such an oath might be a signal that highlights the right direction, but it might not necessarily have a positive impact on the business culture. Another dilemma could occur here. MBA Students in the US were asked if they see the limitation of toxic emissions as an ethical or a business decision. The result was that $55 \%$ saw this as an ethical decision as long as the limitation would be voluntary. However, already small penalties reduced this percentage down to $20 \%$. So it seems as ethical regimentations result in the opposite of their intention. This implies that the more ethical considerations are forced by a code or the law, the less the banker needs to use his/ her compass of values to evaluate his/ her behaviour and its results (Karkowski, 2012).

Banks are important stakeholders especially for struggling companies due to their financial scope. The cooperation with banks seems to need special awareness and prudence. A credit agreement is nothing other than a contract that both sides -the bank 
and the entrepreneur - sign. Contracts have to be reviewed critically as the insolvencies of participants 5, 6 and 8 showed. 
The turnover-break-in that came along with the financial crisis in 2008/ 2009 stressed the stability of German companies significantly. So the year 2009 became an exceptional year concerning the number and damage of insolvencies. Large and wellknown companies like Quelle and Schiesser collapsed. These cases were highlighted in the media, but they were just the tip of the iceberg. In total, 34,300 companies had to file for insolvency in Germany that year. That was an increase of $16 \%$ compared to the year before. The volume of damage was 48.6 billion euros, $67.6 \%$ higher than in 2008 (Creditreform, 2009).

Undoubtedly this period was a difficult environment for the German economy and its companies. Also some of the participants of this research were concerned with severe break-ins of turnover at that time. However, none of them had to file for insolvency solely because of the financial crisis. In all reviewed cases, one or more additional key contributors were identified that tightened the situation and enabled the insolvency. Additional to the turnover-break-in of the crisis, participant 4 lost a large customer that backed out of the business sector that the participant's company was supporting. Furthermore, they had to face very high monthly leasing fees. (Please see chapter 6.1.4 about risky contract designs.)

Participant 11 had just bought and financed three new machines and had to pay high monthly debt retirements when his turnover broke in by $90-95 \%$ in 2009 . (Also this case was presented in chapter 6.1.4 about risky contract designs.)

Participant 3 struggled because of another market crisis. Just after he moved his business into a larger (and more expensive) location for expansion reasons, the demands declined:

"The problem was just that in 2001 the biotech bubble burst, and a lot of companies that had prospered so far, could not go public any more (...) so the companies virtually broke down over night. (...) Then we moved, and then it (the turnover) suddenly declined to zero, because as I said, no biotech company did order any more." 
So also in this case the loss of customers due to a market crisis temporally collided with an increase in the monthly commitments.

Participant 2 had to face a difficult personal life situation that was the beginning of her financial struggle and finally became one of the main contributors to her insolvency. Her father was critically ill, and she took care of him. During the four years while she was nursing him she neglected her business, and no longer acquired enough orders and customers. So her income went down more and more and finally she could not pay her liabilities any more. The problem here was that her liabilities were quite high due to real estate property that she had bought and financed before.

"My income went down rapidly. (...) Especially the real estate property, that I could not afford any more, caused the insolvency. And it also did not yield the money that I had put into it."

Participant 2 had paid a high price for the real estate property and furthermore also the credit agreement itself seemed to have been of risky design:

"I should not have bought this real estate property this way. (...) I got the credit so easily because I had a good income then. And I fully utilised that, I financed more than $100 \%$. And when it (the value) then goes down, you really are in trouble."

Participant 12 ran a supermarket as an entrepreneur. Initially his business was going well. However, then a competitor established a supermarket nearby. The supermarket chain that participant 12 was a part of with his business was located in the upper price segment. Furthermore, the new competitor did aggressive advertising.

"Well, this (competitor) was my undoing after three years. They snatched away the customers from us, that is crystal clear. They used such aggressive advertising."

„I had made very good sales within the Christmas business. (...) They put extra flyers into the leaflets with additional percentages (of price reductions), so that the customers couldn't act differently any more. They 
just did not come to us any more. Well, until October of that year (...) my whole sales broke away. Finally I was able to pay the wages and utilities, but I could not get out anything of this any more."

Participant 12 was in a very difficult situation here. On the one hand, he was entrepreneur, acting on his own behalf and on his own account. On the other hand, he was limited in his freedom of designing and organising his business due to the influence of the parent trading company.

In hindsight, he regarded his former parent trading company very critically:

"My opinion is, that this is part of their system. The supermarkets that did not work well, there they drove the people into bankruptcy. And when somebody was gone, I can tell you, after four weeks there was the next one. And this one then finally had to suffer the same harm."

He narrated that the following entrepreneurs that tried to run their supermarket at that location where participant 12 have had his business also failed. After some years, the parent company quit that location due to economic inefficiency.

The roots of the decline of turnover are as different as the participants' stories. Some suffered from market crises, participant 12 had issues with a new competitor and participant 2 had to deal with private problems. However, the effect of all those different circumstances in these reviewed cases was the same: the turnover went down while costs stayed on the same level. 
Today`s personality literature presents different definitions of the term personality. However, there are some aspects that are universally accepted. According to Herrmann (1991), who compared different definitions, there is agreement about personality as a behavioural correlate that is individual for every person and relatively stable (Herrmann, 1991).

This study follows a trait-based approach of personality research. The goal within such an approach is to identify relatively durable characteristics to describe and explain differences between people's personalities (Laux, 2008).

To research those characteristics of the participant's personality, the NEO-FFI was used, a personality traits inventory developed by Costa and McCrae that includes five dimensions. According to Costa and McCrae, everyone finds themselves somewhere within those dimensions differing gradually from each other (Costa \& McCrae, 1997). The dimensions of the NEO-FFI are the so called "big five": neuroticism $(\mathrm{N})$, extroversion (E), openness $(\mathrm{O})$, agreeableness $(\mathrm{A})$ and conscientiousness $(\mathrm{C})$, and will be explained in the following paragraphs. According to Borkenau and Ostendorf (2008), the reader should be aware that high or low values within these dimensions are not per se good or bad and it is not the goal to research the mental health of the participants but to gain deeper understanding of the participants behaviours and decisions by evaluating their personality traits (Borkenau \& Ostendorf, 2008). Borkenau and Ostendorf (2008) explain the dimension neuroticism as a scale about the emotional stability or instability of a person that captures how the participant deals with uncomfortable experiences or sorrows. People with a high value state more often that they easily become unbalanced. They more often explain that they have feelings such as being doubtful, nervous, sad or afraid. Emotionally stable people rarely have such problems. They describe themselves as balanced and carefree (Borkenau \& Ostendorf, 2008).

The dimension extroversion contains companionability, but this is not the only aspect of that scale. People with a high value also describe themselves as self-reliant, active, communicative, sunshiny and optimistic, and they often like being in groups (Borkenau \& Ostendorf, 2008). According to Barrick (1991), extrovert people with 
their courage, their ambition, their energy and their ability to talk can be successful as strongly noticed leaders (Barrick, 1991).

Borkenau and Ostendorf (2008) point out that the definition of people with low values in extroversion is not easy. It is important to understand that the poles of this dimension are not just the opposite. So people with low values in extroversion are not to be described as pessimistic or unhappy. The main attribute of the introverts is, that they like to be on their own (Borkenau \& Ostendorf, 2008).

Openness here means openness to experiences and indicates to what extent the participant is interested in and active with new experiences and impacts. People with high values in this dimension often state that they are interested in a lot of personal and public processes. They describe themselves as thirsty for knowledge, imaginative and adventurous. Furthermore, they tend to scrutinise existing standards and try to go in new ways (Borkenau \& Ostendorf, 2008).

The dimension agreeableness describes interpersonal behaviour. People with high values see themselves as altruistic. They want to help and support other people, and think that others act the same. They tend to trust, cooperate and have a deep desire for harmony (Borkenau \& Ostendorf, 2008).

The dimension conscientiousness is about self-control concerning activities such as planning, organisation and realisation. People who score high in this category describe themselves as determined, ambitious, busy, accurate, on time and neat. People with a low level of conscientiousness follow their goals with less dedication. They describe themselves as careless, neutral and unstable (Borkenau \& Ostendorf, 2008).

According to Costa and McCrae (1997), the domain of conscientiousness consists of the six facets: competence, order, dutifulness, achievement striving, self-discipline and deliberation (Costa \& McCrae, 1997). Barrick (1991) points out that people with a high value in the dimension conscientiousness are likely to be successful in their job, especially in companies. Their strength of purpose and their sense of responsibility help them to reach their goals and respect (Barrick G. E., 1991). According to McAdams (2006) reviews showed that conscientiousness is the big five-trait that "consistently predicted success across different organizations, jobs and situations" (McAdams, 2006). Barrick and Mount even found that if the given responsibility and autonomy in a job goes up, conscientiousness becomes an even stronger predictor of 
job performance. High scores in this domain could predict job success many years in the future (Barrick \& Mount, 1993).

However, extremely high values within this dimension could imply that these participants might not just be ambitious and organized. An overexaggeration in conscientiousness can lead to workaholism or the setting of extremely high requirements (Borkenau \& Ostendorf, 2008). 


\subsubsection{Group Overview}

The research group consisted of twelve participants. As there was one woman included, and two participants were younger than fifty years old when they answered the questionnaire, the average test values of the group of participants were compared to the values of the general normative comparison group values of the test publisher. The general normative comparison group is the comparison group without any limitations concerning gender and age.

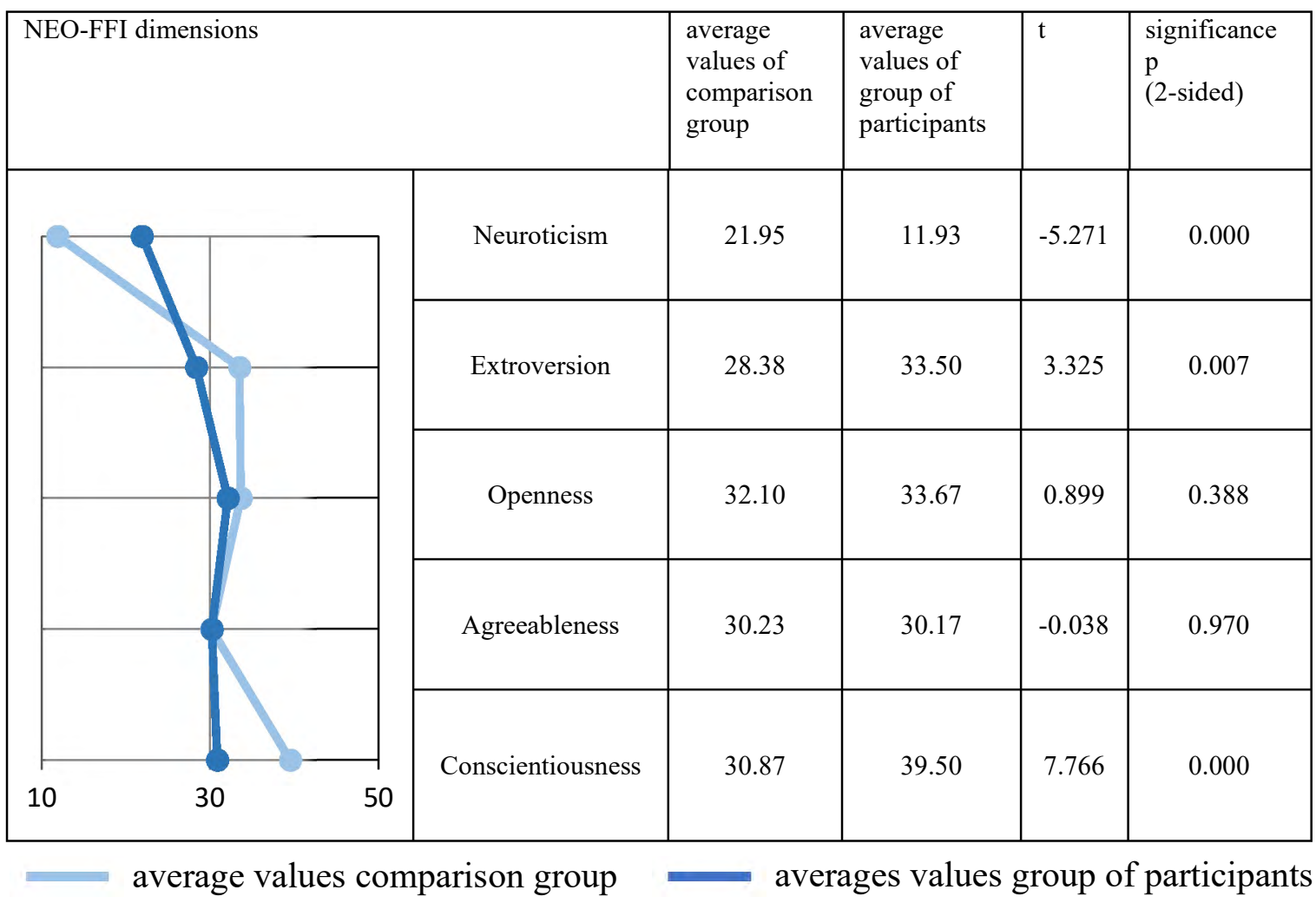

Table 1: Average NEO-FFI values of group of participants compared to the average values of the general normative comparison group

Own presentation

The comparison of the average values of the group of participants within the dimensions of neuroticism, extroversion, openness, agreeableness and conscientiousness against the average values of the general normative comparison group was conducted by a t-test using IBM SPSS Statistics 23.0. 
The t-test shows high significance $(<0.05)$ for neuroticism, extroversion and conscientiousness. These values imply that the participants tended to see themselves as emotionally stable people who do not lose their poise easily.

They also tended to see themselves as social, active, communicative, sunshiny and optimistic and seemed to have good self-esteem.

Furthermore, the participants tended to see themselves as determined, neat, ambitious and busy people that are on time, work accurately and are organised.

Meta-analyses about the context of the big five and the working performance showed that the personality trait conscientiousness correlates with a good performance in diverse job-related fields. The same was found for emotional stability (as the opposite pole to the trait neuroticism) which also correlates with a positive job-related performance (Barrick, 2001). Concluding the findings within this field, there seems to be a correlation between personality and job-related performance, but a weak one (Blickle, 2011). However, this weak correlation also gives no hint for any personalityrelated issue as a potential key contributor to the insolvencies, quite the contrary. 
The test values of the single cases were compared to the specific normative comparison groups of the test publisher which also considered gender and age of the participants. This led to the standard values $(\mathrm{T})$ and their percentage rating.

Only the two NEO-FFI profiles of participant 6 and participant 9 showed the standard values of all five dimensions of neuroticism, extroversion, openness, agreeableness and conscientiousness within the standard range.

The standard range contains all values to a maximum of one standard deviation below and above the average values of the normative comparison group.

Participant 6 was male and 65 years old when the test was conducted. So his test values were compared to the normative comparison group of men older than 50 years old. This led to the following standard values.

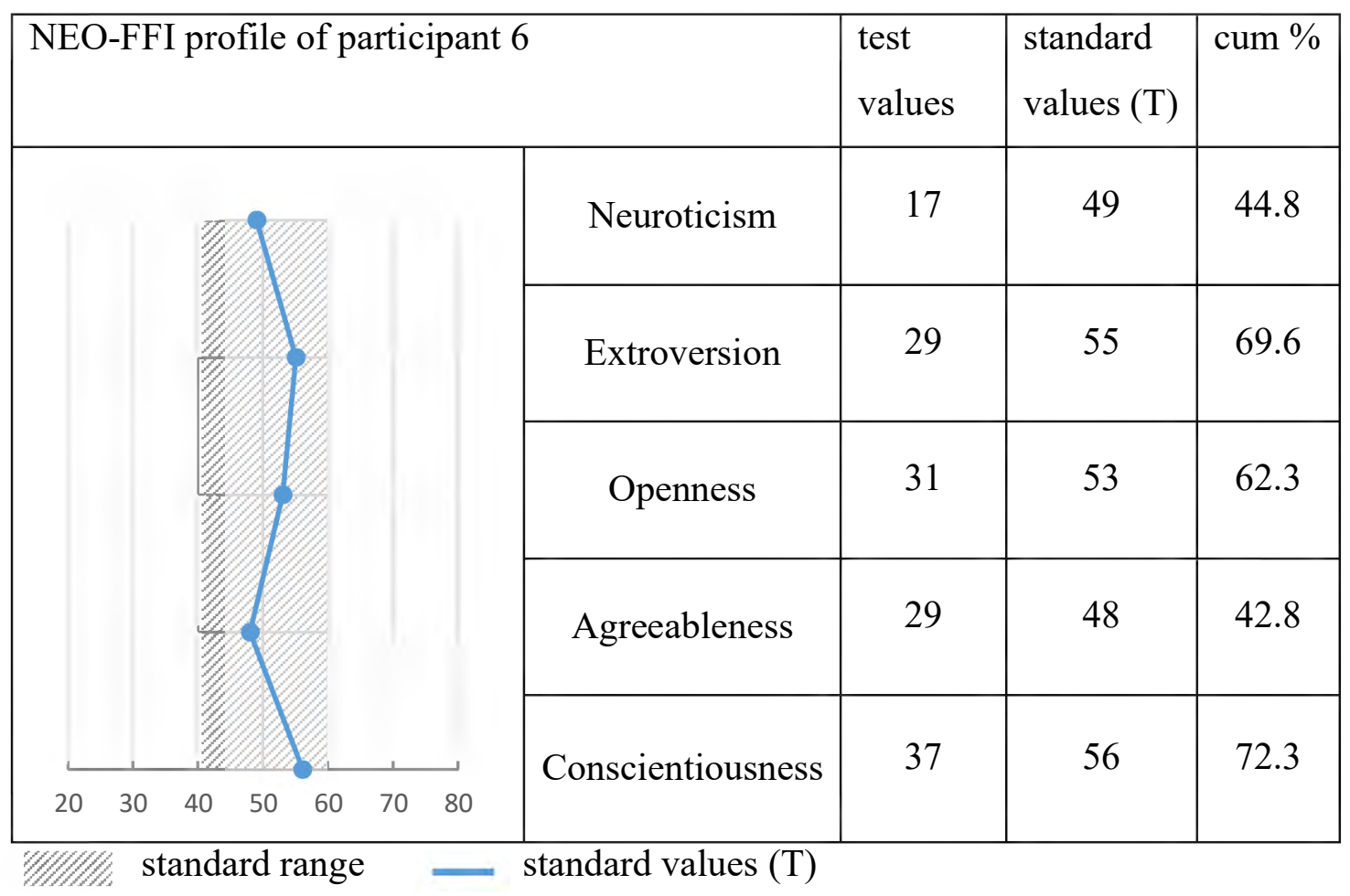

Table 2: NEO-FFI profile of participant 6

Own presentation 
Participant 9 was male and 57 years old when the test was conducted. So his test values were also compared to the normative comparison group of men older than 50 years old. This led to the following standard values.

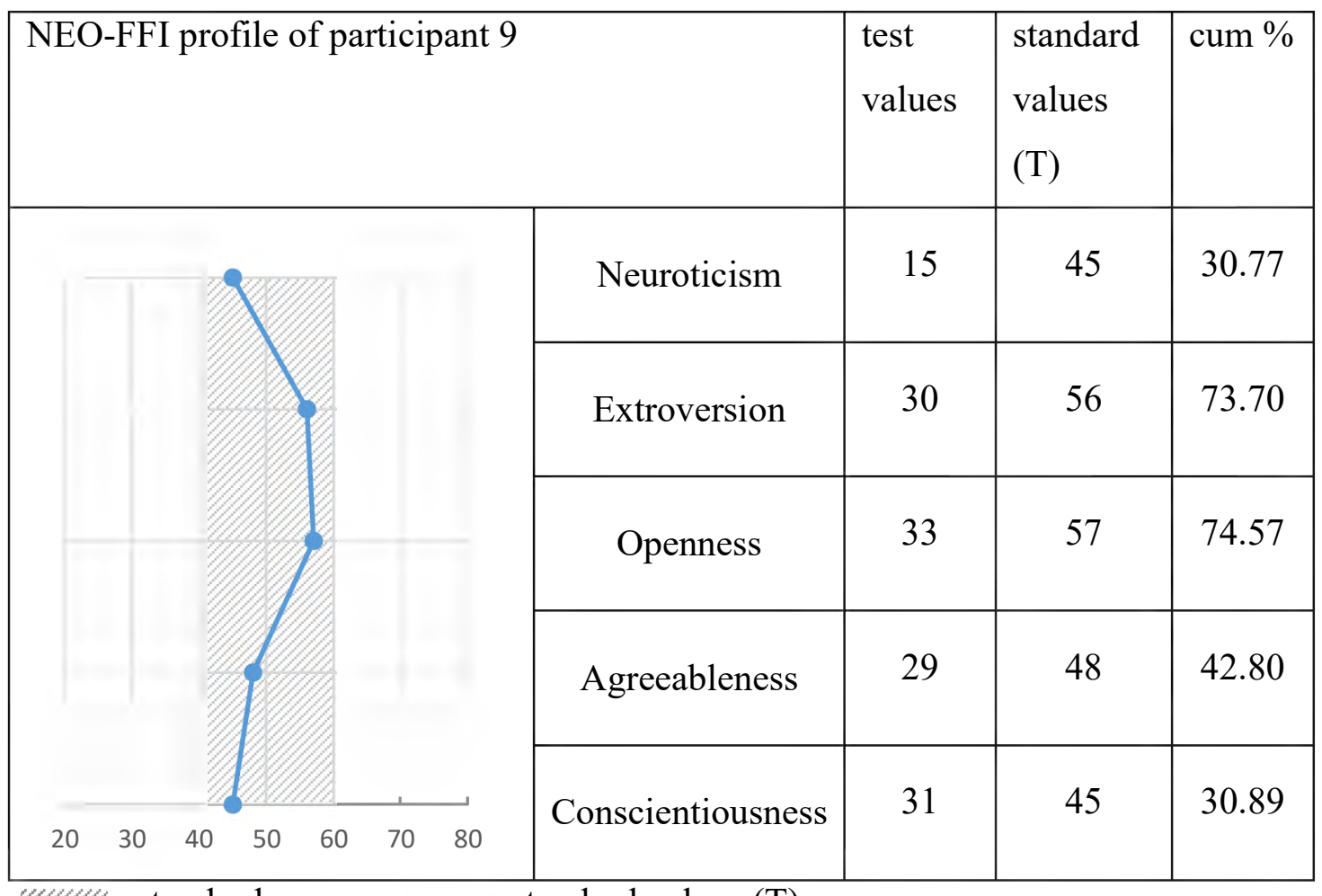

$\mathscr{W} \mathbb{K} \mathbb{L}$ standard range $\quad$ standard values $(\mathrm{T})$

Table 3: NEO-FFI profile of participant 9

Own presentation

As only these two participants had the standard values (T) of all five dimensions neuroticism, extroversion, openness, agreeableness and conscientiousness within the standard range, their interviews were reviewed for similarities.

Both participant 6 and participant 9 had problems with the leadership task of steering their company, especially with the management of their employees (to reread the given information please go back to chapter 6.1.1).

In the following, the cases with values more than two standard deviations below or above the average values of the normative comparison groups are discussed in the context of the relating interview data. 


\subsubsection{Participant 2}

Participant 2 was female and 66 years old when the test was conducted. So her test values were compared to the normative comparison group of women older than 50 years old. This led to the following standard values:

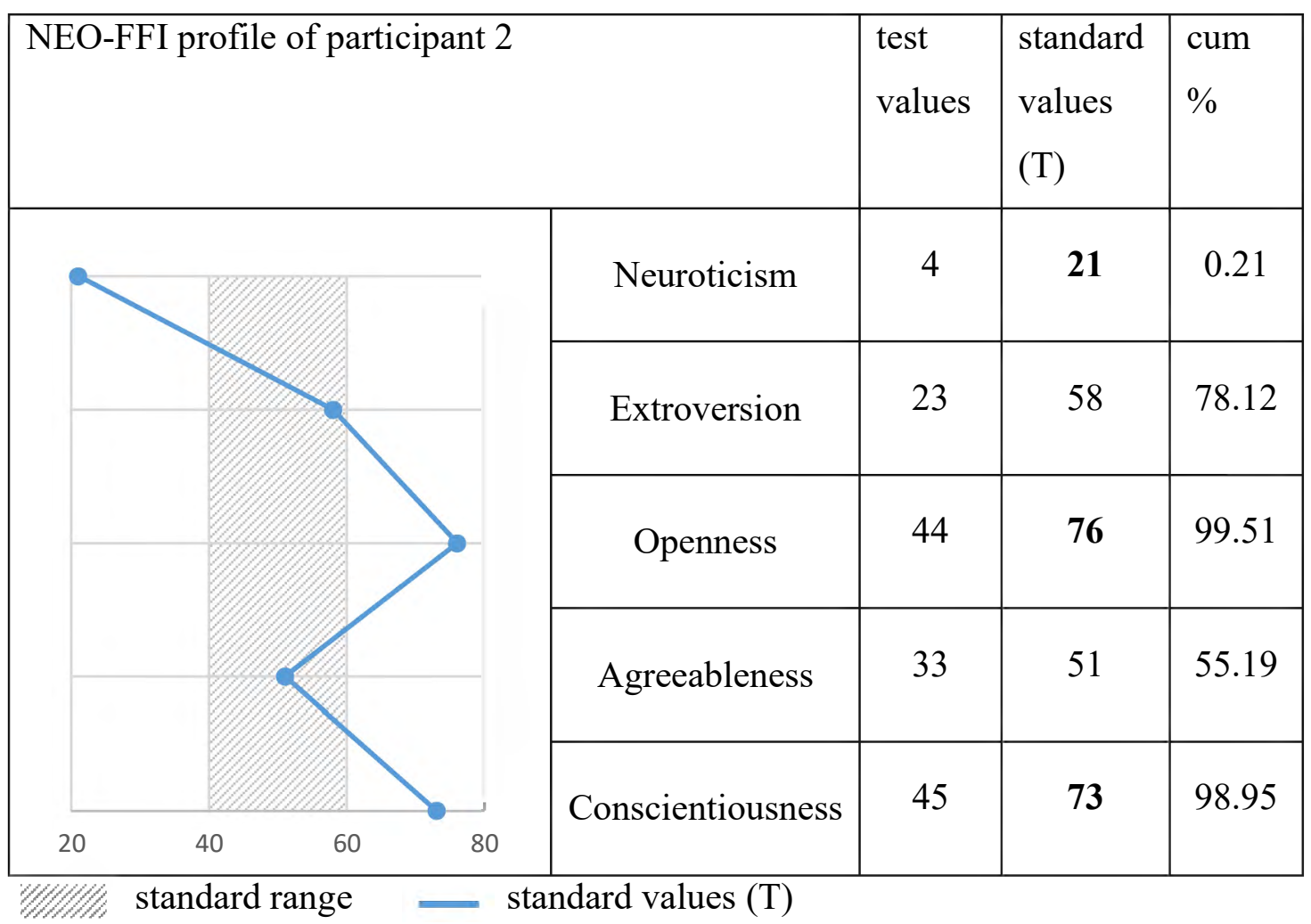

Table 4: NEO-FFI profile of participant 2

Own presentation

The NEO-FFI profile of participant 2 showed three values differing more than two standard deviations from the average of the normative comparison group in the dimensions neuroticism, openness and conscientiousness with the standard values $\mathrm{T}(\mathrm{N})=21, \mathrm{~T}(\mathrm{O})=76$ and $\mathrm{T}(\mathrm{C})=73$.

Looking at the percentile ranking, her standard value in the dimension neuroticism $\mathrm{T}(\mathrm{N})=21$ implies that $0.21 \%$ of the people of the normative comparison group had a value lower than hers within this dimension.

In the interview, participant 2 also narrated about her way into self-employment. This process she saw as an outsourcing process as she was working in the marketing 
department before and should do marketing services on a self-employed basis then. She agreed with her boss to leave the company and start her own business. Her old company should have become one of her customers and also should have given her an address file with other customers. However, when it came to her entrepreneurship, her old company let her down. They gave her an old address pool and also did not mandate her. Although participant 2 has a high value of conscientiousness, she had missed making this safe accordingly in the contracts. Furthermore, she had bought a property that did not develop its value as she had expected. Here she also lost a lot of money. Both examples are in line with her low neuroticism value. She took decisions without worrying too much, and especially the decision to buy that apartment turned out to become one of the main contributors to her insolvency. In the interview she stated:

“Yes, you can do this, don't buy anything, don't move. Whoever doesn't do anything, maybe also makes no mistakes then, right? However, in fact he makes a big mistake, because he wastes his life."

Participant 2 has the highest value of openness $T(O)=76$ that appeared within this study. The percentile rank shows that 99.51 percent of the people of the normative comparison group had a value lower than hers within the dimension openness. The interview reflected this, for example when she romanticised about the impression that the large harbour of her home town made on her in her childhood with its various people and goods. However, the interview included no hints of reasons or enablers of her insolvency that were driven by her being too self-reliant or optimistic.

Participant 2 also had the highest value of conscientiousness $T(C)=73$ of this research. The percentile rank shows that 98.95 percent of the people of the normative comparison group had a value lower than hers within the dimension conscientiousness. One reason for her insolvency was her difficult life situation at that time. Her father was critically ill, and she took care of him. In the four years that she was nursing him she neglected her business, and no longer acquired enough orders or customers. As she was setting high requirements for her father's care, she did it herself and did not take help from professional services that did not meet her requirements. She said they were very unreliable. 
The dimension conscientiousness is often discussed within job related topics. (e.g. McAdams, 2006) However, also in other areas of life, conscientiousness can play an important role and can influence daily decisions as the example of participant 2 showed, who was nursing her old father with full commitment. Of course, it seems to be more than understandable that she wanted the best service for her father, nevertheless this seemed to be one of the key contributors for her insolvency.

The low level of neuroticism enabled participant 2 to take actions and decisions that contained risks without worrying too much. Her high level of openness might have supported these actions and decisions. On the other hand, she also showed high values in the dimension of conscientiousness. However, her priorities changed with the illness of her father, and so her conscientiousness seemed to be focused on that topic instead of her business. 


\subsubsection{Participant 3}

Participant 3 was male and 46 years old when the test was conducted. So his test values were compared to the normative comparison group of men from 30 to 49 years old. This led to the following standard values.

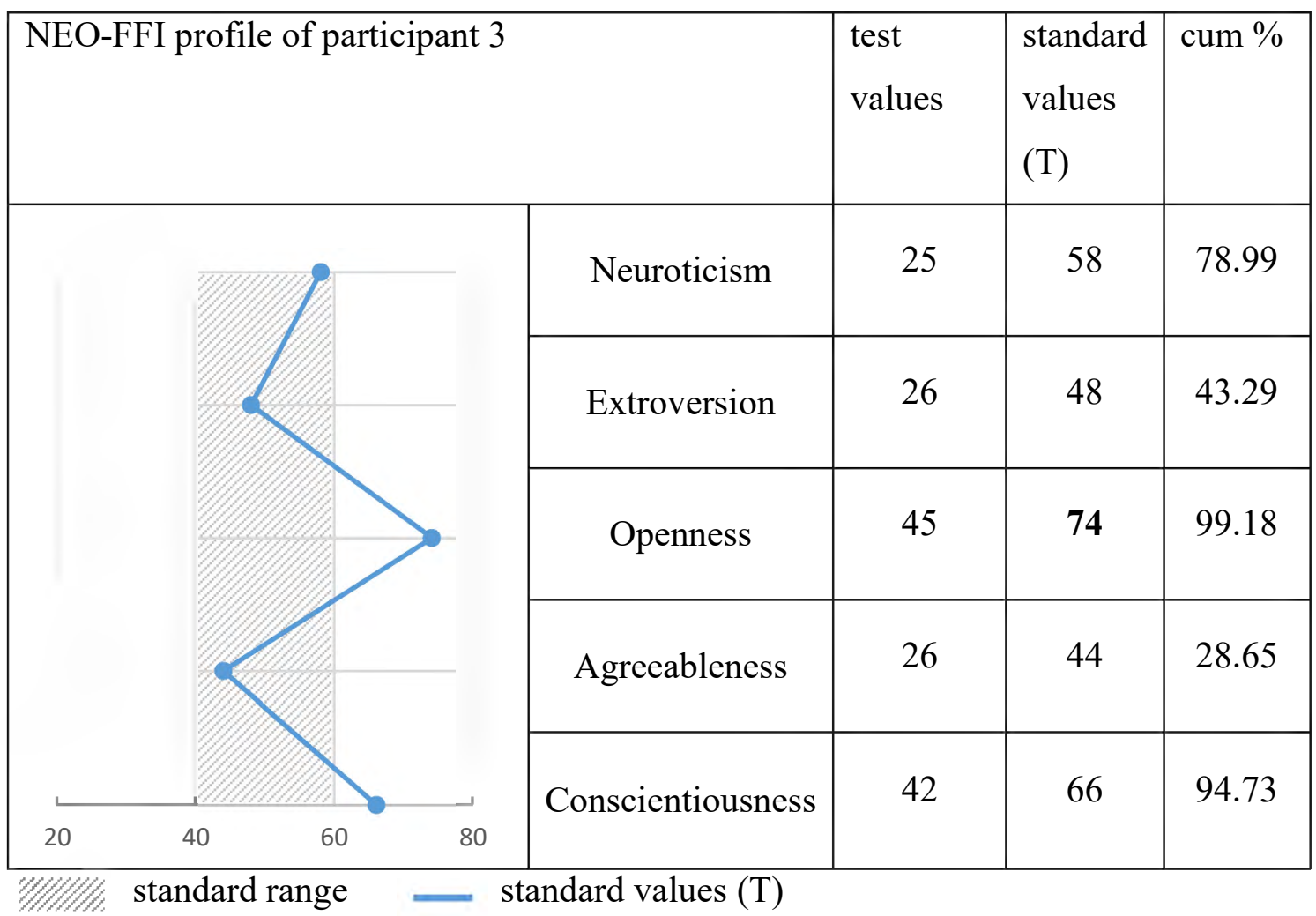

Table 5: NEO-FFI profile of participant 3

Own presentation

The NEO-FFI profile of participant 3 showed one value differing more than two standard deviations from the values of the normative comparison group in the dimension openness with a standard value $T(O)=74$.

Looking at the percentile ranking, this standard value implies that $99.18 \%$ of the people of the normative comparison group had a value lower than his within the dimension openness.

Participant 3 started his business during his doctoral studies without any working experience. Later he had to realise that the business world is hard and that especially the pharma industry had its difficulties (please see chapter 6.1.2). In the interview he 
said that if he had known more about that before, he probably would not have made the step into self-employment. However, later, when it came to the insolvency, there were no hints found in the interview that showed him being too open-minded or adventurous. 


\subsubsection{Participant 5}

Participant 5 was male and 63 years old when the test was conducted. So his test values were compared to the normative comparison group of men older than 50 years old. This led to the following standard values.

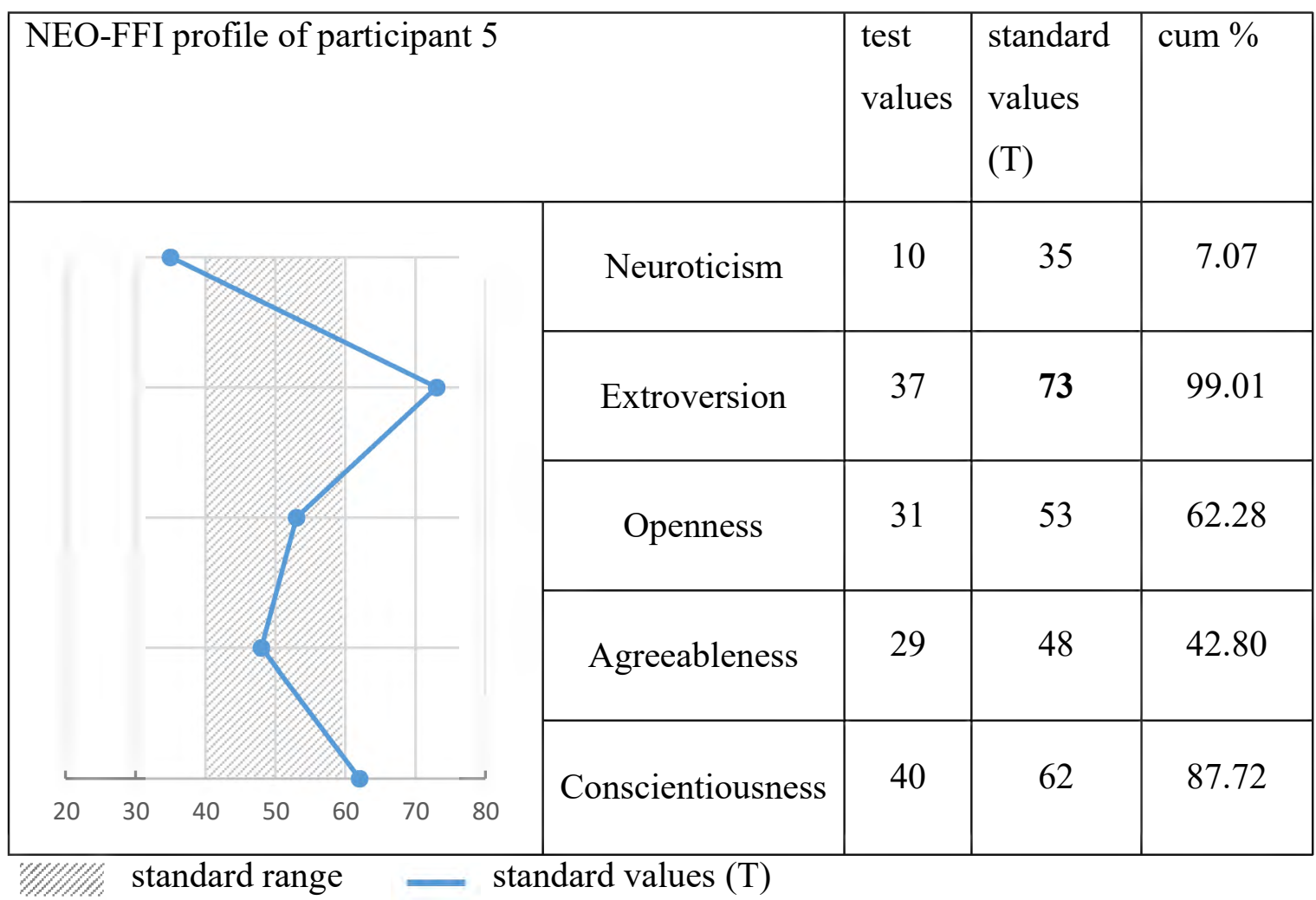

Table 6: NEO-FFI profile of participant 5

Own presentation

The NEO-FFI profile of participant 5 showed one value differing more than two standard deviations from the values of the normative comparison group in the dimension extroversion with the standard value $\mathrm{T}(\mathrm{E})=73$.

The percentile rank shows that $99.01 \%$ of the people of the normative comparison group had a value lower than his within the dimension extroversion.

Participant 5 was head of a service provider in the banking sector, and he enjoyed a good and cooperative relationship with his customers. When one of his customers took over another company, they explained to him that they would need approximately one year to sort everything out, but after that time period he and his company should have 
the new locations running. According to participant 5, they reassured him several times that they needed him and even supported him financially with a credit to endure this year more easily. However, when the year ended, they let him down, cancelled the contract and gave the business to another supplier. He did not have any safety precautions for such a case as he never would have expected the customer to leave him out in the rain as they seemed to have such a good relationship before. Through this incident the participant had to realise that the customer did not value partnership and companionability as highly as he did. He had been optimistic that after this difficult year he could go on with a fair and profitable business relationship.

So the high level of extroversion of participant 5 seemed to have weakened his awareness of possible risks. He was enjoying good relationship and companionability more than he guarded his enterprise against risks. Participant 5's misinterpretation of his customer's loyalty was one of the two identified key contributors to his insolvency. 


\subsubsection{Participant 8}

Participant 8 was male and 67 years old when the test was conducted. So his test values were compared to the normative comparison group of men older than 50 years old. This led to the following standard values.

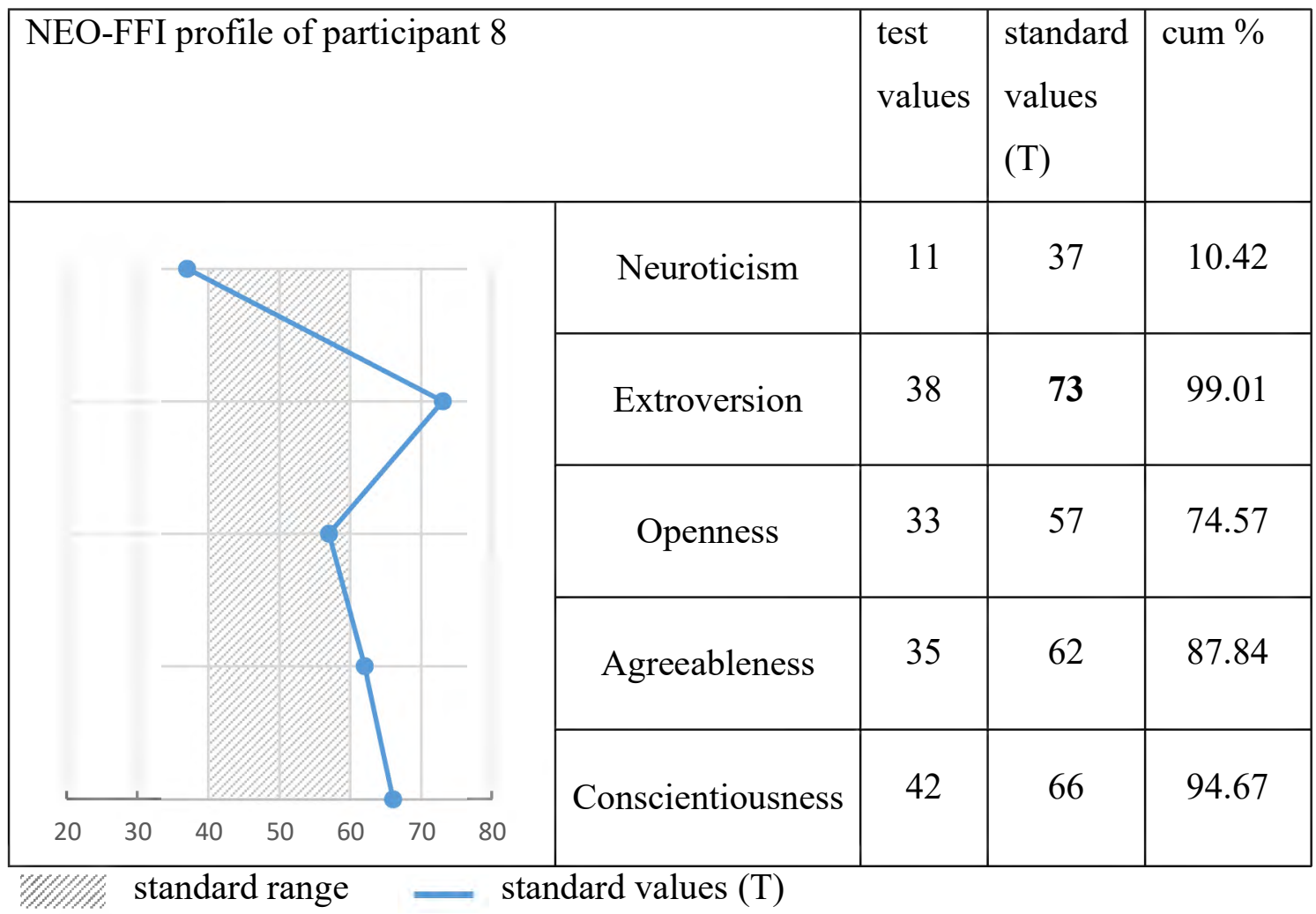

Table 7: NEO-FFI profile of participant 8

Own presentation

The NEO-FFI profile of participant 8 showed one value differing more than two standard deviations from the values of the normative comparison group in the dimension extroversion with a standard value $\mathrm{T}(\mathrm{E})=73$.

The percentile rank of this standard value implies that $99.01 \%$ of the people of the normative comparison group had a value lower than his within the dimension extroversion.

Before he became CEO and partial owner of the respective company, he was working as a consultant specialised in insolvencies and reorganisations. A banker with whom he had worked before persuaded him to join although participant 8 had stated before 
that he did not see a chance for the company. With a smile he narrated in the interview what the banker said about the reorganisation then:

"I am willing to do it but only under the condition that you take the lead."

It seemed that companionability to that banker, who then also went bankrupt, influenced his decision.

The reorganisation was successful to a certain extent, but in the end the bad debts overtook them. In the interview, he stated that for him it was clear that this could happen one day. Nevertheless, he was optimistic that he could make it. This is in line with his high value of extroversion, as it seemed that his self-reliance, optimism and companionability finally made him the responsible CEO within this insolvency. 


\subsubsection{Participant 10}

Participant 10 was male and 74 years old when the test was conducted. So his test values were compared to the normative comparison group of men older than 50 years old. This led to the following standard values.

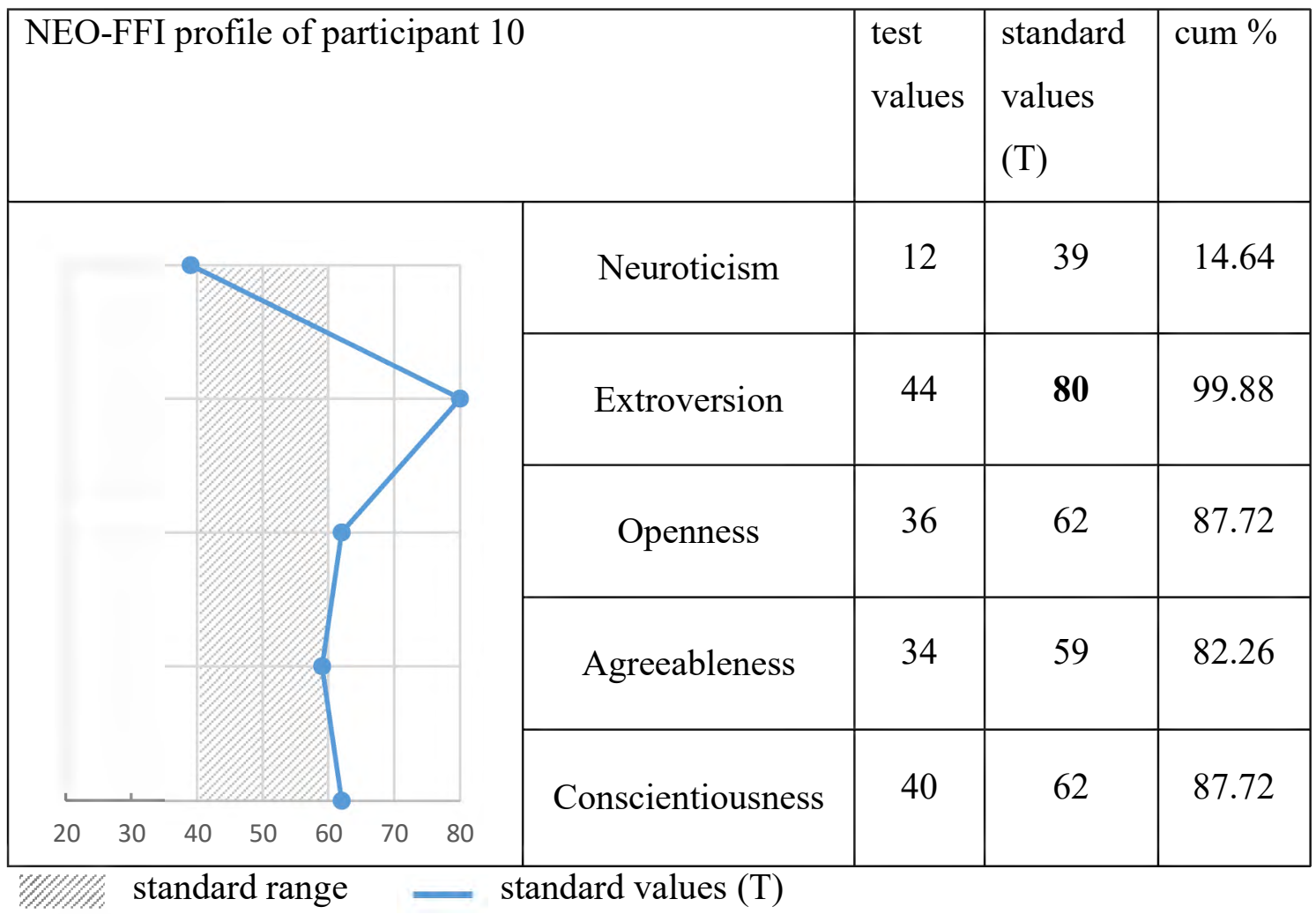

Table 8: NEO-FFI profile of participant 10

Own presentation

The NEO-FFI profile of participant 10 showed one value differing more than two standard deviations from the values of the normative comparison group in the dimension extroversion with a standard value $\mathrm{T}(\mathrm{E})=80$, the highest level of extroversion within this study.

The percentile rank shows that $99.88 \%$ of the people of the normative comparison group had a value lower than his within the dimension extroversion.

When the interview started with the request that he should talk his life along general lines, participant 10 suggested that I should read his biography published in a book with a title like "People that people are talking about" or similar. It did not seem like 
this was a serious suggestion but this situation produced the impression that he was very proud of his success and popularity.

Participant 10 explained in the interview that he was member of 108 associations, in 60 of which he was an honorary member. Furthermore, he described himself as a person that is active and communicative. All that is in line with his high value of extroversion.

Although his business went very well, he got into financial trouble because of a loan guarantee. He always had good connections to customers and business partners. However, his trouble began, when he bailed for customers who then went bankrupt. He indirectly admitted that his extroversion might have had negative effects on his business when he explained:

"My sons are better than I was and this is because I had a lot of side-jobs like county council, town council, master of the construction guild, president of the local soccer club (...) and so on."

However, his extroversion also seemed to help him to start again after the insolvency. Without taking a break, he then established a new company. He explained that this was only possible as he had a lot of good contacts. His customers helped him to bounce back quickly as they stayed with him in the face of the insolvency and agreed to pre-finance the projects to a certain extent. So his extroversion can be seen as a key contributor to his bankruptcy. However, it looks like his communication skills and active networking also helped him restart after the insolvency.

Participant 10 answered the whole NEO-FFI with "strong agreement" or "strong disagreement", the two extreme poles of the five-stage ranking. This response tendency seemed to mirror his strict attitude as a facet of his personality. Reflecting the situation when he answered the NEO-FFI questions, he commented on every answer with "Yes, that I am!/ Yes that I do!" when ticking the box for strong agreement and spoke out loud "No, I am not that way!/ No, I don't do that!" when answering with strong disagreement. Furthermore, he showed his thoughts about every item by nodding or shaking his head. Also, the interview produced the impression that he was a person with clear opinions and strong self-esteem who does not have doubts about what he is doing or thinking. 
These reflections lead to the assumption that his response tendency is not to be seen as a distortion of test results.

The high level of extroversion of participant 10 might have influenced his business in a negative way as he admitted that he had too many commitments outside his job that required his attention and time. However, on the other hand, his high level of extroversion also seemed to be an essential success factor of him founding and establishing his second enterprise after the insolvency of the first one. 


\subsubsection{Participant 12}

Participant 12 was male and 54 years old when the test was conducted. So his test values were compared to the normative comparison group of men older than 50 years old. This led to the following standard values.

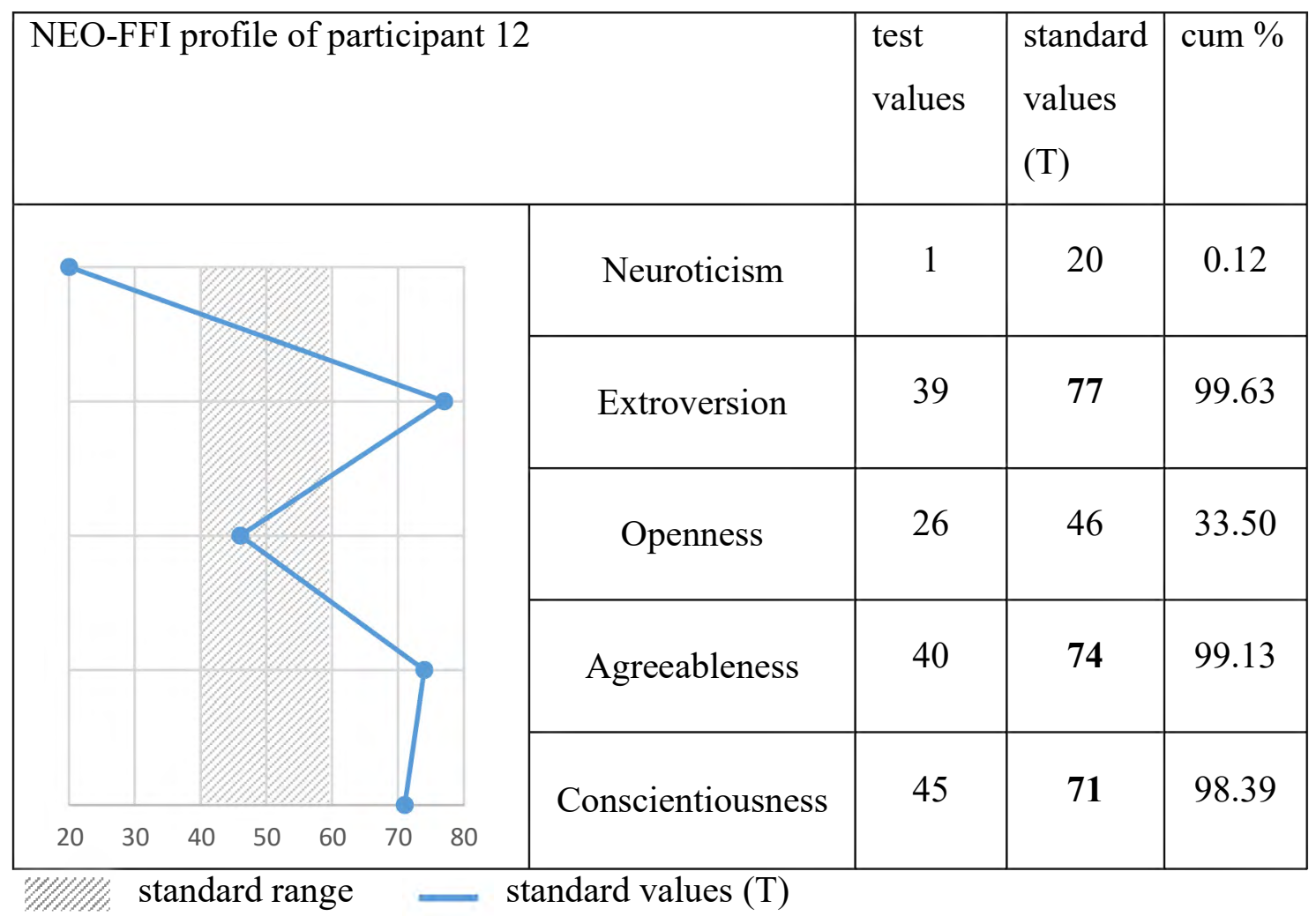

Table 9: NEO-FFI profile of participant 12

Own presentation

The NEO-FFI profile of participant 12 showed four values differing more than two standard deviations from the values of the normative comparison group in the dimensions neuroticism, extroversion, agreeableness and conscientiousness with the standard values $\mathrm{T}(\mathrm{N})=20, \mathrm{~T}(\mathrm{E})=77, \mathrm{~T}(\mathrm{~A})=74$ and $\mathrm{T}(\mathrm{C})=71$.

Participant 12 had the lowest value of neuroticism $\mathrm{T}(\mathrm{N})=20$ within this study. The percentile rank of this standard value implies that $0.12 \%$ of the people of the normative comparison group had a value lower than his within the dimension neuroticism. 
In his interview, participant 12 stated that the accountant that he had authorised had not transferred the money to his health insurance for three years. Although he had a high value of conscientiousness, he never checked the accountant's work. By handing some topics over to him, participant 12 did not care about those topics any more. He took this outsourcing decision without worrying about the accountant's knowledge or reliability. This is in line with his low value of neuroticism. The omission of the accountant was no direct contributor to his insolvency but added debts to his financially tense situation.

The NEO-FFI profile of participant 12 also showed a value differing more than two standard deviations from the values of the normative comparison group in the dimension extroversion with a standard value $\mathrm{T}(\mathrm{E})=77$.

The percentile rank of this standard value implies that $99.63 \%$ of the people of the normative comparison group had a value lower than his within the dimension extroversion. The accountant that he hired was one of his friends. In the interview, he said he allocated the topic wages and add-on cost to him completely. He never questioned his qualification and also did not control his performance as he was a friend.

Participant 12 had the highest value of agreeableness within this study with $\mathrm{T}(\mathrm{A})=74$. The percentile ranking implies that $99.13 \%$ of the people of the normative comparison group had a value lower than his within the dimension agreeableness.

He was running a supermarket as an entrepreneur. When problems started, the parent trading company claimed a high inventory difference that increased his debts. He said in hindsight he thought he should have fought against this false accusation, but then he did not. He was hoping that everything would turn out fine, and they would find a peaceful compromise. This is in line with his high value of agreeableness that implies that he sees himself as a person that has a deep desire for harmony. The additional claim of the parent trading company did not seem to be the neck-breaker in his insolvency case, but it certainly had a large impact and also contributed to him going bankrupt personally.

The NEO-FFI profile of participant 12 also showed a value differing more than two standard deviations from the values of the normative comparison group in the 
dimension conscientiousness with a standard value $T(C)=71$. The percentile rank of this standard value shows that $98.39 \%$ of the people of the normative comparison group had a value lower than his within the dimension conscientiousness.

He mentioned that he always worked from 6 am to $9 \mathrm{pm}$. It was interesting to see that after many years he still knew every position of his insolvency debts list inluding the last euro by heart. However, the interview did not present reasons or enablers for his insolvency due to workaholism or the setting of extremely high requirements or other reasons related to a high value of conscientiousness.

It seems as if his low level of neuroticism and his high level of agreeableness influenced the entrepreneurship of participant 12 in a negative way. Participant 12 had the lowest value of neuroticism and the highest value of agreeableness within this study. Although he also showed a high level of conscientiousness in the NEO-FFI, he took incorrect decisions that harmed his business and his own financial position. 
In the literature about persistency of personality traits during lifetime, it is frequently mentioned that from an age of about 30 years the personality is mainly stable and tends to stay as it is. James (1981) used the picture of congealing gypsum to describe this stability: "In most of us, by the age of thirty, the character has set like plaster, and will never soften again" (James, 1981, p. 126).

However, taking a closer look behind this striking phrase shows that also adult personality is not perfectly static. In fact Costa and McCrae (1994) conducted retests after several years and report a stability value of 0.64 on average. This stability value gives room for change. Furthermore, the stability declines with broader time frames. In this context, Costa and McCrae (1994) pick up James' picture of the adult personality fixed like plaster and point out that also concealed gypsum is not stable forever: "But anyone who has lived in an older house knows that plaster is not granite. With time, moisture and the settling of the house it begins to crack and crumble" (Costa \& McCrae, 1994).

According to Laux (2008), several studies also showed that the stability values become lower as the time periods between test and retest become longer (Laux, 2008).

In a meta-analysis of 92 longitudinal studies, Roberts et al. (2006) even found that personality can change significantly during a lifetime (Roberts, 2006). There are several mechanisms that lead to a change of personality traits with age, and this change is not just random but systematic. So people often change when adopting a new role in life. Through new behaviours connected to that new role or by watching others, changes in personality can be promoted. Also, feedback from others can have a changing effect on people's personality (Roberts, Wood, \& Caspi, 2008).

"Several longitudinal studies have demonstrated that experiences in work (...) are associated with changes in personality traits. Work-related experiences, such as working more than others or attaining higher status, are associated with increases of (...) extraversion and (...) conscientiousness" (Roberts, 2008, p. 387). If such comparatively tame experiences already cause significant effects on the personality traits, it seems to be highly likely that change in personality could also occur through such an intensive experience as an insolvency. 
The appropriate research setting to better understand the change of personality that might take place through an insolvency would be to administer the NEO-FFI questionnaire to the participants twice - once before the insolvency and once afterwards.

Although my research took place years after the participants went through an insolvency, nevertheless the NEO-FFI inventory together with the participants' memory recall of the differences between themselves before and after the insolvencies give insights in their personality development.

Five of the twelve participants mentioned unasked and independently that they are sure that they would have answered the test in a different way before the insolvency. As an example, all five participants mentioned item number 47 of the NEO-FFI explicitly. It says: "I live a bustling life." They all said that before the insolvency they would have fully agreed with this item, but today they no longer do. The item 47 belongs to the dimension extroversion. This implies that through the insolvency the standard value $\mathrm{T}(\mathrm{E})$ of these five participants decreased slightly.

This might be a field for future research. In such further research, the question should also be addressed of whether an identified change of personality would really have its root cause in the experience of the insolvency itself or if it might have occurred through the changed life conditions after the insolvency.

The question of whether the participants felt they had changed though the insolvency was also part of the interviews. Their answers can be reviewed in chapter 6.3.7. 
The background chapters about the legal regulations concerning the insolvency procedure in Germany already contained some effects that the insolvency has for the debtors. However, the judicial aspects are only the tip of the iceberg. An insolvency can have major emotional, social and financial implications for the concerned individuals (Paulus, 2017).

\subsubsection{Failing and Stigmatisation}

Failing in the context of corporate crises and insolvencies can be seen as the personal dimension of the entrepreneur's risk. As the business he/ she founded, established and/ or led reflects his/ her attitudes and experiences, the failing of this business hurts the leader inside. It shakes his/ her opinions and expectations. So the insolvency is not just a crisis for the business but also for its leader personally (Pechlaner, Stechhammer, \& Hinterhuber, 2010).

Participant 3 was the only one who did not have this experience, but he was a special case. In contrast to the other participants, he described his insolvency as a "sequence in an overall process", "that then led to more success step-by-step. (...) It is the overall context (...) So I experience the insolvency differently than people do when their whole lifework gets destroyed."

Through the insolvency procedure an investor was found who made it possible to continue the participant's enterprise. He still holds shares and it is still a successful and well-established company.

However, not all leaders that had to face an insolvency are able to see their enterprise emerge again. Furthermore, the participants suffered because of the blemish of the insolvency and felt the burden of the stigmatisation. Some of my participants explicitly addressed this stigmatisation:

Participant 1: "Insolvency is afflicted by a blemish." 
Participant 2: "You try everything to avoid this way (to go into insolvency) because of the reason that in Germany failing is a stigma."

Participant 5: "In Germany insolvency is still seen as something evil in the common opinion." And: "It is hard for me to say that I had an insolvency. (...) It is a failure."

Participant 12: "I had the feeling at that time that you are stamped somehow."

In Germany insolvencies are still a taboo. According to Häring (2010), the insolvent entrepreneurs are seen as losers, who simply were not able to handle the business challenges accordingly, or they might be swindles who probably even ruined it on purpose (Häring, 2010). This social stigma seems to be connected to the German culture. The management literature as well as the participants did not tire of mentioning the cultural differences in terms of the acceptance of failing between other countries, for example the USA, and Germany. Participant 2 used the well-known phrase "In Germany we do not have a culture of failing" to sum up the dilemma. As a business man in the construction sector, participant 10 explained in this context the cultural differences between the USA and Germany that also became obvious in his daily experiences:

"America has the advantage that redtapism and the legal regulations are weaker than in Germany. (...) America made a development in about hundred years, where Germany needed nearly 2000 years. (...) If you just imagine that performance of building all that infrastructure, (...) I mean streets, channels, bridges and buildings and so on. (...) This was just possible (...) because the freedom that was given to the people to evolve was much bigger than in Germany. (...) On the one hand the limitations in Germany may be good, but what I now realise at other constructors is that the courage of many constructors gets taken away through that red tape. (...) This will become a huge economical problem for Germany in the future." 
These topics that he mentioned here made his point of view of some of the cultural differences clear. Participant 10 saw Germany's development handicapped by too many regulations that restricted the freedom to experiment with what would be needed for further development. This development-adverse culture in his eyes is the same one that stigmatises business leaders that failed with their enterprise.

However, failing is important not just for humans in general, but especially for entrepreneurs. For Stechhammer, failing is "the shadow of success" (Stechhammer, 2010, p. 194). It is natural only that succeeding brings the possibility of failing. However, this does not have to be seen as something negative, it is just an immanent part of success that hides in the darkness (Stechhammer, 2010). Participant 2 also argued in this direction when she explained:

"Yes, you can do this, don't buy anything, don't move. Whoever doesn't do anything, maybe also makes no mistakes then, right? However, in fact he makes a big mistake, because he wastes his life."

In this context, Stechhammer applied to adapt the view of research that is not polluted by the stamps of failing and success. In research, we are talking about falsification and verification instead, and this world view would also be preferable for society and culture to accept failings as a possibility that is necessary for development and innovation (Stechhammer, 2010).

Participant 2: "If you go into this with weak self-esteem, it can kill you."

Participant 5: "If somebody really is at a loss and thinks about suicide, then I understand that. You can only really understand this if you were in those emotionally exceptional circumstances yourself."

Participant 9: "My lawyer was worried that I might have suicidal tendencies." 
Even participant 3, who pointed out that the insolvency was probably was not as dramatic for him as for others as his company could be rescued and he did not have a personal bankruptcy, compares the insolvency with dying.

Although some of the participants emphasised that they were and are not at risk of committing suicide, the analogy between the insolvency and death as well as the general risk for the former leader to commit suicide was mentioned frequently. Koark stated in her article about her own insolvency about her companions in misfortune that "many of the people were suicidal due to the stigmatisation of failure" (Koark, 2012, p. 511).

This statement was supported by research in Japan. There the number of suicides suddenly increased in the year 1998. In his study, Chen et al. (2015) showed that the "dauntingly high level of suicide began in 1998 with an abrupt $35.16 \%$ increase in the suicide rate," and that "the suicide upsurge in 1998 was primarily caused by suicide among middle-aged males aged 40-59 who had suffered from financial problems. Moreover, a disproportionate increase in suicide among self-employed male workers was also uncovered" (Chen et al., 2015, p. 271).

This finding is consistent with the assumption that "bankruptcies and unemployment, followed by the unprecedented 1997 credit crunch had played an influential role in this upsurge in suicide" (Chen et al., 2015, p. 259).

All participants had to handle their failing and in the first instance that meant they had to accept this failure for themselves. Furthermore, failing in Germany is afflicted with blemish. The participants suffered from this stigmatisation. Here it was not the environment but their own point of view. They did not just have to accept their failure but also that imminent stigmatisation for themselves. 
A consequence of the insolvency that ran like a golden thread through the interviews was the loss of social status and influence. The participants experienced this dramatic change from the respected leader to the loser as a very challenging situation as the following quotations show exemplarily.

Participant 2: "It also was some kind of leave that I had to handle. I had to handle the change from this very well-off situation with a position, with car, travels and top people I met, events to where I was invited to nothing."

Participant 4: "The people (the employees) that I had promoted for years turned away from me immediately (...) Basically I had no influence on anything any more."

Participant 5: "You fall from 100 to zero (...) You have been a respected person (...) and then suddenly you were nothing any more. That was blatant."

Participant 6: "The worst part of this whole thing was that in this time (of the insolvency) you are more or less put under tutelage. You are a man of second-class. That is the worst. Before that, you were a boss and took decisions and now you are nothing any more. This is the worst experience of the whole insolvency. (...) This devaluation hurts. This really hurts."

Participant 7: “At the beginning I had huge problems looking my employees in the eyes (...) because I always had the feeling that standing in front of them was no longer a leader (...) but a loser, somebody who guided us into the abyss."

Participant 8: "You do not have to say anything anymore. You have to swallow when you realise that you are basically only good enough to get the others some coffee." 
The narratives imply that this aspect of the insolvency was very displeasing and frustrating for the participants. The interviews point out two effects within this context. On the one hand, the participants had to handle a change in their lives that accompanied fewer possibilities and less money. On the other hand, and that even seemed to be the worst part for them, they had to deal with their loss of power, reputation and influence. Combined with former quotations, they named their status after the insolvency with expressions like being "nothing" and "second-class", felt "stamped" and like "losers", and explained that failing in Germany is a "blemish" and a "stigma".

The German insolvency code disempowers the CEO. The background for the restriction of his/ her rights during the insolvency procedure lies in the very obvious conflict of the interests of debtor and creditors. To arbitrate this conflict, the insolvency administrator is installed to take care of the satisfaction of the creditors' claims. To ensure that the debtor supports the administrator, the insolvency code contains several regulations. On the one hand, these regulations are necessary for a working insolvency procedure but on the other hand, they are very restrictive against the CEO.

$\S 97 \mathrm{InsO}$ for example includes an extensive obligation to give information. As the debtor's will to cooperate in some cases might be not too strong, § 99 InsO even contains a post redirection order that means that the debtor's mail goes to the insolvency administrator instead (Paulus, 2017).

At the beginning of the insolvency procedure, the administrator needs somebody that supplies all the necessary information. In this situation, it is natural for the insolvency administrator to consult the CEO as he/ she probably has the best overview over the company and access to different kinds of information. However, after some time he/ she loses this unique feature and becomes replaceable as the administrator gets more and more information him-/herself and also gets to know the relevant employees within the company. Then the CEO might not be the best choice to fulfil the leader role any more. Often he/ she is frustrated as he/ she sees the company as important lifework as failed. Furthermore, the CEOs often have to face the risk of an insolvency as a natural person. In that challenging situation they are overwhelmed by their personal problems and not fully capable of acting. An important advantage that can 
keep the CEO in the game is the ownership of specific know-how or even patents that are relevant for the continuation of the business (Imgrund, 2009).

Participant 3 established his chemical company after doing his doctorate and it included the application for some patents that were later used in that company. This could be a possible explanation as to why he was the only one of the twelve participants that remained in the company as owner and leader. Instead of an extensive tale of woe and failing, the insolvency for him was an unpleasant interlude that finally ended in a story of success. His company was reorganised and became very successful after an investor was found during the insolvency proceedings. Now, his shares are worth several million euros.

The disempowerment of the CEO by the German Insolvency Code and the Insolvency Administrator as new lead of the company on the one hand imply that there is the potential for conflict between these two actors.

The participants of this study were contacted indirectly via their lawyers/ insolvency administrators and not directly via the author of this study. (The sampling process is presented in detail in chapter 5.2.) This on the other hand implies that predominantly participants found their way into this research that got on well with their insolvency administrators. The comments that the participants made about their cooperation underline that phenomenon:

Participant 1: "I get along well with the insolvency administrator. She is treating me fairly."

Participant 3: "I always felt comfortable with the insolvency administrator. (...) The insolvency administrator was not bad for sure, and also in hindsight there were some things that he solved quite cleverly."

Participant 4: "The insolvency administrator trusted in me very much, well, that was really great. He saw that I am a maker and not a destroyer." And: "Out of all this there developed a friendship within four years. Well, that really worked very, very well." 
Participant 5: "We actually complemented one another quite perfectly." And: "I found a human being in my insolvency administrator. (...) If I had any trials and tribulations, I could call her."

Participant 6: "With Mr. X (name anonymised) I was incredibly lucky. In this whole phase, as I said, I was incredibly lucky with this man."

Participant 7: "The collaboration was excellent."

Participant 8: The collaboration with the insolvency administrator was "brilliant. It could not have been better. He fully relied on what we presented him."

Participant 9: "She processed that dedicatedly and well and also agreeably and positively for me."

Participant 11: "The contact (...) for me was surprisingly comfortable."

Participant 12: "With Ms. X (name anonymised) it is going well. I really cannot complain. (...) It is really great, I have to say."

Participant 2 did not say explicitly that the collaboration with her insolvency administrator was good, but it can be interpreted looking at situations or dialogues she narrated within the interview.

The only one who did not find positive words for his insolvency administrator was participant 10 . He explained that he did not trust or collaborate with him at all. The quotations clearly underline the predominantly very good relationship between the participants and their lawyers. 


\section{3 .3}

According to Rogers (1959) people have the need for positive esteem. This need is about the experience that other people who are important for them and/ or associated with them compliment them and accept them lovingly. On the one hand, Roger sees this as a universal need that everybody has. On the other hand, it is developed during a lifetime, so it is not equally strong in every human being (Rogers, 1959 and 1969). Especially during critical or stressful occasions in life, it is important for those concerned if there is somebody who gives them help with words and deeds, support and love. In this context the expression of social networks established. It means "social patterns of relationships where a person is integrated and that are important to that person's experience, wellbeing and behaviour" (Ulich, 1987, p. 129). Caplan (1964), one of the early crises researchers, already pointed out the importance of supportive persons for those concerned. Various groups of people with different levels of intimacy and institutionalisation can play a crucial role here (Caplan, 1964). Examples for possible supporters are family and partners, friends, neighbours but also professional helpers such as doctors or in our cases consultants, lawyers and insolvency administrators.

Most of the participants found they needed support and comfort from their families. Participant 4 for example found the following words about the support his family gave to him facing his insolvency:

"Family kept together. This love, this unbelievable love rescued me."

In most of the twelve reviewed cases, the experiences of the insolvency seemed to have strengthened the family ties.

Participant 10: "I do owe a lot to my wife, who had respect for my function and a lot of understanding." And: "Next year I am celebrating my golden wedding anniversary. This all became stabilised."

Participant 8: "I am very lucky as I have a wife with whom I can still talk even after many years together. And we have our own ritual here. Every 
evening we talk through what has happened. And so I always had somebody I could often talk to."

Also participant 6 emphasised how much he owes to his partner:

"And I have to say, I am only that well, because I have Mary (name changed). If I did not have her, I would surely not be that well. This is crystal clear for me."

However, there are also cases where the insolvency caused domestic stress.

Participant 11 reported that he often wanted to discuss his business problems with his partner. However, after a while she had had enough and did not want to listen any more. He said that he had not needed this additional conflict but somebody to talk to. On the other hand, he understood that after one or two years she was fed up with listening to problems all the time.

Participant 7 had to master the difficult time of his insolvency without his wife, as she left him to work abroad. They were close to divorce. He remembered this as very hard period in his life but in hindsight he saw this temporary separation positively as he could concentrate on his business and the injured relationship did not suffer further damage through the insolvency problems.

In the end both participants were able to solve their problems and after the crisis of the insolvency their relationships became well again.

While the partner or the near family was predominantly seen as supportive and loving during the insolvency, some participants had different experiences with their friends or other people they had to deal with during that period.

One participant kept his insolvency completely secret and two other participants reported that they cannot reflect on their friends' reactions as they did not have friends due to their excessive working hours or several moves in the time before the insolvency.

For some participants, their friends were a tower of strength. Participant 1 , who had to spend some time in prison during his insolvency proceedings, had good experiences with his friends as they were supportive and did not judge him: 
"They all gave me a pat on the back and said: 'It is ok. For us you are not a criminal!"”

And also participant 11 took comfort in his friends:

"A lot of my friends (...) pointed out that it was not necessarily my fault, but that I endured quite a long time within those troubled waters."

However, not all friends were that helpful. Participant 10 had the experience that some friends were a great support, but some also broke away:

"I felt supported by a lot of friends, but I also had friends who dissociated. (...) Well about two third stayed by my side and one third went away."

And also participant 2 said:

„Yes, friends changed. But when you ask for help, you see, who really helps you."

The participants explained that they had inhibitions about making their insolvency public. The initial reason for these inhibitions was the feeling of being failed and getting stigmatised due to this failure. However, in some cases these initial inhibitions grew because of negative experiences in their environment.

Participant 5: "Before (the insolvency) you have a lot of friends, but not many of them stay. When they realise that you are getting into that situation, then this is like an epidemic. Then they are afraid that they will contract that disease. Then suddenly they are not available for you any more. Then there is nobody who gives you encouragement, who says: 'Hey, if you have a problem, I'll help you.'” 
Participant 8: "What I experienced here during the insolvency made me reflective. I have a lot of acquaintances - I really want to name them so and none of them got in touch with me."

Participant 4: "I do not know the quota, but I feel that $90 \%$ of the responsible entrepreneurs that go into an insolvency start drinking or get divorced or hang themselves. What appears there even out of the village commune, what happens there, how people look at you, how the rumour mill runs!”

The percental estimation of participant 4 is not supported by this research, but his words clearly show the pressure that the environment can cause.

Also participant 2 had unpleasant experiences. She was especially shocked by the "unimaginable impertinence of the authorities" that treated her like "a semi-criminal". She narrated for example that at the finance office a civil servant said to her: "We have an order from above that people like you should be destroyed."

This experience hurt her a great deal and for some time she did not see how to get back on her feet again. What helped her very much in that difficult period was a group of other people who had to go through an insolvency, too, and who she visited from time to time. In this group she could discuss her situation and feelings with likeminded people and had the experience that she was not completely alone with her problems.

There seemed to be the tendency that the reactions of the close environment (family) were supportive but going further outside to friends, acquaintances and others more and more negative reactions appeared. 
An insolvency can have a basic impact on people's lives. In Germany there is no social security system like unemployment insurance for entrepreneurs. This implies that the risk of an insolvency contains the danger of poverty (Fachinger \& Oelschläger, 2008).

Participant 11: "I felt simply empty. Because if you go full speed for over 20 years and in the end there is nothing left, then this is quite a bit disappointing or frustrating."

One of the most challenging topics within this field seemed to be accommodation. Especially for the participants that had to go through a general insolvency procedure as a private person there was the danger of losing their house or flat.

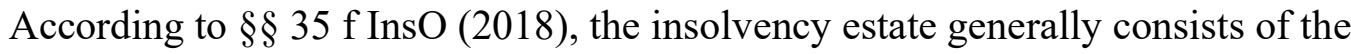
whole seizable property that belongs to the debtor when opening the insolvency procedure or that he/ she aquires during the procedure. It includes tangible goods as well as intangible assets. This clearly implies that the debtor's real estate property belongs to the insolvency estate (Queiser, 2015).

After the insolvency, participant 1 was living in a flat belonging to his father. The family home of participant 5 belonged to his wife, as well as the house of the family of participant 8. Participant 6 lived in the accommodation of his partner, participant 11 in the old house of his parents. However, if one is not that lucky to have a place to live through family or friends, accommodation can become problematic. Participant 2 for example had big issues finding an adequate place to rent after the insolvency. With the following words she explained her experiences:

"You can can search (for accommodation) without an estate agent as you have to manage that as cheaply as possible. And also the rent has to be affordable. So you are quite limited in your search, you are not searching in the (...) whole market, but in a niche, and one where no information on your credit rating is requested. And the probability of encountering somebody that has skeletons in the closet (...) is quite high." 
Participant 2 had to leave her rented semi-detached house after the insolvency. Then she had two accommodations, both of which turned out to be defective after a while.

"You have no money and then you have to move three times within four years. And you lose a lot because of water damage. Then someday you really are at the end of your tether. (...) To have a shelter over your head is such a basic need. It was horrible that this was made so difficult."

However, accommodation is just one aspect of the daily problems and the financial circumstances in comparison to life before the insolvency. Several difficulties can appear, most of them are connected to the General Credit Protection Agency that saves the information on a person's credit rating. This rating significantly influences the possibilities to conclude contracts. The participants reported huge difficulties to obtain a bank account or a contract for a mobile phone for example as long as the credit rating shows that you have had an insolvency.

According to $\S 100$ InsO it rests with the creditors if, and if yes to what extent the debtor and his/ her family receives support payments from the insolvency estate. This affects the lifestyle of the former leader significantly (Paulus, 2017).

Participant 2 pointed out that she suffered from her new poverty during the good conduct phase. Poverty means a distress that is not temporary but constitutive for a longer period in life. Commonly there is the differentiation between absolute and relative poverty (Lin-Hi, 2017). The former implies the absence of a physical breadline as in some development countries (Lin-Hi, 2007). Participant 2 did not seem to suffer from absolute poverty. Nevertheless, she felt poor and extremely limited in her financial possibilities, especially in relation to their life before the insolvency. Her narration showed the experienced limitations in her daily life:

"The worst situation was, that you cannot buy healthy food any more. (...) I had to see how to find a balance here. I can abstain from meat (...) but staple foods like vegetables, fruits and bread I want to have in good quality. (...) That was difficult. 
And that I could even not buy a book or a magazine some time, and not even a cappuccino in the market square. I do not have to go out for a meal, (...) but I want to be able to afford a cappuccino in a café. And that you cannot afford that any more from that money (...) with the high rents. (...) That harmed my self-esteem and my quality of life essentially."

Participant 6 mentioned several times during the interview that he does not own anything any more:

"Now I really have nothing any more. If I just think, what car I drive. I drive an old VW. In 1999 I bought it as the first company car. Then some day I gave it to my son, when I bought the second (company) car. And he passed the car on to his daughter. And she again passed it on my daughter. And now I drive the car again. It has done 400,000 kilometres. I cannot afford another one."

After their insolvencies, the participants found themselves in a new life situation. Besides the losses of influence and reputation, they also had to face problems in daily life due to their small income and their poor creditworthiness. 
In line with the regulations of the World Health Organisation (WHO), Becker (1982) defined health as "a state of full physical, mental and social wellbeing, not just defined by the absence of illness and disability" (Becker, 1982, p. 42). This seems to be a perfection that probably at most 20 percent of people fullfil (Becker, 1982).

Within the insolvency, the social well-being of all participants was highly disturbed. This was already discussed in the previous chapters.

Some of the participants reported that they became seriously ill during their insolvency or in the stressful time directly before the insolvency. They explained this by the stress they experienced.

Prager and Hlous (2006) differentiated two types of stress (Prager \& Hlous, 2006). The participants of this research knew both types. Some of them even mentioned the experience of both, eustress and distress, explicitly.

Eustress is the so-called positive type of stress that every human being needs. It organises the excitement that we need to pass exams and challenges. However, although eustress is experienced positively, it has the same physiological effects as negatively experienced stress. This negatively experienced stress is named distress. In contrast to eustress, it leads to a reduction of performance (Prager \& Hlous, 2006). After every stess-experience, the person concerned needs a phase of regeneration. This is the crux of the matter as often people are not able or willing to take that time. The cumulation of stress without resting and taking time for regeneration causes ongoing and increasing tension and an overcrowding of stress factors. This affects not just emotionally and cognitively but also on vegetative and muscular level. Besides mental disorders, psychosomatic illnesses and physical damage can also be the consequences (Prager \& Hlous, 2006).

The challenging situations that the participants had to cope with imply that the balance of stess and workload on the one hand and gratification on the other hand was highly disturbed. Leading a struggling enterprise meant having an insecure workplace not just for themselves but also for the employees for whom they were responsible. Also the salary was low, as the participants had debts and concordantly explained that they by all means wanted to rescue their company. Some even transferred private reserves into the company in an attempt to change track. Their freedom of action and decision- 
making was depressed by the growing problems. Finally, the participants finally were only able to react to daily challenges instead of planning and leading the enterprise as they wanted. Within all that struggle, they had to face that the problems grew worse in spite of their effort.

The insolvency can be seen here as the end of a period of growing sorrows and strain. In this stressful period, three of the participants suffered from severe physical illnesses.

Participant 4 suffered from a carcinosis in the throat. He explained that he did not smoke or drink although these are typical risk factors for this kind of cancer, but he mentioned other aspects of his stressful day-to-day routine that he saw as enabler for becoming ill:

"And when you are working that much a lot of organs get affected, because you do not care about food. Often I did not eat anything for lunch. And I did not even notice it."

I always had "gastric ulcers, duodenal ulcers, this all sticks together."

Participant 4 is sure that his illness was caused or at least influenced negatively by his ongoing pressure and strain. He sees the insolvency as his saviour as it took him out of the pressure and strain that made him ill.

"And now with some distance I say: 'God, this insolvency somehow was quite good.' Because a second illness like this, that surely would have been coming, I would not have survived any more."

According to Ramsey et al. (2016), severe financial distress and insolvencies after a cancer diagnosis appear to be a risk factor for mortality. Their study, which researched 7,682 patients, of whom half were filing for insolvency gives hints that there might be a connection. However, due to the research design, the question of whether insolvencies have a negative influence on the health of cancer patients could not be fully answered (Ramsey et al., 2016). Here is the need for further research. 
Participant 6 suffered from hypertension for several years. Additionally, he had to face two carcinoses. The first one was not in chronological relation with his business problems, but with another radical change in his life. He received the diagnosis of prostate cancer immediately after the divorce from his wife.

When his business problems got worse, he realised that in case of an insolvency his son also would be involved. Participant 6 had assigned one percent of the company to him when he was eighteen. What was meant as a symbol of togetherness and trust then tortured him later when the business struggled as the liability would have also involved his son personally.

"That really, really distressed me. In fact, that was the worst time for me. The worst time was when my son was involved."

Participant 6 was able to solve the problem and removed his son from involvement. However, immediately after that difficult period, he received the diagnosis of chronic lymphatic leukaemia. This is a kind of leukaemia that colloquially is also known as seniority leukaemia as in the majority of cases older people contract it. The average age of the patients is about 70 years (Wendtner, 2013). Participant 6 was about 60 years old when he received that diagnosis.

In spite of extensive research, so far it has not been possible to understand fully he causes of the genesis of carcinoses. It is commonly accepted that this genesis probably is a multifactural one and that not a single factor leads to cancer. Here for example external influences from the environment, such as radiation, viruses and carcinogenic substances, or genetic aspects can play important roles. However, also psychosocial factors like stress and misbehaviour have to be taken into consideration. That leads to the assumption of a complex model including negative emotions, their effects on functions of the immune system, endocrine processes and behaviour. Behavioural aspects here are not just the commonly mentioned misbehaviours such as smoking and drinking, but also inappropriate nutrition, lack of exercise and disturbed sleeping habits (Tschuschke, 2006).

Three months before participant 7 filed for insolvency he received the diagnosis of Colitis Ulcerosa, a chronic inflammation of the intestinal mucosa. Colitis Ulcerosa is 
known as an illness that is influenced by the psyche of the patients. A study of 62 patients with that diagnosis were monitored for up to 68 months to research the influence of stress, depressive symptoms, and straining life events on the course of the disease. The researchers found that the risk of exacerbation increased significantly with high levels of long-term stress. A relationship between an exacerbation and shortterm stress, depressive symptoms or strainful life events could not be identified (Levenstein, 2000). Experts widely agree that stress is not the trigger factor of Colitis Ulcerosa, but stress seems to provoke the symptoms flaring up (Moser, 2005). Also partcipant 7 experienced a clear relation between his mental (im-)balance and the course of disease:

"It was three months before the filing of insolvency that the illness occurred the first time. And during the initial phase of the insolvency process it hit its peak. And then I found that point (...) where I realised: 'Ok, I really did everything within my possibilities. Now it is beyond my power and I have to move on.' Then everything changed, psychologically and the disease pattern."

Participants 5 and 10 mentioned that they see the insolvency as positive for their health as it stopped their stressful and energy-sapping lifestyle. Participant 5 was sure that he lived healthier without the daily strain of his business and participant 10 even said:

"I do not know if I would still be alive if I had not become insolvent."

Three participants suffered from severe physical illnesses during their entrepreneurship or the insolvency, when the psychological strain was very high. They all saw the reason for their illnesses in this psychological strain. 


\subsubsection{Unemployment}

Just one of the participants had the fortunate position that he still received his salary during and after the insolvency, although he was not involved in the daily business any more. Other participants never really stopped working after the insolvency: One was already working as an employee when he finally had to file for insolvency and was able to keep that job. Others managed to continue their business within a smaller scope or found an investor during the insolvency proceedings.

However, in other cases, unemployment occurred as an aspect that has to be discussed. This unfortunate fate predominantly caught participants who suffered from an insolvency as a natural person. Half of my twelve participants tot only had to go through a business bankruptcy but also had to face an insolvency procedure personally. From the 12 researched participants, 6 no longer had a full-time job after the insolvency, 4 of those 6 people without employment were personally bankrupt, two had to face "just" the insolvency of their company.

The interviews gave different reasons for their unemployment. On the one hand, the good conduct phase is a very difficult situation for starting a new business as an entrepreneur as there is no money for any investment. The insolvency influences the creditworthiness significantly, so that it is also hardly possible to get money from a bank.

Participant 1 for example was looking for a new business:

"Well, new opportunities have to be searched and found", he said.

"Of course, in the meantime I also already tried some things, but it is not easy, especially without money."

In addition, the way into employment is not easy. The participants did not focus on writing applications as they saw a lot of problems there. They had all been selfemployed for years and were not used to working under the orders of another person. 
Even if they wanted to or could do this, recruiters might have doubted their adaptability.

Participant 5 saw his adaptability as a critical factor:

"Because when you have been used to making decisions alone for 30 years, then it is hard to work in a company, where you just hand in your report, and somebody says: 'No, I do not like that, you have to do it more detailed.' Or something like that. I do not know yet, how I would react then. Well, it is quite likely for me that I then say: 'You can kiss my ass!' (...) This could happen."

Participant 1 summed up his concerns in the following words:

"If I apply for a job somewhere, there are two or three negative aspects. The first one is the fact that I have never worked as an employee in the past 30 years. I would have to find an entrepreneur who says: 'I have the confidence that he can integrate himself.' (...) The second is the economic failure. Of course, that is a blemish. (...) And then again the fact that I was in jail. That is quite a package."

"Because of my curriculum vitae I would never get a job. Furthermore, I am 60 years old."

Here participant 1 also mentioned an important aspect. All the concerned participants were in their fifties or sixties.

Participant 9: "What is really stupid is the fact that I am 56 years old now. That is an age where I of course say, an insolvency would have been better at 32 or 28 , because there it would be easier to start again."

Participant 2 narrated her experiences with the labour office when she was searching for a job. The following dialogue she remembered having there showed the dilemma: 
“"What does somebody with your education want here? We do not have anything for you!'

Well, I was already over 60 , but every month I had to present five applications.

I said: 'Just show me a job, I will apply there.'

'We do not have anything for your age.'

'So what shall I do?'

'That is your problem."'

So in many cases there seemed to be hardly any another solution than to stay at home, making plans for new business opportunities and be on unemployment benefit.

"Then there came the slipping into Hartz-IV. That was the most mortifying situation in my whole life" (still Participant 2).

Hartz-IV is the basic social care for work-seekers according to the Second German Code of Social Law (SGB II, 2019).

The employment of people 60+ has become more and more common in Germany. In the last 20 years, the employment quota of people between 60 and 64 years has nearly tripled. Meanwhile, $56.2 \%$ of this age group are still working. The unemployment of older people is declining as they are in less danger of losing their job (Diekmann, 2017).

This seems to be an important facet in this picture. Their employment quota is growing, but the reason therefore seems to be that the employees become older while they are working in their jobs. The problems occur if they lose their workplace and have to find a new one. For a lot of companies, people $60+$ are not considered for filling their vacancies as they have the reputation of being less flexible and less productive. Another reason is that older people often have a good salary because of their long staff record. If they then lose their job, they are often not willing to make financial compromises. However, the numbers show that older people can often only find a new workplace if they accept lower salaries. The older they are, the smaller their chances of finding a new job at all (Hollstein \& v. Borste, 2011). 


\subsubsection{Long Time Frame}

One of the main points that the participants that had to go through the insolvency personally seemed to be adversely affected by is the very long period until the discharge of residual debt. This period is commonly named good conduct phase. However, for the participants concerned it felt more like a stagnancy phase. They felt thwarted and spent their time waiting and making plans for their life after that pause. They could not wait to move on after this period.

Participant 1: "It is a fact that I have been paralysed since then." And: "It simply is this period of six years that I have to get through somehow."

Participant 2: "I felt handcuffed and I could not release my energy. That restricted my life very much. And what now stresses me is how long it takes until you get out of this (situation) again. Of course this also depends on my age."

At the time of the interview participant 2 was 67 years old.

"It was like a stop-sign. Well, now I press the reset key, you know?

However, this reset key is not that easy because I am too old, because six years is really long."

And: "It is an enforced length." (...) "The main feeling is that life development was taken away from me. It is so slowed down and the effects go far into the future. (...) It will take me eight or nine years to get halfway out of this again. I think that is really long."

Participant 11 felt like "somebody had pulled the plug".

And also participant 12, who managed the good conduct phase quite well as he was lucky to obtain a job as an employee, mentioned: 
"Six years is a long time. Yes, I really think so (...) This could be a bit shorter."

So what they mentioned forcefully was that the good conduct period with its six years is very long. Some participants also admitted that they thought about filing their insolvency abroad due to shorter time frames there.

Participant 2 for example narrated:

"A lot of people told me to go to England or France as there it is just one year."

Also participant 6 admitted that he thought about going through the insolvency proceedings abroad, but could not afford that loophole.

"I thought about transferring (...) my place of residence into another country, because abroad insolvency is just half a year. (...) Here it takes five to six years to get out of this shit again. (...) That all was working with lawyers or somebody, whatever. That would have cost 30,000 euros at least, how could I have afforded that? If I had given money to anybody, then it would have been my company and not to such a stupid pettifogger."

On the world wide web, there are several sites of German lawyers who inform about advantages and disadvantages of insolvencies in the neighbouring countries.

Especially the long good conduct phase in Germany seems to make such ideas attractive. In England for example the good conduct period is 12 months (Kraus \& Ghendler, 2017). In parts of France, more precisely in the departments 57, 76 and 68 in Alsace Lorraine, there is a special insolvency law that does not include a good conduct phase at all. There the personal insolvency proceedings can get absolved within 12 to 18 months (Thiele, 2018).

Participant 1 wanted to file his insolvency in England but before he could put this plan into practice, he was arrested: 
"I had registered a place of residence in England and wanted to do the private insolvency (proceedings) in England. Because already in 2008 I realised that I would never be able to pay the tax debts. And the only possibility for me to bounce back financially in the foreseeable future was for me the idea to process the private insolvency in England in 12 months."

To address these differences concerning the time frames in the neighbouring countries since July 2014 there has been the possibility to abbreviate the good conduct phase in Germany. Now it is possible to reach the desired discharge of residual debt not just after six but already after five or even three years. The realisation of such an abbreviation depends on the amount that the debtor was able to pay so far. $\mathrm{He} /$ she can reduce the good conduct phase by one year if at least the procedural costs are paid by then. If the debtor was able to pay the procedural costs and at least $35 \%$ of the declared creditors' claims, he/ she can reach the discharge of residual dept after three years. In this case the debtor has to give account of the source of that money (Burk, 2014).

So if there is no legitimate reason to deny the debtor the discharge of residual dept, he/ she gets it after six years in the worst case. In the past the good conduct phase started after the closing of the insolvency procedure. Today it has already started with its opening.

However, there is another circumstance that handicaps a fresh start for the concerned person: It needs another three years for the cancellation of the entry of the General Credit Protection Agency (Burk, 2014). Therefore, if an entrepreneur needs for example a credit to start a new business, he/ she might be blocked for nine years in total.

"I definitely have the opinion that in Germany the insolvency takes too long. In the neighbouring countries it is shorter. We should strive for European harmonisation here." (Participant 6) 


\subsubsection{Loss of Retirement Provisions and Security}

Real estate property can also be seen as a security for their owners. However, an insolvency does not just take real estate property from the concerned people as discussed in chapter 6.3.4 about poverty and daily life problems. Also, other retirement provisions of entrepreneurs could be occupied.

In Germany the system of old-age provision of employees follows a model consisting of three layers: a general system with obligatory membership, an additional company internal system that can be obligatory or optional, and individual, voluntary retirement provisions (Schmähl, 1999).

There are some self-employed professional groups that also have obligatory security systems, for example farmers or liberal professions. However, the lion's share of German entrepreneurs have to take care of their retirement provisions individually (Schmähl, 1999). The problem is that those individual retirement provisions often do not have the same protection from garnishment as the general retirement provisions of employees.

Some of the participants had to experience the situation of losing their retirement provisions through the insolvency. As an alarming side effect, the participants were already of an age when some employees think of retirement, but they then had to start earning money for a possible retirement again.

Participant 2: "When this starts (the insolvency), all three life insurances are gone, everything is gone that has value and what you wanted to save for your old age."

Also participant 9 lost the provisions for his old age in the form of life insurances. Of course, this is especially a problem for entrepreneurs who have to go through a general insolvency procedure personally. However, also in other cases, the retirement provision was lost, for example for participant 5, who had a private limited company $(\mathrm{GmbH})$ :

"We acted as surety personally, we guaranteed our retirement provision.

Suddenly everything was completely lost." 
Participant 6: "Retirement provisions (...), the bank collected all my investment funds."

Participant 11 explained that he is about to make plans for future businesses. He has to earn money for his old age again as "this is all gone".

To reduce this risk that the entrepreneur stands there emptyhanded at the end of his/ her professional life, $\S 851 \mathrm{c}$ was integrated into the German Civil Process Order (ZPO) in the year 2007 (Ulbricht, 2011). This paragraph regulates the protection of retirement pensions from garnishment. Following the principle of non-discrimination, $\S 851$ protects all defined contracts that are comparable to the protected retirement pensions of employees (ZPO, 2019). So participant 6's investment funds would still have been lost despite this legal change. However, several contracts of life insurances or retirement provisions are in line with $\S 851$ ZPO (2019) and are protected to a certain extent.

However, here also information and knowledge seem to be the key. As well as some participants failing to be fully informed about the legal forms of organisations, this topic also still contains pitfalls for entrepreneurs who fail to adopt the relevant knowledge.

In addition to the difficult situation of the insolvency, there occurred the problem that the participants had to face a poor perspective for their future due to imminent unemployment, the long time frame of the good conduct phase and the loss of their retirement provisions and security. Furthermore, these problems were intensified by the age of the participants as most of the participants were in their fifties or sixties by the time of the insolvency. 
All participants were asked during their interviews if they thought that they had changed through the experience of going through an insolvency.

"This is an exreme occurrence in life. Of course, this changes you" (Participant 3).

Participants 2 and 12 did not feel that the insolvency has changed them. However, participant 2 admitted that this experience caused a huge anger against organisations as she sometimes could hardly believe how harshly she was treated during the time of her insolvency. (In this context please see chapter 6.3.3 about the reactions of the environment.) Participant 12 mentioned that he hopefully learnt through that failure so that he would not make the same mistakes again. However, both do not feel a change in their personality.

The other ten participants experienced different changes:

Participant 1: "Well, it deadened me. I was more energetic before. (...) Well, it took a great deal of energy away from me, yes.”

Participant 3: "I became harder. I am more mistrustful. And I learnt - not just because of that single event but also because of the following years (...) - I got this attitude: Doing business is like you sit down at a table face to face and then you see who can take the other one to the cleaners."

Participant 5: "I would say, I lost a lot of quality of life (...) vitality and ease." Furthermore, he was always open and positive to new people, but today he is more careful, he said. "If somebody poses as a friend, I am more mistrustful now."

Participant 9: "I hope it did not change me in a negative way. (...) If you have to face disappointments from employees (...) whom you trusted (...) I always tried not to become grim or careworn. (...) If you had such 
(negative) experiences, there is the danger, that you change your interaction with the employees (...), that you become mistrustful and question everything, and that is not good either."

Other participants see their changes through the insolvency more positively.

Participant 4: "I became a more likeable person."

He was always under time pressure, driven by his tasks and appointments, he explained.

"Because of tha,t I was hardly sufferable in my environment. That is clear."

For example, if his wife was reading a book or watching TV, he argued that she was wasting her time and should do something that helped her grow as a person.

"My wife then said: 'You are just jealous because you are not able to relax!' And she was right. However, how can you relax, when you only get out of office at 11 in the evening?"

Furthermore, he reported that he has been very niggly concerning housekeeping (e.g. if a picture was crooked) or arguments, where he was always starting harsh discussions if anybody talked inconsistently for example.

"Because here (in business) your statements have to be precise, because you always have to expect that the other one counters (...) I was not able to distinguish (professional from private life)."

However, he no longer has that urge to argue over trivia.

"I am an unbelievably balanced person." 
Participant 6: "Meanwhile I am much calmer. (...) I am still working but I can take it easier. (...) I became more even-tempered through less strain and pressure."

Participant 7: "I do not take everything that seriously any more. Life also has other facets. And I have a completely new appreciation for people. (...) Every human is unique and of value. My interaction with people also changed. (...) I am calmer but that is not all, because I experience situations more intensely, and I am more conscientious, calmer and more conscientious."

Participant 10: "I found to myself again and to my family. Next year I am celebrating my golden wedding anniversary. This all became stabilised. And I listen to people more closely and take more time for them. I see this positively. My secretary (...) says: 'You changed very positively. You became much calmer, more humain and objective.' I believe her."

Participant 11: "I became more myself again. (...) Yes, I think I changed. I am not that stress-maker that I was any more. I was putting pressure on me and others, was pushing all the time. That was not right. In hindsight it is understandable in that situation, but it was not right."

Participant 11 experienced his change also through the reactions of his environment.

"I am more approved now, more accepted. People approach me. I appeared differently, I think. If you have a stressful aura, nobody likes interacting with you. And I think I was able to remove that."

While similarities were found among the participants concerning the other insolvency effects, the answers to the question of their experienced personality change varied. While some felt deadened, with less energy or being more mistrustful, others saw their change more positively and felt calmer and as a more likeable person. 
The expression resilience traces back to the Latin verb "resilire" which can be translated as to rebound or to carom. It means the psychological resistance that helps people to overcome crises or strokes of fate. Here it is important to differentiate between resilience and short-term reactions, so-called coping strategies, such as repression or trying not to think about the problems (Martens, 2016).

"Nobody is invulnerable or immune against fate" (Welter-Enderlin, 2010, p. 22), but people with a high power of resilience recover from the crises, sorrows or difficulties they have to face. Resilience is not a God-given gift but can be developed during life within an interactive learning process between the individuals and their environment. As a dynamic process of adaption and development, it changes over time with the individuals' experiences and depends on their current physical and mental constitution (Martens, 2016).

\subsubsection{Dying or Surviving}

As explained in chapter 6.3.1 about crisis and failing, a Japanese research was conducted that implied a relationship between economic problems and suicide. The number of suicides there suddenly increased after the credit crunch in the year 1997. In their study, Chen et al. (2015) stated that the "dauntingly high level of suicide began in 1998 with an abrupt $35.16 \%$ increase in the suicide rate." And "that the suicide upsurge in 1998 was primarily caused by suicide among middle-aged males aged 4059 who had suffered from financial problems" (Chen, Choi, Mori, Sawada, \& Sugano, 2015, p. 271).

In this study, some of the participants pointed out that the insolvency as they experienced it clearly had the potential to destabilise a person (for the relevant quotations of the participants please also see chapter 6.3.1.).

Indeed, the twelve participants suffered during the business struggle and the insolvency to different extents depending on support, outcome of the procedure for their enterprises, the involvement of private bankruptcy and other factors. However, 
they were all able to recover from these crises and still seem to be looking forward to their future again.

According to Stechhammer (2010), an essential part of resilience is the competence of self-reflection. We all construct our lives according to our values and goals. When we fail, it is essential to make ourselves aware of this construction. We have to be able to understand the components to create a revised design. This includes our commitments towards other people, life, the job, etc. (Stechhammer, 2010).

Schumpeter (1987) talked in this context of reflection about a process of creative destruction, that is the basis for a restart after the crises (Schumpeter, 1987).

All twelve interviews contained hints that the participants had reflected on the difficult period of the insolvency. In all twelve cases, the questions about whether they had made an essential mistake or if there had been situations where they should have decided or acted in another way, seemed to get thought through thoroughly. Especially in the beginning of the reflection phase, these topics seemed to have tortured the participants.

The accomplishment of such difficult situations often goes hand in hand with the adaptation to new circumstances. Here it is essential not only to show adapted behaviour, but to develop a new, positive attitude towards one's environment, fellow men and women, and also to oneselves within the new life situation (Martens, 2016). The participants also seemed to have made that adaptation. After the shock of the crises, and their reflections on the question of guilt, it seemed that they were able to put the necessary distance between them and their problems. This distance to the problems is needed for a successful reflection (Stechhammer, 2010).

The participants described this moment as a turning point, where they moved out from victimhood, self-pity and lethargy. Like emerging from murky water, they could see clearly again and started the reconstruction of their lives.

Also, the fact that the twelve participants agreed to take part in a personality traits inventory and in-depth interviews about their insolvencies could indicate that way that they are people that are willing to cogitate and reflect on their experiences.

Participant 2 even supports her zest for action to restart after the good conduct phase with the following words:

"I probably have a really queen-size power of resilience." 


\subsubsection{Reconstruction}

All twelve participants adapted themselves to the changed life conditions. Accepting the change is the first step to reconstruct finally one's life including attitudes, goals and values, and is essential to overcome the crises for a successful new start (Martens, 2016).

The deceleration of daily life that accompanies with the insolvencies enabled them to lean back and reflect. The participants who had to go through the insolvency as a natural person and did not work full-time during the good-conduct phase seemed to have reflected on themselves intensively as they had a break of six years that thwarted them comprehensively and remorselessly. However, as painful as that period might have been for the participants, they all seemed to have used the time to rebuild their life construction. They changed some of their attitudes, set new goals and discovered new values. As will be highlighted in chapter 6.3.9, very positive experiences were also had through that development process, and they learned for example that satisfaction can also be discovered in the small and simple things of life, and that happiness is not a matter of money or property.

All participants finally made new plans for future projects and business opportunities. There was nobody who reported putting no effort into ideas and plans for the future. However, some participants moved even further on with their reflection and change. When participant 11 had his insolvency, he had already lived apart from his wife for 13 years, but during the phase of redesigning his life he realised that he did not want to go on with these "unregulated circumstances" any more and became divorced.

Furthermore, he integrated topics like reflection and self-awareness into his daily life:

"I use a lot of my time to discover myself. That might sound silly, but it is like that. Well, thinking about what is important for me, what I want, where I see mistakes in myself or in contact with others or difficulties, and what the reasons and backgrounds are. Because if I understand it, then I can stop it." 
Resilience for the main part is a very personal development of dealing with one's attitudes, values and views. However, the environment and social contacts can also play an essential role within that development process. According to Martens (2016), the people concerned want to be seen as normal and usual. They tend to hide things because of the fear of stigmatisation. In addition to their original problems, they also have to carry additional burdens like the fear that people might uncover their secrets, getting isolated, and losing a lot of energy by hiding and controlling information (Martens, 2016).

Two of the participants were also keeping their insolvency and the following goodconduct phase as a secret.

Participant 1 explained: "In my circle of friends I did not make that public. (...) Just very, very few really good friends that I can trust know about it, because this would not be good. People always talk, even if they do not know, and it is always disadvantageous."

This quotation shows the fear of the participant to stand out as negative. In the interview situation, he covered his eyes with his hand when speaking the words "this would not be good", like he was not willing to see this minatory situation of becoming unmasked even in his thoughts.

Participant 10 also hid because of the fear of stigmatisation. Only his son and wife knew about the insolvency. His own parents were no longer alive, but even the parents in law were excluded. After his insolvency, he started a front-office-job as an employee. Dealing with cash every day and having personnel responsibility, he was afraid about his employer's reaction if they found out about his insolvency. This fear seemed to have isolated him and his wife and son and left them alone with the problems and sorrows without the possibility of obtaining advice or comfort from friends.

The two mentioned participants drew the line at close family or friends, but none of the participants was really left completely alone with him-/ herself. This can be seen as 
a positive aspect as one of the most important sources of resilience are attachment persons (Martens, 2016).

The participants emphasised how happy and grateful they are for the support they received especially from their families. This starts with pragmatic easements like having the possibility to live in the father's or the partner's accommodation. Or another participant was even given a car as a present as he could no longer afford one himself. However, what seemed to be much more important are tangible values of attachment persons. The people concerned needed somebody to talk to, needed support and contribution in this difficult period of their lives. Participant four found the following words about his family:

"The family stuck together. This love, this unbelievable love rescued me."

When the research was conducted, the participants' insolvency crisis had occurred some years previously in all cases. All participants showed a certain degree of psychological resistance that helped them to overcome that crisis. Although the association of topics like death and suicide was mentioned frequently, the participants adapted themselves to the changed life conditions. Also here the support of the family seemed to be very valuable. 
Participant 1 could not see anything positive in his insolvency. He was betrayed by his companions, had to face the insolvency proceedings not just for his company but personally too, and had to go to jail. This sum implies that he was hit comparatively hard. Maybe that is the reason that he could not see any positive aspects within his insolvency.

The other participants had the opinion that in hindsight there were also positive aspects to mention. Participant 12 and participant 11 at least pointed out that they were happy that after going through the good conduct phase their debts were abated.

6.3.9.1 Learning through Failure

"In America they say an entrepreneur has to go insolvent once or twice to become a good entrepreneur", participant 10 said.

And also participant 5 had this appeal:

"I think everybody who had to go through this (an insolvency) and afterwards starts again, will do much much better then. I would recommend every bank having some confidence in somebody who starts again after an insolvency (...) because I believe (...) he will surely be lined up completely new with his whole business, his considerations and all his economical things. I am totally convinced about that." 


\subsubsection{The Insolvency as Deliverance}

Gerald Caplan (1964) is considered to be the establisher of our modern crisis research. According to Caplan, crises in general consist of the following four phases.

Phase 1: A stimulus leads to a slight increase of tension that requires common coping strategies.

Phase 2: Failure of these reactions and continuously applied stimulus lead to further increase of tension, excitement and helplessness.

Phase 3: The ongoing increase of tension is an enormous initiator for the person concerned to mobilise inner and outer resources for problem solving. All forces and emergency reserves are activated and new methods are tested. The consequence can be trial-and-error, resignation and redefining of goals and requests.

Phase 4: If the problem persists and all efforts cannot solve it, the emotional tension reaches its maximum where it knocks over into the collapse (Caplan, 1964).

Twenty years after Caplan's publication of these phases, Hobbs (1984) illustrated this model with the following curve.

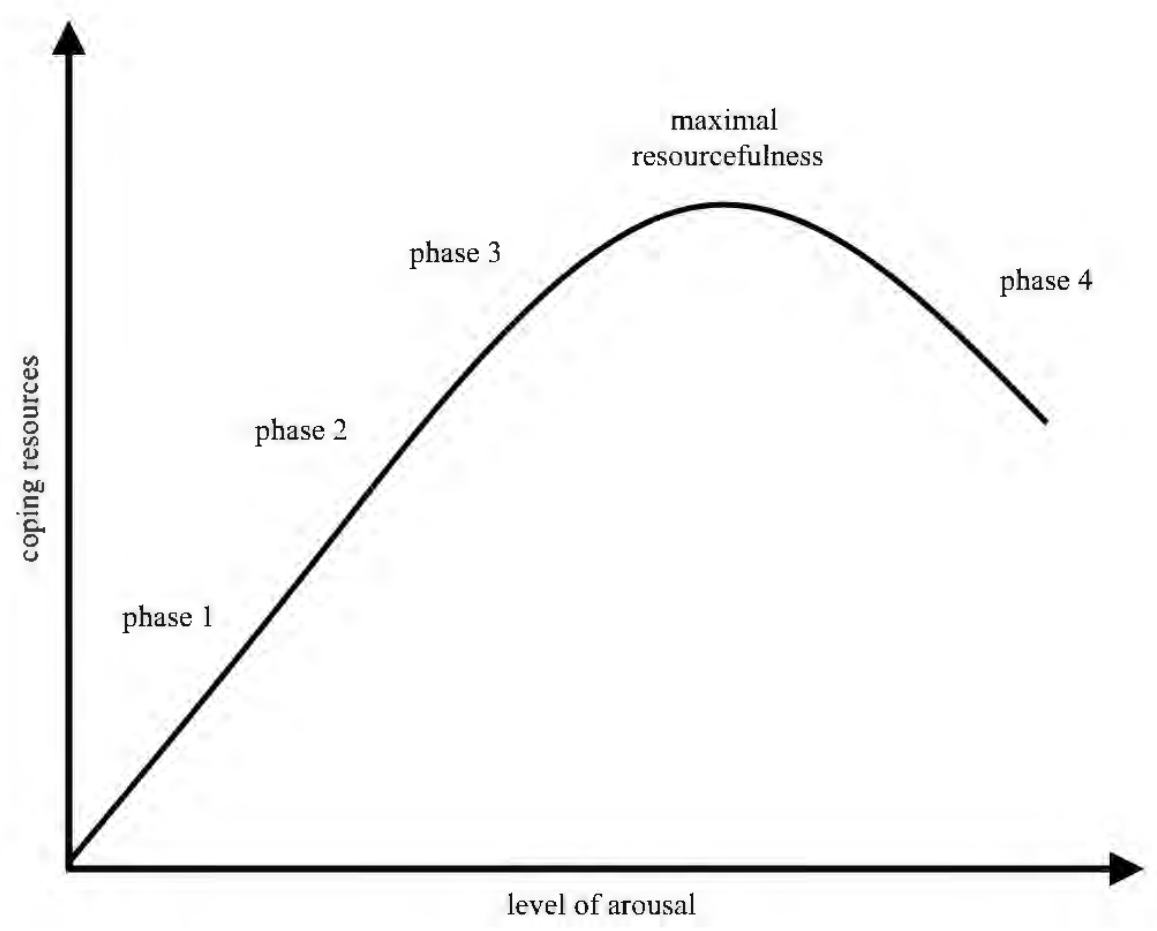

Figure 7: The crisis curve

Hobbs, M. (1984). Crisis intervention in theory and practice: A selective review. British Journal of Medical Psychology, 57, p. 28 
This model was chosen to illustrate this context as it clearly shows the increasing tension that precedes the collapse. This is an aspect that the participants pointed out, too. They explained that before the insolvency as the collapse, they had experienced a hard and challenging period of ongoing and growing tension and stress.

The word stress comes from the Latin expression strictus, which means tightness, depression and misery (Prager \& Hlous, 2006).

Stress is also strain, but has not the interruptive character that the crisis has. It especially includes pressure in time and requests, excessive demands and negative emotions like sullenness, being in a rush, fear and the feeling of being help- and feckless. In the foreground there are more activity-related overcharging demands of daily life and business, while the common expression of the crisis means an experience of strain that affects the whole person and their identity as explained in chapter 6.3.1 about crisis and failing (Ulich, 1987).

Hobbs' crisis curve (1984) shows that the input of resources increases continuously and reaches its maximum right before the breakpoint (Hobbs, 1984). Also, the CEO with his/ her time, effort and work can be seen as a resource in the sense of this graph. The participants unanimously explained that their effort, time and workload increased more and more until the company broke down. With this increase, their stress and sorrows also grew.

Participant 9: "It was a feeling of relief (...) because this martyrdom was over. And then you get to a situation where there are people alongside to get things managed and before that you were just alone."

And: "In the end it was a lot of strain for me. Well, the pressure, the stress, and then of course you are criticied (...) That is gone now."

Participant 8: "The insolvency gave me a piece of freedom that I was not able to reach in another way."

Participant 11: "In comparison, I feel much better today. I do not have that strain. Well, and also even though sounds funny, I am also better off financially, because I do not have loss every month." 
As painful and depressing as the insolvency had been, in hindsight it was also experienced as a deliverance for the former CEOs.

As mentioned before, participant 1 was the only one who did not feel like that. From his point of view, the insolvency did not have any positive aspects at all. However, he seemed to have had the most difficult circumstances of all participants. Like them all, he fell from rich to poor, from influential to powerless, from 100 to 0 . However, like about half of the participants he had to face the insolvency as a natural person with the following six years of the good conduct phase. On top of this, he was the only one who had to go to jail. According to his statement, this was a dramatic experience for him that dwarfed the insolvency. So in his case the stress of being the CEO of a stumbling company was not replaced by any deliverance but by even more stress, pressure and fears during imprisonment.

\subsubsection{Enjoy the Little Things}

Especially participant 2 and participant 4 explained that the insolvency seemed to have changed how they experience their environment in a positive way.

Participant 2: "The most important (positive aspect) is how you can manage your life with little money, how much you can reduce yourself, and what enjoyment is still possible with this reduction. We go for walks much more for example."

And: "I remember our first trip by train (after the insolvency). (...) we took a picnic with us and in the mountain pasture we allowed ourselves an Almdudler (= herbs lemonade). Well, then we felt like kings. This means you experience another aspect of enjoyment, that is not just consumption."

Participant 4: "I now have paradisical circumstances because I am consistent with myself. Hearing a bird singing for example, I did not hear the birds sing any more at that time." 
He also explained his new way of experiencing nature with the way his mountain bike tours have changed:

"Today I ride up the hill, but then I do not ride down again after ten minutes eating a banana. I take a rucksack with me with a snack and a beer and then I sit there for one or two hours."

Especially the awareness of positive little things in daily life, the joyful experience of nature and the cognition that one can also live well and happily with little money are positive aspects that the participants experienced through their insolvencies.

\subsubsection{A Fresh Start}

Another positive aspect that appeared in the interviews is the insolvency as a new start and a chance for change. All participants agreed that it is a painful and hard one, but it is a new start that offers new chances. In Chinese script, the two characters that build the word crisis have two meanings: serious danger and favourable occasion. This dialectic implies that a crisis also includes a potential that can be activated (Stahmer, 1995). Participant 2 mentioned the ambiguity of these Chinese characters and stated that the idea, that every crisis also holds chances was very assuasive for her. For participant 12 for example his company was like a tree that had a lot of rotten branches. With the sawing off of these rotten branches, room for new fresh ones occurred. He now saw this development positively and was happy about that cut. As already mentioned, especially the participants that became unemployed turned towards topics like self-awareness and asked intellectual questions about their situation. Although the unemployed probably had more time for such thoughts, the interest in self-reflection seemed to become important with the crisis of the insolvency generally as all the participants showed the same tendencies here.

The psychotherapist Kast (1987) talked about four phases concerning the handling of crises, which can also be used to explain people's condition during an insolvency (Kast, 1987).

1) The phase of disavowing: Those concerned feel empty and blunt but try to live on as if nothing has happened. 
2) The phase of chaotic emotions: Oppressed feelings like anger, fear or a sense of guilt burst out.

3) The phase of searching, finding and separating: The confrontation with the new situation gets unavoidable. Problems become accepted.

4) The phase of a new relation to the self and the world: After the acceptance of loss and the changed situation, new relationships, opinions and perspectives are developed. This is the phase of reorientation, where victimhood gets unlearnt and self-esteem can heal.

The participants of this research apparently already had made it to the third or fourth phase when this study was conducted.

Participant 7: "This time was dark black, well blacker it could not have been. However, as soon as I looked ahead of this phase of self-pity, I just saw chances. Of course, this needed some time, that is clear, because there are so many aspects that you have to deal with. First and foremost you have to deal with yourself."

Participant 11 seemed to be enjoying his new life after a successful personal restart.

"It is really a pity that it (the insolvency) did not happen earlier. It is really a shame. I would have had 10 more years of this other live."

Besides all the stress and strain most of the participants also reported positive aspects of their insolvencies. Some mentioned that they learnt something through the insolvency. For most of the participants, their insolvency was a deliverance from all the pressure before. After this deliverance, they could enjoy little things in life again, which they did not even realise during their stressful entrepreneurship. Furthermore, the insolvency with its good conduct phase includes the possibility of a fresh start. 
The literature review showed that there is agreement that in most cases the insolvency cannot be traced back to one critical event that led to the crisis, but there are in general clusters of influencing external and internal factors. It is generally accepted that the leaders influence their (especially small and medium-sized) companies significantly through their behaviours and decisions, and that these play a crucial role as key contributors to insolvencies.

A gap for further research was identified as the majority of the reviewed researches did not explain the management-made mistakes or the procedural weaknesses in particular. In this research, narrative interviews with twelve former CEOs covering a broad time frame were conducted to gain deeper understanding of key contributors to the insolvencies of the reviewed cases. The aim of this research followed the conclusions of Hauschildt et al. (2005), who found that corporate crisis research in the past predominantly focused on the end of the crisis while key contributors of earlier stages were ignored (Hauschildt, Grape, \& Schindler, 2005).

In the interviews, two participants underlined this time aspect by mentioning that their business crisis and insolvency was not a short term event but a long term process.

Participant 9: "It is like dying in instalments."

Participant 11: "It was a long-term development. That is like an illness that is aggravating slowly." 


\subsection{Conclusion and Discussion of the Identified Key Contributors}

The first reseach question of this study had the aim to identify and understand the key contributors to the insolvencies of the participants:

RQ1: What key contributors to the insolvencies can be found in the researched cases?

The areas of key contributors to the insolvencies that could be identified in the narrative interviews of the twelve participants were poor leadership, lack of knowledge and experience, overconfidence and overestimation of own capabilities, risky contract design, insufficient funds, and market crisis and loss of customers.

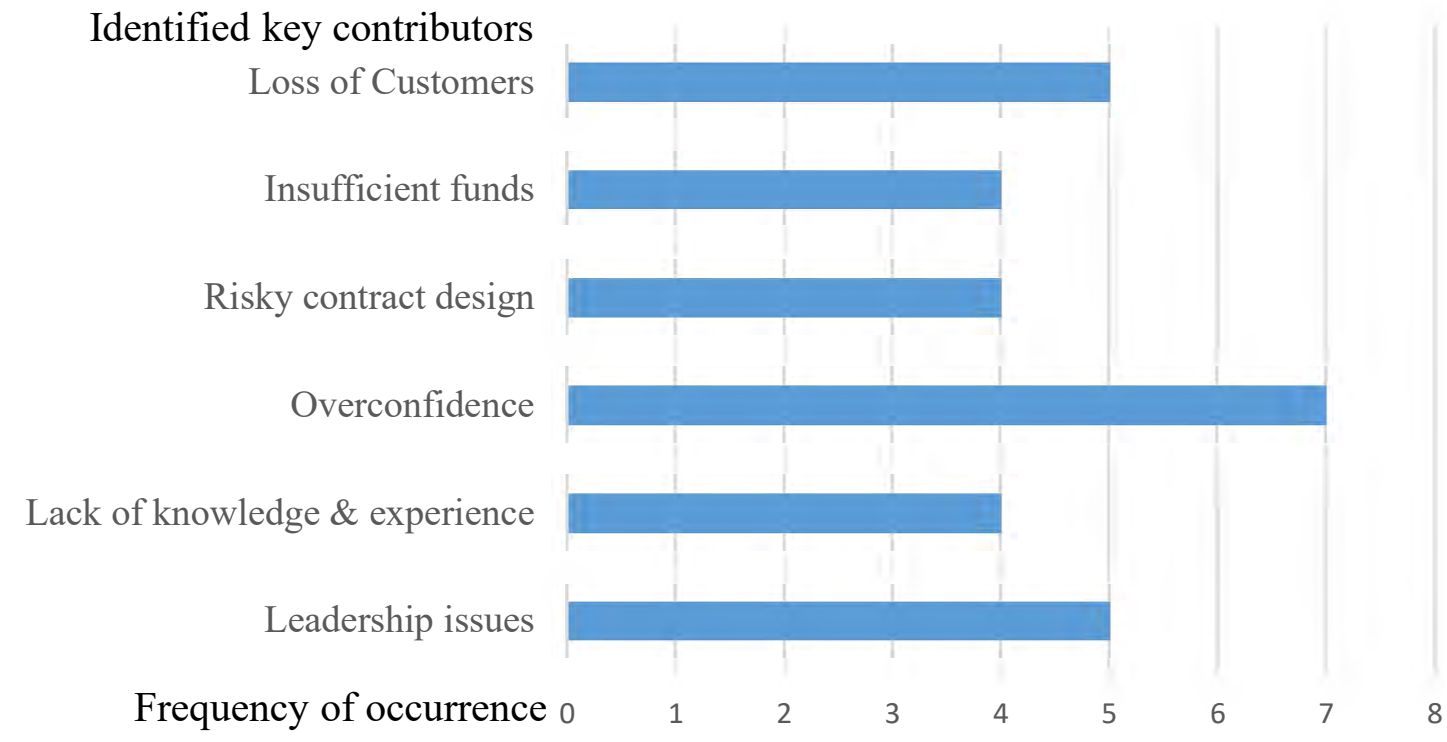

Figure 8: Identified key contributors and their frequency of occurrence in the reviewed interviews Own presentation

Figure 8 showes the frequency of occurrence of the identified key contributors within the 12 analysed insolvency cases. Clusters of influencing factors were also discovered here as in all the reviewed insolvency cases more than one factor interacted. 


\subsubsection{Endogenetic Factors}

Following the terminology of Fleege-Althoff (1930), endogenetic and exogenetic key contributors were identified. Issues with leadership, knowledge, experience, overconfidence and contract design clearly appeared to be within the responsibility of the companies concerned and thereby within the responsibility of the leaders (endogenetic factors).

Also the insufficient funds that were identified as key contributors within the reviewed cases have to be seen as endogenetic factors, as a credit agreement is nothing other than a contract that both sides -the bank and the entrepreneur - sign. If this contract then leads to even more financial trouble, the CEO is responsible on his/ her part. Banks are important stakeholders especially for struggling companies due to their financial scope. The cooperation with banks seems to need special awareness and prudence. Contracts have to reviewed critically as the insolvencies of participants 5, 6 and 8 showed.

\subsubsection{Exogenetic Factors Uncovered Internal Risks}

The influences of market crises and the loss of customers in the reviewed cases may lay outside the leaders' ability to control (exogenetic factors). However, the analysis of the interviews showed that such exogenetic factors or events uncovered further contributors on the part of the leaders, as except for one special case they could only enable the insolvency in combination with other endogenetic factors.

The mentioned special case is participant 12 , who ran a supermarket as an entrepreneur. Initially his business was doing well, but then a competitor established a supermarket nearby. The supermarket chain that participant 12 was part of with his business was located in the upper price segment. Furthermore, the new competitor did aggressive advertising.

This is a special case as participant 12 was in a very difficult and unusual entrepreneurial situation: On the one hand, he was entrepreneur, acting on his own behalf and on his own account. On the other hand, he was limited in his freedom of designing and organising his business within the rules of the parent trading company. 
Participants 2,3,4 and 11 had to face severe reductions of income due to the loss of customers. However, this reduction of income would not necessarily have meant that an insolvency would have been inescapable. However, the sudden financial tightness then showed in at least three of the four cases that the leaders had taken decisions that turned this new financial tightness into a corporate crisis. In all four cases, the monthly expenses were quite high due to the successful business activities before. The leaders seemed to have failed to consider that ongoing success was not guaranteed.

Participant 2 had bought real estate property for a very high price and with a credit agreement that included no personal capital at all. When she was nursing her ill father, income went down and customers broke away. Soon she was no longer able to afford her monthly payments to the bank and in addition the value of the bought real estate property declined.

Participant 11 saw his company as a victim of the financial crisis 2008/2009.

Admittedly, this period was a difficult environment for the German economy and its companies. However, in his case the difficult market environment collided with high monthly payments as he had bought and financed three new machines. Based on some good years before, he had chosen a credit agreement with a high monthly debt retirement. When his turnover decreased due to the market crisis, he soon had to file for insolvency.

In addition to the market crisis of 2008/2009, participant 4 lost a large customer, who backed out of a special market segment. He also had to face very high monthly leasing fees and admitted that he probably would not have had to file for insolvency if he had chosen a longer time frame with a lower monthly payment.

Participant 3 also struggled because of a market crisis. When the biotech bubble burst in 2001, suddenly a large part of his customers broke away. Unfortunately, this rapid decline of income occurred just after his company had moved into a bigger and more expensive location. This did not lead to his insolvency in the short term but intensified the already financially tight situation.

This shows that also when looking at exogenetic factors as key contributors to insolvencies, the CEOs play an important role as they can influence the success or failure of their companies through the framework they have built. Factors that influence the enterprise from outside can then uncover internal risks. 


\subsubsection{Overconfidence as Supporter of Identified Key Contributors}

Figure 6 not only shows the clusters of the key contributors that could be identified within the interview data, but also shows their frequency of occurrence. Signs of overconfidence could be identified in seven of the reviewed twelve cases. Its high frequency can be explained by the study of $\mathrm{Ne} ß$ (2013), who identified overconfidence as an immanent part of entrepreneurs' personality. Connecting her study with the findings of the interviews, it seems to be a critical success factor for CEOs to overcome their overconfidence.

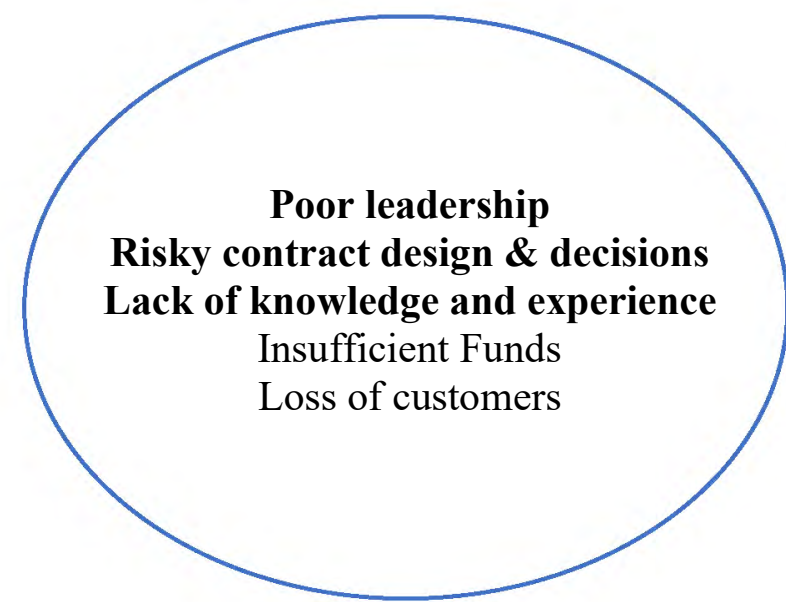

\section{Overconfidence}

Figure 9: Overconfidence as supporter of identified key contributors

Own presentation

As figure 7 shows, overconfidence is not only a point within the clusters of key contributors, but is an important field of personality development for every CEO as it occurs frequently, contains high risks and can influence other key contributors negatively. The reviewed interviews give hints that overconfidence can support and strengthen other key contributors, especially risky contract designs, bad and unreflected leadership, and the lack of experience and knowledge.

The optimistic contract designs of the participants 4 and 11 seem to be strongly connected with the topic overconfidence. Blessed with success, they designed 
contracts according to their current prosperous situation not taking into consideration that more difficult days could also come in the future.

In addirion, lack of knowledge and experience seemed to have been supported by overconfidence. Participants did not ask for help in time or failed to obtain important information as they thought they would manage everything on their own. This includes the problem of poor leadership as some participants saw themselves as leaders without ever thinking about what leadership really means and what it takes to be a good leader. A few participants even reported that they never wanted to have staff or the responsibility for employees. 


\subsection{Conclusion and Discussion of the NEO-FFI Findings}

Research question two aims to gain deeper understanding of the personalities of the participants and their influence on the analysed insolvency cases:

RQ2: Are there patterns within the personalities of the participants that can be seen as key contributors or their supporters?

To gain deeper understanding of the behaviours and decisions of the participants, a personality traits inventory was conducted. The NEO-FFI is a shorter version of the NEO-PI-R and concentrates on the so called "BIG five" (McCrae \& Costa, 1990; John, 1990). It can be seen as the dominant personality theory in modern academic psychology and includes the following five trait domains: neuroticism, extroversion, openness, agreeableness and conscientiousness (Egan, 2009). With its high level of abstraction, its well-established theoretical foundation and its transparency, the NEOFFI is suitable to capture rough but comprehensive personality structures and individual differences (Ziegler, 2002).

\subsubsection{Conclusion of Group Overview}

The comparison of the average values of the group of participants within the dimensions of neuroticism, extroversion, openness, agreeableness and conscientiousness against the average values of the general normative comparison group was conducted by a t-test using IBM SPSS Statistics 23.0.

The test results imply that the participants tended to see themselves as emotionally stable people that did not lose their poise easily (low level of neuroticism).

They also tended to see themselves as social, active, communicative and optimistic, and seemed to have good self-esteem (high level of extroversion). Extroverts with their courage, their ambition, their energy and their ability to talk can be successful as strongly noticed leaders (Barrick, 1991).

Furthermore, the participants tended to see themselves as determined, neat, ambitious and busy people that were on time, working diligently and in an organised manner 
(high level of conscientiousness). People with a high value in the dimension conscientiousness are likely to be successful in their job (Barrick, 1991).

\subsubsection{Discussion of Age and Gender Differences}

The research group consisted of twelve participants. As there was one woman included, and two participants were younger than fifty years old when they answered the questionnaire, the average test values of the group of participants were compared to the values of the general normative comparison group values on the NEO-FFI. The general normative comparison group is the comparison group without any limitations concerning gender and age.

Several studies have been conducted about age differences in the Big Five trait dimensions neuroticism, extroversion, openness to experience, agreeableness and conscientiousness. These studies indicate that conscientiousness and agreeableness show positive age trends, neuroticism shows a negative trend, and extroversion and openness tend to stay on the same level (Allemand, Zimprich, \& Hendriks, 2008; Donnellan \& Lucas, 2008; McCrae et al., 1999).

The group of participants scored low in neuroticism and high in extroversion and conscientiousness. As most of the participants were in their fifties or older when they answered the NEO-FFI questionnaire, their age might have supported their low values within the dimension neuroticism and their high values within the dimension conscientiousness.

According to Costa et al. (2001), there are gender differences in specific aspects of the dimensions of extroversion and openness. Men for example scored higher in openness to ideas, while women for example scored higher in openness to aesthetics and feelings (Costa, Terracciano, \& McCrae, 2001). However, looking at these dimensions as a whole according to Feingold (1994), the reviewed gender differences of extroversion and openness were inconsistent or statistically insignificant (Feingold, 1994).

On the dimensions of neuroticism and agreeableness replicable and distinct gender differences were found. Women score higher in the dimensions of neuroticism and agreeableness (Costa, Terracciano, \& McCrae, 2001; Chapman, Duberstein, Sörensen, 
\& Lyness, 2007). Chapman et al. (2007) researched these gender differences especially for older people as their participants were between 65 and 98 years old (Chapman, Duberstein, Sörensen, \& Lyness, 2007)

As the sample of this research contained just one woman, this might have led to gender imbalance resulting in the low values of neuroticism.

\subsubsection{High Level of Extroversion}

In a second step, the single cases that showed values with a deviation more than two standard deviations were reviewed. For the interpretation, the NEO-FFI data was combined with the data of the interviews to get deeper understanding about possible influences of distinctive personality traits on the participants' behaviours and decisions that had relevance for their insolvencies.

The reviewed single cases showed that significantly high values of extroversion (with more than two standard deviations) seemed to have facilitated decisions that enabled the insolvencies:

Participant $5(\mathrm{~T}(\mathrm{E})=73)$ was head of a service provider in the banking sector. One of his customers took over another company. They explained that they would need about one year to sort everything out but after that year he should get the new locations run. To endure this time, they gave him a bridging credit. However, after that year they let him down, cancelled the contract and gave the business to another supplier. He never would have expected this due to the previous good relationship. This was one of the key contributors to his insolvency and is in line with his high value of extroversion. Participant $8(\mathrm{~T}(\mathrm{E})=73)$ was working as a consultant specialised in insolvencies and reorganisations when a chummy banker persuaded him to join the company although he had stated before as a consultant that he did not see a chance for the company. It seemed that the companionability to that banker influenced his decision and finally made him the responsible leader within this insolvency.

Participant $10(\mathrm{~T}(\mathrm{E})=80)$ got into financial trouble because of a loan guarantee. His trouble began when he bailed for a large customer who then went bankrupt. So it looked like his extroversion can be seen as a key contributor to his bankruptcy as it enabled the loan guarantee. 
Participant $12(\mathrm{~T}(\mathrm{E})=77)$ hired an accountant that was one of his friends. He allocated the topic wages and add-on cost to him completely, but never questioned his qualification and also did not control his performance as he was a friend. Later he had to recognise that this accountant did not pay his health insurance for three years. This did not lead to his insolvency but added debts and problems.

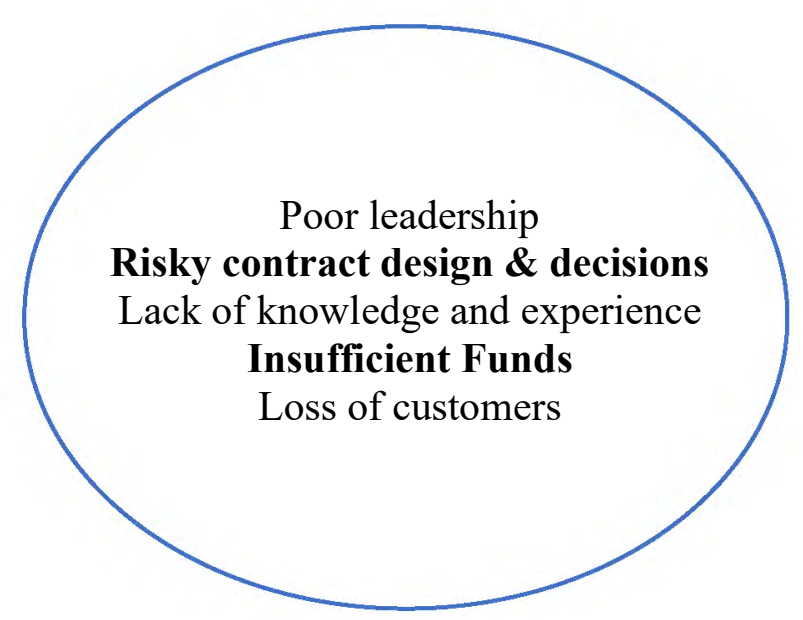

\section{Extroversion}

Figure 10: Extroversion as supporter of identified key contributors

own presentation

The combination of the NEO-FFI values and the information of the interviews imply that the risky decisions of some participants that were identified as key contributors to their insolvencies seemed to have been enabled by their high level of extroversion.

Also within the identified key contributor of insufficient funds, decisions were taken that seem to be connected to high levels of extroversion.

Unfortunately, the sample did not include participants with significantly low levels of extroversion. Here further research is suggested. 


\subsubsection{High Level of Conscientiousness}

Participant 2 had the highest value of conscientiousness $T(C)=73$ of this research. The percentile rank shows that 98.95 percent of the people of the normative comparison group had a value lower than hers within the dimension conscientiousness.

One main reason for her insolvency was her difficult life situation at that time. Her father was critically ill, and she took care of him. In the four years while she was nursing him, she neglected her business, and no longer acquired enough orders and customers. As she set high requirements for her father's care, she did it herself and did not take help by professional services that did not meet her requirements. She said they were very unreliable.

The dimension conscientiousness is often discussed within job related topics. In the literature, high levels of conscientiousness are predominantely seen as success factors for business life (e.g. McAdams, 2006 or Barrick, 1991). So the high level of conscientiousness of participant 2 that was identified in this research as a key contributor to her insolvency might appear confusing at first sight. The explanation for this pretended discrepancy is the focus of participant 2. Her focus was no longer her business, it was the well-being of her father. She was nursing him with full commitment. Of course, it is more than understandable that she wanted the best service for her father; nevertheless, this was one of the key contributors for her insolvency. This shows that also in other areas of life conscientiousness can play an important role, influence daily decisions and can finally become a key contributor to an insolvency instead of a success factor in business life. 


\subsection{Conclusion and Discussion of the Insolvencies' Effects}

Research question three aims to identifiy and understand the effects that the participants had to experience during and after their insolvency procedures:

RQ3: What effects of their insolvencies did the participants experience?

The literature review contained studies about single facets of insolvency effects. The reviewed studies concentrated on specific aspects within that field. To research the broad range of effects the participants had to face after their insolvencies, this study researched these experienced effects by narrative interviews.

Participants had similar experiences within the failing field and its stigmatisation, loss of image and influence, poverty and daily life problems and the poor perspective of the future due to unemployment and the long good conduct phase. However, the reactions of their environment, the experienced effects on their personality and health as well as positive aspects were seen in very different ways.

In the interviews, participants frequently made the connection between the experiences of the insolvency and the topics dying and suicide. It was mentioned that an insolvency feels like dying and includes the good-bye to the life one had before. Some participants ecplicitly mentioned the risk of an insolvent person committing suicide. Chen et al. (2009) support such thoughts with a research that implies that the suicide rate in Japan increased after the credit crunch due to financial problems (Chen, Choi, \& Sawada, 2009).

Chen et al. (2009) found that there were differences in the reasons for suicides between Japan and other OECD countries. They showed that the suicide rate in Japan is to a greater extent influenced by economic variables, for example unemployment, than in other industrialised nations (Chen, Choi, \& Sawada, 2009). Nevertheless, their findings should remind for more thoughtfulness in daily life as not only Japan has a "shame culture" (Chen et al., 2015, p. 254), where financial problems can be seen as a blemish. Also we in Germany have.

According to Pechlaner, the removal of taboos concerning topics such as failing in general and also specifically in an economical context has already started (Pechlaner, 2010). Evaluating the present management literature and academic thoughts, we can 
find several articles that deal with the phenomenon of failing in a philosophical or advice-giving way. However, this research clearly showed that our culture and minds still lag behind this progress.

An interesting movement that took the stigmatisation of failure and attempted to reverse it, are the so-called "Fuckup-Nights". This is a series of events where entrepreneurs that failed in their business give speeches and share their experiences. This initiative started in Mexico in 2012 and now there are events all over the world every month. The original idea was that we generally hear a lot about success but especially sharing experiences about failure can be liberating, interesting and authentic. Every month, about 10.000 people visit Fuckup-Nights (Fuckup-Nights, 2015). It is possible that here probably a certain level of voyeurism, curiosity and maybe even gloating might play a role for the visitors. Nevertheless, it is a development that shows that at least some people are ready to step out of the shadow of stigmatisation, and talk freely and self-confidently about their failures.

The loss of influence is not just experienced due to failing and its stigmatisation. It also has its reasons within the German Insolvency Code that disempowers the insolvent $\mathrm{CEO}$. The participants experienced this aspect very negatively, but here also the interests of other stakeholders have to be taken into consideration. The regulations do disempower the CEOs, but this disempowerment to some extent is necessary for the insolvency administrator to be able to execute the insolvency procedure.

In reactions of the environment, there seemed to be the tendency that the reactions of the close environment (family) were supportive, but going further afield to friends, acquaintances and others, more and more negative reactions appeared. Also the extent of negative effects through poverty and daily life problems seemed to be highly connected to the support of the family.

In Germany there is no security system like the unemployment insurance of employees for entrepreneurs. This implies that the risk of an insolvency contains the danger of poverty (Fachinger \& Oelschläger, 2008). 
Compared to life before the insolvency, most of the participants had a much lower income and also the accommodation seemed to be a challenging aspect within this field.

Especially for the participants that had to go through a general insolvency procedure as a private person, there occurred the danger of losing their house or flat.

Participants 1, 6, 8 and 11 lived in the real estate assets of their parents or partners after the insolvencies. This implies that the family does not only play an important role concerning encouragement but also in terms of basic needs in daily life.

The participants had to face several difficulties that were connected to the General Credit Protection Agency that saves the information on a person's credit rating. This rating significantly influences the possibilities to conclude contracts. So the participants reported huge difficulties obtaining a bank account or a contract for the mobile phone for example as long as the credit rating shows that you have had an insolvency.

For all participants, the insolvency was a time full of sorrow and strain, and three participants even had to face serious illnesses. The concerned participants were sure that their health problems were results of the sorrows and strain they experienced during their corporate crises that then finally ended in the insolvencies.

Participant 4 suffered from a carcinosis in the throat. He explained that he did not smoke or drink although these are typical risk factors for this kind of cancer, but he mentioned other aspects of his stressful day-to-day routine that he saw as enabler for becoming ill, such as poor nutrition.

Participant 6 suffered from hypertension for several years. Additionally, he had to face two carcinoses, both were chronologically linked to difficult life situations. He had the diagnosis of prostate cancer right after the divorce from his wife. Then after a sorrowful period where he had to get his son out of liability concerning the already struggling enterprise, he had the diagnosis of a chronic lymphatic leukaemia.

Three months before participant 7 filed for insolvency, he had the diagnosis of Colitis Ulcerosa, a chronic inflammation of the intestinal mucosa. Colitis Ulcerosa is known as an illness that is influenced by the psyche of the patients.

There is consensus that work strain can have an influence on the mental and physical health of the stressed person (e.g. Richter, 2006). Studies showed that several aspects 
of employment influence the state of health. It is important to have a balance between work-related effort and gratification, such as payment, security of workplace, promotions prospects or appraisal (Larisch, 2003). Also the job-related freedom of action and decision-making play important roles for the somatic and psychological well-being (Tsutsumi, 2004).

The narration of participant 7 implies a stress related course of disease of Colitis Ulcerosa. Experts widely agree that stress is not the trigger factor of Colitis Ulcerosa, but stress seems to provoke the symptoms flaring up (Moser, 2005).

The carcisnoses of the participants 4 and 6 could not definitely be linked to the crises as activator. Here further research is suggested.

Most of the participants mentioned that their prospect of the future suffered seriously due to the insolvency. Here three main topics occurred in the interviews: Unemployment and poor chances to get a new job, the long time frame of the Good Conduct phase, and the loss of retirement provisions and security.

Unemployment predominantly was an issue for the participants who had to go through a general insolvency proceeding as a natural person. The participants saw low chances of finding a job as an employee due to age, their personal adaptability and prejudices of the recruiters. Furthermore, they felt thwarted concerning a new start as an entrepreneur due to the long time frame of the good conduct phase and the associated credit rating.

People who become unemployed do not just lose their salary and security, they also lose values like conversations, commitment, affiliation, responsibility and action (Weig, 2009). Furthermore, unemployment influences people's attitudes and values. However, it may also have a supportive impact and can be seen as the reverse image of the negative effects. Such protective factors are for example having life goals, a differentiated and wide perspective of the future, self-esteem and fulfilling the required actions (Ulich, 1985).

Some of Ulich's findings were echoed in the interviews, although none of the participants seemed to have become resigned or hopeless. This may be due to their strong self-esteem, the very special situation of the insolvency or the small number of 
participants. In any case, the participants seemed to show high interest in the intellectual world, dealing with philosophical questions, and topics of self-awareness.

Asking the participants if they feel like they have changed through the insolvency resulted in different aspects. While some felt deadened, with less energy or more mistrust, others saw their change more positively and felt calmer and as a more likeable person.

The changes of personality that the participants experienced seemed not to be just a change due to the crisis and insolvency itself but also due to the new life conditions and effects that are connected to the insolvencies.

In addition to the mentioned positive changes as a person, other positive outcomes of the insolvencies were also reported. So in some cases the insolvency was seen as a deliverance that stopped the increasing strain and sorrows of the previous corporate crises. Participants explained that now they were more able to enjoy nature or little positive things in life that they had not even noticed before their insolvencies.

Two participants pointed out that after an insolvency one might be a better entrepreneur. These two participants who explicitly asked for more tolerance and trust for the entrepreneurs' new start after the insolvency are two men who went on to work self-employed with new enterprises within the same industrial sector as the first (and insolvent) business. Both have been successful the second time so far. So these are not the self-pitying words of people who could not get anywhere any more, but apparently the words of sustained entrepreneurs who seemed to have made their way successfully after their insolvencies.

Also the academic discussion emphasises that entrepreneurial failure can be seen as a strong enabler for autonomous learning. "Entrepreneurship offers a work context with high levels of autonomy and great freedom in decision-making. (...) Entrepreneurial failure represents a clear signal that something went wrong and motivates entrepreneurs to reflect on what to change" (Seckler, 2017, p. 54).

In general, failure as the non-attainment of goals leads to negative emotions such as frustration or doubt (Carver, 1990). It is commonly accepted that entrepreneurial failure causes an intense negative emotional reaction such as panic or distress (Shepherd, 2004). This leads to two opposing effects. On the one hand, dealing with 
negative emotions ties up resources which then are missing for working on the original task. They handicap the entrepreneur concentrating on problem solving and can interfere with the processing of information. On the other hand, negative emotions have a positive effect on the learning process as they can be seen as feedback indicating the occurrence of a failure (Seckler, 2017). Failure by itself does not automatically lead to learning, but the negative emotions play a crucial role on reflection and the possibility to learn from those failures (Carver, 1990). In the case of an insolvency, the first effect that the negative emotions tie up resources is weakened as the entrepreneurs are released from most of their tasks and responsibilities by the insolvency administrator. However, what remains might be the positive effect of negative emotions as an enabler for autonomous learning. 


\subsection{Contribution to Current Knowledge}

The research contributes to the current knowledge of insolvencies by gaining deeper understanding of the key contributors and the role of the participants within their insolvencies. Instead of just naming the key contributors, the research provides indepth insights through narrative interviews and the NEO-FFI inventory to add further depth and understanding and cross validation of the qualitative data.

The research contributes further to the current knowledge by gaining deeper understanding of the situation of the participants during and after the insolvency proceedings.

In addition to an academic audience, the research is also of value to entrepreneurs as the study uncovered several ommissions of knowledge that led to the insolvencies or supported negative effects of the insolvencies for the participants. 


\subsection{Limitations of the Study}

The findings of this research cannot be generalised due to the relatively small sample size of twelve participants and the way of sampling. To get in contact with the participants, letters were sent to 231 Bavarian lawyers specialised in insolvency law. In these letters, the research was introduced and the lawyers were asked to give the contact details to their clients so that they could make contact if they were willing to join the study. This procedure led to the participation of twelve leaders that had to face an insolvency in the past.

The explained way of sampling could have influenced the findings of this research as several factors played a role making the contacts between the participants and the researcher: As the lawyers officiated as a go-between, they might have forwarded the study request preferentially to clients with whom they had a good relationship. Most of the participants commented positively on their insolvency administrators.

The sampling process also could not capture participants that were not willing to talk about their insolvencies to a researcher and also gives no information if or how many people were asked by their lawyers to join the research but refused it.

Furthermore, it is more likely that people contacted the researcher who coped with their insolvencies to a certain extent. To make it clear by some drastic examples, people who fell into a deep depression after their insolvency might not have shown the initiative to seek the contact for attending this research. People who required hospitalised medical care or had even died meanwhile also could not.

In addition, as the study dealt with people whose insolvencies already went back some years to also research the effects the participants had to face now, people who suffered so much that they could no longer take part in this study also are not known. The participants mentioned topics like depressions and suicide, some became ill but have been able to recover now. The study does not include any information about potential participants that got a severe mental, psychological or physical illness or even died. In this context, this research could to be seen as a research about the "lucky ones", which should especially be kept in mind when dealing with the findings about the effects of the reviewed insolvencies. 
For data collection, interviews with the participants and a personality traits inventory were chosen. In addition to the numerous differences between these two methods, they also have something in common: The participants were the ones who gave the information.

In the interviews, they narrated their stories and another participant would have told another story. The research data contains their point of view, how they saw the world and themselves. Also the data through the personality traits inventory is how the participants saw themselves, and there can be differences between the sense of self and the awareness of others.

Furthermore, the participants narrated their story out of their memories, so the interviews cannot reflect how they experienced the narrated events in real-time. Their content is influenced by different aspects, for example how they dealt and deal with those events, what sense they made out of them and how they coped and cope with them. Moreover, memory can also become distorted or (partly) forgotten over time.

The author understands that therefore limitations are rooted within the chosen processes of sampling and data collection. In spite of the explained limitations and the very sensitive and personal situation of the insolvency, the research offers a deeper understanding of the impact that entrepreneurs may have on their insolvency and that insolvency may have on entrepreneurs. 


\subsection{Suggestions for Further Research}

In conductiong this study, themes for further research occurred. These are explained in the following paragraphs.

The participants predominantely commented positively on their insolvency administrators. However, participant 10 was very dissatisfied. He reported that after 20 years the insolvency administrator still held the values of the former company. He was selling some property from time to time to be able to pay his own salary but did not serve the creditors.

Concerning the control of the insolvency administrator, there might be room for improvement in Germany. The supervision by the court for example is arranged in that way, that the court can request information any time. Due to their work load and the long time period of some insolvency procedures, it would be preferable if the administrator had to provide reports about his/ her progress unasked. Also, a supervision chamber for more control could be useful as the practice that participant 10 reported about his insolvency administrator does not seem to be within the meaning of the sense of justice and might require regulation.

It is possible that just one case of such a drawback was reported because the participants had good relationships with their insolvency administrators. Here further research would be desirable to understand if this is a common problem and if more regulation is required.

Concerning the research design of this study, the researcher decided not to use a second group of participants for comparison. The main reason for that decision was that a comparison group of people who did not go through an insolvency would not have had any value for the research questions 1 and 3 that were answered through interviews. Also for research question 2 that was answered through the NEO-FFI questionnaire, it was not necessary as the test manual includes tables of comparison values. Nevertheless, it could have been interesting to give the traits inventory to a second group of participants. This could have been entrepreneurs leading a successful and growing company, or entrepreneurs who managed the financial crisis of the years $2008 / 2009$ without damage to their companies or employees for example. 
The triangulation of the NEO-FFI values with the information of the interviews imply that the risky decisions of some participants that were identified as key contributors to their insolvencies seemed to have been enabled by their high level of extroversion. Also within the identified key contributor of insufficient funds, decisions were taken that seem to be supported by high levels of extroversion.

Unfortunately, the sample did not include participants with significantly low levels of extroversion. Here further research is suggested.

The research gives hints that the insolvencies might have changed the participants' personalities as they mentioned that they would have answered the NEO-FFI questionnaire differently before the insolvency. This concerns item 47 in particular, which belongs to the dimension of extroversion. This might be a field for future research.

In such further research, the question should also be addressed of whether an identified change of personality would really have its root cause in the experience of the insolvency itself or if it might have occurred through the changed life conditions after the insolvency.

In Germany, insolvencies are still a taboo. According to Häring (2010), the insolvent entrepreneurs are seen as losers who simply were not able to handle the business challenges accordingly, or they might be swindlers who may even have ruined it on purpose (Häring, 2010). This social stigma seems to be connected to the German culture. The management literature as well as the participants did not tire of mentioning the cultural differences in terms of the acceptance of failing between other countries, for example the USA, and Germany. Participant 2 used the well-known phrase "In Germany we do not have a culture of failing" to sum up the dilemma. Here furher research about the insolvency effects for the entrepreneurs in Germany compared to other countries could be conducted.

Three participants had to face serious illnesses. They were sure that their health problems were results of the sorrows and strain they experienced during their corporate crises that then finally ended in the insolvencies. 
Participant 4 suffered from a carcinosis in the throat. Participant 6 suffered from hypertension for several years. Additionally, he had to face two carcinoses, both were chronologically linked to difficult life situations. Three months before participant 7 filed for insolvency, he had the diagnosis of Colitis Ulcerosa, a chronic inflammation of the intestinal mucosa.

There is consensus that work strain can have an influence on the mental and physical health of the stressed person (e.g. Richter, 2006). Experts widely agree that stress is not the trigger factor of Colitis Ulcerosa, but stress seems to provoke the symptoms flaring up (Moser, 2005). However, concerning carcisnoses, the relations are very complex and unclear. Here further research is suggested.

So the topics that occurred within the process of this study where further research is suggested are the relationship between the person who is insolvent and his/ her insolvency administrator, the role of the insolvency administrator in Germany including possible malpractice, the comparison of personality profiles of insolvent entrepreneurs with the profiles of entrepreneurs who managed a market crisis without damage to their companies, comparison of the business performance of entrepreneurs with high and low levels of extroversion, research of the insolvency effects on the entrepreneurs in Germany compared to other countries, and the influence of insolvencies on the health of the entrepreneurs with focus on carcinoses. 
Behind every research there stands a researcher and a doctorate is a journey with ups and downs that lasts several years and influences the researcher's life significantly. So the following chapters provide personal insights into this research journey. According to Moon (2001), reflection is a special form of thinking. People use this kind of thinking for unstructured ideas for which there is no obvious solution. Moon (2001) states further that reflection basically is grounded in the further processing of knowledge, the striving for understanding of our emotions (Moon, 2001).

These thoughts are not new at all. Already Dewey (1933) saw reflection as a special form of thinking, too. For him, reflection consists of turning a subject over in the mind to think it through very thoroughly. Reflection is active and careful consideration that requires effort and rationality (Dewey, 1933).

Mezirow (1990) pointed out that reflection is a tool especially for adult learners. By reflecting influences to their experiences, it is possible to understand those experiences in depth. This deeper understanding can also involve the nature of the structures that influenced experience and dynamics involved in modifying meanings (Mezirow, 1990).

"Reflection suggests looking back over individual experiences, an introspective activity conducted within one's own personal context to reveal one's self to oneself' (Sambrook, 2008, p. 369).

Of course it would be wonderful if this PhD-journey was a straight line without big curves, but it was not. There were several points during the way, where it was necessary to step back a bit to see the whole picture and think about the right way to take further. However, I think that every step during my journey had relevance even if it was a step back, because they made me see things differently or more clearly. 


\subsection{Why I Wanted to do a Doctorate}

During my doctorate there also occurred situations where I asked myself: "Why do I do this (to myself)?" To be fully aware of my reasons in such situations was a good motivation for me to continue my research as in the first instance I did it for myself. I will explain that in the following paragraphs.

Bridges (1999) stated that reflective writing is usually part of a longer personal professional journey as it starts to take shape long before the writing itself begins (Bridges, 1999). I had the same experience. The question of why I wanted to start a doctorate for example occurred already in one of my first DBA course sessions. We were asked to express graphically our personal development that led to the start of our doctorate. I often thought of my pictures afterwards. Drawing them was a very interesting action as it suddenly made my own emotions and thoughts clear for me. It was as if through the painting tacit knowledge would have become obvious. In the following, I show the pictures and explanations that I gave in the DBA course room which remained valid and important for me during my whole doctorate. When I was at university doing my advanced studies, I enjoyed writing my diploma thesis a great deal. Because of that, I always liked the idea of writing a doctoral thesis one day. What I did not know was the right time for that project, and how and when this idea would fit into my life-plan. After working some years, that also became quite clear as the following figures show. 


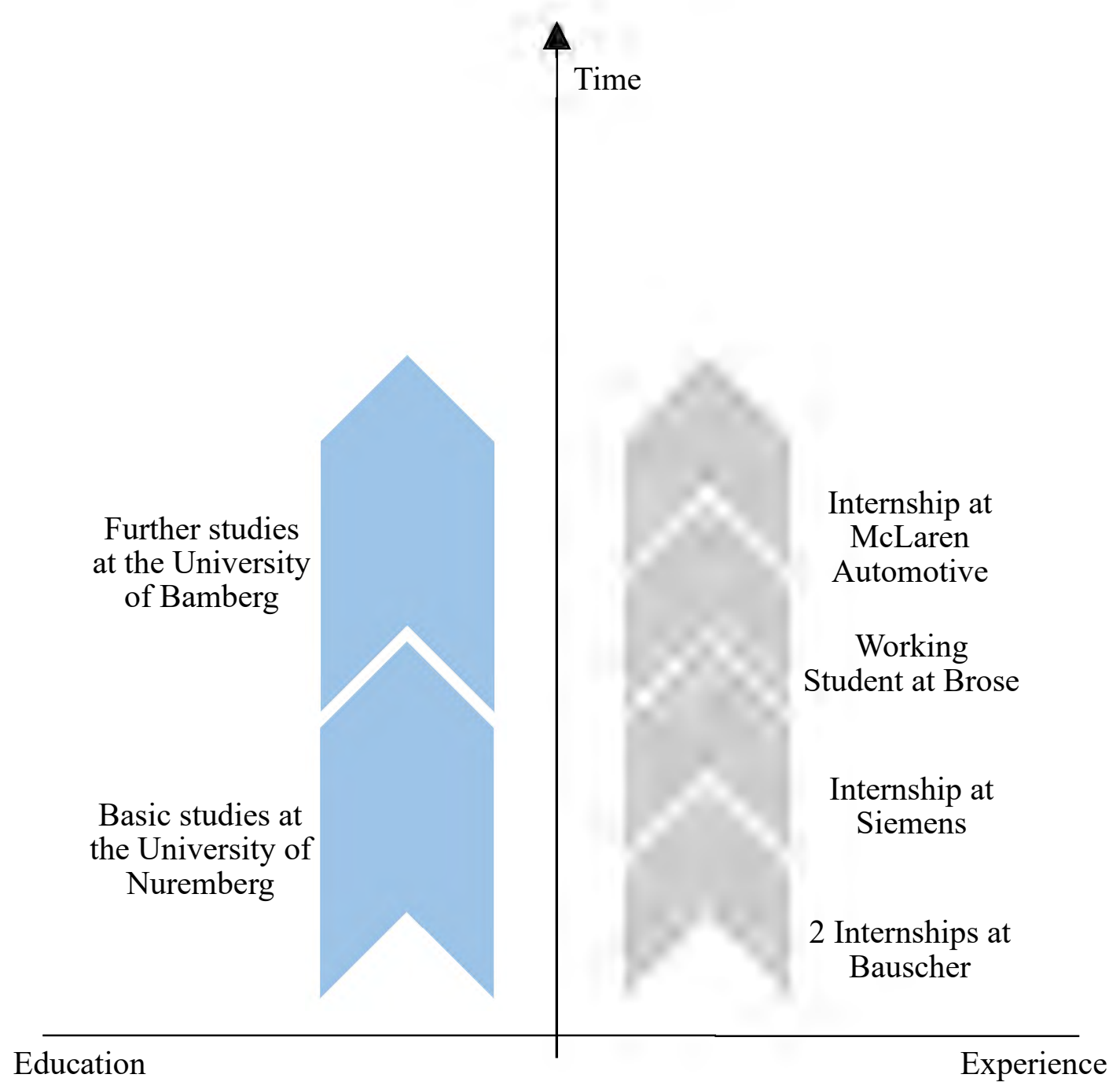

Figure 11: Balance of education and professional experience

Own presentation

During my basic and advanced studies of business administration in order to get the diploma, I always had a good balance between education and professional experience. First I worked during the holidays, then I was a working student for one year in addition to the courses at university. After that, I did an internship abroad in Great Britain near London for half a year. During that internship, I also completed tests at university. So I studied in the evenings and for the tests I flew back to Germany. Although keeping that balance sometimes was challenging, I enjoyed it very much. For me it always felt like education and experience would require different forms of thinking, Sometimes it even felt like different parts of my brain would be in action for 
the different tasks. The daily troubleshooting at work felt more located in the front and on the upper side of my head, whereas philosophical thoughts or theoretical assumptions seemed to come from the back of my head. Of course this is no biological analysis - I just try to explain how it felt for me.

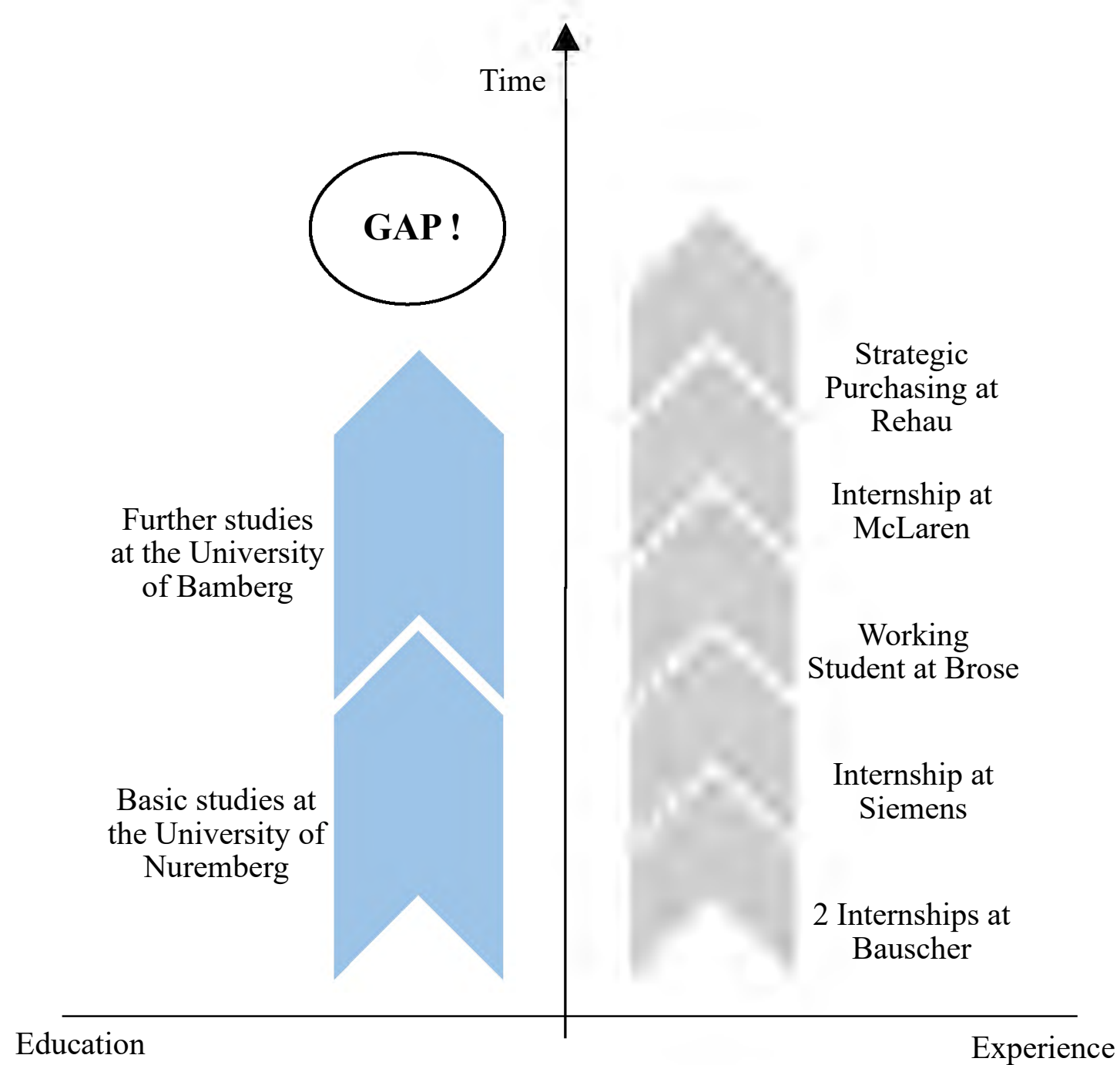

Figure 12: Gap of education

Own presentation

After I started working full-time, I realised very soon that the balance between education and professional experience that I knew from all the years before was disturbed. Maybe it was some kind of reality shock that made that feeling even worse. After a while, I felt a bit like a zombie who goes the same ways, does the same things, faces the same absurdities and problems every day. To stay with the picture of the 
different parts of the brain that I used before - I felt the back of my head was going to seed somehow. That was the point where I realised that it might be the right time to do a doctorate.

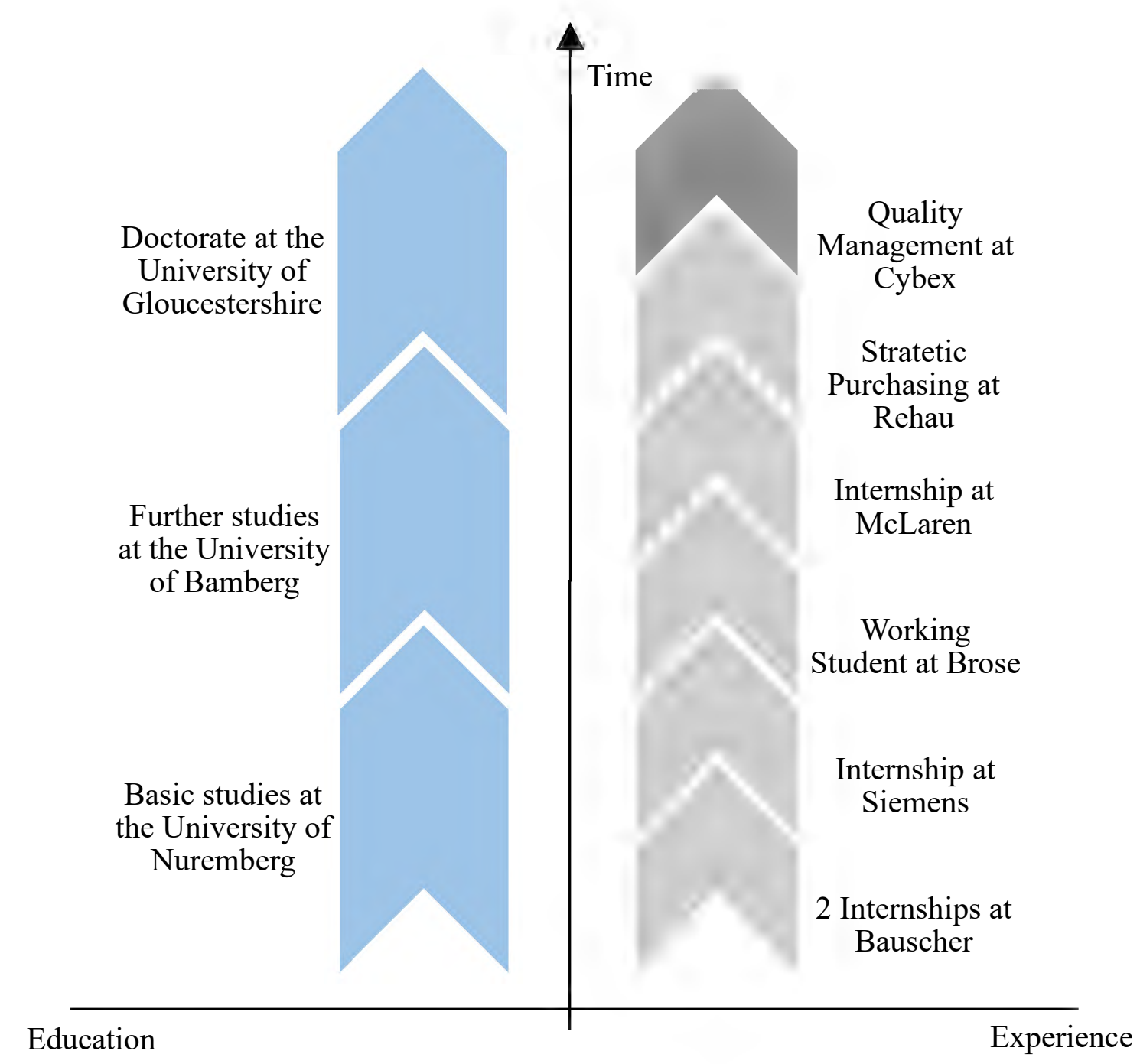

Figure 13: Doctorate to recreate the balance

Own presentation

Starting the doctorate recreated the balance that I missed. Maybe some people really cannot decide. Maybe some really need both, an academic and a professional life to feel complete, and I seem to be one of them. 


\subsection{Finding my Topic}

I needed quite a while to find my research field, and at the beginning of this journey the topic of my thesis changed several times. My first thoughts were that my topic should be up to date and of high relevance and interesting for a broad audience. Probably these thoughts came into my mind because I also do creative writing. A doctoral thesis is no novel of course, but going in line with that idea that my doctorate should have its finger on the pulse my initial plan was to research the impact that transnational terrorism has on the economy. I was highly motivated as I thought this was a very interesting topic, but already in our first action learning set meeting I doubted whether I would be able to access the necessary information. Furthermore, during the DBA courses with the other students, I had to realise that my research goals were very different to theirs. Most of my fellow students were managers who wanted to solve a practical problem within their organisation through the doctorate. This seemed to be a perfect fit as also the University of Gloucestershire wrote on its web page about the DBA: "This programme is for executives able to engage in major projects inside their employing organisations" (Gloucestershire, 2012). But for me it did not fit too well. When I started the doctorate, I was not an executive yet but a normal employee, and when my boss heard that I would start a doctorate he told me that any involvement of the company in my study was not appreciated.

At that time I was working as a strategic purchaser of packaging material. This job was very interesting and seemed to be a perfect professional start for me. Being a strategic buyer of packaging material at Rehau was a challenging job for somebody who does not have too much full-time professional experience. I was given the full responsibility of a purchasing volume of 16 million euros per year right from the beginning. I also liked the material groups as the packaging materials are closely connected to logistics issues that I was always interested in. However, in those days when I was tumbling around between different topics it also became clear to me that it was not the job that I wanted to do forever. So I did not want to concentrate on this field within postgraduate studies. So what to do?

To find my topic I then really made up my mind and thought it through thoroughly. I thought I would have to spend quite some time with the research field I was going to choose, so it should be something that I love doing. There came two areas into my 
mind that I always liked to deal with: nature and people. The only topic I could come up within the research field of nature was something about green packaging. However, on the one hand, this would have meant concetrating on my packaging job which I did not really want to do, and on the other hand, I had to realise that there was already very much written in that field. So I had to admit: If I want do dig into green packaging, I can read a lot about it, but I do not have to research that field. In addition to nature, I was always interested in understanding people and social aspects. If I hear about a decision or action of somebody that seems to be inapproproate or inconsistent to his/ her person or other decisions and actions, I can spend quite a while thinking about that again and again. This sometimes might be annoing for my environment, but it seemed to be a good baseline for a research. So I decided to set my focus here and do social studies for my doctorate.

In a second step, I had to find a field of social studies within the context of business administration. This was actually quite easy. Working in the processing industry, I knew that for every department, process or workplace there are plenty of requirements, tasks and defined processes. As long as everything runs smoothly and accoring to plan, it is quite boring. It starts getting interesting if something goes wrong. (That is why I later made a job change to quality and process management!) How can it go more wrong wthin the field of business administration than when there occurs an insolvency? So, derived from my interests, I finally came to the topic of researching root causes and effects of insolvencies with the focus on the entrepreneur.

In retrospect, I sometimes think it might have been better to put more effort into making up my mind about the topic at an earlier stage and then start the doctorate as $\mathrm{PhD}$ studies right from the beginning to save time. However, if I did it that way, I never would have been part of the DBA courses and I see them as a great benefit. 


\subsection{The Fear of not Finding (enough) Participants}

When I started this research, I saw my biggest challenge in finding participants. As I explained in chapter 5.2. about the sampling, I went a little loop way to get in contact with my participants. I wrote a letter to the 231 lawyers with specialisation in insolvency law that were listed at the three Bavarian bar associations in Bamberg, Munich and Nuremberg. In this letter, I told these lawyers about my research and asked them to forward my call for interview and test partners to possible participants in their pool of clients. As after my letter the further effort of making the contact was in the hands of the lawyers and their clients, I was very much in doubt if I would get reactions. Maybe the lawyers would just throw the letters away? And if they really forwarded my request, maybe then their clients would have no interest in being part of my research? Maybe they would prefer to remain silent about their insolvency instead of sharing this difficult life phase with a person they had never seen before?

All those "maybes" became bigger and stronger in my head the longer I thought about it. After some time, I was sure that my research would end before it had really started because nobody would be willing to talk to me about his/ her insolvency. This led to an irrational fear and blocked me. Although the letter was written and waiting on my computer to be printed and sent out, I waited. It took a long period of procrastination, a period of time that I could have used so much better, not only because I was successful with this loop way. I was hoping to get ten participants in the best case and finally twelve participants took part in my research.

This showed me that often the biggest mistake that you can make is not to act. If you do not act, nothing can get activated by your action at all. This insight also helps me in other areas of life today. There are for example plenty of young writers who do not have any publications because they fear the rejection of publishers. Of course, it takes some overcoming to offer your texts to criticism, but it is the only way. Dealing with this topic actively also brought me positive outcome in other fields. So I have published 17 short stories, four poems and three children's books in the past four years. 


\subsection{The Role of the Interviewer}

Conducting the interviews I also saw as a challenge as the interviewer here holds an important role concerning the success of the data collection. However, being in the interview situation I realised that the role of the interviewer was surprisingly easy for me. I think I was lucky to choose narrative interviews as the main part of my data collection as it seems that I have some attitudes and abilities that are valuable in this context.

Froschauer and Lueger (2003) listed seven requests for the interviewer that are important to conduct a successful interview:

"Learn!"

"Interest and curiosity!"

"No snap judgements!"

"The interviewees are always right!"

"Listen!"

"Don't accept everything as a matter of course!"

"No discrimination of participants!"

(Froschauer \& Lueger, 2003, p. 59f)

Learn!

The interviewer has to accept that he/ she learns from the participants. They are the experts of the relevant social system.

For me, this point was clear right from the beginning of my research. Actually this perception even led to my research questions, as I was seeking understanding and wanted to learn from the experiences of people who had to go through an insolvency.

Interest and curiosity!

It is important for the researcher to engage in new and unknown aspects. If he/ she wants to know more, it is easier for him/ her to discover the participants' reality. Also, with this request I did not have a problem at all. I am interested in new and unknown aspects also in daily life as this is one of my characteristics. I am especially interested in people. When I get to know somebody new or meet somebody again after 
a longer time period, I tend to ask a lot of questions. So one of my annoying attributes in daily life was a very valuable one for the research: I am passionately nosy!

No snap judgements!

The interviewer has to be open-minded and should not pigeonhole topics or people prematurely as this will narrow cognition and prevent deeper understanding. I am always anxious to be free of prejudices. Of course this does not always work, I know that I am not perfect at all. However, I tend to encounter topics or people in a differentiated way.

The interviewees are always right!

This request emphasises the perspectivity of the interview data. Social phenomenons can have different meaning or importance from different point of views. Even contradictions can make sense within the interview context or the social reality of the participant.

This point I see as essential for the success of an interview, and I also had situations where in daily life I would have argued as I had another opinion to the participants. In the interview situation of course I held back my point of view.

\section{Listen!}

The interviewer has to listen actively. It is not enough to sit there, drink coffee and make sure the recording machine is working properly. Listening is an active process that includes the mediation of interest and attention to engage the participant to narrate. However, showing attention of course is not enough, the interviewer also really has to pay full attention to understand the participant.

I was always an active listener. I remember that in school I often held the role of the agony aunt, and my friends said that it would help a lot to talk to me when they had a problem. However, actually I gave advice only in rare cases. Most of the time I was listening and engaging them to talk. In this way, on the one hand, they felt important and heard, and, on the other hand, they often found solutions by themselves just by talking the topic though. 
Don't accept everything as a matter of course!

Some statements in interviews are based on a special social setting. It is important to identify apparent implicitnesses and question and analyse them. This is especially important at the beginning of a research project when some aspects might still be unclear.

Through the research I learnt about a number of psychological, legal and social aspects and interferences. This broadening of my horizon I enjoyed very much and it was the reason for me to research an interdisciplinary topic.

No discrimination of participants!

Of course the researcher may not discriminate the participants. This is absolutely clear, and I was surprised to find this point in the list of Froschauer \& Lueger.

The participants are the ones that enable the researcher to conduct his/ her study. They are the linchpin. So their importance for the researcher should prohibit their discrimination. Furthermore, I see absolutely no reason that could make me discriminate my participants.

Discrimination must always be avoided, also in daily life as it blurs your view. Of course, I am not completely free of judgement and discrimination, probably nobody is. Indeed, there are behaviours that I cannot accept. But as I know that I could not work with people showing these behaviours impartially, I would never try to do a research with such a participant group.

According to Küsters (2009), a narrative interview has to be seen as failed when there arises no extempore narration. Narrative interviews often fail because the relationship between interviewer and participant lacks trust, or the interviewer is not able to give adequate stimuli for the participant to narrate (Küsters, 2009).

I am happy to point out that all my interviews began with an ad-lib narration. The participants were talking freely over large parts of the interviews. As my attributes and abilities seem to be in line with the requests for an interviewer, I could successfully conduct them. 


\subsection{The People I Met}

The best experience of my research were the meetings with my participants. I had the chance to meet twelve interesting people and learnt a lot through the interviews with them. Obviously I gained a lot of information and valuable insights in key contributors to insolvencies and effects of insolvencies on the entrepreneurs. However, this is not what I am talking about now. By telling me about their experiences, they also gave me so much interesting information about their companies and industry sectors.

My participants were leaders of very different enterprises, and so every interview had the wonderful side effect that it also was a private lesson in the specific industry sector for me. Through my data collection process, I learned about marketing services, the pharma industry, IT services, automotive industry, security of banks, engineering, production of the raw material wood, toys industry, trading companies and the construction sector.

When I was a business administration student in Bamberg, I chose the automotive industry as one of my main subjects. It was refreshingly different to study an industrial sector rather than a functional subject. Every Wednesday a specialist visited our course and gave a lecture on a topic out of his/ her daily experience. These lessons were the highlights of the whole week, and while I was listening to my participants, I felt as if I had been thrown back right into such an interesting lecture full of valuable insights and new information.

Furthermore, the participants did not just give me information. They also gave me their time, their company. Most of them invited me into their homes. So for a short time I was very close to them and their daily life and those personal insights touched me. Some of them were living quite a simple and limited life after their insolvencies, but welcomed me, prepared coffee and tea for me. In particular, some of the participants that had to face serious financial cuts in their private lives through the insolvency seemed to be happy and an peace with themselves.

All in all, I have to say that this doctorate was a great benefit to my personal development. It taught me to overcome fears and scepticism, brought me interesting insights and new knowledge, and improoved my skills in self motivation and discrete thinking and working. 
Allemand, M., Zimprich, D., \& Hendriks, A. A. (2008). Age differences in five personality domains across the life span. Developmental Psychology(44), pp. $758-770$.

Allport, G. W. (1936). Trait-names: A psycholexical study. Psychological Monographs, 47 (Whole No. 211).

Anheier, H. K. (1996). Organizational failures and bankruptcies: What are the issues? The American Behavioral Scientist, 39(8), pp. 950-958.

Antoniakis, J., Cianciolo, A. T., \& Sternberg, R. J. (2004). The Nature of Leadership. Thousand Oaks, CA: Sage Publication.

Avolio, B. J. (2004). Leadership Development in Balance: Made/Born. Hillsdayle, New Jersey: Erlbaum.

Avolio, B. J., Bass, B. M., \& Jung, D. I. (1995). MLQ Multifactor Leadership Questionnaire. Redwood City, CA.: Mind Garden.

Back, M. D. (2009). Predicting actual behavior from the explicit and implicit selfconcept of personality. Journal of Personality and Sicial Psychology(97), pp. 533-548.

Barrick, G. E. (1991). The big five personality dimensions and job performance: A meta-analysis. Personnel Psychology(44(1)), pp. 1-26.

Barrick, M. M. (1993). Autonomy as a moderator of the relationship between the Big Five personality dimensions and job performance. Journal of Applied Psychology, 78, pp. 111-118.

Barrick, M. R. (2001). Personality and job performance at the beginning of the new millennium: What do we know and where do we go next? Internatinal Journal of Selection and Assessment, 9, pp. 9-30.

Bartens, W. (2013). Das falsche Signal. SZ-Magazin, Heft 4, Thema Gesundheit.

Bass, B. M. (1985). Leadership and performance beyond expectations. New York: Free Press.

Bass, B. M. (1990). Bass and Stogdill's handbook of leadership: Theory, research and managerial applications (Vol. 3). New York: Free Press.

Bass, B. M., \& Steidlmeier, P. (1999). Ethics, character and authentic transformational leadership behavior. Leadership Quarterly, 10(2), pp. 181-217.

Baum, A. \&. (1998). Stress. In H. S. Friedmann, Encyclopedia of mental health (pp. Vol. 3, 599-606). San Diego, CA: Academic Press.

Becker, B. (1982). Psychologie der seeischen Gesundheit (Vol. 1). Göttingen: Hogrefe.

Bellinger, B. (1962). Unternehmungskrisen und ihre Ursachen, in: Handelsbetrieb und Marktordnung, Festschrift für C. Ruberg zum 70. Geburtstag. Wiesbaden.

Bennedsen, M. P.-G. (2006). Do CEO's matter? Working Paper. Th University of Texas at Austin: McCombs School of Business.

Berelson, B. (1952). Content Analysis in Communication Research. Glencoe: Free Press.

BGB. (2019). Bürgerliches Gesetzbuch; In der Fassung der Bekanntmachung vom 02.01.2002 (BGBl. I S. 42, ber. S. 2909, 2003 S. 738); zuletzt geändert durch Gesetz vom 18.12.2018 (BGBl. I S. 2651) m.W.v. 01.01.2019. 
Bhaskar, R. (1998). Philosophy and scientific realism. In B. R. M. Archer, Critical Realism: Essential Readings, Critical Realism: Interventions (pp. 16-47). London: Routledge.

Bird, C. (1940). Social Psychology. New York: Appleton-Century.

Blaikie, N. W. (1993). Approaches to Social Enquiry. Oxford: Polity Press.

Blickle, G. (2011). Intelligenz, Persönlichkeit und Selbstdarstellung: Aktuelle Perspektiven der Personalpsychologie. In P. W. Gelléri, Potenziale der Personalpsychologie (pp. 113-120). Göttingen: Hogrefe Verlag.

Bohnsack, R. (2014). Rekonstruktive Sozialforschung: Einführung in qualitative Methoden (9 ed.). Opladen \& Toronto: Verlag Barbara Budrich.

Borkenau, P. O. (2008). NEO-Fünf-Faktoren-Inventar nach Costa und McCrae. Göttingen: Hogrefe Verlag.

Borkenau, P., \& Ostendorf, F. (2008). NEO-Fünf-Faktoren-Inventar nach Costa und $\mathrm{McCrae}$. Göttingen: Hogrefe Verlag.

Brähler, E. P. (2002). Brickenkamp: Handbuch psychologischer und pädagogischer Tests. Göttingen: Verlag für Psychologie, Dr. C.J. Hogrefe.

Brandstätter, H. (2011, August). Personality aspects of entrepreneurship: A look at five meta-analyses. Personality and Individual Differences, 51(3), pp. 222-230.

Bridges, D. (1999). Writing a Research Paper: reflections on a reflective log. Educational Action Research(7(2)), pp. 221-234.

Brüderl, J., \& Schüssler, R. (1990). Organizational mortality: The liabilities of newness and adolescence. Administration Science Quarterly(35), pp. 530-547.

Bryman, A. (1988). Quantity and Quality in Social Research. London: Routledge.

Bryman, A. B. (2007). Business Research Methods. New York: Oxford University Press Inc.

Burk, S. B. (2014). Insolvenz erkennen - Insolvenz bewältigen. Wege aus der Krise für Unternehmer. München: Verlag C. H. Beck.

Byrne, B. (2004). Researching society and culture. London: Sage Publications.

Capello, R. (2002). Entrepreneurship and spatial externalities: Theory and measurement. The Annals of Regional Science, 36, pp. 387-402.

Caplan, G. (1964). Principles of preventive psychiatry. New York / London: Tavistock.

Carlyle, T. (1907). On heroes, hero-worship, and the heroic in history. Boston: Houghton Mifflin.

Carver, C. \&. (1990). Origins and functions of positive and negative affect: A controlprocess view. Psychological Review, 97(1), pp. 19-35.

Cascio, W. F. (1995). Guide to responsible structuring. Washington D.C.: U.S. Department of Labour.

Cattell, R. B. (1945). The description of personality: Principles and findings in a factor analysis. American Journal of Psychology, 58, pp. 69-90.

Chapman, B. P., Duberstein, P. R., Sörensen, S., \& Lyness, J. M. (2007, Octobe). Gender Differences in Five Factor Model Personality Traits in an Elderly Cohort: Extension of Robust and Surprising Findings to an Older Generation. Personality and Individual Differences, 6(43), pp. 1594-1603.

Chen, J., Choi, Y. J., Mori, K., Sawada, Y., \& Sugano, S. (2015). An Analysis of Suicides in Japan, 1997-2007: Changes in Incidence, Persistence, and Age Profiles. Soc Indic Res(121), pp. 253-272.

Chen, J., Choi, Y., \& Sawada, Y. (2009). How is suicide different in Japan? Japan and the World Economy, 21(2), pp. 140-150. 
Collier, A. (1994). Critical Realism: An Introduction to Roy Bhaskar's Philosophy. London: Verso.

Collis, J. H. (2003). Business Research: A Practical Guide for Undergraduate and Postgraduate Students (2nd ed.). Basingstoke: Macmillan Business.

Costa, P. T. (1992). Revised NEO Personality Inventory (NEO PI-R) and NEO Five Factor Inventory (NEO-FFI): Professional Manual. Florida: Psychological Assessment Ressources.

Costa, P. T. (1993). Bullish on personality psychology. The Psychologist, 6, pp. $302-$ 303.

Costa, P. T. (1997). Personality trait structure as a human universal. American Psychologist, 52, pp. 509-516.

Costa, P. T. (2008). The Five-Factor Theory of Personality. In O. P. John, Handbook of Personality (3rd ed. ed., pp. 159-181). New York: The Guilford Press.

Costa, P. T., \& McCrae, R. R. (1995). Domains and Facets: Hierarchical Personality Assessment Using the Revised NEO Personality Inventory. Journal of Personality Assessment, 64(1), pp. 21-50.

Costa, P. T., \& McCrae, R. R. (1997). Personality Trait Structure as a Human Universal. American Psychologist, 52(5), pp. 509-516.

Costa, P. T., McCrae, R. R., \& Kay, G. G. (1995). Persons, Places and Personality: Career Assessment Using the Revised NEO Personality Inventory. Journal of Career Assessment, 3(2), pp. 123-139.

Costa, P. T., Terracciano, A., \& McCrae, R. R. (2001). Gender differences in personality traits across cultures: Robust and surprising findings. Journal of Personality and Social Psychology(81), pp. 322-331.

Costa, P., \& McCrae, R. (1994). "Set like plaster?" Evidence for the stability of adult personality. In T. W. Heatherton, Can personality change? (pp. 21-40). Washington DC: American Psychological Association.

Creditreform, V. d. (2009). www.creditreform.de. Retrieved from Insolvenzen, Neugründungen, Löschungen Jahr 2009:

https://www.creditreform.de/fileadmin/user_upload/crefo/download_de/news_t ermine/wirtschaftsforschung/insolvenzendeutschland/Insolvenzen_in_Deutschland_2009.pdf

Creditreform, V. d. (2017). www.creditreform.de. Retrieved from Insolvenzen in Deutschland: https://www.creditreform.de/nc/aktuelles/news-list/details/newsdetail/insolvenzen-in-deutschland-jahr-2017.html

Dawley, D. D. (2003). Do Size and Diversification Type Matter? An Examination Of Post-Bancruptcy Outcomes. Journal of Managerial Issues, XV(4), pp. 413-429.

Denzin, N. K. (1989). The Research Act. A Theoretical Introduction to Sociological Methods (3 ed.). Englewood Cliffs, N. J: Prentice Hall.

Denzin, N. K., \& Lincoln, Y. S. (1994). The Discipline and Practice of Qualitative Research. In L. Y. N. K. Denzin, Handbook of qualitative research. California: Sage Publications Inc.

Dewey, J. (1933). How We Think. A restatement of the relation of reflective thinking to the educative process. Boston.

Dey, I. (1993). Qualitative Data Analysis. London: Routledge.

Diekmann, F. (2017, 01 27). Spiegel Online. Retrieved 03 08, 2018, from Ältere am Arbeitsmarkt: Die Rückkehr der Grauhaarigen:

http://www.spiegel.de/wirtschaft/soziales/arbeitslosigkeit-aelterer-mit-50keine-chance-mehr-gilt-das-immer-noch-a-1129828.html 
Digman, J. M. (1986). Further specification of the five robust factors of personality. Journal of Personality and Social Psychology, pp. 116-123.

Donnellan, M. B., \& Lucas, R. E. (2008). Age differences in the Big Five across the life span: Evidence from two national samples. Psychology and Aging(23), pp. $558-566$.

Egan, V. (2009). The 'Big Five': Neuroticism, Extraversion, Openness, Agreeableness and Conscientiousness as an organisational scheme for thinking about aggression and violence. In H. R. M. McMurran, Personality, Personality Disorder, and risk of Violence: An Evidence-based Approach. Chichester: John Wiley \& Sons, Ltd.

Erlandson, D. A. (1993). Doing Naturalistic Inquiry. Neubury Park, CA: Sage.

ESUG. (2011). Gesetz zur weiteren Erleichterung der Sanierung von Unternehmen; Bundesgesetzblatt Jahrgang 2011 Teil I Nr. 64, ausgegeben am 13.12.2011, Seite 2582 vom 07.12.2011.

Eysenck, H. (1967). Personality Patterns in Various Groups of Businessmen. Occup. PsychoL.(41), pp. 249-250.

Fachinger, U., \& Oelschläger, A. (2008). Selbständige und ihre Altersvorsorge : sozialpolitischer Handlungsbedarf? Retrieved 03 13, 2018, from edoc.vifapol: http://edoc.vifapol.de/opus/volltexte/2008/450/

Feingold, A. (1994). Gender differences in personality - a metaanalysis. Psychological Bulletin(116), pp. 429-456.

Filstead, W. J. (1979). Qualitative methods: A needed perspective in evaluation research. In R. C. T. D. Cook, Qualitative and quantitative methods in evaluation research (pp. 33-48). Beverly Hills: Sage.

Fleege-Althoff, F. (1930). Die notleidende Unternehmung: Krankheitserscheinungen und Krankheitsursachen. Stuttgart.

Flick, U. (2007). Zur Qualität qualitativer Forschung - Diskurse und Ansätze. In U. Kuckartz, H. Grunenberg, \& T. Dresing, Qualitative Datenanalyse: computergestützt. Methodische Hintergründe und Beispiele aus der Forschungspraxis (2 ed., pp. 188-209). Wiesbaden: VS Verlag für Sozialwissenschaften | GWV Fachverlage GmbH.

Fraude, S. (2015). Die Persönlichkeit einer Führungskraft als relevanter Einflussfaktor auf den transformationalen bzw. transaktionalen Führungsstil Mythos oder Realität der Führungspersönlichkeit? St. Gallen: University of St. Gallen.

Frenken, K., van Oort, F., \& Verburg, T. (2007). Related Variety, Unrelated Variety and Regional Economic Growth. Regional Studies, 41(5), pp. 685-697.

Friedmann, H. S. (2004). Persönlichkeitspsychologie und Differentielle Psychologie. München: Pearson Studium.

Frischer, J., \& Larsson, K. (2000). Laissez-faire in research education-An inquiry into a Swedish doctoral program. Higher Education Policy(13), pp. 131-155.

Froschauer, U., \& Lueger, M. (2003). Das qualitative Interview: Zur Praxis interpretativer Analyse sozialer Systeme. Wien: Facultas Verlags- und Buchhandels AG.

Früh, W. (2004). Inhaltsanalyse. Theorie und Praxis (5th ed.). Konstanz: UVK.

Fuckup-Nights. (2015). https://fuckupnights.com/. Retrieved 03 15, 2018, from https://fuckupnights.com/

Garfinkel, H. (1967). Studies in Ethnomethodology. Englewood Cliffs, NJ: PrenticeHalls. 
Gloucestershire, U. o. (2008). Research Ethics: A Handbook of Principles and Procedures. Gloucestershire: University of Gloucestershire.

Gloucestershire, U. o. (2012). Doctorate in Business Administration (DBA). Retrieved from http://www.glos.ac.uk/courses/research/dba/Pages/default.aspx

GmbHG. (2017). Gesetz betreffend die Gesellschaften mit beschränkter Haftung; Gesetz vom 20.04.1892 (RGBl. I S. 477) zuletzt geändert durch Gesetz vom 17.07.2017 (BGBl. I S. 2446) m.W.v. 22.07.2017.

Gösche, A. (1987). Woran scheitern Unternehmungen? (KienbaumUnternehmensgruppe, Ed.) Blick durch die Wirtschaft(204), p. 7 ff.

Gosling, S. D. (2003). A very brief measure of the Big-Five personality domains. Journal of Research in Personality(37), pp. 504-528.

Green, B. N. (2006). Writing Narrative Literature Reviews for Peer-reviewed Journals: Secrets of the Trade. Journal of Chiropractic Medicine, Number 3, Volume 5, pp. 101-117.

Guba, E. G. (1994). Competing paradigms in qualitative research. In L. Y. N. K. Denzin, Handbook of qualitative research (pp. 105-117). California: Sage Publications Inc.

Hahn, G. (1958). Ursachen von Unternehmensmisserfolgen. Ergebnisse von Untersuchungen besonders im rheinischen Industriebezirk. Köln.

Häring, M. (2010). Scheitern per Gesetz: Probleme und Perspektiven am Beispiel des Insolvenzrechts. In P. D. Pechlaner, Scheitern: Die Schattenseite unternehmerischen Handelns (pp. 107- 121). Berlin: Erich Schmidt Verlag.

Harré, R. (1970). The Principles of Scientific Thinking. Oxford University Press.

Hauschildt, J., Grape, C., \& Schindler, M. (2005). Typologien von Unternehmenskrisen im Wandel, Manuskripte aus den Instituten für Betriebswirtschaftslehre der Universität Kiel, No. 588.

Hegmann, G. (2018, 01 24). Die Air-Berlin-Pleite wird teuer für den Bund. Retrieved 03 28, 2018, from Welt: https://www.welt.de/wirtschaft/article172825520/AirBerlin-Pleite-Fuer-Glaeubiger-der-Airline-bleibt-kein-Geld-uebrig.html

Heron, J. (1996). Co-operative Inquiry: Research into the Human Condition. . London: Sage Publications Limited.

Herrmann, T. (1991). Lehrbuch der empirischen Persönlichkeitsforschung. Göttingen: Hogrefe.

Hillebrand, C. (2015). Die Rechnungslegung in der Insolvenz. Hagen: Hagener Wissenschaftsverlag.

Hilmer, H.-J. (2006). Managementfehler als Insolvenzgründe. Krisen-, Sanierungsund Insolvenzberatung(6), pp. 233-234.

Hinterhuber, H. (2010). Persönlichkeiten an der Spitze sind entscheidend für den Erfolg oder Misserfolg des Unternehmens. In P. D. Pechlaner, Scheitern: Die Schattenseite unternehmenrischen Handelns (pp. 181 - 191). Berlin: Erich Schmidt Verlag.

Hinz, A. B. (2003). Urteilseffekte beim NEO-FFI. Diagnostica, 49(4), pp. 157-163.

Hobbs, M. (1984). Crisis intervention in theory and practice: A selective review. British Journal of Medical Psychology, 57, pp. 23-34.

Hollstein, M., \& v. Borste, S. (2011, 09 27). Welt. (A. S. SE, Editor) Retrieved 03 08, 2018, from Alte werden aus der Arbeitslosenstatistik getrickst: https://www.welt.de/politik/deutschland/article13627109/Alte-werden-aus-derArbeitslosenstatistik-getrickst.html 
Hornaday, J. A., \& Aboud, J. (1971). Characteristics of successful Entrepreneurs. Personnel Psychology(24), pp. 141-153.

Horstkotte, H. (2009). Moral für künftige Manager: Ethik findet in den Wirtschaftswissenschaften immer mehr Beachtung. Letter DAAD, 29(3), pp. 20-21.

Hotchkiss, E. S. (1995). Post-bancruptcy Performance and Management-Turnover. Journal of Finance(50), pp. 3-21.

Houtkooper, J. M. (2001). Do subjects answer reliably? A comparison of different measures of unreliable questionnaire reponse behaviour. In B. B. Seiwald, 6 . Arbeitstagung der Fachgruppe für Differentielle Psychologie,

Persönlichkeitspsychologie und Psychologische Diagnostik der Deutschen Gesellschaft für Psychologie (pp. 74-75). Leipzig: Leipziger Universitätsverlag $\mathrm{GmbH}$.

Hungenberg, H., \& Wulf, T. (2004). Grundlagen der Unternehmensführung. Heidelberg: Springer-Verlag.

II, S. (2019). Zweites Sozialgesetzbuch: Grundsicherung für Arbeitsuchende: Art. 1 vom 24.12.2003 (BGBl. I S. 2954), in Kraft getreten am 01.01.2004 bzw. 01.01.2005 zuletzt geändert durch Gesetz vom 18.12.2018 (BGBl. I S. 2651) m.W.v. 01.01.2019.

Imgrund, M. (2009). Der Unternehmer in der Insolvenz - Eine empirische Analyse des Fortführungs- und Sanierungsprozesses insolventer Klein- und Mittelunternehmen. Zeitschrift für KMU und Entrepreneurship, 57. Jahrgang(3-4), pp. 159-185.

InsO. (2018). Insolvenzordnung; Gesetz vom 05.10.1994 (BGBl. I S. 2866), in Kraft getreten am 19.10.1994 bzw. 01.01.1999; zuletzt geändert durch Gesetz vom 23.06.2017 (BGBl. I S. 1693) m.W.v. 03.01.2018.

Jacobs, J. (1969). The Economy of Cities. New York: Random House Inc.

Jäger, R. S. (2013). Pädagogisch-psychologische Diagnostik. In A. L. Frey, Handbuch Berufspädagogischer Diagnostik (pp. 137-165). Weinheim: Beltz Verlag.

James, W. (1981). The principles of psychology (Vol. 1). Cambridge, MA: Harvard University Press. (Original work published 1890).

Kanning, U. P. (2002). Grundlagen psychologischer Diagnostik. In U. P. Kanning, Handbuch personaldiagnostischer Instrumente (pp. 47-92). Göttingen: Hogrefe Verlag.

Karkowski, B. (2012, 07 04). Amoralische Banker. (F. B.-D. F.A.Z.-Fachverlag, Editor) Retrieved 01 30, 2018, from https://www.marktundmittelstand.de: https://www.marktundmittelstand.de/finanzierung/amoralische-banker1096721/

Kast, V. (1987). Der schöpferische Sprung. Olten: Walter.

Keiser, H. (1966). Betriebswirtschaftliche Analyse von Insolvenzen bei mittelständischen Einzelhandlungen. Köln/ Opladen.

Kelloway, E. K., Sivanathan, N., Francis, L., \& Barling, J. (2005). Poor leadership. In J. J. Barling, E. K. Kelloway, \& M. R. Frone, Handbook of work stress. Thousand Oaks: Sage.

Kets de Vries, M. \&. (1984). The neurotic organization. San Francisco: Jossey-Boss.

Kets de Vries, M. F. (1985, November-December). The dark side of entrepreneurship. Harvard Business Review, pp. 160-167.

Kets de Vries, M. F. (1996). The Anatomy of the Entrepreneur: Clinical Observations. Human Relations(49, No. 7), pp. 853-833. 
KfW-Research. (2017). KfW-Mittelstandspanel 2017. Frankfurt: KfW Bankengruppe.

KfW-Research. (2017). Mittelstand ist der Motor der deutschen Wirtschaft. Retrieved 03 28, 2018, from KfW Research: https://www.kfw.de/KfW-Konzern/KfWResearch/Mittelstand.html

Kiefl, W. (1998). Durchhalten oder Aufgeben? Gründe erzwungener Betriebsschließungen und Überlegungen zur Schadensbegrenzung. Internationales Gewerbearchiv, 46(3), pp. 193-205.

Kleiter, E. F. (2005). Weiterentwicklungen zur Persönlichkeitspsychologie: Eine empirische Untersuchung zu globalen Basispersönlichkeits- und speziellen Sozialpersönlichkeitseigenschaften mit Regulationssystem und Fragebogentests zur Selbst- und Fremdtestung. Lengerich: Pabst Science Publishers.

Knoblauch, H. (2011). Transkription. In R. Bohnsack, W. Marotzki, \& M. Meuser, Hauptbegriffe qualitativer Sozialforschung (3 ed., pp. 159-160). Opladen \& Farmington Hills, MI: Verlag Barbara Budrich.

Koark, A. (2012). Back to Start: Insolvent and Nevertheless Successful. J Consum Policy(35), pp. 509-512.

Koenen, J. (2017, 12 17). Insolvenz von Air Berlin: Niedergang vor laufender Kamera. Retrieved 03 28, 2018, from Handelsblatt: http://www.handelsblatt.com/unternehmen/handel-konsumgueter/insolvenzvon-air-berlin-niedergang-vor-laufender-kamera/20696436.html

Koller, E. (2017). Moralisches Fehlverhalten wider besseres Wissen? Zum Ruf nach einem Berufsethos für Banker/innen. In M. Stüttgen, Ethik von Banken und FInanzen (pp. 335-353). Baden-Baden: Nomos Verlagsgesellschaft.

Korunka, C., Kessler, A., Frank, H., \& Lueger, M. (2010). Personal characteristics, resources, and environment as predictors of business survival. Journal of Occupational and Organizational Psychology(83), pp. 1025-1051.

Kraus, A., \& Ghendler, V. (2017). Kraus Ghendler Anwaltskanzlei. Retrieved 03 13, 2018, from Vor- und Nachteile der englischen Insolvenz: https://anwalt$\mathrm{kg}$.de/privatinsolvenz-recht/englische-insolvenz/vorteile-der-englischeninsolvenz/

Kraus, S., Schlepphorst, S., \& Tyshkun, T. E. (2012). Krisen- und TurnaroundManagement in KMU: Ergebnisse einer qualitativ-empirischen Untersuchung. In C. Marxt, S. Kraus, \& D. Müller, Entrepreneural Management (pp. 79-89). Stuttgart: ibidem-Verlag.

Krüger, D. S. (2014). Leasing in Krise und Insolvenz des Leasingnehmers. Köln: RWS Verlag Kommunikationsforum $\mathrm{GmbH}$.

Krystek, U. (1987). Unternehmungskrisen: Beschreibung, Vermeidung und Bewältigung überlebenskritischer Prozesse in Unternehmungen. Wiesbaden: Gabler Verlag.

Kuckartz, U. (2016). Qualitative Inhaltsanalyse. Methoden, Praxis, Computerunterstützung (3rd ed.). Weinheim: Beltz Juventa.

Küsters, I. (2009). Narrative Interviews: Grundlagen und Anwendungen (2 ed.). Wiesbaden: VS Verlag für Sozalwissenschaften | GWV Fachverlage GmbH.

Kvale, S. (1995). The Social Construction of Validity. Qualitative Inquiry(1), pp. 1940.

Kvale, S. (1996). Interviews: An Introduction to Qualitative Research Interviewing. London: Sage. 
Larisch, M. e. (2003). Berufliche Gratifikationskrisen und depressie Symptome. Eine Querschnittsstudie bei Erwerbstätigen im mittleren Erwachsenenalter. Psychoter Psychosom Med Psychol(53), pp. 223-228.

Laux, L. (2008). Persönlichkeitspsychologie. Stuttgart: W. Kohlhammer GmbH.

Lee, S.-H., Peng, M. W., \& Song, S. (2013). Governments, entrepreneurs, and positive externalities: A real options perspective. European Management Journal, 31, pp. 333- 347.

Levenstein, S. P. (2000, May 1). Stress and exacerbation in ulcerative colitis: a prospective study of patients enrolled in remission. American Journal of Gastroenterology, 95, pp. 1213-1220.

Lienert, G. R. (1998). Testaufbau und Testanalyse. Weinheim: Beltz.

Lincoln, Y. S., \& Guba, E. G. (1985). Naturalistic Inquiry. Thousand Oaks: Sage.

Lin-Hi, N. (2017). Gabler Wirtschaftslexikon, Stichwort: Armut. (S. G. Verlag, Editor) Retrieved 03 01, 2008, from http://wirtschaftslexikon.gabler.de/Archiv/382/armut-v13.html

Lin-Hi, N. (2017). Gabler Wirtschaftslexikon, Stichwort: Deutscher Corporate Governance Kodex. (S. G. Verlag, Editor) Retrieved 02 01, 2018, from http://wirtschaftslexikon.gabler.de/Archiv/18161/deutscher-corporategovernance-kodex-v8.html

Linz, J. J. (1978). The breakdown of democratic regimes: Crisis, breakdown and reequilibration. Baltimore: Johns Hopkins University Press.

Lohff, A. W. (2008). Adalloc(TM) - adaptive Skalierung für Online-Fragebögen. In W. S. Sarges, Innovative Ansätze für die Eignungsdiagnosik (pp. 237-251). Göttingen: Hogrefe.

Lohff, A., \& Wehrmaker, M. (2008). Adalloc - adaptive Skalierung für OnlineFragebögen. In W. S. Sarges, Innovative Ansätze für die Eignungsdiagnostik (pp. 239-251). Göttingen: Hogrefe Verlag.

Lüders, C. (2004). Herausforderungen qualitativer Forschung. In U. Flick, K. E. v., \& I. Steinke, Qualitative Forschung. Ein Handbuch. (pp. 632-642). Reinbeck: Rowohlt.

Lüders, C. (2011). Gütekriterien. In R. Bohnsack, W. Marotzki, \& M. Meuser, Hauptbegriffe Qualitativer Sozialforschung (3 ed., pp. 80-83). Opladen \& Farmington Hills, MI: Verlag Barbara Budrich.

Lynn, R. (1969). Personality Characteristics of a Group of Entrepreneurs. Occupational Psychology(43), pp. 151-152.

Maroto, M. (2012). The Scarring Effects of Bankruptcy: Cumulative Disadvantage Across Credit and Labor Markets. (O. U. Press, Ed.) Social Forces, 91(1), pp. 99-130.

Marshall, A. (1920). The Principles of Economics. London: McMillan.

Martens, J. -U. (2016). Das Geheimnis seelischer Kraft. Wie Sie durch Resilienz Schicksalsschläge und Krisen überwinden. Stuttgart: Verlag W. Kohlhammer.

Maslow, A. H. (1987). Motivation and personality (3rd ed.). New York: Harper and Row.

Mayring, P. (2002). Einführung in die qualitative Sozialforschung. Eine Anleitung zum qualitativen Denken (5 ed.). Weinheim und Basel: Beltz Verlag.

McAdams, D. P. (2006). The Person: A new introduction to Personality Psychology. New York: John Wiley \& Sons.

McCrae, R. R., \& Costa, P. T. (2004). A contemplated revision of the NEO FiveFactor Inventory. Personality and Individual Differences(36), pp. 587-596. 
McCrae, R. R., Costa, P. T., de Lima, M. P., Simoes, A., Ostendorf, F., \& Angleitner, A. (1999). Age differences in personality across the adult life span: Parallels in five cultures. Developmental Psychology, 35, pp. 466-477.

McEvoy, P. R. (2003). Critical realism: a way forward for evaluation research in nursing? Journal of Advanced Nursing 43(4), pp. 411-420.

Mehl, M. R. (2006). Personality in its natural habitat: Manifestations and implicit folk theoriesof personality in daily life. Journal of Personality and Social Psychology(90), pp. 862-877.

Mezirow, J. (1990). Fostering Critical Reflection in Adulthood. San Francisco: JosseyBass.

Mielke, J., \& Matern, M. (2013, 07 12). Insolvenz der Baumarktkette: Warum Praktiker vor der Pleite steht. Retrieved 03 28, 2018, from Der Tagesspiegel: https://www.tagesspiegel.de/wirtschaft/insolvenz-der-baumarktkette-warumpraktiker-vor-der-pleite-steht/8485512.html

Moon, J. (2001). PDP Working Paper 4: Reflection in Higher Education Learning. LTSN Generic Centre.

Morgeson, F. P. (2007). Rconsidering the use of personality tests in personnel selection contexts. Personnel Psychology, 60, pp. 683-729.

Moser, G. (2005). Bedeutung von Stress und Depression bei chronisch entzündlichen Darmerkrankungen. Journal für Gastroenterologische und Hepatologische Erkrankungen, 3(2), pp. 26-30.

Mullen, P. D. (2006). The Promise and Pitfalls of Systematic Reviews. Annual Reviews Public Health(27), pp. 81-102.

Mulrow, C. D. (1994, September 3). Systematic Reviews: Rationale for Systematic Reviews. BMJ British Medical Journal(309), pp. 597-599.

Neß, H. (2013). Der Zusammenhang zwischen der Insolvenz von Unternehmern und ihren Persönlichkeitseigenschaften - eine empirische Untersuchung. Bielefeld: Dissertation zur Erlangung des Grades Dr. rer. pol. der Fakultät für Wirtschaftswissenschaften der Universität Bielefed.

Nohl, A. M. (2017). Interview und Dokumentarische Methode: Anleitungen für die Forschungspraxis (5 ed.). Heidelberg: Springer.

O'Donnell, G. A. (1973). Modernization and bureaucratic-authoritharianism. Berkeley: University of California, Institute of International Studies.

Ooghe, H. D. (2004). Conceptual Failure Model. Economisch en Sociaal Tijdschrift, 57(4), pp. 367-393.

Ostendorf, F. \&. (2004). NEO-PI-R; NEO Persönlichkeitsinventar, revidierte Form. Göttingen: Hogrefe.

Palmer, B., Walls, M., Burgess, Z., \& Stough, C. (2001). Emotional intelligence and effective leadership. Leadership \& Organization Development Journal(22/ 1), pp. 5-10.

Park, K. (2004). To File or Not to File: The Causes of Municipal Bankruptcy in the United States. Journal of Public Budgeting, Accounting and Financial Management, 16(2), pp. 228-256.

Pauls, C. \&. (2005). Effects of different instructional sets on the construct validity of the NEO-PI-R. Personality and Individual differences(39), pp. 297-308.

Paulus, C. G. (2017). Insolvenzrecht. München: Verlag C. H. Beck.

Paunonen, S. V. (2000). What Is Beyond The Big Five? Plenty! Jounal of Personality,(68(5)), pp. 821-835. 
Pechlaner, H. (2010). Scheitern - eine prozessuale Betrachtung. In P. D. Pechlaner, Scheitern: Die Schattenseite unternehmerischen Handlens (pp. 207 - 222). Berlin: Erich Schmidt Verlag.

Pechlaner, H., Stechhammer, B., \& Hinterhuber, H. H. (2010). Scheitern: Die Schattenseite unternehmerischen Handelns. Berlin: Erich Schmidt Verlag.

Podbregar, N. (2014, 11 19). Bild der Wissenschaft. Retrieved 01 30, 2018, from Banker auf dem Prüfstand: http://www.wissenschaft.de/kultur-gesellschaft//journal_content/56/12054/5038764/Banker-auf-dem-Pr\%C3\%BCfstand/

Praeg, C.-P. (2017). Bank \& Zukunft: Geschäftsmodellinnovationen für die Bank der Zukunft. In W. Ronzal, \& A. Schmoll, Bank 2025: Digital meets stationär (pp. 17-30). Wien: MANZ'sche Verlags- und Universitätsbuchhandlung GmbH.

Prager, S., \& Hlous, N. (2006). Psychosoziale Krisen in Unternehmen. Wien: Facultas Universitätsverlag.

Pytlik Zillig, L. M. (2002). What do we assess when we assess a Big 5 trait? A content analysis of the affective, behavioral, and cognitive porcesses represented in Big 5 personality inventories. Personality and Social Psychology Bulletin(28), $847-858$.

Queiser. (2015). Wohnungseigentum in der Insolvenz. Die Verwaltung und Verwertung des Wohnungseigentums in der Insolvenz des Wohnungseigentümers. Hamburg: Verlag Dr. Kovac GmbH.

Rädiker, S., \& Stefer, C. (2007). Qualitative Evaluation - Versuch einer Abkürzungsstrategie. In U. Kuckartz, H. Grunenberg, \& T. Dresing, Qualitative Datenanalyse: computergestützt. Methodische Hintergründe und Beispiele aus der Forschungspraxis (2 ed., pp. 78-92). Wiesbaden: VS Verlag für Sozialwissenschaften | GWV Fachverlage GmbH.

Rammsayer, T. W. (2016). Differentielle Psychologie - Persönlichkeitstheorien. Göttingen: Hogrefe Verlag.

Ramsey, S. D., Bansal, A. F., Blough, D. K., Overstreet, K. A., Shankaran, V., \& Newcomb, P. (2016, March 20). Financial Insolvency as a Risk Factor for Early Mortality Among Patients With Cancer. Journal of Clinical Oncology, 34(9), pp. 980-988.

Reinecker. (1995). Fallbuch der klinischen Psychologie. Modelle klinischer Störungen. Göttingen: Hogrefe.

Richter, P. (2006). Occupational Health Psychology. In H. H. Wittchen, Klinische Psychologie und Psychotherapie (pp. 311-330). Berlin: Springer.

Ringelspacher, E. (2012). Unternehmensrestrukturierung aus Sicht der Fremdkapitalgeber: Banken. In M. e. Baur, Stakeholder Management in der Restrukturierung, Perspektiven und Handlungsfelder in der Praxis (pp. 64-80). Wiesbaden : Gabler Verlag | Springer Fachmedien .

Rinklin, T. H. (1960). Die vergleichsfähige und die konkursreife Unternehmung. Versuch einer Typologie notleidender Unternehmungen. Stuttgart.

Roberts, B. W. (2006). Patterns of mean-level change in personality traits across the life course: A meta-analysis of longitudinal studies. Psychological Bulletin, 132, pp. 1-25.

Roberts, B. W., Wood, D., \& Caspi, A. (2008). The Development of Personality Traits in Adulthood. In O. P. John, Handbook of Personality (3rd ed. ed., pp. 375398). New York: The Guilford Press.

Robson, C. (2002). Real World Research (2nd ed.). Oxford: Blackwell Publishing. 
Røed, K. S. (2014). Job Loss and Entrepreneurship. Oxford Bulletin of Economics and Statistics ), 76(5), pp. 727-744.

Rogers, C. R. (1959). A theory of therapy, personality and interpersonal relationships as developed in the client-centered framework. In S. Koch, Psychology: A study of a science (pp. Vol. 3, pp. 184-256). New York: McGraw-Hill.

Rogers, C. R. (1969). On becoming a person. Boston: Houghton Mifflin.

Rohrhirsch, F. (2010). Philosophische Fragen zum Scheitern - Konsequenzen für die Führung. In P. D. Pechlaner, Scheitern: ie Schattenseite unternehmerischen Handelns (pp. 123-136). Berlin: Erich Schmidt Verlag.

Röthing, P. (1976). Organisation und Krisenmanagement. Zeitschrift für Organisation, 45. Jg., pp. 13-20.

Salovey, P., \& Mayer, J. (1990). Emotional intelligence. Imagination, Cognition and Personality(9), pp. 185-211.

Salovey, P., Mayer, J., Goldman, S., Turvey, C., \& Palfai, T. (1995). Emotional attention, clarity, and repair: exploring emotional intelligence using the Trait Meta-Mood Scale. In J. W. Pennebacker, Emotion, Disclosure and Health (pp. 125-154). Washington, DC: American Psychological Association.

Sambrook, S. S. (2008). Developing critical reflection in professional focused doctorates: a facilitator's perspective. Journal of European Industrial Training, pp. 359-373.

Sarges, W. W. (2001). Handbuch wirtschaftspsychologischer Testverfahren. Lengerich: Pabst Science Publishers.

Satow, L. (2011). Psychomeda Big-Five-Persönlichkeitstest (B5T): Skalendokumentation und Normen. .

Saunders, M. L. (2009). Research methods for business students. Essex: Pearson Education Limited.

Sayer, A. (2000). Realism and Social Science. London: Sage Publications.

Schaefers, K. (2017). Anlageberater und Anlageberatung. Eine investmentethische Untersuchung. In M. Stüttgen, Ethik von Banken und Finanzen (pp. 205-232). Baden-Baden: Nomos Verlagsgesellschaft.

Schmähl, W. F. (1999). XIII Armut und Reichtum. Einkommen und Konsumverhalten älterer Menschen. In A. N. Niederfranke, Funkkolleg Altern 2. Lebenslage und Lebenswelten, soziale Sicherung und Altenpolitik (pp. 159-208). Opladen: Westdeutscher.

Schumpeter, J. (1987). Theorie der wirtschaftlichen Entwicklung (7 ed.). Berlin: Duncker und Humblot.

Schütze, F. (1978). Die Technik des narrativen Interviews in Interaktionsfeldstudiendargestellt an einem Projekt zur Erforschung von kommunalen Machtstrukturen. Bielefeld: Fakultät für Soziologie der Universität Bielefeld.

Schütze, F. (1983). Biographieforschung und narratives Interview. Neue Praxis, 3(13), pp. 283-293.

Scott, J. (1990). A Matter of Record. Cambridge: Polity.

Seale, C. (1999). The Quality of Qualitative Research. Thousand Oaks, CA: Sage Publications.

Seckler, C. F. (2017). Learning from Entrepreneural Failure: Integrating Emotional, Motivational and Cognitive Factors. In J. E. Ellingson, Autonomous Learning in the Workplace (pp. 54-77). New York: Routledge. 
Shepherd, D. (2004). Educating entrepreneurship students about emotion and learning from failure. Academy of Management Learning \& Education, 3(3), pp. 274287.

Simmel, G. (1968). Soziologie. Berlin: Humboldt.

Skogstad, A., SEinrsen, S., Torsheim, T., Schanke Aasland, M., \& Hetland, H. (2007). The Destructiveness of Laissez-Faire Leadership Behavior. Journal of Occupational Health Psychology, 12(1), pp. 80-92.

Smith, L. T. (1999). Decolonizing methodologies: Research and indigenous peoples. . Dunedin, New Zealand: Univerity of Otago Press.

Stahmer, I. (1995). Das Spannungsfeld zwischen "ernster Gefahr" und "günstiger Gelegenheit" - für eine Politik der Vernunft und des Pragmatismus. In K. G. Götz, Krise! Welche Krise? Herausforderungen für Menschen und Organisationen (pp. 103-114). Würzburg: Ergon Verlag.

Stechhammer, B. (2010). Unternehmen brauchen eine Kultur des Scheiterns. In P. D. Pechlaner, Scheitern: Die Schattenseite unternehmerischen Handelns (pp. 193 - 206). Berlin: Erich Schmidt Verlag.

Steinke, I. (1999). Kriterien qualitativer Forschung. Ansätze zur Bewertung qualitativempirischer Sozialforschung. Weinheim \& München: Juventa Verlag.

Steinke, I. (2007). Qualitätssicherung in der qualitativen Forschung. In U. Kuckartz, H. Grunenberg, \& T. Dresing, Qualitative Datenanalyse: computergestützt. Methodische Hintergründe und Beispiele aus der Forschungspraxis (2 ed., pp. 176-187). Wiesbaden: VS Verlag für Sozialwissenschaften | GWV Fachverlage $\mathrm{GmbH}$.

Stemmler, H. A. (2016). Differentielle Psychologie und Persönlichkeitsforschung. Stuttgart: W. Kohlhammer GmbH.

StGB. (2018). Strafgesetzbuch; In der Fassung der Bekanntmachung vom 13.11.1998 (BGBl. I S. 3322) zuletzt geändert durch Gesetz vom 18.12.2018 (BGBl. I S. 2639) m.W.v. 22.12.2018.

Strauss, A. (1998). Basics of Qualitative Research: Techniques and Procedures for Developing Grounded Theory. Thousand Oaks, Caifornia: Sage.

Strauss, A., \& Corbin, J. (2008). Basics of Qualitative Research (3 ed.). Thousand Oaks, CA: Sage.

Stüttgen, M. (2017). Ethik der Banken? Herausforderungen und Perspektiven. In M. Stüttgen, Ethik von Banken und Finanzen (pp. 15-42). Baden-Baden: Nomos Verlagsgesellschaft.

Suddaby, R. (2006). From the editors: what grounded theory is not. Academy of Management Journal(49(4)), pp. 633-642.

Tavassoli, S., \& Jienwatcharamongkhol, V. (2016). Survival of entrepreneurial firms: the role of agglomeration externalities. Entrepreneurship \& Regional Development, 28(9-10), pp. 746-767.

Themoshok, L. (1998). HIV and AIDS. In H. S. Friedmann, Encyclopedia of mental health (pp. Vol. 2, 375-392). San Diego, CA: Academic Press.

Thiele, J. (2018). Insolenz in Frankreich. Retrieved 03 13, 2018, from CoCo Europe: http://www.insolvenzinfrankreich.de/impressum.html

Tranfield, D. S. (1998). The Nature, Social Organization and Promotion of Management Research: Towards Policy. British Journal of Management(9), pp. 341-353. 
Tranfield, D., Denyer, D., \& Smart, P. (2003). Towards a Methodology for Developing Evidence-Informed Management Knowledge by Means of Systematic Review. British Journal of Management(Vol. 14), pp. 207-222.

Tschuschke, V. (2006). Psychoonkologie: psychologische Aspekte der Entstehung und Bewältigung von Krebs. Stuttgart: Schattauer Verlag .

Tsutsumi, A. K. (2004). A review of empirical studies on the model of efford-rewardimbalance at work: reducing occupational stress by implementing a new theory. Social Science and Medicine(59), pp. 2335-2359.

Tyroller, M., \& Nienstedt, D. (2012). Unternehmensrestrukturierung aus Sicht der Fremdkapitalgeber: Einführung und Grundlagen. In m. e. Baur, Stakeholder Management in der Restrukturierung, Perspektiven und Handlungsfelder in der Praxis (pp. 61-64). Wiesbaden: Gabler Verlag | Springer Fachmedien .

Ulbricht, E. (2011, 08 12). akademie.de. Retrieved 03 13, 2018, from Pfändungsmöglichkeiten und Pfändungsschutz der Altersvorsorge von Schuldnern: https://www.akademie.de/wissen/pfaendungsschutzaltersvorsorge-schuldner

Ulich, D. (1987). Krise und Entwicklung: Zur Psychologie der seelischen Gesundheit. München: Psychologie-Verl.-Union.

Ulich, D. H. (1985). Psychologie der Krisenbewältigung. Eine längsschnittuntersuchung mit arbeitslosen Lehrern. Weinheim: Beltz.

van Kann, J. R. (2012, 04). Reform Act on German Insolvency Law: New Opportunities for Distressed Investors? Pratt's Journal of Bankruuptcy Law, pp. $436-442$.

Vidich, A. J. (2000). Qualitative methods: Their history in sociology and anthropology. In L. Y. N. K. Denzin, Handbook of qualitative research (2nd ed., pp. 37-84). Thousand Oaks: Sage.

Wagner-Menghin, M. R. (2008). Ein objektiver Persönlichkeitstest zur Erfassung von Impulsivität: Situationsabhängigkeit verhaltensbasierter Kennwerte. In W. S. Sarges, Innovative Ansätze für die Eignungsdiagnostik (pp. 175-185). Göttingen: Hogrefe.

Weerth, C., \& Mecke, I. (2017). Gabler Wirtschaftslexikon, Stichwort: Kooperation. Retrieved 01 30, 2018, from http://wirtschaftslexikon.gabler.de: http://wirtschaftslexikon.gabler.de/Archiv/7992/kooperation-v12.html

Weig, W. (2009). Arbeit und seelische Gesundheit. In M. W. Linden, Salutotherapie in Prävention und Rehabilitation (pp. 209-214). Köln: Deutscher Ärzte-Verlag.

Welter-Enderlin, R. (2010). Resilienz und Krisenkompetenz. Kommentierte Fallgeschichten. Heidelberg: Carl-Auer Verlag.

Wendtner, C. -M. (2013). Chemotherapie-freie Behandlung der chronischen lymphatischen Leukämie? DMW Deutsche Medizinische Wochenschrift, 41, pp. 2104-2106.

Wenzler-Cremer, H. (2007). Der Forschungsprozess am Beispiel einer qualitativen Studie zur bikulturellen Sozialisation. In U. Kuckartz, H. Grunenberg, \& T. Dresing, Qualitative Datenanalyse: computergestützt. Methodische Hintergründe und Beispiele aus der Forschungspraxis (2 ed., pp. 66-77). Wiesbaden: VS Verlag für Sozialwissenschaften | GWV Fachverlage GmbH.

Westhoff, K. (2004). Methoden zur Operationalisierung von Eignungsmerkmalen. In K. H. Westhoff, Grundwissen für die berufsbezogene Eignungsbeurteilung nach DIN 33430 (pp. 89-103). Lengerich: Pabst Science Publishers. 
Whetten, D. A. (1987). Organizational growth and decline processes. Annual Review of Sociology(13), pp. 355-358.

Yarbrough Landry, A. (2009, July/ August). Factors Associated with Hospital Bankruptcies: A Political and Economic Framework. Journal of Healthcare Management, 54(4), pp. 252-272.

Ziegler, B. (2002). NEO-Fünf-Faktoren-Inventar (NEO-FFI). In U. P. Kanning, Handbuch personaldiagnostischer Instrumente (pp. 386-391). Göttingen: Hogrefe Verlag.

ZPO. (2019). Zivilprozessordnung in der Fassung der Bekanntmachung vom 05.12.2005 (BGBl. I S. 3202, ber. 2006 S. 431, 2007 S. 1781) zuletzt geändert durch Gesetz vom 31.01.2019 (BGBl. I S. 54) m.W.v. 16.02.2019. 
Appendix I: Further Information about Approach and Quality of the NEO-FFI

The first tests concerning the dimensions neuroticism and extroversion were developed by Eysenck. Meanwhile, comprehensive research led to the establishment of five factors. (Satow, 2011) The development of these five categories was based on the thought that all personality traits have their counterpart in our language. Following this idea the starting point was to collect as many adjectives for the evaluation of the personality as possible. Those adjectives then were structured and categorised.

Especially Cattell (1945) is to mention here, who worked on the lists of Allport and Odbert (1936) using factor analytical methods to find the main dimensions of the personality. His findings were used and succeeded by different personality psychologists (Rammsayer, 2016).

This "lexical approach (...) has proven to be the most fruitful guide to a comprehensive model of personality." as in these analyses based on trait terms the socalled big five were discovered the first time (Costa \& McCrae, 1995, p. 23).

They became obvious as basic dimensions of individual personality differences. Later studies showed replicability and confirmed the five robust factors (Ziegler, 2002). The so called "Big Five" could be found persuasively consistent in diverse samples and even in different cultures and language groups (Paunonen, 2000).

Quality of Quantitative Research

The quality of quantitative research or measuring instruments commonly is evaluated with the following three criteria: reliability, validity and objectivity (Kanning, 2002). Reliability includes the dimensions accuracy and consistency (Friedmann, 2004). Kanning (2002) depicts that with the example of the scales at the butcher's. We expect it to measure the weight of the meat exactly. One kilogramme has to be measured as one kilogramme and not as 0.8 or $1.2 \mathrm{~kg}$. And we also expect the scales not to make any difference between beef and pork. One kilogramme beef has to be measured the same way as one kilogramme pork (Kanning, 2002).

The question of validity is if a method really measures what it is supposed to measure. Within this field there are several factors that can probably distort the researched 
results, such as response tendencies and prepossessions for example (Friedmann, 2004).

Objectivity here means the independence from the researcher in procedure, evaluation and interpretation (Laux, 2008).

\section{Reliability of the NEO-FFI}

There is no measuring of human personality traits and behaviours that is one hundred percent reliable, as there can always occur faults because of the research situation or the people involved (Kanning, 2002). Because of that the criterion reliability is captured by the reliability coefficient. This numerical value says how reliable the measuring is from 0 to 1 . A test with a reliability coefficient of 1 would be perfectly reliable. Most commercially available tests, like the NEO-FFI, are between 0.7 and 0.9 what can be seen as satisfying and well applicable due to its reliability (Kanning, 2002).

The reliability of personality tests usually gets evaluated by the internal consistency reliability and the test-retest-reliabiliy (Friedmann, 2004).

The internal consistency reliability measures if subordinated or equivalent parts of a test lead to the same result. Friedmann recommends an internal consistency reliability of 80 per cent and more (Friedmann, 2004).

Borkenau \& Ostendorf (2008) conducted more than 50 studies about their NEO-FFI.

For the evaluation of the internal consistency they used 11.724 data sets. This led to an average internal consistency of the NEO-FFI of 0.80 . So the average internal consistency of the NEO-FFI is higher than the ones of comparable personality tests like the German Personality Research Form or the revised Freiburger Personality Inventory (Borkenau \& Ostendorf, 2008).

Ziegler (2002) also tested the internal consistency reliability of the NEO-FFI with a sample of 2112 participants. The results of her study support Borkenau's and Ostendorf's values (Ziegler, 2002).

The internal consistency can be seen as a function of the number of items and their level of correlation. For a personality traits inventory the researcher on the one hand 
needs enough questions to get a stable result. But on the other hand he/ she has to take care that the test does not take too long (Friedmann, 2004).

Studies about the breakups of tests showed that tests with a processing time of 50 minutes get cancelled by the participants significantly more often than tests that just need 17 minutes time (Lohff \& Wehrmaker, 2008).

The NEO-FFI, which is the shorter version of the NEO-PI-R, seems to be a reasonable agreement between a high internal consistency reliability and a good response rate with meaningful answers.

The second aspect of reliability is the consistency of the test in different situations. If a person is tested with a high value of conscientiousness for example, we expect this person to have similar results some time later. This stability during time is called testretest-reliability (Friedmann, 2004).

Borkenau and Ostendorf and Ostendorf (2008) confirm the high test-retest-reliability of their personality traits inventory by two studies. One with 146 participants after a time period of two years and one in the context of a longitudinal study on twins who were tested twice in five years. Both tests showed "remarkable stability over several years“ (Borkenau \& Ostendorf, 2008, p. 18).

Ziegler also found a high test-retest-reliability of the NEO-FFI after the time period of two years. This indicates that the NEO-FFI captures the individual values of long-term structural personality traits and not spontaneous moods or situations (Ziegler, 2002). "When the internal consistency reliability and the test-retest-reliabilty are high, we know that we are measuring something real - we have a solid personality traits inventory.“ (Friedmann, 2004, p. 49)

\section{Validity of the NEO-FFI}

Within psychology validity is a highly considered topic. It tells us with what degree of accurateness a test really measures the personality trait it should measure (Lienert, 1998).

Several studies show a high construct validity of the NEO-PI-R. The validity was verified in comparison with other five factors inventories and important German and international personality tests (Sarges, 2001). 
Back, Schmukle and Egloff (2009) measured the big five with a traits inventory and compared the results with video tapes they took of the same participants. The videos showed the applicants in several situations and got evaluated by trained people using defined criteria. Especially in the domains Neuroticism and Extroversion the study showed a good forecast of behaviours on the base of the inventory results (Back, Schmukle \& Egloff 2009).

Another research showed similar results. There the participants wore a monitoring device for two days that recorded all acoustic signals like voices or ambient noise. The study showed a correlation between the domain extroversion and the frequency of talks as well as a correlation of the domain agreeableness and the frequency or conflicts. The more extrovert a person rated him-/herself, the more often he/ she was involved in conversations. And the more agreeable a person rated him-/herself, the less he/ she tended to dispute. The highest correlation was found between the domain conscientiousness and the participation in lectures as conscientious students spent more time in class than less conscientious students did (Mehl, 2006).

\section{Objectivity of the NEO-FFI}

A test is objective if its results are independent of the researcher who uses it (Lienert, 1998). According to Laux this includes all three steps, the procedure, the evaluation and the interpretation of the test (Laux, 2008).

Looking at the NEO-FFI we find high objectivity in procedure as long as the researcher follows the test instructions consequently. Borkenau and Ostendorf give instructions to the topics researcher, participants, test situation, test instruction and the behaviour of the researcher if the participants have questions (Borkenau \& Ostendorf, 2008).

As requirements for the successful use of the NEO-FFI the researcher has to be trained in test psychology, skilled in statistics and have knowledge in differential psychology (Borkenau \& Ostendorf, 2008).

The advisor of this research is Sonja Hutzler. She is psychologist with a university diploma working in the forensic psychiatry department of the teaching hospital in Würzburg, Germany. With a working experience of more than eight years she writes 
forensic psychiatric examinations and works as a lecturer at the university. In her lectures of master students in psychology and an interdisciplinary seminar test psychology is an essential topic. With her expertise she imparted the needed psychological knowledge to me as I am not a psychologist. I studied Business Administration at the universities of Nuremberg-Erlangen and Bamberg. Courses and tests in statistics were included in these studies.

Concerning the participants it is to consider that they have to write and speak the German language fluently and be able to deal with written/ printed material.

Furthermore, they need to have the motivation to answer the questions truly. These requirements are not specific for the NEO-FFI, but for those tests in general. For the NEO-FFI it is additionally important that it is developed for adult participants (Borkenau \& Ostendorf, 2008).

The participants of this study were adults, able to write and speak German fluently and had no problems with written material. As the participants made the contact to take part in this research, there occurred no problems that the participants would not have been willing to answer the given questions. Also, within the interviews that followed the NEO-FFI questionnaires there were no hints or suspicious facts that indicated that the participants might have had motivation to answer the questions not truly. Two of them even said, they see the personality traits inventory as an interesting tool for self reflection and asked me to send the results to them afterwards.

The advices concerning the test situation when more participants answer the inventory together at the same time are not part of this reflection as within this research every participant answered the inventory alone.

"The location should enable a processing uninterrupted by external influences." (Borkenau \& Ostendorf, 2008, p. 36)

Most of the participants were visited at home or in the office what was appreciated as the interviews as well as the personality questionnaires could get conducted in undisturbed and quiet atmosphere. Just two of the participants wanted to meet in a café. This was not an optimal location. To minimize disturbances a table somewhere in the back and not in the middle of the room was chosen. And the inventory was started after getting the drinks to avoid interruption by the waiter/ waitress. As some participants tend to start with the response of a questionnaire before reading the instructions thoroughly, it is important to take care that the participants get an 
instruction. To avoid negative influence on the comparability of the results it is recommended that the researcher reads the standard instruction out right before the beginning of the test (Borkenau \& Ostendorf, 2008). This was done as recommended in this study.

The manual points out that the researcher often gets questions concerning the test items as they are worded globally and seem to be ambivalent on the first sight sometimes. This was done because such globally worded questions are more valid that detailed ones. If we want to know about a participant's extraversion, we can ask him/ her if he/ she likes parties. This question should be more valid as asking him/ her about his/ her last party. Nevertheless, some participants tend to tell that they cannot answer such questions in general as the situation of the special party plays an important role (Borkenau \& Ostendorf, 2008).

To avoid negative influence on the comparability of the results such questions were answered as recommend that the questions of the NEO-FFI are worded that globally on purpose and that the participants should answer them in all conscience.

The evaluation of the NEO-FFI can be done by computer with testing and statistics software or by hand using the jig that is part of the test package (Borkenau \& Ostendorf, 2008). Due to the comparatively small group of participants it was no problem to evaluate the test results by hand with the test jig. The procedure is explained in detail in the manual. This procedure was followed strictly. The principles that were followed by the interpretation of the test results are explained in chapter 5.4.3 about the analysis of the NEO-FFI data. 
Appendix II: Transcript of Interview 1

I: Vielleicht beginnen wir damit, dass Sie einfach mal Ihren Werdegang beschreiben, beruflich wie privat, dass ich Sie ein bisschen kennenlerne.

B: Ja, fangen wir an beruflich. Ich hab studiert, bin Diplom-Kaufmann, so wie Sie auch, wie ich es verstanden hab. Nach dem Studium war ich zwei Jahre bei BoschSiemens, hab mich mit strategischer Planung beschäftigt und hab dann im Alter von 28 meinen / den Betrieb meines Vaters gepachtet, wenn Sie so wollen, übernommen. Das war ein Handwerksbetrieb mit 50 Mitarbeitern, der sich mit Maschinenbau, Stanzteilen, Werkzeugen beschäftigte. Diesen Betrieb hab ich dann ausgebaut, hab selber noch einen Betrieb dazu erworben. Und um das nicht allzu sehr jetzt auszudehnen, also ich hab im Laufe, sagen wir mal, von 20 Jahren, bis Ende der 90er Jahre eine Firma aufgebaut mit ausländischen Niederlassung in Tschechien, von / mit 700 Mitarbeitern. Hab die Firma dann erfolgreich verkauft und, ja, dann leider eine Fehlinvestition in Polen begangen. Hab das Geld, was ich aus diesem Verkauf dieser tschechischen Firma - und es gab noch eine verpachtete Firma in der Oberpfalz dieses Geld, was ich da eingenommen hab, investiert in Polen. Hab das dabei praktisch gänzlich verloren. Hinzu kam dann später - aber das überschneidet sich jetzt mit dem privaten Teil - im Rahmen meiner ersten Ehescheidung / im Rahmen der Scheidung meiner ersten Ehe / noch weitere finanzielle Verluste erlitten und letztendlich ein Steuerverfahren an den Hals bekommen, weil ich Geld von dem Verkauf in Tschechien, ohne es in Deutschland zu versteuern, in der Annahme, dass ich eigentlich tschechischer Steuerbürger wäre, nach Polen transferiert hab, und dieses Geld eben nach Ansicht des deutschen Fiskus dem Finanzamt schuldig geblieben bin. Musste ich eben Privatinsolvenz dann anmelden. Und das Finanzamt ist auch der whichtigste Gläubiger. Ohne, ohne diesen Gläubiger hätte es keine Privatinsolvenz gegeben. Privat, habe ich jetzt schon erwähnt, ich war / lebe zur zweiten Ehe. Die erste Ehe wurde 1975 geschlossen. Das war noch vor meinem ersten Semester, also kurz nach der Bundeswehr, weil mein Sohn unterwegs war. Ich habe zwei erwachsene Kinder mit 38 und 33 Jahren. Die erste Ehe wurde / also ich trennte mich 1997 von meiner, von meiner Exfrau. Und die Ehe wurde dann 2003 geschieden, beziehungsweise 2006 wurde erst - also nach neun Jahren Kampf - alles Wirtschaftliche untereinander 
bereinigt. Und dieses, dieses Drama hat mehr oder weniger mit in die zweite Ehe hineingewirkt, sowohl moralisch als auch finanziell, so dass es in der zweiten Ehe auch wieder am Wackeln ist, und meine zweite Frau zwar finanziell und wirtschaftlich noch zu mir hält, aber wir momentan getrennt leben. Also wir bilden eine wirtschaftliche Einheit, aber ob die Ehe hält, steht momentan eher in Frage. Hängt zum Teil mit den wirtschaftlichen Ergebnissen zusammen, mein ich mal, und zum, zum Teil natürlich auch mit, ach, Streitigkeiten, die es da gegeben hat mit meinen, meinen Kindern auch, weil die zur Exfrau gehalten haben zunächst und dann erst erkannt haben, dass sie falsch lagen und meine Frau, meine zweite Frau angefeindet haben etc. Das ist jetzt ganz grob umrissen die Situation, in der ich mich befinde. Die Privatinsolvenz ist jetzt im vierten Jahr. Also, ich geh mal davon aus, dass ich im zweiten Jahr / in zwei Jahren wieder / 2016 dann wieder ein freier Mensch bin, auch wirtschaftlich und freu mich darauf dann wieder frei handeln zu können.

\section{I: Was haben Sie dann vor?}

B: Ganz genau kann ich es nicht sagen. Wenn ich es so genau wüsste, würde ich es auch dann nicht sagen, aber ich würde sicherlich etwas Selbstständiges machen. Was anderes bleibt mir ja gar nicht übrig, weil ich hab mein ganzes Leben fast selbstständig gearbeitet, mit Ausnahme dieser zwei Jahre bei Bosch-Siemens nach dem Studium. Und abgesehen von meinem Alter, schon aufgrund dieses Lebenslaufs würde ich als Angestellter nirgendwo unterkommen. Außerdem ich bin 60 Jahre alt. Momentan unterstütze ich meinen Sohn. Der gibt mir dafür 400 Euro im Monat. Der ist auch selbstständig und macht erfolgreiche Geschäfte im Internethandel. Und vielleicht mache ich auf der Schiene weiter, oder ich weiß es noch nicht. Also, es müssen erst noch Gelegenheiten versucht werden und beziehungsweise gefunden werden. Versucht habe ich natürlich schon Einiges in der Zwischenzeit, aber es ist nicht so einfach und ohne Geld sowieso nicht.

I: Ja, klar. Können Sie den Ablauf quasi von Verkauf Ihrer Firma bis heute nochmal ein bisschen genauer erklären, was wirklich - in chronologischer Reihenfolge - was da passiert ist, und was so die größten Hürden und Probleme waren, was vielleicht auch die größten Fehlentscheidungen waren, das ein bisschen genauer beleuchten? 
B: Also '98 habe ich meine Firma verkauft, an einen englischen Konzern, sehr erfolgreich wie gesagt. Ab / gleichzeitig '98 / es hat sich überschnitten, im Rahmen dieses Verkaufs, eine Beteiligung in Polen übernommen von einer ähnlichen Firma, die da gegründet worden war aber wesentlich kleiner. Also die war von einer polnischen Familie gegründet worden in der Nähe von Warschau, die sich aber in dem Metier nicht so richtig auskannten, und die auch in wirtschaftliche Probleme geraten waren. Und dann kam ich eben dazu.

I: Also Sie haben Unternehmensanteile dort erworben?

B: Ich hab dort erst mal 50 Prozent oder 50,1 Prozent übernommen, um die Mehrheit zu haben. Es gab die ersten Jahre, zwischen 1998 und 2001/2002 gab es auch eine Menge wirtschaftlicher Probleme, aber ich hatte genügend Geld in der Tasche sozusagen, um das privat zu finanzieren. Die Firma aufzubauen, das ist auch letztendlich bis zum Jahr 2001 ist das ganz gut gelungen. Wir sind auch in die schwarzen Zahlen gekommen damit.

Aber dann hat sich plötzlich rausgestellt, dass die polnischen Partner mich betrügen, und eine weitere Firma gegründet hatten, wo sie also Einkäufe auf gemeinsame Kosten, insbesondere meine Kosten - ich hatte in der Zwischenzeit 75 Prozent aufgrund der finanziellen Zuwendungen, die ich da reingesteckt hab - dass die Geld abgezweigt haben im siebenstelligen Bereich, und dann habe ich die entmachtet. Dort drüben habe einen Betriebsleiter eingesetzt, aber es hat sich eben herausgestellt, dass da sehr viel im Argen war, was die mir verschwiegen hatten in der eigenen Firma. Also wir sind dann plötzlich mit Titeln von irgendwelchen Gläubigern, die ich gar nicht kannte, konfrontiert worden. Und dann hat man die Buchhaltung noch verschwinden lassen, als die, als die die Geschäftsleitung da drüben aufgegeben haben. Also ich hab praktisch 2002 plötzlich in meiner eigenen Firma ein schwarzes Loch vorgefunden. Hab mich immer auf die Partner dort verlassen in der Annahme, dass sie auch eigenes Geld hatten, dass sie sich fair und partnerschaftlich verhandeln / verhalten, was zunächst auch mal so ausgesehen hatte aber eben dann plötzlich nicht mehr. Und in diesem Streit ist dann die Firma sozusagen untergegangen. Polen ist ein postkommunistisches Land gewesen. Damals zumindest gab es viele Seilschaften, die 
hatten sehr gute Beziehungen bis hinauf zum Innenminister, der der Onkel meiner, meiner Partnerin war da drüben. Die konnten also sehr viel manipulieren in allen möglichen Behörden und so weiter, und auch meiner / meinem Management drüben Prügel zwischen die Beine geworfen, in der Hoffnung mich an die Wand zu drücken. Und dabei ist die Firma vor die Hunde gegangen. Also die Logistik brach dann letztendlich zusammen. Wir waren Just-In-Time-Lieferant für die Automobilindustrie. Wir hätten fast die halbe Produktion in Deutschland mit irgendwelchen Serienteilen, die wir gemacht haben, zum Einsturz gebracht. Also wenn ein Teil von dieser logistischen Kette ja fehlt, dann kann das Auto nicht fertiggestellt werden. Und das ist bei so einem, so einem Massenproduktionsteil ist das absolut tödlich. Und das hat unsere Kunden dann ziemlich schnell dazu bewogen, die Aufträge und deren eigene Werkzeuge abzuziehen, und damit war die Firma ein Schrotthaufen. Und ich hatte die Presshalle da drüben stehen, die nichts mehr wert war. Wollte auch kein anderer mehr rein. Also in der Branche sehr, sehr schnell rumgesprochen.

Dann waren wir obendrein noch auf fremden Grund und Boden, und der Eigentümer des Grundstücks der hat mich dann auch noch geblitzt und hat sich einen Titel besorgt gegen das, was da auf diesem Grundstück war, der auch nie so genau nachvollziehbar war. Jedenfalls hat der dann die Maschinen auch noch eingeheimst, und das Grundstück war ja seins. Die Maschinen waren mit Grund und Boden verbunden auch juristisches Eigentum des Grundstückseigentümers zunächst mal.

Und zum Schadensersatz bin ich nie gekommen, das heißt, aus diesem polnischen Millionenverlust entstand eben ein riesen, riesen Vermögensverlust für mich. Quasi alles, was ich vorher in 20 Jahren erwirtschaftet hatte und, ja, und hinzu kam dann eben noch der erwähnte Streit mit dem Finanzamt, der ja erst, ich sag mal, 2009 am Gericht ausgetragen wurde. Das hat mich auch noch Gefängnis gekostet. Weil der Betrag weit über einer Million lag, mit den Zinsen sowieso. Und ja, also es ist eben ebenfalls aus diesem ganzen / dieser ganzen Entwicklung Debakel in Polen und Steuerschulden ist letztendlich von mir ein negatives Vermögen entstanden und damit die Privatinsolvenz.

I: Wann haben Sie das richtig realisiert, dass die Privatinsolvenz kommt, und dass es nicht mehr aufzuhalten ist quasi? 
B: Eigentlich habe ich es realisiert, nachdem mir meine Steueranwälte / ich war also wie gesagt / habe ungefähr im Jahr 2008 / dass ich da mit meiner Vorstellung nicht durchkommen werde, weil ich hatte / dummerweise muss ich sagen, nachdem ich damals schlecht beraten war, eben bei dem Verkauf 1998, war ich zwar in Tschechien ansässig und hatte dort auch ein Haus, wo ich überwiegend gewohnt habe und auch die Firma drüben leiten musste und wiederaufgebaut habe. Also anders als im Fall Polen, wo ich in der Hauptsache in Deutschland gewohnt habe und immer wieder hingeflogen bin, war es so, dass ich in dem ersten Engagement in Tschechien sehr viel vor Ort war, zwar auch dort drei Partner hatte, die sich gekümmert haben, aber viel mehr mit eingebunden war im Tagesgeschäft und in $<<<$ Ort anonymisiert $>>>$ eigentlich nachdem ich mich '97 von meiner ersten Frau getrennt hatte, nur noch eine kaum eingerichtete Wohnung hatte. Und deswegen war ich in meinen Gedanken eigentlich steuerlich dort ansässig und / aber wie wir sehen, dass die Wohnung in $<<<$ Ort anonymisiert $>>>$ hätte ich nicht haben dürfen. Beziehungsweise die Wohnung hätte kein Bett haben dürfen oder irgend sowas. Da gab es Feinheiten. Es sind / das ist unglaublich in unserem Steuerrecht.

I: Sie haben quasi in Tschechien Steuern bezahlt?

B: In Tschechien waren keine Steuern fällig bei dem.

I: Ach so.

B: Ich hab Tschechien, in Tschechien natürlich Steuern bezahlt, solange das Unternehmen tätig war. Aber der Verkauf der Anteile war steuerfrei in Tschechien. Und hätte ich in $<<<$ Ort anonymisiert $>>>$ diesen Wohnsitz nicht gehabt, den man mir dann vorgeworfen hat, hätte ich auch in Deutschland nie belangt werden können deswegen. Aber es war eben nicht so letztendlich, und das habe ich erst im Jahr 2008 realisiert. Es ging ja / es war ein Steuerverfahren das 2005 eröffnet wurde. Und dann wurde da jahrelang rumgetan und, und habe natürlich auch rechtliche Beratung eingeholt, hat auch sehr viel Geld gekostet. Aber letztendlich hat man mich ganz, also, überraschend beim, beim Gespräch zum Thema mich ins Finanzamt geladen hat, hat man mich verhaftet und mir dann eben im Gefängnis dann mehr oder weniger eröffnet, 
dass, ja, also dass ich jetzt da schwere Straftaten begangen hätte und auch die Verlustvorträge, die man aus Polen, die man vorher immer anerkannt hatte, jetzt dann plötzlich nicht mehr anerkannt hat. Da streite ich heute noch dazu. Also der Zwist ist noch nicht, nicht ganz zu Ende. Tja.

I: Wie hat das begonnen? Sie haben Post vom Finanzamt bekommen, mussten dann dort erscheinen und dann?

B: Ja, also man wollte mehr oder weniger / Es gab eine Betriebsprüfung zu diesem ganzen Vorfall, und das wollte man mir, mit mir abschließend besprechen und auch wegen der polnischen Verlustvorträge. Und das Gespräch ist aber ziemlich banal verlaufen, also ohne, ohne rechten Inhalt. Also es war mehr oder weniger nur, um mich in die Falle zu locken.

Ich hatte - das muss ich auch ganz ehrlich sagen, das habe ich auch dem Finanzamt damals mitgeteilt - ich hatte in der / einen Wohnsitz in England angemeldet und wollte eigentlich die Privatinsolvenz in England machen. Weil ich schon 2008 realisiert hab, dass ich die Steuerschulden nie bezahlen kann. Und die einzige Möglichkeit um überhaupt wieder wirtschaftlich auf die Beine in absehbarer Zeit zu kommen war für mich dann der Gedanke, in England eben in den zwölf oder circa zwölf Monaten die Privatinsolvenz abzuwickeln, die europäisch anerkannt worden wäre. Und abgesehen davon ich hatte in England auch / also ich muss vorausschicken, der Konzern, der meine tschechische Firma gekauft hat, war ein englischer Konzern, und ich hatte in England auch viele Bekannte und Geschäftsbeziehungen, und ich hätte mich da über Wasser halten können da drüben.

I: Woran ist der Plan gescheitert?

B: Dass ich einfach zu dem Zeitpunkt / das war eben gerade Osterferien, ich hab meine Frau hier besucht. Und dann hab ich mich eben dazu breitschlagen lassen, zu diesem Termin im Finanzamt zu erscheinen, und dann war ich verhaftet wegen Fluchtgefahr. (lacht)

I: Wie lange mussten Sie dann dortbleiben? 
B: Dann war ich erst mal 13 Monate oder 11 Monate in Untersuchungshaft, und dann kam es zum Prozess und dann ein Urteil raus dabei mit immerhin zwei Jahren und acht Monaten. Also es gab keine Bewährungsstrafe, weil ich über der Millionengrenze war mit dieser Steuerforderung. Und ich bin davon ausgegangen, dass man hätte mich sofort wieder freigelassen, wenn ich drei Millionen hätte auf den Tisch gelegt. Aber die waren natürlich nirgendwo. Und ich gehe davon aus, dass die gemeint haben, ich hätte irgendwo noch Geld in der Schweiz versteckt und werde es dann schon rausrücken. Es war nicht ausgesprochen, aber es hat mir jeder Anwalt auch so geschildert. Das ist die übliche Vorgehensweise, um die Leute erst mal zu erpressen. Ins Gefängnis setzt sich keiner gern, aber mir blieb nichts anderes übrig, weil ich das Geld nicht hatte.

I: Und wie war die Zeit für Sie dann?

B: Das, das war erst mal für mich unvorstellbar, dass es überhaupt so weit kommen konnte. Und dann war man plötzlich mit Leuten zusammen, mit denen man vorher nie was zu tun hatte. Also es gab natürlich auch zwei, drei andere / also noch einen, der auch so eine Steuerschuld hatte. Auch ein mittelständischer Unternehmer, den ich da kennengelernt habe, und jemand anders der vorher auch eine ordentliche wirtschaftliche Karriere hingelegt hat. Ein promovierter BWLer, ehemaliger Unternehmensberater von McKinsey, den ich da kennengelernt habe und noch zwei andere, also die, ich sage mal von, vom Werdegang her irgendwo vergleichbar waren mit mir. Aber der Rest waren U-Bahn-Schläger auch zwei drogenabhängige Kleinkriminelle. Und ich hab mich nie bedroht gefühlt, aber ich war natürlich nicht gewöhnt mich mit den Leuten, mit diesen Leuten auseinander setzten zu müssen. Jetzt bin ich aber kein Akademiker aus dem Elfenbeinturm. Mein Vater hatte einen Handwerksbetrieb. Ich hatte während dem Studium auch eine Handwerkslehre noch gemacht. Also ich komme schon von der Pike her. Aber, also diese Welt war mir völlig fremd. Und dann natürlich die, diese Umstände, dass man gefroren hat in der Zelle, weil das in $<<<$ Ort anonymisiert $>>>$ ist ja ein Gefängnis aus dem 19. Jahrhundert, und da wurde nicht viel renoviert dabei. Und das ist auch offensichtlich eins, wo, wo man wirklich Leute unter Druck setzen will, weil wenn man dann 
verurteilt wird, dann kommt man in modernere Gefängnisse. Aber so ein Untersuchungsgefängnis, da hält man also die Gefangenen ziemlich hart, und es ist absolut kein Vergnügen. Man will halt Druck ausüben zum Geständnis. Insofern war das nicht sehr schön.

Danach, nach dem Urteil bin ich, also ich bin dann in die Bücherei dort gekommen. Die haben gemerkt, dass ich sehr viel lese. Und das war dann sehr sympathisch dort und, und dann kurz drauf auch in so einem Freigängerhaus hier in $<<<$ Ort anonymisiert $\gg>>$ und konnte dann bei einem Bekannten in einer Unternehmensberatung arbeiten tagsüber. Dann war ich also nach 18 Monaten ungefähr, 18, 19 Monaten war ich wieder in der Freiheit. Nach 7 Monaten Freigänger. Ja, war ein einschneidendes Erlebnis, natürlich nicht nur für mich, sondern auch für meine ganze Familie. Meine Mutter ist noch während der Zeit gestorben. Durch einen Unfall zu Hause. Sie hat mich sehr oft besucht, eben so oft es ging. Also es war eine harte Zeit.

I: Glaube ich, ja. Und wenn Sie jetzt so zurückdenken, was würden Sie jetzt als die, den oder die Hauptgründe für die Insolvenz sagen?

B: Ich sage mal so, ich habe es ein bisschen zu sehr auf die leichte Schulter genommen. Ich hab natürlich / ich wusste / ich hatte einen Steuerberater in der Oberpfalz, an dem Ort wo ich früher meine oberpfälzische Firma hatte, der eigentlich auf Deutsches Steuerrecht spezialisiert war, nicht auf internationales. Und der hat, weil ich ja auch wieder einen anderen hatte etc. und, und den Rest von der deutschen Firma dann noch vor - ein Teil war schon weiter verpachtet an Mitarbeiter in Deutschland also diesen Teil noch verwaltet. Und er war eigentlich für mich der Ansprechpartner. Aber der hat mich einfach nicht darauf hingewiesen was, was ich eigentlich da an Vorsorge treffen müsste im Falle eines ausländischen Anteilsverkaufs. Was ja eigentlich mein Hauptvermögen damals war, diese Firma in Tschechien. War eine richtige Fabrik. Ich hätte mir / kann man natürlich jetzt im Nachhinein sagen, hättest du eigentlich wissen müssen, hast doch BWL studiert und auch Steuerrecht. Ich hätte mir noch zusätzlichen Rat einholen müssen, von jemand, der wirklich auf Auslandssteuerrecht spezialisiert ist. Aber das Problem ist einfach, ich war dermaßen unter Druck damals mit Verkauf und auch mit dem ganzen Management und der 
Aufbau in Tschechien von Null auf 700 Leute in sieben Jahren. Das war eigentlich ein Akt, den man sich kaum vorstellen kann. Da vergisst man manchmal / da bewertet man einfach nur noch die Dinge, die einen tagtäglich betreffen, zum Überleben und zum „die Dinge vorwärts bringen“, und solche administrativen Feinheiten / ich hab sie übersehen buchstäblich. Das war natürlich fatal. War natürlich fatal, hätte mir nur einmal jemand gesagt, musst aufpassen mit deinem Wohnsitz, dann wäre mir das nicht passiert. Weil ich konnte tschechisch. Ich hätte in Tschechien leben können. Ich bin ja fünf Jahre da drübengeblieben. Mir ging es da gut da drüben, also so rein persönlich gesehen. Hatte Freunde und Bekannte, und es war einfach nur ein Fehler. Noch dazu wo ich von meiner Frau ja schon getrennt war und sonst keine weiteren Bindungen hier hatte, außer Freunde und, und selbst meine Kinder waren im Ausland. England und Österreich. Es hätte kein, keinen Grund gegeben für mich in der Zeit, wo der Firmenverkauf stattfand, in diesen zwei Jahren in Deutschland zu leben. Also es waren einfach, es war eine gewisse Schlampigkeit in meinem Kopf, mich da nicht ausreichend beraten zu lassen.

Und dann der zweite große Fehler, den ich gemacht hab, das war einfach, ja den Leuten in Polen zu sehr zu vertrauen, oder darauf zu setzen, sie werden schon nichts tun, was ihnen selber schadet. Aber irgendwie hat die eine Mischung aus Gier und Dummheit und verletztem Stolz so weit getrieben, dass sie lieber alles zerstört haben, als dass sie irgendwo mal eingelenkt hätten, und diese zerstörerischen Machenschaften gegenüber unseren Kunden, gegenüber der eigenen Firma unterlassen hätten. Ich dachte nicht, dass die so weit gehen. Also mit meiner tschechischen Gesellschaft da gab es auch eine Auseinandersetzung, und die hatten natürlich dann - das wusste ich schon irgendwo - einen gewissen Heimvorteil, den man als Ausländer einfach berücksichtigen muss. Und die Staaten da drüben waren also zumindest zu dem Zeitpunkt nicht so Rechtsstaat, wie man es sich in Deutschland erwartet. Wobei da bin ich mittlerweile auch etwas vorsichtiger geworden. (lacht) Recht haben und recht kriegen ist immer zweierlei. Aber, also die, ich meine die, die, die Polen, die haben sich einfach irgendwann am Ende sehenden Auges ihren eigenen Ast abgesägt, auf dem sie saßen mit mir zusammen. Und das habe ich irgendwo / meine Frau hat mich damals gewarnt / ich war ja / meine zweite Frau. Die war ja im Osten aufgewachsen in der DDR, und die kannte die Mentalität ein bisschen und auch die Macht von solchen Seilschaften. Die hatte da viel mehr Respekt davor. Und ich hab immer wieder Geld 
nachgeschossen noch, um diese Firma zu retten. Noch im Jahr 2002, was ich lieber hätte behalten sollen, vielleicht hätte ich dann die Steuerschuld zumindest doch irgendwie zum Teil erledigen können. Vielleicht hätte man irgendwie / Vielleicht wäre mir das Gefängnis dann erspart geblieben oder auch die Privatinsolvenz. Aber ich hab einfach versucht diese Firma zu retten und es, es war, es war am Ende nur noch Casino. Das gute Geld dem Schlechten nachgeworfen.

I: Und die Privatinsolvenz an sich, das Verfahren, wie lief das ab und was waren da so die größten Probleme oder Schwierigkeiten oder Herausforderungen?

B: (seufzt) Ich sage mal so, ich hab, ich hab 21 / also ich musste ja über die 20er Grenze drüber kommen, um diese Regelinsolvenz anzumelden, was mir mein Anwalt empfohlen hatte. Da gab es ein paar Kleingläubiger um überhaupt auf diese Zahl zu kommen, die ich fast nahezu erfinden musste. Die ich normalerweise hätte abfertigen können oder mit Hilfe meiner Familie abfertigen können. Da war erst mal dieses Anmeldungsproblem. Also ich sollte eine Regelinsolvenz machen, obwohl ich eigentlich in der Hauptsache nur einen Gläubiger hatte, nämlich das Finanzamt. Wobei man das wieder aufteilen kann in Finanzamt für Körperschaften und diesen Gewerbesteuerteil, wo es also die Stadtkasse oder das Stadtsteueramt ist, sind allein dann wieder zwei Gläubiger (lacht). Und die also im, ich sage mal vom, im Rahmen von der Privatinsolvenz, außer der Tatsache, dass ich jetzt seitdem lahmgelegt bin irgendwo, gab es keine besonderen Probleme jetzt. Der erste Schnitt ist ja schon, schon passiert mit der Wohlverhaltensphase, also das ist etwas später als vorgesehen ist das eingeleitet worden, dann aber / ich habe auch schon einen Termin bekommen, wann diese, diese Privatinsolvenz zu Ende sein wird. Vorausgesetzt, dass ich mich immer an daranhalte, erwerbstätig zu sein und niemanden als Gläubiger bevorzuge und so weiter. Sie kennen die Regeln ja. Woran ich mich sicherlich halten werde, so dass ich eigentlich also mehr oder weniger momentan abwarte, oder auch versuche dann irgendwie noch Geschäfte anzuzetteln, entweder zusammen mit meinem Sohn oder mit irgendjemand anders oder halt mit meiner Frau zusammen habe ich es auch schon versucht. Die ist momentan angestellt, aber sie hat eine Firma gegründet, wo ich versucht habe, ihr zu helfen, und da wollten wir Solaranlagen vermitteln in Italien. Ich kann ganz gut italienisch, und außerdem ist das wieder etwas Technisches, was mir 
auch liegt. Nur hat sich jetzt die ganze Förderung da unten verändert, und es ist nicht mehr attraktiv für, für Fonds und so weiter also institutionelle Anleger, denen wir hier die Anlagen zubringen wollten. Das Geschäft ist zunächst mal tot. Ich versuche momentan noch eine Vertretung im, mit Biogasanlagenzubehör, wo ich einen Draht habe, aber es ist auch sehr schwierig geworden, weil momentan warten sie alle ab, die Bauern, weil sich die Regeln ständig ändern mit den Förderungen. Also der neue, der Sektor regenerative Energien würde mich sehr interessieren für die Zukunft, mal strategisch gesehen. Aber es gibt halt ein ständiges Chaos in den Förderungen, und jetzt da einen Vertrieb darauf aufzubauen, noch dazu mit wenig Eigenkapital ist sehr schwierig. Man muss die politische Landschaft beobachten, was, was da als nächstes kommt. Vielleicht gibt es da eine Möglichkeit einzusteigen. Mein Sohn ist im Internethandel tätig, das läuft eigentlich momentan ganz gut, der verkauft Badmöbel. Sitzt in $<<<$ Ort anonymisiert $>>>$ auch, und mal schauen, vielleicht kann ich ihn da / der hat auch schon einen Partner. Ich will mich auch nicht zu sehr da einbringen, weil, wie soll ich sagen, meine Familie unterstützt mich zwar, sowohl meine Kinder, als auch meine Noch-Frau als auch mein Bruder, und alle helfen zu mir, wenn es drauf ankommt, aber ich will jetzt nicht irgendetwas von denen verlangen, was ich nicht von einem fremden Geschäftspartner auch bekommen würde.

I: Wenn Sie jetzt so zurückdenken, gibt es dann auch irgendwas Positives in der ganzen Geschichte, wo Sie jetzt sagen, das lief besonders reibungslos oder daran bin ich gewachsen, oder / also irgendein positives Stück in dem Ganzen / in dieser Entwicklung?

B: Sie meinen jetzt in der Karriere insgesamt oder in der Phase der Privatinsolvenz?

I: In der Phase der Insolvenz.

B: Das kann ich eigentlich so nicht sagen, es ist / für mich ist es einfach die Strecke von sechs Jahren, die ich irgendwie rumbringen muss, ja? Ich komme mit der Insolvenzverwalterin gut zurecht, die behandelt mich fair. Die hat mir auch angeboten, wenn sich jetzt irgendwas tun sollte, dass, dass ich halt dann / oder mehr und mehr Geld verdiene, dann habe ich auch bestimmte Freibeträge und so weiter. Das würde 
ich gerne ausnutzen, wenn es denn mal so wäre, aber bis jetzt ist es nicht dazu gekommen. Außer ein paar Vermittlungserfolge, die ich erzielt habe, die jetzt aber nicht so weit aufaddiert haben, dass ich diese Freibeträge weit überschritten hätte, ist da bis jetzt nichts passiert, ja. Also leben tu ich. Ich meine, die Wohnung hier, die gehört meinem Vater noch. Der ist 93 und lebt im Altersheim. Meine Eltern haben ein großes Immobilienvermögen aufgebaut. Und ansonsten, Lebensunterhalt, von dem was ich bei meinem Sohn erwirtschafte und außerdem ist meine Frau noch da, also ich komme schon über die Runden, aber ansonsten, ich muss schauen, dass, dass ich noch irgendwo erfolgreich werde. Aber wie gesagt, ich kann jetzt was die Abwicklung der Insolvenz anbetrifft insofern wenig sagen, weil sich da auch von meiner Seite her nicht so viel getan hätte. Wenn ich jetzt sagen könnte, ich verdiene jedes Monat 10.000 Euro, wovon ich 8.500 Euro abgeben muss, dann könnte man vielleicht darüber reden, wie man das psychologisch verkraftet, aber für mich ist es / die Hürde eher die momentan, dass ich nicht weiß, wie ich überhaupt an - ohne Kapital - an größere Einnahmen kommen kann.

I: Was sind, wenn Sie jetzt zurückdenken an Ihren gesamten Werdegang, was sind so die großen Entscheidungen, die sie heute anders treffen würden? Privat wie beruflich.

B: Naja, privat ist es schwer zu sagen. Ich meine, natürlich kann man sagen, ich habe früh geheiratet, vielleicht zu früh. Aber die Ehe hat auch anderseits gehalten. Ich war immerhin 22 Jahre mit meiner ersten Frau zusammen. Das ist heutzutage schon viel. (lacht) Was man auch also / gut im Lauf des Lebens lebt man sich auch mal auseinander, privat kann ich jetzt nicht so viel sagen, was ich anders gemacht hätte, das wär, wäre töricht, weil wenn ich heute irgendwas anders mach, dann mach ich vielleicht wieder / hab in 20 Jahren etwas zu berichten, was falsch war.

Beruflich. Ich hätte mir vielleicht manchmal / ich habe sehr viel alleine gemacht, ich war halt immer auf mich alleine gestellt. Als Unternehmer - war praktisch Einzelunternehmer - und erst als ich in Tschechien dann angefangen habe, ging das mit Partnern los, die halt auch eben im Ausland waren und die, die hatten mit den neun Prozent, also den 3 x 3 Prozent in der Minderheit waren. Also war ich praktisch immer wie so wie ein Einzelunternehmer, der auf niemanden hören musste, wollte, und auch lange Zeit vom Erfolg gesegnet. Insofern habe ich das auch nicht weiter hinterfragt, 
sondern hab gesagt "never change a running system" und habe weitergemacht. Es hätte mir sicherlich manchmal gutgetan, einen erfahrenen Coach an meiner Seite zu haben. Und der mir ein bisschen über die Schulter schaut. Wäre vielleicht als Unternehmer mir 20 Jahre voraus gewesen wäre / und mir dann mal einen Hinweis gegeben ob / hätte / etwas zu überprüfen was, was ich gerade mache.

I: Die / Sie haben ja recht einschneidende Erlebnisse auch gehabt, auch als Sie in Haft mussten, und Privatinsolvenz an sich ist ja ein einschneidendes Erlebnis. Würden Sie sagen, dass Sie das verändert hat?

B: Naja, es hat mich gedämpft. Also ich war früher im / energetischer, aber es kommt vielleicht auch mit dem Alter. Also es hat mir schon, es hat mir schon sehr viel Energie genommen, ja.

I: Die Auswirkungen so auf Sie selbst oder auch auf, auf Ihr Zusammenspiel mit dem Umfeld, wie würden Sie das beschreiben?

B: Naja gut, also ich war schon immer irgendwie auf, auf Teamlösungen bedacht. Natürlich mehr oder weniger immer in der Form, dass ich halt als in Anführungszeichen patriarchischer, mittelständischer Unternehmer immer an der Spitze stand und auch letztendlich das alles verantworten musste und auch immer bei den Kunden ja den Kopf hinhalten musste, mit denen ich ja unmittelbar zu tun hatte. Es waren große Automobilunternehmen oder große Zulieferer, was mehr oder weniger / ich war denen ja direkt gegenübergesessen, es ist ja nicht so wie beim, beim Unternehmen, dass auf dem freien Markt verkauft, sondern ich war mehr oder weniger von denen im Schach gehalten. Bestimmte Leute, die halt die Vertrauenspersonen für mich waren bei den Kunden. So, das Ganze hat ein bestimmtes Netzwerk bedeutet, sowohl auf Kundenseite als auch im eigenen Unternehmen. Und ich habe natürlich darauf achten müssen, dass bestimmte Stellen nicht falsch besetzt waren. Da habe ich am Anfang auch Fehler gemacht. Also ich habe manchmal den falschen Leuten vertraut. Auch im eigenen Unternehmen, da gab es auch Betrugsfälle. Musste ich halt dann aussortieren, was ja gerade in Deutschland nicht immer so einfach ist arbeitsrechtlich. Aber ich war schon eher immer der Teamplayer, war als ich jung war 
ein bisschen naiv was, was die Möglichkeit anbetrifft, Menschen nachhaltig zu verändern. Also die Leute, die mein Vater übernommen hatte, der ein ziemlicher Patriarch war, ich habe immer versucht die auf eine modernere Schiene zu bringen. Es war aber nicht möglich. Die waren es halt gewohnt, dass einer anschafft, und sie tanzten dann hinterher. Aber von sich aus, die zu Initiativen zu bewegen, daran bin ich gescheitert. Da musste ich mir dann andere Leute suchen auf die Dauer. Das musste ich erst lernen. Aber letztendlich, also ich war schon immer ein Teamplayer, wenn das die Frage war jetzt.

I: Und Sie haben vorhin angesprochen, dass Sie sich wieder selbstständig machen werden oder wollen, weil Sie denken, dass es wenig Sinn macht sich irgendwo zu bewerben.

B: Ja

I: Haben Sie auch das Gefühl, dass die Leute anders mit Ihnen umgehen seit Sie privatinsolvent waren oder seit Sie im Gefängnis waren, dass es da viele Vorurteile gibt?

B: Das würde ich mal befürchten, ja.

I: Oder auch in Ihrem Bekanntenkreis, hat sich da / gab es da negative Erlebnisse irgendwie oder?

B: Ich, ich hab das natürlich / nein, in keiner Weise / Also die Leute, die es erfahren haben, die sind alle, die haben alle auf die Schulter geklopft und haben gesagt: "OK, für uns bist du kein Verbrecher!" Noch dazu bei den Ganzen, also bei der ganzen Geschichte. Weil, man muss sich vorstellen, es ist ja nur, es war eine Gradwanderung mit diesem Wohnsitz hier. Der deutsche Staat hat in keiner Weise dazu beigetragen, dass ich diese Firma in Tschechien aufgebaut habe. Der deutsche Staat, hat aber den Anspruch auf diese Steuer und für Gelder, die ich in Polen verloren habe letztendlich, was mir der deutsche Staat aber nicht geglaubt hat. Also es ist irgendwo schon eine gewisse Absurdität an dem Ganzen. Aber es ist, wie es ist, und es gibt halt die Gesetze 
und werden dann in so einem Fall auch meistens zu Gunsten des Staates ausgelegt, noch dazu, wenn man mal selber in der Untersuchungshaft sitzt, muss der Staatsanwalt sich auch dafür rechtfertigen. Also, kommt man nicht mehr so schnell raus aus der Maschinerie. Also, im Bekanntenkreis / ich hab natürlich / aber trotzdem, ich habe es nicht groß publik gemacht. Also mein Golf-Club, in dem ich immer noch bin von früher, da wissen es die aller, allerwenigsten, also nur die wirklich guten Freunde, die, wo ich mich drauf verlassen kann, weil, das wäre nicht besonders gut. Die Leute reden immer, auch wenn sie nichts wissen, und es ist immer zum Nachteil. Nein, negative Konsequenzen sehe ich da jetzt eher nicht, aber ich meine, es gibt, wie gesagt, es gibt, wenn ich mich als Angestellter irgendwo bewerben würde, gibt es zwei oder drei negative Komponenten. Das erste ist die Tatsache, dass ich ja quasi nie Angestellter war in den letzten 30 Jahren. Also. (seufzt) Da muss man erst mal den Unternehmer finden, der dann sagt: „Dem traue ich zu, dass er sich dann auch einordnen kann" / oder demjenigen der mich dann da einstellt. Und das Zweite ist, naja gut, das gewisse wirtschaftliche Scheitern, was natürlich auch erst mal ein Makel ist. Privatinsolvenz ist irgendwo mit einem Mangel behaftet und, und dann noch die Tatsache, dass ich im Gefängnis war, also / es sind / das ist schon ein ziemliches Paket.

I: Wieso würden Sie sagen, dass eine Privatinsolvenz mit einem Mangel behaftet ist?

B: Ja, da muss / also / ich sag mal so, es muss ja irgendeiner einen Fehler gemacht haben, sonst käme es ja nicht dazu. (lacht)

I: Ist ja nicht so schlimm, man kann ja mal einen Fehler machen.

B: Ja, ja schon. Ja es ist schön, dass Sie das so sehen, vielleicht gibt es auch andere Leute die es so sehen, aber ich bin etwas skeptisch geworden.

I: Ok.

B: Aber, ich glaube, das größte Hindernis ist einfach - mal abgesehen davon, dass ich vielleicht so ein Interimsmanagement irgendwo machen könnte, was ich mir auch schon überlegt habe - ist einfach das Alter. Also ich habe im Bekanntenkreis 
jemanden, der diese / keine Privatinsolvenz hingelegt hat, ist allerdings noch zwei, drei Jahre älter. Die Dame, promovierte Biologin, die ihr Leben lang für die Pharmaindustrie gearbeitet hat, für die ist es so schwer in dem Alter, wo sie so viel Erfahrung hat und, und wirklich, also eigentlich ideale Voraussetzungen hätte, von Erfahrung und Wissen her und auch von Ihrer Fitness noch zu arbeiten / es ist, für die ist es so schwer noch einen Job zu bekommen. Wenn man die sieht, dann glaubt man nicht, dass die schon so alt ist. Also / aber./ Ich weiß nicht, aber die Jungen werden einfach bevorzugt. Ja, ich mein, die jungen Leute müssen auch, die haben noch die Karriere vor sich, müssen da irgendwie in das Arbeitsleben rein und sollen auch irgendwo bevorzugt werden, aber warum muss man gegen die Älteren, die eigentlich noch fit wären und schon so viel Erfahrung haben, und die eigentlich sehr produktiv sein könnten noch / es ist dermaßen vorurteilsbehaftet. Ich verstehe es ehrlich gesagt nicht. Es gibt schon Unterschiede zwischen den Menschen. Es gibt Leute, die sind mit 40 schon K.O., und andere die sind mit 70 noch fit. 
Nachtrag zum Interview:

- spielt Klavier als Ausgleich

- versucht sich körperlich fit zu halten, um so auch der Langeweile zu begegnen

- freut sich, wenn die 2 Jahre rum sind (ihm ist momentan langweilig)

- sein Motto: "nicht nachlassen" 
Appendix III: Transcript of Interview 2

I: Also, als erstes würde ich Sie ja gern einfach ein bisschen kennenlernen. Und deswegen hätte ich ganz gerne, dass Sie mir einfach mal Ihren Werdegang schildern, beruflich wie privat, von der Kindheit bis jetzt.

B: 1947 im August in Hamburg geboren hatte ich eine Nachkriegskindheit im durchaus, sagen wir einmal, gutbürgerlichen Niveau. Wir / ich bin ältestes von drei Kindern, hatte damit schnell viel Verantwortung auch zu übernehmen. Meine Eltern waren selbstständig. Bin sehr, sehr gern zur Schule gegangen, und das fiel mir auch sehr leicht. Habe Klassensprecher, Schulsprecher, Schülerparlamentsämter übernommen schon in jungen Jahren und habe dann nicht so klugerweise meine Tochter zu früh bekommen, als ich schon beim Studieren war. Und habe dann geheiratet, und Mann und Arbeit und Kind war dann zu viel, sodass ich mein Studium leider - weil ich hätte gern promoviert, weil es mir eben alles so leichtgefallen ist abgebrochen habe. (Pause)

I: Was haben Sie studiert?

B: Psychologie. Ja, mit ein bisschen Wirtschaft nebenher. Ich wollte eigentlich so etwas wie Schulpsychologe werden oder sowas. Nachdem ich erst Architekt werden wollte, weil mein Vater Ingenieur war. Aber dann habe ich gedacht, ich bin nicht kreativ genug. Ich bin eher analytisch, stärker als das Kreative. Habe ich auch von meinem Vater, woran Sie erkennen, dass ich ein Papakind bin, eher. Meine Mutter hab ich, hab ich gut gefunden, weil sie ganz toll organisieren konnte, immer, ganz super, quasi ganz schnell und fix und konnte ganz toll mit Menschen. Dann habe ich meine Tochter gehabt und habe gedacht, ich will trotzdem Karriere machen. Das muss irgendwie gehen. Hab mich sehr reingehängt. Hab eine Traineeausbildung dann gemacht in einer / in einem Marktforschungsinstitut bei Professor $<<<$ Name anonymisiert $\gg>>$, der das ausdrücklich eigentlich nur Jungakademikern vorbehalten hatte, und ich war ja nun noch kein Akademiker in dem Sinne mit so ein paar Semestern, vier Semester. Und habe es trotzdem machen dürfen. Und dann ging das 
eigentlich ziemlich zügig weiter trotz Kind und nach Scheidung. Weil, das war mir dann alles zu viel, das hat die Ehe nicht ausgehalten. Und, ja. Und ich war mit 32 dann schon Führungskraft. Habe ich mich da schnell hoch / war vom Abteilungsleiter über Bereichsleiter und Mitglied der Geschäftsleitung international im Unternehmen bei $<<<$ Unternehmen anonymisiert $>>>$ dann. Also meine längste Zeit war ich bei den $<<<$ Unternehmen anonymisiert $>>>-$ werken wo ich auch den Aufstieg, den Hauptaufstieg, geschafft hab. Dann zu $<<<$ Unternehmen anonymisiert $>>>$ ins Management und anschließend war ich Verlagsleiterin hier unten dann. Das heißt es waren ungefähr 20 Jahre, gut 20 Jahre, Führungserfahrung.

Mit diesem Fachverlag gab es einen Generationenwechsel. Und damit war auch ein ziemlicher Bruch in meiner Laufbahn. Denn der junge Herr, ich weiß nicht, mit 40 da, der hat gesagt, ich bin ihm zu alt, er möchte nur junge Leute haben. Dann haben wir einen Weg gefunden, dass ich mich selbstständig machte, weil ich das durchaus auch im Sinne von Kommunikationsdienstleistung gut fand. Und ich hatte aber kein, keinen ererbten Sack Geld oder so, um jetzt irgendwie so ganz groß einzusteigen. Hatte ja nun auch nicht die Kunden, sondern nur noch von vorher so ein paar Bekannte, mit denen ich mich traute, dass das geht. Aber der Hauptteil sollte von diesem Verlag sein. Ein, ein / dann haben wir einen, einen Werk- / ein, ein Kommunikationstool ausgedacht, und das haben die nachher nicht eingehalten, den Vertrag, so dass ich da völlig neu wieder starten musste. Sie haben also das nicht / die ganzen Zusagen nicht eingehalten, nachdem ich dann sozusagen für ihn ja endlich weg war. Und das / da muss man schon sehr jonglieren, das ist / das war ein, ein sehr großer Einschnitt, denn sie rechnen mit diesem festen Betrag und /

I: Verstehe ich das richtig, dass der Verlag quasi der Hauptkunde hätte sein sollen, und der ist dann weggebrochen?

B: Ja, Ja. Damit ist das ganze Geschäftsmodell erst mal weggebrochen, weil das war ein sehr whichtiger / whichtiges Bein. Auch waren 75.000 erst mal ganz abgesicherter Wert, das waren damals noch D-Mark, aber trotzdem, als Jahreswert / und dann konnte ich aber weiter akquirieren, was ich dann auch gemacht hatte, was auch ein bisschen ging. Aber ich hätte die Adressen dafür gebraucht, das war auch ein Bestandteil - also das eine war der Betrag und das andere war der, der Adressenpool. 
Und den / da haben sie mir einen Uralt-Adressenpool gegeben, und ich kriegte lauter Rückläufe. Also / ja egal / sowas passiert. Ich habe nicht darauf bestanden, dass das ein aktualisierter Adressenpool ist. Ich habe mir nicht vorstellen können, dass man jemanden so bescheißt, auf Deutsch gesagt. (lacht) Das heißt, ich habe es vertraglich nicht, nicht gut genug festgehalten. Dann habe ich daraus was umgebaut, und das ging gut, verschiedene sehr gute, witzige Kommunikationsleistungen auch im B2BBereich. So zum / also mein angestammtes Feld ist die / oder die Stärke war Lebensmittelhandel und Lebensmittelindustrie. Und Mittler dazwischen zu sein, da, da hatte ich sehr viel Erfahrung und konnte da eben auch so Kommunikationswerkzeuge, wenn ein Produkt bekannt gemacht werden soll im / in den Läden, dass das richtig platziert wird und solche Sachen, also solche Aufgaben. Das habe ich gemacht.

Wie gesagt, meine Tochter studierte dann. Die hat auch nun einen Abschluss gemacht, die ist Diplomökonomin. Und dann war also diese nicht günstige Immobilie da im / im Bestand (lacht). Und als mein Vater 89 war, hat er gesagt: „Ich kann das nicht mehr alleine.“ ich / er möchte gerne runter nach Bayern. Da er wirklich schwer asthmakrank war und schon fast erstickte immer da oben, hab ich gedacht, ich kann das schaffen, ich mach ihm noch ein richtig schönes letztes Jahr. So. Also, vielleicht müsste ich so sagen, das sollte ich vielleicht noch ergänzen. Also, in $<<<$ Ort anonymisiert $>>>$ geboren, in $<<<$ Ort anonymisiert $>>>$ studiert, in $<<<$ Ort anonymisiert $>>>$ die ersten beruflichen Schritte, dann bin ich ' 75 in den $<<<$ Ort anonymisiert $>>>$ und dort bin ich bis Ende '91 geblieben. Und ab Anfang '92 bin ich jetzt hier unten in Bayern. So das sind die drei großen Schritte. Also $<<<$ Ort anonymisiert $>>>,<<<$ Ort anonymisiert $>>>$ war der, der mittlere Teil von '75 bis Ende '91, zu Anfang '92 war ich hier unten. Und die Selbstständigkeit war ab so Ende '95, Anfang '96 dann aber.

I: Also dann waren Sie also dann schon hier?

B: Da war ich auch schon hier. Ich habe überlegt ob ich wieder rauf gehe nach $<<<$ Ort anonymisiert $>>>$, aber ich hatte doch sehr viel Affinität hier unten hin. Jetzt war ich nun auch schon hier und kannte auch welche und insgesamt, sagen wir mal, fand ich Berge und Wasser schöner als nur Wasser. Und dann habe ich gesagt, na dann bleib ich schon hier. Obwohl ich $<<<$ Ort anonymisiert $>>>$ immer noch als schönste Stadt Deutschlands empfinde. Und wenn mich jemand fragt / Vielleicht schiebe ich das kurz 
ein: Mich hat mal jemand gefragt, der sowas wie / mit Heimat und solche Gefühle / und habe gesagt, kann ich nicht so viel anfangen damit, weil Heimat hängt für mich sehr viel mit Leuten ab, ich also nichts / aber ganz sicher habe ich $<<<$ Ort anonymisiert $\gg>>$ Wurzeln. Diese, also diese Faszination, dass die großen Schiffe in die weite Welt fuhren. Und der Hafen hat mich als Kind total fasziniert, und im / fremde Kulturen / damals war nicht Container, sondern da kamen die Kaffeesäcke und die Bananenstauden und so weiter, richtig in echt, ne? So dass sie die sehen konnten an / fand ich / und die verschiedenen Hautfarben, das gab es ja in $<<<$ Ort anonymisiert $>>>$ schon sehr schnell, zumindest im Hafengebiet sodass sie / manche hier unten haben ja ewig keinen schwarzen Menschen gesehen, farbigen Menschen gesehen. Also damit sind wir schon groß geworden. $<<<$ Ort anonymisiert $>>>$ als Tor zur Welt. War ganz sicher, dass ich auch so viel kosmopolitische Gefühle habe / War ja auch schon sehr weit gereist, also auch so beruflich. Mit Chicago viel gearbeitet und dann hier in Europa. Auch bei $<<<$ Unternehmen anonymisiert $>>>$, also da kamen auch die ganzen sprachlichen Notwendigkeiten hinzu. Ich spreche ziemlich gut Englisch, und mein Französisch war mal besser. Jetzt reicht es noch für Nachhilfe für Schüler. (lacht) Aber übersetzten kann ich Französisch noch, nicht, nicht vom Deutsch ins Französische, dafür ist mir die Grammatik nicht mehr so sicher, aber vom Französischen ins Deutsche.

Aber jetzt wieder zurück, dann war also die Zeit hier. Und da habe ich gesagt: „Ok, das habe ich dir versprochen, dass ich für dich da bin.“ Und mein Vater war bis zuletzt klar. Meine Tochter hat noch zwei Wochen vor seinem Tod mit ihm über die Lehmann-Brothers Pleite gesprochen. Aber körperlich war alles kaputt, also bis eben völlige Inkontinenz und auch immer wieder andere Probleme, auch im Krankenhaus und Darmoperation, und wirklich auch so schlimme Sachen. Aber sein Asthma hatte sich so ganz gut einstellen lassen. Da hat eine sehr nette junge Ärztin in $<<<$ Ort anonymisiert $\gg>>$ das gut hingekriegt, dass er vier Jahre gelebt hatte noch. Das war ein Geschenk, das kann ich nicht anders sagen. Man lernt seinen Vater noch mal ganz anders kennen. Das ist eine völlig andere Beziehung in dieser Pflegesituation. Aber ich habe meine Selbstständigkeit überhaupt nicht mehr ausüben können nachher. Ich habe es erst versucht, dann musste ich Termine verschieben, das macht kein Kunde auf Dauer mit, das mal einmal. Aber das geht nachher nicht wenn das ständig ist. Und ich war dann auch manchmal nicht richtig dabei, weil ich wusste, mein Vater hat jetzt eine 
Operation, oder jetzt ist er gestürzt oder sonst irgendwas. Also da, da ist eine Anspannung, die man sich kaum vorstellt, was, was wirklich so eine, eine Dauerpflege, was das ausmacht. Und wenn man es gut machen möchte, wie ich - alles was ich anpacke, möchte ich schon gut machen - dann ist man eben auch ganz dabei, oder man lässt es, ja. Hab ich auch nur ganz wenig Hilfe gehabt von den Leuten, die also auch so unzuverlässig sind. Ich muss ehrlich sagen, jeder der angewiesen ist auf fremde Hilfe, der tut mir jetzt schon leid. Also, es ist, es ist wirklich irrsinnig was da passiert. Hat aber jetzt nicht mit dieser / mit unserem Thema zu tun. Nur, da habe ich dann halt die Verpflichtungen nicht mehr erfüllen können. Der Verdienst ging rapide runter. Und daraus ist / und damit vor allen Dingen auch dann mit der Immobilie, die dann eben nicht mehr bedient werden konnte, und das auch nicht gebracht hatte, den Wert, den ich reingesteckt hatte. Hätte ja noch auch noch sein können, dass das wenigstens gut ausgeht. Hat dann die Insolvenz bewirkt. Und da ich aber dann nicht mehr so ganz neu war, ist das / die ist ja jetzt erst bis letztes Jahr, also 2013 gegangen. Also das ist / das nennt man Regelinsolvenz, weil ich ja ein / eine Personengesellschaft war, wenn Sie so wollen. Dadurch ist es also keine GmbH, und dadurch nennt man das Regelinsolvenz. Ist eigentlich eine Privatinsolvenz, weil sie haften mit ihrem allen was sie, was sie privat haben. Und das habe ich nicht mehr auffangen können. Ja und jetzt im Alter von 66 muss ich wieder neu starten. Und Sie haben ja jetzt nur gefragt wie, wie das so entstanden ist oder den Lebenslauf, den habe ich Ihnen damit jetzt geschildert. Sie haben sicher noch ein paar Fragen was dann dazu ist. In dem Sinne, sage ich ihnen jetzt nur schon als kleine Arabeske, haben mir viele gesagt, geh doch nach England oder nach Frankreich, da hast du nur ein Jahr. Und, das kam für mich nicht in Frage. Ich hätte wohnen müssen / wie / mit Vater noch und so, das / das hab / das ging noch parallel. Mein Vater ist Ende 2008 dann gestorben. Und / also wäre überhaupt nicht gegangen, dass ich da das zeitlich hätte so steuern können. Aber darauf kommen wir sicherlich noch im Detail, Sie haben dazu noch ein paar Fragen, was das ganze Insolvenzgeschehen betrifft.

I: Ja. Würden Sie noch einmal rausstellen was jetzt genau Ihrer Meinung nach die Hauptgründe waren für die Insolvenz, also einerseits der Rückgang der Aufträge /

B: Ja, ich habe nicht mehr akquirieren können. 
I: Und wie war das mit der Immobilie? Das habe ich noch nicht so ganz verstanden.

B: Die Immobilie muss man ja bedienen, also diesen Wert und den Kredit bedienen sie. Und das konnte ich nicht mehr und dadurch musste Sie verkauft werden.

I: Hat aber dann nicht mehr das eingespielt /

B: Ja über 100.000 Euro Verlust hat es nicht mehr eingespielt, und ich habe sie aber immerhin dann noch verkauft, zwar für ein Appel und ein Ei, um es mal so zu sagen. Aber ich habe zum Glück nicht diese Zwangsversteigerung, das ist ja dann noch blöder. Das habe ich also abwenden können.

I: Könnten Sie mal den, den Ablauf des Insolvenzverfahrens quasi schildern mit allen Höhen und Tiefen. Wie das abgelaufen ist.

B: Wie die Jahre abgelaufen sind?

I: Ja.

B: In meinem Erleben oder im sachlichen Bereich.

I: Beides.

B: Fangen wir mit der Struktur an. Das fängt an, dass das Finanzamt Forderungen stellt, die ich noch wie verrückt versuchte / ich sag's ruhig in größer / kann ich ruhig Zahlen nennen?

I: Ja.

B: Also, ich sag jetzt mal, ganz genau habe ich sie nicht mehr im Kopf, aber sagen wir, das waren 30.000 Euro Forderung, 15 hatte ich erfüllt. Habe ich gedacht: „Ok, habe ich noch 15 , die teile ich mir noch irgendwie auf." Aus den 15 machten die mit 
Gebühren wieder 26, nur mit Zuschlägen und sowas. Das habe ich nicht mehr geschafft. Und dann kommt das Finanzamt und sagt: „Von oben haben wir die Order, solche wie Sie sollen wir platt machen.“ Wörtlich gesagt. Das war die Begegnung, ja? "Solche wie Sie sollen wir platt machen". Obwohl ich erklärt habe, dass ich einen Dienst in unserem Land leiste, indem ich für einen alten Menschen da bin. Null Interesse. Und ich hatte auch immer noch Einkünfte, sodass da auch was wieder geschehen ist. Aber durch diese Gebühren - es ist ungeheuerlich, und ich muss Ihnen wirklich sagen, wenn ich könnte, würde ich dagegen nochmal vorgehen - was der Staat an, an Säumniszuschlägen und Aufschlägen in solchen Fällen sich erlaubt, draufzutun. Es ist ungeheuerlich! Muss ich wirklich sagen. Und solche Sätze wie "Solche wie Sie sollen wir platt machen". Sie sitzen da und sagen "Bin ich im richtigen Land, in der richtigen Behörde?"

I: Das ist krass, ja.

B: "Solche wie Sie sollen wir platt machen" war dann auch das Leitbild. Und dann kommt halt / dann kommen die, die, was sind das, so eine Art Gerichtsvollzieher vom Amt, also vom Finanzamt. Der guckt, ob was zu verwerten ist. Und dann läuft das so seinen Weg, dass sie dann sagen "Ok, ich habe nichts". Und dann müssen Sie Insolvenz anmelden.

I: Also der Hauptgläubiger war quasi der Staat?

B: Nein, der Hauptgläubiger war die Wohnung.

I: Die Wohnung, ok.

B: Der Hauptgläubiger war die Wohnung, und der Zweite der Staat. Ich hatte zum Glück nicht so viel. Ich habe keine Einkäufe oder irgendwas gehabt. Sondern es war, es war, es war die, die Bank mit der Wohnung, also die Hypo- / der Hypothekenbetrag. Es war der, der Staat, und es war noch ein Kredit, den ich aufgenommen hatte. Privat. Ja, und die Sparkasse. Das waren die Wesentlichen. Weil ich natürlich da auch was überzogen hatte, um wieder das Finanzamt zu bezahlen, so 
wie das so ineinander sich verschiebt. Wenn das losgeht, haben sie alle drei Lebensversicherungen weg. Haben alles Mögliche sonst weg, was irgendwo noch an Wert ist, und was Sie auch für Ihr Alter gedacht haben. Und dann, da ich auch nicht mehr, wie gesagt, erst arbeiten konnte, kam also das ganze Ding in Gang. Und dann läuft so, ich weiß gar nicht mehr, wie das geht. Dann, dann müssen Sie zur Insolvenzverwalterin. Dann erklären Sie ihr das, und ich hab einfach vorher auch alles / Sie müssen dann alle Gläubiger anschreiben, wer verzichtet, wer nicht. Also ein Privater hat verzichtet, dann konnte ich das schon mal wegschieben, musste ich nicht mit benennen. Dann müssen Sie Listen erstellen, dann müssen Sie / Kennen Sie solche Listen?

I: Ich habe noch keine gesehen. Ich kenne es nur in der Theorie.

B: Soll ich Ihnen das einmal zeigen? Wollen wir das mal eben stoppen?

I: Ja.

$<<<$ Unterbrechung der Aufnahme $>>>$

B: Mit dem, wir sollen platt machen. Und dann kam eben dann das Abrutschen in Harz IV. Meine demütigende Situation in meinem ganzen Leben.

„Was will den jemand wie Sie, mit Ihrer Ausbildung bei uns? Wir haben für Sie nichts!"

Ich war immerhin schon über 60. Ich musste jeden Monat fünf Bewerbungen vorlegen. Dann habe ich gesagt: „Geben Sie mir doch einen Job, bewerbe ich mich da gerne." „Ja, wir haben nichts für ihr Alter."

Sag ich: „Ja, woher soll ich es hernehmen?" „Ja, ist Ihr Problem."

Nur, dass Sie es wissen, wie man da behandelt wird! Klar hab ich dann aus dem kleinen Blättchen oder sonst wo her, aus dem Internet, ich hab meine fünf Bewerbungen gehabt, ich hab das eingehalten. Hab ich gedacht: „So kriegt ihr mich auch nicht, mit dem plattmachen." Man ist eigentlich schon platt. 
So, und was schlimm ist - das gehört noch zur Struktur - was wirklich schlimm ist, ist die Wohnsituation. Das Amt sagt dann, egal woher sie es holen ihr Geld dazu, das steht ihnen nicht mehr zu diese Wohngröße. Ich hab in so einer Doppelhauswohnhälfte gewohnt in $<<<$ Ort anonymisiert $>>>$.

„Da müssen Sie raus.“ Dann kriegen Sie erst eine Verlängerung, dann kriegen Sie noch eine Verlängerung mit einem Druck, der ist unerträglich! Sie denken, da steht eigentlich schon jemand vor der Tür. Ich hab zum Glück Freunde und Familie gehabt, die mich damals noch mit unterstützten. Weil ich ja auch meinen Vater noch gepflegt hab. Und als er dann verstorben war / da, da konnte ich immer noch mit sagen, ich muss hierbleiben, weil mein Vater hier noch ist, das ist ja der Hauptgrund. So, dann haben Sie einen Druck, irgendwas zu suchen. Da meine Tochter nicht in Harz IV ist und nicht in der Insolvenz, ist die eigentlich immer mit in Sippenhaft genommen worden. Wir haben uns nun mal entschlossen - sie ist immer sehr viel im Ausland gewesen - dass sie mit bei mir wohnt, sozusagen als Standbein. Und wenn sie dann woanders ist, ist sie eben woanders. Arbeitet / hat sehr viel im Ausland gearbeitet. Und wenn sie dann da rauskam, war sie eben wieder da. Das heißt aber, wir hätten zusammenziehen müssen. Wir haben immer zwei so Bereiche gehabt, ja, so wie jetzt hier auch, halbe, halbes Haus geteilt, jeder hat ein Bad. Nur die Küche gemeinsam. Dann hätten wir zusammen auf 60 Quadratmeter ziehen müssen.

Da habe ich gesagt: „Da wird sie ja mit betroffen, das geht doch gar nicht. Wo sollen wir denn mit unseren Sachen hin?"

„Ja, müssen Sie wegtun!"

Dann sag ich: „Und wenn ich es dann wieder brauche?" „Ja, müssen Sie wieder neu kaufen."

Was Sie für Sätze hören, es ist unerträglich! Es ist wirklich unerträglich! Und wenn ich jetzt höre, dass sie, dass, dass Herr Alt sagt - Sie wissen wer Herr Alt ist? Nach Herrn Weiße / Weiß, Weiß, Weiß wie heißt der Chef des Arbeitsamtes in Nürnberg? Der Bundesagentur. Weiß, Weiße heißt der, glaub ich. Weiße nicht Weiß. Und der Herr Alt ist einer seiner, seiner Topmanager - soll es ja jetzt noch weniger individuell eingestellt werden, weil die / das Personal zu hoch ist, sondern noch pauschaler. Sie sitzen dort, beim, beim Amt und denken: „Wo bin ich hier?“ Die ganzen Ausländer wissen genau, was sie für Zettel brauchen, für dies brauchen, für das brauchen, und ich 
wusste gar nichts. Ich wusste überhaupt nicht, was mir zusteht, was ich haben darf. Ich musste fragen. Und dann kriegen Sie sowas wie eben /

Und Sie müssen tun, als ob sie doof sind. Das ist mir sehr schwergefallen. Sie können auch nicht sagen: „Entschuldigen Sie, wie reden Sie eigentlich gerade mit mir?" Auch das geht nicht. Macht, macht das Gegenüber nur ärgerlich. Die sind ja der Chef. Und damit konnte ich ganz schlecht umgehen. Und so Sätze: „Was wollen sie denn hier." / „Mit Ihrem" / „Für Sie haben wir nichts" / und / also / Sätze die man eigent... / da hab ich wirklich geweint. Und deswegen hab ich gesagt, es gibt Situationen, wo ich wirklich sage: „Wie soll ich hier jemals wieder Land sehen?"

Dann kam so ja, gezwungen, raus / dann haben wir was gefunden. Das war ein kleines 50er Jahre Häuschen, oben und unten auch getrennt mit einer Tür. Da schickt uns die Dame vom Amt - „Warum glaube ich ihnen das nicht, dass das so getrennt ist?“schickt sie uns noch jemanden vorbei. Dieser Kontrolleur, der war ganz peinlich berührt und sagt: „Ja, ich seh ja, ich seh ja alles und so." War so klein mit Hut, aber er musste, er musste kommen, ob wir da nicht gelogen hatten. Die Unterstellung, dass Sie erstmal bescheißen, ist beim Amt drin. Und die Begründung heißt, wir werden ja immer beschissen.

Da sag ich: „Das ist trotzdem nicht witzig! Sie müssen jedem wieder neutral begegnen und können nicht sagen, der andere hat beschissen, also macht der das auch."

Funktioniert eigentlich nicht so. „Ja, aber doch, sonst" / tausend doofe Sachen. Fand ich ziemlich unerträglich, diese Unterstellung: „Du willst uns auch bescheißen.“ Ich sag es jetzt bewusst auch so, so, so weil so ist das. Da wird nicht geschummelt oder so, das würd man nicht mehr sagen, sondern das ist Betrug. Diese, die

Betrugsunterstellung ist grauenhaft. Und Sie sind in Not, ja, Sie müssen ja irgendwas essen oder irgendwie ein Dach über den Kopf haben. Und dieses Gefühl war für mich nicht gut erträglich.

Dann haben wir also dieses Haus / Häuschen hier gefunden. Das war auch Betrug, weil die Vermieter haben / also muss man noch dazu sagen, Sie können natürlich nur suchen ohne Makler. Sie müssen möglichst günstig da irgendwie hinkommen, und die Miete muss bezahlbar sein. Also, es ist so klein eingegrenzt, was sie suchen, Sie suchen nicht im freien Markt, im ganzen freien Markt, sondern Sie versuchen in einer Nische irgendetwas zu finden. Und einer, der keine Schufa-Auskunft verlangt. Also, Sie suchen wirklich / und die Wahrscheinlichkeit, dass Sie auf jemanden treffen, der 
auch irgendwie Dreck am Stecken hat, sag ich jetzt mal, für sein Vermietobjekt ist ziemlich hoch. Das habe ich allerdings nicht so vermutet, dass einem Leute direkt ins Gesicht lügen. Das war also ein Haus, da standen / da stieg bei Starkregen der, der Gulli, da kam die ganze Gülle hoch im Keller. Und oben hatten die - ich hab mich immer gewundert warum die Kunststoffrauputz in den Wohnräumen hatten, was man eigentlich so nach draußen bringt. Ja dann wusste ich das. Da kam der ganze Schimmel überall durch, und zwar schneller, als die vermutet hatten. Die hatten gedacht das hält jetzt 2 Jahre, und dann sind wir es, die nicht lüften, ja? Aber es kam leider schon nach drei Monaten, da konnte man uns das mit dem Lüften nicht unterstellen. Wir hatten es ja eingangs. Mit Anwalt / mit / also wirklich, es ist so grauenvoll. Und dann haben die uns mit einer Klage bedroht, die ich überhaupt nie kannte, eine Urkundsklage. Das heißt, die wollten nicht einsehen, dass sie, dass wir Mietreduktion machten und sie gezwungen haben, da etwas zu regeln und zu machen und zu korrigieren. Und da haben sie uns einen Urkundsprozess an die Backe gehängt. Das heißt - und an dem Prozessgeld muss ich immer noch abzahlen - das heißt, sie werden verklagt, sie rutschen rein und haben niemanden, der ihnen hilft. Es ist wirklich ein Graus gewesen. Dann sind wir da weg. Mit Ach und Krach haben wir das dann geschafft, weil wir dann einen Termin ausgemacht hatten, durch diese gerichtliche Auseinandersetzung.

Haben ein Vergleich gemacht, und ich sage ihnen warum. Meine Tochter war so böse mit mir. Die hat gesagt: „Wir hätten das durchziehen müssen!" Da hatte ich nicht mehr die Kraft nochmal zwei Jahre mit diesem Gericht da hin und her. Und der Anwalt hat nur Shit geschrieben und trotzdem / Ok, muss man akzeptieren / hatte ich kein / Und der Richter hatte wieder unseren Schriftsatz nicht gelesen, das ergab sich aus der Diskussion. Da waren Gelder, die wir zurückgelegt hatten, extra auf ein extra Konto, als, als Reserve, und das hat er verwechselt. „Ach so, das liegt da, wo stand den das wo stand /“ Da hab ich gedacht, wir verlieren, wir verlieren, so eine / Das zweite war die Räumungsklage. Hab ich gedacht, das kann ich meiner Tochter nicht antun. Eine Räumungsklage zu verlieren ist ja furchtbar. Sie kriegen ja nie wieder eine Wohnung. Und da sie Mitmieterin war, war das also für mich zu riskant. Und da habe ich gesagt: „Nein, dann gehe ich den Vergleich ein.“ War feige, war schlicht feige, aus Angst der Richter liest nicht alles und, und akze- / und, und hat wieder nur flücht- / ist dem alles / das war ein, ein, ein riesen Berg von Schriftsätzen. Das waren dann zwei Prozesse, 
die er zusammenführen musste. Das heißt für einen Richter wirklich Arbeit. Und bei der Menge, die die haben, wusste ich, dass, dass versucht der schnell, schnell zu lösen. Dann sind wir umgezogen, nach $<<<$ Ort anonymisiert $>>>$ in einen Neubau mit weißer Wanne und 20 Jahre Garantie und dies alles und pipapo. Viel zu teuer. Meine Tochter hatte dann aber einen guten Job. Dadurch konnte ich das machen, und ich hab dann meine Rente genommen. Das Arbeitsamt zwingt Sie dann irgendwann in die Rente, wenn Sie so alt sind. Egal, ob sie Verluste haben. Sie müssen ja Abzüge machen, 0,3 Prozent jeden Monat. Das heißt, ich bin gestraft bis an mein Lebensende, dass ich in dieser Insolvenz war und arm war und nichts mehr hatte. Mit insgesamt zehn Prozent Abzug bis zum Nimmerleinstag. Weiß nicht, ob das nicht eigentlich auch gerecht ist. In dem Fall, ja? Wenn Sie, wenn das Arbeitsamt Sie da raushaben will.

Ich hab dem aber zugestimmt, weil ich keine Lust mehr hatte mit Hartz IV und mit diesen ganzen Behördengängen. Hab ich gesagt, dann mach ich das, dann verzichte ich drauf. Auch wenn ich es nicht gerecht finde, dass man durch sowas noch sein ganzes Leben lang bestraft wird. Aber gut, das ist dann ein Abwägen gewesen. Und dann hab ich das halt gemacht. So, dadurch, dass ich die Rente hatte, die deutlich über Harz IV liegt, weil ich ja mal wirklich gut verdient hatte, auch wenn ich jetzt schon 20 Jahre in Selbstständigkeit war.

Und dann diese Situation mit dem Wohnen. So waren wir wieder in der Situation, dass das am See liegt, und der Grundwasserspiegel bei den Unwettern im Juni 2011 uns wieder alles unter Wasser setzte. Und wieder hatten wir Vermieter, die die Versicherung nicht richtig informiert haben, weil sie Angst hatten, was zu erhöhen und zu verlieren von ihrem Versicherungsschutz. Und wir blieben wieder auf Geld hängen. Und wir haben so viele Sachen entsorgen müssen, die alle vermatscht, verdreckt, versonstwas waren. Und dann sind wir hierher. Und deswegen bin ich jetzt so angefasst, wenn hier irgendwo wieder Wasser sehe. Wenn Sie innerhalb von vier Jahren / Sie haben kein Geld, und Sie müssen innerhalb von vier Jahren drei Mal umziehen. Und Sie verlieren wegen Wasserschäden sehr viel, dann ist irgendwann die Kraft ganz schön am Ende.

I: Ja, das glaube ich. 
B: Wirklich auch nur am Ende. Rein physisch auch die Kraft. Nerven auch, aber damit kann ich eher umgehen. Überhaupt aber auch physisch, dass sie schleppen und machen und tun, Garten und alles, was dann dazu gehört.

So, das waren jetzt mal die Befindlichkeiten, ansonsten hab ich, wie gesagt / Ok, wenn ich jetzt raus bin / ach so, hab ich mit der Insolvenzverwalterin / die hat gesagt, Sie können etwas dazu verdienen. Aber ich sage Ihnen, also wenn Sie im 400 EuroBereich bleiben, dann ist das mit der Rente sehr schwierig. Das müssen wir alles so schwierig verrechnen. Und Sie kriegen höchstens selber raus knapp 100 Euro. Ich verlange es nicht von Ihnen, weil ich durch ihre Rente, Sie haben ein Einkommen, kann ich das abziehen, kann ich was behalten. Und das Verteilen, natürlich nicht viel, sagt sie, aber vielmehr wäre es auch nicht für die Summe, wenn Sie jetzt arbeiten würden. Aber Sie haben, wir haben alles viel mehr Aufwand an Verrechnungen. So und jetzt, nachdem ich draußen bin, kann ich nun wieder verdienen. Ja, und nun ist, dass ich so mit / dieses Jahr werde ich 67, das natürlich auch nicht grad ganz einfach ist. Das heißt, ich muss zusehen, dass ich noch irgendwie zehn Jahre /

Also ich hab ein riesen Glück, ich habe eine sehr, sehr, sehr stabile Gesundheit (hustet, lacht). Ich habe eine, eine wahrscheinlich wirklich überdurchschnittliche Fähigkeit der Resilienz. Und ich habe eine irrsinnige Kreativität, dass ich noch etwas beitragen möchte. Die Gesellschaft lässt mich teilweise, teilweise nicht. Mein angestammter Beruf, da sind so viele Neuheiten und so viel junge Leute, die alles auf schnell und billig haben wollen, was überhaupt nicht meine Erfahrungsgrundlage ist. Ich bin auf analytisch, wertvoll. Das kostet dann halt auch ein bisschen mehr, ja? You pay / You get what you pay for, ist ein alter Spruch. Also, wer alles auf billig will, kriegt auch Schrott. Wenn Sie sehen, was für Analysen da im Internet gemacht werden. Da werden Umfragen über Facebook gemacht und da tu / denken die, die Masse ist Klasse. Überhaupt nicht wahr. Es wird noch eine Weile dauern, bis die Welt das wieder kapiert, dass sie damit nicht den Verbraucher wirklich richtig einschätzen können, vor allen Dingen diesen demographischen Wandel. In dem ganzen Verschub, der / es, es gibt mehr so / früher gab es Cluster, die konnten Sie bilden, und das beschrieb sich Verbraucherzielgruppen / konnten sich so beschreiben, das waren die, was weiß ich, die Sparsamen, und das waren die Luxusorientierten und, also nur um jetzt irgendwas zu sagen. Das oder die Alten. Also, Alles was dann ab 60, 65 war, konnte man wirklich im Sinne von, nicht mehr innovativ und so / das konnte man 
sozusagen / können sie nicht mehr. Es gibt Linien, es gibt Linien / es kann heute jemand, der also, ich würde bestimmt sagen, von meiner Art der, der Neugierde, der Innovation, auch der Energie noch, bin ich ganz bestimmt wie, wie durchaus jemand mit 45 sein kann, der schon eigentlich ein bisschen alt ist. Also, da können Brücken über 20 Jahre sehr wohl geschlagen werden. Und da habe ich natürlich auch ein bisschen Glück, dass meine, meine Bedingungen körperlich und geistiger Art so sind. Aber nichts desto weniger spüre auch ich, dass ich nicht mehr die Kraft hab wie vor 20 Jahren. Und das ist das Problem mit so einer langen Insolvenzzeit. So jetzt kommen Sie wieder.

I: Wann haben Sie denn so richtig für sich auch realisiert, dass ein Insolvenzverfahren nicht mehr abwendbar ist? Sträubt man sich da zuerst dagegen? Ist das ein Erkenntnisprozess? Wie war das bei Ihnen?

B: Ja, es ist ein Vermeidungsprozess. Sie versuchen alles noch um diesen, diesen Weg zu vermeiden und zwar genau aus dem Grund, weil in Deutschland Scheitern ein Stigma ist. Weil ich durch die ersten Sätze wie eben vom, vom Finanzamt oder so, mitgekriegt habe, wie gruselig es werden könnte. Und auch wie / Sie werden ja runtergedrückt auf dieses pfändungsfreie Einkommen, und damit ist nicht gut Leben, um es mal deutlich zu sagen. Also, Sie sträuben sich natürlich vor einem Absturz, Sie sträuben sich vor einem Unbekannten. Sie glauben bis zuletzt, man könnte es irgendwie noch schaffen, dass zumindest die Insolvenz vermieden wird.

Und dann gab es irgendwann einen Punkt, wo ich gesagt habe: „Ok, let‘s do it!" Und dann bin ich aber auch geradeaus gegangen. Dann habe ich alles in die Wege geleitet, um das sauber hinzukriegen. Also nicht mit, mit wie sagt man, Kopf in den Sand stecken oder so, gar nicht. Also, das gar nicht. Ich habe es erst vermeiden wollen, hab gekämpft dagegen, ganz klar. Aber dann habe ich gesagt: „Ok, schaff ich nicht." Und mein Vater war auch noch da, den ich pflegen musste, hab ich gesagt, nein schaff ich nicht mehr. Dann, dann geh ich den Weg. Und dann bin ich ihn ganz konsequent gegangen, also mit allem Selbstorganisieren. Hab ich nachgelesen im Internet, wie ist der Ablauf, hab Bücher mir geholt. Dann habe ich, wie gesagt, diese Listen / da gibt es / da können sie sehen wie Sie das machen müssen, das das rechtlich einwandfrei ist. Die hab ich verwendet. Hab also die Gläubiger alle angeschrieben, hab mir diese, wie 
das da hieß - hab ich jetzt vergessen - diese Einverständniserklärung für den Verzicht hat ja alles rechtlich einen bestimmten Ausdruck - einzuholen. Und haben eben das mit der Wohnung in Gang gesetzt, also ganz aktiv, dass wir die los werden noch. Und, ja, so / also alles Schritte die dann sein müssen, gemacht. Und hab mich auch / und Sie hatte dann so niedlich gesagt, meine Insolvenzverwalterin / irgendwo stand es dann auch / Ich kann mich noch gut erinnern, sagt sie: „Wie Sie dasaßen und voller Mut und Zuversicht Ihren, ihr, ihr diese, diese schreckliche Zeit" - also schrecklich hat sie nicht gesagt aber - „diese Insolvenz angenommen haben.“ Das hab ich dann auch gemacht. Also, ab da war nicht mehr: „lass mich bloß in Ruhe damit", sondern dann habe ich gesagt: „Ok, da bist du jetzt, und jetzt handelst du das so gut es geht.“

I: Und was waren so die größten Probleme, Schwierigkeiten oder Hürden, denen sie so begegnet sind?

B: Einmal die unvorstellbare Frechheit von Ämtern. Dann, ja eigentlich nicht nur von Ämtern, dass Sie eigentlich wie ein, wie ein, wie soll ich sagen / wie ein halber Verbrecher auch so mit Banken und solchen Leuten behandelt werden. Und dass Sie wissen, Sie rennen in eine, in eine Situation rein, die wirkliche Armut bedeutet. Das, das war nicht leicht. Ich hatte immer / wir haben also zwei Autos gehabt, jetzt haben wir schon seit sechs Jahren gar keins mehr. Damit kann man leben. Aber wenn zum Beispiel / die schlimmste Zeit in der, der Insolvenz mit dem kleinen Betrag oder auch mit Harz IV oder so was dann auch noch war. Die schlimmste Situation war, dass Sie kein, kein gesundes Essen kaufen können. Sie können nicht gutes Obst kaufen, Sie müssen irgendwie zusehen / Gemüse, irgendwo sehen, dass Sie noch halbwegs günstig was finden. Und wir ernähren uns immer gut. Wir essen gutes Brot. Musste ich zusehen, wie wir eine Balance finden. Auf Fleisch kann ich verzichten, dann gibt's eben nur einmal das, aber so, so Grundnahrungsmittel, wie Gemüse, Obst und Brot, das in einer guten Qualität zu haben. Ich kauf nicht Luftbrot beim Lidl oder irgendwas. Auch wenn es vielleicht nicht schlecht ist, darum geht es nicht. Mit nicht schlecht / sie sterben nicht davon, aber ich wusste, ich muss mindestens meine Gesundheit erhalten. Und das war schwierig.

Und dass ich mir noch nicht einmal ein Buch und eine Zeitung kaufen konnte. Und auch nicht mal einen Cappuccino auf dem Marktplatz oder so. Das heißt, ich brauch 
nicht essen zu gehen, das ist alles nichts, diese, diese Einschränkung von Luxus kann ich. Aber ich möchte mir einen Cappuccino in einem Café leisten können. Und das können Sie nicht mehr von dem Geld. Was übrig bleibt, ist wirklich in unserer Gesellschaft mit den hohen Mieten hier unten nicht mehr drin. Und das hab ich als / das ging mir auch an meine / an mein, an mein Selbstbewusstsein und mein, ja meine Lebensqualität in ganz entscheidendem Maße.

I: Gibt's auch irgendwas Positives, was Sie aus der Erfahrung rausziehen?

B: Ja, natürlich. Das Eine, das Whichtigste ist, mit wie wenig Sie letztlich auskommen können. Was man/ wie man sich reduzieren kann. Wie man mit dieser Reduktion auch / oder welche, welche Genüsse man mit der Reduktion noch möglich machen kann. Dass wir zum Beispiel sehr, sehr viel mehr spazieren gehen. Aber Sie wissen hier unten - selbst wenn Sie den Zug nehmen - wenn wir von hier nach München, dann kostet das 27 Euro. Da wir da irgendwas trinken müssen, sind Sie also mindestens, sag ich jetzt mal, 35 Euro los. Das ist für eine, nur, nur einen kleinen Bummel, dass Sie mal Großstadt sehen. Ich muss mal, ich muss auch mal / wissen Sie ich kann auch verzichten auf Urlaub. 2006 war mein letzter Urlaub, damit kann ich auch leben. Obwohl ich jetzt ganz gerne mal wieder - es ist ja jetzt doch acht Jahre her - ganz gerne mal wieder wegfahren würde. Wir haben / ich weiß noch, wie wir den ersten Ausflug gemacht haben nach Oberstaufen mit dem Zug. Dann haben uns diese 28 Euro / haben unser Fresspäckchen mitgenommen und haben dann oben auf der Alm uns ein, einen Almdudler gegönnt. So, da fühlten wir uns wie die Könige. Das heißt, Sie kriegen einen anderen Genussaspekt, der nicht nur Kaufen heißt, sondern anders Genießen. Das ist ganz klar gut. Aber das könnte man ja auch ja anders, weiß ich nicht, wie man das anders lernen könnte, weiß ich nicht.

Und Sie lernen natürlich wie immer, wenn auch wenn, wenn Sie zum Beispiel einen Todesfall in der Familie haben. Sie leben bewusster. Das ist also, ja, ist nochmal das Bewusstere in den Tag erleben und auch den Tag annehmen, möchte ich mal sagen, ja. So steht man sonst auf, sagt, ,Ja, heut, heut machst du das, machst du das, machst du das." Hast deinen Plan oder, oder nicht. Je nachdem, wie man strukturiert arbeitet. Da ich aber immer strukturiert war, habe ich / bin ich nie in so ein Loch gefallen, sondern ich habe mir immer Aufgaben genommen. Ich hab dann versucht, neue Methoden zu 
entwickeln oder irgendeine Idee zu verfolgen, sehr viel zu lesen, mir Gedanken zu machen über, ja / mich vielleicht politisch bisschen zu engagieren und sowas.

I: Sie haben ja in den letzten Jahren auch wenig gearbeitet, oder? Sie haben jetzt nicht den ganzen Tag, jeden Tag acht Stunden irgendwo in einem Büro absitzen müssen.

\section{B: Nein.}

I: Was haben Sie mit Ihrer Zeit gemacht? Wofür haben Sie sie genutzt?

B: Ja, also ich hab immer was / ich hab nie Langeweile. Ich habe in meinem ganzen Leben noch nie Langeweile gehabt. Das kann ich wirklich mit Fug und Recht sagen, weil, ich kann mich auch hinsetzen und mal eine Stunde nur die Vögel in der Natur beobachten. Aber ich habe / ich lese sehr gerne und auch sehr viel.

Und ich habe mich anders beteiligt, in dem ich meinetwegen dann auch / also zum Beispiel bin ich zu den anonymen Insolvenzlern gegangen um zu gucken, ob man seine Erfahrungen weitergeben kann, oder ob die mir was geben können. Ich habe / was hab ich denn noch / ja, ich habe mich in der Familie ein bisschen engagiert / meinen Neffen zu helfen, der sein Abitur machte, und dann startete sein Studium. Dann war der bei uns hier / Monat während des Abiturs und danach nochmal während Studiumbeginn vier Wochen. Dann, ja, ich kann Ihnen das gar nicht sagen, ich hab / ich denke sehr viel, das heißt, ich habe eigentlich so getan, als ob ich arbeite. Ich habe versucht mich hinzusetzen und auch mit ein paar Bekannten zu sagen, könnten wir das machen, könnten wir das machen? Ich habe also kommuniziert mit denen, die noch im Leben stehen. Ist das von Interesse, ist das was Whichtiges? Könnte man da ein Angebot draus machen? Das habe ich denen dann zugespielt.

\section{I: Schön.}

B: Ja, so. Also da / das hab ich / Ich hatte da gar nicht drüber nachgedacht, aber Sie haben recht. Ich hab eigentlich dadurch, dass ich aber selbstständig war und immer meine / also davor auch schon eine ganze Weile, ja, seit '95, '96 / Sie können sich nur selbstständig machen, wenn Sie ihren Tag strukturieren können. Wenn Sie ihre 
Arbeiten erledigen. Wenn Sie das nicht schaffen, dass Sie sagen: „Oh, ich muss ja nicht aufstehen." Ich bin jemand, der morgens langsamer in Gang kommt. Ich, also, frühstücke sehr gerne lang. Aber ich arbeite sehr gerne ruhig bis zehn, elf abends, manchmal auch bis nachts um eins. Je nach dem, wenn ich eine interessante Geschichte hab. Also, ja, ich habe wirklich solche, solche Projekte beschrieben für irgendetwas, oder mir Gedanken gemacht oder eben auch wirklich viel gelesen. Sehen Sie, mich interessieren eben auch Sachen. Wir sind in einer, einer Transformationsgesellschaft, und das wissen wir noch gar nicht, wie spannend diese Transformationsgesellschaft ist. Und da bin ich in dem Blog von Professor Malik mit dabei immer mal und lese auch sehr gerne, der auch sehr viel in dieser wirtschaftlichen Geschichte hat. Und jetzt hier das Ende der Wirtschaft wie wir sie kennen. Ab jetzt zählt der Mensch. Ich sag nur, weil es interessieren mich solche Bücher. Neustart. Wir haben, wir haben den Menschen wirklich vergessen. Und wenn Sie sehen mit wieviel Burnout, gab es überhaupt nicht früher - mit wieviel kaputten Menschen, aggressiven Menschen wir jetzt mittlerweile umgehen, die, die, also auch sehr unter Druck stehen an ihrer, an ihrem Arbeitsplatz. Manchmal, Sie sehen, wenn, wenn in der wieder irgendwelche Reportagen kommen über schreckliche Bedingungen. Aber, aber zum Glück gibt es mutige Menschen, wie jetzt diese eine Praktikantin bei REWE, die 17.000 Euro nachbezahlt bekommt, weil sie ausgenutzt wurde bei ihrem Praktikum. Die hat geklagt. Das können sie sich nur erlauben, wenn sie ein bisschen Geld im Hintergrund haben, sonst können Sie sich so eine Klage nicht erlauben. Und das / unsere Gesellschaft verändert sich, durch die / den demographischen Wandel, müssen wir die Älteren anders einbinden. Das wir uns alle so wehren / ich hab mich / habe zum Beispiel / das hab ich auch in der Zeit gemacht / so ein bisschen verfolgt, wie sich das Älterwerden äußert. Wie das passiert. Es gibt wirklich viele Menschen, die sich ja sträuben mit dieser Rente mit 67 oder noch später. Ist für mich überhaupt kein / sie sehen ich werde 67 / also ich habe überhaupt gar kein Problem noch später zu arbeiten. Aber was natürlich passiert ist, dass diese Menschen nicht mehr in so einer Tretmühle sein möchten. Mit diesem Druck, der zum Teil da ist, der ja auch größer geworden ist als früher.

I: Wobei das die Jungen ja eigentlich auch nicht wollen. 
B: Die wollen das auch nicht, aber die könnten das grad noch aushalten. Die wollen das gar nicht. Und die ganz jungen, glaub ich, da kommt auch ein Wandel dagegen. Diese Mittelschicht, die hat sich noch nicht getraut zu formieren. Die Jüngeren sagen, mach ich nicht. So, ja. Ich geb doch nicht alles auf, nur für die Arbeit. Und recht haben sie, wir haben jetzt zum Teil gar nicht gelebt. Was hab ich in meinem Leben geschuftet! Ich hab meine Familie auch, meine Tochter, also das war schon nicht so einfach. Und Sie sehen, Job und Kind, es blieb keine Chance noch für einen Partner, hätte ich nicht mehr unterbringen können, wenn Sie so wollen. Und das sind natürlich auch so Entwicklungen, warum mir diese Zeit überhaupt nicht schwergefallen ist. Also, ich hab / ich bin nicht versunken. Ja, das / habe ich gar nicht daran gedacht, aber das könnte natürlich sein, dass man versinkt in ein Loch, in eine Bedeutungslosigkeit, in ein Ausgeschlossensein. Das habe ich nie erlebt. Weil, ich habe mir diese Kontakte gehalten, wo ich mit teilnehmen kann. Hab natürlich auch das Glück, dass ich meine Tochter hab, mit der ich viel diskutieren kann. Wie sich zum Beispiel junge Leute entwickeln, was da whichtig ist. Und eben auch gerade jetzt hier mit unserer / diese Transformation. Unsere Institutionen funktionieren nicht mehr. Das ist einfach nicht mehr zeitgemäß. Das ist / diese, dieses nur nach, nach Shareholder Value oder Profit denken ist Käse. Sie müssen sich an den Menschen ausrichten, Sie müssen sich am Kunden orientieren. Wenn Sie dem was Gutes tun, dann ist der bereit dafür zu zahlen. Wenn Sie den aber nur miese Schicke geben, dann will der das nicht mehr. Oder unter Druck setzten oder irgendwas. Wir, wir wollen eigentlich unser Leben. Ich mein, das ist ja auch schon schwierig genug. Wir wollen es zumindest mit einer gewissen, also, auch Leichtigkeit und auch Freude oder auch familiäre Bindungen, soziale Kontakte, leben. Ohne, dass das immer nur gleich / es ist ja so übergeschwappt, wissen Sie, in diese Spaßgesellschaft, wie man gesagt hat. Also, das ist weit weg von meinem Lebensgefühl. Ich brauch nicht immer Spaß. Das Leben ist nicht Spaß, und das lernt man sehr schnell. Die, die Margarete Mitscherlich hat einmal so schön gesagt: „Wir müssen viel mehr lernen, abschiedlich zu leben." Und da ich die Mitscherlich sehr geschätzt habe, auch ihren Mann, habe ich vielleicht auch das / es ist ja auch ein Abschied gewesen, mit dem ich umgehen musste. Ich musste umgehen von diesem sehr gut situierten Situationen, mit, mit einer Position, wo ich vom Auto über Reisen, über top Leute, die ich getroffen habe, über irgendwelche Events, wo ich eingeladen war. Im, in, in nichts, so. In mich. In mein Umfeld. Und das war mir, manchmal, also 
in / mit Armut leben kann ich nicht so gut. Das kann ich nicht so gut. Ich hab oft gesessen und habe gesagt: „Lieber Gott, wenn du mir doch schon einen guten Geschmack gegeben hast, und wenn du mir Freude an schönen Dingen gegeben hast, dann lass sie mir doch wieder verdienen."

I: Ja, verstehe ich. Was würden Sie denn sagen, wie haben Sie sich durch Ihre Erfahrungen persönlich verändert? Oder wie hat sich Ihre Sichtweise verändert? Wie hat sich auch Ihr Verhältnis zu Ihrer Umwelt oder zu den Mitmenschen verändert?

B: Nicht so einfach.

I: Das ist ja schon ein sehr einschneidendes Erlebnis.

B: Irrsinnig einschneidend. Also, es hat eine Wut auf Organisationen gemacht. Ist durchaus eine Wut auch da gewesen. Ein fast, ein, ein mehr so Nichtfassenkönnen, wissen Sie? So: „Was? Glaub ich gerade gar nicht, was da jetzt geschieht! Wie die mit mir umgehen! Kann ich, kann ich ja gar nicht fassen!" Über eine / aber ich bin vorhin / und ehrlich gesagt, bin zum ersten Mal, eigentlich auf so einen Gedanken gekommen, ob ich nicht irgendwie so versunken wäre, oder irgend sowas. Es hat mit mir selber nur gemacht, dass ich mich wie an Stricken gefesselt / ich, ich kam mir gefesselt vor, und meine Energie konnte ich nicht so leben. Das hat mein Leben sehr eingeschränkt. Ich konnte das, was ich eigentlich aktiv hätte bewerkstelligen, bewirken / ich bin jemand der gerne auch ergebnisorientiert arbeitet, zielorientiert arbeitet. Das konnte ich nicht mehr machen. Aber / und das hat eigentlich auch mein persönliches Gefühl beschränkt.

Aber irgendwie, wissen Sie, Sie können / es gibt so diese schönen Sprüche, die einem manchmal helfen. Also der eine heißt: „Lieber Herrgott, gib mir den Mut, die Dinge zu erkennen, die ich ändern kann. Gib mir die Gelassenheit, die Dinge hinzunehmen, die ich nicht ändern kann. Und die Weisheit, das eine vom anderen zu unterscheiden." Das ist so eine Sache, die man dann manchmal durchdenken muss. Und kann sagen, gut, jetzt versuche wirklich zu sagen, wo kannst du noch was tun, und wo nimmst du es jetzt mal so hin. Das andere ist, dass man eben auch sagt: „Geht nicht, gibt‘s nicht!" Es gibt immer einen Bypass-Weg. Es gibt immer / und dazu gehört, dass man im 
Leben / Solange man eine Wahl hat der Entscheidung, geht's einem nicht wirklich schlecht. Wenn ich noch irgendwas entscheiden kann, irgendwas tun kann, aus meiner Situation mehr zu manchen, kann ich die nutzen. Und dann habe ich das nur auf einer anderen Ebene verschoben. Was mich jetzt mehr belastet, ist, wie lange das dauert, da wieder rauszukommen. Und das hat natürlich jetzt durchaus auch mit meinem Alter zu tun. Und eben, dass ich sage: „Mensch, hab ich ja nicht mehr so viel Zeit." Und ich hab auch natürlich von der Gesellschaft her / gut, wenn ich daherkomme, wirke ich noch nicht wie eine Oma, glaub ich. Aber trotzdem sieht man, dass ich nicht mehr jung bin. Und ein bisschen Glück habe ich noch dadurch, dass ich auch von der Stimme her nicht gleich wie eine Oma bin. Also das heißt, ich kann noch gut telefonieren und solche Sachen machen. Und ich habe die Gabe, mit der Sprache ganz gut umzugehen, ich kann recht gut Briefe formulieren, oder schriftlich formulieren. Und ich bin eben sehr analytisch. Für mich leben Zahlen sofort, ich sehe sofort eine Geschichte aus Zahlen. Und all diese Dinge, wissen Sie, die / oder eben auch Bücher, ich liebe es, wie andere Leute mal, mal irgendeinen Weg denken. Dann kann ich wieder sagen, ja liegt mir oder liegt mir nicht. Und das ist das Einzige, dass ich jetzt finde, dass / also ich finde, das ist jetzt mal genug mit der Armut. Muss ich Ihnen ehrlich sagen. Also ich hab jetzt gerade / I am fed up / also da bin, bin ich jetzt soweit, dass ich sage: „Ich hab keinen Bock mehr auf Armut." Und die ist noch nicht überwunden.

I: Und würden Sie jetzt sagen, Sie sind jetzt eine andere als vor sechs Jahren?

B: Nein, nein, gar nicht. Hat mich eher nur behindert. Wie, wie so ein Stopp-Zeichen. So und jetzt drücke ich die Reset-Taste, wissen Sie? Und die Reset-Taste geht nicht ganz einfach, weil, weil ich zu alt bin. Weil sechs Jahre wirklich lang sind.

I: Ja, ist wirklich lang, das stimmt.

B: Und, und weil ich auch Dinge erfahren habe, die einfach extrem schwierig sind. Die aber durch / in dem System liegen, ja? Die also / die, die Leute machen ja nichts falsch, die müssen das ja so durchziehen. Und die sechs Jahre, wissen Sie, von wegen geläutert, oder Sie müssen lernen mit weniger auszukommen / Also, Sie müssen mit so 
viel Armut auskommen, dass man das nicht unbedingt lernen muss, das ist nicht unbedingt ein, ein Lernprozess. Dann können Sie auch sagen, wir müssen alle durch den Krieg, damit wir Not kennenlernen oder so. Obwohl eins auch richtig ist, wir Menschen lernen nur unter Druck und in der Not. Das, das ist so. Also, um uns weiter zu entwickeln, also, ich bin sicherlich viel / ja, man hat einen großen / ein, einen großen Erfahrungsschatz gebraucht, um aus dieser Situation irgendwie etwas zu machen. Wenn Sie das mit einem geringen Selbstwertgefühl angehen, kann Sie das umhauen. Weil Sie ja / sechs Jahre kommen / Ich sage Ihnen ja, Sie können ja noch nicht einmal einen Cappuccino trinken. Sie können keine Zeitung lesen, kein Buch kaufen, das müssen Sie sich schenken lassen. Das finde ich entwürdigend, muss ich Ihnen ehrlich sagen. Das geht bei mir gegen das Grundgesetz.

I: Sie haben vorhin gesagt, Sie waren bei den anonymen Insolvenzlern. Was haben Sie da für Erfahrungen gemacht oder für Geschichten gehört?

B: Wie, wie / eigentlich was für tolle Menschen da sind. Die auch aus ganz unterschiedlicher Ecke da was, was auf die Beine stellen. Und der, der Gründer hat selbst Insolvenz gehabt, auch aus einer, einer ganz dämlichen Situation heraus. Also, auch nicht, weil er eingekauft hat wie blöde oder irgendwas. Sondern auch aus, aus geschäftlicher Sicht einen Fehler halt gemacht, ja? Und ein Fehler geschieht, und man macht das. Ich hab es Ihnen ja auch erzählt, Sie, Sie / ich bin ja kein Jurist, der an jeder Ecke immer irgendwie sowas macht. Ach so, noch was, völlig ungezogen ist, dass der Schufa-Eintrag nochmal sechs, Augenblick nochmal drei Jahre, mindestens drei Jahre noch bleibt.

I: Was nach den sechs Jahren?

B: Nach den sechs Jahren. Das heißt, Sie sind eigentlich neun Jahre stigmatisiert.

I: Ja.

B: Und das muss ich Ihnen ehrlich sagen, finde ich eine Unverschämtheit. Also diese dämliche Schufa / oder überhaupt diese / 
I: Das wusste ich gar nicht. Ich dachte das wird dann nach den sechs Jahren auch wieder /

B: Nein. Ich möchte Ihnen das gerne geben. Weil, ich halte den für einen sehr klugen Menschen und eventuell hilft Ihnen das auch was. Ich hab / weiß aber nicht mehr wo ich es herhole, also müsste ich es Ihnen, warten Sie mal. Da unten sind ein paar Websites angegeben. Vielleicht hilft Ihnen das auch. Möchten Sie das?

I: Gerne, ja.

B: Also, Sie sehen, ich habe auch versucht was draus zu machen. Und ich war / und die sagen mir / also gerade der Attila von Unruh ist ein, ein sehr, sehr überzeugender, großartiger Mensch. Also da / ach das ist übrigens noch was / Sie dürfen es in Deutschland überhaupt nicht sagen, dass Sie in der Insolvenz sind. Und das hab ich als / ich bin so ein Geradeaus-Mensch, ich möchte dann auch eigentlich zu meiner Situation stehen können. Das habe ich mich nicht ganz getraut. Das heißt, weil Sie fragten nach dem Einfluss, das heißt, es macht Sie ein Stück unehrlicher. Weil Sie was vertuschen, und das geht eigentlich gegen meine Natur. Und das waren so, so Ventile, die ich mir gesucht hab, da konnte ich das dann sagen. Ich hab natürlich auch in meinem Umfeld das gesagt. Aber Sie können zum Beispiel beim Wohnen, zum Mieten, das können Sie überhaupt nicht sagen. Sie, Sie kriegen, Sie kriegen ein Gartenhäuschen vielleicht, selbst wenn Sie mit Ihrer Tochter zusammen / und die sagt, die hat doch noch ihr Einkommen oder sowas. Also, Sie, Sie fangen an zu, zu vertuschen. Aber das ist weil, weil unsere Gesellschaft da nicht bereit ist dazu, das zu akzeptieren. Das einer geradeaus steht und sagt: ,Ja, ok, es ist passiert, ich weiß auch warum." Und der engagiert sich großartig, wirklich großartig, also das muss ich sagen, das / gut das andere, dass könnten Sie nochmal / nee, das ist auch von dem / das glaube ich, können Sie aber auf den Einträgen sehen. Ja, das steht, wenn Sie sich das abschreiben. Das ist, das ist auch ein Positionspapier von BV INSO heißt der Verband oder Verein. Und die fordern die Abschaffung des Schufa-Eintrags, auch jetzt in diesem / und das steht dann da nochmal. 
Das ist natürlich auch etwas, gemeinsam dafür kämpfen, macht wirklich Mut und stark, und Sie haben das Gefühl. wenn, wenn man so ein Mensch ist mit Energie, dann möchte man was tun. Also, aber nicht so - deswegen, mit Ihrem Fragebogen, ja - nicht so überaktiv, also so wäwäwä / ihr tut mit was / ich so / ich bin überhaupt kein aggressiver Mensch, also das / deswegen, wenn ich sage, so eine Wut, ist das mehr aus einer Ohnmacht heraus. Wissen Sie, was ich meine? Also nicht so eine aggressive Wut, sondern aus dieser Ohnmacht heraus. Eigentlich habe ich sogar eine ganz schön kreative Zeit gehabt. Weil ich mich auf viele neue Ideen gestürzt habe. So was zu entwickeln. Ja und ehrlich gesagt, das ist was, mich jetzt wirklich betrifft, dass wir immer noch nicht raus sind aus den, aus dem Strudel. Wenn Sie überlegen, ich habe also ohne Probleme, wenn ich also meine Kundenaufträge hatte, habe ich, also ja, sagen wir mal, zwischen wenn es ganz schlecht lief 400, aber auch bis 1200, 1400 Euro pro Tag verdient für bestimmte Aufträge. Und jetzt Mühe ich mich, für 40 Stunden 600 Euro zu kriegen und muss darüber schon diskutieren wie doof. Und das muss ich ehrlich sagen, trifft mich schon ein bisschen. Weil einfach nicht sagen: „Mensch, Ihr nutzt einen alle aus!" Da steckt ja natürlich, selbst wenn ich jetzt nur telefoniere und Termine mache, da steckt natürlich ein irrsinniger Erfahrungs- / das ist nicht nur terminieren, sondern das ist ein Kundenbeziehungsmanagement-Tool.

I: Sind Sie jetzt Angestellte?

B: Nein.

\section{I: Selbstständig?}

B: Ja. Ja als Angestellte. Also, ich hab ja meine Rente. Und ich / Angestellte würde ich jetzt nicht mehr machen, ich will mir das selber aussuchen. Und will verschiedene Arbeiten machen. Und bin dabei, aber die in meinem angestammten Beruf da sind / da habe ich wirklich Verschiedenes versucht. Jeder will eigentlich nur, dass ich Kunden ranschaffe. Und dabei möchte ich, ich möchte eigentlich nur die, die kreative Leistung, ja? Den Ansatz, den methodischen Ansatz oder irgend sowas oder eine Analyse, so etwas möchte ich machen. Die Kunden zu gewinnen, können meiner Meinung nach eine Organisation viel besser. Ich hab auf keinen Fall jetzt neu gestartet unter meinem 
Namen. Das traue ich mir in meinem Alter nicht mehr zu. Das muss ich ehrlich sagen. Obwohl ich bestimmt mutig bin. Aber das traue ich mir nicht mehr zu. Was völlig Neues aufzubauen. Ich habe keine Idee, die, die, sagen wir mal, wie so, wie so eine App oder so ein Computerprogramm oder Facebook entwickeln oder irgend so etwas. So, so eine Idee habe ich nicht. Die auch jetzt in die Zeit passt. Ich kann also nur Tools entwickeln, die, sagen wir, für Firmen sind. Sagen wir jetzt mal, wie ist der / wie gehen / geht die, die Zielgruppen, also die Kundenkreise, die verschiedenen mit Online- und Offlinekäufen um? Irgendwie so. Wo sind Schnittstellen? Also die ärgern sich zum Teil, dass sie also im Laden sich das Produkt anschauen und dann versuchen im Internet am billigsten zu kaufen. Da hat der Handel wirklich damit zu tun. Und auf der anderen Seite, ist dann auch wieder, dass Sie im Internet natürlich diese ganzen Unsicherheiten haben und dann auch wieder sagen: „Ach nee, hab ich auch keinen Bock mehr. Ich geh jetzt in den Laden, ich will jetzt auch das Einkaufserlebnis haben." Was gerade bei Mode, und für Jüngere. Darum kümmere ich mich jetzt. Die Älteren nehmen den Versandhandel zum Teil, weil sie sich genieren in so einer Umkleide noch, noch alles auszuprobieren, und den Umstand mit Umziehen und, und auch so die Sachen wieder anziehen. Die haben zum Teil mehr Freude daran, wenn sie sich das nach Hause schicken lassen. Aber die Jüngeren / ja / wenn Sie sich so überlegen, der Versandhandel hat eine / also die haben / ich hab neulich gerade was gelesen / wer 40 Prozent Retoure hat, ist schon gut dran. 40 Prozent!

I: Das ist krass.

B: Das geht hoch bis 65.

I: Das ist dann wahrscheinlich wirklich so, dass die Umkleide halt zu Hause ist.

B: Dass die Umkleide zu Hause ist, und die holen sich das auch in verschiedenen Größen. Zum Beispiel, also das gleiche Modell in drei Größen, so, also zumindest in zwei, ja. Wenn Sie sagen: „Weiß ja nicht, ob mir das passt. Der Schuh in 38 oder 39, die Hose in 40 und 42 oder irgend sowas." Und dann schicken sie nicht die Hose, wenn sie sie in 40 / meinen sie haben 40 und schicken sie nicht dann zurück, wenn sie wirklich nicht passt, sondern sie holen sich gleich die beiden. Es ist ein riesen 
Problem. Und auch ein riesen Kostenberg für die Firmen. Und man muss auch wissen, wie sie die jungen Leute, mit ihrem Erlebnis, wie die Balance da ist. Also, das sind schon auch spannende Dinge, wie sich unsere / unser Konsumverhalten verändert und sowas.

I: Auf jeden Fall, ja.

B: Und, und wie gesagt, dadurch / ich hab wirklich viel gelesen in der Zeit. Und zuerst hatte ich noch die Pflege, das ist wahr, aber nur noch die erste Zeit. Naja, ehe das anfing, doch schon noch fast zwei Jahre. Sie / bevor der, dieses Verfahren eröffnet ist, was bei mir Ende Oktober 2007 war, ist ja ungefähr schon noch fast ein Jahr, wo Sie eigentlich alles zusammensuchen und sortieren und so. Also im Grunde genommen ist es ja die sechs Jahre plus eine Zeit vorher, und wenn Sie jetzt die Schufa auch noch drei Jahre danach haben. Also wenn Sie da was erreichen können, dass Sie da mal wenigstens was in Gang setzen, auch durch Ihre Forschungsarbeit, das wäre gut. Und ich, Sie können mich auch immer noch anrufen, wenn sie noch wieder was wissen wollen.

I: Ja, gerne.

B: Wenn Sie mich für interessant genug erachten, da eine Auskunft zu geben.

I: Ja, mache ich gerne. Eine letzte Frage habe ich noch, eine Abschlussfrage. Wenn Sie jetzt an die letzten Jahre zurückdenken, was ist dann das vorherrschende Gefühl?

Fühlen Sie sich als Opfer, sind Sie, wie Sie gesagt haben, wütend, blicken Sie zuversichtlich nach vorne? Was, was ist jetzt so die Quintessenz?

B: Ne, kann ich alles so nicht sagen. Also, ich muss Ihnen ganz ehrlich sagen, ich würde es wieder machen. Also, ich kann nicht verhindern, dass ich einen Fehler mache und eine falsche Immobilie kaufe. Machen Millionen andere auch.

I: Gibt es irgendwas, was Sie heute anders machen würden, mit dem Wissen, dass Sie heute haben? 
B: Ich hab mich das auch gefragt, und ich muss Ihnen ehrlich sagen, ich hab zunächst einfach mal nein gesagt, weil ich würde auch meinen Vater wieder pflegen. Aber ich glaube, das Einzige was ich anders mache, ist, dass ich etwas weniger äußerlich bin. Also, ich brauch nicht in noch 'ne neue Hose und zehn Paar Schuhe oder irgend sowas. Obwohl ich nie extrem / aber ich hab für Kleidung schon viel Geld ausgegeben. Wenn man im Beruf ist als Frau und so, muss man schon immer / also eher als, als Mann. Die können eine andere Krawatte und ein anderes Hemd anziehen und den gleichen Anzug und wirken so / Als Frau sagt man: „Ach, hat sie wieder das Kostüm an" oder so. Also, ein bisschen, ein bisschen weniger Konsum bleibt hängen. Aber da möchte ich auch nicht wissen, ob das auch eine alt / mit dem Altersprozess mit, mit, mit verbunden ist, ja? Wütend bin ich nicht wirklich. Die Menschen versuchen da, ihren Job zu machen. Ich glaube, dass unsere Institutionen eben einfach nicht funktionieren, das ist was ich da rausnehme. Und die kann ich alleine nicht beeinflussen, ich würde nach wie vor gerne mehr solche wie Herrn von Unruh unterstützen. Das hab ich ein bisschen wenig gemacht. Auch aus Geldgründen. Die sitzen in München, ich hätte immer nach München fahren müssen.

I: Ja, klar. Jetzt zusätzlich zu dem Punkt, den wir besprochen hatten, dass sechs Jahre natürlich sehr lang sind, der Schufa-Eintrag jetzt dann noch länger bestehen bleibt, vorher ja schon eine Zeit ist, in der man gehandicapt ist, also jetzt zusätzlich zu dieser langen Zeitspanne, gibt es noch Sachen, die Ihnen begegnet sind, wo Sie, wo Sie sagen: "Das muss man doch irgendwie besser machen können, dass muss man doch anders lösen können."

B: Ja, ich glaube schon, dass der reine Prozess der Abwicklung sicher anders gelöst werden kann. Zum Beispiel / nein da bin ich nicht so Fachfrau. Ich, ich seh eigentlich nicht, dass man so furchtbar lange vorher diese Aufstellungen und dieses Feststellen / aber Sie müssen natürlich, deswegen sage ich, das sind sicher rechtliche / Sie müssen die ja wieder zurückfragen. Die werden ja alle angeschrieben, und dann müssen die wieder was sagen. Ich finde das jetzt gar nicht so schnell. Das wollte ich ihnen noch zeigen, manche haben nicht geantwortet, die fallen eben bei mir auch, die fallen dann durch das Raster. Eine Bank hatte nicht geantwortet, und wenn die bis zu einer Frist 
nicht antworten, ist es weg. Und die haben natürlich gesagt, ich buch das gleich aus, ich krieg da sowieso nichts, also warte ich gar nicht die sechs Jahre. Also, das ist für die auch zum Teil viel zu lang. Dass sie das noch sechs Jahre mit fortführen müssen. Also, es ist auch auf der anderen Seite, auf der Gläubigerseite so, dass die sagen für, für das, das buch ich ab als Bank, so groß war der Betrag nicht, und jetzt hab ich damit nichts mehr zu tun. Aber von dem, wie Sie sagen, dem /

I: Also, Sie haben ja schon gesagt, vor allem auch wie man behandelt wird am Amt.

B: Ja, oder auch zum Beispiel, dass Sie, dass Sie mit dem Wohnen so Schwierigkeiten haben. Es darf nicht / das Wohnen / Ein Dach übern Kopf ist doch ein, ein ureigenstes Bedürfnis, ein Grundbedürfnis für Menschen, dass Ihnen das so schwergemacht wird. Also, das habe ich als extrem furchtbar empfunden. Und, und dass dann sogar noch jemand klagen darf. Wenn Sie das nicht gesagt haben, darf er das noch als, als was weiß ich Verschleierung von, von / obwohl Sie die Miete zahlen können, das heißt eigentlich nicht / Aber wenn er glaubt er könnte das oder will, er wollte ja von seinen Problemen selber ablenken, von seiner Schummelei. Es ist eigentlich / das Recht ist so, wenn sichergestellt ist, dass Sie die Miete zahlen können, müssen Sie es nicht sagen. So. Das war bei uns nachweißbar. Auch allein schon dadurch, dass wir zu zweit ja sind. Und auch sowieso lag der Betrag da. Trotzdem kann der Vermieter sagen, Sie haben es mir nicht gesagt, das ist Betrug. Das ein Gericht sowas annimmt, verstehen Sie, solche Abläufe, die kann ich nicht verstehen, da müsste, da müsste jemand sagen, hör mal das muss die nicht aus dem und dem Grund. Nein, da führen sie einen Prozess darüber. Also, ich möchte mal sagen, die, die Umfeldregeln, die Regeln, wie das abläuft, die sind sicher da. Aber die Umfeldregeln sind nicht konkret genug. Und nicht sicher genug. Sie brauchen ein bisschen Sicherheit in dieser Zeit, ein bisschen. Und wie gesagt, wir haben in Deutschland keine Kultur des Scheiterns. Das ist zwar ein alter Spruch jetzt, aber das ist so.

I: Hatten Sie auch das Gefühl, dass, dass Sie, dass Leute anders mit Ihnen umgehen, wenn sie das wissen?

B: Ja, deutlich. Auch im privaten. 
I: Hätte ich jetzt nicht erwartet.

B: Hatte ich auch nicht erwartet. Aber tatsächlich, ja.

I: Also, haben Sie dann auch erleben müssen, dass sich Freunde distanziert haben oder so etwas?

B: Ja. Aber gut, das kann man eher als natürliche Auslese verstehen, wissen Sie? Wenn, wenn ich dann denen nicht mehr / ich muss Ihnen sagen, ich hatte einen, ein paar Freunde, die ich sehr lange Jahre habe und hätte ich es eigentlich auch nicht erwartet, weil, ich hab auch deren Ehe ein bisschen mit gerettet und all solche Sachen. Also, schon sehr / die haben Kind / ihr Kind verloren, und dann war das dann sehr schwierig. Die sind sehr wohlhabend durch, auch durch Glück / ja man hat auch mal Glück, ist ja nicht nur Fähigkeit / aber das, ich gönne das jedem. Also, das ist etwas, dass ich auch gar / jeder soll so viel Geld haben, wie er hat. Also, ich hab nie ein Neidoder ein, ein, ein, ein ungutes Gefühl, oder so, auf andere gehabt. Wieso der und ich nicht - ist mir total fremd. Aber das ist meine Natur. Und, und das zerfrisst Sie ja sonst nur. Das ist / also ich hab eher gesehen, was kann ich machen? Ja? Ich hab es auf mich bezogen.

I: Das war der bessere Weg, ja.

B: Ja, ich habe es auf mich bezogen. Und, also die haben, wissen Sie, die fahren / die haben ein Haus in Kiawah. Das ist bei Amerika, da Hilton-Head-Island in der Nähe, Kiawah, South Carolina, vor der Küste. Und die haben ein Haus in Südfrankreich. Und dann haben sie mich eingeladen. Ja, ist gut, ich konnte nicht kommen, weil ich hätte irgendwas auch bezahlen müssen. Also, selbst wenn sie mir die Fahrt nach / sie müssen irgendwie ein Geschenk oder / ich habe kein Geld für solche Experimente, und dann finden die das vielleicht undankbar. Aber ich kann ja nicht sagen: „Ich kann euch noch nicht mal ein Eis spendieren." Und da, da hat sich das dann, dann haben die das nicht mehr gemacht. 
Und ich finde, dass auch, dass man ruhig / also ich habe in meinem Leben schon sehr viel abgegeben, Wann immer, als es mir gut ging, wann immer ich konnte, ich hab wirklich auch Freunde unterstützt. Und ich hab sehr, sehr, sehr / war vielleicht doch noch was, was ich gelernt habe / ich hab wirklich gelernt auch mal um Hilfe zu bitten. Konnte ich ganz schlecht. Weil ich lieber ein Geber-Mensch bin. Und ich musste um Hilfe bitten jetzt in der Zeit. Hatte ich zum Glück dann auch. Ich müsste auch jetzt wieder um Hilfe bitten, und das fällt mir unendlich schwer. Und ich muss Ihnen sagen, die Hilfe war nötig auch / wenn sie dreimal umziehen, wegen so einem Mist noch. Und dann sind Sie arm. Das ist katastrophal. Das haut ihnen eigentlich die Füße weg. Und jeder Umzug, Sie wissen selber, unter 5000 Euro ist ein Umzug nicht zu machen. Sie haben die Umzugskosten. Sie haben die Kaution. Sie haben irgendwie nochmal Renovierung, es ist überhaupt nicht anders machbar. Und ohne Geld geht es nicht. Selbst wenn / wir haben sehr viel selbst geschleppt, wir haben Sprinter gemietet und geschleppt bis zum Umfallen. Ich weiß nicht, ich hab so viel getragen, dass ich eigentlich nicht mehr tragen konnte. Und das Tragen alleine ist das eine, aber Sie müssen ja mit dem Gewhicht noch Treppen laufen. Das ist das Schwierige.

I: Klar.

B: Aber das ist, das ist vielleicht was, dass man / also Freunde ja, die haben sich verändert. Aber, dass man auch um Hilfe bittet und dann auch sieht, wer einem wirklich hilft. Das sind die positiven Erfahrungen auch ganz klar. Wer auch wirklich sieht, dass man nicht aus Verschwendungssucht in so eine Insolvenz geraten ist, sondern einfach / muss man auch sagen, muss man ja auch selbstkritisch sehen / auch natürlich aus Fehlern, ich hätte diese Immobilie so nicht kaufen sollen. Aber gucken Sie mal wie die ganzen Immobilienblasen / also ich habe sie viel zu hoch / ich hab's eigentlich hinterhergeworfen bekommen den Kredit, weil ich eben gut verdient habe. Und dann habe ich den auch ausgenutzt, und ich hatte den über 100 Prozent finanziert. Und wenn die dann noch sinkt, sind Sie nun wirklich gekniffen. Ich habe gedacht, die Steigerung fängt dann dies auf, sodass Sie die normalen Eigen / Eigenbeda / Eigenanteil, der früher lag der bei 20 Prozent, jetzt ist der ja schon gestiegen auf 30, glaube ich, oder so. Banken machen das ja gar nicht mehr. Ja, und dass Sie eigentlich 
jetzt nicht mehr in der Lage sind, eine Zeit zu überbrücken für eine Investition, das heißt, Sie können nicht mehr wirklich investieren.

Das sind ja dann Gelder, die nicht einfach Verschwendung sind, sondern ich würde gern nochmal ein bisschen in, in Aufbau eines, eines Business investieren, und das kann ich nicht mehr. Das ist mir genommen diese Chance. Vielleicht gäbe es einen Weg, wenn ich dann nochmal Klinkenputzen würde und fragen welches, weiß ich nicht, irgendwelches Startup-Kapital zu bekommen. Aber das habe ich noch nicht probiert, und das glaube ich auch, dann muss ich ehrlich sagen, glaube ich, dass ich zu alt dafür bin, um das zu kriegen.

Also von daher / natürlich, also wissen Sie, ich hab es schon auf mich bezogen. Ich fand eigentlich, dass es eher ein bisschen verlorene Jahre sind. Ich, ich fand wirklich, dass ich von meiner Energie her so ausgebremst wurde, dass ich als / bisschen als lebensverlorene Jahre waren. Das, das man einen Schritt machen muss, dass man, dass man auch dafür geradestehen soll, das kann ich alles verstehen, dass da auch ein Gläubiger hinter steht. Aber gucken Sie mal, ich muss Ihnen auch ganz ehrlich sagen, ich hab das auch als geteilte Schuld gesehen. Ja, ich hab auch den Fehler gemacht, dass ich diese Immobilie, dass ich das falsch eingeschätzt hab, dass $<<<$ Ort anonymisiert $\gg>>$ nicht steigt. Aber die Bank hat es ja auch falsch eingeschätzt. Da sitzen die Fachleute, verstehen Sie? Ich will das nicht abschieben, aber ich will nur sagen, ich war nicht allein saublöd. So in dem Sinne, so dass Sie wirklich sagen: „Ei, wie kannst du denn das tun?“ Ja kann ich machen, kann ich machen, kauf gar nichts, beweg dich gar nicht. Da passiert / wer nichts macht, tut / macht vielleicht keine Fehler, ja? Aber eigentlich macht er einen großen Fehler, nämlich sein Leben verdaddeln.

I: Ja, das stimmt.

B: Es ist ganz klar. Wer nicht selbst handelt wird gehandelt oder behandelt. Wer nicht selbst lebt, wird gelebt. Sie können / wie, wie Watzlawick sagte: „Man kann nicht nicht kommunizieren." Und so kann man auch nicht nicht leben. Und das sind Dinge, Sie müssen ein bisschen sich einfügen, anders einfügen, aber, aber ich muss wirklich sagen, mit der Armut komme ich nicht gut zu Rande. Einfach weil ich zu viele Interessen hab. Wir wollten jetzt ins Theater gehen, wir können das noch nicht. Das 
fällt weg. Wissen Sie, das sind so Dinge, die tun mir auch weh. Aber, aber sonst, also ob es noch eine Hose wäre / ist oder so ist egal / und ich würde eben gern auch mal wieder / gut, das ist so mein Traum, den werde ich auch nochmal schaffen. Ich hab mir gesagt, ich möchte im Leben - irgendwie ist meine Seele da - ich möchte nochmal nach Südafrika. Ich war in vielen anderen Ländern, Asien interessiert mich nicht so sehr, China, alles spannend, aber ich würde gerne nochmal nach Südafrika. Und so kann man seine kleinen Träume bewahren. Die kann man sich bewahren.

I: Dann drücke ich die Daumen, dass es klappt.

B: Ja. Und wann immer Sie noch was brauchen, oder irgendwie noch / jetzt sind wir ja so ein bisschen durchgegangen, aber es kann ja sein, dass Sie irgendein Detail während Ihrer Arbeit nochmal sehen. Also, die Insolvenz sag ich mal, wenn ich das so zusammenfassen würde, die Insolvenz hat mich eigentliche insgesamt stärker gemacht. Weil, weil / und zwar nicht in dem Sinne, dass ich dankbar bin, dass sie passiert ist, das wäre auch durch irgendetwas anderes geschehen. Aber weil sie / weil ich wieder erfahren hab, dass ich mit Krisen ganz gut umgehen kann. Das, das ist vielleicht der Punkt. Und, und dieses alte chinesische Zeichen, dass Krise gleich Chance ist, von dem haben Sie vielleicht auch schon gehört, das finde ich so beruhigend, und so soll man das auch sehen. Und diese, es ist eine Krise / man hat einen Teil ganz klar auch Fehler gemacht, dass diese Krise entstanden ist. Vielleicht ist mein größter Fehler, dass ich gedacht hab, die Aufwärts / der Aufwärtsweg geht immer weiter. Durch meinen Aufstieg und beruflich und immer mehr verdienen oder so. Vielleicht habe ich mich darin zu sehr ausgeruht, oder nein / nicht ausgeruht habe ich mich gar nicht, hab ja immer weitergemacht. Die Annahme, es wird immer aufwärtsgehen, die ist sicher nicht richtig. Aber die ist lebensunrichtig. Und wir haben also auch / zum Beispiel mein Bruder ist tödlich verunglückt als er 42 war, und meine Nichten und Neffen / Nichte noch gar nicht geboren, Neffe ganz klein. Das sind / das ist der größte Schmerz gewesen in meinem Leben. Und beim Tod meiner Eltern, die ich / den ich beide begleitet hab, auch bei meiner Mutter, die sehr krank war. Und mein Vater eben nur durch diese Pflege. Das macht einen / das nimmt einem viel Kraft, aber es gibt einem auch was zurück, dass man den Abschied begleitet hat, dass man, dass man das Gefühl hatte, da ist nicht noch was, was gesagt werden müsste oder aufgeräumt werden 
müsste, das sind auch gute Dinge, ja? Das ist dann das, das andere Gebiet. Und für dieses / es ist ganz klar eine Krise, ich finde, dass Sie eine erzwungene Länge hat, diese Krise, die ich nicht gerechtfertigt finde. Wobei ich nun auch sagen muss, wenn einer natürlich immer nur shoppen geht und weiß, er hat es nicht, dann ist das eigentlich nicht so günstig. Und wenn Sie eine Immobilie haben, die nun mal leider an Wert verliert, können Sie das nicht so vorhersehen, wie wenn ich mir zwanzig Hosen kaufe.

I: Ja, das ist richtig. (lacht)

B: Oder?

I: Ja.

B: Also für, für das / sag ich mal das Krise als Chance / es ist wieder ein, ein Weg, dass man sagt, das Leben hat halt solche Aufs und Abs, und je mehr und je besser du damit umgehst, umso leichter. Hier ist es aber eine erzwungene Länge, die wirklich, wie ich Ihnen gesagt habe, das Gefühl ist eigentlich das Hauptgefühl. Es ist mir, es ist mir Lebensentwicklung genommen. Es ist so gebremst, es war so lange gebremst, und die Auswirkung jetzt noch, gucken sie mal, ich bin ja jetzt nur schon / also was haben grad, sechs, sieben, acht, also dann sind das ja fast acht, neun Jahre ehe ich da irgendwie halbwegs wieder raus bin. Das finde ich schon viel. Das ist wirklich viel, ja. Wenn sie es so auf so ein Leben sehen, ja? Finden Sie nicht?

I: Doch auf jeden Fall, ja.

B: Und um nochmal so zu sagen, die Summe um die es ging, mit der Wohnung und mit dem Finanzamt, also ich hab ungefähr 140.000 Euro oder sowas Schulden gehabt. Weiß gar nicht ganz genau. Irgendwas ist da nachher noch reduziert worden. Ist Wurst, ob es jetzt 120 oder 140 waren. Es ist nicht genug gewesen, als dass mir jemand den Teppich trotzdem ausgerollt hätte. Hätten Sie Millionen, wären sie immer noch irgendwie gepempert, damit sie da noch wieder was retten, und hier ist es einfach so, dass Ihnen / natürlich, dass da auch Partner waren, die, die, ja die Ihnen eigentlich 
keine Warnzeichen gesetzt haben. Wie Sie jetzt mit der Wohnung sehen. Und dass man vielleicht / wie häufig ist, dass jeder sagt: „Ah, du hast so viel Steuern, sieh zu, dass du eine Immobilie hast und Abschreibung und so weiter." Also, wissen Sie? Da ist auch so ein systemischer Effekt dahinter, der vielleicht gar nicht mal so gut ist. Warum ist die Immobilienblase in Amerika gekommen? In Italien wird eine kommen. Da ist es genauso. Meine Tochter hat gerade eine Freundin, die ist Mitte 20. „Ah, wir müssen eine Wohnung kaufen, wir müssen eine Wohnung kaufen". Ja, ich möchte auch wieder Eigentum jetzt haben. Und, wissen Sie, und deswegen ist es zu lang, weil, Sie kommen gar nicht dahin wieder anzusparen irgendetwas. Und wenn Sie zehn Jahre rausgenommen sind, dann ist das verdammt lange. Das meine ich damit.

I: Ja, auf jeden Fall.

B: Und dieses, was es sonst mit einem macht / Denn der Lernprozess, der ist auch schneller da. Ich weiß auch schneller, dass ich keinen Cappuccino kriegen kann und kein Buch kaufen kann. Wobei das natürlich nicht Jedermanns ist. Oder ins Theater gehen kann. Manche sagen vielleicht auch: „Ob ich jetzt ins Theater gehe oder nicht, ein Buch lese oder nicht". Für mich ist es lebenswhichtig. Ich kann nicht ohne Bücher. Und das sind / ja und zwar sag ich deshalb, ich kann nicht ohne Bücher, weil ich, weil es Menschen gibt, die etwas gedacht haben, was mich fasziniert. Und diese Faszination, die, die wird mir genommen. Oder auch lernen.

I: Ja, ja ich verstehe Sie schon, ja.

B: Und dafür finde ich es wirklich zu lang, und ich finde eben diese Armut aushalten, in dem Sinne Armut, verstehen Sie, finde ich nicht gut.

I: Gut, also ich wäre durch mit meinen Fragen, wenn Sie noch etwas loswerden möchten?

B: Nein, nein, ich, ich eigentlich gar nicht so viele Gedanken gemacht. Ich habe mit Ihnen eben geantwortet, und wenn mir noch wirklich was Whichtiges einfällt / Also das Whichtige wusste ich, dass Sie mich fragen, wie ich das erlebt habe, und wie ich 
das bewerte diese Phase. Die ist ja, die Frage ist ja nicht so vom blauen Himmel, die ist ja logisch. Dann ist das eben so und, und etwas erstaunt war ich über ihre Frage, ob ich eigentlich mit meiner Zeit was hab anfangen können. Und, und dieses Loch habe ich überhaupt nicht empfunden und konnte im Moment auch gar nicht damit umgehen. Wieso, Zeit? Ich steh auf, ich tu was. Ich mach was.

I: Ja, weil wenn man das Angestelltenverhältnis gewöhnt ist, dann denkt man sich, wenn man jetzt nicht mehr den ganzen Tag im Büro ist, dann hat man plötzlich so unglaublich viel Zeit.

B: Ja, aber wissen Sie, dass ist der Punkt, warum viele ja im Rentendasein eigentlich dann doch keine Zeit haben. Das heißt, Sie machen es anders, wenn Sie einigermaßen mit Ihrem Leben umgehen können. Das ist die Kritik, und das ist berechtigte Kritik mit der Jugendarbeitslosigkeit. Wenn Sie als junger Mensch, nicht in einen strukturierten Tag hineinkommen, und es gibt auch viele Menschen, die es auch nachher immer noch nicht schaffen, die sitzen nur vor der Glotze und saufen. Das muss man mal so brutal sagen. Wenn Sie aber ein interessierter Mensch sind und ein Mensch sind, der den Tag strukturiert, so wie gesagt durch die Selbstständigkeit schon allein bedingt, und die war ja schon vorher lange Jahre, bin ja aus der Selbstständigkeit raus, da rein. Dann haben Sie das Problem null. Und das, deswegen ist die Jugendarbeitslosigkeit so tragisch, weil die Menschen kommen nachher nie mehr in einen strukturierten Tag hinein. Die haben ja auch zum Teil, zum Beispiel nicht dann die Struktur gehabt für, für ein Studium oder so. Wie man lernen lernt. Sondern die haben einfach eine Ausbildung, die sie geführt und gezogen und gedrückt hat nach einem Schema, das die absolvieren mussten, aber nicht in einer Selbstständigkeit. Und das sehen Sie ja auch an ihrem Studium, Sie müssen sich da alleine Ihre Sachen zusammensuchen, da sagt Ihnen zunächst mal keiner was. Arbeiten Sie eigentlich jetzt noch neben her schon?

I: Also, ich bin im Qualitätsmanagement für Kindersitze. Da hab ich jetzt zum 01.01. angefangen. Vorher war ich bei der Firma REHAU, also die machen alles aus Kunststoff, vom BMW-Stoßfänger über Fensterprofile, alles unterschiedlich. Und hab 
/ war eben erst im Einkauf, dann im Qualitätsmanagement und im

Qualitätsmanagement jetzt geblieben.

B: Das heißt für Sie, was machen Sie? Tests dann auch und solche Sachen?

I: Ja, auch, also /

B: Oder machen Sie Materialprüfungen oder sowas?

I: Nein, das machen wir extern. Also bei mir ist das so, ich bin zuständig für die Qualitätssicherung in Entwicklungsprozessen. Also, ich mach dann Risikoanalysen oder schau eben dass /

B: Sind sogenannte No-Go-areas oder solche Sachen?

I: Ja, oder auch eben es gibt ja verschiedene rechtliche Standards auch eben um, um Kindersitze und solche Sachen dann zuzulassen. Dass dann alles kindgerecht ist sozusagen.

B: Ja gut, das ist schön. Das ist interessant auch. Also, ich, ich wünsche Ihnen, dass, dass Sie - und was ich beitragen kann, dass tu ich gerne - ich kenne noch ein paar Leute, die vielleicht das auch in die Politik noch leiten könnten oder so, auch mal einen Hinweis dann geben, das würde ich gerne machen, wenn sie mir irgendwann auch ihr Ergebnis oder so in Kurzform geben mögen. Auch in Langform natürlich gerne, aber ich sag mal auch in Kurzform würde auch schon reichen. Darum würde ich Sie sehr gerne bitten.

I: Gerne.

B: Weil ich wirklich gerne / das ist was, was ein Anliegen ist, ich möchte gerne beitragen, dass man den Menschen diese Phase so macht, das sollte ich vielleicht so sagen: diese Phase sollte so sein, dass sie nicht das Leben ausbremst, sondern dass sie irgendwie eine Art der Korrektur meinetwegen - es ist ja zum Teil eine Art der 
Korrektur - einleitet. Aber wieder ein, einen Start, nicht in Let- / also nicht in dieser Lethargie verharren bleiben. Viele Menschen fallen bestimmt ins Aus. Weil die Zeit so lang ist. Und bei mir ist es so, dass ich nun / eigentlich könnte ich dann sagen, nimmst du eben dann halt deine Rente, dann muss das reichen und das muss später auch. Ja, muss später auch. Wird es dann auch, wenn alle, alles Weitere reduziert ist. Aber da bin ich noch nicht, verstehen Sie?

I: Ja.

B: So reduziert bin ich noch nicht auf nur die Grundbedürfnisse, wie Schlafen, Essen und was weiß ich, drei Schritte gehen. Aber insgesamt gesehen, muss ich wirklich sagen, dass man da auch / und ich glaube es sollten mehr auch von der Politik / also wir müssen einfach in Deutschland generell das Thema Scheitern anders angehen. Das ist ja ein Scheitern, es ist in irgendeiner Form ein Scheitern. Ich habe es so empfunden. Aber es ist nicht so ein Scheitern, dass ich jetzt „Asche über mein Haupt" oder irgend sowas, so habe ich das auch nicht empfunden. Dass ich irgendwie was Böses gemacht habe oder irgend sowas. Es kann nichts Schlechtes sein, seine Eltern zu pflegen. Es ist eher schlimm, dass man da / jetzt, jetzt wird erst nachgedacht wie man die finanziell auch unterstützt. Was habe ich noch mit dem medizinischen Dienst gekämpft, um überhaupt die Pflegestufe zu kriegen.

I: Aber es ist auch grundsätzlich so / es fängt ja schon damit an, dass in vielen Unternehmen die Kultur eigentlich so ist, dass wenn was schief läuft, nur geguckt wird, wer hat es verbockt, anstatt die Lösung zu suchen. Es ist ein Kulturproblem auch irgendwie.

B: Es ist wirklich ein Kulturproblem, und ich mein, wissen Sie, genauso wie man sagt, einer guten Idee ist es egal von wem sie stammt, so ist es eigentlich / gut, es gibt Menschen die immer wieder Fehler machen oder so, da muss man schon mal auch mal gucken. Aber es ist genauso blöde, wenn Sie sich auch selber sehen / ist doch viel wertvoller, Sie bauen an ihren Stärken, als dass Sie ständig versuchen die Schwächen zu eliminieren. Wird Sie nicht viel weiterbringen. Sie werden vielleicht nicht das Sprachgenie, also Entschuldigung, kann jetzt irgendwie ganz was anderes sein oder 
Technikgenie oder irgend sowas werden, um was zu sagen. Aber der andere hat vielleicht ganz andere Fähigkeiten. Wir müssen unsere Stärken einfach mehr so bündeln, und deswegen sage ich, deswegen finde ich das kybernetische Management so faszinierend. Das habe ich also da angefangen in dieser Zeit, dass ich mich um kybernetisches Management mehr kümmere. Was das bedeutet? Was bedeutet das auch für bestimmte Prozesse zum Beispiel / Und das ist ein Gebiet, das kannte ich vorher nicht, da muss ich mich jetzt reinknien. Also, ich habe, wenn Sie so wollen, die Lernphase, also wirklich Neulernphase oder Weiterbildungsphase genutzt. Und nicht so sehr, was ich denn ach so Großes, Schlimmes verbrochen hab. Weil das nicht so groß und schlimm war. Ich würde meinen Vater immer wieder pflegen. Und ich konnte nicht sagen, nachdem ich gemeint habe nach einem Jahr, länger hält er wohl nicht durch, dass er noch 93 geworden ist / kann ich nicht sagen nach 2 Jahren oder 2,5: „Nu stirb mal endlich." oder so. Also, bei aller Liebe nicht. Und da mein Vater eine sehr, sehr arme Kindheit hatte, wollte ich unbedingt, dass er, dass er das Gefühl hatte, es ist alles geregelt, wenn er alt ist und seinen letzten Weg antreten muss. Das wollte ich wirklich, wirklich von Herzen gern. Ja und das / ich finde, dass unsere Gesellschaft da ein bisschen mehr Unterstützung noch leisten sollte. Aber natürlich, ich bin niemand, der immer nur nach dem Staat schreit, sondern, wenn ich sag Gesellschaft, dann mein ich nicht nur den Staat. Aber was der Staat im Moment uns abknöpft an Steuern und so weiter und dann noch verlangt, dass wir fürs Alter vorsorgen. Ich weiß nicht, wie Sie das machen wollen. Es funktioniert nicht. Wir müssen jetzt irgendwie überleben, und die Wenigsten haben wirklich noch so eine Summe übrig. Was nützt es denn, wenn Sie zum Alter dann 30.000 Euro angespart haben, davon können Sie auch nicht wirklich 20 Jahre leben. Also, da muss man noch, muss man nochmal drüber nachdenken, wie das gehen soll. 
Appendix IV: Transcript of Interview 3

I: Also, als erstes möchte ich Sie erst ein bisschen kennenlernen. Deswegen wäre es für mich am besten, wenn Sie einfach mal Ihren Werdegang von der Kindheit bis jetzt, privat wie beruflich einfach mal ihre Lebensgeschichte erzählen.

B: Also, ich bin 1968 hier in $<<<$ Ort anonymisiert $>>>$ zur Welt gekommen. Hatte ein bürgerliches Elternhaus, wie man so sagen würde. Bin also ohne große, spektakuläre Dinge aufgewachsen. Habe auch nach der Grundschule das Gymnasium besucht. Dann im Anschluss ein Studium der Chemie aufgenommen, dieses auch abgeschlossen, wobei ich am Ende, also im letzten Semester, ewig Zweifel hatte, weil damals die Berufsausbildung relativ schlecht war. Anfangs hat jeder so gesagt, ja Chemie das ist so / das fing schon nach dem Studium an / Dann gab es eine richtige Delle, wo ganz viele Leute - und auch extrem gute Leute - auch mal Taxi gefahren sind oder beim Aldi waren. Da kenne ich welche, das war dann eher schlimm, und dann fing ich meine Promotion noch an und naja, je nach Laune, bis ich fertig war, hat es fünf Jahre gedauert. Da war ein großer Experimentalteil. Promotionen gingen so relativ / können relativ frustrierend sein, weil wenn sie dann die Aufgabe vor sich haben, und es gelingt nicht, da können Sie noch so gut sein oder was. Das ist schwierig das umzusetzen. Wenn Sie dann auch noch einen Professor haben, der sie gerne zum Vorträge vorbereiten oder Posterschreiben hat, dann sind fünf Jahre keine Seltenheit. Ich kenn sogar welche mit sechs, sieben Jahren. Das war sehr frustrierend. Deswegen war ich auch im letzten Semester ein bisschen weg davon. Ich war zu diesem Zeitpunkt mit meiner Frau verheiratet, die Pharmazie / erst mit der Chemie begonnen hat, die aber eine Wartezeit hatte. Ihr Vater hatte eine Apotheke, deswegen war Pharmazie auch so mal im Hinterkopf. So hab ich letztlich Pharmazie noch dazu studiert, weil ich das Gefühl hatte, ich werde jetzt zwar nicht eine Apotheke führen oder als Angestellter in einer Apotheke arbeiten. Aber ich kann zumindest mal, da die wirtschaftliche Situation sehr schlecht ist, hab ich wenigstens was, auf das ich mich zurückziehen kann. Als Chemiker ist so gar nicht drin. Das ist ungefähr so, als wenn man Zahnarzt ist, dann kann man halt nur Zähne plombieren, es gibt kein rechts und links davon. Es gab da auch keinen Aufbaustudiengang. Es gibt Aufbaustudiengänge 
in Wirtschaftsingenieurwesen, das sind so Sachen, die fingen aber erst eigentlich an. So gegen Ende meines Studiums, hat sich das erst etabliert. Ich bin ja aus dem letzten Jahrtausend, deswegen ist, war da alles noch ein bisschen anders. Ich bin ja auch Diplom-Chemiker und kein Master oder irgendwas. Also, das sind so / waren dann einige Schwierigkeiten, die sich / Da gab's, ich weiß noch ein Aufbaustudiengang Patentrecht und, und sowas, das hat mich überhaupt nicht angesprochen. Ich konnte mir nicht vorstellen, dass ich da an einem Patent dann einen ganzen Tag sitze nach dem Studium. Und Pharmazie und so / Ich habe mir das Pharmaziestudium anfangs ein bisschen anders vorgestellt, hatte das sehr industriell gesehen, also auf Forschung ausgerichtet, und dachte mir, ich lerne da eigentlich so die Sachen, die ich in Chemie nicht gelernt habe. Weil Chemie ist ja / ein großer Anteil des Studiums speziell in der $<<<$ Universität anonymisiert $>>>$, ich habe Chemie and er technischen Uni studiert, Pharmazie an der $<<<$ Universität anonymisiert $>>>$. Chemie kann man zwar an beiden Universitäten studieren, Staatsexamen-Studium in Pharmazie wird aber nur an der $<<<$ Universität anonymisiert $>>>$ / deswegen gibt es auch kein Aufbaustudium, um die Frage zu beantworten, weil das eine ist ein Staatsexamen-Studiengang, weil das ist einfach vorgeschrieben, was da für Prüfungen zu absolvieren sind. An der $<<<$ Universität anonymisiert $>>>$ Chemie zu studieren heißt, dass man sehr, sehr viel technische Chemie, physikalische Chemie und Mathematik, solche Sachen hat. Und mich hat eigentlich mehr so medizinische Chemie, pharmazeutische Chemie interessiert. Oder was heißt hätte mich mehr interessiert, das habe ich am Schluss gemerkt, dass das eigentlich sehr interessant ist. Und ich dachte, dass das auch in das Pharmaziestudium ein bisschen greift. Das war dann aber nicht ganz so. Das Pharmaziestudium war sehr viel, also, was den chemischen Teil beinhaltete, sehr wenig forschungsorientiert, sehr sinnlos eigentlich. Auswendig zu lernen, wie man gewisse Arzneistoffe einerseits synthetisiert oder andererseits analysiert, das ist relativ sinnlos eigentlich. Man hat eigentlich sehr wenig über das Verständnis gelernt, wie wirkt ein Arzneistoff an einem bestimmten Rezeptor, was eigentlich die Grundlage jeder Arzneimittelforschung darstellt. Das war ein bisschen schade. Aber wie gesagt, ich habe es ja eigentlich gemacht, weil ich sehr viel anerkannt bekam natürlich. Normal dauert das Pharmaziestudium, welches sehr verschult ist, acht Semester, und ich habe viereinhalb gebraucht. Viereinhalb deswegen, weil es war ein Semester dabei, wo wirklich nur ein Botanik Praktikum drin lag. Das musste halt im Sommer 
stattfinden, deswegen ging das nicht anders. Und das musste man vor dem ersten Staatsexamen noch haben. Und so hab ich in dem Sinn in dem Semester nichts gemacht. Ein bisschen Blümchen analysiert. Den Rest hatte ich eigentlich frei. Bzw. ich habe das dann genutzt, um in der chemischen Industrie mal ein halbes Jahr zu jobben, in der Qualitätssicherung einer Pharmafirma. Das war eigentlich relativ spannend. Ja, irgendwann war ich mit dem Studium fertig. Und ich habe nebenher neben dem Studium schon immer mehr das Gefühl bekommen, das ist eigentlich genau die Richtung, auf die ich zusteuern will, so als Betriebsleiter. Das war dann so mein Wunsch, als Betriebsleiter irgendwie so in die Pharmaindustrie zu gehen sozusagen. Da sind sehr oft an dieser Schnittstelle Leute gesucht, die eigentlich von der Ausbildung her Chemiker sein müssen, speziell von der technischen Chemie sehr viel Ahnung haben müssen, die aber aus formalen Gründen Apotheker sein müssen, um gewisse Unterschriften nach Arzneibuch richtig leisten zu können und und und. Und, ähm, das war eigentlich so lange Zeit mein Ziel. Ich habe dann das zweite Staatsexamen auch absolviert und dann bei dieser Staatsexamensfeier meinen alten Professor, den ich in der Diplomarbeit schon hatte, wiedergetroffen. Und der hat mich dazu überredet, unbedingt noch zu promovieren in Chemie. Das hatte ich eigentlich nicht vor. Ich habe mich dann da ein bisschen breitschlagen lassen.

I: Das haben Sie dann auch bei ihm gemacht, oder?

B: Das habe ich dann wieder in Chemie in $<<<$ Ort anonymisiert $>>>$ gemacht. Und das war immer so, ich hatte schon den Wunsch zu promovieren irgendwann einmal, aber ich habe / Viele in Pharmazie haben, das soll jetzt nicht arrogant klingen, so eine Tennisplatzarbeit gemacht. Das heißt, man geht mit dem Dozenten, vorzugsweise in so Fächern wie Pharmazie, Geschichte ein paar Mal zum Tennis spielen, und dann hat man so nach wenigen Wochen eine Promotion. Und in Chemie ist das halt ganz anders, wie schon geschildert. Das hat mich dann doch wieder irgendwie gereizt. Es hat auch noch ein Studienfreund auch zu dieser Zeit promoviert. Der hat auch zwischendurch was ganz anderes gemacht. Und haben wir uns dann an der Uni wiedergetroffen und haben zusammen in Chemie promoviert beim Professor über Multikomponentenreaktionen in der pharmazeutischen Chemie. Während dieses Studiums hat sich dann bei uns / Ich habe dann dazwischen das Staatsexamen 
natürlich noch fertiggemacht. Dann musste ich auch noch ein Jahr in der Apotheke arbeiten, um sozusagen approbierter Apotheker zu sein. Das erfordert eben noch so ein praktisches Jahr. Und dann zum Ende der Promotion ist eine Biotech-Firma, die in $<<<$ Ort anonymisiert $>>>$ lokalisiert war, an uns herangetreten mit der Nachfrage nach bestimmten Forschungsintermediaten, für die wir während unserer Doktorarbeit ja durchaus ein Patent hatten, aber auch sehr viel Knowhow einfach. Und das haben wir dann gemacht. Da haben wir uns noch am Anfang gefreut, dass man da so 500 - 1000 Euro nebenher verdienen kann. Waren natürlich dann gezwungen, ein Gewerbe anzumelden, damit es auch steuerlich korrekt lief. So waren das dann die Vorzeichen, dass wir irgendwann eine Firma gegründet haben. Diese Firma hat sich dann am Anfang ausschließlich mit chemischer Synthese für pharmazeutische Forschung beschäftigt im Auftrag oder auch als, ja, Distributor für eben gewisse chemische Intermediate, die in der Forschungsindustrie bei Big Pharma gefragt sind. Das war so der Startschuss. Das war 2001. Also 2000, 2001 zur Gründung der ersten Firma. Jetzt brauche ich mal eine Pause.

I: (lacht) Sonst wird er kalt.

B: Sie können sich jetzt überlegen, ob Sie jetzt aus dieser Epoche noch Nachfragen haben. (lacht)

I: Ja, erzählen Sie erst mal fertig, und dann schaue ich mal auf meinen Leitfaden.

B: Wir haben diese Firma gegründet. Wir waren die erste Zeit noch an der Universität, die damals so begonnen hatte, ein bisschen Starthilfe für Firmengründer zu geben. Beispielsweise, ähm, ich habe da ein sehr kritisches Verhältnis zu dieser Starthilfe, weil das war sehr wortreich, und es waren sehr viele politische Absichtserklärungen. Und der Unipräsident hat natürlich in seinen politischen Kreisen da sehr viel darüber geredet. Wenn es aber konkret beispielsweise darum ging, ob man irgendwo ins Labor kommen kann, und es war damals ein großer Lehrstand in den Laboratorien, weil die Studentenzahlen so gesunken sind, war das nicht möglich. Also, das war ein bisschen kompliziert. Man hat dann lieber Gründerzentren gebaut, die aber völlig ungeeignet waren für Chemiker, weil als Chemiker braucht man da halt ein 
Labor. Und da nützt einem nicht ein Schreibtisch oder ein repräsentatives Gebäude etwas.

I: Ja.

B: Und so habe ich da ein bisschen ein gespaltenes Verhältnis dazu. Aber wir hatten einen Professor, der uns persönlich sehr protegiert hat wie unser Doktorvater. Der war aber da schon emeritiert. Aber da war ein anderer Professor, der uns da wirklich ein bisschen geholfen hat. So, ja ich würde jetzt mal sagen, so einfach sehr pragmatisch. Und da sind wir dann, das war auch unsere Absicht, sehr schnell raus, weil uns das dann zu klein wurde, so ein kleines Promotionslabor, und haben dann in der Nähe von $<<<$ Ort anonymisiert $>>>$ nach sehr viel Suchen in $<<<$ Ort anonymisiert $>>>$ in den ehemaligen Räumlichkeiten der $<<<$ Unternehmen anonymisiert $>>>$ Räumlichkeiten gefunden, die als Labor ausgebaut waren. $<<<$ Unternehmen anonymisiert $>>>$ hatte damals vor, dieses ganze Riesengelände, was sehr malerisch am $<<<$ Ort anonymisiert $\gg>$ gelegen ist, zu einer Art Gründerzentrum und Biotech-Zentrum, nach Martinsried auszubauen. Also, im Stil von Martinsried eben, da ist ja in München eine sehr große Biotech-Szene beheimatet. Das hat aber nie so recht geklappt, weil man sich da auch ein bisschen blöd gestellt hat, und auch die Politiker dann irgendwie nur das Gründerzentrum oder nur das Biotech-Zentrum haben wollten, aber keine Pharmazie oder Chemie, die da drin gemacht wird. Ja, also, ich formuliere das schon immer so ein bisschen ironisch, zynisch, weil man will sich dann schon politisch damit schmücken, dass man auch ein Biotech-Zentrum hat oder gehabt hätte in $<<<$ Ort anonymisiert $\gg>>$, hätte aber gerne haben wollten, dass da keiner mit Chemikalien drinnen umgeht, weil das will man dann nicht dazu haben. Also, das ist immer so, hm, ja. Da hat man dann / und dann hat man so viele Auflagen gemacht, die veranlasst haben, dass sich das nie verwirklichen hat lassen. Leider, weil da hätte man wirklich was draus machen können. So waren nur zwei Firmen mehr oder weniger da beheimatet. Das eine Mal eine Firma, die heute ... (unverständlich) macht, also etwas weniger geschwollen ausgedrückt Tierversuche.

I: Ach so, ok. 
B: Sehr renommiert, ein sehr renommiertes, sehr gutes Unternehmen hier im $<<<$ Ort anonymisiert $\gg>$. Und wir waren eben noch drin auf ca. 400 oder $500 \mathrm{~m} 2$ und haben dort unseren Service gemacht. Haben dann aber mal sehr schnell gemerkt, dass die ganzen Sachen sich sehr schnell umdrehen. Wir hatten die Firma gegründet eigenfinanziert. Das heißt, ein Kompagnon und ich haben gesagt: „Das machen wir fifty-fifty", sind zur Bank hin und haben uns jeder, glaub ich, so 350.000 abgeholt und haben gesagt: „Damit gründen wir jetzt eine Firma.“" Und allein für die erste Analytik-Anlage waren dann schon 150.000 weg. Das ging also / war also nicht sehr viel, das Geld. Das war dann auch mit sehr viel Optimismus alles geplant, wobei ich sagen muss, die Firma, für die wir hier produziert haben unsere Forschungsintermediate, hatte eine sehr große Nachfrage. Wir haben das halt in einem Businessplan, wie man das so macht, ein bisschen, relativ konservativ optimiert, nach oben gerechnet. Haben dann gesagt, so nach einem Jahr kommt dann eine zweite Firma dazu, die da vielleicht Interesse haben könnte. Und dann kommen irgendwelche Serviceleistungen dazu. Das Problem war nur, dass 2001 die Biotech-Blase geplatzt ist. Und ganz viele Biotech-Firmen, die bis dahin prosperiert haben, konnten dann nicht mehr an die Börse gehen. Das heißt, der Exit konnte nicht mehr verwirklicht werden. Und so sind die Firmen alle praktisch über Nacht, ähm, zusammengebrochen. Und ich weiß noch, diese Firma, von der ich da spreche, die hat eigentlich sehr viel bei uns bestellt. Wir haben also vor dem Umzug aus der Universität raus, aus einem winzigen Forschungslabor, was nur mein Kompagnon und ich zu zweit mehr oder weniger betrieben haben, ab und zu hatten wir mal eine studentische Hilfskraft, mehr nicht. Da haben wir einmal einen Umsatz ein Jahr dabeigehabt, da haben wir dann, ich glaube, 100.000 DM, waren das glaube ich, da bin ich mir nicht mehr so ganz sicher / Umsatz bereits gehabt. Das war natürlich super.

Wir sind dann umgezogen, und dann ging er sofort auf 0 zurück, weil wie gesagt, keine Biotech-Firma mehr bestellt hat. Und dann ging es los. Wir mussten international agieren. Und das ist natürlich dann alles nicht mehr so einfach und geht auch nicht so schnell. Und dann tickt die Uhr, und die Raten für Laboreinrichtung etc., auch für die ersten zwei Mitarbeiter, die wir da irgendwie hatten, die Löhne, das muss natürlich weiterlaufen. Und dann war das schon nicht mehr so einfach, und wir haben dann noch eine ganze Zeit das so mit Friends \& Family überbrückt. Die Kreissparkasse in $<<<$ Ort anonymisiert $>>>$ hat uns damals sehr, sehr unterstützt. Das 
war ungewöhnlich, hat auch dann mal die Kreditlinie noch ausgeweitet und so, weil sie eben auch diese Ansiedlung da fördern wollte. Wir haben dann aber irgendwann oder relativ bald gesehen, dieser Sprung / Wir können jetzt eigentlich nur / Entweder sperren wir sozusagen den Laden wieder zu, haben dann natürlich die ganzen Verpflichtungen, die wir eingegangen sind, am Hals. Das heißt, die GmbH ist zwar gut und schön, aber man bürgt ja letztendlich doch für alles selbst, weil sonst kriegt man ja kein Geld. Das heißt, die Überlegung war: „Machen wir weiter?“ Und für uns war dann eigentlich die Flucht nach vorne das Entscheidende. Das heißt, wir haben gesagt: „Wir können eigentlich sehr viel mehr." Wir haben auch in den ersten, ich weiß nicht mehr so genau, zwei Jahren auch schon gelernt, dass wir nicht nur irgendwelche simplen Forschungsintermediate machen können. Sondern dass wir letztlich auch ganze Forschungsprojekte begleiten können immer sehr stark vom chemischen Fokus herkommend, was zu der Zeit, und auch bis heute eigentlich noch, schon eine Marktlücke auch war. Weil man hat lange Zeit in den Jahren vorher in der Boomphase von Biotech geglaubt, die Chemie ist uninteressant, man hat genügend Moleküle, man konzentriert sich nur darauf, das Genom zu entschlüsseln, neue ... (unverständlich) zu identifizieren. Und dann schmeißt man halt irgendwas aus den gängigen Molekülbibliotheken drauf, sprich man bedient sich irgendwelcher Verbindungen, die halt existieren. So ähnlich, wie wenn man in ein Supermarktregal geht und nimmt da war raus. Dann hat man schon genügend. Man hat aber sehr schnell gemerkt, dass das doch nicht so geht, und dass dann plötzlich, wenn man eine Biologica machen will, also klassische Arzneistoffe, sogenannte small molecules, wo halt klassische Aspirin, Diclophenac/

Also die meisten Arzneistoffe sind heute immer noch klassische Arzneistoffe, kleiner Seitenausflug. Meiner Meinung nach wird das aber noch sehr lange so bleiben, die nächsten Jahre, weil sie einfach billiger in der Produktion sind. Es zeigt sich heute, dass die ganzen Biologica vielleicht schon an der einen oder anderen Stelle toll sind. Den richtigen Durchbruch sehe ich bei keinem im Vergleich zu anderen Produkten. Aber es hängt halt davon ab, was man macht. Manche sind sehr teuer in der Produktion. Und es ist heute kaum mehr vorstellbar, naja, dass man einen Krebspatienten mit einem Arzneistoff behandelt, der monatlich 30.000 kostet, oder so was. Das ist sehr schnell beieinander. Und dann kommt man doch wieder auf die Klassischen zurück. Also, insofern ist dann der Chemiker gefragt, und das haben wir 
auch gemerkt. Wir haben hier aber eine neue Chemie etabliert, die wir aber eigentlich schon während des Studiums und während der Doktorarbeit etabliert hatten, die im Wesentlichen auf der Multikomponentenchemie beruht. Das war ein neuer Zweig gewesen, und da war dann auch eine Nachfrage da. Und dann haben wir uns einen Investor gesucht, der über Friends \& Family hinausging und, ja. Das war es mal so bis dahin.

I: Aha.

B: Jetzt müssen Sie mir mal irgendwie ein Feedback geben, in welche Richtung ich weitererzählen soll.

I: Ist das Unternehmen, von dem wir die ganze Zeit sprechen, auch das, das dann letztendlich insolvent gegangen ist?

B: Ja.

I: Weil, es hört sich ja bisher alles recht erfolgreich an. Auch wenn jetzt da mal ein bisschen Umsatzeinbußen sind, muss das ja noch nicht der Todesstoß sein.

B: Also, es war schon immer - das ist aber typisch für die ganze Biotech-Branche eine Gratwanderung. Das große Problem ist, dass die Kapitallaufzeiten, also egal, wann die Banken ihr Geld zurückhaben wollen, oder noch schlimmer eigentlich, wann professionelle, institutionelle Anleger ihr Geld zurückhaben wollen, dass die viel zu kurz denken und auch zu betriebswirtschaftlich. Ich sage das mal mit einem Lächeln, weil einfach Forschung ein Hochrisikofeld ist, Sie können das nicht voraussagen. Ich kann eine Produktentwicklung, beispielsweise - nehmen wir durchaus einen komplexen Gegenstand - einen neuen ICE, Automobil, was auch immer, das kann ich relativ klar planen. Es existieren aus der Vergangenheit heraus gewisse Entwicklungszyklen. Das kann ich relativ klar planen. Ich kann auch sagen: „Da ist vielleicht irgendwas für das Auto nicht mehr fertig geworden." Das wird dann nicht eingebaut. Das kommt erst im nächsten Modell. Ich kann es trotzdem verkaufen. Vielleicht bringt es dann nicht die Rendite, den Umsatz, was man da mal geplant hatte. 
Aber es ist / ich will damit darauf hinaus: Es ist sehr viel planbarer als ein solches Hochrisikofeld wie Pharmaforschung, wo dann noch dazu kommt, dass heutzutage auch noch eine Haltung vorhanden ist - sowohl vom Verbraucher wie auch von der Politik - es soll möglichst ein Medikament mit kurzer Entwicklungsspanne auf den Markt kommen, was einen wirklichen Durchbruch in der Behandlung irgendwelcher ernster Krankheiten bedeutet und null risikobehaftet ist. Also, überhaupt einmal Arzneistoffe wie Diclophenac oder sogar Aspirin, glaube ich, würden heute gar nicht mehr zugelassen ... (unverständlich). Und das macht mich etwas nachdenklich, und das ist natürlich ein Problem. Speziell wenn es in der ganzen Pharmabranche, also auch bei Big Pharma dann, das ineinander verschränkt haben, diese Erwartungshaltung, dann funktioniert das ganze System sehr schlecht. Und wie gesagt es ist in der Biotech-Branche auf jeden Fall so, dass es sehr schwierig ist, Entwicklungszeiten vorauszusagen. Sie können / klar können Sie projektieren. Ich habe jetzt so und so viele Chemiker, dann / Das ist schon die Frage, wie lange es dauert, irgendeine chemische Verbindung zu synthetisieren. Sie können Glück haben, dass irgendwas sehr Kompliziertes in zwei Wochen fertig ist. Manches wird in einem halben Jahr nicht fertig. Das kann man einfach sehr, sehr schlecht im Vorhinein abschätzen. Das heißt, Sie müssen ständig korrigieren. Das macht den Investor nervös. Der Investor versteht das dann auch sehr wenig, weil er hat dann - berechtigter Weise auch wahrscheinlich - immer Gefühl: „Ja, der kann mir alles erzählen. Ich kapiere es eh nicht." Dann wenn wir zum Beispiel nochmal zum Automobil zurückgehen: Das ist dann für einen Außenstehenden, auch wenn er kein Ingenieur ist, doch leichter zu verstehen. Wenn mir jemand sagt: „Um eine neue Tür mit einem besseren Aufprallschutz für ein neues Auto zu entwickeln, brauche ich sieben Jahre." Dann würde jetzt sagen: „Aha, das ist aber viel." Wenn ich jetzt sage, ein bestimmtes Arzneimittel oder ein bestimmtes Intermediat dauert so und so lang. Das kann eigentlich ein Außenstehender schon gar nicht mehr bewerten. Das kann eigentlich schon zumeist der nicht mehr bewerten, für den sie die Auftragsforschung eigentlich ausführen. Das heißt Bayer, Boringer oder wie sie alle heißen, sind selber schon nicht mehr in der Lage, zu erkennen, was macht jetzt die $<<<$ Name anonymisiert $>>>$, so hieß die Firma ja damals, was macht die jetzt eigentlich, wie lange dauert das. Und wir haben uns eigentlich schon damit natürlich immer / war das immer eine Gratwanderung. Wir haben dann auch immer gesehen, da kommen oft auch übereilte 
Forderungen von Investoren, die dann sehr, sehr schnell nach Einsparungen suchen und dann natürlich als erstes sehen: „Warum haben sie dann / Da tut es doch ein Chemiker weniger auch.“ Aber dann natürlich nicht verstehen, dass ich dann überhaupt nicht mehr hinkomme.

Also, noch dazu ist es so, dass so ein ganzes Forschungslabor ein unglaublich hohes Grundrauschen erzeugt, von den Personalkosten her, von den Unterhaltskosten. Weil Sie müssen ja im Prinzip mit allem Schritt halten können, was Big Pharma auch hat. Das heißt, Sie können nicht sagen: „Ich mache das hier irgendwie in so einer Hinterhofgarage." Es sind einfach gewisse Standards verlangt. Es ist eine gewisse Analytik vonnöten. Das sind sauteure Geräte. Die kosten sehr viel. Die kosten im Unterhalt sehr viel. Sie brauchen jemanden, der die Dinger bedient, wartet, in Schuss hält, dass die auch messen können. Und das ist auch wieder ein Punkt, der schwer zu vermitteln ist. Ja, dann habe ich halt nur noch zwei Chemiker. Aber dass es dann so ist, dass die zwei Chemiker eigentlich nur noch entweder die Analytik bedienen und keine neuen Substanzen mehr synthetisieren oder umgekehrt. Das ist dann schon schwieriger verständlich zu machen. Also insofern ist das ein sehr heikler Ritt immer gewesen. Das kann ich auch beurteilen, weil ich eigentlich in der Branche bis Ende letzten Jahres noch tätig war.

I: War Ihnen das von Anfang an bewusst, dass Sie auf diese Problematik oder auf dieses Unverständnis stoßen würden, oder mussten Sie dann erst erfahren dann?

B: Das war mir natürlich nicht in dem Maße bewusst. Das ist ganz klar. Das / Also, wäre mir alles so bewusst gewesen, hätte ich wahrscheinlich das überhaupt nie gemacht.

I: Aha.

B: Dann hätte ich auch nie eine Firma gegründet. Wäre mir das alles bewusst gewesen, hätte ich nicht mich selber so hoch verschuldet, bis über beide Ohren, um das durchzuziehen. Es ist natürlich dann ab einem gewissen Moment so, wo Sie so hohe Schulden selber haben, da kam ja auch dazu, dass auch Friends \& Family wie gesagt dann noch mit involviert waren über Bürgschaft über was weiß ich. Also, das 
ist dann schon eine ziemliche persönliche Belastung auch. Und dann will man es natürlich auch durchreißen. Ich bin sowieso, das haben Sie vielleicht auch an den Fragen gesehen, also, dass ich vorschnell etwas aufgebe, dazu neige ich sowieso nicht. Das ist bei mir dann immer so eine Phase, dass ich zuerst einmal mich furchtbar entmutigt fühle und vielleicht auch so „ooohh" ins Jammern komme und zusammenbreche. Aber wenn es richtig Spitz auf Knopf geht, werde ich ganz, ganz hartnäckig, dann fechte ich das durch bis zum äußersten. Und das ist hier dann auch so. Natürlich speziell mit der Bürde im Rücken, dass sie im Falle eines Scheiterns jetzt nicht nur einfach persönlich gescheitert sind. Sie müssen dann Friends \& Family oder auch dem Kapitalgeber offenbaren: „Hm, habt ihr euer Geld wohl verloren.“ Sie müssen - was noch eine Stufe schlimmer ist - selber eingestehen: „Ja, mein Geld ist auch weg. Ich meistere irgendwie eine private Insolvenz oder so." Was sieben Jahre Überfreundlichkeiten bedeutet. Sie müssen ihren Mitarbeitern sagen: „Das war's." Also, das sind alles Dinge, die man natürlich nicht so gerne macht. Und da ist man dann sehr findig und schon sehr bemüht, dass man so was weiter zum Erfolg führt irgendwie.

I: $\mathrm{Hm}$.

B: Und wir hatten dann auch eine ganz gute Phase über einen professionellen Investor nennen wir es jetzt mal, der bei uns eingestiegen ist, was sich aber als großer Bumerang leider erwiesen hat. Das hing aber mit der speziellen Geschichte um den Investor rum zusammen. Das ist eine sehr lange Geschichte. Und ich hatte bis Mitte letzten Jahres ja noch Prozesse aus der Insolvenz heraus, die zum Teil sehr unter der Gürtellinie waren, sehr hanebüchen, also, Gerichtsverfahren, Anschuldigungen. Also, das war ein gewaltiger Rachefeldzug, der sich vorher schon ergeben hatte. Das ist also nochmal eine Geschichte, die auf der Insolvenz von damals mit draufgesattelt war.

I: Aha.

B: Und die das sehr, sehr unerfreulich gemacht hat. Und auch mit sehr großen Belastungen, persönliche Belastungen natürlich, verbunden war, wo ich auch bis zum Schluss eigentlich nicht wusste, wie geht das aus. Weil, ich wusste zwar, was ich 
gemacht hab, und ich wusste, dass eigentlich / Ich habe mal zu meinem Kompagnon: „Also eigentlich müssten wir uns/“"Weil, wir hatten es dann tatsächlich geschafft, über die Insolvenz hinaus, irgendwann mal sogar die Firma wieder mit aufzubauen helfen, oder haben wir geholfen. Wir hatten Gott sei Dank in letzter Sekunde jemanden gefunden, der da noch einmal rein investieren wollte und sozusagen über einen Asset Deal die Sache wieder rausgekauft hat. Wir haben lange nicht gewusst, ob wir da überhaupt oder ob ich - ich spreche jetzt mal nur für mich - da überhaupt wieder eine Rolle irgendwie jemals wieder drin spielen würde. Am Anfang sah das so aus, als seien wir da nur irgendwelche Leute, die ja, naja. Da schaut man halt mal so, dass man das Wissen absaugt von denen. Das bin ich sogar ein Stück weit mitgegangen, weil ich eben auch eine Verantwortung gegenüber den Mitarbeitern gesehen habe, deren Arbeitsplätze alle erhalten wurden bei diesem Asset Deal.

I: Wie viele Mitarbeiter waren das dann?

B: Das waren 16. Wir hatten immer so - also wie die Firma mal so richtig ausgebaut war - so um die 20 Mitarbeiter. Davon waren 4 Industriepraktikanten, die jeweils ein Jahr blieben, aus Frankreich, da gab es so eine spezielle Konstellation. Und das waren insgesamt 16, also alles wissenschaftliche Kräfte. Da waren auch jetzt immer ein/ zwei Doktoranden mit dabei, die bei uns promoviert haben. ... (unverständlich) Dann schaut man, wie kann man die Personalkosten minimieren, wie kann man aber auch ein Forschungsteam so ansteuern, dass dort wirklich Kreativität stattfindet, dass auch ein gewisser Konkurrenzkampf da ist und ein gewisses Wetteifern, eine, nenne ich mal, positiv-kreative Atmosphäre. Wenn Sie sehen, Sie brauchen ungefähr regelmäßig 20 oder 16 Leute in dem Laboratorium, dann kann ich natürlich hergehen und sagen, ich suche mir jetzt acht Chemiker und acht CTAs. Das machen Sie, stellen die da rein, da kommt überhaupt nichts raus, weil da keiner motiviert ist. Da haben sie vielleicht einen dabei, der vielleicht wirklich das entscheidende Quäntchen mehr hat. Der wird aber ganz schnell zurückgestutzt durch die anderen. Also, das ist sehr, sehr schwer, da im Kleinen so eine kreative Mannschaft zu haben. Große Firmen machen das ja immer, indem dann immer wieder die Personalrocharde läuft. Dann werden immer zweihundert Leute entlassen, dann bibbern wieder alle. Dann werden die wieder gemischt, kommen in neue Abteilungen. Da macht man es so, und wir haben natürlich 
einen anderen Weg gesucht als kleine Firma. Und wir hatten - das behaupte ich jetzt ein sehr kreatives und positives Team. Ähm, ja. Jetzt habe ich mich ein bisschen verzettelt. Ich merke, ich starre immer das Aufnahmegerät so an, was mich verwirrt.

I: (lacht)

B: ... (unverständlich) Ich stelle mal den Kuchen davor. (lacht)

I: Was würden Sie denn sagen, was waren dann letztendlich die Gründe, dass es zur Insolvenz kam? Reden wir eigentlich von einer Unternehmensinsolvenz oder auch von einer Privatinsolvenz?

B: Nur eine Unternehmensinsolvenz.

I: Ok, und wie kam es da letztendlich dazu? Was waren da die Hauptgründe, oder wo würden Sie die Hauptgründe dafür sehen?

B: Die Hauptgründe waren, um es mal prägnant zusammen zu fassen, eine völlige Entzweiung mit dem Investor, den wir drin hatten, der ganz andere Dinge plötzlich gemacht hat, als eigentlich angedacht war. Zum Teil - wie es sich aus meiner Sicht darstellt, und ich bin da immer noch vorsichtig mit solchen Äußerungen - die zum Teil auch kriminell waren. Das kann ich gerne auch erläutern, was ich damit meine. Und natürlich eine unerfreuliche Situation, dass einfach gewisse Projekte dann sehr viel länger gedauert haben, dass man auch die Zeit bis zum Abschluss von irgendwelchen Deals falsch kalkuliert hat. Wobei ich jetzt sagen muss, nicht wissentlich falsch. Ich meine in einem Businessplan oder in einer Finanzplanung, in einer Budgetierung kalkuliere ich natürlich mal einen aus heutiger Sicht realistischen Fall ein. Denke mir so und so könnte das sein. Im Laufe der Zeit wird man dann natürlich vorsichtiger. Und es war jetzt keinesfalls so, dass das irgendwelche Utopien waren, das gar nicht sein kann. Ich bin heute auch vorsichtiger. Aber Sie haben oft das Problem bis sich Big Pharma letztlich / Vielleicht noch kurz dazu, so eine Biotech-Firma, wie wir es waren, ganz stark mit chemischem Fokus, also eigentlich keine echte Biotech. Das Biotech sagt man zu allem, was halt um Pharmaforschung und Life Science / 
Eigentlich müsste man eher sagen, wir waren Teil des Life Science Bereiches aber mit ganz stark chemischem Fokus. Und da gibt es fast keine Firma. Da sind wir bundesweit fast so mit die / Da gibt es vielleicht drei, die irgendwie eine Rolle spielen. Und dann gibt es halt Auftragssynthesefirmen, so was gibt es schon, wo man hingeht und sich irgendwelche Synthesen machen lässt. Sie brauchen aber dazu was Besonderes, vielleicht rundet das auch das Bild etwas ab, ähm, oder jetzt verzettel ich mich gerade, ähm. Es ist natürlich so, dass Sie nur ein winziges Rädchen im ganzen Forschungsprozess drin sind. Sie haben ja angefangen, wenn Sie ein Pharmaprodukt auf den Markt bringen wollen, Sie brauchen Biologen, Mediziner, Sie brauchen ganz am Anfang jemanden, der den Zusammenhang zwischen einem konkreten Rezeptor in der Zelle, also dem sogenannten Target, herstellt und dem Genom, was dazu gehört. Sie brauchen die Tests dazu. Dann irgendwann kommt mal die Stelle, wo wir jetzt tätig waren, dass ich sage: „So schaut der Rezeptor also aus", mutmaßlich natürlich auch nur, weil Gewissheiten gibt es da nie. Und dann muss ich ein Molekül konstruieren, was sozusagen - ja, ein bisschen sehr vereinfacht gesprochen - so nach dem Schlüssel-Schloss-Prinzip da auch angreifen kann. Und dann muss ich das Molekül so konstruieren, dass es keine Nebenwirkungen hat und und und. Und dann irgendwann wird das mal auch ganz, ganz spät erst mit tausend Verfahren getestet. Und noch viel später kommt dann der Tierversuch. Und dann kommt die erste Dosis für einen Menschen und und und. Und das ist ein Prozess, der letztlich - ja, man spricht immer davon - eine Milliarde verschlingt. Bis ein - mit diesen ganzen Zwischenrates, die da dazwischen sind - bis ein Arzneistoff am Markt ist, kann man sagen, dauert es tatsächlich im Schnitt eine Milliarde und 12 Jahre.

I: Aha.

B: Das macht so die Dimension vielleicht deutlich.

I: $\mathrm{Hm}$.

B: Und da ist natürlich eine Schießbude, wie wir es waren, mit - auch wenn ich glaube, dass wir sehr gut waren - aber mit 20 Leutchen, natürlich nur so ein winziger Ausschnitt in diesem ganzen Gesamtkontext drin. Das heißt, Sie sind auch immer 
wieder von ganz anderen Dingen abhängig. Und Sie sprechen beispielsweise mit einer Firma, mit einer großen Pharmafirma, die letztendlich immer hinter dem ganzen steht, über einen Vertrag. Da sind Sie schon ganz weit, wenn es so weit überhaupt mal ist. Und dann dauert das ein halbes Jahr, und dann wundern Sie sich: „Warum geht nichts weiter?" Und dann stellen Sie fest, der Mann, der Hauptansprechpartner, ist gar nicht mehr bei der Firma. Da hat sich das Personalkarusell gedreht. Der ist bei der Konkurrenzfirma mittlerweile. Die Firma hat den Forschungsbereich Onkologie jetzt plötzlich eingestellt, macht nur noch in Diabetes. Man will plötzlich an der Börse irgendwas bewirken, weil man ja immer unter quartalsmäßigen Druck steht. Es muss sich immer was tun. Das sage ich auch immer so ironisch jetzt ein bisschen schon. Naja, bei solchen Entwicklungszeiten tut sich halt quartalsmäßig nur sehr wenig. Also wird dann ständig eine andere Sau durch das Dorf getrieben. Und dann werden Sachen wieder, wo alle Wissenschaftler aufschreien: „Ja, da hätten wir schon hinkommen können, aber es hätte halt vielleicht noch zwei - drei Jahre gedauert.“ Das zählt natürlich überhaupt nicht, also fängt man lieber was Neues an, verspricht wieder der Börse was, dass die wieder Hoffnung hat, der Markt. Und nach drei Jahren ist der Atem wieder zu Ende, und dann macht man wieder das Nächste. Deswegen, glaube ich auch, kommt so wenig raus zur Zeit.

I: Ok.

B: Weil das einfach nicht mehr übereinstimmt. Aber warum ich das vorhin so ein bisschen so ausschmücke ist, einfach mal ein Gefühl zu geben, jemanden, der jetzt nicht in der Branche drin ist, und der das nicht kennt, mit was für Widrigkeiten man da kämpft, und wieviel anders das dann ist, im Gegensatz zu einem Apotheker. Der Apotheker kauft auch, hat auch seine Schulden, hat eine neue Inneneinrichtung, die er da machen muss, und so weiter, oder zu irgendeinem anderen Betrieb, Möbelschreinerei, Frisiersalon, was weiß ich. Man ist da irgendwelchem Unbillen ausgeliefert, die man dann überhaupt nicht mehr in der Hand hat, und wo man eigentlich dann schon an dem Tag, wo man die Budgetierung fertig hat, eigentlich schon wieder sieht: „Naja, jetzt ist es gerade aus dem Druck raus, jetzt muss ich es eigentlich schon wieder ändern, weil ich habe gerade den Anruf gekriegt und jetzt ist schon wieder alles ganz anders." 
I: Ok.

B: Und da stecken Sie drin. Und jetzt haben Sie eine Finanzierung, die auch zu knapp ist, eine Finanzierung, die auch anders aufgesetzt wurde, als ursprünglich gedacht. Und dann kommt es halt sehr leicht zur Insolvenz. Dann kommt irgendwann der Punkt, wo Sie merken, jetzt wird es ganz, ganz eng. Dann hat man die Krisengespräche. Und dann stellt man fest, dass der Investor dann auch noch was anderes will. Und dann geht es halt nicht mehr. Ich behaupte, dass solche kritischen Situationen in der Biotech-Szene auch bei den großen, mit 200 Mann aufwärts, Tagesordnung sind. Das ist üblich, das ist leider so.

I: Und was war dann genau das Problem mit dem Investor? Hat der dann auch die Pläne geändert, waren ihm die Zyklen zu lange oder was war es dann?

B: Das kann man viel konkreter sagen. Wir hatten uns nicht für einen klassischen, institutionellen Investor entschieden, eine klassische Pharmaziegesellschaft, weil wir eben das Gefühl hatten, da sind wir vielleicht auch ein bisschen zu klein, auch von den Volumina her, die wir benötigen, weil wir ja schon Umsätze auch gemacht haben. Das ist etwas, was uns manchmal ein bisschen gehindert hat, manchmal aber auch ausgezeichnet hat, dass wir schon im Markt sind. Also, viele Biotechs machen ja irgendwas und machen das ein Jahr, zwei Jahre, drei Jahre, und irgendwann stellen sie fest, das will gar keiner. Ja, das war bei uns jetzt nicht so, aber es waren die Finanzierungsvolumina relativ überschaubar bei uns. Also, das lag im unteren einstelligen Millionenbereich. Die Erstfinanzierung war gerade mal bei 1,3 Millionen, also sehr, sehr gering. Und weil wir eben auch sehr viel durch laufende Umsätze, aus dem Cashflow, selber finanzieren wollten und auch konnten zum großen Teil. Wir hatten uns deshalb für eine Firma aus dem Lohnhersteller-Generika-Bereich entschieden, die auf uns aufmerksam wurden, und die ein Invest platzieren wollten. Und es war am Anfang auch eine strategische Allianz geplant, dass wir sozusagen mit unserer Chemie auch bei der Herstellung von Generika mitwirken können. Das heißt, es hätte sich sozusagen eine Synergie auch ergeben. 
I: Klingt ja eigentlich ganz gut.

B: Das wurde dann / Also, erstens war es dann so, dass plötzlich / Das ist auch ein typisches Vorgehen eigentlich in den Kreisen, das Ganze ist wie ein Pokerspiel. Es ist dann irgendwann klar, ich als Firma brauche Kapital, deswegen gehe ich ja nach außen. Und dann habe ich auf der anderen Seite meinen Investor. Und jetzt beginnt das Pokerspiel: Wann brauche ich das Kapital. Jeder Investor, das ist leider meistens immer so, sagt dann: „Naja, jetzt warte ich halt mal. Schaue ich mir das mal an. Je später ich da reingehe, umso mehr kann ich natürlich die Bedingungen diktieren, und desto mehr Anteile bekomme ich auf den allerwertesten Arsch, um das mal ganz platt auszudrücken, desto besser werden meine Konditionen. Und vielleicht entdecke ich ja noch in der Zeit, wo ich zuwarte, dass irgendwas nicht so funktioniert, wie die in ihrem Budget drin haben. Dass es vielleicht deswegen nicht so funktionieren konnte, weil ich schon mit dem Rücken zur Wand stehe und mich gewisse Investitionen oder eine gewisse Untersuchung / wenn ich jetzt sage: „Ja, geben wir das jetzt raus oder lass uns das mal für 20.000 Euro schnell untersuchen, dann weiß ich, ist es A oder B. Hm, jetzt hast du kein Geld mehr. Naja, stellen wir das mal zurück, wird schon A sein." Dann ist es doch B.

Also, dass man mit so einem Verhalten einfach auch den Erfolg ausbremst. So etwas ist einem dann oft wieder nicht bewusst. Jedenfalls war es hier so, dass man natürlich sehr lange gewartet hat. Am Schluss waren von - es waren 1,3 Millionen ausgehandelt für 30\% der Firmenanteile. Am Schluss war es dann so, das erfuhren wir sehr überraschend, es sind nur 300.000 Eigenkapital und eine Million Kredit. Aber die 30 \% Anteil blieben natürlich. Das ist eine völlig andere Situation. Weil wenn sie eine Million Kredit haben - oder es waren in der ersten Runde, glaube ich, nur 700.000. Aber die Größenordnung, also, so genau habe ich es jetzt auch nicht mehr im Kopf. Die Größenordnung stimmt aber - Dann haben sie natürlich ganz erhebliche Zinslasten.

I: Ja, klar.

B: Das waren damals 5 oder $6 \%$. 
I: $\mathrm{Hm}$.

B: Und plötzlich geht natürlich das Budget erst recht nicht mehr so auf, selbst wenn alles läuft. Und das war dann so das Erste, wenn Sie fragen, was habe ich da zu kritisieren, oder was lief schief. Das Zweite war, dass diese strategische Zusammenarbeit, davon nie wieder ein Sterbenswörtchen die Rede war. Und das Dritte war, dass letztlich der Vorstand dieser Fima, dieser Lohnhersteller-Firma, eine sehr große europäische Lohnhersteller-Firma, zusammen mit einem befreundeten Anwalt über sehr wenig durchsichtige Privatfirmen verfügte zum Teil in der Schweiz und sonst wo lokalisiert, in die wir dann hineinverschoben werden sollten.

I: Aha.

B: Und die Idee war letztlich, und das, habe ich gesagt, würde ich als kriminell erachten, die Idee war letztlich, dass sich ein Vorstand seiner Firma, der er vorsteht, bedient, insbesondere der Investmentabteilung dieser Firma, um eine Firma zuzukaufen, die Firma dann in einen Zustand triebt, wo sie nichts mehr wert ist, sie dann mehr oder weniger für einen symbolischen Euro - das war tatsächlich so - in eine obskure Unterfirma verschiebt, hinter der er über viele Mittelsfirmen dann plötzlich wieder selber steht. Das würde ich jetzt als kriminell erachten so ein Vorgehen, weil es eigentlich Betrug an dem Unternehmen ist, und zwar ein nicht unerheblicher, für das ich eigentlich arbeite. Das meinte ich damit. Das ist hier genau passiert. Und da kam es halt irgendwann zu der Situation. Ich glaube, diese beiden Herren waren dann sehr stark der Meinung, dass sie mit meinem Kompagnon und mir und auch den Mitarbeitern, die uns sehr loyal gegenüber waren, die auch nur geringe Löhne hatten, weil natürlich auch immer die Hoffnung war, dass das besser wird. Da war, glaube ich, der Glaube vorhanden, dass man am Schluss eigentlich mit uns alles machen kann. Und es war dann eine unerträgliche Situation, in der wir im Endeffekt kein / dann war noch eine Finanzierungszusage, eine Zwischenfinanzierungszusage, ich muss jetzt, glaube ich so ein bisschen / Ich stocke jetzt so im Erzählen, weil ich einerseits muss ich mich versuchen, korrekt zu erinnern an die Zeit. Es liegt jetzt doch schon einige Jahre zurück. 
I: $\mathrm{Hm}$.

B: Das war 2007. Andererseits will ich es auch jetzt nicht zu umständlich machen. Aber da wurden dann auch Finanzierungszusagen nicht mehr eingehalten. Und wir hatten am Schluss eine Situation, wo die Firma insolvent ist. Es gibt immer einen Graubereich, wann muss ich Insolvenz anmelden, und bis zu welchem Grad kann ich da noch vorbeigehen. Ich kann beispielsweise natürlich sagen, in dem Moment, wo sie Krankenkassenbeiträge oder Lohnsteuer oder so was nicht mehr abführen können ist es klar, dann ist es höchste Eisenbahn in dem Moment. Sie können aber schon Rechnungen offen haben. Wenn sie zum Beispiel eine Finanzierungszusage haben, dann, das ist Gang und Gäbe, dass ich dann natürlich auch sagen kann, das ist auch vor den Buchstaben des Gesetzes durchaus korrekt, dass ich dann sagen kann: „Ich habe die Finanzierungszusage. Ich bin zwar jetzt rein rechnerisch, ähm, (Pause) insolvent und zwar nicht aufgrund der Überschuldung." Das ist sowieso nie ein Thema. Überschuldung können Sie eigentlich immer aufheben, dann werden halt Kredite einfach nachrangig. Das ist nicht das Thema. Aber rein liquiditätsmäßig ist es ja eine sehr schwierige Frage, wo ist genau der Euro, der das Fass zum Überlaufen bringt.

I: Ja.

B: Den gibt es natürlich nicht. Das ist eine Spannbreite. Und man kann natürlich hergehen, wenn ich mich auf den Investor verlassen kann, wenn ich eine Finanzierungszusage habe, dann kann ich da ein Stückchen weitergehen. Wir sind ohnehin schon sehr weit gegangen, hatten keine Finanzierungszusage, und deswegen waren wir einfach gezwungen, dann irgendwann Insolvenz anzumelden. Denn in so einer Situation kann ich es natürlich nicht riskieren, dass ich mich noch strafbar mache wegen Insolvenzverschleppung. Dann bin ich ja völlig geliefert.

I: Ich meine, es ist klar, dass man wahrscheinlich versucht, das möglichst hinauszuzögern, dass man es vielleicht auch nicht wahrhaben will. Aber wann war Ihnen dann wirklich sonnenklar: ,Jetzt geht es nicht mehr anders, jetzt muss ich wirklich Insolvenz anmelden."? 
B: (Pause)

I: Was war für Sie so die Situation, wo Sie gesagt haben: "Jetzt ist es soweit."?

B: (Pause) Die Situation war eigentlich dann erreicht, wo hier letztendlich auch über massiven Gehaltsverzicht / Wir haben / Also, mein Kompagnon und ich als Geschäftsführer hatten ohnehin nicht besonders viel. Also, als wir gesehen haben, eine Zusage des Investors, dass er eine Zwischenfinanzierung beibringen würde, wo das praktisch dann behauptet wurde, das hätte er nie gesagt, oder hätte er nie geäußert.

I: Ok.

B: Ich bin heute auch sehr viel vorsichtiger. Ich würde zu sowas zu jedem Satz ein Protokoll machen, würde es zeichnen lassen, wenn es whichtiger ist. Habe ich damals nicht gemacht. Also, ich finde auch im Nachhinein, ein gewisses Grundvertrauen sollte unter Geschäftsleuten vielleicht auch da sein. War es hier offensichtlich nicht. Aber, ich habe es Ihnen erzählt, es war ja auch ein ganz anderer - aus meiner Sicht ein ganz anderer Hintergrund bei dem Investor. Er wollte letztlich / Wir hatten ein Projekt in der Firma, wo er und auch wir alle dachten, das könnte mal ein erfolgreiches Biotech-Projekt werden, ein richtig erfolgreiches. Da hat auch viel an Finanzierung benötigt oder gefehlt. Und wahrscheinlich war sein Gedanke, er könne sich die Firma, wenn es jetzt nichts wäre, in das eigene Portfolio sozusagen einverleiben, braucht dann sozusagen nicht mehr mit seiner Firma teilen. Ja, was heißt teilen, er hätte gar nichts gehabt letztendlich, weil es hätte ja die Wagniskapitalabteilung dieser Firma hat den Gewinn gehabt, aber nicht er persönlich. Und so hätte er das persönlich gehabt. Das war, glaube ich, der große Grund. Und er dachte, er kann das unendlich ausreizen. Und es kam dann auch zum offenen Schlagabtausch und zum Streit darüber, was das doch für ein Gebaren ist. Und da war irgendwann die Situation, wo mir eigentlich klar war: „Ich kann mich da überhaupt nicht verlassen." Wo ich dann auch gewahr wurde, was da für ein Spiel mit mir gerieben wird. Und wo ich dann auch gesagt habe: „Naja, also, entweder kommt jetzt noch Geld. Im Budget steht es drin, dass wir an dem Tag oder dem Monat dringend die und die Summe brauchen, sonst muss ich Insolvenz anmelden." Die Summe kam natürlich wieder nicht. Er hat wahrscheinlich gedacht, ich 
erkläre dann: „Ja, dann verzichte ich auf mein Gehalt, und ich bin ja schon dankbar, wenn ich überhaupt weiter dabei sein darf." Oder irgendwie so. Und das habe ich halt dann nicht gemacht und habe halt dann gesagt: „Dann muss ich Insolvenz anmelden."

I: Haben Sie das vorher mit ihm abgesprochen, oder haben Sie ihn damit überrascht?

B: Überrascht würde ich nicht sagen. Er hat sich zwar sehr überrascht gegeben. Das war dann seine Grundlage für die späteren Prozesse. Aber überraschend war es natürlich nicht, weil er ist ja vom Fach. Wir haben vorher laufend Krisensitzungen gehabt. Wir haben wöchentliche Telkos gehabt, wo die Situation besprochen wurde. Und wir hatten eigentlich am Schluss in diesen wöchentlichen Telkos nur noch wirklich wüstes Geschrei und Gestreit. Wir haben uns angebrüllt am Telefon. Und er hatte das Budget, wo absolut ersichtlich war. Und zu dieser Zeit, das waren dann Kurzfristbudgets, die auch nicht aus dem Ruder gelaufen sind, wo es genau klar war, dass wir da halt einfach so stark unterfinanziert sind, dass ich das nicht mehr aufrechterhalten kann, dass ich zum Amtsgericht hinlaufen muss, sonst mache ich mich strafbar. Und vielleicht war das auch seine Absicht. Das sind Mutmaßungen natürlich von mir, ich würde ja nie etwas Böses über den Investor sagen. Vielleicht wollte er das, um uns noch besser im Griff zu haben.

I: Man weiß es nicht.

B: Und so sind wir dann halt zum Amtsgericht gekommen leider.

I: Und der Ablauf des Insolvenzverfahrens, was waren da so die größten Hürden oder Probleme, oder lief das recht reibungslos? Wie haben Sie das empfunden? Also, wirklich die Zeit der Insolvenzphase.

B: Die größte Hürde war, überhaupt einen Schritt zu tun, weil man sich mit der ganzen Problematik eigentlich nie auseinandersetzt. Das ist vielleicht so ähnlich ein bisschen tabuisiert, ähm, wie der Tod. Es hat ein bisschen was davon, wie so man besucht eine Intensivstation und schaut sich gar nicht so genau um. Will ich auch gar nicht so genau sehen, die, die da liegen. Das ist noch nicht so weit. Fällt mir gerade ein 
bisschen so ein, diese Parallele. Und es läuft sehr viel anders. Es ist aus meiner Sicht ein sehr großer Ermessensspielraum aller Beteiligten, der sehr ungewohnt ist. Ich hatte immer das Gefühl, solche Dinge sind sehr klar und starr geregelt. Und wir haben uns da natürlich auch eine Beratung gesucht, eine Insolvenzberatung durch einen Anwalt. Und zwar hatten wir die im Prinzip schon ein halbes oder dreiviertel Jahr vorher erstmalig. Das war da, wo wir aus der ursprünglichen Finanzinvestor-Situation, die ich geschildert hatte, in dieser merkwürdigen Firmen hinüber transferiert wurden. Und da, klar, da war ich auch mit dem Rücken zur Wand. Und da habe ich mich natürlich mal auch vertraut damit gemacht, wann muss ich überhaupt Insolvenz genau anmelden. Wie läuft das ab? Was muss ich beachten? Wie gesagt, da war dann eben der Rettungsanker, dass wir für einen Euro verkauft wurden an einen neuen Investor, wo dann doch wieder der alte plötzlich aufgetaucht ist, zumindest in Persona. Insofern hatte ich da natürlich Vorkenntnisse. Die waren sehr whichtig. Ohne diese Vorkenntnisse wäre ich, glaube ich, sehr, sehr stark aufgelaufen. Denn es hat mir sehr geholfen, dass ich zum Amtsgericht hin bin und gut präpariert war mit Unterlagen, die man einfach für so einen Fall braucht. Ich wusste zu dem Zeitpunkt bereits so banale Dinge, wie ich brauche eine Angestelltenliste, die ganzen Lohnunterlagen ... (unverständlich) Ich hatte das wirklich in einem Schnellhefter schön vorbereitet. Und was unser Ziel war der Insolvenz, die größte Angst war / Es gibt ja so zwei Typen von Insolvenzberatern. (Pause) Das ist einmal der Zerschlager und einmal der Sanierer. Mittlerweile ist die Gesetzeslage sehr stark geändert worden. Man sieht offenbar mehr Sinn darin, den Gläubigerschutz etwas zurückzudrehen. Das ist natürlich immer die Balance zwischen Gläubigerschutz einerseits, das ist ganz klar, und Erhalt der Firma auf der anderen Seite. Man sieht heute, glaube ich, mehr als früher die Notwendigkeit an, mal am Gläubigerschutz ein bisschen zurückzugehen. Wahrscheinlich auch deswegen, weil die meisten Gläubiger dann sowieso oft auch institutionelle Anleger sind. Und weil letztlich, das ist ja meine Interpretation, ich stimme da voll und ganz zu, weil es letztlich auch egal ist, ob ich am Schluss eine Quote von 25 oder $30 \%$ rauskriege als Gläubiger. Das macht den Kohl nicht fett. Wenn das Ding aber erhalten werden kann, und ich kann später wieder Geschäfte damit machen, dann profitiere ich als Gläubiger sehr viel mehr davon.

Da war aber bei uns erst so die Umbruchphase. Die Gesetzeslage war leider noch nicht geändert. Das heißt, ich hatte die große Sorge, dass wir vorschnell an einen 
Zerschlager kommen, der das vielleicht auch gar nicht versteht, was wir machen, der da nichts Erhaltenswertes in der Firma sieht, und wir dann sozusagen die Reste da ausverkaufen, was nicht viel gewesen wäre. Und ich habe mich deswegen auch sehr gründlich vorbereitet, weil ich natürlich klar irgendwie die Hoffnung hatte, ja vielleicht kann man das irgendwie sanieren, vielleicht gibt es da eine Möglichkeit. Ich wusste ja auch nicht, was im Einzelnen auf mich zukommt. Und das hat sehr viel gebracht, dass wir sehr / Wir sind zu zweit da hin, der Kompagnon und ich, war eine sehr angenehme Tour, und waren eben dann aber sehr positiv aufgenommen, weil die halt gemerkt haben, da ist jetzt nicht irgendwie so die klassische Insolvenz: Hat einer eine Firma gegründet, der Geldkoffer steht schon auf den Seychellen, und jetzt melde ich halt schnell Insolvenz an. Da gibt es die unterschiedlichsten Dinge. Wir kamen deswegen auch zu einem Insolvenzverwalter, ähm, Berater habe ich vorhin immer gesagt, Insolvenzverwalter meinte ich natürlich, zu einem Insolvenzverwalter, der sehr stark auf Sanierung aus war. Und damit konnten wir natürlich sehr gut leben.

Die Zeit der Insolvenz selber war sehr ruhig. Das waren drei Monate. Da sind alle Beteiligten wie wild auf Investorensuche gegangen. Wir haben uns auch bemüht. Wir haben zu dem Zeitpunkt leider keinen gefunden. Der Insolvenzverwalter hatte 2-3. Da wurden Gespräche geführt. Die wollten aber nicht. Dann waren / Das Ganze war untermalt von einem grauenvollen Szenario des Investors, der als sich / der also gedrückt hat, weil jetzt offensichtlich sein Plan nicht aufgegangen ist, und die Firma insolvent war. Und natürlich die Summe, die er dann jetzt sofort reingeben musste, natürlich erheblicher war, als das immer kleckerleweise zu machen. Das heißt, es waren hier laufend wüsteste Streitereien, die aber dann Gott sei Dank der Insolvenzverwalter noch etwas abgefangen hat, der sich da meiner Meinung nach auch sehr gewundert hat, was da so läuft. Und es hat dann eigentlich unser Forschungsleiter und die, da war damals noch eine Finanzfrau bei uns, zusammen mit dem Insolvenzverwalter haben die dann einen Asset Deal ausgehandelt, weil die in letzter Sekunde, wirklich ein paar Tage vorher, eine andere Chemiefirma gefunden hat, die EPIs herstellt, also Intermediate für die Arzneimittelproduktion nicht die Forschung, für die Produktion, also richtig, $100 \mathrm{~kg}-\mathrm{Chargen}$ und so. Und die haben Erweiterungsbedarf gehabt laborseitig. Und die haben sozusagen investiert in die Firma $<<<$ Name anonymisiert $>>>$, oder die Assets der Firma $<<<$ Name anonymisiert $>>>$, mit dem Hintergedanken auch, dass die Firma $<<<$ Name 
anonymisiert $>>>$ ihnen dann auch die Hälfte der Räumlichkeiten für sehr günstige Konditionen zurückvermieten kann. So dass für die das Investment gar nicht mehr so groß war. Das hat sich aber wirklich erst in der letzten Sekunde ergeben. Ich muss dazu sagen, wir sind - das habe ich in der Erzählung vergessen - in der Zeit längstens aus $<<<$ Ort anonymisiert $>>>$ weggewesen. Wir waren in $<<<$ Name anonymisiert $>>>$ auf $1400 \mathrm{~m} 2$. Wir hatten zum Schluss ja so knapp 20 Mitarbeiter.

I: Aha. Also, das heißt, während des Insolvenzverfahrens haben sie sich eigentlich auch bei ihrem Verwalter gut aufgehoben gefühlt und auch fair behandelt. Kann man das so zusammenfassen? Das schwarze Schaf war eigentlich der Investor.

B: Das war absolut das schwarze Schaf. Ich habe beim Insolvenzverwalter mich immer wohl gefühlt, weil ich oft nicht durchschauen konnte, weil keine Transparenz für mich da war. Das ist eine völlig neue Situation gewesen. Ich hatte jetzt mittlerweile gelernt, wie es sich anfühlt, wenn man zu einer Bank geht und keinen / Wenn der Kreditrahmen ausgeschöpft ist. Oder man hat ein Gefühl, wenn man Verhandlungen führt, klappt es, klappt es nicht. das war alles Neuland für mich. Insofern konnte ich das wenig bewerten. Der Insolvenzverwalter war mit Sicherheit nicht schlecht. Er hat jetzt im Nachhinein einige Dinge durchaus ganz clever gemacht, die mir im ersten Moment sehr abstrus erschienen, und ich dachte: „Jetzt schlägt er sich plötzlich auf die Seite des anderen, des Investors. Was soll das jetzt?" Und das waren aber gewisse Handlungen, die ich erst sehr viel später als korrekt erkannt habe, wo ich dann auch erst gelernt habe, welcher Hintergrund da bei dem Investor vorhanden war.

I: Aha, ok.

B: Also er hat das sehr gut / Ich hätte mir gewünscht, dass mehr Transparenz da ist. Ich habe wenig Rechtssicherheit empfunden.

I: Ok.

B: Es kamen viele Forderungen. Ich meine, klar, da wird dann auch verhandelt bei dem Asset Deal, für was müssen wir bürgen, ... (unverständlich) Also, da kommen 
einerseits natürlich alle Banken auf einen persönlich zu. Das ist dann mein Privatvergnügen natürlich, wie ich mich mit denen arrangiere. Aber es kommt dann auch der Insolvenzverwalter auf dich zu, der sagt: „Naja, Kolb, also wir machen jetzt mal, also 600.000 möchte ich von Ihnen noch haben." Natürlich. Das ist ja noch einmal so viel, wie das, was ich mir von der Bank schon eh geleistet hätte. Wo sollen die jetzt herkommen? Das hat sich mir nie erschlossen. Ich habe erst sehr viel später gelernt, dass das so Zahlen sind, die man mal in den Raum wirft, und wo man dann verhandelt. Und am Schluss waren es bei dem Asset Deal, ich glaube, 5.000 Euro.

I: Aha. (lacht)

B: Es ist aber, glaube ich, wahrscheinlich für den Insolvenzverwalter nicht unbedingt ersichtlich, was es für einen persönlich bedeutet, wenn man plötzlich nach Hause geht, und die Familie ist da, hatte zu der Zeit ein zweijähriger Sohn. Das heißt, den habe ich immer noch, aber ist nicht mehr zwei. (lacht) Und man legt sich dann ins Bett und denkt: „So, da haben wir jetzt nochmal 600.000. Naja, ist ok." Ich habe mir dann bloß immer gedacht: „Naja, spielt auch schon keine Rolle mehr, weil ob ich jetzt 700.00, eine Million, zwei Millionen zurückzahlen muss, kann ich eh nicht."

I: (lacht)

B: Also, und das ist natürlich ein Gefühl, was nicht so wahnsinnig angenehm ist.

I: Klar, ja. Hatten Sie auch Angst in die Privatinsolvenz zu rutschen?

B: Ja, natürlich, natürlich. Das war das Damoklesschwert, was andauernd über uns geschwebt ist. Und es konnte im Prinzip erst in mehreren Etappen verhindert werden. Also, der erste Schritt dazu war / Das wäre natürlich passiert. Man hat ja auch privat nichts mehr auf dem Konto, weil das, was man am Konto hatte, habe ich ja natürlich schon in die Firma gesteckt. Ja, das ist auch klar.

I: $\mathrm{Hm}$. 
B: Das heißt, die erste Etappe, der erste Etappensieg war, dass tatsächlich in letzter Sekunde jemand gefunden wurde, aus einem, ja, sehr flüchtig bekannten Unternehmen, der uns - ich sage immer noch uns, auch wenn ich zu dem damaligen Zeitpunkt keine Managerrolle gespielt habe - der in die $<<<$ Unternehmen anonymisiert $\gg>$ oder in diese Firma investiert hat und gesagt hat: „Ich glaube an die. Ich verstehe das. Und zugleich sehe ich noch den Nebeneffekt, dass ich mir dann vielleicht über die nächsten Jahre, 60 - 70.000 Euro Miete spare." Und das ganze Investment von ihm waren nur 150.000 oder so was, ich weiß es nicht mehr so genau. Ich meine klar, da wird natürlich dann ein Schuh draus.

I: Ja.

$\mathrm{B}$ : Ab da war es mal zumindest so, dass wir wussten, es kann überhaupt irgendwie weitergehen. Dann kam dazu, dass der Insolvenzverwalter oder auch der Investor natürlich auch uns mit an Bord halten wollte als Berater, also nicht in einer Managementfunktion. Das konnten wir zu dem Zeitpunkt ja gar nicht, aber man hätte auch sagen können: „Ja, die zwei haben es in die Insolvenz geführt" - was so nicht stimmt natürlich, aber hätte man natürlich sagen können, oder hätten andere vielleicht gesagt - „Wir bauen das mit völlig neuen Leuten neu auf." Aber dadurch haben wir natürlich da wenigstens irgendwie ein Einkommen gehabt, was es uns ermöglicht hat, da auch nochmal zu überdauern. Und wir hatten dann auch die Möglichkeit / Na, dann kam noch eins dazu. Wir haben dann auch wieder in letzter Sekunde, das Ganze war im Februar 2008, wenn ich mich recht entsinne, und im Mai 2008 haben wir völlig unerwartet einen echten institutionellen Risikoinvestor gefunden aus Finnland, einen deutsch-finnischen Investmentfonds, der in uns investiert hat, in die Firma. Wir haben die Firma $<<<$ Unternehmen anonymisiert $>>>$ wurde die dann genannt. Das war auf mein Anraten. Weil man musste einen neuen Namen ja geben, und wir hatten ja dann schon auch Altkunden, die Aufträge hatten. dass die dann irgendwie eine Verwandtschaft erkennen.

I: Ja. 
B: Weil es ist sehr schwer, überhaupt mal wieder eine Kundenbeziehung aufzubauen, deswegen haben wir dann kein $\mathrm{X}$ für ein $\mathrm{U}$ vorgemacht, sondern ein $\mathrm{X}$ für ein $\mathrm{D}$. Und dann war das eigentlich sehr, sehr knapp, und ich habe mich eigentlich immer gefragt: „Ja, das ist jetzt nur noch eine Frage der Zeit." Und ich hatte zufällig Ende März einen, das war gar nicht mit der Absicht, den Manager dieses Investmentfonds hier in München getroffen. Und der war begeistert von der Idee. Das war er wahrscheinlich deswegen, weil er selber Chemiker ist. Ganz selten, also, die meisten haben natürlich einen betriebswirtschaftlichen Hintergrund. Viele haben Mediziner- oder Biologenhintergrund, ganz wenig Chemiker. Die Gründe habe ich Ihnen am Anfang genannt, warum das so ist, warum die Chemie da ein bisschen unterbesetzt ist. Auch weil die Chemie immer am Anfang des Prozesses steht, also nicht da, wo es richtig um Werte geht.

I: Ok.

B: Das ist dann immer während der klinischen Phasen, und da sind natürlich Mediziner und Biologen gefordert.

I: Aha.

B: Und der war Chemiker, und dem hat das Projekt so gut gefallen. Und der hat dann seinen Fonds dazu gebracht. Dann habe ich gesagt: „Ja, dann, wir brauchen dringend, damit wir uns richtig bewegen können, damit das jetzt nicht eine Eintagsfliege bleibt." Und so weiter und so fort. Dann konnte der innerhalb von, ich glaube, das habe ich noch nie erlebt, innerhalb von 40 Tagen dem zugestimmt und hat dieses Investment gesetzt gegen den Rat fast aller seiner Leute. Nur weil er persönlich das wollte. Das ist ein riesen Glück gewesen.

I: Existiert das Unternehmen jetzt?

B: Ja, ja.

I: Und in welcher Form? 
B: Als $<<<$ Unternehmen anonymisiert $>>>$. Das Unternehmen hat dann / (Pause) Ja, das war / Die erste Finanzierungsrunde hat nicht viel, hat auch nicht lange gereicht, weil unheimlich viel Geld in einen ganz komplizierten Anwaltskrieg mit dem Altinvestor geflossen ist, der über alle drei Instanzen die Gläubigerversammlung angefochten hat, die diesem Asset Deal zugestimmt hat. Das waren so die Highlights aus der Geschichte. Der dann, wie er gemerkt hat, er hat sich jetzt da mit seinem Verhalten total ausgebotet, eigentlich nur noch ein Ziel hatte, uns persönlich, also meinen Kompagnon und mich, wie auch die Firma zu zerstören. Er hat daraufhin uns beide vorm Amtsgericht staatsanwaltlich über alle drei Instanzen verklagt. Er hat zivilrechtlich uns verklagt. Er hat die Firma verklagt. Er hat die Gläubigerversammlung angefochten. Und das hat gleich mal im ersten Jahr die Firma so viel Geld / und auch die Gesellschafterverträge korrekt aufzusetzten, so viel Geld gekostet, dass auch nicht zuletzt dadurch sehr, sehr stark das Geld wieder aufgebraucht war. Das war also innerhalb vom Einstieg dieses Investors bis Jahresende, wie gesagt im Mai war das. Bis Jahresende waren, ich glaube, 250.000 nur für Anwälte draufgegangen.

$\mathrm{I}: \mathrm{Hm}$.

B: Das fehlt natürlich in der Forschung dann. Und deswegen war es dann wieder einmal knapp. Wobei die Situation da nicht so bedrohlich war, weil wir endlich mal einen Investor hatten, der irgendwie an die Sache geglaubt hat. Mit dem man auch Dinge besprechen konnte, der das auch verstanden hat. Natürlich ist keiner erfreut, wenn er in die zweite Runde muss. Das ist aber, glaube ich, auch gängig, dass ein Investor immer über mehrere Runden finanziert. Egal. Jedenfalls haben wir dann, das war 2008. Anfang 2010 hatten wir tatsächlich einen riesen Erfolg. Wir haben einen großen Pharmadeal mit Böhringer-Engelheim gemacht. Das ist auch überall publiziert. Das sind diese typischen Biotech-deals. Wir haben eine Entwicklung, die wir samt gesicherter Patentlage an Big Pharma auslizensieren.

I: Und sind Sie jetzt noch Teil der Firma, oder haben Sie sich zurückgezogen? 
B: Ich habe mich jetzt operativ zurückgezogen, aber mir gehören halt Anteile an der Firma. Ich habe mich jetzt Ende letzten Jahres aus ganz anderen Gründen entschieden, mich operativ zurückzuziehen. Und momentan, ja, es ist sehr durchmischt. Ich habe gerade die Zeit auch nach dem Pharmadeal, dann schwebt man erst mal so auf Wolke sieben und kriegt nen Anfall, ob wohl jetzt mehrere Millionen auf das Konto überwiesen werden. Das ist alles sehr toll. Das sind dann ganz andere Dimensionen, als das, was vorher mal so war. Aber es ist trotzdem sehr / es bleibt immer ein Ritt auf Messers Schneide irgendwie. Weil da kommt dann irgendwann der freundlichste Investor und will sein Geld um den Faktor sieben gemehrt zurück. Und das ist natürlich dann auch wieder eine Herausforderung. Ne, es langt ja dann nicht, wenn er das Doppelte hat. Und wir haben dann jetzt im Prinzip, das hat mich auch etwas geärgert, hat auch persönlich dazu geführt, dass ich mich jetzt aus der Firma zurückgezogen habe / Wir hatten 2011, 2012 Diskussionen über einen Firmenverkauf. Da war eine Summe im Spiel, die hätte gemessen an den Anteilen, die letztendlich mir gehören, dazu geführt, dass ich hier ein schönes Eigenheim gehabt hätte in $<<<$ Ort anonymisiert $\gg>$. Und das war aber zu wenig.

I: Aha.

B: Also, sprich die ganze Firma wäre dann für sagen wir mal 20 Millionen rund über den Tisch gegangen. Wir hatten auch nur einen Gesamtinvest, ja, so schnell vergisst man die Zahlen, von (pause) 4-4,5 Millionen oder so was drin. Vier Millionen, glaube ich, von dem finnischen Investor. Das heißt, das wäre eigentlich ganz ordentlich gewesen. Und dann gibt es ja auch Earn Out Komponenten. Also, ich hätte das sehr gerne gemacht. Das wollte man nicht. Man hat dann ein bisschen zu sehr die Dollarzeichen wieder mal in den Augen gehabt, hat sich dann auch - diesmal nicht bösartig (lacht) sondern blöd verhalten - und dann habe ich mir irgendwann Mitte des Jahres gesagt: Ich habe jetzt zwei Bs von Investoren kennengelernt, einmal Bösartigkeit, einmal Blödheit.

I: (lacht) 
B: Ich mag nicht noch auf ein drittes B warten, was da noch kommt. Und es war auch, da hatte ich gesundheitlich ein paar Probleme mal mit in den letzten Jahren durch den ganzen Stress. Dann die ... (unverständlich) alles sich zu kümmern, auch die Verkaufsverhandlungen zu führen. Da habe ich mit einer Firma gesprochen, die in USA sitzt. Wir haben dann noch - ja, das kam auch noch dazu - eine Dependance, Biologie-Dependance, in Philadelphia gegründet. Das heißt, alle vier Wochen nach Philadelphia hin, dort wieder angerührt. Und ich habe immer so das Bild vor Augen, ich kam mir da immer vor, wie - Sie kennen das vielleicht vom Chinesischen Staatszirkus - diese Tellerjongleure. Wie der seine 10 Stangen hat und in der Hand reibt, und wenn man da an einem Ende ein bisschen ... (unverständlich), dann eiert der schon wieder und hastet wieder zurück. Und mit jeder Stange, die man mehr reinsetzt, wird es mehr. Und wie gesagt, es gab dann auch persönlich noch Ärger bei mir, wo ich das auch nicht mehr so wollte. Und da gab es keinen Streit, wir haben uns im Guten getrennt, und das passt alles. Aber ich hatte dann keine Lust, auch nach den Dingen, die vorher waren. Und das ist dann halt so, dann waren wieder, also, erst einmal Verkaufsverhandlungen für die Firma, dann schwebt man auf Wolke sieben. Es ist wieder eine Brautschau, man bläht sich auf, man schickt sich auf.

I: (lacht)

B: Es soll einen jemand anders ja kaufen. Man investiert noch mal in eine Dependance in Philadelphia, weil das macht ja interessant. Das ist jetzt nicht nur alles Optik, das hat natürlich auch handfeste Gründe. Und dann kommt plötzlich / Dann scheitert das, oder man lässt es ja fahrlässig scheitern. Und dann ist natürlich sofort die andere Seite da. Ja, dann muss man wieder sanieren, muss wieder einsparen, Dinge ... (unverständlich). Dann habe ich Leute entlassen müssen. Und ich hatte einfach auch das Gefühl, ich mag nicht wieder. Es kann / ich mag das jetzt nicht mehr so. Und, ja, das ist es bis heute. Und seit Dezember versuche ich mich jetzt als freiberuflicher Berater selbstständig zu machen.

I: Aha. 
B: Da brauche ich nur noch mein Arbeitszimmer, meinen Computer, meine Homepage, meine Visitenkarten, die ich irgendwie nicht dabeihabe, habe ich vergessen, habe ich vorhin festgestellt.

I: (lacht)

B: Und keinen Angestellten mehr finanzieren muss.

I: Ja.

B: Davon habe ich immer geträumt.

I: Sie haben vorhin in Bezug auf die Insolvenz das Wort scheitern verwendet. Fühlen Sie sich so, als wäre das ein Scheitern gewesen?

B: Nein, überhaupt nicht. Ganz im Gegenteil. Ich fühle das als gewaltigen Sieg, weil es ist uns beiden, da nehme ich mal ausdrücklich meinen Kompagnon dazu, weil wir haben das wirklich gemeinsam durchgestanden. Es hat jeder gesagt, es ist ein gewaltiges Husarenstück das so hinzubekommen. Und da wir da doch nicht unerheblich mitgewirkt haben, erfüllt mich das eigentlich mit Stolz, dass es gelungen ist, letztlich mit diesen ganzen Anfeindungen auch fertig zu werden auch mit diesen endlosen Prozessen. Das war eine sehr schwierige Zeit, da einerseits nach diesem Asset Deal für die Firma zu arbeiten.

I: $\mathrm{Hm}$.

$\mathrm{B}$ : $\mathrm{Zu}$ versuchen, dass das wieder hochkommt. Dass das alles funktioniert, das habe ich eigentlich vorher schon immer gedacht, da langen 24 Stunden am Tag nicht. Ich habe aber dann lernen müssen, dass ich noch viel mehr Zeit damit verbringen muss, andererseits die Anfeindungen des Altinvestors abzuwehren, diese unendlichen Anwaltsschreiben und Gerichtsprozesse usw., die da erfolgten, die eigentlich nur ein Ziel hatten: zu zerstören. Der Mann hat selber dafür - wir haben das mal geschätzt (Pause) ... (unverständlich) derselbe Anwalt, der das gemacht hätte, hat eine eigene 
Kanzlei, da hätte er natürlich was Vernünftigeres auch machen können - das hat ihn schätzungsweise 60 - 70.000 selber gekostet.

I: $\mathrm{Hm}$.

B: Und das eigentlich in einem aussichtlosen Kampf. Es waren dann am Schluss Klagesummen im Raum gestanden von - was war das höchste? - 15 Millionen. Also, das ganze Investment von ihm waren bloß 600.000 .

I: $\mathrm{Hm}$.

B: Und er hat das dann irgendwie hochmultipliziert auf das Jahr 2020, so ungefähr. Ich übertreibe jetzt auch ein bisschen natürlich. Was es dann hätte wert sein müssen, nach seinen, seinen /

I: Ja.

B: Und das Schlimme ist halt, dass dort auch Gerichte sehr unberechenbar sind, eben auch weil sie die Materie wieder nicht verstehen, weil der Mann sehr massiv, sehr bedrohlich, zum Teil mit Privatdetektiven auch, aufgetreten ist.

I: Ok.

B: Das macht es sehr unangenehm.

I: Ja. (Pause) Würden Sie sagen, dass die Insolvenz Sie verändert hat?

B: Ja. das ist ein wesentliches Ereignis im Leben. Das verändert einen natürlich. Wobei ich sagen würde, es ist in meinem Fall nicht die Insolvenz, sondern es ist das Gesamtgeschehen.

I: Aha. 
B: Ich empfinde jetzt nicht, dadurch dass ja letztlich heute, Stand heute wie ich hier sitze, alles sehr gut ausgegangen ist, wir unglaublich viel Glück hatten - das Verhältnis ist im Leben dann doch immer ein Nullsummenspiel, Pech und Glück, was man so hat - geht es mir heute sehr gut.

I: Aha.

B: Auch finanziell, trotz der ganzen Prozesse.

I: Ja.

B: Und klar könnte ich jetzt genauso nach Steuern 100.000 mehr haben, wenn ich diese Prozesse nicht hätte führen müssen. Da denke ich aber gar nicht drüber nach, weil da wird es mir schlecht.

I: Und wenn Sie jetzt nochmal zurückdenken /

B: Das ist der Gesamtkontext.

I: Ja.

B: Das ist es. Ich erlebe von daher die Insolvenz anders, als Leute, die Insolvenz erleben, wo ihr Lebenswerk beispielsweise zerstört ist, zerschlagen ist.

I: zerschlagen wird, ja.

B: Und dann ist Ende. Und möglicherweise schließt sich noch eine Privatinsolvenz an. Das ist etwas komplett anderes. Für uns war das so ein Abschnitt in einem sehr langen Prozess, wo einfach Dinge nicht funktioniert haben, wo natürlich vielleicht auch Fehler von mir gemacht wurden. Es wäre ja vermessen zu sagen: „Ich habe alles 100\%ig richtiggemacht." Das geht ja gar nicht. Wenn ich eine Firma gründe, natürlich mache ich 1000 Fehler. Und wenn ich eine Firma führe, mache ich noch mehr Fehler. Es hätte aber meiner Meinung nach nicht zur Insolvenz kommen müssen, wenn man 
sich mit dem Investor hätte arrangieren können. Dann hätten wir gemeinsam vielleicht nach einem anderen Investor gesucht. Dann hätte man vielleicht diesen deutschfinnischen Investor damals schon finden können, hätte gesagt: „Ok, der erstattet dem das eingesetzte Kapital einfach eins zu eins zurück." Und macht bei uns neu. Weil, dann das wäre alles billiger gewesen für alle Beteiligten. Und so war es sinnlos. Aber so wollte man es halt.

I: Sie haben jetzt ja sehr erfolgreiche Zeiten und auch weniger erfolgreiche Zeiten durchlebt. Haben Sie das Gefühl, dass die Menschen anders auf Sie reagieren oder anders mit Ihnen umgehen je nach Abschnitt? Haben Sie das irgendwie erlebt, dass Freunde anders zu Ihnen waren während der Insolvenzzeit als jetzt heute?

B: Nein.

I: Oder irgendein Unterschied im Umgang?

B: Nein, überhaupt nicht. Aber, ich glaube, das hat auch wieder sehr stark damit zu tun, dass eben die Insolvenz bei uns Teil eines Gesamtprozesses war, der eigentlich schrittweise dann zu mehr Erfolg geführt hat am Ende des Tages. Und man hat sehr viel gelernt auch dabei. Und man ist / Es war spannend. Es war zur rechten Zeit auch sehr erschöpfend. Und weil Sie fragen, wie hat es mich verändert. Ich bin härter geworden.

I: Aha.

B: Ich bin misstrauischer. Und ich habe gelernt einfach - natürlich nicht nur aus diesem Ereignis allein, auch aus den Jahren danach, auch so im internationalen Bereich, wo wir vorher eher verhalten tätig waren aber die letzten Jahre eigentlich nur noch in USA, zum Schluss auch in Japan. Speziell in USA, das ist halt / Ich habe irgendwie so die Einstellung bekommen: Geschäft zu machen, das ist heute halt man setzt sich gegenüber und dann schaut man, wer kann den anderen über den Tisch ziehen. Das ist so eine Einstellung. 
I: Aha.

B: Da musst du halt clever sein. Also, ich würde da nie mehr blauäugig mich da hinsetzen und sagen: „Naja, wenn mir der das verspricht. Also, so ein Handschlag gilt schon was, oder man hält sich dann da dran, was man da mal sagt." Das würde ich vollkommen wegschieben.

I: $\mathrm{Hm}$.

B: Also, es hat mich härter und misstrauischer gemacht. Leider.

I: Sind Sie noch mit der Dame verheiratet, der Pharmazeutin?

B: Ja.

I: Ja. Und die war ja während der ganzen Zeit auch berufstätig? Oder war Ihr Einkommen das Einzige?

B: Ja. Naja, es war / Sagen wir mal so, das einzig beruhigende in der Zeit der Insolvenz war, dass mein Gehalt, das relativ gering war als Geschäftsführer einer solchen Firma, weitergezahlt wurde durch das Arbeitsamt.

I: Ach so, ja.

B: Durch die Insolvenzzahlungen. Weil ich ja von der Seite als Angestellter zu sehen war. Insofern hatte ich die drei Monate ja Gehalt. Das Schlimme war eigentlich, die immensen Kosten für die Prozesse aufzubringen. Das war aber eigentlich erst in den Jahren danach. Und so richtig Gott sei Dank als die Firma sich als $<<<$ Unternehmen anonymisiert $>>>$ Dank des finnischen Investors soweit positiv entwickelt hatte, dass sie auch ein ordentliches Gehalt für die Vorstände zahlen konnte. Damit war das abgefedert.

I: Und aber die Prozesse, die haben Sie jetzt auch überstanden? Das ist jetzt erledigt? 
B: Das ist jetzt durch alle Instanzen durch. Da kann jetzt nichts mehr kommen. Also, selbst da würde ich noch ein Prozent Restwahrscheinlichkeit ... (unverständlich) offenlassen.

I: (lacht)

B: Aber das ist jetzt durch. Ich meine, man erlebt das sehr oft, dass im Rahmen einer Insolvenz, wo verschiedene Investoren eine Rolle spielen, es danach dann zu zivilgerichtlichen Streitigkeiten kommt. Ich glaube, das ist Gang und Gäbe. Das ist nichts Besonderes. Nur die Form und Art, wie es hier war, das war absurd so.

$\mathrm{I}: \mathrm{Hm}$.

B: Das war hanebüchen.

I: (Pause) Na gut. Also, Ich bin mit meiner Liste durch. Wenn Sie noch etwas loswerden möchten?

B: Ich würde, glaube ich, nicht mehr, ja / Ich meine, man verklärt im Nachhinein immer viele Dinge. Und ich bin heute in einer Phase, wo ich sehr auf dem Stand bin, weil ich jetzt auch den Schritt gemacht habe, nach 13 Jahren, oder 14 Jahren fast, na 13 Jahren, in dieser Branche da rauszugehen und zur Mitte meines Lebens nochmal was Neues zu machen.

I: Würde Sie, wenn Sie so zurück denken jetzt irgendwas anders machen, als Sie es gemacht haben?

B: Naja, mit dem Wissen würde ich wahrscheinlich keine Firma mehr gründen.

I: Würden Sie nicht mehr?

B: Nein. 


\section{I: Obwohl es gut ausging letztendlich?}

B: Das war ein reiner Kampf, das war ein richtiger Kampf, richtig auf Leben und Tod irgendwie. Und es war viel, viel Glück dann dabei zum rechten Zeitpunkt.

\section{$\mathrm{I}: \mathrm{Hm}$.}

B: Hätten wir jetzt die Firma nicht gefunden, die den Asset Deal gemacht hat, oder die finnischen Investoren. Ich hätte ja nie gewusst / Ich hätte ja nichts gehabt. Ich meine, die Banken standen dann schon sehr stark klopfend an meiner Tür und wollten ihr Geld wiederhaben. Und dann haben Sie ja nur die Chance, Sie müssen einen Vergleich aushandeln. Da müssen Sie aber wenigstens mal was anbieten können. Ich kann ja keinen Vergleich aushandeln und sagen: „Ich gebe Ihnen jetzt 5.000, verzichten Sie auf die restlichen 350." Das macht kein Mensch mit.

I: Ja.

B: Das muss / Das geht dann auch nur / Da wurde dann zum Teil Gehalt sozusagen vorab dafür hergenommen, und ich habe dann die nächsten Monate halt weniger verdient.

I: Aha.

B: Um das überhaupt aufzubringen auch. Das war halt alles ein bisschen ... (unverständlich) Das war halt auch nur möglich, weil wir dann halt wirklich einen sehr, sehr guten, oder sagen wir gutartigen, Investor hatten, wo wir da auch ganz offen kommuniziert hatten von Anfang an, was da eine Rolle gespielt hat und auch sehr transparent ihm gesagt haben, was auch zur Insolvenz geführt hat. Ich glaube, es war mit Sicherheit nicht die Idee eine schlechte. Das hat ja auch der Erfolg dann gezeigt. Wir haben mittlerweile auch einen Deal mit ... (unverständlich) in Philadelphia oder bei Philadelphia. Also, wir haben eigentlich für so eine kleine Firma sehr viel erreicht, was andere in der ganzen Biotech-Szene nicht erreichten. Sieht man mal von den 
Großen ab, die irgendwo an der Börse notiert sind. Insofern ist das eigentlich eine Erfolgsstory, die halt da so eine Zacke drin hatte, die sehr, sehr ungut war und auch vorher nicht rund lief. Und ich würde keine Firma mehr gründen, die ein solches Investment erforderlich macht. Das würde ich wirklich nicht mehr machen.

I: Aha.

B: Auch speziell mit Angestellten, wo sie solche Verpflichtungen eingehen. Da bin ich vielleicht einfach nicht / Also, ich habe große Schwierigkeiten immer damit gehabt, wenn ich - das war Gott sei Dank jetzt erst so im letzten Jahr - Leute zu entlassen zum Beispiel. Das ist / da fehlt mir bis heute die Härte, die möchte ich mir aber auch nicht unbedingt zuziehen. So, deswegen habe ich jetzt keine Leute mehr. (lacht) 
Nachtrag zum Interview:

Er hat später die Frage nochmal aufgegriffen, ob die Insolvenz ihn verändert hat. Er betont erneut, dass er die Insolvenz nicht als Einzelereignis erlebt hat. So kann er nur den Gesamtkontext "Selbstständigkeit in der Biotech-Branche“ bewerten. Er sagt, er sei immer auf 180 gewesen und extrem gestresst. Deshalb musste er nun endlich einen Schlussstrich ziehen und aussteigen. Er sagt, ein zweistündiges Gespräch führen, ohne immer zu auf das Handy zu schauen, das hätte er noch Ende letzten Jahres nicht machen können. Da wäre er verrückt geworden, weil er Angst gehabt hätte, er könnte etwas verpassen. Und er habe wirklich volle drei Monate gebraucht, um sich zu erholen und aus dem Hamsterrad zu befreien. 
Appendix V: Transcript of Interview 4

I: Gut, also ich würde Sie als erstes natürlich gerne ein bisschen besser kennenlernen. Deswegen wäre es mir jetzt am liebsten, wenn Sie einfach mal Ihren Werdegang schildern von Kindheit bis heute, beruflich und privat, so die Eckpfeiler, so die großen Schritte mal so ein bisschen durchgehen.

B: Ich bin geboren in $<<<$ Ort anonymisiert $>>>$, aufgewachsen in $<<<$ Ort anonymisiert $>>>$, mein Vater war Hilfsarbeiter. Meine Mutter hat einen kleinen Nebenerwerbshof gehabt. War eigentlich ein wiefer Bursch in der Schule. Hab immer das Bestreben gehabt, auf das Gymnasium zu gehen. Wurde mir aber verboten von den Eltern. Weil mein Vater wollte einen Job für mich, der seinem entspricht, das heißt also Hilfsarbeiter in einem Zementwerk. Und dann habe ich das abgelehnt, und dann hat er gesagt, dann machen wir einen Installateur aus dir. Nein, habe ich auch abgelehnt. Dann ging es übern Fliesenleger und so weiter und irgendwann war dann die Zeit vorbei, dass ich auch auf das Gymnasium nicht mehr gehen konnte, und dass ich dann auch nicht mehr auf die Handelsschule gehen konnte. Und war dann 15 Jahre, nach der neunten Klasse, hab einen qualifizierten Abschluss gemacht. Und habe dann die Lehre gemacht als Einzelhandelskaufmann. Und die habe ich erfolgreich abgeschlossen. Bin dann nachher auf die Berufsaufbauschule gegangen, um die Fachschulreife zu erwerben. Starke Widerstände wieder in der Familie. Dann musste ich Geld verdienen, weil ja von zu Hause keine Unterstützung gehabt, und habe dann nachher den Beruf Einzelhandelskaufmann auch ausgeübt. War dann noch bei der Bundeswehr. Allerdings eine kurze Zeit, da habe ich einen guten Trick gefunden, wie man rauskommt. Das war nicht schlecht. Fachschulreife wie gesagt habe ich abgeschlossen. Und hab aber sehr, sehr wenig verdient, damals 800800 Mark brutto, sodass es mir unmöglich war, eine Familie zu ernähren.

Und ein ganz, ganz großes Ziel oder das größte Ziel, das ich als Junger überhaupt gehabt habe, weil ich ja selbst keine Erziehung genossen habe, soviel Geld zu verdienen, dass ich es mir leisten kann, dass meine Frau nur für die Erziehung der Kinder da ist. Und dafür tue ich alles. Und das heißt, dass ist sogar so weit gegangen, obwohl ich da eine gute Position gehabt habe, habe ich bei der Firma 
$<<<$ Unternehmen anonymisiert $>>>$ angefangen in $<<<$ Ort anonymisiert $>>>$ als Hilfsarbeiter. Weil es da geheißen hat, beim $<<<$ Unternehmen anonymisiert $>>>$ kannst du so lange arbeiten wie du willst. Also Tag und Nacht und Samstag und richtig Kohle machen. Das habe ich dann auch gemacht.

Wir waren da neun Mitarbeiter. $<<<$ Name anonymisiert $>>>$ hat dann erkannt, dass ich ein fleißiger Mensch bin und ein waches Köpfchen habe. Und hat gesagt, nachdem ich ein Jahr nur Material zugeschnitten habe und Brotzeit geholt habe und das Material gewaschen und das Lager zusammengeräumt und die Halle rausgeweißelt habe, also richtige Drecksarbeit gemacht habe, hat er gesagt:

„Können Sie Schreibmaschine schreiben?"

Da sagte ich: „Ein bisschen."

„Ok, dann machen Sie bei mir den Einkauf."

Ja, wenn das auch geht, einfach vom Materialsäger zum Einkäufer. Und dann habe ich aber gesehen, dass mir die Arbeit einfach zu blöd ist und habe bei $<<<$ Unternehmen anonymisiert $>>>$ gekündigt. Hat $\operatorname{der}<<<$ Name anonymisiert $>>>$ zu mir gesagt:

"Ja jetzt brauchen Sie nicht mehr kündigen, wir gehen nach $<<<$ Ort anonymisiert $>>>$, bauen da droben eine Halle und werden eine richtige Firma, nicht bloß neun Leute.“ Kündigung wieder zurückgezogen. War in $<<<$ Ort anonymisiert $>>>$ droben, und mich der $<<<$ Name anonymisiert $>>>$ gefördert, und dann haben sich die jungen zwei $<<<$ Name anonymisiert $>>>$, die haben sich auf den Schlips getreten gefühlt, weil sie gesagt haben: „Der fördert ja den $<<<$ Name anonymisiert $>>>$ und nicht, nicht uns.“ Der Junior war schon an den Geschäftsführer herangetreten und hat gesagt: „Der $<<<$ Name anonymisiert $>>>$ muss raus.“ Weil der wäre sonst gefährlich. Und wenn der nicht geht, dann gehen sie. Haben sie sechs Wochen durchgehalten.

Nach sechs Wochen hat mich der Vater angerufen und hat gesagt: „Herr $<<<$ Name anonymisiert $>>>$, ich setz auf Sie, was halten Sie davon, wenn ich Sie zum

Geschäftsführer mache?" Das war dann schon 1985. Ja, Geschäftsführer hört sich gut an, mach ich den Geschäftsführer.

Und so ist das entstanden, und dann war es aber dadurch, dass ich jetzt zwei so starke Widersacher gehabt habe, war es einfach für mich nichts. Wenn ich auf dem Papier der Geschäftsführer bin. Dann habe ich mich nochmal angelegt, und dann habe ich gesagt: „Die müssen abberufen werden, dann bleibe ich weiter in der Geschäftsleitung, 
und ich möchte beteiligt werden." Ja gut, Beteiligung mit 10 Prozent, und so ist das dann gegangen.

Um das jetzt abzukürzen, es war also 1985. 1990 habe ich dann schon die große Halle da oben gebaut, dann habe ich schon das Sagen gehabt und zuhause dann auch immer kräftig gebaut. Inzwischen waren dann schon Kinder da. Ein Sohn, der 1982 geboren ist, und eine Tochter, die 1989 geboren ist. Und es reihte sich eine Erfolgsstory nach der anderen. Wir waren ja nicht die beste Firma in $<<<$ Ort anonymisiert $>>>$ und nicht in $<<<$ Ort anonymisiert $>>>$ und nicht in Bayern, sondern es ging dann hinaus, England, Italien, ist ja dann McLaren, Ferrari, Red Bull, Porsche und die alle sowieso / Ich hab also die Firma dann aufgebläht auf / wie war das? / 207 Leute. Und immer wieder umstrukturiert, immer wieder neu. Ist ja klar, weil die Organisationsformen müssen immer angepasst werden. Alles eine riesen Herausforderung. Hat nur geklappt, weil ich immer 6,5 Tage gearbeitet habe. Und also Sonntagmittag habe ich immer aufgehört. Das war das für die Familie. Auf Nacht bin ich immer bis um 11 oder sowas im Büro gewesen und dann ins Bett gegangen, wieder raus / Habe eine wunderbare Frau, weil jede andere hätte mich sofort rausgeschmissen. Ist ja klar. Und tolle Kinder, und das ist ohne zu übertreiben das größte Kunstwerk, das ich geschaffen habe, dass ich so eine Familie habe, wo eine unglaubliche Liebe und Geborgenheit da ist.

Und wenn wir dann zur Insolvenz kommen. Insolvenz ist ja nur deshalb entstanden: 2008 Weltwirtschaftskrise, die größte nach dem Krieg oder nach dem 1. Weltkrieg sogar. Und alle haben gleichzeitig den Stecker rausgezogen. Also wir hatten von heute auf morgen keinen einzigen Auftrag mehr, weder von einem Porsche, Daimler, BMW, Opel, wie sie alle heißen. Und es war eigentlich so eine Katastrophe, weil wir gerade mitten in einer Investitionsphase waren. Weil 2006 habe ich den großen Neubau hingestellt für 15,7 Millionen, das war für uns Kleinen sehr viel Geld. Neubau und Maschinen, so war das der Gesamtwert. Und wir hätten nur noch / Dann mussten wir Insolvenz anmelden, weil BMW aus der Formel 1 ausgestiegen ist. Also wir hätten sogar die Weltwirtschaftskrise, hätten wir noch gepackt mit anderen Firmen. Ich war ja Tag und Nacht unterwegs mit kleinen Firmen, dass ich hier was kriege und dort was kriege. Aber den Ausstieg von BMW, den haben wir nicht mehr verkraftet. Weil eben wir im letzten Jahr der Investitionsphase waren. Wir haben das Jahr 2006 gut überstanden, 07, 08 wir haben bis zum September 2008 wo die Wirtschaftskrise 
losgegangen ist, den mit Abstand höchsten Auftragsbestand gehabt, den es jemals auch nur annähernd bei $<<<$ Unternehmen anonymisiert $>>>$ gegeben hat. Aber das ist natürlich schnell aufgebraucht. Und dann geht es natürlich den Bach hinunter. Wir haben alles Mögliche noch versucht, uns zu retten, und da steigt BMW aus der Formel 1 aus. War für uns unvorstellbar, weil BMW hat ja erst, kann nicht sagen 200, wahrscheinlich 400 Millionen investiert, um sich bei Sauber einzukaufen, beim Sauber Formel 1-Team. Und da hätte ich nie auch nur im Traum daran gedacht. Und BMW hat eine starke Abhängigkeit zu uns gehabt, später dann auch umgekehrt. Weil ja wir an dem Auto fast alles gemacht haben. Also Motor, Getriebe und ein bisschen was vom Fahrwerk, aber die Hauptkosten sind ja beim Motor und Getriebe. Da haben wir 10 Millionen Euro Umsatz gemacht. Ja, die steigen aus, und da habe ich innerhalb von drei Wochen, habe ich dann Insolvenz anmelden müssen. Habe ich keine Chance mehr gehabt.

Die, die Banken / das war eigentlich für mich das Verwerfliche / am / das / Basel II, der Ausdruck sagt Ihnen was? Basel II das ist ein Rating, ist ein Rating. Und wir wurden nach Basel II gerated mit dem Hinweis oder mit der Bedingung, dass wir Zulieferer der Automobilindustrie sind. Die Banken haben gesagt, nur um Geld zu verdienen, die Automobilindustrie bricht zusammen. Damit haben die die Möglichkeit gehabt, über das Rating die Zinsen zu erhöhen. Wenn ich zum Beispiel eine Hypovereinsbank nehme, da waren wir an Position sechs von der Einstellung her. Bis Stufe 18 geht das, Stufe 18 oder was ist das schlechteste. Da haben die uns gleich von sechs auf 13 zurückgestuft und haben damit die Zinsen um zwei Prozent erhöhen können. Wir hätten ja einen Sanierungszins gebraucht, nicht achteinhalb Prozent, sondern wir hätten die vier oder fünf Prozent gebraucht. Oder auch die ganzen, wie sagt man gleich / jetzt habe ich den Faden verloren / die Leasingfirmen, wir haben ein sehr kurzfristiges Leasing gehabt über vier Jahre. Das wäre kein Problem gewesen, die hätten das Leasing nur strecken brauchen / aber die / auf sechs Jahre, dann hätten wir die Luft gehabt. Weil wir hätten ja immer noch Gewinne geschrieben. Aber dadurch, dass die das Leasing nicht gestreckt haben, mussten wir in dieser Zeit, wo wir fast kein Geld verdient haben, noch 2,7 Millionen Euro Leasinggebühren zahlen. Es wäre / Wenn man sauber zusammenarbeitet, und wenn man daran glaubt an die deutsche Industrie, dann hätte man gesehen, dass das ein europäisches Spitzenunternehmen ist und man kurzfristig aufgrund der Krise, nicht weil wir zu blöd waren zu wirtschaften, 
hätte man / Also ich hab mir so vorgestellt, dass es eine Unterstützung gibt. Und das ist dann noch gelaufen über Förderbanken, dann haben wir noch Ilse Aigner und den Guttenberg damals eingeschaltet. Die haben sich zwar richtig toll verhalten, von der Politik her, habe ich nicht erwartet.

Nur die Förderbank wieder, die bayrische, sind solche Lahmärsche. Die sagen halt: „Der Stapel ist so hoch, und ich weiß jetzt nicht wo ihr Anliegen gerade ist, und außerdem brauchen wir das und das." Und dann wie sie es endlich entschieden haben zu helfen, haben sie gesagt, was das Vermögen ist von der Frau und von den Kindern, und dieses Vermögen muss auch alles mit eingebracht werden zu Risiko 100\% Verlust. Und dann brauche ich keine Förderbank. Verstehen Sie? „Da kannst heimfahren.“, habe ich gesagt. „Das ist gut, habt ihr super gemacht, schämt euch und schleicht euch.“

Und so sind wir in die Insolvenz geraten, war eine unvorstellbar schwierige Zeit, in dem man mal / Ich kenn allerdings die Quote nicht, aber rein gefühlt 90 Prozent derjenigen verantwortlichen Unternehmer, die in Insolvenz gehen, die fangen entweder das Saufen an oder lassen sich scheiden oder hängen sich auf. Das, was da kommt selbst aus der Dorfgemeinde heraus, was da alles passiert. Wie die Leute einen anschauen, wie die Gerüchteküche kocht. Was alles hineininterpretiert wird.

I: Kam jetzt bei Ihnen auch eine Privatinsolvenz dazu?

B: Ja, da komme ich jetzt gerade dazu. Es war dann so, dass wie gesagt, ich habe ja zwei Kinder, Frau und mich. Familie hat zusammengehalten. Diese Liebe, diese unglaubliche Liebe, hat mich da gerettet und diese Kraft. Ich habe ja anscheinend gute Gene. Habe eine schwere Krebserkrankung gehabt, wo ich lange Zeit ausgefallen bin mit Chemo, Strahlen, Operationen, alles. Und da habe ich mich immer wieder daran erinnert, dass so eine Insolvenz, gegen das, was ich da gehabt habe, diese 13 Wochen wo ich in $<<<$ Ort anonymisiert $>>>$ war, ein Kindergeburtstag ist. Also habe ich das besser verarbeitet, als der Rest der Familie. Die haben schon immer Angst gehabt, wenn der Postbote gekommen ist, wenn es wieder geheißen hat, unser Haus wird versteigert. Das waren auch alles so Sachen, dass man sagt: „Jetzt habe ich die Firma schon verloren, warum verliere ich jetzt das Haus noch?“ Die ganze Existenz ist beim Teufel, Harz IV war natürlich das absolute Thema bei uns. 
Und dann habe ich ja statt des Insolvenzverwalters, weil der Insolvenzverwalter hat mir sehr vertraut, also war ganz toll von dem $<<<$ Name anonymisiert $>>>$. Der hat das gesehen, dass ich der Macher bin und nicht der Kaputtmacher. Also ist der mit mir rausgefahren zu den ganzen Kunden hin, haben in Vier- Augen-Gesprächen / "Was haltet ihr vom $<<<$ Name anonymisiert $>>>$ ? Ist das einer? Oder Sprüchemacher, oder wollt ihr mit dem zusammenarbeiten?" Und dann hat der $<<<$ Name anonymisiert $>>>$ zu mir gesagt, die ganzen Verkaufsgespräche soll ich führen von dem Unternehmen. Und ich habe gesagt: "Ja, mach ich, aber nur Private." Da habe ich kein Capital Venture mit dem und dem und keine Consulting Firmen. In Wirklichkeit sind nur solche Firmen gekommen, da habe ich 23 Verhandlungen geführt. Da habe ich abgebrochen. Habe ich gesagt: "So jetzt haut's ab, packt's zam euren Scheißdreck". Ich habe gesagt, ich will mit denen nicht mehr reden und habe das abgebrochen. $<<<$ Name anonymisiert $>>>$ war aber nicht in der Lage zu verhandeln, weil das Bild nach außen hin bin ja ich, und von mir wollen ja die was wissen. Nicht von einem Insolvenzverwalter, der sagt: „Ja wir berichten Ihnen, und Sie hören wieder von uns." Und nehmen da schriftlich Stellung und so ein Scheiß. Sondern die wollen dir ins Auge reinschauen, und wollen sagen, warum hast du das gemacht und warum das, zack, zack, zack. Und dann habe ich drei Firmen gefunden und habe mit denen scharfe Verhandlungen geführt. Und eine dieser drei Firmen hat dann den Zuschlag gekriegt. Und den Preis den ich rausgehandelt habe, der war so hoch, dass mir fast das ganze private Vermögen geblieben ist.

Deswegen sage ich ja: „Gell, braucht's euch fei nichts denken, diejenigen, die mich gerne so richtig gerne im Dreck gesehen hätten, also ,Jetzt ist der fertig, der hat nichts mehr und hoch gepokert und alles verloren. 'Sagt allen denjenigen einen ganz schönen Gruß, ich habe noch meine Häuser, ich habe ein paar Autos, und das Leben wird für mich weiter gehen. Und ich habe den Geschäftsführerposten dann in der neuen Firma, der auch nicht schlecht dotiert ist." Und so haben wir es halt Stück für Stück aus dem ganzen herausgerettet. Ich sage mal, ich habe den Verstand nicht ganz verloren, obwohl ich oft drauf und dran war, weil du hast ja nur noch mit Anwälten zu tun. Und du musst ja nebenbei das Geschäft noch alleine führen. Und da sind 200 Leute verdammt viel. Und etliche Gute sind sofort abgehauen. Weil die gesagt haben: "Puuh, Insolvenz!" Zum Beispiel meine zwei Vertriebsleute. Die haben sich sofort abgesetzt und sind zum Wettbewerber gegangen. Das heißt, ich habe den England-Vertrieb dann 
auch noch machen müssen. England, Italien, Schweiz, Österreich und Deutschland sowieso, das heißt das war ununterbrochen.

Aber ich habe keine Antenne mehr gehabt, ich habe nichts mehr aufgenommen, verstehen Sie? Das ist, als wenn du in einen, in einen / ich habe einmal dran gedacht, wie ich letztes Jahr war in Bolivien war, Peru, an dem Urubama Fluss bin ich ganz nah dran gehockt, ein reißender Strom, da wo wir in Machu Picchu waren. Da denke ich, jetzt bin ich schon wieder da drin, da ist mir das eingefallen, ich war in einem reißenden Strom drin, wo ich nur noch geschaut habe, dass ich den Kopf draußen habe, dass ich Luft schnappen konnte, weil jeden Tag eine neue Horrornachricht gekommen ist. Der hört auf, der kündigt, die Firma schmeißt uns raus, für den habe ich zu wenig Zeit gehabt. Und so ist das die ganze Zeit gegangen.

Gut, und dann haben wir verkauft an den neuen, an die Firma $<<<$ Name anonymisiert $>>>$, und das war eine gute Entscheidung von daher, weil Geld geflossen ist. Und daher war es gut, weil ich mich mit dem Geld retten habe können. Was schlecht war an der Entscheidung ist das, dass wir ganz andere Philosophien gehabt haben, aber gleich um 100 Prozent versetzt. So muss man sich das vorstellen. Weil, ich bin einer, der es macht über die Emotionen, den Leuten freien Lauf lässt, und damit die Kreativität von denen Leuten fördert. Darum sind wir aus dem Bestand heraus so gut geworden. Weil die Leute nicht von ihrem "Ich will jetzt das wissen" zack, zack, zack. Sondern das ist die Aufgabe, das ist das Ziel, und da musst du es erreicht haben. Und das waren die Leute natürlich gewohnt. Und so hat jeder auf Messen fahren können. Ich habe die auch gut versorgt mit Geld und mit Autos und so weiter, weil ich gesagt habe, wenn die viel Ahnung haben, wird es auch viel bringen. Und der neue Investor, der hat gesagt: "Nichts, aufhören mit dem Ganzen. Wir arbeiten nur noch über Prozesse und Strategien." Und da war es natürlich brutal. Da habe ich so eine Auseinandersetzung gehabt mit dem zweiten Geschäftsführer, weil, der Neue hat natürlich einen eigenen Geschäftsführer mitgebracht. Hat selber als Unternehmer auch noch mitgewirkt. Und konnte gegen mich aber nichts machen. Dann haben sie einen Mentor noch beauftragt, die Frau $<<<$ Name anonymisiert $>>>$, ganz eine tolle Frau, blitzgescheit, erfahren. Hat alles was man braucht dafür. Die hat gesagt: "Herr $<<<$ Name anonymisiert $>>>$, da werden Sie aber nicht weit kommen." Hat es gesagt, weil, das ist ja so, nicht nur in Bayern, Geld schafft an. Da sagte ich: "Ja, Frau $<<<$ Name anonymisiert $>>>$, wenn der von mir 20 Prozent Wachstum 
erwartet, dann muss ich dem sagen, oder habe ich ihm gesagt: ,Das können Sie nicht mal von der Deutschen Bank erwarten. Und da auch nur knapp, wenn die entsprechende Zukäufe haben. Aber aus der eigenen Dynamik heraus, Rationalisierungsmaßnahmen, Preise erhöhen, Leute rausschmeißen, unmöglich. ““ Und dann, das hat er sich noch angeschaut acht Monate, und dann ist er gekommen und hat gesagt, sofortige Freistellung und nur noch als Berater.

Dann denk ich mir, super, für mich ganz gut. Meine Ärzte, Physiotherapeutin und, und, und, die haben gesagt: "Herr $<<<$ Name anonymisiert $>>>$, jetzt gehen wir in das Biologische, schauen Sie bloß, dass Sie da wieder reinkommen, Sie halten das nicht aus. Das hält keiner aus. Wer so am Rad dreht wie Sie, und dann von heute auf morgen nichts mehr zu tun." Dann sag ich, also was hat das mit nichts mehr zu tun zu tun, was anderes halt. „Nein, Sie verlieren doch alles, das ist doch ihr Werk“ und so weiter. Sag ich, jetzt lasst mich mal. Ich habe das Ganze, um jetzt abzukürzen, habe das in den Griff gekriegt, dass ich zuhause genauso weitergearbeitet habe, wie in der Firma. Also nicht diese 6,5 Tage, sondern nur noch 6 Tage. Und bin meine ganzen Hobbies durchgegangen. Das heißt, ich war dann der Schreiner / was war das alles / der Schreiner, der Zimmermann, der Elektriker, der Maurer, der Pflasterleger. Ich habe alle meiner Häuser, bin ich ja selber noch mittendrin, restauriert. Aber nicht organisatorisch, dass ich gesagt habe, da kenne ich einen Elektriker, und da kenne ich so einen. Sondern ich habe da ein Fenster dann gemacht, und habe da eine Hausbank gemacht und da einen Tisch und da eine Mauer aufgezogen und da ein Pflaster gelegt. Und dann, jetzt bin ich gerade bei mir an der / ich habe da so eine Berghütte, wo ich 30 Jahre nichts mehr getan habe. Die richte ich jetzt gerade her und dann Holzfäller, alles, was man sich vorstellen kann. Und das sind für mich paradiesische Verhältnisse, weil ich mit mir im Einklang bin.

Das ist zum Beispiel so, in der Natur einen Vogel pfeifen hören, ich habe keinen Vogel mehr pfeifen mehr hören damals, sondern ich bin heim, auf das Rad drauf, bin den Berg raufgefahren eine Stunde oder zwei bis es dunkel geworden ist und dann wieder runter, schnell geduscht und wieder ins Büro gegangen. So ist das gewesen, und heute fahre ich mit dem Mountainbike rauf auf den Berg, aber dann fahr ich nicht nach zehn Minuten, nachdem ich schnell eine Banane gegessen habe, wieder runter, dann habe ich einen Rucksack dabei, da habe ich eine Brotzeit drin, da habe ich eine 
Halbe Bier drin, und dann sitz ich da zwei Stunden droben. Und dann lege ich mir was weiß ich Obergreiner auf oder sonst irgendwas.

Das heißt also / Und dann habe ich gefragt, wie ich damals war oder wie ich jetzt war, bin ein unglaublich ausgeglichener Mensch. Und von daher sage ich, vielleicht hat alles so kommen müssen, dass ich / Ich habe dann ein Buch gelesen "Schenk mir einen Olivenbaum", von so einer krebskranken Managerin. Das wenn Sie einmal lesen, da werde ich beschrieben. Also, ich habe das gelesen, ich habe es jetzt zum vierten Mal gelesen, weil ich gesagt habe, das gibt es ja nicht solche Parallelen. Weil die anderen gesagt haben, da, wo ich dann wirklich am abnippeln war, wo man nicht gewusst hat, ob die nächsten Wochen was werden. Da haben die gesagt, wie ich wieder zurückgekommen bin: „Wirst sehen den kennst nicht mehr. Der macht das nicht mehr und das nicht mehr und hat die Power nicht mehr, kein Dampf mehr dahinter.“ Und ist alles anders gekommen. Nachher habe ich erst richtig angerissen, weil ich gesagt habe, ich bin unangreifbar. Alles was ich anpacke, wird zum Erfolg. Von dem war ich besessen. Weil es halt immer nur aufwärtsgegangen ist. Und jetzt mit ein bisschen Abstand sage ich: „Herrgott, diese Insolvenz war irgendwie ganz gut." Weil die zweite Erkrankung in der Form, die sicherlich gekommen wäre, hätte ich nicht mehr gepackt. Und ich habe in der Zeit so viele junge Leute sterben sehen, die alles dafür gegeben hätten.

Ich habe einen Rauch- und Alkoholikerkrebs gehabt, obwohl ich nie geraucht habe und nie, also ich trink halt ein Radler oder sowas. Aber ich trink keinen Cognac oder keinen Whiskey oder sonst irgendwas. Aber mit denen, was ich in der Strahlungstherapie war, da war kein Einziger dabei, der so wie ich / doch einer war dabei, den haben sie den rechten Fuß, ein Volleyballspieler oder Basketballspieler, den rechten Fuß amputiert, der hat da ein Krebsgeschwür drin gehabt. Aber sonst waren alle solche, die geraucht haben. Und wenn du so viel arbeitest, da werden so viele Organe auch in Mitleidenschaft gezogen. Weil du passt ja nicht aufs Essen auf. Ich habe mittags oftmals nichts gegessen. Und habe es gar nicht gespannt, weil ich habe keinen Hunger mehr gehabt. Oder immer Magengeschwüre,

Zwölffingerdarmgeschwüre, das hat alles mit dem zu tun.

Das ist alles von mir weit weg. Und jetzt genieße ich das halt richtig. Ich werde als Geschäftsführer noch 2,5 Jahre gezahlt oder 2 ein Viertel. Und dann schau ich halt, wie weit, dass ich mit meinen Instandhaltungen bin und überleg mir dann, ob ich 
irgendwo als Berater anfange. Weil ich könnte ja durch meine ganzen Verbindungen. Ich brauche nicht rumtelefonieren bis ich einen Termin kriege, sondern ich rufe den an bei VW und den bei Porsche und den bei Ferrari, und dann bin ich morgen da. Das ist der Unterschied. Nur ich weiß nicht, ob ich mir nachdem ich jetzt das Leben von der Seite kennengelernt habe, ob ich mir das nochmal antue. Weil wenn du das gewohnt bist, dass du 30 Jahre lang die Entscheidungen alleine triffst, dann ist das schwer, jetzt bei einer Firma zu arbeiten, wo du dann einen Bericht abgibst und dann sagt der, also das gefällt mir nicht, und da müssen sie nochmal nachhaken und so Zeug. Weiß ich noch nicht, wie ich da reagiere. Also, die Wahrscheinlichkeit wird bei mir dann groß, dass ich sage: "Kannst mich am Arsch lecken. Da hast du dein Scheiß, mach was willst, servus, ich brauche es nicht." Das könnte sein. Also, ich habe das noch zwei ein Viertel Jahre weg, und schaun wir mal, was die Zeit jetzt da bringt.

I: Interessante Geschichte. Auf jeden Fall haben Sie einiges erlebt.

B: Viel. Und viele Dinge, die ich nicht sagen darf. (lacht)

I: Jetzt wenn wir nochmal den Ablauf der Insolvenz an sich nehmen. Wie lange hat sich das ungefähr hingezogen?

B: Vier Jahre. Das heißt nein, nicht vier Jahre, drei ein Viertel, Moment mal. Den Rest von 2009, 2010, 2011 / spinn ich jetzt / 2009 das letzte Quartal, Insolvenz haben wir angemeldet im August, und das Ganze war dann 2010, 2011 / jetzt komme ich in Schwierigkeiten, weil das habe ich noch nicht gesagt, weil das ist das nächste Problem gewesen. Wir hatten dann die Firma verkauft an einen Schweizer Investor. War alles wasserdicht, Notarvertrag unterschrieben, Notar auch bezahlt, Anwälte bezahlt, shake hands, wir machen das gemeinsam. Und dann stellte sich heraus, dass dem seine Finanzierung nicht geklappt hat. Über einen Griechen, $<<<$ Name anonymisiert $>>>$, Fondsmanager. Weil wir hatten geglaubt, dass der der Chef von dem Fonds ist. Dabei ist er Chef von einem Fonds, aber gekauft hat ein anderer Fonds. Und das haben wir dann erst herausbekommen, als das Geld nicht gekommen ist. Und darum haben wir nochmal ein Jahr verloren. Das heißt also, jetzt haben wir 2014, 2013, 2012, ja zwei ein Viertel Jahre, hat es gedauert. 
I: Und während des Ablaufs, was waren da die größten Schwierigkeiten, die größten Hürden? Was waren die Sachen, die am wenigsten gut geklappt haben?

B: In der Insolvenz? Meinen Sie jetzt geschäftlich oder privat?

I: Alles.

B: Also, privat habe ich es Ihnen schon gesagt. Der Druck das private Vermögen zu verlieren und bei Harz IV zu landen. Der Druck der war ununterbrochen, war der da. Und die Krise ist ja schon, darum sage ich immer vier Jahre, die Krise ist eigentlich ein Jahr vorher angegangen. Im September 2008 rum, dann wären es drei ein Viertel. Das war ein unmenschlicher Druck. Durch die vielen Anwälte involviert und der Insolvenzverwalter, wer packt dich wann, wo, was sind die Konsequenzen. In der Firma hat mich schwer verletzt, dass der Insolvenzverwalter musste natürlich einen Interimsmanager einsetzen. Und die Leute, die ich Jahre oder Jahrzehnte gefördert habe, haben sich sofort von mir abgewandt und sind dem $<<<$ Name anonymisiert $>>>$, dem Insolvenzverwalter nachgelaufen. Das heißt, ich hatte im Prinzip auf nichts mehr Einfluss. Und der Insolvenzverwalter musste auch einmal am Anfang zumindest, die ersten drei Monate davon ausgehen, dass ich der Schuldige bin an der der Insolvenz. Ist halt mal so. Und zur Verzweiflung haben sie mich dann getrieben, Mitarbeiter in Verbindung mit dem Interimsmanager, als sie dann Betriebsversammlungen veranstaltet haben, wo ich gerade in England war oder in Italien. Dass sie meinen Sohn abberufen haben, als Abteilungsleiter und mir dann, der Betriebsleiter und der Interimsmanager das neue Organigramm gezeigt haben. Din A3.

„Wo bin da ich?" Herr $<<<$ Name anonymisiert $>>>$ ist ja 28 Jahre oben dran gestanden. Dann hat der $<<<$ Name anonymisiert $>>>$ gesagt: "Ja hier."

Dann sag ich: „Das ist doch nicht Teil vom Organigramm, was steht denn da dort? Verkauf?"

Sagt er: „Ja, warum?"

Also sag ich: „Dann sind Sie mein Chef und Sie auch Herr $<<<$ Name anonymisiert $>>$, Betriebsleiter?" Sag ich: „Also, jetzt passt auf, jetzt mach ich einen Vorschlag. Ich ernenne Sie Herr $<<<$ Name anonymisiert $>>>$, heute zum 
Projektmanager von McLaren Mercedes. Sie kümmern sich ausschließlich nur noch um die Clamshells und wenn die Clamshells in 14 Tagen nicht geliefert werden, dann schmeiß ich Sie raus!"

Der Betriebsleiter springt auf und sagt: „Ja was soll denn das jetzt? Kenn ich mich überhaupt nicht mehr aus so, ich geh jetzt eine rauchen!"

Sag ich: „Gut, können Sie eine rauchen, in acht Minuten sind Sie wieder da. Wir bleiben sitzen, Herr $<<<$ Name anonymisiert $>>>$."

Gut, kommt er wieder rein. Sagt er: „Und habt ihr es jetzt?"

Sag ich: „Ja, Sie haben es ja mitbekommen, dem ist nichts hinzuzufügen. Ich habe gedacht, von Ihnen kommt noch was nach der Zigarette."

Ja, da ruft er sofort den Herrn $<<<$ Name anonymisiert $>>>$, hat der $<<<$ Name anonymisiert $\gg>$ gesagt.

Sag ich: „Gut, sagen Sie es dem Herrn $<<<$ Name anonymisiert $>>>$. Sollte er wider Erwarten eurer Meinung sein, dass ich da herin der Verkäufer bin und nichts mehr zu sagen habe, werde ich am Montag nicht mehr an meinem Arbeitsplatz erscheinen." „Ja, das können wir machen."

Danach ruft mich der $<<<$ Name anonymisiert $>>>$ an: „Was war denn da los, was habt ihr denn da wieder gehabt?"

Dann sag ich: „Ja“, sag ich, „die zwei Idioten, die wollten aus mir einen Verkäufer machen." Sag ich: „Hinten und vorne nichts verstehen, verdienen 18.000 Euro im Monat und keine Ahnung, ist auf mich angewiesen und dann mir sagen, ich bin der Verkäufer. Und dann bin ich überall ausgeschlossen. Herr $<<<$ Name anonymisiert $>>>$, überlegen Sie es sich, wie Sie es haben wollen. Sie bekommen es so, wie Sie es haben wollen. Weil wenn ich am Montag nicht mehr komme, kann ich mich um andere Sachen mehr kümmern, weil ich /" „Nein, kommt überhaupt nicht in Frage."

Montag eine Sitzung, alle sitzen da die ganzen Führungskräfte. Da scheißt der $<<<$ Name anonymisiert $>>>$ den $<<<$ Name anonymisiert $>>>$ zusammen, weil es mit ihm nicht abgestimmt war.

Hat er gesagt: „Wie lange sitzen Sie jetzt schon drin? Nichts haben Sie bis jetzt zu Wege gebracht. Die Zahlen, die Sie abgeliefert haben, sind unbrauchbar, immer nur Visionen und Strategien, ich will Geld verdienen!" So ist das halt ein Fall gewesen von Einigen, wo ich mich dann durchgesetzt habe, wo ich alles immer auf eine Karte 
gesetzt habe. Und mein Sohn ist dann auch wieder installiert worden als

Abteilungsleiter. Und das ist halt alles aus der Enttäuschung heraus, weil du es an und für sich nicht glauben kannst, wenn du mit einem 20, 30 Jahre zusammenarbeitest, ohne dass du da Information gegeben hast.

Oder der Herr $<<<$ Name anonymisiert $>>>$, das ist mein Adlatus gewesen. Mit dem habe ich alles getan, der hat nicht die Fähigkeiten gehabt, aber das war einer, der die ganzen Informationen alles gehabt hat. Auch der hat mir keine Information gegeben, dass da im Führungskreistreffen beschlossen worden ist, dass ich da komplett rauskomm

Also, das ist aus der menschlichen Enttäuschung her, ist das so schlimm, dass ich heute sagen müsste, ich glaube heute fast überhaupt keinem mehr was. Nur wenn du keinem mehr was glaubst, dann kannst du auch nichts mehr bewegen. Sondern du musst halt, die Erfahrung / das hört halt nie auf, diese Erfahrung, die was du machst, die musst du halt dann nutzen für andere Situationen, um damit besser umzugehen und das besser zu erkennen. Aber dadurch, dass ich so viel unterwegs war, und die ganzen Aufträge geholt habe, habe ich keine Antenne mehr gehabt in der Firma. Ich bin ja nur ab und zu mal vorbei gekommen wegen einer Besprechung. Dann habe ich ja auch noch die Kalkulationen gemacht und die Arbeitspläne. Das ist auf so hohem Niveau, da können sie nicht sagen, da geben sie dem 10.000 Euro und dann macht der ihnen das. Sondern ich habe es ja gesehen, wie ich dann ausgeschieden bin. Dann haben nur den Bereich Kalkulation von mir vier Leute gemacht. Das machen die heute noch. Vielleicht sind das jetzt schon fünf. Und aufgrund der Erfahrung, weil ich halt gewusst habe, wie man einen Zylinderkopf oder Getriebe oder sowas herstellt oder ein Zahnrad, ist das bei mir alles viel schneller gegangen. Und nur dass sich dann solche Leute das anmaßen, das kompensieren zu können, zum Nulltarif, das habe ich als unfassbare Frechheit, habe ich das empfunden. Aber man lernt halt nicht aus, jetzt hake ich es halt ab, wieder eine Erfahrung reicher.

I: Wann war der Moment, wo Sie realisiert haben, dass Sie Insolvenz anmelden müssen? Dass es / Also ich könnte mir vorstellen, dass man versucht das erst noch irgendwie / dass man denkt, man kann es noch rumreißen, ich warte noch ein bisschen und so weiter. Aber wann ist wirklich der Moment, wo man merkt: „Ok, jetzt ist es so weit, jetzt geht es nicht mehr.“ 
B: Das ist damals gewesen, ich glaube im Mai oder im Juni, in dem Jahr wo wir dann Insolvenz angemeldet haben, wo der Umsatz dann / weil wir wollten ja Kurzarbeit anmelden. Wir haben ja immer noch Vollzeit gearbeitet. Obwohl die Wirtschaftskrise da schon sechs oder acht Monate gedauert hat. Aber dann mussten wir Kurzarbeit anmelden, und Kurzarbeit kannst du nur anmelden, wenn du die ganzen Überstunden und Alturlaube abgebaut hast. Das heißt, wir haben die Leute heimschicken müssen und haben nichts mehr produzieren können. Dann haben wir in dem Monat Juni statt / was haben wir sonst immer gehabt? Ja 1,5 Millionen, 1,4 Millionen Umsatz, haben wir bloß noch 324 Tausend gehabt. Und dann natürlich: „Oh, jetzt wird es gefährlich, wie können wir das kompensieren?" Habe aber gewusst, ab September geht's richtig aufwärts, weil dann kommt BMW mit neuen Motoren. Und den machen ja wir und das Getriebe. Und dann ist eben das dazwischengekommen an dem 31. Juli, dass BMW gesagt hat, sie steigen mit sofortiger Wirkung aus der Formel 1 aus. Dann war es klar, dann habe ich innerhalb von drei Wochen die Hand heben müssen. Und da bin ich auf eine tolle Frau gestoßen, ich weiß bloß nicht, wie die geheißen hat, vom Amtsgericht drunten. Das war eigentlich ein riesengroßes Glück für mich. Weil, bin ein bisschen neugierig, zumindest was das betrifft. Jetzt habe ich nicht, wie es normalerweise einer macht, ein Fax geschickt oder ein Einschreiben ans Amtsgericht und Insolvenz angemeldet, sondern da habe ich gesagt, da fahre ich selber runter, das schau ich mir an, wie es da zugeht.

„Ja, Herr $<<<$ Name anonymisiert $>>>$, wir haben die Frau sowieso" Und dann hab ich halt das gesagt, ja Firma $<<<$ Unternehmen anonymisiert $>>>$, Geschäftsführer, Insolvenz anmelden. „Ja“, hat sie gesagt, „Moment“, dann hat sie ein Buch aufgeschlagen, dann hat sie da so geblättert, ,der hat erst was gehabt“ und der und der und so, ist das also durchgegangen.

„Ja, wieso könnt ihr euch das aussuchen? Wer der Insolvenzverwalter wird?“

Hat sie gesagt: „Ja, aber wir müssen das halt einigermaßen verteilen, wer ein Geschäft hat und wer" / Dann hat sie gesagt: "Ja wieso? Kennen Sie jemanden?"

Dann sag ich: "Ja, den $<<<$ Name anonymisiert $>>>$, aber nur aus der Zeitung. Weil der zwei Mal die Tölzer Löwen im Eishockey durch die Insolvenz geführt hat." Und so kaputt wie die Tölzer Löwen waren, waren wir nicht. Das weiß ich zufällig, weil ich ja 
bei den Tölzer Löwen Hauptsponsor war. Also, war ich in allen Details, Spielergehälter und wer was. Da war ich involviert.

Da sagt die Frau zu mir: "Herr $<<<$ Name anonymisiert $>>>$, wenn Sie mir jetzt versprechen, dass Sie den $<<<$ Name anonymisiert $>>$ " noch nie gesehen haben, weder telefonisch noch persönlichen Kontakt zu ihm gehabt haben, dann ruf ich den jetzt an." „Das verspreche ich ihnen, das unterschreibe ich, mache ich alles.“ Hat sie angerufen, der war gerade in Berlin. Ja die nächste Maschine geht da und dann. Um eins, viertel nach eins ist er in München. Und um zwei wäre er dann in $<<<$ Ort anonymisiert $>>>$. Also die hat in der Früh noch nichts gewusst, dann hat sie den angerufen, gleich runtergeflogen und dann haben wir uns zusammengesetzt. Und dann war am Anfang, war er sehr nett, weil er von mir natürlich Informationen gebraucht hat, aber dann ist es heftig geworden. Dann prallen natürlich zwei aufeinander. Er, der Machtmensch und ich vor Selbstbewusstsein immer noch strotzend aus der Erfahrung, die ich gemacht habe, wie ich die Firma aufgebaut habe, und wie ich es halt zu europäischen Ruhm gebracht habe. Und das ist dann mal eskaliert, da haben wir einen Termin gehabt in München, beim Hauptabteilungsleiter BMW, den $<<<$ Name anonymisiert $>>>$.

Und auf der Autobahn packt mich der auf einmal wie ein Irrer, weil ich fei nicht / Ich habe keine Demut gezeigt. Das haben mir die Banken schon vorgeworfen. „Etwas Demut wäre doch angebracht."

Sag ich: „Warum denn? Ich habe doch nichts angestellt." Ja, dann geht auf einmal ab wie eine Rakete und sagt: „Sie haben nichts mehr zu sagen, gar nichts mehr. Überhaupt, Sie hängen nur an mir, und ich treffe die Entscheidungen, was jetzt da gemacht wird."

Dann habe ich zum $<<<$ Name anonymisiert $>>>$ gesagt: "Herr $<<<$ Name anonymisiert $\gg>$, täuschen Sie sich nicht, da vorne an der nächsten Tankstelle, da lasse ich Sie aussteigen, und dann schauen Sie wie sie heimkommen."

„Was?"

Da sage ich: "Ja, an der nächsten Tankstelle. Weil Sie werden doch nicht glauben, dass ich nicht weiterhin die ganzen Entscheidungen treffe. Sie können mich zwar in den Hartz IV reintreiben, aber für mich die persönlichen Entscheidungen, treffe ich doch alle alleine." Sage ich: „Kein Einziger von euch braucht's damit ärgern." 
Dann hat er umgeschwenkt: "Ja, seien sie doch vernünftig, wir haben doch den Termin in der BMW drin, das werden wir doch wohl noch rumbringen. Sie können mich nicht aussteigen lassen."

Dann sag ich: "Gut, dann fahren wir noch nach München, aber das will ich nie mehr hören."

Und da ist der dann heimgekommen zu mir und hat sich meine Frau angeschaut und meine Kinder, ob da alles in Ordnung ist, ob da Rückhalt da ist und war sehr, sehr angetan. Und aus dem Ganzen wurde dann innerhalb von vier Jahren eine Freundschaft. Also, das ist wirklich ganz, ganz toll gelaufen. Weil dann ist das Vertrauen gekommen.

Auch mit dem $<<<$ Name anonymisiert $>>>$, das von dem, den habe ich dann wirklich rausgeschmissen. Zwar nicht da, aber ein halbes Jahr später. Weil ich das einfach nicht eingesehen habe 18.000 Euro für nichts, für nichts, nur Papier, endlos Papier und, und PowerPoint-Präsentationen, Larifari, wo nichts dahinter war.

Ich habe gesagt: "Wo ist die Kohle? Ich will Geld sehen!" Der $<<<$ Name anonymisiert $\gg>>$ auch, wir brauchen Geld.

Sage ich: „Das hilft mir alles nichts, wenn ihr jetzt nicht irgendwann mal einen Beweis antretet, dass es da eine Wende gibt, dass ihr erkennt, dass der Kunde im Mittelpunkt steht." Und das vergisst man ja, wenn der Kunde nicht im Mittelpunkt steht, sondern nur das Geld und Streit, dann wird der Kunde auch irgendwann vergessen. Und das haben die halt zusammengebracht. Und von daher war es nur gut, weil ich gesagt habe: „Herr $<<<$ Name anonymisiert $>>>$, machen wir eine Lohnerhöhung für mich und den anderen nehmen wir die 18, dann haben sie selber noch ein gutes Geschäft gemacht." Sagt er: „Ja hauen wir ihn raus". Und dann, ja der $<<<$ Name anonymisiert $>>>$ hat das begleitet, bis zum Verkauf an die Firma $<<<$ Unternehmen anonymisiert $>>>$.

I: Und Sie haben vorhin beim Fragebogen schon gesagt, dass Sie sich verändert haben durch die Insolvenz. Inwiefern?

B: Ich sage mal, ich bin ein angenehmerer Mensch geworden. Nicht immer / Ich habe ja immer in einem Zeitfenster gelebt. Und zwar so, da habe ich den Termin, da habe ich den, da habe ich den. Wenn ich da hinfahre, da wenn ich hinfliege, dann kann mich 
der abholen, dann kann ich auf Nacht wieder wegfliegen, dann kann ich da / So ist das die ganze Zeit gegangen. Und von daher war ich ja schwer erträglich für mein Umfeld. Ist ja klar. Meine Frau hat gesagt: „Ja, dann les ich ein Buch." Sage ich: „Bist du wahnsinnig? Scheiß Buch zur Unterhaltung, du musst irgendwas tun, was dir weiterhilft." Es war immer irgendwas, wo ich gesagt hab / oder ein Film anschaun, jetzt sag ich mal extrem, Rosamunde Pilcher. Da sitz ich dort, nach fünf Minuten sehe ich, aha, der nimmt sich das Leben und der, es ist ja immer das gleiche, und der hat was mit der und, und das nehme ich heute alles so hin. Dass ich sage, ach scheiß drauf. Meine Frau hat immer gesagt: „Du bist ja nur neidisch, weil du dich nicht entspannen kannst." Und sie hat in gewisser Weise ja recht gehabt. Nur wie sollst du entspannen, wenn du abends um elf erst vom Büro runterkommst?

Und auch in der Diskussion, die Schärfe, die ich immer drin gehabt habe. Wenn jetzt einer zum Beispiel ein Dampfplauderer war und hat sich nachher widersprochen, „Ja weiß ich auch nicht mehr genau, so ungefähr oder so ähnlich oder so." Weil bei uns ist es ja so, du machst eine Aussage, und das muss punktgenau sitzen, weil du immer erwartest, dass der andere einen Konter startet, dass der noch ein Ass im Ärmel drin hat, wo er dich dann widerlegt. Das habe ich nicht auseinanderhalten können.

Oder was Sauberkeit betrifft, oder Ordnung, wenn ich oft wo reingekommen bin, sag ich mal ganz extrem, aber hat es oft noch gegeben, dass bei denen an der Wand ein Bild schief gehängt ist. Das ist unmöglich, sage ich: "Seht ihr nicht, wie das Bild da hängt?" Oder beim Schubwagen Griff der Klappgriff nach oben gestanden ist, sondern der Klappgriff fällt immer nach unten. Es sind solche Kleinigkeiten, aber wenn du so ein Perfektionist bist und immer mit diesen Hundertstel und Tausendstel zu tun hast, dann verstehst du nicht, dass andere Leute so sein können.

Und einfach so einen Trott einlegen, ohne einen Plan zu haben oder/also, ich habe immer einen Plan B, das habe ich allerdings heute auch noch. Und das habe ich nicht verstanden und von daher, wenn ich jetzt in einer, irgendwo eingeplant bin und es gibt eine Diskussion, wo ich sage, da wäre ich früher auf und davon. Jetzt denke ich mir, die reden so einen Schwachsinn daher, so einen unvorstellbaren Blödsinn, und ich nicke dazu, denke ich mir, ja der hat Bildzeitung gelesen und hat Abendzeitung und der TZ und eine super Meinung habt ihr. Nichts wissen, aber den Schmarrn halt nacherzählen, das, was da dringestanden ist. Und das macht mir heute nichts aus. Da bin ich restlos drüber hinweg. Also in keinem Fall schimpfen oder bösartige, 
böswillige Bemerkungen machen, sondern eher schmunzeln über die Blödheit der Leute, wieviel oder wie wenig Bildung vorhanden ist, und wie gefährlich das ist, wenn keine Bildung vorhanden ist. Das ist eine Katastrophe. Bei uns, in unserem Bereich, sag ich mal, ist das schon ein mittleres Niveau, aber dann kannst du dir vorstellen, wie es in den afrikanischen oder arabischen Staaten zugeht. Es ist eine Katastrophe, wenn die nicht lesen können und nicht schreiben können und keine Zusammenhänge erkennen, dann machen natürlich die Leute auch Blödsinn und dann sind furt die ganzen Geisteskranken, die das alles bewusst steuern, natürlich extrem leicht beeinflussbar. Und im Kleinen, im Ansatz ist das eben so, wenn ich das, sag ich jetzt mal, bei Geburtstagsfeiern oder Sportfeiern oder so irgendwas. Wenn ich es da mal wieder so höre, da denk ich mir, so einen Scheiß erzählen. Und da können die sich noch freuen einen ganzen Abend, und da hat der Franz-Josef Strauss das gesagt, und der hat das gesagt, und der hat auf den Tisch draufgehauen, dann sag ich toll, toll, toll. Und das ist, das ist der Vorteil, weil da bleibt natürlich auch viel Ärger erspart. Weil ich habe immer das Gefühl gehabt, ich kann doch das nicht so stehen lassen. Wenn die jetzt so einen Schmarrn erzählen, und ich weiß doch wie das / weil ich mir immer Gedanken mache über die Zusammenhänge. Es ist ja immer so, von der Firma her auch so geprägt. Du kannst ja nicht, wenn du ein großes Unternehmen hast, in den Tag hineinleben. Sondern du brauchst ja ein Netzwerk, brauchst deine Verbindungen, wann kommt wo ein Motor her? Da kommt ja keiner und sagt, jetzt haben wir einen Motor. Sondern du musst ja das ein Jahr vorher wissen, wo es noch keiner weiß. Nicht wenn du es in der Auto-Motor-Sport liest oder sonst irgendwas.

I: Sie haben vorher auch gesagt, dass Mitarbeiter sich auf die Seite von diesem Interimsmanager geschlagen haben, oder dass es auch Leute gegeben hat, die vielleicht missgünstig waren oder neidisch oder so. Inwiefern haben Sie bemerkt, dass sich jetzt durch die Insolvenz auch Ihr Umfeld Ihnen gegenüber verändert hat. Also, gab es auch jetzt im schlimmsten Fall Freunde, die sich abgewendet haben, oder wie war da so das Zusammenspiel?

B: Nein abgewendet nicht, abgewendet nicht, aber unglaubliche Schadenfreude.

I: Schadenfreude? 
B: Ja klar. Sie müssen sich das mal vorstellen, wenn Sie das jetzt zurückdrehen das Ganze. Da kommt ein Bauernjunge, wo der Vater Hilfsarbeiter ist, und drei Kühe daheim sind. Da kommt ein kleiner Bauernjunge, der drei Kühe daheim hat, und der Vater Hilfsarbeiter ist, kommt auf einmal in so eine Situation, dass es heißt, da hat er gebaut, dort hat er gebaut, dann die Urlaube. Ich habe ja sowieso dazugehalten, es hat ja bei uns kein Schwein im Dorf wissen dürfen, dass ich das Unternehmen habe. Ich bin zwar mit einem 750er BMW gefahren, aber die Leute haben gesagt, ich bin Chauffeur, das / weil es sich einfach bei denen so, Chauffeur ohne Kappe. Die waren gar nicht drauf gekommen in so einem Dorf mit 1500 oder 2000 Einwohner, dass da auf einmal einer da ist, der diesen Reichtum verkörpert. Also, wenn die geredet haben, ja der / und erst wie sie es dann erfahren haben durch einen größeren Artikel von der Süddeutschen Zeitung, dann ist es natürlich aufgegangen im Dorf. „Ja, des gibt es ja nicht!“ Und dann hast du natürlich die Neider: „Wo wird er das Geld wem gestohlen haben? Und so mit ehrlicher Arbeit kannst du das ja fast nicht glauben." Und $<<<$ Ort anonymisiert $\gg>>$ ist halt so ein abgeschiedenes Bauerndörfchen, das halt keine oder kaum Kontakte hat nach $<<<$ Ort anonymisiert $>>>$. Und von daher, auch die, die mit mir in die Schule gegangen sind, oder auch die, die auf das Gymnasium gegangen sind und nichts geworden / gibt ja sehr, sehr viele von den Geistesblitzen, die unglaublich lebensuntüchtig sind. Das ist ja auch was, was du immer wieder erfahren kannst, null soziale Kompetenz. Dass sich die natürlich drüber freuen und sagen: „Schau ihn an, jetzt hat es ihn auch zerbröselt! Super, jetzt muss er bald sein Auto verkaufen, und jetzt wird er das und das." Und zu mir hat einmal ein Architekt gesagt, der $<<<$ Name anonymisiert $\gg>$, der hat gesagt: "Du kannst dir nicht vorstellen, was du für ein interessanter Mensch bist! Ich würde dir mal wünschen, dass du in den Wirtshäusern in $<<<$ Ort anonymisiert $>>>$ drin bist und dich versteckt hältst und mal das anhörst wie es jeden / unter der Woche die Alten zusammenkommen oder am Sonntag beim Frühschoppen / wie da über dich geredet wird, wie da gedacht wird / Also, ich will es gar nicht wissen, ich kann es mir vorstellen, dass keiner an dem Reichtum eine Freude hat. Weil du bist ja / in dem Moment sagst ja du, ich bin selber ein Versager. Verstehen Sie? Weil die haben ja alle eine bessere Möglichkeit gehabt vom Elternhaus her, um zu starten sowas zu machen. Da sagen die: „Warum hab da ich nichts gemacht?“ 
„Ja, wahrscheinlich wird es ja so sein, dass er sich es irgendwo zusammengestohlen hat oder den beschissen hat oder geerbt hat oder sonst irgendwas." Wie sich halt die Leute einen Reim daraus machen.

I: Eine Sichtweise, die mir eigentlich erst durch meine Gesprächspartner begegnet ist, was ich vorher eigentlich nicht so gehört hatte, dass eine Insolvenz als Makel angesehen wird. Sehen Sie das auch so?

B: Ja Extrem! Versager!

I: In der Öffentlichkeit?

B: Ja, klar! Totalversager! Nicht ein / ich habe es halt einfach übertrieben, nicht mehr genug gekriegt wie man sagt. Ich hatte ja bloß, das hat zu mir ja sogar einer gesagt in der Firma: „Sie hätten halt da nicht mehr bauen dürfen!" Klar. Sage ich: "Wenn ich so wäre wie Sie, wäre ich heute immer noch in der Werkhalle dort und würde was zusammenschrauben."

Aber das war nicht mein Lebensziel. Weil wenn du solche nicht mehr hast, die etwas riskieren. Und das / für mich wäre es zum Beispiel schlimm gewesen, wenn die Firma zerbrochen wäre. Dass alle ihren Arbeitsplatz verloren hätten, keiner mehr Geld gekriegt hätte, und alles verschrottet worden wäre. Aber das ist ja nicht der Fall, sondern die Firma, sie glänzt ja nach wie vor, ist immer noch eine schöne Firma. Und das Gebäude gehört immer noch mir. Also ich habe ja, es hat ja / mir und dem $<<<$ Name anonymisiert $>>>$. Wir haben ja eine Trennung gehabt von der $<<<$ Unternehmen anonymisiert $>>>$, Gebäude und Grundstück und GmbH ist insolvent gegangen, aber die Gbr hat natürlich gestrauchelt ohne Ende, weil die ja für die ganzen Schulden gerade steht musste. Also, habe ich gedacht, wenn es so ist, dass die jetzt da drinbleiben, dann haben wir eine gute Perspektive, dass es passt. Aber die Marke die ist ja, die ist ja riesig. Mein Selbstbewusstsein, das reicht aus, dass ich sage: „Ihr habt es alle nicht drauf, ist mir sowieso Wurst." Weil wenn du dich immer nach den Leuten richtest, da musst du ein Chamäleon sein, und da bin ich weit davon entfernt. Es geht einfach nicht, du musst den eigenen Weg gehen und abschätzen, ob das machbar ist. Und dann trauen sich die einen was, und die anderen trauen sich halt 
nichts. Es ist halt / und / jetzt bin ich auch nicht gerade gestrandet, sag ich jetzt mal, es wäre jetzt noch schlimm gewesen, weil es hätte ja sein können, die Firma geht weiter, und ich bin trotzdem Hartz IV. Das hätte auch passieren können, aber da sind wir auch weit davon entfernt. Also, es droht von daher, muss ich mal sagen, keine Gefahr mehr, dass da irgendwas aus dem Ruder läuft.

I: Sie haben es vorhin auch schon angedeutet, dass es jetzt im Nachhinein auch durchaus positive Aspekte gibt, dass Sie sagen, naja vielleicht hat es kommen müssen, Sie sind jetzt ausgeglichener.

B: Ja, vor allem die Gesundheit, dass ich das überlebt habe. Also, es wird dir dann schon ab und zu später bewusst, wenn Leute die, die früher, die auch gestrotzt haben vor Gesundheit, die dich bedauert haben durch die Schwere der Erkrankung, dass die heute viele schon nicht mehr leben. Dass es die also selber zerbröselt hat. Einer hat zu mir gesagt, bei den Tennismeisterschaften, da habe ich natürlich auch nicht mehr mitspielen können und so. Der hat gesagt: „Ich glaube, wenn ich sowas haben würde wie du, ich würde nicht kämpfen. Ich würde einfach einschlafen sterben und das war es."

\section{I: Jetzt bezogen auf die Insolvenz oder auf Ihre Krankheit?}

B: Auf die Krankheit. Das Kämpfen, weil du kriegst ja das auch / durch die Krankheit durchläufst ja du da ein Stahlbad. Und der hat das zu mir ja auch gesagt / weil ich habe damals wie es mit / ich war ja top, top, top fit, als ich die Diagnose gekriegt habe. Ich bin ja nicht so im Siechtum gewesen. Sondern ich war/ich habe am Freitag noch ein Doppel gespielt, Einzel und Doppel, und war am Sonntag noch am Berg, am Brauneck. Und am Montag habe ich halt so einen Untersuchungstermin gehabt wegen so einem Tinnitus, wegen so einem Hörsturz. Und dann schaut der da rein, und sieht den riesen Tumor da drin. Und da habe ich mir gedacht, das erste natürlich gleich mal Zahlen, wie hoch ist die Überlebenschance.

„Ja“, sag er, „bei dem Tumor $40 \%$ “.

Sag ich: „Gut, da bin ich dabei.“ 
Und dann sagt er: „Ja, jetzt schaun wir mal.“ Dann hat er gleich einen Termin gekriegt, also am Montag wurde er festgestellt, am Mittwoch musste ich in $<<<$ Ort anonymisiert $\gg>>$ sein.

Dann sagte ich: „In der Woche geht es nicht mehr, weil ich habe noch zwei Termine, einen beim BMW und einen bei Audi.“

Dann sagt der Doktor zu mir: "Herr $<<<$ Name anonymisiert $>>>$, die stellen wir jetzt mal ganz hinten an. Mir würde es gefallen, wenn Sie den Termin noch machen könnten irgendwann. Aber wenn Sie jetzt nichts machen, dann gibt es Sie in drei Monaten nicht mehr."

Weil der so aggressiv ist. Und es war bei mir, ich habe ja schon Metastasen gehabt, das heißt es war immer knapp, wenn sie nach unten gehen, dauert es ein bisschen länger, und wenn sie nach oben gehen, macht es Zack, und du bist weg. Und da ist es schon dahingegangen. Und da habe ich mir natürlich auch gedacht: „Kruzitürken, wenn ich da jetzt nicht hingehe, mir fehlt doch nichts. Ich kann doch alles machen. $\mathrm{Ob}$ das nicht ein Scheiß ist, dann schneiden die auf, und dann geht es erst richtig los." Ja, dann haben wir halt geredet daheim, hat meine Frau gesagt: „Bist du wahnsinnig? Ich fahr dich da jetzt rein und ab die Post!" Und dann ist es richtig aufgegangen, dann habe ich das ganze Programm gehabt. Und das macht dich natürlich schon stark. Ist auch sowas mit Krankheit, ist von der Herangehen- / von der Psychologie her / viele wo ich gemeint habe, das sind meine engsten Freunde, haben sich nicht reingetraut zu mir. Bin natürlich zusammengefallen ohne Ende, habe nicht gehen können, vier Monate künstlich ernährt worden und so. Die haben mich nicht besucht. Die haben nur gesagt: „Ja, freilich, wenn ich da reingehe, womöglich schiebt der dann gerade ab oder so." Oder wenn ich dann /

I: Wann war das?

B: Das war 1996. Also, wie ich gerade gebaut habe, da habe ich das Werk gerade ausgebaut. Teil zwei. Und / oder wenn ich dann unterwegs war, da haben die Leute die Straßenseite gewechselt. Bloß, dass sie mich nicht grüßen brauchen, oder dass die mich nicht anschaun müssen. Also, das waren schon harte Sachen. Naja ist so, habe ich Ihnen am Anfang ja gesagt über das, wenn du so eine Krankheit hast. Heut hörst du ja auch, die hat einen Brustkrebs, und dann kriegt die neue Brüste oder sonst 
irgendwas. Das mag schon auch schlimm sein, aber es gibt halt verschiedene Arten. Wo es dann anders aussieht, die einen gehen nach drei Wochen wieder in die Arbeit oder nach vier Wochen und / also, ich habe da ein riesen Programm gehabt, sag ich ja, auch das hat mir geholfen in der Situation, um da bestehen zu können. Weil das ist dann so schlimm, nicht die Firma zu verlieren. Die hasst du ja dann die Firma, weil du ja sagst: „Für wen mach ich das eigentlich jetzt? Ist doch scheißegal / ja gut / aber eigentlich waren ja nur die Führungskräfte gegen dich. Ja, stimmt genau. Ich habe ja noch Verantwortung gegenüber den anderen 180 Leuten." So bist du immer im Zweifel. Aber das Extreme ist halt dann, wennst du aus dem Haus raus musst, das du dir gebaut hast, wo du drin lebst, wo die ganzen individuellen Geschichten von meiner Frau drin sind.

I: Aber so weit kam es ja nicht.

B: Nein, dann nicht. Vom Gerichtsvollzieher habe ich den /

I: Da war nur die Angst da, dass das passieren hätte können.

B: Naja, der hat aber jeden Tag kommen können. Weil der hat ja schon einen Bescheid gehabt. Jeden Tag haben wir darauf gewartet. Aber wie gesagt, man geht gestärkt daraus hervor.

Nachtrag zum Interview:

I: Was würden Sie heute anders machen?

B: Es gab eine personelle Fehlentscheidung bezüglich meines Stellvertreters. Da bin ich nach Engagement gegangen. Das war ein sehr engagierter Mensch, der aber eigentlich von den Fähigkeiten her ungeeignet war. Das hat sich dann in der Insolvenz gezeigt. Der ist sofort weggebrochen.

Außerdem hatten wir ein Problem mit der Laufzeit der Leasingverträge für die Maschinen, Betriebsausstattung. Da habe ich einen sehr kurzfristigen Zeitrahmen gewählt. Da hätte ich statt drei lieber sechs Jahre nehmen sollen. Dann wäre die 
finanzielle Belastung nicht so hoch gewesen. Vielleicht hätte ich die Insolvenz dann nicht anmelden müssen.

Auch hätte ich nicht damit gerechnet, dass es so wenig Zusammenhalt gibt, so wenig Flexibilität, so wenig Eingeständnisse, so wenig Entgegenkommen, wenn man doch eigentlich ein gut funktionierendes Unternehmen hat, das rettenswert ist. Ich hätte da gedacht, dass mir vielleicht auch die Leasingfirma entgegenkommt und den Zeitrahmen verlängert, dass da einfach mehr Flexibilität drin ist.

Dass bei den Banken auch mehr Flexibilität drin ist. Die Geschichte mit der Förderbank, die ich erzählt habe. Das war alles so schwerfällig. Da hatte niemand den Erhalt der Firma und der Arbeitsplätze im Fokus von den externen Partnern. Und die hatten ja aber maßgeblichen Einfluss auf die Geschichte. 
Appendix VI: Transcript of Interview 5

I: Ich möchte Sie ja auch ein bisschen besser kennenlernen, deswegen wäre es mir am liebsten, wir würden einfach mal damit starten, dass Sie mir so ihren Werdegang erzählen, von der Kindheit bis jetzt. Wie waren denn so die Meilensteine, was Ihnen whichtig ist.

B: Also, ich bin 1950 geboren in Hessen. Wollen Sie mal testen ob das geht?

I: Das geht schon, hat bisher immer geklappt.

B: Ok, gut. Ja. Dann habe ich meine 8 Jahre Schulausbildung gemacht. Das waren ja noch damals 8 Jahre nur. Habe eine Lehre begonnen zum Auslands-Kaufmann. Habe dann sehr früh meine Frau kennengelernt. Wir haben 1969 geheiratet.

I: Und hat es gehalten?

B: Ja, hat gehalten. (lacht)

I: Ja, schön (lacht)

B: Wir waren jetzt am 18. April 45 Jahre verheiratet.

I: Herzlichen Glückwunsch. Schön.

B: Ja, ich habe einen Sohn, zwei Enkel. Der große Enkel ist 17, der Kleine ist 14. Habe also sehr früh schon Verantwortung übernehmen müssen für eine Familie. Weil meine Frau war damals 16, ich wurde 19. Und, ja, durch die Übernahme der Verantwortung war natürlich auch das Leben schon bestimmt mit Geld verdienen. Ich habe also nach dem Hauptschulabschluss, meine Mittlere Reife nachgeholt, immer berufsbegleitend. Habe dann meinen praktischen Betriebswirt dabei gemacht und habe dann nach dem praktischen Betriebswirt in einem Unternehmen gelernt, welches mit 
Sicherheit im Bankenbereich beschäftigt war, also so für Neukunden war das. Äh, ich bin damals als Angestellter eingestiegen, weil wir waren wirklich, wir waren vier Leute. Und sind gestartet in Frankfurt. Nach einem Jahr bin ich Gesellschafter geworden. Wir haben dann die Niederlassungen aufgebaut in Düsseldorf, Berlin, Stuttgart und in München. Ich habe die zwei Niederlassungen in Frankfurt und in Düsseldorf aufgebaut. Habe sie eigentlich, ich denke, ganz vernünftig geleitet und auch zum Erfolg geführt. Wir haben in den 80er Jahren das Unternehmen dann verkauft an die Firma $<<<$ Unternehmen anonymisiert $>>>$. Damit merkte ich, dass ich eigentlich, das was ich gerne getan hab, verkaufen, plötzlich Nebenbeschäftigung wurde, weil wenn du als kleines Unternehmen in ein großes Unternehmen integriert wirst, bedeutet es eigentlich zu 70\% Arbeit am Schreibtisch und irgendwelche Zahlen generieren. Und das, was man eigentlich tun wollte, das Unternehmen weiterbringen, das funktioniert halt nicht mehr. Also bin ich dort ausgestiegen, habe ich mit meinen / meine ganzen Leute sind mit mir gekommen. Wir haben also ein neues Unternehmen gegründet, eigentlich mit denselben Funktionen, mit dem selben Kundenkreis. Haben uns dann eigentlich immer weiterentwickelt mit einer Niederlassung in Hamburg. Wir haben betreut sehr viele Sparkassenkunden. Wir haben betreut viele Genossenschaften. Dann ist dazugestoßen die Deutsche Bank, viele Privatbanken, die Dresdner Bank, wobei sich die Dresdner Bank mit ihrem Filialnetz zu einem meiner Großauftraggeber entwickelt hat, das heißt also dass ich bis zu 65 \% meines Umsatzes mit ihnen gemacht habe. Mittlerweile waren wir 17 Leute. Und ich muss sagen, es war eigentlich ein schönes Arbeiten. Wir haben dann in dieser Zeit die ganzen Sicherheitszulassungen bekommen, sei es vom Landeskriminalamt, sei es von den Versicherungen. Wir haben uns weiterentwickelt, wir waren / Wir haben die Zulassung für die Luftfahrt gehabt. Das heißt, wir haben im Bereich der Flughäfen gearbeitet und konnten eigentlich ganz zufrieden sein, mit allem, was da so lief. Also alles wirklich, ich würde sagen, es war wirklich toll. Also wir als kleines, wirklich kleines Unternehmen. Unser Wettbewerb war Siemens und Bosch und, da kann man eigentlich sagen, ja, da bist du eigentlich stolz auf das.

I: Ja. 
B: Tja, dann kam irgendwann die Situation, dass die Dresdner Bank von der Commerzbank übernommen wurde. Die Commerzbank hatte uns zugesichert, dass wir keinerlei Nachteile haben, sondern ganz im Gegenteil wir sollten eigentlich das Filialnetz dann der Commerzbank, die technisch schlechter aufgestellt waren wie die Dresdner Bank, eigentlich auf das Niveau der Dresdner Bank bringen.

I: Hört sich erstmal ganz gut an.

B: Hört sich wunderbar an. Man hat uns nur gesagt: „Ok, wir brauchen ein Jahr bis wir konsolidiert haben, bis wir wissen, welche Geschäftsstellen jetzt bleiben." Weil es war ja so, dass meistens die Dresdner Bank und die Commerzbank teilweise in Sichtweite lagen und da blieb natürlich immer nur eine Stelle über. Man hat mir dann gesagt: „Ok, wir werden dieses Jahr keine Aufträge vergeben können, also keine weiteren Aufträge mehr, sondern wir können eigentlich nur den Service dann leisten." Meine Einwendungen waren natürlich: „Wie kann ich ein Jahr ohne Umsatz überstehen?" Man hat mir da gesagt: „Ok, wir kriegen das geregelt." Man hat mir Gelder zur Verfügung gestellt, damit ich keine Mitarbeiter entlassen musste. Weil die Mitarbeiter waren das Kapital des Unternehmens. Die Mitarbeiter waren diejenigen, die eigentlich das Thema Dresdner Bank oder Commerzbank beherrschten von der Technik her. Weil auf dem Markt gab es keine Mitarbeiter, die man einfach mal so schnell generieren konnte, sondern das waren top ausgebildete Leute um speziell dieses Thema Mutex. Mutex war der Begriff für die Sicherheitsstufe der Dresdner Bank. Ja und am letzten Tag - wir waren übrigens vertraglich abgesichert. Das heißt, wir hatten also einen Vertrag der sich jährlich verlängerte, wenn er nicht gekündigt wurde. Und am letzten Tag der Möglichkeit hat man uns den Vertrag gekündigt. Zwischenzeitlich war die Firma, die die Commerzbank mit ins Boot nehmen wollte, die in Norddeutschland war, die eigentlich überhaupt keine Niederlassungen hatten im süddeutschen Raum, die waren mittlerweile an meine Mitarbeiter herangetreten, um sie abzuwerben. Weil es war einfach nicht möglich ohne diese Mitarbeiter einen Vertrag zu übernehmen.

\section{I: Und erfolgreich?}


B: Ja, dann wie die Insolvenz / wie ich dann ins Schleudern kam. Das konnte ich meinen Mitarbeitern auch gar verübeln. Was ich ihnen verübelt habe, dass sie mir nicht früh genug gesagt haben, dass eine Fremdfirma an sie herangetreten ist.

I: Ja. Hätte man das besser durchschaut alles.

B: Ja, was ich sehr übelnehme, war einfach das Verhalten der Commerzbank, weil man hat mich bis zum Schluss, bis zum letzten Tag im Glauben gelassen, dass alles seine Ordnungsmäßigkeit hat, dass alles funktioniert. Ich meine, ich hätte das alles vielleicht noch überstanden, aber ich hatte ein Unternehmen, was für mich tätig war, wo ich verbunden war. Und zwar war das eine Sicherheitsleitstelle, die saß in Düsseldorf. Dort waren eigentlich alle Geschäftsstellen aufgeschaltet, also dort liefen alle Informationen auf. Und diese $<<<$ Unternehmen anonymisiert $>>>$ hat für mich gearbeitet. Die Verträge waren natürlich uralt, die liefen schon seit 20 Jahren. Und ich hatte einen Versatz, das heißt, ich konnte den Vertrag nicht mehr kündigen ... (unverständlich). Und das Gespräch dann mit diesem Unternehmen $<<<$ Unternehmen anonymisiert $\gg>$ ergab, dass die eine Regessforderung für die Auflösung des Vertrages in Höhe von 200.000 Euro haben wollten. Mittlerweile hatte ich natürlich durch das Darlehen der Dresdner Bank insgesamt, ich würde sagen, 600.000 Euro Schaden, den ich eigentlich nicht mehr stemmen konnte. Und das führte dann letztendlich nach Absprache mit meinem Anwalt dazu, dass ich mich für die Insolvenz entscheiden musste. Muss dazu sagen, das Unternehmen war ja von klein auf geprägt auf die Person, auf meine Person, auf die Person meiner Frau und die von meinem Sohn, das heißt wir waren überall komplett in Haftung. Diese GmbH / wir haben persönlich gebürgt, wir haben gebürgt mit unserer Altersversorgung, und da war schlagartig komplett alles weg.

I: Kam es dann auch zu einer Privatinsolvenz oder konnten Sie das abwenden?

B: Nein, das konnte ich abwenden. Gott sei Dank. Aber ich muss sagen, wenn ich heute drüber nachdenke, ich habe im Moment schon alles verloren. Weil alle Gelder, die dafür vorgesehen waren, wurden dazu benutzt um die Bürgschaften auszulösen. Mein Glück war, dass ich noch sehr viele gute Kunden hatte, die mir gesagt haben: 
„Herr $<<<$ Name anonymisiert $>>>$, wenn Sie weitermachen wollen, wir stehen zu Ihnen." Und so habe ich dann auch eigentlich eine kleine $\mathrm{GmbH}$, also eine UG, gegründet und führe heute eigentlich mit einem alten Mitarbeiter, der schon bei mir war, und mit einem zweiten Mitarbeiter eigentlich das Unternehmen weiter. Wir machen nicht mehr sehr viel, weil wir schaffen einfach nicht mehr, aber wir leben.

I: Aha. Wann war so der Moment, an dem Sie gemerkt haben, jetzt geht es nicht mehr anders, jetzt steht die Insolvenz wirklich vor der Tür. Weil man versucht wahrscheinlich schon relativ lang noch das zu retten und auch vor sich selbst vielleicht auch nicht einzugestehen.

B: Ja, ja, Wahnsinn. Ja, du kämpfst ja darum. Du hast ja, du hast ja / Ich habe in meinem ganzen Leben noch keine einzige Bilanz gehabt mit einem negativen Ergebnis. Und wir haben eigentlich uns aus uns heraus immer selber finanziert. Wir haben also eigentlich kein Geld jetzt in irgendwelche privaten Zwecke hineingesteckt, sondern wir haben gesagt: "Ok, neue Mitarbeiter nehme ich mit dazu." Das heißt, es waren immer Investitionen in Arbeitsplatz, in PKW und und und. Das heißt also, es gab keine großen Rückstellungen. Sondern es war der Punkt erreicht. Plötzlich waren diese Gelder, die von der Dresdner Bank uns zur Verfügung gestellt worden waren noch, die wurden fällig gestellt. Tja, da kommt der Punkt, wo du dann persönlich noch vielleicht im Bekanntenkreis / Weil du kannst ja nicht erkennen, dass es so / dass es plötzlich kaputt sein soll. Du glaubst es nicht. Du schiebst es ja weg. Du sagst: „Es geht weiter." Aber du hast einen Kostenapparat, einen, der auf maximal ausgelegt war, den kannst du nicht so schnell herunterbringen, das geht ja nicht. Du kannst zwar abbauen langsam, aber Mitarbeiter abzubauen, das ist dein Kapital, und das kann niemand anders.

I: Ja.

B: Wenn man kein herstellender Betrieb ist sondern ein Dienstleister, dann beginnt das Problem. Was mir da bei diesen 20 Jahren auch nahe geht. Kannst nicht auf die Straße setzen, das geht gar nicht. Ist nicht möglich. 
I: Und die Insolvenz an sich, wie haben Sie die empfunden? Was waren so die größten Schwierigkeiten oder Hürden, die Ihnen so begegnet sind?

B: Nochmal die Frage?

I: Die Insolvenz an sich, also die Phase der Insolvenz, was waren da die größten Schwierigkeiten und Hürden?

B: Also, ich will mal so sagen, die Vorstufe bis zur Entscheidung, die Insolvenz anzumelden, das war die schlimmste Zeit. Das war die Zeit, wo man gekämpft hat mit den Banken, mit dem Finanzamt, mit den Lieferanten, weil, ja, weil ich mich persönlich verpflichtet sah, eigentlich Schaden abzuwenden.

I: Wie sind diese ganzen Leute, Banken, Lieferanten, Finanzamt, wie sind die Ihnen gegenübergetreten? Wie war das Miteinander so?

B: Ich würde mal sagen Finanzamt knallhart. Da gibt ein kein links, kein rechts. Banken sehr unterschiedlich. Langjährige Banken, mit denen ich schon sehr lange zusammengearbeitet habe, waren / ich hatte vier Banken, vier Hausbanken. Weil wenn du für die Banken tätig bist, wollen die meistens auch, dass du ein Konto bei denen hast. Ja, die gehen bis zu einem bestimmten Punkt mit, und wenn der Punkt dann überschritten ist, dann ist es einfach vorbei. Und wenn dann eine Bank zusammenbricht und ihre Forderungen fällig stellt, dann kannst du das nicht über die anderen mehr refinanzieren, das geht dann nicht mehr. Ist vorbei dann. Aber man glaubt immer, man findet noch einen Weg. Aber es gibt keinen. (lacht) Wenn man es / ich hätte vielleicht, vielleicht habe ich den Fehler gemacht, dass ich mir vielleicht ein halbes Jahr früher professionelle Hilfe nicht gesucht habe. Aber ich dachte, ich schaff das. Ich schaff das alleine.

I: Abgesehen davon, gibt es noch andere Sachen, die Sie heute anders machen würden?

B: Ja! (lacht) 
I: Was denn?

B: Ich würde nicht mehr den Umsatz vorne anstellen, sondern ich würde sagen, den Ertrag. Wobei ich sagen muss, man achtet ja dann schon darauf, dass Ertrag da ist, aber wenn du im Wettbewerb bist, musst du manchmal Umsätze tätigen die, ja, ich sage mal keinen großen Ertrag generieren, aber deine Kosten decken. Heißt also Zeit und die Manpower und alles, was du hast, verbrätst du dort, wo du es eigentlich verbraten konntest.

I: Und jetzt, als es dann auf die Insolvenz zuging, und durch die Insolvenz durch, gab es da Sachen, wo sie sagen, würde ich heute anders machen? Vielleicht wäre es dann anders gelaufen.

B: Nein. Nein das war, also bis zu diesem Zeitpunkt, muss ich sagen, waren wir ein grundsolides Unternehmen. Also, ein Unternehmen, wo man sagen kann, das passt. Gab es auch keinen / wir haben keine Reichtümer verdient, aber wir hatten eigentlich immer einen guten Deckungsbeitrag, das passte. Wir hatten regelmäßige Arbeiten. Es war eigentlich immer, man kann sagen, Vollpower zu tun, und wir haben die besten Kunden gehabt, die es gibt. Es gibt eigentlich keine besseren Kunden wie Banken. Es gab keine Forderungsausfälle, es gab / Alles super sauber und ordentlich. Also, man erwartet das nicht. Ich würde einfach mal sagen, man erwartet das nicht.

I: Wenn sie jetzt zurückdenken, hat sie die Insolvenz verändert?

B: Ja.

I: Inwiefern?

B: Ich würde sagen, ich habe viel Lebensqualität verloren. Ich habe verloren in den es ist ja jetzt / es hat sich ja jetzt / Jetzt war ja das dritte Jahr im April - ja, Lebensfreude, Leichtigkeit. Ja, ich denke das sind so Sachen, die ich mal ganz vorne anstellen sollte. 
I: Aha. Und im Zusammenspiel mit ihrer Umwelt, mit ihren Freunden, ihrer Familie oder mit Geschäftspartnern. Hat sich da was verändert?

B: Ja, natürlich hat sich da was verändert. Man hat ja vorher viele Freunde. Und da bleiben nur nicht sehr viel über.

I: Ja, wieso? Wie äußert sich das?

B: Das äußert sich darin, dass man glaubt, dass / Das ist die Bedeutung mit dem Wort Freund, weil, ich sag mal Bekannte, ja? Denen man sehr nahe steht, mit denen man Jahre lang zusammen ist. Mit denen man viel Freude und viel Leid auch geteilt hat. Wenn die mitkriegen, dass du in diese Situation kommst, dann ist das wie eine Seuche. Dann haben die Angst, dass man sich ansteckt. Dann sind sie plötzlich nicht mehr erreichbar für dich. Dann gibt es niemanden, der dir einfach so mal ein bisschen den Rücken stärkt, der mal zu dir sagt: „Hey, wenn du ein Problem hast, ich helf dir." Ich will jetzt nur an den einen Tag mal erinnern, den wir hatten. Wir haben Insolvenz angemeldet. Ich glaube ein Tag später oder zwei Tage später waren wir beim Einkaufen. Sagt meine Frau zu mir: „Wieviel Geld hast du noch einstecken?" Sagte ich: „40 Euro oder 50 Euro" Sagte sie: „Wir brauchen ein bisschen mehr. Ich geh jetzt an den Geldautomaten und hol mir Geld." Gibt die Karte ein, flupp, war die Karte weg. Habe ich gesagt: „Das kann nur ein Missverständnis sein." Das war die Geschäftsbank darunter auch die Privatbank. Das kann nicht sein, da ist irgendwas schiefgelaufen. „Da ist meine Karte." Auch weg.

I: Auch weg? Ach Gott.

B: Dann machst du dein Portmonee auf, guckst rein, eins, zwo, jetzt habe ich noch vielleicht hundert Euro. (Pause)

I: Hm, blödes Gefühl, oder?

B: Ja. 


\section{I: Glaub ich.}

B: Das ist ein sehr blödes Gefühl! Ich denke im Nachhinein, ich glaube, das ist der Augenblick, wo du über dein Leben nachdenkst. Wenn du dann die Freunde, wo du denkst, das sind Freunde. Das ist ja nicht so einfach überhaupt zu sagen: „Du, ich brauch Geld." (Pause)

I: Hm. Da hat man auch Hürden in sich selber.

B: Ja, das ist auch so. Man kann einfach nichts einfordern. Man kann nicht. Man vermittelt damit ja das Gefühl: „Mir geht es nicht gut." Und, ich glaube, wenn dann rüberkommt: „Kann ich was für dich tun?", dann kann man einen Einstieg finden. Aber man kann nicht hergehen und sagen / Es fällt einem unheimlich schwer zu sagen: „Du, kannst du mir helfen?“" Das machst du vielleicht einmal, und wenn dann kommt: "Na schaun wir mal." Ja. Dann / (Pause)

I: Dann hat man schon wieder einen Dämpfer.

B: Hat man einen Dämpfer. Ja.

I: Ja. Wie war denn das eigentlich, Sie haben ja / Sie sind ja im Moment auch selbstständig in der gleichen Thematik. Haben Sie das Unternehmen fortgeführt? Oder wurde das irgendwie saniert? Oder neu?

B: Ich habe / Wir haben einen sogenannten Asset Deal gemacht. Ich habe das Unternehmen / also man muss dazu sagen, mein Sohn war mit im Unternehmen. Dann haben wir gesagt: „Okay, wie kriegen wir das gelöst?" Dann ist ein Mitarbeiter, also ein Ex-Mitarbeiter und mein Sohn, die zwei zusammen / Haben gesagt: "Okay, wir könnten es eigentlich so machen, ich betreue meine ... (unverständlich), und ihr könnt eigentlich neu gründen. Also auch von der Technik her, die Technik ändert sich vom Geschäft her sehr, sehr schnell. Dann sind wir hergegangen, haben mit der Insolvenzverwalterin gesprochen, haben gesagt: „Besteht die Möglichkeit, dass wir 
das fortführen können?" Dann haben wir einen Deal gemacht, wir haben eigentlich alles herausgekauft. Geschäftsräume, die Geschäftsräume gehören ja auch nicht uns, aber den Mietvertrag, wir haben die Räumlichkeiten, wir haben alle Verträge übernommen, die jetzt bestanden. Inklusive haben wir die Möbel gekauft, wir haben das Equipment gekauft. Wir haben dann aus dem Lager stückweit Waren herausgekauft. Und das hat uns es dann eigentlich das erst ermöglicht zu sagen: „Okay, wir machen weiter." Aber die Voraussetzung war dafür, dass ein gewissen Klientel von meinen Kunden gesagt hat: „Komm, wir bleiben bei dir."

\section{I: Okay.}

B: Tja, und dann ging das los, äh. Ich habe versucht, dann ein Konto wieder zu bekommen, das war auch nicht so einfach. Das habe ich dann wegen meiner Haus-, zweiten Hausbank / Die hat gesagt, ok, sie geben mir wieder ein Konto, aber nur auf Privat-Basis. Dann hat die Familie, hat hier ein bisschen Geld zur Verfügung gestellt, damit wir einfach mal diesen ganzen Start machen konnten. Ja und seitdem arbeiten wir auf dieser Basis, ohne jegliche Gelder, die wir von der Bank generieren können. Das heißt, wir müssen sehr genau, sehr genau alles planen. Ich habe bei einem Lieferanten alles immer in Vorkasse gemacht. Das heißt, also, ich glaube diesem Lieferanten, aber, weil der mir die Ersatzteile für die Anlagen, die wir bekommen, auch zur Verfügung stellt. Bei einigen Lieferanten, mit denen ich wirklich zusammengearbeitet habe, die haben gesagt: „Ok, wir kennen uns so lange, und die waren bisher immer ein guter Kunde von uns. Wir sprechen ihnen das Vertrauen aus." Dann bekam ich auch Rechnungen wieder. Das war immer ein, boah! (Geste der Erleichterung) Da hast du / ich denke jeder, der das mal hinter sich gebracht hat das Ganze, und dann wieder durchstartet, der macht das garantiert viel, viel besser. Und ich würde jeder Bank empfehlen, wenn heute jemand jetzt nicht aus kriminellen Machenschaften, sondern aus erklärbaren Machenschaften heraus in die Insolvenz gehen musste, und der wieder anfängt, ihm ein bisschen Vertrauen auszusprechen, weil ich glaube, wenn es ein seriöser Mensch ist, dass das zweite Mal mit Sicherheit der sein ganzes Geschäft, seine Überlegungen, seine kaufmännischen Sachen total neu aufstellt. Davon bin ich felsenfest überzeugt. 
Ich denke, wir haben ja / in Deutschland ist nach wie vor eine Insolvenz ist etwas Schlimmes. Also in der Allgemeinheit. Wenn da einer insolvent macht, das ist gleich wie / das ist / das ist wie / Ähm, auch in dem ganzen Bekanntenkreis bist du geächtet, ja geächtet. Ich denke im angelsächsischen Bereich ist eine Insolvenz durchaus denkbar ist, weil man da auch wieder rauskommt.

I: Ich muss sagen, ich dachte eigentlich auch, dass es in Deutschland so ist. Ich habe erst jetzt durch die Gespräche mitbekommen, dass das wirklich als Makel betrachtet wird.

B: Ja, ich habe noch nicht mal einen Handyvertrag. Gar nichts. Es war nur, man kann sagen nur über Schleichwege, über, ja, Sachen die man eigentlich nicht als gut empfindet. Dann hatte ich ein Handy, aber dadurch, dass ich ab und zu mal nach Österreich rüberfahre, das kaufte ich dann im Ausland, nicht?

I: Aha.

B: Also du fällst von Hundert auf null. Etwas, wo du jahrelang für gearbeitet hast, wo du ein, sag ich mal, ein geachteter Mensch warst. Wo jemand sich um dich bemüht hat. Wo man, sag ich mal, für die Sicherheit - ich hab sehr viel am Flughafen München gemacht - wo du für die Sicherheit von hunderten von Menschen verantwortlich warst, warst du plötzlich nichts mehr. Das war, das war krass.

I: Und gibt es jetzt aus dieser ganzen Geschichte auch etwas Positives, was sie mitnehmen?

B: Ja, dass ich gelernt habe, Menschen zu verstehen, besser zu verstehen. Also nicht mehr ganz so, sag ich mal euphorisch. Also, ich habe immer Menschen einen Vorschuss gegeben, heute bin ich vorsichtiger. Oder im Bekanntenkreis, wenn sich jemand als dein Freund ausgibt, bin ich auch vorsichtig geworden. Von den vielen Bekannten sind mir ganz wenige Freunde übriggeblieben, die / ich sag immer ein Freund kommt dann, wenn andere gehen. 
I: Ja, das stimmt.

B: In dem Geschäftsbereich, okay. Ich bin sehr, sehr dankbar vielen von meinen Kunden, die mir einfach die Stange gehalten haben, die bei mir geblieben sind.

I: Ja. Und das Insolvenzverfahren an sich, wie haben Sie das empfunden, auch das Zusammenspiel mit dem Verwalter oder /

B: Ja, ja ich habe also, ich habe mich verantwortlich gefühlt. Ich habe mit dem Insolvenzverwalter zusammen Telefonate geführt. Ich habe mich also nicht zurückgelehnt und habe gesagt: „Okay, mach mal, das interessiert mich nicht mehr." Sondern wir beide haben zusammen eigentlich ausstehende Gelder eingetrieben. Wir haben alles, was zusammen abzuwickeln war, abgewickelt, weil ein Insolvenzverwalter arbeitet ja schematisch ab. Er hat ja eigentlich gar nicht viel Zeit, so ein bisschen ins Detail zu gehen. Da haben wir uns eigentlich fast super ergänzt. Wir haben eigentlich, glaube ich, alles sehr, sehr, sehr sauber gemacht. Wir haben wirklich / ich bin heute noch, wenn irgendetwas ist, mach ich. Ich bin heute noch immer erreichbar für ihn. Und wir arbeiten heute noch zusammen.

I: Schön.

B: Und, ich denke, das ist auch wahrscheinlich etwas, warum die Frau $<<<$ Name anonymisiert $\gg>$ wahrscheinlich auch meinen Namen genommen hat. Ja, weil sie einfach das auch mitverfolgen konnte, wie geordnet so eine Insolvenz laufen kann, wenn, wenn die Beteiligten oder wenn der Verursacher, sag ich mal, dazu steht.

I: Und, habe ich das richtig verstanden? Sie haben praktisch eigentlich durchgehend gearbeitet, also es gab jetzt keine Phase /

B: Nein ich habe / ich kann auch genau sagen, seit ersten April diesen Jahres hab ich erst mit dem Arbeiten aufgehört. Ich habe also alles, Arbeit, Studium, Ausbildungen, Weiterbildungen immer parallel gemacht. 
I: Also, es gab jetzt auch dann zwischen altem und neuen Unternehmen keine Phase irgendwie /

B: Ich habe, man kann sagen, sogar während ich das Neue aufgebaut habe, habe ich geholfen, die Altdaten ... [unverständlich].

I: Aha. Okay.

B: Also, es war ein fließender Übergang, kann man sagen.

I: Ja. Und wie sehen Sie jetzt in die Zukunft? Mit welchem Gefühl?

B: Ich habe bis jetzt mit allen eine Vereinbarung getroffen, das heißt also klare / im Rahmen meiner Möglichkeiten, meiner finanziellen Möglichkeiten, Schaden beglichen. Ich sag jetzt einfach mal, überall dort, wo ich gebürgt habe, oder wo ich mich verpflichtet fühle, habe ich mit Privatgeld eigentlich versucht, das abzugelten. Aber natürlich, weil mein Sohn ja auch mitten noch drin war, für ihn natürlich auch noch viel mit abgefedert. Dann weil er ist / er hat zwei Kinder. Und die hat es natürlich auch gewaltig getroffen. Ich habe bis auf eine einzige Bank, die bis heute nicht bereit war, mit mir einen Kompromiss zu schließen, alles erledigt.

I: Die nicht bereit war was?

B: Mit mir ein Kompromiss zu machen.

I: Ach so. Okay.

B: Also, sage ich mal, auf einen Teil der Forderung verzichten. Wir haben, wir haben ja wirklich schon, möchte mal sagen die Hälfte angeboten, aber nicht. Sie will 100\%. Liegt aber daran, dass es, dass der Sachbearbeiter, sag ich mal, ich würde schon fast sagen, persönliche Gelüste hat oder irgendwas. Ja. Ja, würde ich fast sagen. Wirklich, ich habe das noch nie erlebt bei einem Menschen, der so bösartig mit einem anderen Menschen umgeht. Ich glaube, der ist so, der ist verbittert. Der hat irgendwann mal 
irgendso ein traumatisches Erlebnis gehabt. Der hat mir dann auch immer so gesagt: "Du machst dieses, machst jenes, machst Urlaub, und ich sitz hier." Und für den ist das irgendwie was Persönliches.

I: Und war das früher auch schon so? Das Verhältnis so angespannt?

B: Nein, überhaupt nicht. Nur, das hat der ja übernommen. Es gibt ja / du wirst ja dann outgesourced in der Bank. Dein Mitarbeiter, den du hast, oder dein Betreuer, mit dem du ja jahrelang gut gearbeitet hast, der hat da keine Funktion mehr. In diesem Augenblick wird diese ganze Akte geschlossen und wird dann in die sogenannte Abwicklung übergeben.

I: Ach so. Okay.

B: Und wenn du dann dort einen Menschen hast, der sag ich mal, dich leben lässt. Der sagt, „den Mann" / der sich wirklich auflegt und sagt: „Hör mal, ich bin bereit, aber ich kann dir das nicht hundert prozentig geben."

„Gib mir eine Chance, die mich leben lässt, wo ihr auch mitreden könnt." Das haben wir ja versucht. Es ging da, wir haben es bei allen hingekriegt, nur / (Schulterzucken)

I: Schade.

B: Und ich habe mir immer wieder gedacht, diese Bank, mit der habe ich über dreißig Jahre zusammengearbeitet, mit der ich wirklich wahnsinnig gute Geschäfte gemacht habe. Die wirklich super Geld angeliefert haben. Wo wir wirklich extrem viel gemacht haben. Gerade diese Bank, wo ich als erstes erwartet hätte, dass man gesagt hätte: „Okay, komm, wir kriegen den Weg hin." Aber nichts. Wirklich diese Bank. Wie sagt man zu Menschen die, wenn einer am Boden liegt, wo man auch noch drauftritt. Ich glaube das ist /

I: Aber es ist oft einfach personenabhängig. 
B: Ja, unbedingt so. Das habe ich mein ganzes Leben / ich bin so ein Mensch gewesen. Ich glaube, ich merke so in den ersten zwei Minuten, ob ich mit dem kann oder nicht kann. Ob das passt, zwischen mir passt, auch bei meinem Kunden. Ich wusste immer eigentlich, ob die Möglichkeit eines Auftrags besteht, oder ob es nicht passt zwischen uns.

I: Ja.

B: Wenn es zwischen zwei Menschen nicht passt, dann sollte man das nicht tun.

I: Ich habe das immer bei den Bewerbungsgesprächen gemerkt, nach zwei Minuten weiß man eigentlich, ob man den Job hat oder nicht.

B: Ja, ist so. Stimmt.

I: Na gut, also, auf meiner Liste ist nichts mehr offen. Wir sind durch. Dankeschön. Dann schalte ich das mal aus.

B: Ich hoffe, man kann es verstehen.

I: Bestimmt.

B: Also, ich könnte jetzt noch / ich könnte wahrscheinlich, wenn ich mal so richtig ins Reden komme, dann komme ich bis in die Details hinein.

I: Dann lasse ich es doch noch laufen. (lacht)

B: Ja, ja.

I: Wer weiß, was Sie mir noch alles erzählen.

B: Ja, ich denke das sind so, sind zwar Kleinigkeiten manchmal, aber die manchmal sehr whichtig sind. (Pause) 
I: Also, die Hauptgründe würde sie eigentlich darin sehen, dass die Bank, also ihr Hauptkunde nicht zu ihrer Zusage stand.

B: Richtig.

I: Und dass dann die Vertragslaufzeiten zum Sublieferanten /

B: Nicht möglich waren zu kündigen.

I: Genau. War der Hauptgrund.

B: Das war der Hauptgrund. Entstanden ist das wahrscheinlich daran, dass mein Sublieferant, der vielleicht auch schon sehr alt war / wir sind immer / Da hätte man irgendwann den Vertrag mal auf neue Beine stellen müssen, auf neue Füße, Anpassungen machen müssen, Teil dazu, aber das ist so gewachsen. Das ist einfach immer so gewachsen und dann wieder etwas dazugekommen, und man hat das auch einfach / Ich habe das erst in diesem Augenblick mir wirklich zur Gemüte geführt wie das Problem der Verfügbarkeitsplanung / Da habe ich erst gemerkt: „Hey, das war ein Fehler." Ich hätte die beiden Verträge direkt miteinander verbinden müssen. Aber hinterher weiß man inzwischen was man falsch gemacht hat.

I: Naja klar, hinterher ist man immer schlauer, das stimmt schon.

B: Und das Verrückte daran war, dass meine ganzen Bezugspersonen, die bei der Dresdner Bank Kompetenzen hatten, Vertragsleute, mit der Übernahme entmachtet wurden. Die hatten ihre Kompetenz verloren und wurden eigentlich in andere Abteilungen versetzt.

I: Ach, Gott.

B: Und ich war / Plötzlich hatte ich neue Bezugspersonen. Und diese Bezugspersonen, die konnte ich natürlich nicht einschätzen. Aber wie man immer so 
denkt, geht man erst mal davon aus, dass das seriöse Leute sind, die da sitzen. Nur im Nachhinein weiß ich, dass die also uns wirklich missbraucht haben. Wir haben / das eine Jahr haben die gebraucht, damit dieser Übergang der Dresdner Bank Organisation in die CoBa abgewickelt wird. Das haben wir gemacht, wir haben eigentlich dieses, diese Überleitung der, der ganzen Daten der ganzen Sensibilität, der ganzen Abwicklung, das haben wir in dem Jahr noch gemacht. Erst wie wir fertig waren, da hat man sich entschlossen, zu sagen, so, jetzt brauchen wir sie eigentlich nicht mehr. Da hat die CoBa - müssen Sie sich mal überlegen - wir haben in den letzten vier, fünf Jahren, haben wir die Dresdner Bank, man kann sagen eigentlich technisch aufgerüstet. Das heißt, also wirklich High-Tech verbaut. Und die war vom Level her, vom Sicherheitslevel her, war die eigentlich die bestgesichertste Bank in Deutschland. Also gesichert bedeutet also auch organisatorisch von der Abwicklung, von den Abläufen in der Bank. Das war wirklich, man kann sagen höchstes Niveau. Und die Commerzbank war eigentlich, man kann sagen fünfzig Prozent von dem. Es gab in der Commerzbank / da hatten die nichts. Es gab keine geregelten Abläufe. Die Technik war wild zusammengestellt. Es gab eigentlich kein funktionierendes / und jeder geht ja nun mal davon aus - also wir sind davon ausgegangen - dass man nicht einen Schritt zurück machen will, dass man die Dresdner Bank und die ganze Struktur wegnimmt und die Struktur der CoBa drüber setzt.

I: Ja.

B: Das war unvorstellbar. Also, für uns war nur vorstellbar, dass man das Level dann anhebt. Weil das ist die Logik, anders geht es nicht.

I: Ja.

B: Ja. Das hat uns auch in den Glauben gelassen. Die Herren waren da, die haben also das akzeptiert. „Machen Sie sich mal überhaupt keinen / wir brauchen Sie. Ohne Sie geht das gar nicht." Aber dass man im Hintergrund eigentlich schon ein Unternehmen, die mittlerweile seit einem Jahr rausgeflogen sind. Die sind da ein Jahr lang rumspaziert. Das war, das war / Man hat eine Firma, man hat gesagt, die sind besser, die sind billiger und können alles. Nur wir wussten, die hatten gar nicht die Manpower 
da. Die haben zum Beispiel angeboten, nur ein kleines Beispiel. Bayreuth haben wir ja auch die Dresdner Bank betreut. Die haben gesagt, wir geben eine pauschale An- und Abfahrt für 50 Euro, egal welche Strecke. Habe ich gesagt, das geht nicht. Das ist höchstwahrscheinlicher Selbstmord, wenn jemand das macht. Aber um den Einstieg in den Vertrag zu bekommen, hat man das gemacht. Nur die Commerzbank hatte keine Fürsorgepflicht gehabt, sie haben das gar nicht kapiert, dass kein Unternehmen überleben kann, wenn sie Geld mitbringen. So, das neue Unternehmen, also die neuen Vertragspartner, die haben nach einem halben Jahr gesagt: „Es geht nicht, wir brauchen mehr Geld."

I: Und haben die es dann bekommen?

B: Nein. Die haben den Vertrag verloren, so ist es gekommen. Und der ist dann letztendlich bei einem ... (unverständlich) gelandet, der ... (unverständlich)

I: Wie sind Sie eigentlich ursprünglich in der Branche gelandet? Das ist ja eine sehr spezielle Branche. Was das Zufall, oder/

B: Nein, ich würde sagen, die Branche gab es einfach in dem Sinn noch nicht.

I: Okay.

B: (lacht) Ja, die Bank war etwas, ja, von den Abläufen her / es gab schon Strukturen. Aber es gab, also den Bankensektor gab es, aber das Drumherum, das ist erst durch die Verwaltungs-... (unverständlich) entstanden und durch die Sicherheit, das Sicherheitsdenken. Durch die vielen Überfälle ist das erst entstanden. Wir waren eigentlich immer dafür da, dass Sachwerte, Menschenleben und so weiter, dass das Ganze alles gegengesichert war. Wenn man sich so eine Struktur, einen Ablauf in einer Bankfiliale mal vorstellt. Da gibt es wirklich Sachen, die richtig geregelt sein müssen, die müssen wirklich im Ablauf definiert sein. Das haben wir eigentlich erst hergestellt. Also mit der Arbeit im Endeffekt.

I: Aber das ist bestimmt sehr spannend, oder? 
B: Das war sehr spannend. Ist auch heute noch spannend.

I: Glaub ich auch.

B: Das ist superspannend, weil man kann etwas, man kann etwas mitgestalten. Man ist jetzt nicht nur der Befehlsempfänger, sondern man ist also an uns herangetreten:

„Wir haben ein Problem." oder so. Oder wir haben gesagt: „Wir haben eine Problemlösung für euch.

I: Ja, schön. Und wie war das eigentlich für ihre Familie?

B: Schlimm.

I: Können Sie sich noch daran erinnern, wie Sie es ihnen erzählt haben?

B: Ich muss ja sagen, meine Frau hat ja immer mitgearbeitet. Sie war mit im Unternehmen.

I: Hat es also live miterlebt.

B: Live miterlebt, ja.

I: Das stell ich mir schon schlimm vor. Ja das stimmt. Auch wenn dann so die Privatinsolvenz so wie so ein Damoklesschwert über einem schwebt und so.

B: Also, wir haben ja auch / In dem Augenblick denkst du ja auch darüber nach, weil du sagst, das kannst du gar nicht stemmen. Weil plötzlich war / Das war wie ein großes Loch, wo du da standest. Jeder wollte etwas von dir. Du hast ja nichts. Deine Karte war gesperrt, deine Konten, alles war gesperrt. Ich hatte ja auch, sag ich mal, in der Zeit, in diesem einem Jahr, in diesem einem Jahr, da hab ich ja sehr viel Geld von mir selber noch in die Firma reingesteckt. Ich habe das alles gemacht, was man nicht machen sollte. Wenn man etwas / Man sagt ja immer, wenn du etwas hast, dann tue es 
weg und lass es liegen und nimm es nicht mehr. Weil du vernichtest es. Aber ich konnte es nicht, weil das ist das Lebenswerk. Wenn du ein Unternehmen aufgebaut hattest, kannst du ja nicht / das kannst du ja nicht machen.

I: Ja.

B: Dann bin ich / dann bist du ja / pfändest deine Lebensversicherung als Sicherheit. Irgendwann bringst du alles ein, und dann hast du nichts mehr.

I: Würden Sie das wieder so machen?

B: (lacht) Gute Frage. Aus heutiger Sicht sicherlich nicht mehr. Ich würde erst mal rational denken und würde sagen: „Ok." Aber das ist auch ein bisschen Alterssache. Ich denke, aus heutiger Sicht, weiß ich eigentlich, wenn ich jetzt aufhöre zu arbeiten, wie viele Mittel mir noch zur Verfügung stehen, um meinen Lebensabend zu gestalten. Und das ist nicht mehr so viel. Das heißt also, ich muss da gewaltige Abstriche machen in meinem Leben. In Moment kann ich es noch einigermaßen, weil ich dadurch, dass ich noch arbeite auch ein Gehalt habe, was sicherlich auf einem kleinen Niveau ist, aber es ist einfach da.

I: Und die Familie von Ihrem Sohn? Der hat sich wieder derappelt?

B: Ich würde sagen, auch immer noch nicht. Aber / Weil das ist ja bei ihm auch alles weg. Und ich denke, er wird noch ein, zwei Jahre brauchen, um, sag ich mal, wieder in die Fahrt zu kommen, dass man, ja, eine Krankenversicherung hat. Krankenversicherung spielt eine ganz große Rolle. Du kommst ja nicht mehr in die Gesetzliche hinein.

I: Ja stimmt. Ja, es sind viele Sachen.

B: Wahnsinn. 
I: Wo man überhaupt nicht merkt, also wo man erst merkt, wenn es soweit ist. Wo man nicht dran denkt vorher.

B: So ist es.

I: Viele Sachen. Ja.

B: Ich denke, ich bin kein Mensch, der jetzt irgendwelchen Luxusgütern oder dem Luxus hinterherläuft. Nur im Laufe der Zeit hat man, sag ich mal, ein Niveau erreicht, ein Niveau, wie man lebt, man kauft mal schnell das ein oder sagt: „Okay, jetzt mach ich mal ein Wochenende Urlaub oder so." Dass man sehr locker damit umgeht. Auch so was wie ein Belohnungsfaktor spielt natürlich auch eine große Rolle. Das geht natürlich jetzt gar nicht mehr.

I: Hätten Sie sich bei der Abwicklung der Insolvenz irgendetwas anders gewünscht? Wenn da irgendetwas anders organisiert gewesen wäre, oder irgendwas anders gelaufen wäre.

B: Ich muss sagen, ich habe das so zur Kenntnis genommen, und ich hatte in der Insolvenzverwalterin einen Menschen gefunden. Und ich habe auch immer das Gespräch gesucht. Ich habe mich jetzt also nicht so dem Schicksal ergeben, sondern ich habe das irgendwie hingekriegt, dass die Insolvenzverwalterin mit mir gesprochen hat. Weil, also wenn ich irgendwelche Probleme oder Sorgen oder Nöte hatte, dann konnte ich Sie anrufen. Und sie hat ja, sie hat ja auch sehr viel delegiert. Klar, die haben ja ihre Helfer, die so für die Abwicklung der Insolvenz da sind. Die machen ja nicht alles selber. Und auch dort waren dann Menschen. Oder ich hatte jedenfalls das Gefühl, dass da Menschen waren, die jetzt nicht nur dich zerschlagen wollen. Und vielleicht hatte ich das Glück, dass bei mir, sage ich mal, dass das Zusammenspiel gepasst hat.

I: Ja, das ist möglich, ja. 
B: Ja. Deswegen habe ich also diese Abwicklung der Insolvenz nicht als ganz schlimm erlebt. Weil das war auch ein gegenseitiges Vertrauen. Ich hab ja noch ein viertel Jahr das weitergeführt als Geschäftsführer. Und da hat man erkannt, das ist korrekt, was abläuft. Das war, sag ich mal, das hat mir gutgetan.

I: Ja. Als sie sich entschlossen hatten, die Firma weiter zu führen, was war das für ein Gefühl? Haben sie da Bedenken gehabt? Oder ängstlich? Oder eher zukunftsfreudig? Oder wie war das?

B: Nein / da war alles von. Da war alles.

I: (lacht)

B: Ähm, ich habe die Aufgaben angenommen ... (unverständlich). Ich war sechzig beziehungsweise einundsechzig, was ganz schön was ist, das merkt man dann erst. Aber es hat, hat mir nichts ausgemacht. Und am Anfang, es war nur so ein Gedanke, der dann aufgefallen ist, und dann habe ich gesagt: „Ok, den Namen kannst du übernehmen. Die Telefonnummer kannst du übernehmen." Das war super natürlich. Mich rufen heute Kunden noch an die, wie soll ich sagen, die vor 15 Jahren oder so schon Kunden waren. Ich erzähl das dann auch gar nicht groß von der Insolvenz.

I: Ja, klar. Ist ja auch nicht nötig.

B: Mein Name ist geblieben. Und ich, ähm, ja, ich versuche das auch gar nicht zu thematisieren. Mein ältester Mitarbeiter, den alle kennen, ja, der ist noch da. Die Telefonnummern sind geblieben.

I: Ja, das ist gut, das stimmt.

B: Es war eigentlich für den, sag ich mal, für den Kunden eigentlich gar nicht mehr relevant. Das Verrückte ist, das Verrückte ist, diese Bank, die mir so riesen Probleme bereitet hat, für die arbeite ich heute noch. 
I: (lacht) Ja, es ist personenabhängig.

B: Ja, die Bank hat das outgesourced an so Facility Management, und die beauftragen mich damit. Und ich denke auch mal, es ist so verrückt. Wir machen dieselbe Arbeit, wir kümmern uns drum, dass die Tresortechnik funktioniert, dass die Leute morgens ihre Filiale eröffnen können, weil irgendwelche Sicherheitstechnik / Und auf der anderen Seite hast du da einen Menschen sitzen (lacht) der immer noch mich nicht in Ruhe lässt! Also das ist, das ist /

I: Ist komisch.

B: Das ist sehr komisch. Also, ich glaube, das gibt es garantiert nicht oft. Diese Konstellation. Auf der einen Seite möchte der dich zerstören. Der möchte mich wirklich zerstören. Und auf der anderen Seite ist dieselbe Bank / dieselbe Bank sagt: „Wir brauchen dich, damit es für uns weitergeht."

I: (lacht) Vielleicht ist es dem gar nicht so bewusst?

B: Ich habe ihm / wir haben es ja versucht ihm klar zu machen. Es ist tatsächlich sinnlos. Ich habe dann schon versucht über / ich habe versucht irgendwo einen Weg zu finden in der Bank, dass man, dass man denen, denen man hilft, die einen auch haben wollen, dass der vielleicht mal eine Brücke schlägt über, über einen Weg der zu ihm gelangt, der sagt: „Mensch lass den doch. Das ist doch irgendwie / Der hilft uns doch." Es ist / ja aber /

I: Sagt er nicht.

B: Nein, die Einkäuferin mit der - weil wir liefern auch dort noch Tresortechnik - mit der ich wirklich lange Jahre / ich hab schon gesagt / mir haben zusammen / „Mensch, können Sie mir helfen?" Die kennt ja meine Leidensgeschichte. „Können Sie mir da helfen?" Hat sie gesagt, sie probiert es. Hat sich einen Termin geben lassen. Nichts. Das ist irgendwo bei dem einfach ganz schlimm. 
I: Komisch. Kann man nicht nachvollziehen.

B: Nein. Ja, das ist / Ja, wenn dieser Mensch sagt auch hilfsbereit: „Ok, wir können irgendwie sagen, ok, das war, wir haben es bewältigt. Wir haben es gelöst." Und für mich gibt es ein Leben, das weitergeht. Aber so steht das natürlich im Widerspruch. Was da abgeht, das ist / Gerichtsvollzieher und Mahnschreiben und Urteile und Widerspruch. Das hat mich ein Wahnsinnsgeld schon gekostet, nur um aus der Nummer rauszukommen. Also, nicht rauszukommen, aber es sieht so aus: die wollen 120.000 Euro. Und ich habe es einfach nicht.

I: Hm.

B: Ich habe es einfach nicht. Und der will anscheinend mich zwingen in die Privatinsolvenz.

I: Echt krass.

B: Ich habe ihm die Hälfte angeboten. Die Hälfte wäre darstellbar. Aber nicht, nein. Alles oder nichts.

I: Haben Sie ein Haus?

B: Nein, ich nicht. Meine Frau.

I: Weil sonst hätte ich jetzt gesagt, vielleicht spekuliert er darauf.

B: Ja, ja, ich denke das ist auch so sein Hintergrund. Weil er weiß von meinem Betreuer, der hat ihm also viele private Informationen gesagt. Ich habe den Betreuer eigentlich gebeten zur Verschwiegenheit und habe ihm auch sehr viel über ihn gesagt. Hab mit ihm viele Sachen besprochen, die er jetzt natürlich weitergegeben hat, denke ich.

I: Ja. Das kann schon sein, ja. 
B: Deswegen auch, wirklich, man muss die beiden unbedingt trennen. Du darfst die Geschäftsbank nicht auch zu deiner privaten Bank machen.

I: Ja. Vielleicht sollten Sie einfach eine Bank überfallen, Sie kennen doch alle Schwachstellen.

B: (lacht) Ja, ja.

I: Ich wäre da schon in Versuchung, glaube ich (lacht)

B: (lacht)

I: (lacht) wenn ich da so genau Bescheid wüsste. Ist doch toll.

B: Ja. Ja, wir haben schon viel gesehen da. Wir haben für die Berufsgenossenschaft mit Abläufe entwickelt, damit die Mitarbeiter geschützt sind. Ich habe / Ich war für die Sicherheit von manchen Bankvorständen zuständig und alles so was. Das ist so, du bist so mitten im Leben und weißt, du wirst gebraucht, und du hast so viel gemacht und, und, ähm, und das im Oktober das hat mich wirklich wahnsinnig gemacht, weil ich dort wissentlich hintergangen wurde zugunsten einfach eines anderen Unternehmens. Der Mitarbeiter, der da für diese Sache zuständig war, der ist in Altersteilzeit gegangen, der hat das umgesetzt. Ich weiß heute, dass die sehr eng bekannt waren. Also, da hat auch eine persönliche Beziehung bestanden von dem Unternehmen, das reinkommen sollte.

I: Ok.

B: Das wurde mir dann ja von Mitarbeitern wieder zugesteckt, die mich kannten. Du hast keine Chance. Du weißt, man ist hier schlimm mit dir umgegangen, aber du hast keine Möglichkeit irgendwas anzuführen oder zu sagen: „Ok." Ich kann nur für mich sagen, ich habe sicherlich Einiges zu verantworten letztendlich, ich hätte es merken 
müssen. Aber im Nachhinein weiß man natürlich Bescheid. In dem Augenblick glaubt man es nicht.

I: Ja, man will es auch wahrscheinlich gar nicht. Wahrscheinlich schiebt man das auch ein bisschen weg von sich.

B: Klar, das ist so. Ich könnte Ihnen noch alles Mögliche sagen. Viele schlafen nicht mehr. Nächte, wo man nicht schlafen kann, wo man abends schon mit, ähm / die vielen Sorgen / das weckt dich, wo man selbst um 2 oder um 3 Uhr in der Nacht wach wird, hast du sofort wieder im Kopf. Du stehst auf, rennst in der Wohnung rum, willst dich wieder hinlegen, versuchst, es deinen Partner, der vielleicht nervlich noch mehr, der noch empfindsamer ist, es nicht merken zu lassen. Versuchst Stärke zu zeigen, wo du sagst: „Wird schon, wir kriegen das schon."

I: Ja.

B: Wobei du dann selber weißt, du bist selber so richtig viel im Hamsterrad, und es gibt kein Ergebnis. Da sind schon viele Menschen betroffen, und ich denke, wenn heute einer, sag ich mal, nun wirklich nicht mehr weiterweiß, und dann über Suizid oder so denkt, dann verstehe ich das. Das kann man nur wirklich dann verstehen, wenn man selber mal in dieser, in dieser seelischen Ausnahmesituation gewesen ist. Es gibt sicherlich welche, die eine Insolvenz kalt lässt. Die Ihren Namen da gar nicht reinbringen. Oder da einfach so eine Sache gegen die Wand fahren aus wirtschaftlichen Gründen, aus Gewährleistungsgründen, oder weil es eben so ist, weil es eben so passt. Aber wenn man, so wie wir oder wie ich, das von Null aufgebaut hat und dann plötzlich so nach 30 Jahren, 35 Jahren alles vernichtet wird. Und du nicht unbedingt das Gefühl hast, dass du schuld bist. Das ist schon /

I: Das glaube ich, dass das schwer ist.

B: Das ist heavy. 
I: Wenn dann auch noch Familie so involviert ist, das ist ja dann gleich doppelt schwierig.

B: Ja. Und du im Alter bist. Wo du nicht mehr sagen kannst: "Ok, ich starte voll durch." Das, was ich im Moment mache, dass weiß ich, das ist nicht durchstarten, sondern das ist eine lebenserhaltene Maßnahme. Ich kann jetzt nicht mehr nochmal vollpower lospowern. Ich könnte, ich könnte vielleicht, aber ich habe die Kraft nicht mehr. Also, mit dem Wissen, mit dem Können und mit dem ganzen Hintergrund von unseren Kunden, mit dem Kundenkreis, könnte ich sofort wieder anfangen. Wenn ich jetzt sagen könnte, ich hol mir jetzt, sag ich mal, eine Vertriebsmannschaft, hol mir Applikateure / ich kann nicht, ich kann das gar nicht mehr finanzieren. Ich wäre, wenn ich heute zur Bank gehe und sage: „Hier ist mein Geschäftsmodell." Das könnte noch so super gut sein. (lacht) Du hast keine Chance. Die Kreditreform / Ich versuche seit drei Jahren bei einem Lieferanten wenigstens dahin zu kommen, dass man mir wenigstens im kleinen Rahmen Angebote macht. Aber so lange Kreditreform sagt, da war eine Insolvenz, solange kriegst du bei uns kein grünes Licht.

I: Wie lange dauert das noch? Bis das gelöscht wird?

B: Ja, sieben Jahre. Ich glaube 7 Jahre stehen noch aus. Ja, ich glaube, da gibt es mittlerweile ja ganz viele Clevere, die gehen dann / melden sich dann, was weiß ich, in England an oder in Frankreich, und da ist es glaub ich ein, zwei Jahre.

I: Ein Jahr ja, in England.

B: Aber die Schufa ist auch / die vergisst nichts. (lacht) Ich hatte, ich hatte einen Score Wert von 98,5. Mit der Insolvenzanmeldung bin ich abgestürzt auf 0,5. Also ich, ich probiere es erst gar nicht. (lacht) Obwohl ich nie irgendwelche Einträge hatte, meine Konten waren immer sehr sauber abgewickelt, pünktlich alles. Es gab keine Probleme bei mir. Nur ein einziger Eintrag, nur ein einziger Eintrag: Bürgschaft in Anspruch genommen. Das war alles. Also, ein jüngerer Mensch, der am Anfang seines Lebens steht oder seines Berufslebens steht, ist damit komplett vernichtet. Der kriegt keine Wohnung, kein Handy, nichts mehr. Da gibt's einfach nichts. Also, ich denke in 
der heutigen Vernetzung und dem heutigen Datenaustausch, der ist so perfekt geworden mittlerweile, dass du da keine Chance mehr hast. 
Appendix VII: Transcript of Interview 6

I: Um Sie ein bisschen besser kennenzulernen, wäre es mir am liebsten, wenn wir damit starten würden, dass Sie einfach mal Ihren Werdegang erzählen, von der Kindheit bis jetzt, beruflich und privat, alles was Ihnen whichtig erscheint.

B: Wie lang soll das dauern?

I: Bis wir fertig sind. (lacht)

B: Sehen Sie vielleicht wie alt ich bin? (lacht)

I: Sie werden bestimmt weise wählen. Aber ich weiß nicht wie alt Sie sind. Wie alt sind Sie denn?

B: 66, ja in vier Wochen werde ich 66. Ja, bin 66, am 30.05.48 geboren. Mein Vater war Lagerverwalter, Lagerarbeiter beziehungsweise kaufmännischer Angestellter. Meine Mutter hat mit Nähen uns zusätzlich noch ein bisschen über Wasser gehalten. Ich habe zwei Geschwister noch. Ja, ich war eigentlich Papas Liebchen (lacht).

I: Waren sie der Jüngste?

B: Nein, Sandwhich. Aber ich war eigentlich / Das ist ja das Problem, Sie sehen, ich bin '48 geboren, es ist / mein Bruder ist ` 44 geboren. Und das ist genau das. ' 44 ist der geboren. Mein Vater war damals im Krieg, und als er nach Hause kam, war mein Bruder bereits drei Jahre. Dann hat er zu seinem Papa ,Onkel‘ gesagt. Dann kann man sich so vorstellen, wie danndas Verhältnis zwischen Papa und Sohn ist. Und dann kam ich. Ich war halt dann der Sohn.

I: Hm, da fehlt dann einfach die Zeit.

B: Ja. Und das ist ein Problem. Dadurch war ich halt gegenüber meinem Vater in einer sehr, in einer positiven Geschichte, mein Bruder eigentlich mehr in einer 
negativen Geschichte. Und von der Mutter her ist es genau umgekehrt. Ja, da war ja / Die Mutter war ja da die ersten drei Jahre. Und mein Bruder war dann halt nach wie vor der Sohn. Und nachdem ich dann ja mehr auf der Vaterseite war, das war halt ziemlich schwierig.

Ja, das Lernen ist mir eigentlich relativ leicht immer gefallen. Hm, ich musste schon ein bisschen was machen. Das Einzige, wo ich riesen Probleme hatte, oder wo ich immer auch heute noch Probleme habe, ist eigentlich in der deutschen Sprache oder beziehungsweise im Deutschen. Bei meinen Aufsätzen waren die Überschrift länger als der Aufsatz (lacht). Also, weil ich das einfach nie auch gelernt hatte. Also, ich hatte da eine Antipathie warum auch immer. Vielleicht war es die erste Zeit der Schule, wo die Lehrer mir das nicht irgendwo nahebringen konnten oder so. Ich meine, obwohl ich heute ja meine Geschäftsbriefe oder sowas schreibe. Also, das ist kein Thema mehr. Aber früher war es halt einfach ein riesen Problem. Mathe hatte ich eins, Deutsch die 5 so ungefähr. Nicht ganz immer aber so diese Spannungsbreite, wenn man das mal anschaut. Ja, ich habe halt dann die Hauptschule fertiggemacht. War jetzt kein so ein / „Ja, die Schule schafft er sowieso nie." / „Viel zu deppert dazu" / und solche, solche Aussagen kamen dann halt von den Lehrern. (lacht)

Ja, ok. Ist aber / Ich meine, das sind die Einschätzungen. Und, ja, ich habe dann meine Lehre dann eben fertiggemacht als Maschinenbauer und dann anschließend mein Studium an der Fachhochschule in $<<<$ Ort anonymisiert $>>>$ gemacht. Danach bin ich nach $<<<$ Ort anonymisiert $>>>$, da habe ich erst mal ein halbes Jahr gearbeitet, bis ich dann an die technische Uni gegangen bin, um dort dann den Diplom-Ingenieur zu absolvieren. Wollte eigentlich anschließen noch einen Doktor machen, war aber dann schon zwischen 28. Und habe dann den Doktor sausen lassen, weil da genauso wie bei Ihnen ein Lehrstuhlwechsel war. Der alte Professor wurde emeritiert, der Neue war noch nicht ganz so etabliert. Es war dann dumm. Ich habe zwar mit dem dann mal gesprochen, ob er eventuell eine Doktorarbeit hätte für mich oder so irgendwas. Das war alles noch so ein bisschen in der Schwebe. Und dann habe ich gesagt: „Ok, gehe ich dann jetzt in die Industrie." War dann zwei Jahre, von / das war, ich glaub '78 bis '80 war ich bei $<<<$ Unternehmen anonymisiert $>>>$. Sollte dort die technische Leitung für das Konstruktionsbüro übernehmen.

Ja, ich war mit den Leuten zu Laissez-faire oder vielleicht dann wieder auch zu autoritär. Das war sehr interessant. Ich habe einen sehr lockeren Führungsstil gehabt, 
oder habe ich nach wie vor. Und habe aber dann so mit den Leuten vereinbart, wenn es also wirklich drauf ankommt, brauch ich da nicht groß was sagen, es muss laufen. Also, wenn wir eine Sitzung hatten, musste ich dann im Endeffekt nur mit der Hand winken, da wussten sie, was sie zu machen hatten. Und manchmal wurde da auch mal der Ton so mal ganz kurz: „Jetzt mach mal schnell" oder so, weil es einfach gezwickt hat. Und das hat denen dann auch wieder nicht gepasst. Wobei das alles vorher ja schon durch diesen lockeren Führungsstil eigentlich alles abgeklärt ist. Aber das hat ihnen nicht gepasst, ja.

Dann habe ich halt nie eine Krawatte getragen. Die Zeit, das war halt auch die Zeit / die damalige Zeit, so die '68er, wo man halt das Ganze so ein bisschen / Irgendwann habe ich halt dann gesagt: „Ok, ich vertrete euch gern, wenn jemand kommt, ich habe eine Krawatte in der Schublade liegen, dann ziehe ich die an, aber so" / Ich mag keine Krawatte. Für mich ist das nicht denkbar. Ja, dann ging das so ein bisschen hin und her, und dann habe ich gesagt: „Ok, ich wollte ja sowieso gehen." So ungefähr, dann haben sie mich von einem Tag auf den anderen dann entlassen, und ich hab mich dann selbstständig gemacht. 1980 war das. Und dann habe ich gedacht: „Ich, der $<<<$ Name anonymisiert $>>>$, ha, ich brauch bloß irgendwo hinzugehen, da kriege ich eine Arbeit.“ (lacht) Ja, dann habe ich mir die Hacken abgelaufen, damit ich Arbeit krieg. Und dann war ich am letzten / weil ich da zu lange überlegt / den Auftrag, wenn du jetzt nicht kriegst, dann fängst du wieder irgendwo in der Industrie an zu arbeiten, also das heißt also als Angestellter. Ja, dann habe ich den Auftraggeber besucht, den letzten, und hab dann angefangen. Und dann war / das war dann im Herbst '80. Und '81 habe ich dann einen Kompagnon dazu gekriegt, also sind wir zu zweit gewesen. Und dann ging es halt langsam so ein bisschen erst in $\langle<<$ Ort anonymisiert $>>>$, dann waren wir in $<<<$ Ort anonymisiert $>>>$, dann hatten wir teure Angestellte. Bis zu fünf Angestellte, hatten wir eine Zeit lang.

I: Was genau war das für ein Unternehmen?

B: Das war ein Konstruktionsbüro für Maschinenbau und Berechnung. Und wir haben dann dort dann damals '81 schon angefangen oder beziehungsweise versucht, mit CAD zu arbeiten. War ein heiden Geld. Ich habe damals auch viel Geld in den Sand gesetzt. Allein ein Terminal hat schon 120.000 D-Mark damals gekostet, also es war 
unheimlich. Das war eigentlich für uns als kleine Firma für die Katz'. Große hätten das schon eher machen können, aber damals war das schon / Und dann haben wir halt ein bisschen so gezeichnet und haben eigentlich über Hilti Baumaschinen über, über / wir haben eigentlich alles quer durch den Raum konstruiert, was man so kriegen kann. Hat natürlich auch den Nachteil gehabt, dass wir halt sehr vielseitig waren, was für uns sehr interessant war. Also für mich war es wahnsinnig interessant, sehr vielseitig. Aber halt durch die Vielseitigkeit hast du halt nie Beständigkeit erreicht, sondern musstest immer wieder neue Sachen machen und hast halt nicht in der Kürze der Zeit viel Geld verdient, ja? Sondern du hast halt immer wieder / dann habe ich ja / dann war das ja so, dass ich '81 wann habe ich denn geheiratet? '71 habe ich geheiratet, bevor ich noch an die Uni gegangen bin, an die TU. Und die damalige Frau war auch Pädagogikstudentin damals noch, haben also beide studiert. Und, ja und dann, als ich mich selbstständig gemacht habe, habe ich da gleichzeitig ein Haus gekauft und haben noch ein Kind bekommen. Also, das war ein bisschen viel. Volles Programm, wobei ich also ihr gesagt habe immer, es war sehr interessant für mich immer zu hören, wenn ich in die Schule gekommen bin: „Ja, jetzt fängt der Ernst des Lebens an.“ Ich habe auf den Ernst des Lebens gewartet. Dann habe ich die Lehrzeit gemacht: „Jetzt fängt der Ernst des Lebens an, du wirst sehen!" Ich habe auf den Ernst des Lebens / Was wollen die eigentlich? / Was reden die vom Ernst des Lebens? So ein Schmarrn. Hab immer nur Spaß gemacht. Dann war ja die Uni: „Ja, wirst schon sehen, jetzt geht‘s los!" / ... (unverständlich) / Als ich dann selbstständig war, ein Haus hatte, ein Kind hatte, eine Frau hatte, und das Geld jeden Monat für die Zinsen und das Essen da sein musste, da war für mich dann der Ernst des Lebens da. (lacht)

Das war dann ziemlich hart, ja. War schon sehr / Ja, dann kamen dann natürlich immer wieder so Krisen dazwischen, so Wirtschaftskrisen, die dann einem das Leben schwer gemacht haben während der Arbeit. Es ging ja nun viel mit Arbeit / es war schon sehr / sagen wir, es plagt natürlich viel. Gut, die Angestellten mussten bezahlt werden, das Zeug musste da also / das war schon sehr haarig. Es ging oftmals so, dass ich also um fünf Uhr nach Hause fuhr zum Abendessen, Kind ins Bett, damit ich wenigstens den Kleinen ein bisschen gesehen habe, und um zehn Uhr am Abend ging es dann wieder zur Arbeit bis abends um eins und dann um eins dann wieder nach Hause. Also, so ungefähr war so ein Arbeitstag. Ja, dann ging das weiter. Dann war '91 dieses kleine Haus, das dann umgebaut. Haben aus diesen $90 \mathrm{~m}^{2}$-Haus ein $250 \mathrm{~m}^{2}$-Haus gemacht. 
Viel in Eigenregie gemacht, viel selbst gebaut. Gleichzeitig die Firma noch gemacht mit. Also, es war sehr, sehr anstrengend. Dann ging / jetzt sind wir '91, das Haus war fertig, dann kam die nächste Wirtschaftskrise. Oh ja, wunderbar, dann war es ziemlich haarig mit den ganzen Sachen. Dann hat der Kompagnon eine Stelle in der Industrie, also bei einer Firma gefunden. Da hat er sich dann abgesetzt. Dann haben wir die Sachen, auch die Schulden ein bisschen geteilt. Und ich habe dann die Firma alleine weitergemacht. Habe dann auch noch drei, vier Angestellte noch gehabt zum Teil. Ging dann, Gott sei Dank, nachdem das Große überwunden war, ging es dann wieder aufwärts. Ich mein, ich weiß, es geht immer irgendwann aufwärts, man muss die Zeit halt überbrücken können. Das ist das große Problem immer an der ganzen Geschichte. Und es war auch so, es ging danach auch wieder gut aufwärts.

Dann war bei mir ein ziemlich starker Knick, die Scheidung zwischen meiner früheren Frau und mir. Und ich wurde dann auch krank. Ich hatte dann Prostatakrebs. Und als ich da aus dem Krankenhaus rauskam, das Jahr danach habe ich den meisten Umsatz gemacht.

I: Wann war das ungefähr?

B: Das war '96. Dann war auch für mich so ein bisschen klar, ich mach noch ein bisschen was Neues. Ein bisschen was anderes. Und ich hatte dann über die Zeit jemanden kennengelernt von der Uni her noch / zykloide Getriebe bauen. Und dasmwar so ein bisschen der Gedanke von mir: „Du baust dann irgendwann solche zykloiden Getriebe."War noch nicht ganz klar wie, aber ich habe dann jemanden getroffen, das war ein Kaufmann, und dann haben wir uns so zusammen unterhalten: „Was würdest du da sagen, Investitionssumme 120, 130.000 Mark damals noch, dann könnten wir es schaffen.“ Ja, ich war langsam begeistert, wir haben uns beide begeistert. Haben dann versucht die Summe irgendwo aufzutreiben und hatten unsere Finanzberater. Und haben dann gemerkt, dass ist deppert. Also mit 100.000 brauchst du gar nicht anfangen. Dann haben die gemeint: „Ja, kaufen Sie doch eine Firma. Das können wir finanzieren." und, und, und. So ist das dann irgendwann entstanden, dass man sagt: „Ja, können wir, wäre doch toll".

Dann habe ich die Firma $<<<$ Unternehmen anonymisiert $>>>$ hieß die damals, angeschaut und war fast schon verliebt. Das war gefährlich, wenn ich im Nachhinein 
sage: „Ich war in die Firma verliebt.“ Und wollte dann die Firma kaufen, und der Kaufmann war mit dabei, und alles so angemacht. Und als wir zusammen dann so richtig anfangen haben, das anzukurbeln, ist er dann mit einem Herzinfarkt im Bett gelegen, ausgefallen. Dann habe ich das versucht, alleine zu machen. Dann hat der gesagt: „Spinnst Du? So wie du das gemacht hast / anders verhandeln!" oder so irgendwas. Dann hat er sich im Endeffekt zurückgezogen. Also, ich hätte ihn so mehr oder weniger hintergangen oder so. Die Bank wollte von ihm Unterlagen haben, dass er da mit dazu einsteigt. Er unterschreibt da nichts und so weiter. Es war ziemlich haarig, und er hat sich dann sehr / Ich habe ihn dann auch nie wiedergesehen. Ich weiß nicht. Dann plötzlich war er weg. Ja, ich habe mich dann alleine auf die Suche gemacht nach einer Finanzierung gemacht und habe dann die $<<<$ Unternehmen anonymisiert $>>>$ Bank gefunden, die hab das Ganze finanzierte, und ich muss sagen im Nachhinein einfach zu teuer.

B2: Nicht die Finanzierung, sondern die Firma gekauft.

B: Die Kaufsumme.

I: Ach so, ich dachte, die Konditionen.

B: Die Konditionen waren auch nicht so besonders gut. Es war also / Aber sie haben das damals gemacht, die Finanzierung, und ich habe es halt überteuert gekauft. Dann habe ich / ja das kann ich im Nachhinein erzählen / zurück in der Zeit wo ich, wo ich drin war, habe ich das nicht so empfunden. Kann man halt nur im Nachhinein erst sagen, dass es einfach zu teuer war. Zumal dann / das ist wieder super toll gelaufen / kaum hatte ich die Firma, ging die von ... (unverständlich) wieder mal so ein bisschen in den Keller. Das war 2000, Mai 2000 / hey 01. Mai 2000, das ist 14 Jahre her, ja 01. Mai 2000. Ja und dann ging es damals schon gleichzeitig wieder ein bisschen so leicht bergab, das heißt also, ich musste mich wieder mühen, dass ich die ganzen Kosten und Zeug wieder im Griff halten konnte. Ich habe zwar damals es schon gemacht, als ich die Firma gekauft habe, dass man Gütertrennung hatte. Also, damals war ich noch verheiratet. Also, ich war noch verheiratet, aber wir bereits schon getrennt gelebt. Aber gleichzeitig haben wir da schon mit der Gütertrennung einen Schnitt gemacht, 
damit wenigstens ein bisschen was erhalten bleibt, wenn mal was ist. Wobei ich für mich / also mir, mir passiert sowas nie / was soll mir passieren? Nie und nimmer! Also, so ein Schmarrn, also, das kann ja mir nicht passieren. Mir, $<<<$ Name anonymisiert $\gg>>$ gleich gar nicht, nie! (lacht) Andern ja, aber ich, ich mach das schon, geht schon.

Ja, dann hatte ich noch den zweiten Fehler, den ich damals noch gemacht habe, dass das eine OHG war. Und ich wollte die Geschäfts- / als OHG nicht.

B2: Die Rechtsform.

B: Ja, die Rechtsform nicht ändern. Da habe ich meinen Sohn, der mit damals 18 war, einfach mit 1 Prozent so mit reingenommen. Naiv. Ja, Ingenieur ist naiv. Das ist natürlich so, dass der, obwohl er nur 1 Prozent hat, in der OHG auch voll mithaftet. War mir zu dem damaligen Zeitpunkt nicht klar. Ja. Dann ging es mir relativ gut, so bis 2006 ungefähr, dann fing der Haupt- /

B2: Der Hauptauftraggeber.

B: Ja der Hauptauftraggeber, der Kunde fing an zu kriseln. Kam immer weniger.

I: Wie war da ungefähr so das Verhältnis? Also wieviel Prozent hat der bei Ihnen ausgemacht?

B: (lacht) 95\%. Ja das Problem ist folgendes halt gewesen. Ja. Ich mein, ich kann jetzt im Nachhinein kann man das sehr gut / es war auch in der Zeit, wo ich da, denn es war immer die Entscheidung gestanden, wenn ich meine Bilanz gemacht habe, dann habe ich meine Miete angeschaut. Die Miete belief sich alleine auf etwa 75.000 Euro im Jahr. Also, das schmeiß ich einfach zum Fenster raus. Das wäre eigentlich besser, wenn ich jetzt auf der grünen Wiese mir irgendwas bauen würde oder hinstellen würde, und gleichzeitig könnte ich erweitern. Denn wo ich jetzt in der Miete war, war ich zu bis unter den Stehkragen, das heißt also, ich konnte nicht erweitern. Es war einfach, ja / und gleichzeitig ging es aber nicht / Ich habe mit der Bank gesprochen: „Schaut's her, dieses Geld ist zum Fenster raus, wie schaut's denn aus, mit 
Finanzierung oder so?" „Ja, 100 Prozent Eigenkapital.“ Sag ich: „Entschuldigung?" „Ja, finanzieren wir nicht." Sag ich: „Ihr habt's doch mehr davon, wenn ich jetzt mal Pleite gehen würde, dann habt ihr zumindest das Gelände oder beziehungsweise die ganzen Sachen doch da!"

I: Ist ja auch eine Sicherheit doch eigentlich, oder?

B: Ist eigentlich die Sicherheit, ja, noch zusätzlich. Haben die nicht finanziert. Ja gut, musste ich also drinbleiben, und das heißt, ich konnte / ich war mit dem Kunden zu. Das heißt ich / entweder wenn ich einen reingeholt habe, musste ich die anderen irgendwie schieben und gleichzeitig konnte ich nicht, ja / also es war eine ganz blöde Abhängigkeit, die du einfach nicht die irgendwo wegkriegen konntest.

B2: Es gab auch eine Kapazitätsgrenze.

B: Ja, es war die Kapazitätsgrenze, es Ende, wir waren teilweise auch zehn Leute. Also zehn Angestellte, die ich da hatte. Die musste ich also ständig irgendwo und ich konnte / und wir haben uns auch zeitweise in der Firma auf den Füßen rumgestanden, nicht weil wir nichts zu tun hatten, sondern weil es zu eng war. Aber ich konnte gleichzeitig nicht raus, weil der Umzug oder das ganze Zeug, wären Summen gewesen, die ich einfach momentan nicht stemmen konnte. Ja, dann war das also '86, und da habe ich mir das erste Mal so Gedanken gemacht drüber.

B2: '86?

B: Äh, Entschuldigung, 2006. Dass, wenn jetzt was passieren sollte, mein Sohn mit drinhängt. Und der war gerade so am Ende des Studiums in diesem Jahr, und ich wollte ihn rausbringen. Das hat mich damals wahnsinnig, wahnsinnig bedrückt. Das war für mich, das war für mich eigentlich die schlimmste Zeit. Die schlimmste Zeit, war die Zeit, wo der Sohn eigentlich in der ganzen Schose mit drin gehängt wäre. Und gleichzeitig die Firma, die alles so, alles versucht hat abzubauen. Ich habe zwar versucht von der anderen Seite aufzubauen. Hat nur bedingt geklappt. Ich habe jemanden also, so einen Rentner wie ich jetzt bin, angestellt und zwei Mal die Woche 
kommen lassen. Der hat Telefon-Akquise gemacht. Kaum was kam raus. Also nichts, nichts irgendwo. Es kam schon der ein oder andere, aber es ist noch nicht das Polster. Naja, ich hatte dann 2006 war das / zwischen 2006 und 2008 habe ich das langsam wieder geschafft, den Kunden der da abgesprungen ist, wieder aufzufangen War schon wieder bei meinem alten Umsatz-Soll, oder ein Umsatz der wieder ganz gut gelaufen ist, aber mit einem Arbeitsaufwand zwischen 12 und 14 Stunden, 16 Stunden am Tag. Also, schon damals sehr boah. Wobei ich / irgendwas mit Stress / man steht irgendwo / irgendwo habe ich auch den Stress gebraucht. Ein bisschen Stress tat gut. Ein bisschen ist gutgesagt, es war aber schon ziemlich, ziemlich hart. Bis ich dann irgendwann, wann was das? Ich glaube, das war dann schon später, ich glaube 2009, nein das war noch vorher, 2008. Wo ich da bei dem $<<<$ Unternehmen anonymisiert $>>>$ drüben war, wo du heute Morgen gefahren bist. Die Firma hat mich so gestresst, das war wirklich extrem. Da habe ich dann Bluthochdruck gekriegt, und das war wirklich böse.

B2: Durch die, durch die EU-weite Vergabe von Aufträgen, das ist ja so, dass man von der Umgebung irgendwas bekommt, sondern das ist / war mehr oder weniger Lohnvergabe, also man muss sich um jeden Auftrag bemühen.

B: Aber die haben mich dann richtig fertiggemacht. Also das / Preise gestellt, Termine gestellt, ich habe angeboten. Ich habe für zum Beispiel 50 Teile angeboten, dann haben sie zwei bestellt und wollten den gleichen Preis haben. Also, solche Sachen und so. Ich habe dann auch Sachen gemacht und geliefert. Als bei einer Lieferung / habe ich die anderen / ich habe mir die Haxen ausgerissen, damit die ganzen Leute drin arbeiten sehen, stehen rum, drehen Däumchen, lesen Zeitung, und ich reiß mir die Haxen aus. Soweit bin ich ja schon. ... (unverständlich) Dann bin ich gegangen, von der Firma gegangen, und dann wollte ich gehen.

Dann hatte ich Nasenbluten gekriegt. Denke ich: „Hoppla, was ist das?“ Kenn ich nicht, Nasenbluten gekriegt, und denke ich „Hoppla, was ist das? Das kenne ich nicht, Nasenbluten. “Naja, ok. Ein bisschen unter das kalte Wasser gehalten, dann war es in Ordnung. Und dann zwei Tage später gehe ich abends ins Bett, will meine Schuhe ausziehen, Zack läuft die Nase wieder. Lege ich mich hin, geht schon wieder. Morgens stehe ich auf, zosch, läuft die Nase. Booh, bin ich in Panik geraten. Bin erst mal zum 
Krankenhaus, Notaufnahme, haben die mir also das da zugestöpselt und zugemacht, gleichzeitig misst er den Blutdruck, 220. Boah. Bin ich dann zum Herzspezialisten und so. Ja, dann ging es halt dann so los, dann habe ich neben meinem Bluthochdruck, habe ich dann den Anfang einer BZL, das heißt also Blutkrebs. Scheiße. Da habe ich den Stress nicht ertragen, das war dann der Stress, dass mein Sohn, wenn ich in eine Insolvenz laufen würde, mit betroffen wäre. Dieser Stress, der hat mich also fertiggemacht, definitiv. Dann wie gesagt, dann 2008 habe ich mit dem Haus, da wo ich noch eine Wohnung hatte, habe ich mit der Maßgabe an meine Exfrau verkauft, dass die Bank an meinen Sohn keine Ansprüche mehr stellt. Und dann war ich frei. Dann war ich frei. Da denke ich: „Ha, super! Jetzt kann mir nichts mehr passieren. Jetzt ist es mir wurscht. Wenn es jetzt den Bach runtergeht, ha! Was soll's." (Seufzt) Aber das war eine ziemlich harte Zeit. Das war dann 2008, ja. Ende 2008 hatte ich die Auftragsbücher noch gut, super, Umsatz war toll. Alle Leute haben schon gejammert. Ich habe noch volle Auftragsbücher gehabt, und im März von einen Monat auf den anderen 50\% Auftragseinbruch, 2009 im März. Januar war gut, Februar war gut, März zack! Aber wirklich 50\% auf einen Schlag. Da denke ich: „Wie kann das sein?" Man hat damals natürlich schon gehört, die Konjunktur und so, die ganze Wirtschaft bricht zusammen. Denke ich: "Mir? Ne, bei mir läuft‘s gut!" Und im März ging es dann dahin.

In weiser Voraussicht bin ich sofort, als ich das gemerkt habe, was da los ist, bin ich sofort zur Bank. Da habe ich mit denen gesprochen, habe gesagt, also, um das Jahr zu überstehen, brauche ich ungefähr 100 - 150.000 Euro. Ja, können wir nicht machen, und so. Also, sie geben mir das Geld nicht. Da war dann die erste Überlegung, oder bzw. das erste Nachdenken, was passiert mit einer Insolvenz. Wie das ist. Was muss ich dann tun? Habe dann damals mit der Sekretärin schon geschaut, was, also alles internetmäßig, was Insolvenz bedeutet. Habe dann geguckt und versucht, mal so Beratungen zu machen, aber das sind ja Gauner. Also, das ist ja furchtbar. Was Sie da erleben. „Ja, können wir schon machen, Insolvenz, aber das kostet dann noch so 10 15.000 Euro." So, und hin und her. Und schwarz und irgendwo. Ah, wunderbar. Da sage ich: „Entschuldigung, wenn ich insolvent bin, bin ich pleite! Wo soll ich das Geld herkriegen?"

I: Und waren das dann so Unternehmensberatungen, die darauf spezialisiert waren? 
B: Ja, ja, so was. So was Ähnliches, ja.

B2: War das nicht auch bei der IHK?

B: Ja, einmal war es auch bei der IHK, wo ich nachgehakt habe. Aber es waren auch immer so irgendwelche Rechtsanwälte so. Also, ganz dubiose Geschichten. ich hatte mir dann auch kurz überlegt, den Firmensitz, bzw. den Wohnsitz ins Ausland zu verlegen, weil Insolvenz ist zum Beispiel im Ausland ein halbes Jahr. Dann ist die Sache erledigt. Hier dauert es ja mit der Insolvenz bis zu fünf bzw. sechs Jahre, bis du wieder aus der ganzen Scheiße draußen bist. Ja, und das wollten die auch alle. Das ging ja auch nur alles über Anwälte oder sonst irgendwas, wie auch immer. Das hätte alles mindestens 30.000 Euro gekostet. Die habe ich ja nicht gehabt. Wenn ich wem was gesteckt, dann hätte ich es in die Firma gesteckt und nicht irgend so einem blöden Winkeladvokaten.

Ja, auf jeden Fall habe ich gesagt, aufgeben tust du nicht so schnell. Das haben wir alles schon mal geklärt gehabt, Insolvenz haben wir schon mal geschafft gehabt, aber ich habe gesagt: „Das muss anders gehen.“ Habe ich gesagt: „Ok, machen wir Folgendes: Wir gehen 50\% Kurzarbeit." Aber Kurzarbeit ist auch nur so, dass man die Sozialabgaben selber tragen muss. Das ist nicht 50\% weniger beim Gehalt, sondern es ist ja nur 50\%, aber die Sozialabgaben zahl ich dann wieder voll. Das heißt also, (schnaubt) im Endeffekt bringt nichts. Also rein theoretisch, ja, bringt was, ok. Aber gut. Aber, das ging ja dann so, das hat sich dann geändert gehabt, dass diese Sozialabgaben dann auch das Arbeitsamt übernimmt, wenn, glaube ich, drei Monate oder so gelaufen sind. Dann hat damals / ob sich das jetzt inzwischen schon wieder geändert hat weiß ich nicht, aber damals war es so, dass sich das nach drei Monaten, dass die Sozialabgaben dann auch das Arbeitsamt übernommen hat. Das heißt, dass man dann wirklich nur 50\% Lohnkosten hat. Gleichzeitig habe ich die Leasinggebühren versucht zu drücken. Ich habe denen Arbeitspläne aufgestellt und Zeug gestellt und denen gesagt: „Ok, Leasing, das schaut schlecht aus momentan, wahrscheinlich auch für das nächste halbe Jahr." Oder für ein dreiviertel Jahr habe ich die ganzen Pläne gemacht und habe dann halt das Ende der Leasingrate nach hinten rausgeschoben oder so irgendetwas. Und versucht, über die Mietkosten noch runter zu 
kommen. Die haben sich dann am Anfang auch quer gestellt. Haben aber auch gesagt, sie wollen das Geld aber trotzdem haben später. Habe ich gesagt: „Ok, mir ist es erst mal egal, ich muss jetzt schauen." (Pause)

Dann hatte ich endlich alles zusammen. Und mit diesem Konzept bin ich zur Bank gegangen und habe gesagt: „Können Sie da mitmachen?" Da sagen die: „Ja." Da hatte ich das endlich alles so weit, habe die ganzen Konzepte und das Ganze alles irgendwie soweit aufgestellt, habe alles durchgerechnet, Finanzpläne gemacht und und und. Und dann hat die Leasinggebühr gesagt: „So, jetzt brauche ich endlich hier die Unterschrift von der Bank, dass die das jetzt mittragen auch." Also, im März war ich das erste Mal bei der Bank. Und dann bin ich im September zur Bank und habe gesagt: „Ich habe alles soweit drücken können. Die Leasinggebühren und das ist so weit unten. So, wie schaut es jetzt mit euch aus? Macht ihr weiter mit?" Und dann sagten die von einem Tag auf den anderen: „Nein.“" Dann habe ich gesagt: „Ok, wenn ihr das macht, dann bin ich morgen beim Insolvenzgericht.“" Bum. Ja, und jetzt? So ungefähr. (Seufzt) Und dann war ich halt dagestanden. Dann bin ich nach Hause, habe meine Insolvenzpläne, die ich mir ja schon mal alle so mal ein bisschen habe durch den Kopf gehen lassen, aus dem Internet die Formulare, Unterlagen runtergezogen. Habe dann meine ganzen Sachen zusammengeschrieben. Ich wusste ja, welche Schulden, oder was ich also nicht / oder bzw. die ganzen Finanzen hatte ich alles da. War kein Thema. Habe alles zusammengeschrieben. Habe es in ein Briefkuvert und bin an einem Freitag zum Insolvenzgericht marschiert. (Pause) Da bin ich durch die Hallen da durchgelaufen. Keiner wollte sich da dem Insolvenzantrag annehmen. (lacht) Da dachte ich: "Spinn ich?" (lacht) Bin ich da rein und da. Der hat mich dahin geschickt, der hat mich dahin geschickt und dahin geschickt. Ich hatte immer meinen Brief, bin da durchgelaufen. „Gehen Sie zum Posteingang." Bin ich. Musste ich doch tatsächlich zum Posteingang runter, und da haben die den Poststempel draufgehaut. (haut auf den Tisch) Dann haben sie es intern weitergeleitet. Das ist Wahnsinn. Das war, also / (schnaubt) Da ist mir schon das Herz in die Hose gerutscht.

I: Was war das dann für eine Insolvenz? Wenn Sie eine OHG hatten, dann sind Sie ja privat mit drin, oder? 
B: Ja, das war eine Geschäftsinsolvenz inklusive Privatinsolvenz. Wobei es halt so war, dass ich schon wie eine GmbH war.

B2: Ne, ne, ne. Eingetragener Kaufmann. e.K.

B: e.K. war ich dann, ja. Weil ich den Christoph, meinen Sohn, ja vorher aus der Firma rausschmeißen konnte.

I: Ja, das hatten Sie geändert.

B: Ja, das war dann schon etwas einfacher. Aber die meisten Leute glauben, egal ob sie eine $\mathrm{GmbH}$ sind oder sonst irgendetwas, sie haften nicht. Entschuldigung, das ist egal. Was bei einer $\mathrm{GmbH}$ den Unterschied ausmacht: Entweder hat die $\mathrm{GmbH}$ wahnsinnig viel Geld in der Rücklage, dann kriegen Sie ja auch das Geld von der Bank. Oder sie ist groß genug, dann kriegen sie das Geld von der Bank, kein Problem. Wenn Sie aber klein sind, und Sie wollen eine Maschine anschaffen und wollen die Maschine finanzieren, dann kriegt die GmbH keinen Cent. Dann müssen Sie als Gesellschafter, als GmbH-Gesellschafter, haften. Ist doch scheißegal, ob ich dann ein e.K. oder ein BGB oder sonst was bin. Gegenüber außen haftend, da ist dann / Also, wenn ich jetzt Mist für eine Firma gemacht hätte oder sonst irgendwas, da haftet die Einlage der GmbH. Aber, ich weiß nicht, in wieweit die Gerichte da nicht auch auf den Gesellschafter durchgreifen.

Ja, da bist du immer dabei. Also, habe ich da diese ganze Geschichte gemacht, und dann habe ich eine Woche nichts gehört vom Insolvenzgericht. Meine Mitarbeiter haben gefragt: „Ja, was ist denn jetzt los? Wenn wir am Arbeitsamt anfragen wollen oder so irgendwas, dann brauchen wir eine sogenannte Bearbeitungsnummer eine interne vom Gericht." Hab keine gekriegt, hab keine gehabt. Das Gericht hat sich nicht gerührt. Dann ungefähr eine gute Woche später rufe ich beim Insolvenzgericht an. Ich sage: „Ich habe doch den Antrag da abgegeben. Ich brauche eine Bearbeitungsnummer, damit meine Leute ans Arbeitsamt gehen können."“" Dann habe ich kaum den Telefonhörer aufgelegt, da ruft plötzlich ein Richter an und sagt: "Ja, die Nummer ist so und so. Die haben Sie jetzt, glaube ich, gekriegt. Aber heute Nachmittag schicke ich ihnen einen vorläufigen Insolvenzverwalter hin." Also, das 
war innerhalb von vier Stunden. Da war der Insolvenzverwalter da. Also, der $<<<$ Name anonymisiert $>>>$.

Ja, und dann kam das Ganze dann so richtig ins Rollen. Das Schlimmste an der ganzen Sache ist, dass Sie in der Zeit mehr oder weniger entmündigt sind. Sie sind ein Mensch zweiter Klasse. Das ist das Schlimmste. Wenn Sie vorher Chef waren und Entscheidungen getroffen haben, und dann sind Sie jetzt nichts mehr. Das ist eigentlich so das schlimmste Erlebnis aus dieser ganzen Insolvenz. Also, das ist eine Persönlichkeitsgeschichte, eine Abwertungsgeschichte, die völlig / Die tut weh. Das tut weh. Das tut richtig weh.

I: Und wie haben Sie das Verfahren an sich empfunden? Wie haben Sie sich da behandelt gefühlt, und wie ist das abgelaufen?

B: Ich hatte mit dem Herrn $<<<$ Name anonymisiert $>>>$ wahnsinnig Glück. (stottert) ...in dieser ganzen Phase, wie gesagt, ich hatte ein wahnsinniges Glück mit diesem Menschen. Ja, der kam halt so daher. Nachmittags um zwei, oder war es schon vier, kam er mit seiner Assistentin da. Und ich habe ihm dann die Sachen alles vorgelegt. Habe gesagt: „Da, so und so." Ja, und er wollte meine Privatwohnung noch sehen. Sage ich: „Ja, da oben wohne ich gerade noch ein bisschen." Kann er anschauen. Ja. Naja, der hat halt gemeint, ich habe irgendwo was versteckt. Aber nein, ich habe nichts versteckt. Und dann war es abends 10 oder 9 Uhr. Und dann abends um neun fragt er mich: „Können Sie sich vorstellen, weiterzumachen?“" Da habe ich gesagt: „Das kann ich jetzt nicht entscheiden. Da muss ich meine Mitarbeiter mal fragen. Vorstellen kann ich es mir schon." Aber hm. Naja, da habe ich dann halt meine Mitarbeiter gefragt: „Wollt ihr mit? Zieht ihr es mit durch? Macht ihr mit?" Dann haben die gesagt: „Ja." Dann habe ich gesagt: „Ok. Versuchen wir weiterzumachen.“” Für mich war eigentlich / An dem Tag, wo der kam war, war für mich klar die Firma ist (pfeift) liquidiert sofort. Also, weil wer nimmt so eine kleine Firma. Wer lässt so eine kleine Firma, wie wir waren, weitermachen? Das ist für Insolvenzverwalter völlig untypisch. Und ja, dann haben wir halt angefangen. Und dann ging es halt los. Dann kam der nächste Hammer, der für mich irgendwo sehr extrem war. Ja, sie haben die Firma geschätzt. Da kam dann so ein Firmenbewerter, oder was das auch immer, keine Ahnung, wie der heißt. Damals hieß der $<<<$ Name anonymisiert $>>>$. Da kann 
ich mich noch sehr gut entsinnen. Ich denke: „Aha, bist der Richtige." Und dann hat er für das Inventar und die Maschinen irgendwas /

B2: 50.000 oder was?

B: Irgendeinen Wert. Mir haben die Augen getränt. Ich habe damals zwei Millionen für die Firma bezahlt. Und der wollte mir da jetzt dann, glaube ich (kurze Pause) äh, ich glaube 100.000 Euro geben. Also für das ganze Zeug. „Wie bitte? Sag mal, spinnt ihr? Seid ihr verrückt?" Das war der nächste, das war der nächste. Da denk ich: „Ja, leck mich am Ärmel. Das wird aber heikel." (seufzt) Also, ich war wirklich von den Socken. Also, ich habe das nicht checken können. Weil auch wirklich für meine Begriffe Werte dagehabt habe. Für diese Werte, sowas alles, völlig wurscht. Ja.

B2: Das war halt veraltet. (lacht)

B: Ja, es ist veraltet. Für die ist es vielleicht veraltet und abgeschrieben. Aber wir können da produzieren darauf. Wir können da arbeiten. Wir können da Sachen erstellen und alles machen. Naja. Das war der erste Schritt. Und dann. Was mich dann noch geärgert hat: Ich hatte ja eine unheimlich gute Sekretärin, die sich in diese ganzen Lohn- und alle Geschichten eingearbeitet hatte. Einen Lohnbuchhalter hat da die Insolvenzgesellschaft angebracht, der von Tuten / Das Einzige, was er wusste, was man für Anträge stellen musste an das Arbeitsamt, möglichst schnell, dass die Leute Geld kriegen. Das ist das Einzige. Alles andere war unter aller Sau. Meine Sekretärin musste jedes Mal nachrechnen und schauen, was der für einen Scheiß macht. Und der hat Geld gekriegt, nicht wenig! Ich habe mich geärgert jedes Mal, was das Geld da rausgeschmissen wird. Wir sind / Ja, das ist das Problem. Der Insolvenzverwalter hält ja einen / nachdem ja die Firma insolvent ist, hält er dich für blöde. Ja. Sonst wäre es ja nicht zur Insolvenz gekommen. Aber wir sind ausschließlich in die Insolvenz gekommen, weil die Wirtschaftslage, bzw. weil die Aufträge weggebrochen sind. Nicht, weil wir die Unternehmensführung nicht machen konnten. Ja. und das war ja das. Das war der Grund. Das war das, was so ein bisschen, weißte, dass wir einfach zu blöd sind. Und dann hat es geheißen: „Ja, schauen wir, dass wir irgendwelche Aufträge reinziehen." Da sage ich: „Ja, helfen Sie mir gerne dabei. Was können wir 
tun?" Ja, er hat wieder mal einen Brief geschrieben. Gut, der $<<<$ Name anonymisiert $\gg>>$ konnte sich natürlich im sprachlichen Ausdruck wesentlich blumiger ausdrücken als ich als Ingenieur. Ja, ich bin Ingenieur. Drei Sätze, dann muss das stimmen. Und der macht aus den drei Sätzen so ein Pamphlet, es ist heiß, ja. Ich habe dann auch gesehen, er hat da mal so einen Lebenslauf über mich da geschrieben. Denke ich: „Hä, bin ich das überhaupt?" Ja. Weißt, das war alles da irgendwie so, hä, das kann doch nicht stimmen, oder? (lacht)

Dann die nächste Geschichte, wo ich also so ein bisschen denke. Der ist dann als Insolvenzverwalter zu unserem Vermieter gegangen und hat die Miete auf 1000 Euro gedrückt innerhalb von zack. (schnippst) Und wo ich umeinander gemacht hab wie verrückt. Das war für mich / Plötzlich ist das gegangen alles. (haut auf tisch) Plötzlich ist das alles gegangen. Nur weil der halt der Insolvenzverwalter war oder so. Wenn ich gesagt habe: „So, jetzt pass auf, bitte, es ist Zeit, wir müssen." (schnaubt) Das war für mich eine sehr interessante Erfahrung, dass der allein, ich denke wegen seiner Stelle Insolvenzverwalter, soviel Macht hat und auch das umsetzen kann. Das ist irre. Das ist Wahnsinn. Es ist irre, was da plötzlich geht, was vorher nicht geht.

B2: Der sagt halt: „Ok, das machen Sie jetzt, oder Sie kriegen gar nichts." (lacht)

B: Ja, so in der Form. Aber wenn ich das aber sage, dann ist das in den Wind gesprochen. Dann ist das nur eine Drohung. Und da scheint es zu funktionieren., keine Ahnung wie. Das ist echt heiß. Ja, dann war dann so eine Ecke. Das war dann so ungefähr Mitte 2010. Dann hat er noch einen Trick gemacht. Er hat dann eine Insolvenz in der Insolvenz gemacht. Dadurch konnte er einen langjährigen Mitarbeiter, der leider das nicht mehr gebracht hat, was er hätte bringen sollen, ist egal, der war halt auch einfach geistig nicht in der Lage mehr, ja, zu entlassen. Ohne Abfindung. Das war eben genau der Trick. Wie er das gemacht hat, ich weiß nicht, wie das funktioniert. Naja, dann in der Zeit da haben wir, während wir die Firma fortgeführt haben, haben wir versucht, oder er versucht, wir versucht, ich versucht, er versucht und andere auch versucht, die Firma zu verkaufen, was sich als sehr schwierig herausgestellt hat. Weil wie gesagt die Konjunktur für Maschinenbauunternehmen halt wahnsinnig bescheiden war. Und keiner halt in ein Fach / Jede Bank, jede Wirtschaftszeitung hat geschrieben: „Maschinenbau - forget it erst mal. Lass die 
Finger davon." So ungefähr. Dadurch war es halt wahnsinnig schwierig, die Firma zu verkaufen. Und da war dann auch mal noch eine Ecke, das war auch fast um die gleiche Zeit herum. Ich hatte noch eine Leasingmaschine. Da kam dann so ein / Da hat die Leasingfirma die Maschine, die ich hatte, abgeholt oder abholen lassen. Und da kam dann so ein junger Bursche, der so richtig frech aufgetreten ist. Und das war auch so eine Ecke, die mir sehr nahe gegangen ist. Weil der /

B2: 23 oder so war der, oder?

B: Ja, 23. Oder war er 24. Ich weiß nicht. Auf jeden Fall sehr, sehr forsch. Und hat dann die Maschine innerhalb von einem halben Tag oder so, oder einem Tag, abgeholt. Und dann habe ich gesagt: „Wenn Sie jetzt nochmal zur Tür reingehen / Da kommen Sie mir nicht mehr rein. Das sag ich Ihnen. So nicht." Dann kam er im / Wann war das? Die ist verkauft worden zum ersten November, glaube ich. Ja. Dann kam er. Dann habe ich mir also schon gedacht, ok, die Firma lässt sich also überhaupt nicht verkaufen. Dann kam der junge Bursche, stand vor meiner Tür. Und dann hat er zu mir gesagt: „Ich möchte mich entschuldigen. Aber ich würde Ihre Firma kaufen."

I: (Lacht) Das ist ja wie im Fernsehen.

B: Ja. Dann habe ich gesagt: „Ok, ich nehme die Entschuldigung an. Können's die Firma kaufen. Ist ok.“ Dann hat der die Firma gekauft, aber nicht um die Firma am Leben zu lassen, sondern um die Firma auszuschlachten. Der hat also nur den Namen kaufen wollen.

B2: Und die Maschinen.

B: Ja, die Maschinen, die hat er halt ausgestellt. Der hat die ganzen Maschinen verhökert (wird lauter). Alles.

B2: Er war Maschinengroßhändler eigentlich.

B: Er war Maschinengroßhändler. 
I: Ach so. Ok.

B2: Und hat auch für Leasingfirmen gearbeitet, dass er die eben wieder zurückgenommen hat und geholt hat.

B: Ja. Gut. Er hat dann noch eine Fertigungsfirma eigentlich noch gehabt. Oder zumindest so sagt er das, oder warum will der das machen. Auf jeden Fall hat er ein paar Sachen gefertigt immer wieder. Naja, aber auf jeden Fall nicht mehr auf meinen Maschinen. Die hat er alle verhökert. Mir war das egal. Es hat zwar alles / Es hat sehr weh getan. Das Schlimmste noch, oder noch eine der schlimmsten Situationen war, wie er mich anruft, der $<<<$ Name anonymisiert $>>>$, und sagt: "Er müsse die Leute entlassen." Von heute auf morgen.

B2: War das noch vor dem Verkauf oder was?

B: Das war vor dem Verkauf, kurz vor dem Verkauf. Da war ich, da war ich / Ja, und ob ich das den Leuten selber sagen will oder nicht. Da war ich dann wirklich, da war ich / Da wusste ich, jetzt ist Schluss, und jetzt geht es dahin. Und da war ich auch ziemlich (seufzt) total unten. Ich konnte es nicht einmal unter Tränen meinen Mitarbeitern sagen. Das war scheiße. Das war richtig, richtig, richtig scheiße.

Naja, wie gesagt und dann hatte ich das Glück, dass dieser junge Bursche das Ding gekauft hat. Es gab dann zwar mit der Bezahlung noch ein bisschen Probleme. Und ich habe dann gesagt: „Ok, ich arbeite dort mit als, ich sag mal (...) unverständlich, für den Bereich Fertigung. Da arbeite ich mit. Und, ja, im Endeffekt war ich dann unten in der Werkstatt gestanden, habe gearbeitet als / und Fertigungen habe ich also nicht gemacht. Also, ich habe keine Unternehmensführung oder so was mehr gehabt, sondern ich habe halt nur dort irgendwelche handwerklichen Dinge gemacht. Und ich habe mir dann zwar dort unten einen Computer und alles eingerichtet, was ich ja alles kann. Und da habe ich dann gemerkt, dass das ein Filou ist, in der Zeit. Also ich habe dann von Januar, ja im Dezember bin ich an den Baum gefahren, Dezember bis Februar habe ich dann bei ihm gearbeitet, und in der Zeit war das. Also, da habe ich 
gesehen, was der / Also, erstens mal wie der mit den Maschinen und den Leuten umspringt. Und dann ging es halt so. Ja, er hat alles versprochen. Was der alles versprochen hat! (wird lauter) Das war boah. Also, da hätte man, das wäre schon echt toll. Und dann sage ich, dann irgendwann mal kam wieder mal ein Auftrag. Meine ganzen Kunden hat er vergällt. Alle Kunden, die ich mühsam aufgebaut hatte, hat er vergällt. Alle. Er hat mir versprochen, dass er/ich hatte irgendwo Probleme mit einer Maschine, die hat er schon wieder abgezogen gehabt, damals wie er sie gekauft hatte. Sagte ich: „Du, ich muss die Sachen machen." Sagte er: „Ja, er kennt jemanden, der macht das und fertig." Sagte ich: „Ja, jetzt wie schau es aus? Machen, machen!" (schnipst) Er hat es also nicht hergebracht über sechs Wochen. Termin war natürlich längst verstrichen, aber wir wollten den Job nicht einstellen oder so. Und dann sage ich: „So, und ich soll jetzt ans Telefon gehen und denen sagen so und so." Und dann kam ein Kunde, den ich in der Insolvenz auch kennengelernt hatte, und hat gesagt: „Ok, ihr kriegt den Auftrag. Den müsst ihr abwickeln mit den Teilen und so weiter." Und dann sagte ich: „Ok, pass auf, das können wir schon machen aber nicht mit dem Personal. Wir brauchen mindestens einen Mann mehr. Und wir brauchen noch eine zweite Maschine. So können wir den Auftrag nicht abwickeln." Dann sagte er: „Ja, dann machen Sie halt Überstunden." Dann sagte ich: „Ja, mit Überstunden geht das nicht. Das ist unmöglich. Diesen Auftrag können wir nicht erledigen auch mit Überstunden nicht." „Ja, dann stellen Sie sich noch zusätzlich mit hin." Sagte ich: „Kann ich schon, aber es langt nicht. Es langt definitiv nicht. Außerdem können wir nicht in dem großen Laden dürfen wir nicht einen Mann alleine stehen lassen. Das geht nicht. Wir müssen mindestens zwei Leute sein immer, jede Schicht. Und wir sind nur zwei. Wir können nicht einer so eine Schicht fahren, eine so eine Schicht fahren. Das geht nicht." „Das muss gehn, das muss gehen. Das machen andere auch. Das muss gehen." Sagte ich: „Nein, das geht nicht. und außerdem haben Sie mir jetzt die letzten drei Monate, seit / Sie haben die Firma gekauft zum 1. November. November, Dezember, Januar, Februar noch keine Sozialabgaben überwiesen, oder bzw. meine Krankenversicherung." Und das hat er alles versprochen gehabt.

B2: Ganz zu schweigen vom Gehalt. Aber Krankenversicherung war eben ein Anliegen. (lacht) 
B: Ja, ganz zu schweigen vom Gehalt. Gehalt habe ich ja, naja / Gut.

B2: Krankenversicherung war ja über 800 Euro im Monat.

B: Ja. Und das ganze über drei oder vier Monate. da ist schon ein bisschen was zusammengekommen. Zumal du ja keinen Vertrag mehr hast. Und dann sagte er: „Das juckt mich nicht." Sag mal! Dann sagte ich: „Dann juckt es mich auch nicht. Auf Wiederschaun." Dann bin ich gegangen. Das war Mitte Februar. (seufzt) Ja, dann stand ich erst mal auf der Straße. Vom Leasingauto hat er die Leasinggebühren nicht bezahlt die ganze Zeit.

I: Waren Sie jetzt da auch noch belastet durch die Insolvenz? Da gibt es ja diese sechs Jahre und Schufa-Eintrag und so.

B: Ja, das war jetzt. Schufa-Eintrag ja, aber der ist ja jetzt mittlerweile schon auch weg. Weil die Bank hat mir jetzt auch wieder eine Kreditkarte gegeben. Also, muss der Schufa-Eintrag gelöscht sein. Ähm, EC-Karte. Aber 400 Euro kann man überziehen. Aber ich will auch gar nicht mehr überziehen. (lacht) Also, Banken / Für mich sind Banken definitiv gestorben. Und wenn ich zu einer Bank wegen irgendwas gehe, nur noch zu zweit, definitiv nur noch zu zweit, wobei der andere sofort einen Block zieht und mitschreibt. Denn der Banker weiß zwei Tage später nicht mehr, was der vorher mit dir ausgemacht hat. Es ist so. Es ist so, definitiv. Und das ist also ganz schlimm.

Und dann, ja / Das war also ganz im Groben eine Ecke, wobei es also beim $<<<$ Name anonymisiert $\gg>>$ wirklich ganz gut war. Er hat mir in meiner Zeit relativ freie Hand gelassen. Er hat natürlich alles kontrolliert und im Hintergrund gemacht. Also, er hat schon sehr viel auch im Hintergrund getan. Er hat mir auch, glaube ich, wenn mich nicht alles täuscht, zumindest 1000 Euro pro Monat, wo ich frei verfügen konnte, das heißt Werkzeuge einkaufen oder so etwas. was er nicht hätte machen müssen. Ja, er hätte auch sagen können: „Ok, jeden Cent." Aber das hat er nicht gemacht. Und das muss ich ihm hoch anrechnen. Und dadurch, dass er es, auch wenn es von mir aus ein Lump war, verkauft hat, auch super. Denn dann kam es zum Vergleich. Und im Januar, also das war 2009, da habe ich die Insolvenz angemeldet. Im November wurde 
der Laden verkauft. und im Januar 2011 war der Vergleich durch. Das heißt vor Gericht war ein Vergleich gekommen. Und damit war ich aus der Insolvenz entlassen. Das war mein großes Glück. Also, ich hatte eigentlich, wenn man das Ganze so will, außer dass ich viel, viel Geld verloren habe, Glück im Unglück.

B2: Naja, ein bisschen doof war es schon. Also, für die Zeit, wo keine Sozialversicherung gelaufen ist, da hatte er Arztrechnungen. Und er hat zwar nachgezahlt diese Krankenversicherung, aber die haben nicht die Arztrechnungen bezahlt. (lacht)

B: Das ist auch so was gewesen, ja. Genauso Gauner. Das sind genauso Gauner. Also, die Versicherungen. Das Schöne eigentlich ist aus der ganzen Geschichte, dass die ganzen Versicherungen der Insolvenzverwalter gekündigt hat. So etwas funktioniert in der Insolvenz. Alles, was ich als Versicherung hatte, das heißt also

Lebensversicherung und all solches Zeug alles weg, bis auf Krankenversicherung. Ja, Hausratversicherung, alles, alles, was da an Versicherungen war. Das heißt, ich lebe jetzt nur noch mit der Krankenversicherung. Da kommst du nicht umhin, Krankenversicherung, Autoversicherung, da kommst du nicht umhin. So, na dann war ich aber dagestanden, nicht? Ohne Geld.

B2: Vor allen Dingen ohne Alterssicherung. Das ist es halt.

B: Ja, das ist ja das nächste. Ich meine, meine Fonds hat alle die Bank kassiert. Wobei ich bei dem meinen Fonds schon sehr sauer war, als ich damals zusagte. Ich habe gesagt: „Das kriegt ihr nicht das Geld. Das ist meine Lebensalteransparung. Könnt ihr nicht haben." "Ja, dann gebe ich Ihnen kein Geld.“" Das war also ganz, ganz starke Erpressung. Und das ist es halt immer. Das ist das riesen Problem an der Geschichte. Du bist abhängig in einer gewissen Form. Und in diese Abhängigkeit würde ich mich in dieser Art und Weise nie mehr schaufeln. Nie mehr in meinem Leben. Nein.

I: Wenn Sie zurückblicken, was würden Sie heute anders machen? 
B: Also, selbstständig würde ich mich wieder machen. Das würde ich also mit Sicherheit, weil ich durch die Selbstständigkeit meine eigene Persönlichkeit erhalten konnte. Ein Beispiel: Ich habe ja konstruiert schon in der Firma oder sonst irgendwas. Und das war dann klar, du hast konstruiert, und der Chef hat gesagt: „Hm, ok, fertig." Ja? So. Ich habe das Gleiche in Anführungsstrichen konstruiert als Selbstständiger. Plötzlich wurdest auf Augenhöhe angeschaut. Ja? Absolut. Man konnte jetzt diskutieren. Vorher war: „Schieße, was soll das?"“" Das war eine ganz andere / Das gleiche gemacht, aber plötzlich eine ganz andere Wertschätzung erfahren. Das war sehr interessant. Ja, was ich heute bezüglich des Firmenkaufs / Also, ich würde die Firma nie mehr unter solchen Bedingungen kaufen. Die Hälfte wäre noch fast zu viel. Und man muss die Emotionen rauslassen. Das heißt, Emotionen beim Kauf sind schwierig. Ich war einfach viel zu verliebt in diese Firma. Und das darfst du nicht. Dann die nächste Geschichte, die ich machen würde, ich würde dann heute, wenn es heute wäre, sofort schauen, dass ich, wenn ich jetzt den Vertrag mache, aus so einer kleinen Ecke rausgehe und mich auf jeden Fall erweitere. Weil a) Wie gesagt durch die Abgängigkeit, die 100\%, oder fast, sagen wir mal 100\% Abhängigkeit, ist es eine wahnsinnig schwierige Geschichte. Wenn dort sich der Geschäftsführer ändert, bist du weg. Es ist so. Aber du kannst dich ja nicht erweitern, weil du bist ja voll ausgelastet für die Firma. Du kannst ja nicht. Wie willst du freischaufeln. Ich meine, die Firma ist wirklich in dem Rahmen eingeschränkt. Du kannst nichts anderes annehmen. Du kannst nämlich dann die Termine nicht mehr halten. Es geht nicht. Und wenn du einmal einen Termin versiebt hast, bist du für eine neue Firma gleich sowieso draußen. Und für die alte: „Pff, ja, der liefert ja schon nichts mehr." Bist auch draußen. Also, das darfst du nie machen. Das ist das Schlimmste, was du machen kannst. Das heißt, du kannst höchstens schauen, dass du irgendwie auf die Wiese oder wo auch immer, dass du Platz hast, dass du immer wieder ein bisschen zukaufen oder zuwachsen kannst. Damit kriegst du eine Vielfalt von Kunden. Weil, dann bist du nicht mehr so abhängig. Das würde ich also auf jeden Fall machen heute.

Und was ich noch anders machen würde: Also, eigentlich ist mein Fehler ja ein ganz anderer. Mein Fehler ist ein ganz anderer. Ich bin ein viel zu viel Ingenieurmensch. Das heißt, ich bin kein Netzwerker. Und jetzt bringe ich das völlig neu rein. Ich habe kein funktionierendes Netzwerk aufgebaut in meinem Leben. Ja, ich kenne vielleicht mal den, mal den. Aber während dem Studium musst du Leute/ oder schon vorher oder 
über die Eltern / Das ist einfach nicht da. Und das kostet dich auch viel Zeit, so ein Netzwerk zu halten. Und das ist ein Fehler, wenn du als Unternehmer auftauchen willst. Die Geschäfte werden über Netzwerke vergeben. Und das ist mein Problem. Das würde ich heute ganz anders machen. Und ich habe das auch meinen Kindern immer wieder gesagt. Baut ein Netzwerk auf jetzt schon, und zwar ein solches, was euch auch dann vielleicht später mal trägt, und pflegt dieses Netzwerk. Das ist leider so. Das würde ich heute wahrscheinlich komplett anders machen.

I: Aha, ok.

B: Alles andere ist ein unternehmerisches Ding. Aber es hängt weiter oben. Dieses Netz hast du nicht. Ja? Gut man kennt schon einen von der Gewerkschaft, man kennt den, man kennt den, ja. Aber pff. Und eine Hand wäscht die andere. Das ist einfach so. Das heißt ja nicht, dass es Schmierage ist. Sondern es ist einfach ein Wissen um Vergabe von Arbeiten oder so.

Ich würde auch versuchen, ein eigenes Produkt mir aufzubauen. Ach das. Also, du kannst nicht einfach nur abhängig von jemand anders leben. Du musst schauen, dass du dein Produkt, deine Ideen, deine Sachen weiterbringst. Auch das müsstest du machen. Und dass wenn du Rückschläge hast, musst halt wieder schauen, dass du weiterkommst. Da kannst du nicht einfach sagen: „Ok, ich habe jetzt da ein Produkt. Wenn das aufs erste Mal nicht funktioniert, dann ääähhh.“ Sondern gleich wieder weitermachen. Und da müsstest halt mal genügend Geld haben. Das ist das Problem. Ich hatte ja die Firma eigentlich gekauft mit der Maßgabe: „Ok, die Firma läuft. Wunderbar. ich gehe daneben und baue jetzt dann hier nebenher meine eigene Fertigung mit auf." Das heißt also, ich entwickle das Ganze noch ein bisschen, und mache da weiter. Aber die Firma hat mich dann so in Anspruch genommen, dass ich keine Zeit mehr hatte, daneben was zu tun. Und das war auch am Anfang ganz gut, dass es mal nach sehr viel Stress langsam nicht unbedingt gleich wieder in die Vollen weitergehen konnte. Das war mal ganz gut. Aber es hat nicht so viel nebenher / ich konnte nicht einfach so viel nebenher machen, dass das einfach ganz locker so mitgelaufen wäre. Rein theoretisch hätte ich wahrscheinlich mir einen Geschäftsführer nehmen müssen, und den mir da reinsetzen. Und ich hätte mir die Zeit nehmen sollen, um das Getriebe, oder was ich halt dann hatte, weiterzuentwickeln und zu entwerfen 
und zu schauen, was da für Sachen da weitergehen. Das wäre vielleicht das Richtigere gewesen. Naja.

I: Und nach der Insolvenz, was haben Sie dann gemacht.

B: Haha. Arbeitslos. Da habe ich also für 600, was habe ich gehabt? 600 Euro.

B2: Nein.

B: 300 Euro.

B2: 300 Euro. Diese Grundsicherung.

B: Ja, ja, gut, 300 Euro. Und 820 Euro musste ich Versicherung bezahlen.

I: Oh je.

B: Ja, das muss ich ganz ehrlich sagen, wenn ich die $<<<$ Name anonymisiert $>>>$ nicht hätte, pff. Also, das da /

B2: Aber das mit der Versicherung, das konnten wir dann ein bisschen /

B: Ja, das konnten wir dann ein bisschen verändern.

B2: Die haben ja verschiedene Tarife, aber die bieten das nicht von sich aus an. (lacht)

I: Ach so.

B2: Da muss man halt nachfragen und immer wieder nachfragen, ob es da nicht noch was Günstigeres gibt oder so.

B: Ja, ich hatte halt von einem Bekannten gehört, dass es so etwas Ähnliches gibt wie einen sogenannten Hausarzttarif. 
B2: Ja, auch bei den Privaten.

B: Auch bei den Privaten.

B2: Ja, und er hatte keine Chance mehr, in das gesetzliche Versicherungssystem zu kommen. Ab 55 ist der Zug abgefahren.

B: Das ist auch wieder so eine Ecke. Ja, und dann wie gesagt, da habe ich dann lange insistiert und lange mit umeinander gemacht, und dann bin ich halt von 820 auf 350 runtergefallen und bin inzwischen schon wieder auf 400 oben mittlerweile.

B2: Mit Abstrichen, dass man ein bisschen was selber zahlen muss und so.

B: Aber das ist in einem Monat herinnen, wenn man so will (lacht). Also gut, da war ich selbstständig, dann war ich beim Arbeitsamt gewesen, und dann / ich habe auch Bewerbungen versucht zu schreiben. Ich habe mal eine Bewerbung / das war sehr interessant. Ich habe eine Bewerbung abgegeben auf eine Stelle, die absolut, also wirklich $1000 \%$ zu mir gepasst hätte. Das war wirklich genau das gleiche Arbeitsspektrum, genau das hätte ich abgedeckt. Naja, kam eine Absage, ist doch logisch. Die haben halt mein Alter gesehen mit 63. Damals war ich 63. Ja. Da war es vorbei.

So, dann habe ich langsam / Dann ging es also langsam wieder los. Es ging dann so los, dass ich in $<<<$ Ort anonymisiert $>>>$ bei dem Bekannten, der früher bei mir hat arbeiten lassen. Der hat gesagt: „,Du, du kannst doch das ganze Zeug. Komm, magst du nicht zu mir kommen? Magst bei mir ein bisschen? Können ja ein bisschen, wäre doch was." Sagte ich: „Ja, kann ich anfangen. Ist nicht schlecht."

Dann habe ich gleichzeitig weitergesucht. Dann hatte ich eine Möglichkeit als Dozent oder als Seminarleiter zu arbeiten für Hydraulikgeschichten. Das wäre ein gut bezahlter Job gewesen. Da hätte ich eine Woche arbeiten können, und der Rest war / Hätte gereicht für einen Monat. Ok, auf jeden Fall war da alles soweit in Ordnung. Ich habe auch den ersten Kurs gehalten. Und dann habe ich einen schweren Verkehrsunfall gehabt. Und dann war ich fast ein Jahr außer Gefecht. Das heißt als, 
ich habe einen Rollerunfall gehabt, und war da in $<<<$ Ort anonymisiert $>>>$. Und zwar war das am 13. Oktober 2011. Und dann war ich bis Dezember schon mal in $<<<$ Ort anonymisiert $>>>$ gelegen, also nicht ganz in $<<<$ Ort anonymisiert $>>>$. Und dann war auch noch auf der Reha. Ja, und das ging einfach nicht.

Die ganzen Aufträge waren natürlich wieder / (lacht) Dann ging es wieder von vorne los. Wieder Arbeitslosenunterstützung beantragt, also, Hartz 4, dass ich zumindest mal ein bisschen Geld hatte, um die / und die $<<<$ Name anonymisiert $>>>$ hat mich natürlich gut verköstigt.

B2: (lacht)

B: Wunderbar. Und ich muss sagen, ohne $<<<$ Name anonymisiert $>>>$ wäre für mich das Leben /

B2: Ja, weil du hättest nichts mehr. Du hättest keine Wohnung, du hättest gar nichts mehr.

B: Ich habe nichts mehr. Ich habe ja meine Wohnung verkauft, also, die musste ich ja verkaufen. Ich habe nichts mehr, also wirklich nichts mehr. Ich habe gesagt, alles geht flöten auf ein Zimmerchen, das ganze Vermögen, alles. Das ist alles / Das ganze Leben ist eigentlich weggefallen, verloren. Alle Ideale, alle Wünsche, alle Träume, alles was du dir irgendwann einmal im Leben vorgenommen hast, ist einfach mit einem Schlag fort. Das sind so diese Ecken. Und dann wie gesagt, dann hatte ich wieder angefangen, wieder ein bisschen was zu machen. Dann hat es mich gleich halt mit dem Roller zerlegt. Dabei ist mein Kreuz ziemlich kaputtgegangen. Und dann musste ich im Mai 2012 nochmal operiert werden. War ich nochmal 12 Tage im Krankenhaus, wurde der Rücken wieder operiert. Danach war ich im Juni wieder auf Reha. Und eigentlich dann im Sommer 2012 ist es dann langsam wieder ein bisschen aufwärtsgegangen. Und dann habe ich in $<<<$ Ort anonymisiert $>>>$ wieder ein bisschen angefangen, in $<<<$ Ort anonymisiert $>>>$ wieder ein bisschen was gemacht. Habe dann zwischendurch wieder ein bisschen Konstruktionen gemacht. Und so halte ich mich so einigermaßen ein bisschen über Wasser. Gott sei Dank ist mit meinem Körper soweit wieder alles überstanden. Gott sei Dank. Also, für viele ist das, was ich 
so höre, ja Todesurteil kann man nicht gerade sagen, aber ein Dahinsiechurteil. So ein Unfall. Aber ich habe Gott sei Dank das Ganze wieder überstanden und habe eigentlich fast keine Einschränkungen. Und nachdem ich eh wieder alles / Ich lasse das Leben jetzt auf mich zukommen.

I: Sie haben ja vorhin, als wir den Fragebogen gemacht haben, schon gesagt, dass Sie früher viele Sachen anders angekreuzt hätten als jetzt.

B: Ja, sicher.

I: Was sind so die größten Veränderungen? Wie hat Sie die Insolvenz verändert?

B: Ich bin mittlerweile wesentlich ruhiger. Vorher habe ich gearbeitet, und auch während der Insolvenz auch habe ich gearbeitet zwischen 12 und / Also, unter zehn Stunden am Tag ist nicht gewesen. Das waren 12, waren 14, waren 16, waren 18 Stunden. Und das aber nicht bloß über ein Jahr, sondern über zwei, drei, vier Jahre. Und das hat sich eben schlagartig geändert, logisch, ja. Ich kann das Ganze jetzt viel ruhiger angehen. Ich arbeite nach wie vor. Wenn ich nichts zu arbeiten habe in meiner Firma oder irgendwo bei einer Fremdfirma, mache ich mir selber was. Da tu ich gar nicht mehr lang rum, wie gesagt, hier ein bisschen was, da ein bisschen was, bisschen mehr lesen. Ich komme nicht mal zum Lesen, siehst du, ich bin nicht einmal zum Lesen gekommen. Das ist Wahnsinn. Ja, das ist jetzt einfach / Na, und dann tut sich wieder sehr, sehr viel. Und ich muss aufpassen, dass es nicht zu viel wird. Mein Sohn hat sich ein Haus gekauft. Das muss umgebaut und angebaut werden. Wahrscheinlich werde ich im Juli gar nicht in $<<<$ Ort anonymisiert $>>>$ arbeiten, sondern da werde ich auf der Baustelle von meinem Sohn sein. Und dann anschließend mache ich halt zwischendurch für meine Tochter ein bisschen was. Die macht ein EnglischSprachcamp in der Schweiz. Da soll ich Koch spielen. Ja, dann mache ich Koch drei Wochen lang. Da verdiene ich auch Geld, das ist nicht so wenig. Was habe ich ungefähr? 1000 Fränkli in der Woche. Da kann ich schon bisschen was leben.

\section{B2: Für eine Woche?}


B: Ja, für eine Woche.

B2: Ja? Ok. (lacht)

B: Ja, für eine Woche 1000 Fränkli.

I: Sie haben vorhin gesagt, wie Sie sich selbstständig gemacht haben, hat sich so das Miteinander verändert, also, dass Sie dann plötzlich auf Augenhöhe waren und so.

B: Ja. Gegenüber den Firmen.

I: Haben Sie auch Reaktionen bemerkt, als es dann in die Insolvenz ging, dass man anders mit Ihnen umging oder dass auch Freunde anders mit Ihnen umgingen? Hat das irgendwas verändert?

B: Also, es ist schon / Es fällt mir schon schwer zu sagen: „Ich habe eine Insolvenz hingelegt." Also, mir fällt das schwer.

I: Warum?

B: Ja, das ist für mich schon ein bisschen eine scheiternde Existenz. Ja, und das Schlimmste war eigentlich mit der Insolvenz die Abhängigkeit wiederum, wenn ich arbeiten / Oder wenn ich Hartz 4 habe, die Abhängigkeit von irgendwem. Und das ist einfach für mich / Ich habe ja ein gewisses Ego, und dieses Ego lässt das nicht so einfach zu. Aber die Meisten, wenn ich das dann irgendwo, wenn ich das dann sage: „Ich habe eine Insolvenz gehabt.", da habe ich nicht das Gefühl, dass dann so (macht einen erschrockenen Luftschnapper) so etwas auftaucht. Die nehmen das als / Ja. Die sehen mich, glaube ich, mehr als Mensch. So sehe ich das. Auch zum Beispiel, im Bekanntenkreis sind lauter Banker zum Beispiel von dir, in deiner Ecke, das ist ok. Das wird nicht irgendwie als negativ / Habe ich nicht das Gefühl, dass die das negativ sehen. Oder?

B2: Ja, das weiß ich jetzt nicht genau. 
B: Nein, also, ich habe nicht das Gefühl, dass sie deswegen jetzt irgendwo / Viele Bekannte habe ich nicht. Ich habe halt viel gearbeitet, deshalb habe ich nicht viele Bekannte. (lacht) Das ist das Problem, ja. Das ist das, was ich sagte. Diese Zeit, die ich in die Überstunden gesteckt habe, die hätte ich lieber in ein Netzwerk stecken sollen. Ja. Oder halt in den Bekanntenkreis. Das sind so diese Dinge, die würde ich heute völlig anders machen.

I: Gibt es auch irgendetwas Positives, einen positiven Effekt, wo Sie sagen, es hatte auch was Gutes?

B: Ja, natürlich. Also, für mich hat es in der Form was Gutes: Als erstes hatte ich das Glück, dass ich den $<<<$ Name anonymisiert $>>>$ hatte. Das war für mich ein riesen Glück, dass er auf einen Vergleich rausging. Dadurch war ich / Weil sechs Jahre lang diese Anhängigkeit von einem Insolvenzverwalter, ob ich die so locker weggesteckt hätte, kann ich mit Sicherheit verneinen.

B2: Also, das ist die Privatinsolvenz, die sich dann angeschlossen hätte.

B: Ja. Das kann ich mit Sicherheit verneinen, dass ich das nicht ganz so locker weggesteckt hätte. Ähm. (Pause) Ich lebe heute stressfreier. Obwohl ich nichts habe, lebe ich trotzdem stressfreier. Und wenn ich heute nichts mehr habe, dann habe ich halt nichts mehr, ok. Dann gehe ich halt von mir aus aufs Sozialamt, oder sonst irgendwas. Oder wenn irgendwas mit $<<<$ Name anonymisiert $>>>$ passieren sollte oder was auch immer. Ich meine, es wird irgendwas anderes kommen, wo ich nicht weiß was, aber es wird irgendwas anderes kommen.

I: Sie sind gelassener geworden.

B: Ja, auf jeden Fall.

I: Jetzt muss ich mal spicken, ob meine Liste schon abgearbeitet ist. 
B2: (lacht)

I: (Pause) Nein, wir sind fertig.

B: Was?

I: Ich habe alles.

B: Haben Sie alles? (lacht) Ja, ich habe dann auch den Herrn $<<<$ Name anonymisiert $\gg>>$ hintennach mal gefragt. Habe ich gesagt: „Warum?" Ich meine, da hat er halt zwischendurch mal erzählt, dass bei einer anderen Insolvenz, der hat ja mehrere Insolvenzen, nicht bloß mich, aber es war schon interessant zu sehen, ... (unverständlich) hat er, glaub ich 75.000 Euro gekriegt für das Jahr. Das ist schon / Also für das, was er / (lacht) Also, ich finde das schon heftig. Aber, mein Gott, das ist halt so. Dann habe ich ihn mal gefragt, warum er eigentlich bei mir weitergemacht hat. Dann sagte er: „Das hat eigentlich alles so gepasst, das heißt, Sie wussten genau warum, weshalb, wieso Sie in eine Insolvenz schlittern." Also, es liegt nicht an der Unternehmensführung, sondern es liegt eigentlich an von außen aufgesetzt. Und da hat er halt dann versucht, dass er da was ändert. Und deswegen hat er mit mir weitergemacht. Also, das hat mich natürlich auch wieder ein bisschen mit Stolz ausgefüllt, muss ich ganz echt sagen.

I: Ja.

B: Und das war / Wobei Vieles zwischendurch auch schmerzhaft war. Ja. Ähm, weil eigentlich diese Firma eigentlich so ein bisschen meine Rente sein sollte. Entweder dass die Firma das Ganze auf Rentenbasis verkauft hätte, oder aus dem Verkaufserlös halt dann mir die Rente zusätzlich finanziert hätte, neben dem, was ich halt schon angespart hatte ein bisschen. Und das war halt ein bisschen / Das ist ohnehin weg, ja. Und deswegen war ich auch ein bisschen an der Firma gehangen, so richtig, ja, hm / (lacht)

I: Ja. Kann ich mir schon vorstellen, ja. 
B: Rein theoretisch ist es so. Also, wenn ich heute anschaue, für einen Arbeitnehmer ist es eigentlich sehr viel geregelt. ... (unverständlich) Sicherung und so weiter. Wenn du aber als Unternehmer insolvent gehst, so wie ich, dann ist einfach nichts mehr da. Nichts. Nothing. Definitiv. Egal, was du tust, es ist nichts mehr da.

I: Hat das auch noch weitere Auswirkungen auf den Alltag gehabt? Zum Beispiel hat mir jemand erzählt, er hat keinen Handyvertrag mehr bekommen. oder solche Sachen.

B: Ja, ja. Ja, Handyvertrag sowieso nicht mehr. Das ist alles weg.

I: Alles weg.

B: Ja, ja, klar. Du kriegst keine EC-Karte mehr, du kriegst kein / mit Konten ha! Beim Konto verlangen Sie eine Kontogebühr, das ist ja utopisch. Du hast eh kein Geld. Und wenn du ein Konto willst, verlangen sie Kontogebühren, dass es die Sau graust. Also, ich habe lange kein Konto mehr gehabt, sehr lange kein Konto mehr. Du kriegst nichts mehr. Du kriegst überall, wo du irgendwo, kriegst du keinen Cent mehr. Das ist aus. Du kannst / Wenn du Glück hast, kriegst du vielleicht von einem Bekannten, den du kennst, aber selbst da ist es schwierig, ja. Mal einen Euro, wenn du sagst: „Ja, kannst du mir mal oder so."

$\mathrm{Ne}$, auch dann zum Beispiel eine Wohnung finanzieren. Wie willst du das machen? Das ist / Es geht nicht. Null. Im Endeffekt ist das dann das erste Eck, wo du dann plötzlich unter der Brücke schläfst.

Was ich mit Handy gemacht habe, ich habe einfach eine Prepaidkarte gekauft. Das ist die einzige Chance. Vertrag kriegst du keinen. Die habe ich heute noch, und ich werde einen Teufel tun, die Prepaidkarte wegzutun. Kein Handyanbieter kriegt meine Nummer oder Kontodaten. Das fällt mir doch im Traum nicht ein. Also, das sind so / Das kriegst du heute nicht mehr. Keine Chance. Und wenn du dann zum Beispiel jetzt heute, Ich kann zum Beispiel heute zu einigen Ärzten nicht gehen, weil die in der Insolvenz die Sachen nicht bezahlt haben.

I: Aha. 
B: Mir tut das leid, ja, weil ich schon gute Ärzte hatte. Also das ist das, was mich schon sehr eingeschränkt hat, einschränkt. Du hast halt auch wirklich wenig, wenig Geld. Du hast wenig Geld. Gott sei Dank habe ich Bekannte gehabt, die haben mir ein Auto geschenkt. Ja, der hat mir ein Auto geschenkt! Das war ein kleiner Skoda gewesen. Hat er gesagt: "Da, $<<<$ Name geändert $>>>$, du warst immer so freizügig, oder bist so. Da hast mein Auto!" (lacht)

I: (lacht) Nicht schlecht.

B: Ja, es ist aber nicht so. Nicht jeder macht das, ja.

I: Ja, klar.

B: Ja, und du musst dann halt auch wieder schauen, dass du halt die Autoversicherung ja / Wenn du eine Insolvenz gehabt hast, wer will dann noch dein Auto versichern? Hm. Ich hab's über sie laufen lassen. Da hast du ein Problem. Du kannst es nicht. Du bist / Das ist das Problem. Ich meine, ich habe Gott sei Dank das Glück ein bisschen, dass da dieser Vergleich zustande gekommen ist. Aber du bist in einer Insolvenz ein Mensch zweiter Klasse. Definitiv.

I: Hm, und lahmgelegt irgendwie.

B: Voll! Man muss sich vorstellen, du bist ein Mensch, der Entscheidungen getroffen hat, der verantwortlich ist für Leute, also zumindest war das ich. Ja, für die Mitarbeiter, für die ganzen / oder ich fühlte mich verantwortlich. Und dann im Endeffekt bist du ein Nichts. Ja, von heute auf morgen. Da kommt einer her und sagt. „So, jetzt zeig mal deine Taschen. Was hast du denn da drin?" Und du musst ihm die Taschen zeigen. und wenn er sagt: „Geh auf die Knie." Dann musst du auf die Knie gehen. Das sind Insolvenzverwalter. Wenn du einen erwischt / Ich habe da mal mit anderen Leuten da so gesprochen, die in einer Insolvenz sind. Die haben einen Insolvenzverwalter gehabt, mein Lieber, wenn ich das da von denen gehört habe, sage ich: „Gott sei Dank habe ich den $<<<$ Name anonymisiert $>>>$ !“ 
I: (lacht)

B: Ja! Es ist so.

B2: Ja, der war menschlich.

B: Ja, es hat halt gepasst, ja. Und es war ok. Wie gesagt, er hat mir auch die Freiheit gelassen, mit 1000 Euro im Monat zu hantieren in der Firma. Das macht kein anderer. Definitiv. Er muss ja doch für diese 1000 geradestehen. Jeden Monat muss er geradestehen. Wenn ich die jetzt versaubeutelt hätte oder so, müsste er die draufzahlen. Wer macht denn das? Sorry. Und das ist natürlich hier der Vorteil. Als ich dann draußen war erst mal, ja und das war ja blöd. Da musste ich dann irgendwo mal vom Arbeitsamt mal zu so einer Unternehmensgründungstussi, die vom Arbeitsamt angestellt war oder so, oder beauftragt war. Und die sagt halt, was ich da so zu machen hätte, oder so. Ja, sagte ich: „Mir kommt es jetzt schon wieder, ich werde jetzt demnächst wieder eine Firma anmelden. Weil, es hat keinen Sinn in meinem Alter, wenn ich da irgendwo / ich meine irgendwann muss ich ja mal meinen Lebenslauf zeigen, ob ich den vorne hinschick oder hinten hinschick. (lacht) Irgendwann muss ich mein Datum ja reinschreiben. Und wenn da einer sieht 63, pff!“ ich hatte ja noch, das war ja kurz bevor ich /

B2: Jetzt bist du 66. (lacht)

B: Ja, 66, da fängt es ja wieder an. (lacht) Kurz vorher hatte ich ein Angebot von einem Kollegen, der mit mir im Badminton war, oder ist, oder war, oder ist, er ist eigentlich noch. Der hat gesagt: „Du, bei mir in der Firma fehlt der technische Geschäftsführer. Magst du das machen?" Und dann war ich knapp dran. Und dann hat es mir im Unfall das Zeug zerlegt. Und dann haben sie dann im Januar oder im Februar einen eingestellt. Also, die letzte 5, 6 Jahre hätte ich locker noch, oder zehn Jahre, bis 70 oder so, locker machen können.

I: Ja. 
B: Aber, dann kommt das auch noch dazu, nicht? Es ist natürlich auch, das ist / ich meine, Viele sagen, das ist eine Idiotie, und das stimmt nicht. Aber es ist auch noch der psychische Faktor, der noch dazu kommt. Der Körper, der rebelliert dann danach. Also, es ist nicht so, dass die Insolvenz / Wenn ich wahrscheinlich nicht den Unfall gehabt hätte, hätte ich was anderes gehabt. Da bin ich mir ziemlich sicher. Ja. Weil ich kann im Nachhinein ziemlich gut immer sagen, wo es so war. Sagen wir mal, diese Krebsgeschichte, die war nach der Trennung von meiner Frau. Das habe ich nicht verkraftet. Dann der Blutkrebs, das ist eigentlich ein Altersblutkrebs, der nicht tödlich ist, also ganz so schlimm ist es nicht, wie es sich anhört. Aber, ja, man hat das Zeug. Der kam auf den Stress mit meinem Sohn und dieser ganzen Geschichte. Das war genau ein Jahr später, da habe ich den (klatscht) zack! Ja. Und die Insolvenz war dann das, wo der Unfall gewesen ist. Jeder sagt, das ist Spinnerei, aber ich denk, da ist was dran. Ja. Das war genau ein Jahr später. Ungefähr. Ein ein Viertel Jahre. Als das schlussendlich vorbei war.

Im Moment geht es mir saugut. Ich hoffe, dass nicht wieder was kommt in irgendwelcher Form. Aber auch nur deshalb, ich glaube, weil ich eine gewisse, weil ich auch durch den Prostatakrebs eine bisschen andere Lebenseinstellung gekriegt habe. Das ist schon mal eine andere Geschichte. Durch den Blutkrebs weiß ich nicht, ob ich da etwas verändert habe. Aber durch die Insolvenz habe ich schon, natürlich. Ich muss anders umgehen. Ich darf auch gar nicht daran denken, dass ich zwei Millionen, also / ich meine, wenn ich zusammengerechnet habe, von den zwei Millionen hatte ich 1,5 Millionen schon abbezahlt. (Pause) Und dann macht es patsch.

I: Ja.

B: Ja, und jetzt habe ich wirklich nichts. Wenn ich jetzt überlege, was für ein Auto fahre ich. Ich fahre einen alten VW. 1999 habe ich den als erstes Firmenauto gekauft. Den ich dann irgendwo mal meinem Sohn vermacht habe, als ich das zweite Auto gekauft habe. Und der hat das Auto weitergegeben an seine Tochter. Und die hat ihn wiederum an meine Tochter weitergegeben. Und jetzt fahre ich das Auto wieder. Ja, ähm. Das Ding hat 400000 km drauf. Ich kann mir ja gar kein anderes leisten. Sorry. Und ich muss sagen, mir geht es nur deswegen auch so gut, weil ich die $<<<$ Name 
anonymisiert $\gg>>$ habe. Wenn ich sie nicht hätte, würde es mir mit Sicherheit nicht so gut gehen. Das ist für mich ganz klar. Ich habe jetzt hier ein schönes Heim mit ihr zusammen. Fühle mich wohl. Aber nur aufgrund der Tatsache, dass ich die $<<<$ Name anonymisiert $\gg>>$ kennengelernt habe. Es ist so.

B2: Hast auch mal Glück gehabt in deinem Leben. (lacht)

I: (lacht)

B: (lacht) Manchmal habe ich das, Gott sei Dank. 
Nachtrag zu Interview 6

Er ist eindeutig der Meinung, dass die Privatinsolvenzjahre in Deutschland zu lang sind. Die ganzen Nachbarländer haben das alle kürzer. Man sollte hier eine europaweite Angleichung anstreben.

Sagte angeblich zum Insolvenzverwalter: "Wenn du dir auch nur einen Euro von meinem Sohn holen willst, dann bring ich dich um!"

Sagte, als es darum ging, dass er jetzt flexibel sein muss, um alle sich bietenden Chancen zu ergreifen: "Ich habe halt Glück, weil, wissen Sie, ich kann ja alles." 
Appendix VIII: Transcript of Interview 7

I: Mir wäre es am liebsten, wenn wir damit starten, dass Sie mal so Ihren Werdegang schildern, beruflich und privat von der Kindheit bis heute so in groben Zügen mal durchgehen.

B: Also, geboren auf jeden Fall im Juni 67 in Belgien in $<<<$ Ort anonymisiert $>>>$. Die ersten 15 Jahren aufgewachsen in Belgien, auch dort zur Schule gegangen. Und geschiedene Eltern, seit ich 2 Jahre alt bin, waren sie schon geschieden. Mutter Friseurin, Montag bis Samstag von früh sechs Uhr bis abends sieben Uhr im Geschäft. Einen Bruder habe ich, der ist älter, zwei Jahre älter. Wir haben keinen Kontakt. Und das Einzige was mir als Merkmal aus meiner Kindheit in Belgien bleibt, ist mein Sport. Ich habe mich viel sportlich engagiert, und das war eigentlich mein Leben. Dann mit 15 Jahren / Meine Mutter hat eine Zwillingsschwester in Südafrika. Und mit 15 Jahren war die Situation privat, dass meine Mutter nicht mehr mit uns umgehen konnte, mit zwei Brüdern. Und sie hat einfach die Frage gestellt, wer Lust hätte, nach Südafrika zu ziehen zu ihrer Zwillingsschwester. Und da habe ich sofort zugeschlagen. Und mit 15 habe ich dann das Haus verlassen, bin nach Südafrika und hab dann eine Lehre angefangen als Werkzeugmacher bei der Firma $<<<$ Unternehmen anonymisiert $>>>$ in $<<<$ Ort anonymisiert $>>>$. Habe dann die Lehre auch durchgezogen.

I: Ist das dann genauso organisiert wie in Deutschland eine Lehre?

B: Weiß ich nicht. Den Vergleich habe ich noch nie gemacht. Da es eine deutsche Firma war und mein / der Chef von der Ausbildungsstelle war ein Herr $<<<$ Name anonymisiert $\gg>$, das war ein Engländer sogar, vermute ich, dass die Standards auf gleichem Niveau waren. Meine Ausbildung ist auch hier in Europa anerkannt. Also, gehe ich davon aus, dass es auf gleichem Niveau ist. Musste dann / kam dann zu einer Entscheidung entweder zwei Jahren Armee, in Südafrika Pflicht zu machen, oder das Land zu verlassen. Also zu neutralisieren, Armee machen, oder nicht neutralisieren, 
und dann das Land verlassen. Habe mich für das Neutralisieren entschieden. War dann zwei Jahren aktiv in der Armee.

I: Wie alt waren Sie da?

B: Ja, 21, 20, 21. Doch, 20, um den Dreh rum. Und nach der Armee dann zurück zu $<<<$ Unternehmen anonymisiert $>>>$, wobei ich dann für mich festgestellt haben, den Beruf, den ich erlernt habe, will ich eigentlich nicht mein ganzes Leben lang ausüben. Mich interessieren andere Aspekten, und bin dann in der Logistik eingestiegen bei $<<<$ Unternehmen anonymisiert $>>>$. Das hat mir sehr gut gefallen. Und ich habe mich dann so weitergebildet. Erst 2-3 Jahren bei $<<<$ Unternehmen anonymisiert $>>>$ selbst, Logistik, Prozesse, Produktionsplanung. Und da habe ich gespürt, ok, das ist genau, was mir am meisten gefällt. Habe mir dann das Ziel gesetzt, mehrere Industrien zu durchlaufen. Ich wollte ja / bin sehr wissensbegiert. Ich möchte am liebsten jeden Tag komplett neu lernen. Und war dann in $<<<$ Ort anonymisiert $>>>$, wo zum Beispiel Stahlfelgen hergestellt worden. Das war damals für Mazda, für Toyota. Habe dann gemerkt, ok, Prozesse sind mir jetzt geläufig. Ich möchte jetzt wieder was Neues lernen. Und bin dann in der Foundgy Business heißt das auf Englisch, das Gusseisen, also alles, was man gießt, eingestiegen. Auch für drei Jahre. Und wollte dann / habe dann wieder gewechselt danach. Wollte ich eigentlich so ein bisschen eine Kombination zwischen einer höheren Fertigungstiefe und Handel kennenlernen. Bin dann in einer Firma eingestiegen, die heißt $<<<$ Unternehmen anonymisiert $>>>$. Das ist die größte Kleinelektrogerätenhersteller in Südafrika und auch einer der größte Handelsunternehmen in Südafrika. Da bin ich dann in der Produktion als Prozessmanager eingestiegen. Habe dann auch einen Zeitraum von 2 - 3 Jahren den Export auch geleitet. Bin dann auch in der Welt gereist auf Ausstellungen und so weiter. Was mir auch sehr gut gefallen hat, habe ein sehr gutes Netzwerk da aufgebaut. Da war ich schon zusammen mit meiner Frau. Meine Frau habe ich davor kennengelernt. Die ist von deutschen Eltern. ' 84 haben wir uns kennengelernt, ' 90 haben wir geheiratet, '92 ist der Sohnemann gekommen, '95 die Tochter. Beide in Pretoria geboren. Und um `95 herum haben wir dann entschieden, bzw. es war immer schon ein Wunsch meiner Frau, in Deutschland zu wohnen. Und sie arbeitet für $<<<$ Unternehmen anonymisiert $\gg>>$. Damals auch schon. Und da kam zufälligerweise 
zu dem Zeitpunkt, wo wir mit dem Gedanken gespielt haben, das Land zu verlassen, kam ein interessantes Jobangebot von $<<<$ Unternehmen anonymisiert $>>>$ hier in Deutschland. Und da haben wir dann zugeschlagen. Ich habe meinen Job aufgegeben. Und wir sind dann hier her gezogen nach Deutschland `98 mit den Kindern. Nicht weit von hier, also, $<<<$ Ort anonymisiert $>>>$. Das ist $80 \mathrm{~km}$ von $<<<$ Ort anonymisiert $>>>$ weg. Weil da gibt es einen Innovationspark, und da ist $<<<$ Unternehmen anonymisiert $>>>$, und da war die Stelle. Ich bin dann ohne Job hierhergezogen. Hatte aber mit der letzten Firma einen Deal gemacht, ich versuche hier eine Niederlassung zu eröffnen in Deutschland. Habe ich dann auch gemacht. Nach einem Jahr aber festgestellt, dass die Investitionskosten und der Etablierungszeitraum viel zu groß ist für das Produkt. In Europa der Wettbewerb ist viel zu groß. Dann haben wir uns geeinigt, dass ich dann wieder aufhöre, aber ich / ein Jahr war ich damit beschäftigt. Und gleichzeitig wurde dann zufälligerweise direkt auch in $<<<$ Ort anonymisiert $>>>$ in dem Innovationspark eine Stelle für Distribution, also in der Logistik, frei. In einer der Zulieferer von $<<<$ Unternehmen anonymisiert $>>>$. Und die habe ich dann wahrgenommen und habe dann sofort das Angebot angenommen. Bin dann sozusagen vom Werdegang wieder von vorn anfangen, was ok war. Ich fand das sehr interessant, habe Vieles gelernt. Und in der Firma hauptsächlich dann auch Logistik und Prozesse, also Einkauf, Logistik, Prozesse, Kundenbetreuung, das waren so die Hauptaspekte. Habe zehn Jahre lang das gemacht bei der Firma $<<<$ Unternehmen anonymisiert $>>>$. Vieles gelernt, sehr automatisiert, also kaum Handgriffe, kaum Mensch beteiligt. Das war sehr interessant aber ist auch an einen Punkt gekommen, wo es mich dann nicht mehr herausgefordert hat. Es war zwar schön auch da zur Arbeit zukommen, um vier Uhr schön heimkommen, alles funktioniert, Sport machen, aber es war für mich langweilig. Und dann ist zufällig, das sind solche Zufälle immer wieder, ist ein Jobhunter über Xing damals, damals hieß es B2B oder so etwas, auf mich zugekommen. Und erst hatte ich kein Interesse, ja die haben einen Prozessmanager gesucht im $<<<$ Ort anonymisiert $>>>$, und hatte kein Interesse, und habe dann abgelehnt. Und drei Monate später ist der nochmal auf mich zugekommen von dieser Firma. Habe ich auch nach dem Motto, es schadet ja nicht das mal anzuhören und zu kucken, was das ist. Und dann bin ich im Juli `98 zum ersten Mal hier nach $<<<$ Ort anonymisiert $>>$ gekommen, um den Betrieb mir mal anzuschauen. War dann gleich sowohl schockiert als auch wahnsinnig interessiert an dem, was ich vorgefunden habe. 
Schockiert, weil die hier im Vergleich zur Automobilindustrie also 50 Jahren hinterher sind mit der Automatisierung mindestens. Und gleichzeitig fand ich das sehr aufregend wegen dem Rohstoff Holz. Und genau, weil wir so weit hinterher sind die Herausforderung, den Betrieb nach vorne zu bringen. Also, es ist egal, was man anfasst, man kann es verbessern. Und da gibt es 100000 Baustellen. Und das ist wie ein kleines Kind, das man jetzt gerade in einen Raum hineinsteckt mit 100000 neuen Spielzeuge. Jetzt fassen wir mal jedes an und gucken wir, was wir damit machen.

Habe ich mich dafür entschieden im Oktober 2007 hier bei $<<<$ Unternehmen anonymisiert $\gg>>$ damals anzufangen als Prozessmanager.

Da gab es zwei Geschäftsführer. Der Geschäftsführer hatte - das habe ich im Nachhinein erst mitbekommen - die Geschäftsführer waren beide dann bereits mit dem Vertrag Alterszeit beschäftigt. Und der eine ist dann letztendlich 2008 ausgestiegen, und der andere dann sechs Monate später. Und der Gesellschafter von der damaligen Firma hat mich dann gebeten, ob ich die Firma übernehmen würde, geschäftsführungsmäßig. Wir haben uns dann zwar geeinigt, ich habe dann gesagt, technisch kein Problem, kaufmännisch nein. Das ist nicht mein Metier. Und haben uns dann leider ohne schriftlich oder irgendetwas haben uns dann mündlich geeinigt. Er macht die Finanzen, ich mache das Technische. Und so bin ich da eigentlich in die Geschäftsführung eingestiegen von der Firma.

Ja, und seit 2007 bis März 2010, wo ich die Firma Insolvenz angemeldet habe, war dann die $<<<$ Unternehmen anonymisiert $>>>$. Und dann kam $<<<$ Unternehmen anonymisiert $>>>$, also nach langem Hin und Her mit dem Insolvenzverwalter und Kundensuche, in einer zweite Runde ist dann $<<<$ Unternehmen anonymisiert $>>>$ zum Zug gekommen. Und seit Dezember 2010 gehören wir zur $<<<$ Unternehmen anonymisiert $>>>$ unter dem Namen $<<<$ Unternehmen anonymisiert $>>>$ bis zum heutigen Tag. Und das ist jetzt der Werdegang.

I: Ok, Gut. Gehen wir nochmal auf die Insolvenz an sich ein. Wie kam es dazu? Wo würden Sie die Gründe dafür sehen?

B: Sind zwei Paar Stiefel. Man muss die Frage sogar trennen. Wie kam es dazu? Das ist für mich das Erste, was ich beantworte. Ich war kaufmännisch wenig involviert, habe zwar Kontrollen gehabt, aber der Gesellschafter hatte seinen Sitz in $<<<$ Ort 
anonymisiert $\gg>>$. Der hat noch mehrere Firmen. Und da saß eine Kontrolle, und hier $\mathrm{sa}$ eine Kontrolle, und die haben eigentlich alles miteinander ausgekaspert. Bis zu einem Punkt es ist schwer gegangen, das habe ich ja alles mitbekommen, auch mit Lieferanten gesprochen, habe gemerkt, ok, hm, saisonbedingt / der Markt / die Aufträge sind weggebrochen. Die Kosten sind natürlich nicht weggebrochen. Wir waren damals noch die doppelte Mannschaft hier, über 200 Leute waren hier. Habe ich mitbekommen, dass die Verhältnisse natürlich immer schwerer werden finanziell. Die Lieferanten zu bezahlen, Löhne zu bezahlen und so weiter. Und dann mehr, mehr, mehr eingestiegen auch in die Finanzseite bis zu einem Punkt November 2009, oder ein bisschen davor sogar, wo aus Gesprächen heraus mit dem Herrn $<<<$ Name anonymisiert $\gg>>$, das war der Gesellschafter, und der war / zweimal pro Monat war er hier, haben wir Besprechungen gehabt. Und aus den Besprechungen heraus bin ich suspekt geworden auf seine Vorgehensweise, und was er eigentlich bezwecken will. Hat angefangen, sich zu widersprechen. Er hat angefangen, Sachen zu wollen, die selbst aus nicht-kaufmännischer Sicht nicht richtig waren. Und der Druck ist gestiegen. Bis zu einem Punkt, wo er dann auf einmal angefangen hat zu sprechen über Management-Buy Out. Und verlangte von mir / hat dann mich in 2-3 Termine sogar mit Anwälten von ihm konfrontiert, um über Management-Buy Out zu sprechen, um Fördergelder von der LFA zu holen, um die Firma mit dem Management-Buy Out in die nächste Stufe zu bringen. Und das war mir dann alles ein wenig zu viel, ein wenig dubios und suspekt. Und ich habe dann / ich kenne einen guten Steuerberater hier in der Gegend, der auch mit Insolvenzen zu tun hat. Habe ich ihn darauf angesprochen und habe ihn darum gebeten, mal ein paar Stunden mit mir zu verbringen, die Bücher mal durch zu gehen. Und daraufhin hat der mir empfohlen, eine Kanzlei, eine Fremdkanzlei, in der Firma einzusetzen und alles checken zu lassen. Das habe ich dann gemacht, ohne das mit dem Gesellschafter zu besprechen. Weil, wenn ich es besprochen hätte, dann wäre das nicht gut gegangen. Der hätte dann andere Wege gefunden. Sehr gewieft. Also, der ist ein guter Geschäftsmann. Der macht sein Leben, aber er hat viele Leuten bereits in Mitleidenschaft gezogen. Und das habe ich im Nachhinein alles herausgefunden. Sogar seine eigene Familie, die Firma $<<<$ Unternehmen anonymisiert $>>>$. Der ist Cousin, der Herr $<<<$ Name anonymisiert $>>$ ist Cousin von der Firma $<<<$ Unternehmen anonymisiert $>>>$. 
Und der $<<<$ Name anonymisiert $>>>$ ist in 2004 verstorben kurzfristig. Und das war eigentlich der Startpunkt für die Schieflage der Firma, also um den Zeitraum. Davor auch schon war die Wirtschaftslage für Spielzeuge immer schwieriger, aber die eigentliche Schieflage im Nachhinein betrachtet war mit dem Sterben vom Herrn $<<<$ Name anonymisiert $>>>$. Da ist dann erst ein Fremdgesellschafter rein gekommen in die Firma. Der hat viel Geld vernichtet, wahnsinnig viel Geld vernichtet. Und dann ist der Herr $<<<$ Name anonymisiert $>>>$ eingestiegen als Cousin. Also die Frau $<<<$ Name anonymisiert $>>>$, die immer noch da wohnt, hat dann ihren Cousin gebeten, da zu unterstützen. Und so ist er eingestiegen. Ja. Dann habe ich eine Kanzlei aus Passau privat, also fast geheim muss man sagen, ganz geheim war es jetzt nicht, damit beauftragt, die Büchern zu kontrollieren. Ich habe ihnen dann alle Unterlagen zur Verfügung gestellt. Das war über Weihnachten 2009/2010. Anfang Februar ist dann das Ergebnis gekommen von der Kanzlei mit / das war eindeutig, dass entweder Insolvenz anmelden oder einen gewissen Betrag eintreiben. Also Cash eintreiben liquid. Dann habe ich natürlich mir die Gesetze nochmal mir vor Augen gebracht. Man hat ja vom Wissen einer Insolvenz genau drei Wochen, und dann muss man anmelden. Und in diesen drei Wochen habe ich auch Gesellschafterversammlungen einberufen, wozu der Eigentümer nicht gekommen ist. Hat sich auch über seinen Anwalt bei mir gemeldet. Und am Ende des Tages das Geld, das wir gebraucht hätten, ist dann auch nicht vom Gesellschafter rübergewachsen. Also, Kapitaleinlagen hätten wir gebraucht. Die Banken haben dann auch nicht mitgespielt. Ist ja klar. Ich habe dann noch versucht, bei den Banken irgendwie was zu bewegen. Da haben sie auch nicht mehr mitgemacht. Und da war am 17. März, oder 19. März, das weiß ich jetzt nicht mehr so genau, der Tag ist sowieso verdrängt, bin ich dann nach $<<<$ Ort anonymisiert $\gg>>$ gefahren früh morgens mit allen Unterlagen. Und normalerweise, ich wohne in $<<<$ Ort anonymisiert $>>>$, nach $<<<$ Ort anonymisiert $>>>$ ist eine halbe Stunde, ich denke, ich bin knapp über eine Stunde gefahren. Ich bin 60 gefahren auf der Autobahn. Ich habe bis zur letzten Minuten gehofft, da ruft jemand an jetzt und sagt: „Stopp, das machen wir so und so". Es hat niemand angerufen natürlich. Und ich war dann beim Insolvenzgericht, und ja / genau 20 Minuten hat es gedauert. Die Richterin hat die Sachen angeschaut, hat dann sofort Insolvenzverwalter $<<<$ Name anonymisiert $>>>$ angerufen, ob er da Interesse hätte. Und dann habe ich auch sofort mit ihm telefoniert. Der war auf dem Weg nach $<<<$ Ort anonymisiert $>>>$. Dann haben 
wir uns verabredet, dass wir um $11 \mathrm{Uhr}$ uns hier treffen in $<<<$ Ort anonymisiert $>>>$. Das hat dann auch so stattgefunden. Dann haben wir gleich eine

Belegschaftsversammlung gemacht. Ich habe mir dann auch überlegt, Polizeischutz zu nehmen, weil in dem Moment die Gemüter waren schon sehr heiß bei der Belegschaft. Und ich hatte auch schon Drohungen bekommen. Und da war ich mir nicht sicher, wie gehe ich jetzt damit um. Habe ich mich dann nicht dazu entschieden. Das Team von dem Insolvenzverwalter war Gott sei Dank vor mir hier. Und das hat vielleicht schon der Wind herausgenommen. Und von da an war eigentlich die Firma in der Insolvenz. So ist das zustande gekommen die Anmeldung.

Woher kommt das? Es haben mittlerweile natürlich viele Leuten viel zu Sagen gehabt über woher die Schieflagen kommt. Für mich zusammengefasst ist die Schieflage tatsächlich der Übergang vom Familien- zum Fremdinhaber. Der Fremdinhaber, Herr $<<<$ Name anonymisiert $>>>$, war auch regional hier. Hatte zwar gute Visionen aber nicht die Auffassung, das umzusetzen in der Realität. Also, er hatte die Werkzeuge nicht dazu aus meiner Sicht. Und hat innerhalb anderthalb Jahren über zwei Millionen DM damals vernichtet an ein Thema für Japan, weil Japan der größte Exportkunde ist. Mit einer neuen Marke ... (unverständlich). Und das war für die Kapitalgrundlage der Firma aus meiner Sicht bereits der Stich ins Herz. Dann war das gesamte Kapital raus. Die Frau $<<<$ Name anonymisiert $>>>$ und der Herr $<<<$ Name anonymisiert $>>>$ haben dann über Gespräche mit der Sparkasse und so weiter dann das bewirkt, dass sie aus dem Thema rausgeht. Und 2004, ne 2006/ 2007 ist die Firma dann übernommen worden vom Herrn $<<<$ Name anonymisiert $>>>$. Mit die Tochter von Frau $<<<$ Name anonymisiert $>>>,<<<$ Name anonymisiert $>>>$, war dann die Zweitgesellschafterin mit $20 \%$ Beteiligung. Und der Herr $<<<$ Name anonymisiert $>>>$ mit $80 \%$. Der Herr $<<<$ Name anonymisiert $>>>$ kommt auch aus einem ganz anderen Metier. Der ist Immobilienspezialist und beschäftigt sich mit erneuerbaren Energien, also Wasserkraftwerke. In $<<<$ Ort anonymisiert $>>>$ zum Beispiel gibt es dann Wasserkraftwerk Rüssel, Rüsselkraftwerk. Und das ist seines. Und das ist eigentlich sein Metier. Sein erster Angriff war dann auch das Heizkraftwerk. Er hat dann eigentumsmäßig das Heizkraftwerk aus der Firma herausgezogen, damit Geld bewegt links und rechts, aber da bin ich leider nicht der Spezialist, um das jetzt genau wiedergeben zu können. Und das war dann eigentlich die Weiterführung der schlechten Lage dann. Große Kunden sind abgesprungen. $<<<$ Unternehmen 
anonymisiert $>>>$ und $<<<$ Unternehmen anonymisiert $>>>$ sind dann Hauptkunden geworden. Und $<<<$ Unternehmen anonymisiert $>>>$ und $<<<$ Unternehmen anonymisiert $\gg>>$, jeder der schon mal für die geliefert hat oder gearbeitet hat, weiß, da gibt es kein Geld zu verdienen. Im Gegenteil, wenn man nicht aufpasst, vernichtet man sogar Geld. Riesen Volumen. Riesen Kosten. Aber kein Verdienst. Und das war auch mit ein Grund, warum die Firma dann letztendlich den Bach runter gegangen ist. Und auch der Herr $<<<$ Name anonymisiert $>>>$ selbst, seine Absichten jetzt im Nachhinein betrachtet, waren von Vorhinein nie, die Firma zu behalten. Das ist dann sogar aus Gesprächen herausgekommen, also wortwörtlich gegenüber jemand anderes, dass er mich direkt in das Messer laufen lassen wollte. Hauptsache, er ist die Firma los. Mit Aussagen gegenüber anderen Leuten, die jetzt herausgekommen sind. „Der versteht das sowieso nicht, der ist zu blöd, der macht das alles mit". Und dann: „Ich krieg sogar noch eine Million raus, und was mit ihm passiert ist mir auch sch... egal". Also. Das ist jetzt meine Geschichte und 100.000 Leute werden eine andere Geschichte erzählen, das ist meine. Ich habe es glücklicherweise, Gott sei Dank, erkannt, mit Hilfe von den Steuerberatern, dass da was schiefläuft.

Und Gott sei Dank auch für die Belegschaft, weil ich sehe das mittlerweile als Segen. Ich glaube fest daran, alles was passiert, passiert, weil es hätte passieren sollen. Da glaube ich fest daran. Und auch in diesem Fall war es zwar jetzt drei Jahren sehr schwer, das war auch psychologisch sehr schwer, also psychisch und daheim und mit der Familie, aber es hat sich alles zum Positiven entwickelt, auch für die Firma. Weil jetzt, wo die $<<<$ Unternehmen anonymisiert $>>>$ die übernommen hat. Ohne diese Übernahme wäre die Firma auch ohne mich, mit jemand anderes, oder mit mir, mit anderen Banken, das wäre nicht gegangen auf Dauer. Und jetzt haben wir eine Grundlage, wo ich weiß, wo ich mich sehr wohl fühle, und sage: „Ok, die Firma wird es weitergeben und die Belegschaft“. Einen Großteil der Belegschaft, konnten wir retten. Und haben jetzt sogar eine Situation, wo die auch für deren Leistungen, für das, was die Menschen hier alles tagtäglich so leisten, belohnt werden. Und es auch Sinn macht für sie zur Arbeit zu kommen. Wo man wieder glänzen kann, lachen kann, das ist die positive Seite.

I: Und wenn Sie jetzt noch mal daran denken, als es begann, quasi als Sie das Ergebnis von dem Steuerbüro bekommen haben. Man hofft ja immer noch, dass man das Ruder 
rumreißen kann. Aber wann war denn so der Moment, wo Sie wirklich gemerkt haben, jetzt geht es nicht mehr?

B: Ja, wo ich keine Reaktion vom Gesellschafter bekommen habe. Das war für mich / Ich habe es auch vermutet, ich habe gewusst, wo ich die Gesellschafterversammlung ein-/ in diesem Zeitraum, wo ich dann zwischen dem Wissen und alles prüfen lassen, habe ich natürlich auch viel gefragt. Habe ich viel mit Leuten telefoniert, die schon mit der Gesellschaft zu tun gehabt haben. Habe ich mir auch über andere Kanäle mal erzählen lassen, "wie funktioniert denn der Typ eigentlich, wie macht der seine Geschäfte?". Und da ist eigentlich nur Negatives gekommen. Und da habe ich gewusst, ok, der lässt mich auflaufen. Weil der Management-Buy Out war auch ein whichtiges Thema. Das war eigentlich, wo ich schon skeptisch war, und das hat sich mir dann bestätigt. Wir waren bei der LFA in München, haben wir eine große Sitzung gehabt. Und das war das erste Mal, wo Zahlen auf dem Tisch waren. Ich habe ihn auch vorher immer gebeten, gib mir doch ein Grundwerk Zahlen zu geben. Ich lasse das durch einen mir vertrauten Wirtschaftsspezialisten prüfen, ob ein Management-Buy out überhaupt Sinn macht. Und ich habe die Zahlen nie gehabt, oder nie bekommen. Das, was ich bekommen habe, war wischiwaschi, also, das hätte ich mir genauso gut aus der Bild herauskopieren können. Und da waren das erste Mal wirklich Zahlen im Gespräch, die mich absolut vom Hocker gehauen haben. Und das habe ich dann natürlich dem vertrauten Steuerberater erzählt, und dann hat er mir auch gesagt, die Reise geht eindeutig in eine Richtung. Und das ist für mich nicht die richtige Richtung, oder nicht die positive Richtung. Habe trotzdem noch versucht, das zu retten, weil ich / Irgendwie glaube ich an das Gute im Menschen. Wir haben uns gut verstanden die anderthalb Jahren, also, so ist es nicht, als Mensch. Es ist nicht, dass ich ihn nicht leiden konnte, oder so etwas. Man glaubt halt doch an das Gute irgendwie. Habe ihm gesagt, ok, ich brauche so viel Geld, so viel Kapitalanlagen, das muss bis da und da passieren, Gesellschaftsversammlung / Und wo er dann sich gemeldet hat, "du, ich habe keine Zeit". Dann dass war für mich der Strich, da habe ich gewusst, ok, da kommt nichts. 
I: Und das Insolvenzverfahren an sich, also die Zeit der Insolvenz von Antragstellung bis dann klar war, man ist gerettet, weil der neue Investor aufgetaucht ist. Wie ist das abgelaufen? Wie lange hat sich das hingezogen? Wie war das?

B: März bis Oktober im gleichen Jahr.

I: Ach ja, relativ zügig also eigentlich.

B: Ja. Das ist gut gelaufen. Die ersten drei Monate waren / Vielleicht muss ich es anders sagen. Wo der Insolvenzverwalter das Thema übernommen hat, an dem Tag, wo er dann hier war, wo ich angemeldet habe, hat er mir auf der Treppe gesagt: „Herr $<<<$ Name anonymisiert $>>>$, Sie können sich jetzt zurücklehnen, Sie haben getan, was Sie tun konnten. Und ab jetzt können Sie sich nur noch auf das Positive fokussieren". Das war ein Satz, den ich mitgenommen habe, aber es hat allerdings drei Monaten gedauert, fast drei Monate, länger sogar, drei bis vier Monate, bis ich tatsächlich für mich persönlich das Gefühl bekommen haben, ok, das läuft jetzt unter jemand anderes seinem Regenschirm. Ich muss mich nicht mehr um die negative Sache kümmern, ich kümmere mich nur darum, den Insolvenzverwalter so zu unterstützen, die Kunden so zu beraten, dass jemand kommt und sagt: „Jawohl, den Laden will ich haben". Aber es hat eine Weile gedauert.

Das Psychologische dann auch im Hintergrund. Ich habe dann auch eine Krankheit bekommen. Ich habe Colitis Ulcerosa seitdem. Das war drei Monate vor Insolvenzanmeldung, wo die Krankheit sich zum ersten Mal gezeigt hat. Und während der Anfangsphase, in der Insolvenzverwaltungsphase, hat sie sich dann auf den Peak gebracht. Und dann habe ich irgendwo einen Punkt gefunden, das war komischerweise fast der gleiche Punkt, wo ich für mich gemerkt habe, ok, ich habe tatsächlich alles in meinen Möglichkeiten gemacht, jetzt kann es nur vorausgehen. dann hat sich das alles wieder gedreht. Psychologisch, Krankheitsbild hat sich verbessert, ich habe wieder Sport gemacht.

Ich stand auch kurz vor der Scheidung. Meine Frau hat sich sogar während der Insolvenz / Genau, kurz vor der Insolvenz, wo ich gewusst habe, es geht schief, habe ich dann ein Gespräch mit meiner Frau geführt. Und die hat sich dann mit $<<<$ Unternehmen anonymisiert $>>>$ zwei Jahre nach Südafrika absetzen lassen, um 
weg zu kommen von dem Thema. Was an sich auch wieder im Nachhinein gut war, positiv. War zwar in dem Moment sehr hart, weil ich habe mich dann wirklich verlassen gefühlt. Schau mal hier, jetzt wo es am Dampfen ist, fliegt jeder links rechts weg. Im Nachhinein war das sehr gut, weil ich konnte wirklich das erste Jahr mich komplett fokussieren auf den Erhalt der Firma, was mir leidenschaftsmäßig sehr whichtig ist. Ich, mittlerweile liebe ich diese Firma. Ich liebe diese Leute. Ich liebe diesen Rohstoff mittlerweile. Und ich möchte die Firma wirklich so weit bringen, dass wir sagen: „Jetzt haben wir es wieder geschafft". Und da ist für mich meine Aufgabe wirklich erledigt an dem Punkt. Und da sind wir kurz davor. Das ist nicht mehr weit weg. Und das Jahr, wo sie in Südafrika war, konnte ich natürlich viel Zeit investieren in erstens meine Gesundheit, Sport wiederaufnehmen, daheim alles in Ruhe bringen. Meine Tochter war ja hier, mein Sohnemann auch, wobei der so gut wie aus dem Haus war bereits. Das zweite Jahr ist dann meine Tochter für ein Auslandsjahr nach Südafrika gegangen, ja, das dann auch noch. Also, es sind viele Facetn, die vom Vorhinein betrachtet negativ waren, im Nachhinein betrachtet positiv sind eigentlich. Und es ist so gekommen, wie es hätte kommen sollen. Alles andere wäre nicht ok gewesen.

I: Sie haben gesagt, Sie haben sich ein wenig verlassen gefühlt, auch wie Ihre Frau sich abgewendet hat, oder dann ins Ausland gegangen ist. Wie hat so allgemein das Umfeld reagiert?

B: Welches Umfeld?

I: Also, wie haben Familie, Verwandte, Freunde / Wie wurde das Thema aufgenommen?

B: Jein. Also, die Kinder waren erst / der Sohnemann fand es gut, dass Mami weg ist ein bisschen. Daheim war die Situation sehr angespannt. Es war sehr unangenehm, und wie gesagt standen wie bereits kurz vor der Scheidung. Dann haben wir gesagt, ok, statt scheiden, weil ich glaube nicht da dran, ich bin da zwar nicht religiös, aber ich finde, gerade, wo es ein bisschen schlecht geht, ist doch kein Grund zu scheiden. Muss man sich halt durchkämpfen. Er fand es gut. Bianca hat sich zurückgezogen, meine 
Tochter. Freunde, so einen Freundenkreis habe ich eigentlich nicht, da sind wir zu viel umeinander gegangen. Also, so einen richtigen Freundenkreis habe ich nicht, es gibt Bekannten und Nachbarn. Die haben es angesprochen, aber so wirklich tiefführende Gespräche habe ich mit niemanden darüber gehabt. Ich habe auch keine Zeit dafür gehabt, muss ich ehrlich sagen.

I: Und bezüglich der Insolvenz haben Sie das Gefühl gehabt, dass sich das Verhältnis von irgendwelchen Leuten zu Ihnen dadurch / dass das beeinträchtigt war oder dass es sich verändert hat dadurch?

B: Ja. Man merkt schon in der unmittelbaren Umgebung, also Nachbarschaft, dass eine gewisse Sympathie entstanden ist dadurch. Und dass Leute auch mal hinterfragen und sagen: „Wie geht es dir jetzt? Und wie läuft das jetzt ab?" Da steckt teilweise auch eine gewisse Neugier drin natürlich, also Tratsch. Man will ja über etwas Tratschen können. Das braucht jede Nachbarschaft. Aber es war auch eine Sympathie drin. Und es war auch ein gutes Gefühl zu wissen / Ich habe es eigentlich auch ein bisschen bewusst genutzt, um darüber sprechen zu können, um das eine oder andere loszuwerden, das ich zum Beispiel hier nicht loswerden kann oder hier vor der Belegschaft nicht loswerden kann. Also, ich habe es auch zu meinem eigenen Nutzen wahrgenommen. Aber es gab auf jeden Fall Sympathie. Ob wir dadurch stärkere Freundschaften haben, würde ich sagen nein, nicht wirklich.

Es hat bei mir Vieles bewirkt im Sinne von was ich mir vom Leben erwarte. Wie ich weitergehen will. Was ist mir whichtig, was ist mir nicht whichtig? Wie whichtig ist mir meine Familie? Da hat sich Vieles bewegt. Insoweit, dass man nach anderthalb Jahren / ich bin ja alle sechs Wochen nach Südafrika gegangen. Haben wir uns getroffen. Das erste Jahr war nicht gut. War eher so, es hätte genauso gut eine Freundin gewesen sein können die Besuche. Im zweiten Jahr, eigentlich sechs Monate bevor die zwei Jahre vorbei waren, hat sich tatsächlich was bewegt in dem Sinne. Und ich denke, beide Parteien haben für sich einen Wert gefunden, der whichtig ist, einen familiären Wert, einen Beziehungswert. Und wir haben dann auch, wie sie dann wieder zurück war, eine Gruppe in München haben wir kennengelernt, wo wir jetzt öfters hingehen. Und das hat uns sehr viel / das ist eine Gruppe aus allen Schichten. Keine Psychologiegruppen oder so etwas, eine Gruppe von Leuten, die sich 
gegenseitig aussprechen und kümmern, und man kann loswerden, und daraus ist Vieles entstanden jetzt. Haben wir ein paar Seminare auch gemeinsam jetzt gemacht, die psychologisch sind, also, wo es schon darum geht, sich mit sich selbst auseinander zu setzen. Und das hat auch Vieles bewirkt. Und diese Bausteine, die mittlerweile gelegt worden sind und umgesetzt worden sind zum heutigen Tag, haben dazu geführt, dass wir / also das Thema Scheiden ist mittlerweile lächerlich, wenn wir darüber denken. Und wir haben für beide von uns einen schönen Weg gefunden jetzt, und für die Kinder auch vor allem einen Weg gefunden. Aber in erster Linie für uns beide einen Weg gefunden. Es ist sehr vieles Positive daraus resultiert.

I: Also, wenn Sie jetzt auch zurückdenken an die Insolvenz ist es kein rein schwarzer Fleck.

B: Nein.

I: Sondern Sie sehen da auch positive Aspekte.

B: Mittlerweile ja.

I: Also auch Chancen quasi, die sich daraus ergeben haben.

B: Genau. Die Zeit war dunkelschwarz, also schwarzer konnte es eigentlich nicht sein. Aber obald man über diese Eigenmitleidphase, muss ich fast sagen, sobald man da hinüber hinausgeblickt hat, dann habe ich halt nur noch Chancen gesehen. Das hat natürlich Zeit gebraucht, das ist klar. Weil es gibt viele Aspekte, mit denen man sich dann auseinandersetzen muss. In erster Linie muss man sich mit sich selber auseinandersetzen. Und man muss für sich selbst auch erkennen, was für einen ok ist, und was für einen nicht ok ist. Welche Werte ich für mich setze, und welche Werte ich ablehne und ablege sozusagen. Und das ist / das dauert, das habe ich gemerkt. Aber mittlerweile sage ich, jawohl, also.

I: Bevor Sie so weit waren, auch das Positive zu sehen, wie haben Sie sich da gefühlt? Hatten Sie das Gefühl, Sie haben jetzt da versagt, das ist Ihre Schuld, oder haben Sie 
das eher neutral gesehen, dass dieser Herr $<<<$ Name anonymisiert $>>>$ Sie da reingetunkt hat, oder wie haben Sie das bewertet die Situation?

B: Also neutral auf keinen Fall. Ich habe das schon sehr persönlich genommen, nicht nur versagt, sondern verraten. Verraten und versagt.

I: Hatten Sie auch das Gefühl, dass das die Umwelt so wahrnimmt?

B: Ja.

I: Oder wahr das eher Ihre eigene Wahrnehmung?

B: Nein, generell. Ich habe am Anfang mich sehr schwer getan, meinen Mitarbeitern ins Auge zu schauen, die ersten paar Monate wieder. Weil ich immer das Gefühl gehabt haben, dass vor denen steht jetzt kein Führer, oder kein Vorgesetzter, sondern ein Versager. Jemand der uns in den Abgrund geführt hat.

I: Und die Veränderung in Ihrem Selbstbild, wo Sie dann wieder positiver gedacht haben, war die Veränderung zuerst in Ihnen und dann in der Umwelt, oder haben Sie gemerkt, die Umwelt sieht es gar nicht so und haben sich selbst dann auch wieder anders gesehen?

B: Nein. Das war erst ich und dann die Umwelt. Also, nach dem Motto, wie ich mein Gegenüber anschaue, behandle und respektiere, so wird es auch wahrgenommen. Wenn ich jemandem gegenüber also Opfer oder leidend entgegenkommen, dann wird er von dem Gegenüber auch so wahrgenommen. Also, es war eher ich, ich selber. Der Wendepunkt war tatsächlich, also der größte Wendepunkt war, bei der zweiten Runde der Insolvenz. Die erste Runde, da waren alles Sharks, Geldsharks, Finanzfirmen dabei. Und ich hatte da kein gutes Gefühl. Ich hatte eher das Gefühl, ok, die Firma wird zerschlagen, und das geht den Bach hinunter. Dann in einem Gespräch mit dem Insolvenzverwalter habe ich das auch zur Kenntnis gegeben, dass ich da nicht einverstanden bin mit denen, die jetzt drin sind. Und dass das nicht der richtige Weg sein kann für die Firma. Da sind etliche Sachen passiert und dann plötzlich wurde der 
Deal nicht gemacht. Einerseits schlecht, andererseits habe ich mich persönlich gefreut, weil ich habe gewusst, ok, das war ja sowieso nichts Gutes. Und in der zweite Runde / Komischerweise $<<<$ Unternehmen anonymisiert $>>>$ war in der erste Runde auch schon dabei bei den Anfragen, aber der Insolvenzverwalter hat sie abgelehnt. Warum auch immer, ich weiß es nicht. In der zweiten Runde waren eigentlich nur noch drei Firmen dabei, zwei sind auch in der gleichen Branche und ein Fremder. Und von den zweien in der gleichen Branche, ist $<<<$ Unternehmen anonymisiert $>>>$ das größte. Ja. Und da war auf einmal dann doch der Fokus. Und dann gab es mal ein Gespräch. Die haben mich dann mal angerufen, der Eigentümer von $<<<$ Unternehmen anonymisiert $>>>$, ob ich nicht mal samstags, bevor ein Deal mit der Insolvenzverwaltung gemacht wird, nach $<<<$ Ort anonymisiert $>>>$ zur Zentrale komme, und dann miteinander mal Klartext reden. Habe ich dann gemacht, und seitdem, habe ich gewusst, also, jetzt geht es vorwärts. Und das war für mich persönlich auch der Wendepunkt, wo ich gesagt hab, schau, jetzt können wir diese / Im Nachhinein betrachtet, in dem Moment, wenn man nach vorne schaut, sieht man sich selbst nicht so, wie man sich benimmt. Und dann habe ich gewusst, ok, dieser leidende, armselige Mensch da, der sich jeden Tag so schuftet und so, den können wir ablegen. Jetzt können wir wieder Brust voraus und zielgerecht wieder auf unsere / auf das, was wir wollen, fokussieren. Das war der Wendepunkt.

I: Und wie haben Sie das Verhältnis und die Zusammenarbeit mit dem Insolvenzverwalter empfunden?

B: War ok. Völlig in Ordnung. Der hat seinen Job zu tun. Was da abläuft am Ende und finanziell und so bin ich nicht mit einverstanden, weil wenn wir das Geld hätten, dann hätten wir auch nicht Insolvenz anmelden müssen. Das Prozedere, was da läuft, wie viel Geld man damit macht, das ist ein Geschäft am Ende des Tages. Die machen es ja nicht umsonst, keiner von uns. Aber die Zusammenarbeit, die war hervorragend, muss ich ehrlich sagen. Das war / alle meine Fragen sind beantwortet worden. Ich habe sehr gute Hinweise bekommen, die haben mich auch, wo sie selbst herausgefunden haben, dass der Herr $<<<$ Name anonymisiert $>>>$ da kein sauberes Spiel gespielt hat, haben mich auch bei mehrere Sachen beraten, wie ich mich da zu benehmen haben jetzt, und was auf mich zukommt, und wie ich da rauskomme und / Also, auch vom 
strafrechtlichen Verfahren, die gelaufen sind, sind ja etliche Verfahren jetzt mittlerweile gelaufen. Und das hat sehr gut geklappt. Und da waren Personen vor Ort, der wohnte gar nicht weit von mir, sehr lustiger Mensch, hat auch seinen Job gemacht. Man muss ja nicht mit allem einverstanden sein, Hauptsache das Ziel wird erreicht. Und, würde ich ihn empfehlen für eine Insolvenz? Nö! (lacht) Ehrlich, nein! Hat geklappt, ja.

I: Ok. Würden Sie jetzt, wenn Sie so zurückdenken, mit dem Wissen, das Sie heute haben, manche Entscheidungen anders treffen? Oder sagen Sie, ich habe alles nach bestem Wissen und Gewissen gemacht, und ich würde alles wieder so machen?

B: Das ist ja die Kernfrage, gell. Also, das ist die Frage, die einen beschäftigt vom ersten Moment, wo man weiß, da ist eine Schieflage. Eine klare Antwort habe ich nicht dazu. Das Einzige, was ich sagen kann, ich würde ein auf jeden Fall / mache ich auch mittlerweile, ich mache keine Vereinbarung mehr, die nicht schriftlich festgehalten wird. Das hat sich geändert, und das werde ich / Ich werde nicht mehr aus menschlicher Wohltätigkeit etwas zustimmen, ohne dass es festgehalten ist, was diese Zustimmung eigentlich beinhalten soll. Alles andere, ich hätte weiterhin die Geschäftsführung übernommen, ich hätte weiterhin die Belegschaft genauso unterstützt und geführt, wie ich sie bis jetzt geführt habe. Also, was die operative Seite angeht, vielleicht sogar der ein oder andere Projekt schneller angegriffen, um schneller zu (unverständlich) Kostenbasis zu kommen. Aber das sind so Details, so operative Details. Aber im Groben, ich würde die Firma wieder nehmen.

I: Und während des Insolvenzverfahrens gab es jetzt da Punkte, wo Sie sagen, das ist zwar gut ausgegangen, aber das hätte eigentlich anders laufen müssen? Da habe ich mich übergangen gefühlt oder da habe ich Kritikpunkte, da lief irgendetwas zu langsam oder zu undurchsichtig oder keine Ahnung, irgendwas? Oder hat das alles gepasst?

B: Ja, aus meiner Sicht, das Einzige, was ich mir wünschen würden, wenn für jemand anders, weil ich will nie wieder so eine Insolvenz durchmachen. Ich möchte das nicht, und ich wünsche es auch niemandem, keinem, sogar nicht der Herr $<<<$ Name 
anonymisiert $\gg>$. Das muss nicht sein. Das Einzige, was ich mir wünschen würde vom Insolvenzverwalter ist, dass er die, also in unserem Fall, mir Respekt und Anerkennung oder, wenn ich sage, dass ein bestimmter Kunde nicht geeignet ist, dass er das akzeptiert.

I: Dass er quasi auf Ihre Erfahrung und Ihre Branchenkenntnis vertraut?

B: Ja. Genau. Und nicht nur rein kaufmännisch unterm Strich betrachtet. Vor allem für mittelständige Firmen bin ich da fest davon überzeugt. Konzernen, das ist ein anderes Vorgehen. Da geht ja nur über Shareholders und was auch immer. Aber für mittelständige, bodenständige Firmen, wo handwerklich was hergestellt wird, kann ich jedem Insolvenzverwalter nur empfehlen, hör auf was die Belegschaft sagt, was aus deren Meinung die richtige Situation wäre, die richtige Gruppe wäre, die richtige Struktur wäre, und bau da drauf. Es kann sein, dass man dann insolvenzmäßig nicht den gleichen Preis erzielt, aber man erzielt auf jeden Fall ein / Außer man im Vorhinein macht die Entscheidung, ok, wir machen die Firma platt. Das ist auch eine Entscheidung. Aber wenn man sagt, ich will die Firma weiterführen, ich will, dass sie wieder auf eigene Beinen kommt, dann soll man das mehr in Acht nehmen.

I: Ok.

B: Das ist, wenn dann die einzige Empfehlung, die ich habe.

I: Eine letzte Frage noch. Würden Sie sagen, dass Sie die Insolvenz verändert hat?

B: Ja, auf jeden Fall.

I: Und inwiefern?

B: Alles.

I: Alles? 
B: Ja. Ich nehme alles nicht mehr so ernst. Das Leben hat auch andere Facetn an sich. Ich habe für Menschen generell, also, die Belegschaft, männlich, weiblich eine ganz andere Wertschätzung, eine ganz andere Hochachtung mittlerweile in mich. Und jeder Mensch ist unique und jeder Mensch ist wirklich sein Leben wert. Und auch mein "wie ich mit den Leuten umgehe" hat sich Vieles geändert. Nicht mehr so aufliegen, alles hat eine Lösung, Vielleicht nicht heute, aber dann morgen. Morgen kommt, egal, was wir heute machen. Das ist sicher.

I: Also, kann man das so zusammenfassen, dass Sie gelassener geworden sind?

B: Das ist ein weiter Begriff, gell, gelassener, locker in south hätte ich gesagt mellow, gelassener / Zuverlässig und irgendwie doch ernsthaft gelassener. Vielleicht muss man das so kombinieren.

I: Aha.

B: Also, gelassen an sich reicht eigentlich nicht.

I: Ok.

B: Ich nehme schon die Situationen intensiver wahr. Generell nehme ich mein Umfeld viel intensiver wahr mittlerweile, und man ist gewissenhafter. Gewissenhafter gelassener, so kann man sagen. 
Nachtrag zum Interview:

Das Insolvenzverfahren läuft noch, also, ist noch nicht abgeschlossen. Es laufen noch verschiedene Verfahren. Es waren insgesamt drei, eines läuft noch.

Und es schwebt auch noch das Damoklesschwert Privatinsolvent über ihm. Da muss wohl sein Anwalt mal gesagt haben, es könnte eventuell noch passieren, aber er sieht das relativ gelassen. Und er hat gesagt, "wenn es so ist, dann ist es so", er sieht das als Chance, und er verweist auf den Spruch: "Wenn dir das Leben einen Arschtritt gibt, dann nutze den Schwung um vorwärts zu kommen." Also, er sagt, es muss alles so passieren, wie es passiert, und das birgt alles Chancen in sich. 
Appendix IX: Transcript of Interview 8

I: Ich möchte Sie ja ein bisschen besser kennenlernen heute, deswegen wäre es mir am liebsten, wenn Sie einfach mal Ihren Werdegang schildern, beruflich und privat von der Kindheit bis heute.

B: Gut. Wieviel Zeit haben wir insgesamt? Wieviel haben Sie heute eingeplant?

I: Also, ich habe keinen weiteren Termin.

B: Ok. Gut. Also, ich bin Jahrgang `46. Habe die mittlere Reife gemacht, danach eine Versicherungslehre. Habe mich dann bereits mit 21 Jahren direkt nach der Verheiratung selbstständig gemacht. War auch schon unmittelbar nach der Lehre im Grunde genommen selbstständig bei einem Versicherungsvertreter und bin dann nach $<<<$ Ort anonymisiert $>>>$ gegangen. Habe mich dort mit mehreren als Versicherungsmakler selbstständig gemacht und habe danach eine Beratungsgesellschaft gegründet. Das war dann fast 18 Jahre später, habe also meine Anteile verkauft und habe mich im Rahmen dieser Beratungsgesellschaft konzentriert auf Insolvenzen. Und habe das ausschließlich nur für Banken gemacht und bin dann 1998 so auch hier nach $<<<$ Ort anonymisiert $>>>$ gekommen zur $<<<$ Unternehmen anonymisiert $>>>$ Bank. Ich kannte die Leute $<<<$ Name anonymisiert $>>>,<<<$ Name anonymisiert $>>>$, aus einigen gemeinsamen Arbeiten recht gut.

Und seinerzeit hat mir $<<<$ Name anonymisiert $>>>$ angeboten, hier ein Unternehmen zu übernehmen, wo er nicht wusste, wie er dort weitermachen sollte. Ich hatte ein paar Wochen vorher an und für sich eine Kurzexpertise gemacht, die lautete: Machen Sie das Unternehmen zu. Es hat keine Chancen. Und ich werde nie vergessen, es war abends um halb 10 in seinem großen Sitzungszimmer, machte er einen Bocksbeutel auf und sagte: "So, $<<<$ Name anonymisiert $>>>$, jetzt sag mir mal, wieviel kostet es denn, wenn wir es machen?" Und ich habe damals ganz salopp gesagt: „50 Millionen D-Mark müssen Sie rechnen, aber da haben Sie noch keine Auslandsgesellschaften, noch gar nichts drin." Lange Rede kurzer Sinn, er hat damals gesagt: „Ich bin bereit das zu machen, unter einer Bedingung: Wenn Sie dieses Objekt führen." Und ich habe 
mir damals vier Wochen Zeit ausbedungen, denn ich war immer noch der Senior im Unternehmen mit rund acht Mitarbeitern. Und es war schon eine sehr whichtige Entscheidung. Meine Frau hat sie auch dann mitgetragen. Und wir sind also dann / im November 98 habe ich dann die Anteile der damaligen $<<<$ Unternehmen anonymisiert $\gg>$ gekauft, und ich habe mich in dieses Abenteuer gestürzt, dieses Unternehmen dann nicht als Berater, sondern als Eigentümer durchzuziehen. So, das ist also jetzt rein mit wenigen Worten mal der berufliche Werdegang.

Privat, ich habe es eben schon gesagt, habe ich mit 21 Jahren geheiratet. Habe dann mit 37 Jahren das zweite Mal geheiratet, nachdem die Trennung durch war. Und wir haben beide unsere Kinder mit in die Ehe reingebracht. Und leben also jetzt auch schon ich glaube seit 37 Jahren zusammen. Und das ist also alles vom Privaten her im Grunde genommen nichts Spektakuläres. So wie es viele zig Tausend ähnlich erleben. Im Beruf habe ich / und vor allen Dingen auch hier habe ich eins versucht, ich habe immer gesagt, ein verrückter Banker und ein verrückter Unternehmensberater sind zusammengekommen. Und wir haben beide ein Ziel gehabt, an und für sich mit anderen Methoden zu zeigen, dass man ein Unternehmen nach vorne bringen kann und vor allen Dingen, dass man im Mittelpunkt aller Überlegungen nicht den Markt stellt, der zwar letztendlich entscheidet, was passiert, aber doch in erster Linie die Menschen, die im Unternehmen sind. Und versucht für diese Menschen eine andere Arbeitswelt zu schaffen. Das ist auch / ich wusste, das Unternehmen war total marode. Und zu dem Zeitpunkt war der Börsengang von $<<<$ Unternehmen anonymisiert $>>>$. Und die $<<<$ Unternehmen anonymisiert $>>>$ Bank, vor allem $<<<$ Name anonymisiert $>>>$, wollte zu dem Zeitpunkt überhaupt keine Wertberichtigung bei bestehenden Krediten. Denn Meine Absicht war es natürlich damals, dieses Unternehmen durch eine Insolvenz zu schicken und damit alle Altrisiken vom Tisch zu kriegen. Er sagte aber, der einzige Weg, den er gehen kann, ist dieser Weg mit Neufinanzierung, und Altrisiken werden in einer separaten Gesellschaft geparkt und fertig. Ich habe das dann damals auch gemacht, weil ich da eine riesen Chance drin sah. Das, was ich jetzt viele Jahre lang als Berater gemacht habe. Ich habe immer eins gesehen, der Fisch stinkt vom Kopf. Das ist eine alte Devise, die ich in jeder Sanierung immer wieder gesehen habe mit ganz, ganz wenigen Ausnahmen. Und da habe ich gesagt, gut, das wollen wir hier mal anders machen. Und damit wir nicht bei der ersten Schwierigkeit gleich wieder zurück nach $<<<$ Ort anonymisiert $>>>$ gehen, haben wir dann hier gesagt, 
meine Frau und ich, wir kaufen uns sogar ein Haus. Damit wir einfach beginnen, hier Wurzeln zu schlagen.

Was ich nicht wusste, was ich nicht ahnte, dass im Grunde genommen zwei Jahre später die $<<<$ Unternehmen anonymisiert $>>>$ Bank selbst pleiteging. Und damit waren wir über Nacht ohne jede Finanzierung. Und Sie können sich vorstellen, dass das eine ganz, ganz schwierige Geschichte war. Und ich habe damals meine Leute zusammengetrommelt, habe gesagt: „So, wir haben zwei Möglichkeiten. Entweder wir geben auf, wir hatten Abwicklungs-, Zerschlagungsbilanzen gemacht, alles fertiggemacht, also, das Thema ist dann durch, oder aber wir gehen Schritt für Schritt weiter, ohne zu wissen, ohne, dass ich euch sagen kann, was morgen passiert." Und die gesamte Führungsmannschaft, die sich damals so in den Grundzügen bildete, hat gesagt: „Wir kämpfen.“ Aufgeben können wir immer, wir machen weiter. So, und daraus hat sich dann im Grunde genommen die Story von $<<<$ Unternehmen anonymisiert $>>>$ entwickelt, wo man zeigen konnte, dass aus einem völlig unbekannten Unternehmen mit Umsätzen unter 15 Millionen Euro in wenigen Jahren an und für sich ein Unternehmen herangewachsen ist, was hier plötzlich im Markt den Ton mit angibt. Und das in einer Branche durch ganz neue Wege, durch ganz neue Produkte / Und da könnte ich Ihnen jetzt Stunden lang / ich habe viele Vorträge zu dem Thema gehalten. Da könnte ich Ihnen jetzt Stunden lang was dazu erzählen. Meine Kernaufgabe hier habe ich gesehen / Mich hat man dann auch gefragt, ob ich mir vorstellen könnte, hier in der Industrie überregional als Sprecher tätig zu sein. Auch aus dem Hause $<<<$ Unternehmen anonymisiert $>>>$, auch die Eigentümer waren mehrfach bei mir gewesen. Ich habe dann 2001 gesagt, mache ich. Ich übernehme hier das Industrie- und Handelsgremium als Vorsitzender, um hier bestimmte Sachen voran zu bringen. Ich habe damals vor allen Dingen sehr stark hier auch dann für Schüler was gemacht, für Auszubildende was gemacht, dass hier immer wieder der Mensch im Mittelpunkt steht. Und ich kann es vielleicht so mal rüberbringen, wir haben bei uns bei $<<<$ Unternehmen anonymisiert $>>>$ eine Firmenphilosophie gehabt, die auch jetzt von den neuen Eigentümern mit übernommen wurde, die ist abgeleitet von dem Wort "Team". Und da steht das T ganz einfach für Transparenz, das E für Eigeninitiative. Ich habe immer gesagt, ich muss der erste sein, der überflüssig ist, dann bin ich auf dem richtigen Weg. Das A für Ausgewogenheit, und das M für Motivation. Und ich habe in allen Gesprächen, in allen Vorträgen immer wieder gesagt, und bei 
Transparenz sind drei Worte für mich das Ausschlaggebende: Wahrheit, Klarheit, Verlässlichkeit. Und das ist das ganz Erstaunliche, dass sich das auch in der Insolvenz als das tragende Gerüst für das gesamte Unternehmen herausgestellt hat. Denn diese / und da kommen wir sicherlich nachher zu / diese Insolvenz ist völlig anders gelaufen, als Viele das erwartet haben. Wir haben weder einen Kunden verloren, noch einen Lieferanten verloren, noch haben wir einen Mitarbeiter in der Insolvenz verloren.

I: Aha, ok.

B: Ja, und das ist also schon eine Ausnahmesituation.

I: Ja.

B: Jetzt durch den Wechsel, nachdem alles in relativ trockenen Tüchern ist, und ich auch nicht mehr aktiv operativ tätig bin, hat sich fast die gesamte Führungsmannschaft verabschiedet. Die haben dann gesagt: „Ne, wenn du nicht mehr da bist, wir wollen nicht mehr. Dann gehen wir woanders hin." Und sie sind auch alle sehr, sehr schnell überregional und regional aufgenommen worden. So, das ist jetzt mal mit / Sie müssen mich bei dem Thema immer bremsen, weil ich sonst automatisch zu viel rede. Und da könnte ich Ihnen wirklich Stunden lang was dazu erzählen, auch zum Thema synchrones Produktionssystem, Fehlervermeidung, Verbesserung, Motivation. Wenn Sie dann so sehen, dass Sie ungelernte Frauen, dass das plötzlich Träger in der Innovation werden. Einfach weil sie denen / ich hatte, als ich hinkam 240 Leute, davon waren 200 ungelernte Frauen. So, und was wir dann Schritt für Schritt halt gemacht haben, wir haben Programme aufgelegt, wir haben Schulbildung angeboten. Und ich werde es nie vergessen, wie eine / das war Jahrgangsbeste dann im Bereich des Ausbildungsweges. Die konnten dann ihre Lehre praktisch nachmachen. Und sie war Jahrgangsbeste in Bayern geworden. Und ich habe sie dann nur gefragt: „Was hat Ihnen denn am meisten gefallen?" Da sagte sie: „Dass ich mit 42 noch lernen dufte. Das hat mir am meisten gefallen." Da habe ich gesagt: „Mensch, Sie haben das Zeug, Sie könnten jetzt innerhalb von drei Jahren alles andere nachholen, machen Sie weiter." Da sagt sie: „Das macht meine Familie nicht mit.“ 
I: Hm.

B: Also, Sie könnten jetzt sogar noch einen Studiengang dranhängen. Ich sage, wir können Ihnen alles / Aber das sind halt so Ergebnisse und Erlebnisse, die prägen. Losgelöst davon, dass wir / 2000 kannte uns keiner. 2002 haben wir dann das erste Mal an Partner des Fachhandels teilgenommen oder fielen auf. Sie können nicht teilnehmen, Sie werden von 12000 Händlern bewertet. Und wir haben da den ersten Platz gemacht. Und wir haben dann in den Folgeelfjahren einmal den zweiten Platz gemacht, sonst nur den ersten. Da können Sie sich vorstellen, was das bedeutet, wenn solche großen Unternehmen geschlagen werden, wie $<<<$ Unternehmen anonymisiert $>>>$, wie $<<<$ Unternehmen anonymisiert $>>>$, wie $<<<$ Unternehmen anonymisiert $>>>$, die dazu gehören. Aber das haben wir durchgängig dann eben geschafft. Und selbst in der Insolvenz, wie gesagt, jetzt werden wir wegrutschen, haben die Kunden obschon wir grottenschlecht liefern konnten, weil wir Zuwächse hatten im Auftrag von $25 \%$ im Auftragseingang. Und wir konnten einfach nicht mehr liefern. Sie haben sowieso in der Insolvenz Lieferschwierigkeiten über einen Zeitraum von 6 - 8 Wochen. Das können Sie gar nicht verhindern. Und da habe ich gesagt, jetzt werden wir völlig weggesägt, da waren wir auf Platz 2. Und jetzt war gerade im März die Verleihung für 2012. Und da haben uns die Kunden auf Platz 1 wieder gesetzt. Das heißt, auch da können Sie dann sehen letztendlich, dass sie bei so einem Unternehmen, wenn sie es richtigmachen, eine gewisse Philosophie und gewisse Werte auch nach vorne tragen müssen, die nichts mit law and order zu tun haben. Und das ist jetzt auch einer der Gründe, warum viele Leute gegangen sind, weil jetzt ein völlig anderes System kommt. Jetzt ist ein Finanzinvestor, den ich zwar selbst ausgesucht habe, weil ich ihn für den besten hielt, von denen, die Interesse hatten. Aber die sind natürlich ganz anders gepolt. Für die zählen nur Zahlen. Wir waren auch ein gläsernes Unternehmen, wenn Sie in die $<<<$ Unternehmen anonymisiert $>>>$ reinkommen, sehen sie überall Glastüren. Das war das erste, was ich gemacht habe, gläsern werden. Dass sie Zahlen aktuell hatten, stand doch außer Frage. So, und ja, das ist das. Und sie merken auch so noch, das hat unwahrscheinlich mich begeistert und auch viele Leute hier. Wir sind auch dann zu vielen Vorträgen unterwegs gewesen, wir haben etliche Auszeichnungen gewonnen, den deutschen Mittelstandspreis und und und. Aber wissen Sie, irgendwann kam dann so der Punkt, wo ich sagte, uns holen die Fehler der 
Vergangenheit ein. Sprich auch durch die $<<<$ Unternehmen anonymisiert $>>>$ Bank, denn auch diesen Wechsel dort / ich hatte erst so die Befürchtung, dass wir das nicht überleben. Aber ich konnte auch diese / wir kamen ja sofort in die ... (unverständlich) rein, diese Abwicklungsleute begeistern, dass die wirklich mitgemacht haben. Und mitgearbeitet haben, dass wir hier in der Lage sind, uns neue Partner langsam aufzubauen. Das das sechs Jahre dauert, hätte ich nie geglaubt. Und dass wir das überleben. Aber wir haben es dann geschafft. Jetzt kam aber dann eben der Punkt, wo ich gesagt habe, ich war da 67, entweder arbeite ich mein Leben lang im Grunde genommen ohne, dass mir irgendetwas übrigbleibt, oder aber wir haben jetzt den Mut, diesen Knoten durchzuschlagen, auch wenn es sieben Jahre zu spät ist, und das Unternehmen endlich auf gesunde Füße zu stellen. Was durch andere Gespräche, durch andere Verhandlungen mit den Banken so nicht ging. Und dass hat dann eben dazu geführt, dass wir präzise vorbereitet / die Insolvenz also nicht völlig unvorbereitet, wir haben alles vorbereitet über Wochen vorher, mit sehr teuren Beratern. Wir haben dann auch noch $<<<$ Unternehmen anonymisiert $>>>$ mit reingeholt. Wir haben die Rechtberatung $<<<$ Unternehmen anonymisiert $>>>$ mit drin gehabt aus $<<<$ Ort anonymisiert $>>>$. Selbst $<<<$ Name anonymisiert $>>>$ sagt, eine solche Insolvenz, so vorbereitet, hatte ich noch nie gehabt. Und das hat dann eben auch dazu geführt, dass wir vom Tag der Anmeldung bis zum Closing genau sechs Monate gebraucht haben. Wir haben / am 01.09. war das Closing, und schon sechs Wochen vorher, oder acht Wochen vorher waren im Grund genommen / die Neuen habe ich schon reingeholt, dass der Übergang relativ problemlos und zeitnah über die Bühne ging. Das heißt, am 01.09. war schon alles vorbereitet. Wir haben für die klassische Insolvenz, wenn wir ehrlich sind, drei Monate gebraucht. Und das ist das, was wir hier erlebt haben, was unser Leben hier doch gravierend beeinflusst hat. Das kann man nicht anders sagen.

I: Inwiefern?

B: Ja, Sie wurden ja gefordert mit Aufgaben, die Sie so als Berater kaum haben. Es ist ein großer Unterschied, ob Sie abends um neun Uhr nach Hause gehen, oder ob Sie die Probleme, die da sind, mitnehmen. Und $<<<$ Unternehmen anonymisiert $>>>$ hatte immer ein Hauptproblem, wir waren immer zu niedrig mit Kapital ausgestattet. Von 
Anfang an. Das war mal geplant nach fünf Jahren einen Börsengang zu machen.

Damals war der neue Markt noch nicht geplatzt. Und das war das Konzept, was wir auch mit dem $<<<$ Name anonymisiert $>>>$ ausgearbeitet hatten, aber was dann durch das Platzen des neuen Marktes obsolet wurde. Und vor allen Dingen das Unternehmen machte damals bei 15 Millionen Umsatz drei Millionen Verlust. Das Unternehmen hatte etwa einen Investitionsstau von gut und gerne zehn Millionen. Das heißt, es war an und für sich eine ausweglose Situation, die man nur dann über einen Börsengang mit `ner Vision nach vorne hätte kompensieren können.

So, und in 2003, ich werde das nie vergessen, rief mich dann der Vorsitzende vom Aufsichtsrat an, sagt: "Du, ich habe in $<<<$ Ort anonymisiert $>>>$ den Automobilzulieferer $<<<$ Name anonymisiert $>>>$ kennengelernt. Den musst du nach $<<<$ Ort anonymisiert $>>>$ holen. Ich habe dann das Büro in $<<<$ Ort anonymisiert $>>>$ / $<<<$ Name anonymisiert $>>>$ spricht nur japanisch und hat immer Dolmetscher mit / in $<<<$ Ort anonymisiert $>>>$ angerufen, ja, die wollten kurz die Story haben. Habe ich ihnen erzählt, Familienunternehmen, die und die Probleme, die ich sehe, und wir stehen eben davor, dass wir sagen, es geht nicht weiter, oder aber wir finden Wege. Sag ich, ich bin kein Techniker, ich bin mehr der Kaufmann, der Vertriebler, aber, ich sage, irgendwo hänge ich fest. Auch weil ich das Geld nicht habe um neu zu investieren in dem Maße, wie ich es bräuchte. Und dann kriegte ich binnen drei Wochen / der hatte zwei Jahre Wartezeit / kriegte ich binnen zwei Wochen kriegte ich dann Nachricht, er kommt im April nach $<<<$ Ort anonymisiert $>>>$. Dann habe ich über einen Übersetzer einen Brief geschrieben auf Japanisch dann ihm ins Hotelzimmer gelegt. Und da fragte er mich am nächsten Abend dann, wer hat diesen Brief übersetzt? Ich sage, ich habe einen Übersetzer aus dem Branchenbuch engagiert. Sagte er, das ist ein sehr, sehr gutes Japanisch. Das hat er mir dann erläutert, wie schwierig das sei, das richtig zu treffen. Sagte er, als ich diesen Brief gesehen habe, gelesen habe, war mir klar, wir kommen zusammen. Und er hat dann im Grunde genommen nach diesem Tag, nach diesem Workshop gesagt, wenn ich binnen zwei Wochen, drei Aufgaben erfülle, dann kommt er. Und ich hatte am nächsten Tag schon die Aufgaben erfüllt. Und am 02. Mai 2003 haben wir dann gemeinsam angefangen. Also, und das hat an und für sich dann / im Grunde genommen können Sie das, was $<<<$ Name anonymisiert $>>>$ gemacht hat, auf den Punkt bringen und sagen, versuche alles im Haus selbst zu machen. 
I: Aha.

B: Komplett. Das heißt, wir haben dann die gesamte maschinentechnische Entwicklung im Haus selbst gemacht von A bis Z. Wir haben die Forschung selbst gemacht von A bis Z. Und wir haben dann natürlich auch Kooperationen mit anderen gemacht. Denn in der Forschung da war einfach unser Volumen / so ist dann auch mit $<<<$ Unternehmen anonymisiert $>>>$ der Kontakt gekommen. So, und das hat dann eben dazu geführt, dass wir eine völlig neue Maschinentechnik entwickelt haben, die auch selbst gebaut haben. Und jetzt die letzten Jahre eine völlig neue Brenntechnik entwickelt haben, die mit einem hohen Grad an Automatisierung verbunden ist. Nur ich war in der Lage mit der Bundesstiftung Umwelt den Prototypen zu machen. Den haben die bezahlt, weil ich einfach das Geld nicht mehr hatte. Und jetzt die Implementierung in die Serie konnte ich allein natürlich überhaupt nicht umsetzen. Das machen jetzt auch die Finanzinvestoren. Die bauen jetzt in den nächsten / ja, 12 Monate wird es dauern / investieren die nochmal über sechs Millionen in diese Technik. Und dann haben sie an und für sich $<<<$ Unternehmen anonymisiert $>>>$ so stehen, wie wir uns das 2005/ 2006 in der Vision vorgestellt hatten. Und wie gesagt, dann können wir mit Standorten in China von der Kostenseite mit konkurrieren, weil einfach die Personalkosten in der Fertigung soweit runtergedrückt sind, dass sie mit zehn Prozent von den Gesamtkosten keine Rolle mehr spielen in dem Sinne oder unter zehn Prozent. Und wir können uns dann konzentrieren auf das, was whichtig ist. Dann diese Technik eventuell / wir hatten Amerika dann 2010 als Niederlassung mit einem Partner gegründet, eine Joint Venture. Und zum Beispiel nach Amerika, und das war viel whichtiger, dass diese neue Technik rüberkam. Aber das, ich sag mal, diese Früchte dürfen jetzt halt die neuen Eigentümer letztendlich ernten. Und ich bin sehr sicher, dass diese neue Technik hier in der Lage sein wird, dass diese Fertigung / Es gibt nur noch zwei Hersteller in Deutschland, die überhaupt das hier machen. Und da ist einer $<<<$ Unternehmen anonymisiert $>>>$ und der andere ist $<<<$ Unternehmen anonymisiert $\gg>>$, alle anderen fertigen schon längst im Ausland, natürlich im günstigeren Ausland. Das ist so also der Schritt, der da vollzogen wurde. 
I: Ok. Können Sie dann nochmal ein bisschen genauer schildern, wie es dann dazu kam, dass Sie entschieden haben, Insolvenz anzumelden ist der richtige Weg?

B: Ja. Wir hatten hier ja eine laufende Liquiditätsplanung, die im Grunde genommen täglich rollierend immer auf dem aktuellen Stand war. Und wir sahen ja einfach, dass wir / Oder ich muss es anders herum, dann wird es verständlicher. 2007 hatten wir das beste Geschäftsjahr. Und ich habe gesagt, so, jetzt noch fünf Jahre, 6 Jahre, dann sind wir schuldenfrei. Dann sind wir wirklich durch. 2008 im August war es, als wenn jemand den Stecker rausgezogen hätte. Es war über Nacht ruhig. Ich bin dann rumgegangen und habe gesagt: „Leute, sind die Faxgeräte nicht angeschlossen? Oder ist das Telefon nicht in Ordnung?" Es war nichts mehr. Das heißt, wir kriegten in 2008 einen Umsatzrückgang von 25 Prozent. Und den konnten wir einfach so nicht verkraften. Und ich habe dann sofort eine Bankenrunde einberufen und habe gesagt: „Leute, wenn dieser Weg so weitergeht, wird das die und die Folgen haben." Ich sagte: „Wir werden das so nicht schaffen." Erste Reaktion der Banken. Wir geben erst mal sofort eine Million. Das war das Erste, das sie gemacht haben, damit hier das Notwendigste erst mal geregelt ist. Und wir kucken mal, wie sich 2009 entwickelt. Nun ich hatte in 2007 die Entscheidung getroffen, einen deckungsbeitragschwachen Kunden rauszunehmen, einfach, wir waren voll bis oben hin. Ich sagte: „Wenn wir es jetzt nicht machen, wann wollen wir es noch tun?" Und der fiel dann genau in 2009 raus. Das heißt, wir verloren insgesamt rund 40 Prozent unseres Umsatzes insgesamt, weil der Trend auch in 2009 sich fortsetzte. So, und dann haben wir in 2009 wieder die Bankenrunde zusammengerufen. Und ich habe dann präsentiert, habe gesagt: „Wir werden eine Insolvenz kriegen mit Voransage." Und dieses Thema, ich sage, das können wir ganz genau sehen, wann das passiert, weil wir einfach Zinslasten und Tilgung, wenn Sie allein bei der Größenordnung, wir machten 40 Millionen Umsatz, Tilgung war drei Millionen, Zinsen waren fast drei Millionen. So, egal was wir machten, diese beiden Rucksäcke fraßen alles komplett auf. und auch damals haben die Banken dann auch gesagt / Ich hatte sehr, wirklich ausgezeichnetes Verhältnis zu den Banken. Weil unser Verhältnis immer geprägt war von Klarheit, und die haben nie irgendwo eine dritte Person mit reingeholt. Weil sie gesagt haben, die Aussagen, die wir vom Unternehmen kriegen, sind uns so umfangreich und aussagefähig, und jede Prüfung ist ohne jede Beanstandung über die Runde gegangen. „Wir können dem 
glauben, was da gesagt wird." Sie haben dann nochmal gesagt: „Wir geben nochmal drei Millionen." Und das haben sie dann auch gemacht mit dem Ergebnis, dass ich auch gesagt hab: „Jetzt müssten wir an und für sich durchkommen." Aber wie das halt so ist, sie haben dann eine sogenannte Sucessfee, das heißt, die Banken nehmen dann zwar auf den ersten Blick Zinssätze, die relativ niedrig sind, die zwischen vier und sechs Prozent lagen, wenn sie aber die Sucessfee obendrauf rechnen, was sie sobald sie bestimmte Stufen wieder in der Liquidität erreichen, an die Banken zurückzuführen haben, und was sie auch in der Bilanz zurückzustellen haben, dass da sehr, sehr schnell oben eine Million nochmal draufkam. Das heißt also, wir berappelten uns ab 2010 so langsam. Und die Banken wollten dann auch eins haben, sie wollten dann, dass wir einen M\&A-Prozess aufsetzen, um das Eigenkapital im Unternehmen zu verbessern. Und ich habe immer gesagt: „Ein M\&A-Prozess wird nicht funktionieren, schlicht und einfach, weil wir zu viele Altrisiken in diesem Mantel mit rumtragen." So, das hat aus dem ganzen Pool heraus nie einer geglaubt. Weil sie alle gesagt haben: „Da wird ein Unternehmen kommen, da sind wir sehr sicher, das hier mindestens 30 Millionen zahlt." Ich habe gesagt: "Das ist ein Trugschluss. Es wird nicht passieren."

I: Hm.

B: Gut, ich habe dem Druck nachgegeben. Ich habe dann gesagt, dann machen wir einen M\&A-Prozess. Und den haben wir dann auch eingeleitet. Der ist genau zu dem Ergebnis gekommen. Etliche, die hochinteressiert waren, hochgradig, aber nie zum Abschluss kamen. So. Viele wollten natürlich auch nur mal gucken, was ist da. Da musste ich die Bude halt wirklich abschirmen. Aber das Ergebnis war dann eben in 2000 und / jetzt muss ich schon überlegen. 2012, am 19. Dezember hatten wir die letzte Sitzung. Ich habe dann unmissverständlich gesagt: „Leute, ich sage, wir haben wachsende Lieferantenverbindlichkeiten. Wir können Rad insgesamt /“ Der Umsatz hatte sich wieder erholt. Wir waren im EBIT ja nie negativ gewesen. Der lag immer noch bei 1,8 Millionen. Aber sie sahen natürlich, wenn sie nach vorne guckten, wo ihnen die Liquidität hinläuft. So, und der Pool sagte verständlicherweise, mit Krediten - und das wollte ich auch nicht mehr, weil wir wirklich genug hatten - können wir nicht weitermachen. Wir müssen hier dann versuchen, über Eigenkapital das zu machen. Und Eigenkapital, ich hatte sehr, sehr viele Leute, die interessiert waren, 
wenn die Altrisiken abgeschnitten waren. So, und keiner war bereit zehn Millionen reinzugeben, wenn die Banken nicht mindestens auf zehn Millionen verzichten, was ja ganz normal ist. So. Und da haben die Banken immer die Situation so eingeschätzt, dass sie sagten: „Das macht der schon."

$\mathrm{Na}$, ich bin dann im Januar aus dem Weihnachtsurlaub wiedergekommen, am sechsten, und dann sagte das Controlling, wir müssen uns mal hinsetzen, wir haben jetzt Perspektive, die Rechnungen fertig detailliert bis März, dann bis Juni, weil wir den Zweijahreszeitraum insgesamt uns angesehen hatten, und uns werden dort über eine Million fehlen. So, und das könnten wir zwar noch über das und das regeln, aber / Und dann habe ich gesagt, so jetzt ist der Punkt, jetzt muss ich von außen Fachleute reinholen, das können, dürfen wir nicht mehr selbst machen. Habe dann einen Partner von mir von den Aktionären gefragt, die $<<<$ Unternehmen anonymisiert $>>>$. Ich sagte: „Wen könntet ihr euch vorstellen?“ Haben die gesagt: „Mensch, nehmen Sie doch den $<<<$ Name anonymisiert $>>>$, den kennen wir aus $<<<$ Ort anonymisiert $>>>$. “ Habe den dann angerufen. Das ist ein großes Beratungsunternehmen, die sich auf Planinsolvenzen spezialisiert haben. Wir haben uns dann sofort in $<<<$ Ort anonymisiert $\gg>$ getroffen, und die haben sich dann die Sachen angeguckt, haben gesagt, wenn einer prädestiniert ist, eine Planinsolvenz zu machen, dann seid ihr das.

Das könnte nicht besser passen. So, lange Rede kurzer Sinn. Aufsichtsrat hat zugestimmt, dass wir einen Status machen, dass die / drei Wochen waren sie mit sechs Leuten, glaube ich, im Haus / alles aufbereitet haben. Und dann haben wir, nachdem diese Analyse fertig war, dann die Entscheidung getroffen, wir gehen das Planinsolvenzverfahren an. Was wir zu dem Zeitpunkt nicht wussten, war, dass bei den Banken dieses Unternehmen Persona non grata war. Vor allen Dingen bei der $<<<$ Unternehmen anonymisiert $>>>$. Das war das total falsche Unternehmen. Das heißt, alles, was im Vorfeld danach schieflaufen konnte / also es fiel dann auch die Entscheidung, jawohl, wir gehen diesen bereinigten Weg. Die Altaktionäre waren bereit, nochmal drei Millionen nachzuschießen, frisches Geld. Da haben wir gesagt, die anderen / wir brauchten irgendwo 10, 12 Millionen / die kriegen wir auch irgendwo. So. Wir gehen jetzt diesen Weg. Ich habe gesagt, ich bin es leid wie Steine tragen. Ich kann es auch den Leuten so nicht mehr zumuten. Ich sagte, und sonst haben wir in zwei Jahren einen völlig demotivierten Laden, dem jede Kraft fehlt. Naja, und dann wurde mir an und für sich was abverlangt, was ich so überhaupt nicht erwartet 
hatte, nämlich die Banken sagten dann schlicht und einfach nein. Wir machen das nicht, wir lehnen alles ab, was da auf den Tisch kam. Das können Sie sich überhaupt nicht vorstellen, was das für ein Tohuwabohu war. Auch die erste Gläubigerversammlung wurde völlig torpediert. Zumal ich, und das muss ich auch sagen, dann vorher natürlich die Banken, oder die wesentliche Bank, unterrichtet hatte, drei Wochen vorher. Ich sagte: „Wir beabsichtigen diesen Weg zu gehen. Ist der richtig? Tragt ihr das mit? Geht ihr mit?" Da haben sie ja gesagt. So, und nachher in der Gruppe, im Pool, haben sie nein gesagt. So, also, das ging dann recht kunterbunt zur Sache. Ich hatte dann das große Glück, dass $<<<$ Name anonymisiert $>>>$, den wir uns ausgesucht hatten als Sachwalter, dass wir mit dem an uns für sich einen hatten, der sehr pragmatisch war. Denn ich habe dann entschieden am 28. Februar auf der ersten konstituierten Gläubigersitzung / ich hatte zwei Varianten vorbereitet, einmal das Planverfahren und einmal die ganz stinknormale Insolvenz. Und ich habe dann das normale Insolvenzverfahren eingeleitet, weil ich gesagt habe, gegen den Willen der Banken mache ich es nicht. Erstens habe ich nicht unerhebliche Bürgschaften drin, und wenn ich die mir alle zum Feind mache, komm ich da nie wieder raus. Und das habe ich dann auch vor den Gläubigern gesagt. Wir hatten neun Gläubiger im Ausschuss. Ich sagte nein. Weil die sagten, ja, wir können ja die Banken überstimmen. Wortwörtlich. Wir sieben hatten ja diesen Gläubigerausschuss zusammengestellt. Wir sieben gegen die beiden Banken, überhaupt kein Problem. Sieben zu zwei, so überstimmen wir dann. Ich habe gesagt, nein, das mache ich nicht. Ich habe wirklich auch eine Minute überlegen müssen, ist das richtig? Aber ich finde es auch heute noch richtig. Weil das an und für sich die Wogen dann wieder mittelfristig geglättet hat. Und die Banken waren deswegen sehr stinkig, weil einmal dieses Beratungsunternehmen ja von denen nicht gelitten war, weil sie sehr konsequent draußen vorgehen. Und auf der anderen Seite waren sie stinkig, weil ich sie nicht vorher eingeweiht hatte. Sie haben gesagt, über Jahre haben wir ein traumhaftes Verhältnis aufgebaut. Sie haben auch gesagt: , $<<<$ Name anonymisiert $>>>$, du kommst zu uns ins Haus und machst Vorträge vor unseren Leuten und bei so einer elementaren Geschichte bindest du uns nicht ein.“ So. Jetzt kann man sich lange unterhalten, war das der elementare Fehler oder war das trotz allem noch der richtige Weg. Es ist müßig, die Wogen haben sich geglättet, und eben letztendlich war es die drohende Liquiditätslage. Wo ich einfach sagte, ich muss wieder neues Geld 
reinpumpen. Und wieder über die Aktionäre und über die Banken was machen, und wieder die alten Schulden auf den Buckel packen. Das kann so nicht funktionieren. So, das war der Hauptgrund gewesen. Und wir sehen ja jetzt auch von den neuen Eigentümern, sie setzen 100 Prozent von dem um, was wir geplant haben. Im Grunde genommen haben sie unsere Planung genommen, unseren Fahrplan, und arbeiten den jetzt konsequent ab. Da ist also bis heute, und ich bin auch im Lenkungsausschuss drin und im Beirat drin, es ist bis heute nicht eine neue Idee und ein neuer Weg eingeschlagen worden. Schlicht und einfach abarbeiten dessen, was wir geplant hatten. Das zeigt halt, dass wir da auf dem richtigen Weg waren.

Und wir haben es auch bei den Kunden gesehen. So wie die Großen, ob das der $<<<$ Unternehmen anonymisiert $>>>$ ist, ob das $<<<$ Unternehmen anonymisiert $>>>$ ist, ob das $<<<$ Unternehmen anonymisiert $>>>$ ist, die alle nur ein Bestreben / ob das $<<<$ Unternehmen anonymisiert $>>>$ ist, da ist sogar der Vorstand selbst runtergekommen. Man hat gesagt, wir wollen alles tun, damit ihr hier überlebt und nicht hier auf der Strecke bleibt. So.

Das hat funktioniert, und das Unternehmen ist jetzt zum ersten Mal wieder ohne jede Bankschulden. Das ist ein Fonds aus dem Haus $<<<$ Unternehmen anonymisiert $>>>$, die institutionelle Anleger haben und so immer im Schnitt fünf Jahre im Unternehmen bleiben und dann wiederverkaufen, nicht? Und das, ja, das machen die gut. Das war auch einer der Hauptgründe gewesen, die haben eigenes Management mitgebracht. Das ist deren Philosophie, generell mindestens zwei Leute mitzubringen und die so lange im Unternehmen zu lassen, bis eine neue Führungsmannschaft da ist. Rechnen sie immer zwei Jahre für. Und bis das Unternehmen sich soweit gesettled hat, dass sie sagen, so, jetzt ist unser Investment in relativ sicherem Fahrwasser. Und so haben sie es hier auch gemacht, und das war für mich an und für sich das Ausschlaggebende, denn ich hatte mehrere Beteiligungsgesellschaften, die ja sich klar positioniert haben, sie würden zu gleichen Konditionen einsteigen. So, aber alle konnten kein eigenes Management mitbringen. Nur die. Und das war für mich das Whichtige, weil ich einfach gesehen habe, ich selbst allein, habe gesagt, schaffe es nicht. Und die Belastung wäre zu groß gewesen für mich. Es muss hier jemand sein, der Know-how mitbringt, und der Management mitbringt. Und das waren die, die es auch dann gemacht haben, die es auch dann innerhalb weniger Wochen das hier durchgezogen haben. Die sind nach drei Wochen gekommen, haben gesagt, wir sind bereit, wir 
haben alle Beschlüsse, wir können. Nicht? Und auch heute im Nachhinein, jetzt sind einige Monate ja ins Land gegangen, halte ich es für richtig, dass ich diesen Weg so eingeschlagen habe. Die Insolvenz war hier letztendlich der einzige Weg, um die Fehler aus '98, das muss man einfach so deutlich sagen, zu kompensieren. Was '98 vielleicht ein Drittel gewesen wäre, oder die Hälfte, das hat sich halt kumuliert.

I: Ja.

B: Nicht? Und es gab dort überhaupt keine andere Möglichkeit aus meiner Sicht, was zu tun, nicht? Und wenn Sie dann irgendwo erkennen, sie sind technisch auf dem richtigen Weg, marktseitig haben sie eine Bombenstellung, sie haben eine hochmotivierte Mannschaft quer durch alle Bereiche. Sie hängen nur immer wieder an einem einzigen Tropf, das ist der Tropf der Banken. So konnte ich 2010 zum Beispiel, naja, wollte mich der Weltmarktführer kaufen. Wir sind in Frankreich gewesen zu den Verhandlungen, und ich habe dann nachts gesagt, nein. Da würde ich heute wahrscheinlich auf Mallorca leben, nicht hier. Die hatten einen Bombenpreis geboten unter der Bedingung, ich schließe das Werk. Das heißt, sie hätten irgendwo 60 Leute übernommen, den gesamten Vertrieb. Alles andere, Technik abgebaut, rüber in ihre Werke, Techniker natürlich auch mit rüber. Die hätten sie gerne mitgenommen. Aber die haben 18 Werke weltweit, die wollten die Technik haben, unsere Marke haben. Und Schluss. Und da habe ich dann schweren Herzens muss / es hat schon / war eine schwierige Entscheidung, da dann nein zu sagen. Aber meine Frau hatte einen Ausspruch. Sie hat gesagt: „Hör mal, du hast nicht, zu dem Zeitpunkt waren es rund ja zwölf Jahre, zwölf Jahre geackert wie ein Gaul, um dann der eigene Totengräber zu sein. Egal wieviel die bieten, ich unterstütze immer, wenn du nein sagst." Und dann haben wir auch, die riefen mich dann nachher auch an: „Na, wäre es nicht besser gewesen, Sie hätten 2010." Ich sage, nein. Jetzt sind alle Leute in der Insolvenz zu 100 Prozent mit übernommen worden. Es ist keiner entlassen worden.

I: Aha. Sie haben gesagt, also, rational betrachtet, wenn Sie zurückdenken, war die Insolvenz der richtige Weg.

B: Hm. 
I: Aber, wenn man in der Situation ist, wie war das für Sie? Wie haben Sie das empfunden?

B: Ja, sie sind ja in dieser Phase unter einem enormen Druck. Denn es ist ja nichts mehr normal.

Der erste Punkt, sie haben überhaupt nichts mehr zu sagen. da schlucken sie ja schon mal, wenn sie sehen, sie sind im Grunde genommen noch fürs Kaffee holen gut. Das ging bei uns so die ersten drei Wochen, und danach hat sich das völlig gewandelt. Weil nämlich der Insolvenzverwalter gesehen hatte, dass wir den Laden im Griff haben, dass wir sehr genau wissen, was wir tun und wie wir das auch managen, und er dann sofort gesagt hat: „Komm, ich ziehe mich aus allem zurück.“ Hatte seine Leute dann abgezogen. „Macht ihr euren Job, keiner kann es so gut wie ihr.“ Ich glaube, ich habe die Insolvenzverwalter gesehen, wenn ich ehrlich bin, sieben Tage im ganzen Insolvenzverfahren. Die kamen mal eben eine Stunde oder zwei rein, und das war es. Nichts desto weniger ist das wie so ein Film, der abläuft. Also, ich glaube nicht, dass ich da realistisch gesehen habe, was und wie die Zukunft aussieht. Da ging es nur darum, das Tagesgeschäft zu managen, Rohstoffe zu kriegen, mit Leuten zu sprechen, mit Kunden zu sprechen, das einfach vernünftig hintereinander zu kriegen.

I: Jetzt war es ja bei Ihnen so, dass Sie sich darauf vorbereitet haben, dass Sie auch planvoll quasi da ran gegangen sind.

B: Ja.

I: Würden Sie trotzdem sagen, dass das ein einschneidendes Erlebnis war, das Sie geprägt oder verändert hat?

B: Die Frage habe ich mir oft schon gestellt. Vor allem ich habe immer gesagt, ich sehne mich danach mal drei Monate Ruhe zu haben. Drei Monate einfach mal zu überlegen, was tue ich? Und was habe ich getan? Und wie hätte ich was verändern, verhindern können? Und, tja, die Insolvenz hat / Wir dürfen ja nicht vergessen, ich bin 
in einem Alter, wo normalerweise die Mehrheit längst in Rente ist. Das heißt, es ist ja nicht so sehr, dass ich sage, was mache ich denn danach?

Aber sie erschüttert sie schon erst mal gewaltig. Weil ja alles doch / Sie hatten ja auch langfristige Pläne. Wie sie was / Das funktioniert dann halt alles nicht mehr. Und sie müssen plötzlich im Grunde genommen ihre Philosophie Dritten gegenüber vertreten und sie begeistern und sagen, das machen wir. So, und dann kriegen sie natürlich mit, dass sie die fast genauso begeistern, wie sie selbst erst begeistert waren. Aber die ein ganz, ganz whichtiges Mittel haben, was wir hier nie hatten, ausreichend Kapital. Und das Schritte, die wir schwer nur vollziehen konnten oder umsetzen konnten, wie zum Beispiel neue Techniken, dass das für die das Selbstverständlichste der Welt ist. Prüfung, serienreif machen, Leute von außen mit reinholen, die das Know-how haben dafür, und dann wird das Auftragsvergabeverfahren nach der Ausschreibung angeschoben. Wir hatten immer / Wir mussten immer mit knappstem Geld auskommen. Dadurch sind wir natürlich immer hochgradig kreativ gewesen, das steht außer Frage. Aber während der Insolvenz sind sie so vollgepackt, da hatte ich so überhaupt keine großartige Zeit. Aber danach kam so eine Phase, wo, ja, wo so eine gewisse Leere war, nicht? Und das kann ich / Das müssen sie erst mal verarbeiten. Und ich habe das große Glück, eine Frau zu haben, mit der ich auch nach vielen Jahren des Zusammenlebens immer noch sprechen kann. Und wir haben eine eigene Art. Wir sprechen generell abends immer durch, was war. Und dadurch haben sie immer einen, mit dem sie viel reden.

I: Ja.

B: Und was ich hier halt erlebt habe auch in der Insolvenz, das hat mich sehr nachdenklich gestimmt. Ich habe ja viele Bekannte, ich will es bewusst so sagen, von denen hat sich ein einziger gemeldet. Und von denen, die geschäftlich mit mir liiert waren, war es natürlich ein bisschen anders. Von der Uni $<<<$ Ort anonymisiert $>>>$, der Professor $<<<$ Name anonymisiert $>>>$ vom $<<<$ Unternehmen anonymisiert $>>>$ auch, das war aber der Einzige der sich da wirklich gemeldet hat, der gesagt hat: „Wenn Sie Hilfe brauchen, was ich tun kann zu jeder Zeit." Und das müssen sie erst mal so ein bisschen verarbeiten. 
Und ich hatte vor sechs Monaten meiner Frau ja den kleinen Hund geschenkt, weil sie sagte, Mensch, dann habe ich ein bisschen was zum Laufen und so weiter.

Mittlerweile ist das mein Hund, und ich hätte nie geglaubt, dass es mir so viel Freude macht, mit dem eineinhalb Stunden am Tag unterwegs zu sein. Und auch mit dem zusammen zu sein. Und dadurch, ich will mal sagen haben sie irgendwie so ein Mittel gekriegt, dass sie erst mal rausbringt aus dieser Depression, die sonst droht. Denn da sah ich immer das größte Problem drin. Und ich kann mir also eines nicht vorstellen, dass man nichts mehr tut. Aber ich habe immer gesagt, drei Monate mache ich nichts. Nichts, klar, ich habe an Konzeptionen gearbeitet, habe Informationen zusammengetragen, und jetzt beginne ich also mal langsam wieder zu sagen, so. Ich sage immer, ich mache nur noch das, wo ich Spaß dran habe. Wir sind jetzt gerade auch mal ein paar Wochen unterwegs gewesen, haben uns Einiges angesehen draußen. Jetzt habe ich es auf zwei Punkte eingegrenzt, habe jetzt die Projektbeschreibung im Grunde genommen für beide Projekte aufgebaut und werde mich jetzt irgendwo die nächsten Wochen entscheiden, welches ziehe ich jetzt davon durch. So, es sind zwei völlig unterschiedliche Projekte, eins tangiert mich im Alter. Wie lebt man im Alter? Wir sind beide Gott sei Dank, obschon meine Frau zwei schwere Krebserkrankungen hatte, kerngesund. Und haben aber hier ein relativ großes Haus. Und sagen natürlich heute, wir haben vier Kinder und sieben Enkelkinder, ja, da war das Haus / Die leben nicht mehr hier. Aber dafür war das Haus an und für sich mal ausgebaut. Und jetzt sind wir beide hier auf 350 Quadratmetern, nicht? Muss das sein? Wie will man im Alter leben? So, und da haben wir uns Einiges jetzt mal angekuckt, was es da für Lösungen gibt. Und welche Trends sich abzeichnen. Da könnte ich mir sehr gut vorstellen, was zu machen. Und eben was ganz anderes, was mit dem Garten und mit dem Leben im Garten außerhalb des Hauses zu tun hat. So, und das wird jetzt halt, das ist jetzt in Projektform gegossen. Die Informationssammlung ist ja fast fertig. Und da bin ich sehr sicher, dass ich da jetzt in den nächsten Wochen schrittweise mich entscheide, welches Projekt mache ich dann? Und dann an und für sich die Mannschaft dafür mal wieder zusammenstelle. Aber nur mit Externen, nicht? Mein Sohn macht die Beratung in $<<<$ Ort anonymisiert $>>>$ weiter. Und man muss mal kucken, was sich daraus ergibt.

Also, ich kann mir zum Beispiel heute nicht vorstellen, dass ich / Ich war jetzt in zwei Firmen, die mich händeringend gebeten hatten, mal reinzukucken, da habe ich denen 
dann in zwei Stunden gesagt, was sie falsch machen. Ich sagte: „Leute, aber macht das ohne mich." Ich sagte: „Ich habe da im Moment keine Lust mehr, ob schon ich mit Leib und Seele Berater war." Kann ich nicht anders sagen, aber noch mehr Spaß hat mir halt das Unternehmertum gebracht, kann ich nicht anders sagen. Einfach, wenn sie sehen, wie sie Menschen verändern können, in der Form, dass sie ihnen was zutrauen. Und dass sie ihnen auch die Möglichkeit geben, sich zu verändern. Auch das ist ein ganz whichtiger Punkt, nicht? Und das gelingt zwar nicht mit allen, aber wenn sie dann so zehn, zwanzig haben, deren Leben einen ganz anderen Weg genommen hat, weil sie ihnen einfach was zugetraut haben, und ihnen die Möglichkeit gegeben haben, sich weiter zu bilden, ne? Das hat mir also schon enormen Spaß gemacht, kann ich nicht anders sagen. Und wenn sie jetzt in $<<<$ Ort anonymisiert $>>>$ das Europäische Zentrum für $<<<$ Name anonymisiert $>>>$ nehmen, ja, das würde ohne mich da nicht stehen.

\section{I: Aha.}

B: Das sind halt so Sachen, wo sie dann pragmatisch rangehen müssen. Wo auch dann der Regierungspräsident hier gesagt hatte: „Sie haben uns mal gezeigt, wie es geht. Was wir mit neuen Materialien nicht hingekriegt haben, das machen sie jetzt mit dem dort." Nicht? Und ich habe gesagt, so lange ich / meine Familie ist / die sind alle um die 90 bis 100 Jahre alt geworden. Also, die Gene, sage ich mal, die werden es mir wahrscheinlich erlauben, noch ein paar Jahre aktiv zu sein.

I: $\mathrm{Hm}$.

B: Aber, ich möchte eben / Vorgestern hatte ich dann mal eine Krawatte wieder umgebunden zu einem Termin. Da habe ich gesagt: „Was ist?" Das kam mir ganz komisch vor, nicht? Da habe ich gesagt: „Ne, an und für sich will ich das gar nicht mehr." Ich habe da keine Lust mehr daran. Nicht? Und die Insolvenz hat mir jetzt auch so ein Stück halt Freiheit gegeben, weil ich sie anders nicht erreichen konnte. Auch das muss ich ganz deutlich sagen. Denn natürlich hätte ich lieber einen anderen Weg gehabt, das steht ja außer Frage, Aber das für mich immer das Wesentliche, dass ich gesagt habe: „Habe ich alle Schritte unternommen, die ich machen konnte? Oder habe 
ich was nicht unternommen, was ich nicht machen konnte?" Und das Erstaunliche, selbst die Banker haben mich unabhängig voneinander alle zum Essen eingeladen in der Zwischenzeit und haben gesagt: „Mensch, kommen Sie doch mal rüber. Ich komme auch zu Ihnen, dass wir abends mal Essen gehen, dass wir den Kontakt aufrechterhalten, dass wir nicht abreißen lassen." Das ist also die einzige Schiene, wo sich die Leute emotional geoutet haben, nicht? Denn sie wissen genau: „Moment, ich brauche keine 20, 30 Millionen.“ Altersmäßig werde ich wahrscheinlich kaum etwas machen in deren Auge. Und trotzdem haben sie den Kontakt gesucht." Nicht? Das hat mich dann zum Teil berührt, fand ich auch sehr schön, haben auch dann gesagt, das wollen wir nicht abreißen lassen.

I: Sie haben ja gesagt, dass wenige Bekannte sich gemeldet haben.

B: Ja.

I: Haben Sie auch so den Eindruck gehabt, dass sich der Umgang verändert hat?

B: $\mathrm{Hm}$.

I: Dass sie anders aufgenommen werden?

B: Ja, hier in $<<<$ Ort anonymisiert $>>>$ ist es sowieso schwierig. ich war gerade ein halbes Jahr hier, wir haben hier am Tisch gesessen, da hatte ich einen Unternehmer zum Essen eingeladen. Und der hat zu mir dann gesagt, weil wir dann gesagt haben, Mensch, wir haben ein offenes Haus und wir finden das sehr schön. Wir haben hier schon viele eingeladen gehabt. Und dann stellte der mir nur die Frage, oder meiner Frau: „Wie oft sind Sie denn schon eingeladen worden?" Dann haben wir einen Moment überlegt und haben gesagt, Wir wohnten da, glaube ich, ein Jahr hier: „Ja, noch gar nicht." Er sagte, ,Sehen Sie, ich bin auch schon 20 Jahre hier, ich kann Ihnen sagen, das bleibt so."

Sagt er: „Das ist $<<<$ Ort anonymisiert $>>>$. Die Leute sind so." Und das haben mir zwei Unternehmer, die beide nicht von hier kamen, genauso gesagt. Und unsere Erfahrung ist so, dass es wirklich eingetreten ist. Ich bin also hier, ich war bereit 
öffentliche Ämter zu übernehmen. Ich habe also sehr, sehr viel, denke ich, auch gemacht. Aber wir sagen immer: „Wir wohnen hier, aber wir leben hier nicht." Und das ist etwas, wir sind jetzt am Wochenende in meiner Geburtsstadt gewesen, ich bin $<<<$ Ort anonymisiert $>>>$, habe dort fast 30 Jahre gelebt, und da habe ich wirklich gesagt, siehst du, das merke ich jetzt, so wie die in $<<<$ Ort anonymisiert $>>>$ oder die in $<<<$ Ort anonymisiert $>>>$ sagen: „Ich bin wieder zu Hause." So sage ich da hinten auch: „Ich bin wieder zu Hause." Obschon ich jetzt über 35 Jahre weg bin. Nicht? Trotzdem ist Vieles vertrauter so. Hier ist es uns nie gelungen, soziale Kontakte zu knüpfen, ich will es mal so sagen. Ich habe unwahrscheinlich viele Bekannte, aber soziale Kontakte konnten wir nicht knüpfen, war nicht möglich. Und wir leben jetzt ja fast 15 Jahre hier. Es ging nicht. Nicht? Insofern wir sagen immer, leben wir hier wie in so einem goldenen Ei. Nicht? Das ist hier immer so, auch dass sie mal / Wir hatten ja nie ein Richtfest gemacht. Wir haben natürlich die Leute eingeladen. Das kenne ich aus, ich habe auch mal eine Zeit in $<<<$ Ort anonymisiert $>>>$ gelebt, das kenne ich da nicht anders, ne? Aber hier gibt's das nicht. Die sind zwar alle gekommen, wir hatten ja 80 Leute, nicht? Oder ich habe Veranstaltungen gemacht in der $<<<$ Ort anonymisiert $>>>$, da habe ich den $<<<$ Name anonymisiert $>>>$ gehabt, ich habe den $<<<$ Name anonymisiert $>>>$ gehabt, ich habe den $<<<$ Name anonymisiert $>>>$ gehabt, und wir haben dort wirklich versucht eine Botschaft rüber zu bringen. Ja, aber die fanden das alles toll, waren 400 Leute immer da, nicht? Oder auch wenn wir in der Firma was gemacht haben, wo wir zu bestimmten Themen, auch Philosophie, was gemacht haben, war immer voll. Aber sie kriegten nichts zurück.

Und das war für mich so / Irgendwann habe ich dann gesagt: „Du, was soll's. Es ist witzlos. Du rennst hinter was hinterher, was du so nicht kriegst." Und da habe ich so auch die Entscheidung getroffen, dann gehe ich stufenweise überall raus. Bin dann 2010 auch, oder 2008 war es schon, sukzessive überall rausgegangen, nicht? Oder auch ob das hier Aufsichtsräte waren in öffentlich-rechtlichen, ob das das Klinikum war und so weiter, sie waren immer gern gehört mit ihrem Rat, und mir hat hier mal die Stadt 2004 die goldene Medaille überreicht. Da waren nur ganz wenige Leute, dann habe ich das da mal beim Essen dann gesagt. Da guckte der mich fassungslos an, der Bürgermeister, und sagte: „Ja, aber das ist der große Respekt, den man vor Ihnen hat." Ich sage: „Warum, sie wissen doch alle meine Türen stehen immer auf." Ich sage, ja, sagt er, aber das ist der Respekt. 
I: Aha.

B: So. Und insofern war das ja auch eine etwas andere Situation mit der Insolvenz. Da werden Etliche gesagt haben: „Naja, also, wir haben ja immer schon gesagt, das geht nicht mit rechten Dingen zu." Aber, ich glaube, ein Großteil hat gesagt: „Uns hat es einfach leidgetan, dass das passiert ist." Aber dadurch, dass wir nie diese ganz engen Kontakte hatten, hat sich da auch nicht so viel daran verändert.

I: Aha.

B: Nicht? Wir sind also im sozialen Umfeld ganz bewusst geblieben. Wir haben sofort überlegt, wollen wir hier wegziehen? Wenn ich das Werk geschlossen hätte mit dem Verkauf, wären wir hier sofort weggezogen. Aber, ich finde es auch heute noch richtig, es nicht getan zu haben. Muss ich ganz nüchtern sagen.

I: Gibt es andere Dinge, wo Sie heute sagen, das hätte ich lieber anders machen sollen?

B: Ja, ich würde nie wieder direkt am Werk wohnen. Nie wieder. Weil jeder reinguckt, was meine Frau einkauft. Wenn Sie ein Filet kauft, teilt sie es auf auf drei Metzger, damit nicht jeder / Das hat sich einfach so schon eingebürgert. Das war der elementarste Fehler, direkt am Werk zu wohnen oder in der Nähe, im gleichen Ort, nicht? Denn sie, egal, ob sie in eine Gaststätte oder was kommen, man kennt sie ja, nicht? Das war aus meiner Sicht der elementarste Fehler, ansonsten, also ich habe Vieles überlegt: „Habe ich was falsch gemacht? Könnte ich was anders noch gemacht haben?" Mir ist so nichts aufgefallen.

I: Sie haben vorhin gesagt, dass man auch nach der Insolvenz wie so eine Art Leere spürt, oder dass man sich dann auch überlegen muss, was man macht, damit man nicht depressiv wird. Meinen sie das eher so, weil man plötzlich so viel Zeit hat, sich mit sich zu beschäftigen? Oder meinen Sie das eher so, weil man grübelt, weil man die Insolvenz vielleicht ein Stück weit auch als eigenes Versagen durchleuchtet? 
B: Ja, ich denke, das geht ja mal Hand in Hand, nicht? Dieses Überlegen, hast du versagt? Aber das ist ja schon... (zögert, Pause)

\section{I: Haben Sie sich so gefühlt?}

B: Ja, solche Stunden haben sie auch, nicht? Wo / Ich bin Löwe, und da sagen sie generell: „Das hättest du verhindern können:" Ne? Wobei, wenn ich dann ganz nüchtern, und ich versuche immer anhand von Fakten was abzustimmen, dann sage ich: „Ne, du hast alles unternommen, was, ich sag mal, was in meinen Kräften stand."

I: Der Gedanke kam der nur aus Ihnen raus oder hatten Sie das Gefühl, Sie werden so gesehen, dass Sie es verbockt hätten?

B: Ne, da wurde also, das konnte man hier so sagen, dass da, zumal wir uns auch in der Presse / Wissen sie, wenn so ein $<<<$ Name anonymisiert $>>>$, der gerade $<<<$ Unternehmen anonymisiert $>>>$ auch gemacht hat, $<<<$ Unternehmen anonymisiert $\gg>$ gemacht hat, und sich dann hinstellt und sagt: „Wie man es richtigmacht, da guckt euch mal den $<<<$ Name anonymisiert $>>>$ an." So macht man es richtig auch als Unternehmer, um so eine Situation im Griff zu behalten. Das hat natürlich hier schon Viele beeindruckt. Und wir müssen, denke ich, immer unterscheiden zwischen, ja, dem normalen Nachbarn, der sicherlich Angst hat überhaupt zu sprechen, und dem Unternehmer, der gestanden ist. Und da hätte ich schon gedacht, dass die intensiver sich damit mal auseinandersetzen und auch mal auf einen zukommen. Und da ist hier null. Absolut null.

I: Sie haben vorhin mal erwähnt, dass Sie auch mit dem Unternehmen irgendwie mit Bürgschaften oder so verknüpft waren. Hatten Sie auch Angst vor einer Privatinsolvenz oder ist das nicht gedroht?

B: Ja, nicht Angst, sondern das war ganz klar Bestandteil auch des Planes. Das musste man einkalkulieren, dass das passiert. Denn alles andere wäre dann ein großer Glücksfall. 
I: Aber es ist nicht passiert.

B: Ist nicht passiert, nein, nein. Es ist mir dann gelungen, im Grunde genommen innerhalb ganz kurzer Zeit mit denen dann schon eine Vereinbarung zu treffen, die auch von der finanziellen Last her so vernünftig war, dass wir sagen konnten: „Komm, das ist gegessen und abgehandelt."

I: Und wie weit haben Sie sich mit dem Thema Privatinsolvenz auseinandergesetzt?

B: Ja.

I: Wie war das?

B: Was das heißt, was das bedeutet.

I: War das schlimm? War die Drohung jetzt schlimm für Sie?

B: Ne, das waren nüchterne Fakten, welche Voraussetzungen muss man treffen, nicht?

I: Also, Sie haben es jetzt nicht als Damoklesschwert empfunden, das da über Ihnen schwebt?

B: Ne. ne. Das nicht. Dazu habe ich auch zu viele begleitet in so einer Situation.

Nicht? Denn das einzige Problem war, dieses Haus hier lautete auf meinen Namen und nicht auf den Namen meiner Frau. Und /

B2: Hallo!

I: Grüß Gott!

B: Ach, $<<<$ Name anonymisiert $>>>$, darf ich dir Frau Rauch vorstellen. Frau Rauch, meine Frau. 
I: Hallo! Tag!

B2: Hallo!

B: So, wir reden gerade über unser Lieblingsthema.

B2: Über was?

B: Insolvenz. (lacht)

B2: Ach so, ja. (lacht) Na, dein Lieblingsthema ist es ja wohl nicht.

B: (lacht) Ja. Und, wo waren wir jetzt gerade stehen geblieben?

I: Bei der Privatinsolvenz.

B: Ja.

I: Dass Sie viele begleitet haben.

B: Ja. Und da sehen Sie natürlich auch, wie whichtig das ist, dass dann Vorkehrungen dafür getroffen werden. Denn da ist alles andere Unsinn, wenn man es nicht macht. Und ich war heilfroh, dass es mir hier gelungen ist, das Haus da rauszuhalten, dass da die Banken mitgezogen haben. Auch keine Selbstverständlichkeit. Möchten Sie noch einen Kaffee?

I: Nein, danke.

B: Hm. Wasser? Gut.

I: In der Durchführung der Insolvenz hab es da irgendwas, wo Sie sagen, das hätte man anders machen müssen, oder da war ein großes Problem in der Abwicklung oder irgendwas? 
B: Ja, es gab ein Problem, was wir überhaupt nicht gesehen haben, auch $<<<$ Unternehmen anonymisiert $>>>$ nicht, auch die anderen Berater nicht. Und zwar gehören / Wir haben auf unseren Schleifscheiben ein Sicherheitszeichen drauf. Das ist die OSA. OSA heißt Organisation für Sicherheit im Schleifscheibenbereich. Und wir kriegten nach Eröffnung der Insolvenz am 1. Mai, wo auch dort dann $<<<$ Name anonymisiert $\gg>>$ nochmal wieder angeboten hat: „Ich mache auch ein Planinsolvenzverfahren, Ihr müsst nur sagen, ihr wollt es. Machen wir sofort." Und ich mich entschieden habe, nein, wir machen das geregelte Verfahren. Einfach weil ich Leitplanken hatte links und rechts. Kriegten wir 14 Tage später von unserer Organisation, der OSA, die Mitteilung, dass aufgrund der Eröffnung des Insolvenzverfahrens wir satzungsgemäß ausscheiden aus der OSA. Und sie bitten darum ab sofort nicht mehr OSA zu produzieren, mit dem OSA-Label, und sämtliche Produkte, für die wir Aufträge haben, dürften wir noch verkaufen. Jetzt müssen sie sich vorstellen, wir haben $80 \%$ unserer Produkte mit OSA-Label. Und diese Label alleine auszutauschen, diese Etiketten, hätte zwei Millionen gekostet. Und die Wiederbeschaffungszeit 8 Wochen, 10 Wochen. Das heißt, das wäre das K.O. gewesen für das Unternehmen. Aber die OSA bestand darauf. Und sie müssen sich vorstellen, in der OSA sind unsere Wettbewerber, genau wie wir. Und die haben da jetzt natürlich eine Riesenchance gesehen, uns über diese Schiene K.O. zu kriegen. So. Jetzt will ich gar nicht alles/ also das hat dann drei Wochen höchste Alarmbereitschaft bedeutet. Wir haben dann eins gemacht, wir sind dann sofort zu allen whichtigen Kunden hin und haben das kommuniziert, und haben gesagt, wir können wieder Mitglied in der OSA werden, wenn das Insolvenzverfahren beendet ist. Das wird irgendwann September/ Oktober sein. Wir können in der nächsten OSA-Sitzung, die im November schon festliegt, können wir wieder Mitglied werden. Aber das heißt, bis dann wieder alles umgestellt ist, wird es Januar werden. Das heißt wir müssen jetzt in etwa rechnen ein halbes Jahr ohne OSA-Label. Und siehe da. Es haben 100\% aller Kunden gesagt: „Machen wir." Und da hat die OSA nie damit gerechnet, dass das so funktioniert.

Wir haben dann an alle deutschen Gerichte eine Schutzschrift geschickt, falls die OSA eine einstweilige Verfügung erlässt. Denn wir haben bestimmte Entscheidungskriterien sehr, sehr weit ausgelegt. Und um da nicht eine einstweilige 
Verfügung zu bekommen, half nur eine Schutzschrift. Das heißt, die haben an 100soundsoviel Gerichte haben dann unsere Anwälte eine Schutzschrift geschickt, 60 Seiten stark, wo alles aufgearbeitet war. Was auch hier wieder/Wir haben das Thema sofort kommuniziert für unsere Kunden. Haben denen aber auch gesagt, was wir tun wollen, um das zu beheben. Und haben dann auch mit der OSA den Kontakt gesucht, haben gesagt: „Natürlich, wir regeln so, wie ihr das wollt, werden wir das machen." Die sind dann auch gekommen, fanden dann auch Bestände gesperrt. Das hatten wir alles ordentlich gemacht, aber eben in einer Art und Weise, die für uns sehr verträglich war. Und wir haben dann auch ein neues Audit machen müssen von A bis Z, obschon wir die Beanstandungen hatten. Auch dieses neue Audit ist dann im August gemacht worden ohne jede Beanstandung. Das hat dann dazu geführt, dass wir im November wieder OSA-Mitglied wurden, die neue Gesellschaft. Also das war in der Insolvenz, das hatte keiner auf dem Schirm. Und das hätte den Insolvenzverwalter, wenn wir das nicht so im Griff gehabt hätten, hätte den das bewogen, eine Ausfertigung zu machen. Der hätte gesagt: „,Gut, Fertigung läuft aus. Und Schluss." Denn das wären Millionenkosten, die hätten wir nicht auffangen können. Aber durch dieses Vorgehen haben wir es halt in den Griff gekriegt. Aber das war so das Einzige, was uns neben den üblichen Geschichten, wo Lieferanten sagen: „Ja, nur gegen Vorkasse”. Das ist dann halt $100 \%$, die das machen. Aber wir hatten eben auch ausreichend Liquidität zur Seite, um diese Phase durchzustehen.

I: Und die Zusammenarbeit mit dem Insolvenzverwalter, wie lief die?

B: Brilliant. Konnte nicht besser sein. Der hat sich blind auf das verlassen, was wir ihm vorgelegt haben. Und fertig. Es konnte nicht besser sein. Auch wenn sie überlegen, der Insolvenzverwalter hat die außertariflichen Mitarbeiter zu 100\% bezahlt. Auch das ist keine Selbstverständlichkeit. Aber ich habe ihn da auch immer überzeugt: „Wenn wir die nicht an Bord halten, wird es schwierig. Und an Bord halten wir sie nur, wenn sie das gleiche Geld kriegen. Nicht weniger." Das hat er gemacht.

I: Gut. Also, ich bin meine ganzen Fragen losgeworden. Gibt es noch irgendetwas, was Sie ergänzen möchten, irgendetwas, was Sie noch loswerden möchten? 
B: Nein. Das Whichtigste wäre gewesen, wir hätten es vermeiden können. Das steht außer Frage. Aber das ist halt ein Instrument, wenn Sie feststellen müssen, es geht nur so. Einen Punkt kann ich zum Beispiel sagen, wir hatten in unserem Insolvenzplan für die Banken vorgesehen zwischen fünf und sieben Millionen. Das hielten sie für unangemessen. Gesamtvolumen Banken waren 19 Millionen. Sie haben jetzt im Insolvenzverfahren 3,4 bekommen und sagen noch: „Wir sind sehr zufrieden." Das ist halt der Unterschied, wenn es keine Alternative gibt. Im Vorfeld ist es mir nicht gelungen, die zu überzeugen, wir müssen über einen Haircut hier das Unternehmen auf vernünftige Füße stellen. Und das haben sie halt alle nicht geglaubt, weil sie alle der Meinung waren, wir finden einen, der 20 Millionen zahlt. Ja, den haben wir auch gefunden. Aber die 20 Millionen zahlt er nur, wenn die und die und die anderen Risiken auch weg sind. So, und die hätten halt wieder die 20 Millionen aufgefressen. Und das ist mir nicht gelungen, denen klarzumachen. Da sind wir jetzt mit dem $<<<$ Name anonymisiert $>>>$ dran, ob wir daraus vielleicht mal eine Seminarreihe machen für die Banken, um die frühzeitig auf eine derartige Spur zu bringen. Aber meine Erfahrung ist so, in dem Moment, wenn das Insolvenzverfahren abgewickelt ist, das heißt das Closing stattgefunden hat, sind die Insolvenzverwalter schon wieder in einer neuen Welt bei neuen Fällen, ist das Thema abgehakt und durch. Es ist eine recht kurzlebige, schnelllebige Welt mit einem niedrigen Verfallsdatum. Und wir haben uns jetzt im Dezember noch einmal gesehen. Wir werden uns, denke ich, im Juni noch einmal sehen. Aber das wird es dann auch im Großen und Ganzen gewesen sein. Also, wer es vermeiden kann, sollte es vermeiden, das steht ja außer Frage. Steht außer Frage, denn es ist auch immer eine Vernichtung von Werten. Auch das gehört dazu. Aber was ich auch festgestellt habe, das bis auf einen Lieferanten alle Lieferanten nachher wiedergesagt haben: „Wir sind dabei, wir machen mit." Und das sind immerhin, ich rede hier über 400 Lieferanten. Konsequent, alle haben mitgemacht. 
Appendix X: Transcript of Interview 9

I: Am besten, Sie schildern einfach mal Ihren Werdegang von der Kindheit bis heute, die großen Meilensteine beruflich und privat.

B: Ok. Dann fang ich mal an mit der Geburt, das war 1956 in $<<<$ Ort anonymisiert $>>>$. Ich bin in einem Vorort von $<<<$ Ort anonymisiert $>>>$, in $<<<$ Ort anonymisiert $>>>$, aufgewachsen bei meinen Eltern. Die hatten da ein Haus mit großem Garten, eigentlich behütete Kindheit. Bin in $<<<$ Ort anonymisiert $>>>$ zur Schule gegangen. Bin nach der Volksschule dann nach $<<<$ Ort anonymisiert $>>>$ auf das $<<<$ Name anonymisiert $>>>$ Gymnasium, habe da Abitur gemacht. Ich hatte da auch einen netten Bekanntenkreis und Freundeskreis. Also, das war alles eigentlich ideal. Nach dem Abitur kam ich zur Bundeswehr nach $<<<$ Ort anonymisiert $>>>$ und später nach $<<<$ Ort anonymisiert $>>>$. Bei der Luftwaffe war ich da, Grundausbildung halt und die normale Wehrpflicht zu der damaligen Zeit. Und nach der Bundeswehr fing ich hier in $<<<$ Ort anonymisiert $>>>$ an der Uni ein Studium an der Betriebswirtschaftslehre.

Ich hatte in $<<<$ Ort anonymisiert $>>>$, sprich $<<<$ Ort anonymisiert $>>>$, einen Freund, und der Vater hatte so eine kleine Fernsehreparaturwerkstätte mit zwei Lehrlingen. Damals gab es so etwas noch. Und da man halt als Jugendlicher zu machen angefangen, Dinge zu verkaufen im Unterhaltungselektronikbereich.

Lautsprecherboxen selber gebaut und Stereoanlagen. Das ist in dem Alter ja damals sehr attraktiv gewesen. Heute sind es dann halt so die IPhone und Playstations wahrscheinlich und Wiis. Ja, und da hatte ich dann relativ jung irgendwann mal einen Gewerbeschein ausgefüllt. Und dann bist du ja quasi selbstständig. Und ich hatte damals Musikkassetten verkauft. Und über die Musikkassetten hatte ich dann eine Anfrage nach Disketten. Ich wusste damals gar nicht, was das ist. Also, das gab es halt vorher nicht. Und hatte dann Disketten von der Firma $<<<$ Unternehmen anonymisiert $\gg>>$ besorgt. Die Firma kannte man auch nicht. Das war ein reiner OEMLieferant. Die haben halt Plattenlaufwerke und so etwas ... (unverständlich) und so geliefert. Das $<<<$ Name anonymisiert $>>>$ - Institut, das es später gab, gab es damals auch noch nicht. Und habe damit Leute beliefert, die halt so Apple 2 Computer hatten. 
Da habe ich also erst zehn Disketten verkauft und dann 50 und dann 100 und dann 500. Und während des Studiums dann hier in $<<<$ Ort anonymisiert $>>>$ in meiner Studentenbude hatte ich dann zu Spitzenzeiten 150.000 Dreieinhalbzolldisketten im Monat verkauft. So halt einfach akquiriert, irgendwelche Leute angerufen. Und dann irgendwann habe ich einen Auszubildenden, das war hier in der $<<<$ Ort anonymisiert $>>>$ im zweiten Stock in meiner Studentenbude. Das war am Ende so, dass da fünf Mitarbeiter waren, und ich hatte nur noch meine Matratze in meinem Zimmer. Und die kamen früh um acht und sind abends teilweise um zehn gegangen. Ja, und dann gab es halt so ein paar Irrwege auch, sprich man hat dann neben den Disketten auch mal versucht, Hardware zu verkaufen. Und dann hatte ich eine Software entwickeln lassen für die damaligen Minicarunternehmen. Ich weiß nicht, ob Ihnen das etwas sagt?

I: Das sagt mir nichts, nein.

B: Das gab es hier in $<<<$ Ort anonymisiert $>>>$ und auch in $<<<$ Ort anonymisiert $>>>$, das war so eine Alternative zu den Taxis. Die hatten ein bisschen andere gesetzliche Regularien. Und da gab es halt in der Zentrale einen Menschen, der letztendlich das Ganze gesteuert hat, also das nächste Fahrzeug halt zum entsprechenden Fahrgast gebracht hat. Und der Eigentümer dieses Unternehmens hatte immer das Problem, dass die Leute, die auch nachts arbeiten mussten, irgendwann die Nase voll hatten und gegangen sind, und es nicht ganz einfach war, irgendwie so 30/ 40 Autos da so optimal zu dirigieren. Und da war meine Idee so eine Folientastatur, also eine Tastatur zu nehmen, GPS gab es leider noch nicht, sonst wäre das einfach gewesen, mit den Planquadraten des Stadtplans, und dann die Fahrzeiten, denn die fahren zu bestimmten Orten, wie was weiß ich, $<<<$ Ort anonymisiert $>>>$ oder ja, da die Zeiten einfach zu messen, so dass der dann einfach nur antippt und weiß, wann das Fahrzeug bei der Haltestelle oder bei dem Gast ist. Aber der Mensch, der das gemacht hat, der war nicht sehr seriös, um nicht zu sagen kriminell. Ich hatte ja selber von Softwareentwicklung keine Ahnung, habe das extern entwickeln lassen von jemandem. Und von $<<<$ Unternehmen anonymisiert $>>>$ hatten wir einen Computer gestellt bekommen. Aber letztendlich habe ich dann, das war dann in $<<<$ Ort anonymisiert $>>>$ wurde das dann installiert, in so einem Turm, Sendemast ... (unverständlich) Die haben ja alle 
über Funk damals gearbeitet. Und ich habe es dann in einer Nacht-und-Nebel-Aktion abgeholt, weil da versucht wurde die Software runter zu kopieren. Das war also meine erste Negativerfahrung in diesem Bereich.

Und dieser Mitarbeiter, der diese Software entwickelt hatte extern, der hat dann gewechselt von diesem Unternehmen zu mir. Und legte mir da eine Visitenkarte hin von der $<<<$ Unternehmen anonymisiert $>>>$ Bank. Der wollte nämlich Electronic Banking mit der damaligen $<<<$ Unternehmen anonymisiert $>>>$ Bank machen. Ja. Und, die hatten das voll beworben. Und auf Nachfrage dann, was sie anbieten können, hieß es, keine Ahnung, wissen wir nicht, hier hat ja keiner einen Plan. Und man hat ihm dann die Visitenkarte gegeben von jemandem hier in $<<<$ Ort anonymisiert $>>>$ in der Zentrale. Und 4/ 6 Wochen hatte ich mit dem mal Kontakt aufgenommen, und dann gab es einen Termin. Und jedenfalls hat sich das so hin entwickelt, dass wir dann eine Software entwickelt haben. Die hieß dann $<<<$ Name anonymisiert $>>>$ für die $<<<$ Unternehmen anonymisiert $>>>$ Bank, und das war ein Zahlungsverkehr, so Diskettenclearing, ein Inlandszahlungsverkehr. Konnte man Daueraufträge und solche Dinge verwalten. Und das wurde dann über die sogenannten $\mathrm{OKBs}$, das waren die $<<<$ Unternehmen anonymisiert $>>>$ Bank Kundenberater, Organisationskundenberater oder wie das hieß, vertrieben. Das war dann bei $<<<$ Unternehmen anonymisiert $>>>$, $<<<$ Unternehmen anonymisiert $>>>,<<<$ Unternehmen anonymisiert $>>>$ und vielen, vielen Mittelständlern im Einsatz. Also da, lange ist nichts passiert, und es ging ja dann alles über $<<<$ Ort anonymisiert $>>>$. Und normalerweise geht alles von der Zentrale aus bei den Banken und nicht anders herum. Also, das war sehr schwierig. Und dann hieß es auch, man fliegt jemanden in die USA, und kommt mit so einer Software zurück, da gibt's das schon hundert Jahre. Der ist dann rüber geflogen, kam aber mit leeren Händen zurück. Und dann gab es eben einen Termin. Und das war damals ganz lustig. Die Spezifikation der Software, also die Beauftragung von einem Menschen damals, einem Herrn $<<<$ Name anonymisiert $>>>$ von der $<<<$ Unternehmen anonymisiert $>>>$ Bank, der gesagt hat, ok, wenn der Auslandszahlungsverkehr, den es ja noch nicht gab, dieselbe Qualität hat wie der Inlandszahlungsverkehr, dann würde er das beauftragen. Haben wir gesagt, hat er. Und davon wurden dann, ich glaube, so tausend Lösungen verkauft. Also das hatte damals so, ich glaube, ich weiß nicht mehr genau, der Inlandszahlungsverkehr 400 Euro und der Ausland 800 Euro und im Package zusammen 900 Euro, wenn Sie Inland und 
Ausland einmal zusammen abnehmen. So habe ich das angeboten. Oder 100.000 DMark Einmalzahlung und dann Kopierlizenz. Und Banker sind vorsichtig, die haben dann die Einzelvariante gewählt. Es war zwar noch kein Vertrag unterschrieben, aber das hat er so gesagt. Und dann war die Erstbestellung, das waren 100 Pakete, Inland und Ausland. Da hat er mich zwar gefragt, ob ich auch noch zu der anderen Alternative stehen würde. Das habe ich dann verneint. Da hat er gemeint, das könne er verstehen und ist auch darauf eingegangen. Und dann bin ich halt in das $<<<$ Ort anonymisiert $>>>$ nach $<<<$ Ort anonymisiert $>>>$ gefahren und habe die Verträge da dann mit den Juristen verhackstückt.

So das war praktisch/ so bin ich von der Diskette über, oder von der Musikkassette und Unterhaltungselektronik zur Diskette und dann zur Software gekommen. Quasi wie die Jungfrau zum Kind. Und dann hatten wir Hardwareverkauf, also damals halt wurden ja so Taiwanrechner importiert. Da musste man drei importieren, damit einer funktioniert hat. Und habe Diskettenlaufwerke verkauft von $<<<$ Unternehmen anonymisiert $>>>$ und wie gesagt dann parallel eben auch die Disketten, danach dann mehr Hardware, Netzwerktechnik, $<<<$ Unternehmen anonymisiert $>>>$, $<<<$ Unternehmen anonymisiert $>>>$ als Netzwerksysteme. Und auch dann kamen immer mehr Anfragen nach Software, Warenwirtschaft. Dann haben wir angefangen, eine selbst zu entwickeln. Haben das dann aber aufgegeben. Haben dann KAK, SageKAK, sagt Ihnen vielleicht etwas, damals hieß es nur KAK, lizenziert. Das war dann so eine Kopierlizenz, da musste man Geld bezahlen. Das hat aber überhaupt nicht funktioniert. Aber die Hotline war immer belegt, und viele Dinge haben nicht so wirklich funktioniert. Und wir konnten das nicht machen, was wir wollten. Dann habe ich irgendwann die paar Kunden, die wir damit gewonnen hatten, und die Software an einen Wettbewerber verschenkt. Der hat Dinge gemacht, die wir vorgemacht haben, hat er immer nachgemacht. Damit die Kunden halt weiter betreut werden, und wir keine Altlasten haben.

Weil zu dieser Zeit zwei Dänen bei uns ankamen, ein $<<<$ Name anonymisiert $>>>$ und ein $<<<$ Name anonymisiert $>>>$, und haben gesagt, schaut mal, wir haben hier eine ganz tolle Software. Zu denen habe ich heute noch Kontakt. Das waren zwei der drei Deutschlandgeschäftsführer, und dann haben wir uns angekuckt `ne Zeit lang und haben dann gesagt, ok, das machen wir. Und dann haben wir ein erstes Projekt gemacht, realisiert, also entwickelt, akquiriert mit denen noch gemeinsam. Die waren 
da ganz in den Anfängen. Und haben dann einen Auftrag bekommen von der Firma $<<<$ Unternehmen anonymisiert $>>>$ in $<<<$ Ort anonymisiert $>>>$ für deren Werkstätten eine Werkstattlösung zu entwickeln. Da haben wir dann entwickelt und entwickelt und entwickelt. Haben einen Differenzkunden gehabt in $<<<$ Ort anonymisiert $>>>$. Und als wir mit der Software fertig waren, ich war dann in $<<<$ Ort anonymisiert $>>>$ mit einem Anwalt, großen Anwaltskanzlei, mit einem Anwalt, den $<<<$ Unternehmen anonymisiert $>>>$ da engagiert hatte, und habe die ganzen Verträge da unterschrieben. Das war auch Hardware liefern und Datenaktualisierungsvertrag und Softwarelieferungsvertrag und und und. Und just als das alles fertig war, hatte die $<<<$ Unternehmen anonymisiert $>>>$ Insolvenz angemeldet. Und unsere Vergütung war ja praktisch der Abverkauf der Lösungen. Das war weniger schön. Das war im Prinzip das erste Projekt mit Navision und gleich ein ordentlicher Rückschlag. Ich hab dann, ich glaube, vier Jahre später 100.000 D-Mark aus der Insolvenzmasse da bekommen. Aber das war natürlich schon mal ein herber Rückschlag. Aber da haben mir auch ein paar Leute gekündigt bereits, da waren wir nicht viele, aber die sind dann gegangen. Und wir haben das aber dann weiter betrieben und haben dann halt diese NavisionLösung versucht im Markt zu platzieren und haben da akquiriert. Das war eine reine Lösung, Handelslösung, für kleinere Großhändler, sag ich mal. War auch funktional noch nicht so stark, da die Unternehmen in Dänemark meist kleiner sind als/ und weniger funktionale Anforderungen an so eine Software stellen als das in Deutschland der Fall ist. Aber wir haben den einen oder anderen Kunden gewonnen und haben dann ein Projekt auch relativ früh realisiert in $<<<$ Ort anonymisiert $>>>$ bei der Firma $<<<$ Unternehmen anonymisiert $>>>$. Das ist ein großer Anlagenbauer. Die hatten eine große IBM-Anlage und da gab es einen Herrn, einen IT-Leiter, einen $<<<$ Name anonymisiert $\gg>>$, und der hat uns das zugetraut. Andere waren da sehr skeptisch, dass wir das realisieren können. Wir hatten ja keine Referenz in diesem Bereich. Und das haben wir dann getan. Und es war dann auch eine Lösung, die gut funktioniert hat. Und daraufhin haben wir dann auch ein anderes Projekt in $<<<$ Ort anonymisiert $>>>$ bekommen, auch ein Anlagenbauer mit 200 Usern, also sehr komplexe Lösungen, anspruchsvolle Lösungen. Wir hatten da auch eine gute Truppe, gute Leute. Und da gab es einen externen Berater auch, einen Herrn $<<<$ Name anonymisiert $>>>$, mit dem ich mich ganz gut verstanden hatte. Hat da überall beraten, hat uns da überall ins Spiel gebracht. Insofern ging das halt dann immer weiter, dass wir da halt immer mehr 
Projekte akquiriert hatten im Bereich der Projektabwickler. Da haben wir auch heute noch eine Lösung, die den Namen $<<<$ Name anonymisiert $>>>$ bei uns intern trägt oder auch nach außen so beworben wird. Und ist eben für Unternehmen, die Projektgeschäft haben, ja, und ihre Projekte steuern müssen, unterschiedliche Sichten auf ein Projekt benötigen, Terminsicht, Budgetsicht, Resourcensicht usw., Dinge nach außen geben, bearbeiten lassen und dann wieder in die Anlage verbauen. Also, für solche Unternehmen war das gedacht. Davon gab es noch einen Ableger für Messebauer, die noch ein paar spezielle Themen hatten, wie Mietmöbel und so etwas. Aber letztendlich auch/ ein größerer Messebau ist ja letztendlich auch ein Projekt. Aber ansonsten hatten wir auch bei Hopfenhändlern Lösungen installiert. Ein größeres Projekt, internationales, haben wir realisiert für $<<<$ Unternehmen anonymisiert $>>>$, also die diese Getriebe für Autos und so, Busse, Schiffsgetriebe und solche Dinge bauen, ein Automobilzulieferer, für deren Servicegesellschaften weltweit, oder hier für die $<<<$ Unternehmen anonymisiert $>>>$ in $<<<$ Ort anonymisiert $>>>$, die auch, schätze Mal Größenordnung, 20 Auslandsgesellschaften hat.

Also das waren schon eher komplexe und große Projekte, was uns im Nachhinein wahrscheinlich auch zum Problem wurde, weil wenn dann Leute weggehen, die diese Projekte realisiert hatten oder betreut hatten, dann sind die so komplex, dass Sie ganz schwer durch andere Leute, die eben nicht erfahren sind und 15 Jahre Erfahrung in der Branche haben und in den Projekten haben, es schwierig ist, diese Unternehmen zu betreuen, geschweige denn auch so ein Produkt weiter zu vertreiben und einzuführen bei Kunden. Das heißt, man hat da eine hohe Abhängigkeit einfach von einzelnen Personen. Und die Lösungen das ist ja nicht nur eine Lösung, sondern es sind ja Schnittstellen und Edifact und andere Dinge integriert und Archivierungssysteme, so dass man auch immer mit Kopfmonopolen letztendlich jonglieren musste.

Ja. Also letztendlich dann am Schluss war $<<<$ Unternehmen anonymisiert $>>>$ dann ein IT-Dienstleistungsunternehmen. Wir hatten über zehn Millionen Umsatz gemacht und waren so knapp über 100 Mitarbeiter. Und ja, danach ging es bergab, und jetzt sind es noch, weiß ich nicht, 25 oder 30.

I: Dieses "Bergabgehen", was genau waren da die Auslöser? Sie haben schon gesagt, dass vielleicht Mitarbeiter gegangen sind, die nötig gewesen wären. Aber das war ja 
wahrscheinlich nicht der einzige Grund. Können Sie den Weg in die Insolvenz und durch die Insolvenz nochmal genau schildern auch?

B: Ja, also das ist natürlich / Da spielen viele Aspekte mit rein. Das geht hin zu Fehlentscheidungen durch mich, bis hin zu Entscheidungen, was Personal betrifft. Ich hatte, um diese Abhängigkeit zu Microsoft zu reduzieren, als dieser Internethype war, mit einem Mitarbeiter, der sehr fähig ist, überlegt, was könnte man denn zusätzlich machen ohne Microsoft. Und wir hatten damals dann entschieden, eine Lösung ähnlich wie das heutige Facebook zu entwickeln. Und das Produkt hier $<<<$ Unternehmen anonymisiert $>>>$ war auch am Markt, konnte man auch Locations eingeben, wo man sich aufhält. Man konnte Bilder hochladen mit dem Iphone zum Beispiel, Fotos schießen, draufstellen und so. Hat auch ganz gut funktioniert. Haben die Dänen sehr intensiv genutzt, die Navision-Dänen. Aber gut, das ist in Deutschland quasi nicht zu machen. Man kriegt nicht die Resourcen, man kriegt nicht die finanziellen Mittel und gegen ein Facebook / Ich meine, die haben/ Es gab viele andere Alternativen auch, aber ich glaube, Facebook hat halt alles plattgemacht. Insofern, das hat mich 750.000 Euro gekostet. Das hätte ich lieber sein lassen sollen.

Dann hatte ich vor zehn Jahren in $<<<$ Ort anonymisiert $>>>$ ein sanierungsbedürftiges Gebäude gekauft mit / Das war eine alte Brauerei, Sandsteingebäude, sehr zentral neben dem Rathaus, ein sehr schönes Gebäude. Und habe das saniert mit zehn Prozent Denkmalschutzabschreibung. Dacht ich, das ist eine gute Geschichte, um da halt auch einen Vermögensaufbau zu machen. Bevor ich das Geld ans Finanzamt zahle, lieber in so eine Immobilie investieren. Die Entscheidung war zum damaligen Zeitpunkt sicherlich auch richtig. Aber wenn dann irgendwann das Geld nicht mehr verdient wird für die Abschreibung, wird es halt schwierig. Und ich musste dann immer noch einen Betrag zuzahlen für die Zins und Tilgung halt, den Kapitaldienst. Und das hat etwa 70.000 Euro halt auch jedes Jahr aus der Firma rausgezogen. Das wäre jetzt günstiger, aber damals waren halt auch noch höhere Zinsen. Ich musste zu dem Zeitpunkt, als die erste Finanzierung auslief, halt nach- / verlängern. Und unter normalen Bedingungen wäre das auch gut machbar gewesen.

Wir hatten früher, wie man halt so anfängt, waren alle in einem Raum gesessen und haben gemacht, und alles war irgendwie gut. Und irgendwann wurde das Unternehmen größer, und dann fing ich halt an, das Unternehmen zu strukturieren. 
Wollte einzelne Business Units einfach aus dem Gedanken heraus, dass nicht alle hier Chef spielen. Aber wenn kein Geld da ist, bin ich schuld. Sondern dass die Leute eben nicht nur ihre Projekte machen oder programmieren oder so, sondern eine Businessverantwortung übernehmen, also, dass ihre Einheit halt profitabel ist. Und das war mein Gedanke, dass man ja auch neue Einheiten mit neuen Themen dazu bauen kann für das Wachstum. Und mein Gedanke war eigentlich, das Unternehmen so aufzustellen, dass ich nicht mehr whichtig bin. Dass es einfach funktioniert. Dass es einen Vertrieb gibt, der Aufträge reinholt. Dass es ein Controlling gibt, das eine Planung mit Vertrieb und den Business Unit Leitern macht, den Plan zur Verfügung stellt. Das wird dann ausdiskutiert und umgesetzt. Und nachdem er ja ein reiner Fixkosten-Laden ist halt so ein Dienstleister. Ich meine, das teuerste sind die Gehälter, und dann hat man halt noch ein paar Autos, ein paar Versicherungen und Miete, alles Fixkosten im Prinzip. Da hatte ich gesagt, ok, ich muss jetzt gucken, dass ich den Vertrieb so aufstelle, dass der gut funktioniert. Weil, die Leute brauchen ja permanent neue Aufträge. Es muss ja Futter reinkommen, damit man diese Kosten auch immer wieder bedienen kann und noch einen Gewinn erwirtschaftet. Und so habe ich dann mal zufällig jemanden in München getroffen. Da gab es einen MUK, Münchner Unternehmerkreis. Die haben mich immer angeschrieben, und irgendwann mal war ich da auf einer Microsoft-Veranstaltung. Das war, glaube ich, einen Tag vorher. Da habe ich gesagt, gehe ich da mal hin. Und da habe ich jemanden kennengelernt, der so auch im Bereich Personalrekruiting tätig war. Jedenfalls von diesen Headhuntern habe ich so pauschal nicht unbedingt die beste Meinung, beste Erfahrung. Und der machte aber einen ganz vernünftigen Eindruck. Hat auch gleich das Thema, das Geschäft verstanden. Das ist bei manchen ja auch nicht der Fall. Ja, und dann hat er irgendwann mal akquiriert. Und da sage ich, nein, im Moment noch nicht. Aber es könnte sein, dass ich irgendwann mal auf Sie zukomme. Und weil wir hatten da mit Vertriebsleitung immer so ein bisschen unsere Schwierigkeiten. Weil das nie Leute waren, die das mal irgendwie gelernt hatten oder Erfahrung hatten in dem Bereich, sondern das war halt ein Mitarbeiter, der im Vertrieb tätig war und dann halt diese Funktion übernommen hat. Und das hat dann oft nicht so funktioniert, wie es vielleicht hätte funktionieren sollen. So, der hat mir dann zwei Leute genannt. Einen, der war mehr im Banken- und Versicherungsbereich unterwegs. Sag ich, nein, das passt nicht. Und jemand anderen, der war bei $<<<$ Unternehmen anonymisiert $>>>$ vorher und 
danach bei $<<<$ Unternehmen anonymisiert $>>>$. Das sind beides Unternehmen, die im Mittelstand bei Anlagenbauern, Maschinenbauern, also in dem Fertigungsbereich sehr stark unterwegs sind. In dem wir eben auch mit unserem $<<<$ Name anonymisiert $>>>/$ was auch unser Zielmarkt war. Und da sage ich, ja genau, der ist es, der passt. $<<<$ Unternehmen anonymisiert $>>>$ war auch noch vertrieblich ganz gut unterwegs, und auch vom Produkt her im selben Zielmarkt positioniert. Da sage ich, das ist ideal, das ist genau der Kandidat, den ich brauche. Und dann habe ich dieses Thema endlich vom Tisch. Und da war ich dann ein paar Mal in $<<<$ Ort anonymisiert $>>>$, er auch. Und es hat alles prima geklappt. Er hat dann auch unterschrieben, hat hier angefangen. Aber das hat überhaupt nicht funktioniert.

Also, am Anfang schon. Mit der Person hatte ich dann irgendwann meine Schwierigkeiten, weil, er hatte dann halt immer mehr Vertriebskosten aufgebaut. Da gab es dann Telesales und Presales und die Assistentin, die Ehemalige, hat er dazugeholt, also mit meiner Erlaubnis. Und wir hatten dann eine Million Vertriebskosten, aber die Aufträge dafür sind ausgeblieben. Gut, und dann hat man natürlich die Situation, dass man mit der Person das natürlich auch ansprechen muss irgendwann. Und dann war er von seiner Persönlichkeit jemand, der dann gleich sehr gebissen hat, sehr aggressiv war. Und ich war ja sonst immer im Vertrieb mit eingeschaltet und war da auch immer mit vor Ort. Gerade, wenn man eine Firma aufbaut, dann muss man ja im Prinzip selber Vertrieb machen, damit überhaupt was vorangeht. Ich hatte dann zwar immer die Leute, die auf der fachlichen Ebene unterstützt haben und so. So, und er wollte halt auch seine Visitenkarte haben, Geschäftsführung, damit er mit dem, der den Projektbereich geleitet hat, also Delivery oder Operations wie man sagt, verantwortet hat, auf einer Augenhöhe sprechen kann. Und auch beim Kunden entsprechend auftreten kann. Ja, ist kein Thema, machen wir. Das hat aber dann dazu geführt, dass er seinen Vertrieb letztendlich eine Mauer herum gebaut hat und seine Leute, ja die Abteilung, die Leute halt dann zum Kunden gefahren sind, und ich eher nicht mehr. Das wollte er auch nicht, so nach dem Motto, das passt funktional nicht, weil, er hat ja die Geschäftsführung, und er ist Vertriebsleiter, und ich hätte da keinen aktiven Part und was auch immer. Ich habe dann da natürlich interveniert, aber das hat immer dazu geführt, dass es halt Konflikt gab. Irgendwann waren wir dann drüben, glaube ich, im Nebenraum gesessen, hat er mich mal gefragt, was ich denn glaube, woran es liegt, dass der Erfolg nicht so sich 
einstellt. Und dann habe ich ihm gesagt, ich kann es dir nicht sagen, ich schaue nicht durch eine klare Glasscheibe, ich schaue durch eine Milchglasscheibe. Ich habe dann immer die Projektsachen, die Delets, gekriegt, die gerade weggebrochen sind, ja. Wo sie dran waren aber dann eben nicht zum Erfolg führten, wo man merkte, die sind jetzt / Wo dann quasi nichts mehr zu retten war. Und das war schwierig, war natürlich dann irgendwann auch konfliktbeladen. Erst war das natürlich alles prima, auf meiner Seite, dann hat er sich auf die Seite des Projektverantwortlichen gestellt. Und der hat sich sehr diplomatisch zwischen beiden hin und her bewegt. (lacht) Also, das heißt, mit dieser Situation, und das kannte ich vorher hier nicht, begann im Unternehmen die Situation, dass Politik gemacht wurde.

Politik im Marketing, es wurden Informationen lanciert, und es wurde einfach wirklich aktiv Politik gemacht, um eigene Interessen zu verfolgen. Und das kostet natürlich viel Energie und Zeit und Nerven und bringt Unruhe. Und man kann sich dann natürlich nicht auf das eigentliche Geschäft und die Kunden konzentrieren. Und es ist nervenaufreibend einfach auch. Und dann habe ich einmal versucht, ok, damit man sich besser versteht, gehen wir abends ab und zu mal weg, waren zusammen essen. Aber es hat einfach nicht wirklich funktioniert. Und da war dann mein Thema, da haben natürlich viele Leute dann gesagt, ich hätte ihn eher kündigen müssen. Habe ich nicht getan. Ist halt auch immer schwierig, wenn man jemanden reinholt und verkauft ihn erst mal intern, und dann hatte ich ja zwei Leute. Wir haben einen Axapta Bereich gehabt und einen Avision Bereich. Der Axapta Bereich wurde von einem $<<<$ Name anonymisiert $>>>$ verantwortet und der Avision Bereich von einem Herrn $<<<$ Name anonymisiert $\gg>>$. Mit denen hatte ich mich / Also, das waren Leute, die waren 10/ 15 Jahre schon hier im Unternehmen. Der Vertriebsleiter fünf Jahre. Und ich habe dann gesagt, das geht so nicht weiter, man muss sich trennen. Und habe dann / Wollte das aber nicht über deren Köpfe hinweg einfach entscheiden, denn wenn sie die Business Units verantworten, und das ist ihr Vertrieb, der den Input da liefern soll. Und da wollte ich deren Ok haben. Bin dann mit jedem irgendwo abends Essen gegangen, habe gesagt, lass uns mal reden, und habe eben halt erzählt, wie ich das sehe. Aber die haben sich nicht positioniert. Alle beide nicht.

Ja, und eines Tages dann, habe ich mitbekommen, dass jemand hier Leute akquiriert. Das war vor etwa zwei Jahren / zweieinhalb Jahren. Und dieser eine Mitarbeiter, der war zehn Jahre vorher war der mal bei $<<<$ Unternehmen anonymisiert $>>>$, mal ein 
Projekt in Wien geleitet, kam aus $<<<$ Ort anonymisiert $>>>$. Wir hatten da ein freundschaftliches Verhältnis, hatten gemeinsam auf Geburtstagen gefeiert oder waren / Er war, nachdem er schon weg war, er ist dann zu einem Endkunden gegangen zu $<<<$ Unternehmen anonymisiert $>>>$ nach $<<<$ Ort anonymisiert $>>>$. Weil, es gab Probleme auch in der Beziehung und seiner damaligen Freundin, die war Innenarchitektin und hat hier keinen Job gefunden. Und ging dann zu den Eltern, oder Schwiegereltern, zurück. Und dann kamen Kinder. Und er ist dann halt zurück gegangen auch um der Familie Willen. Und wir haben dann auch ein Projekt gemeinsam gemacht, haben also dort bei $<<<$ Unternehmen anonymisiert $>>>$ Avision eingeführt mit ihm. Er dann auf der Kundenseite in dem Fall. Und wir sind dann immer mal Skifahren gegangen, einmal im Winter, so Freitag, Samstag, Sonntag, so $<<<$ Unternehmen anonymisiert $>>>-$-Skifahren, wo wir so zwischen 8 und in der Spitze mal 25 Leute waren, die da gefahren sind. Und da war er dann als einziger Externer immer noch dabei. Der ging dann irgendwann von $<<<$ Unternehmen anonymisiert $>>>$ weg zu einer Firma $<<<$ Unternehmen anonymisiert $>>>$ nach $<<<$ Ort anonymisiert $>>$. Die das gleiche Navisiongeschäft machen, wie wir. Das ist ein Amerikaner, die haben sich da mal eingekauft bei einigen Unternehmen, unter anderem eine Firma $<<<$ Unternehmen anonymisiert $>>>$ gekauft, die aus $<<<$ Ort anonymisiert $\gg>>$ stammte. Und ein Mitarbeiter von mir hatte ein sehr enges und freundschaftliches Verhältnis zu ihm. Die haben zusammen Silvester gefeiert oder haben sich getroffen immer wieder mal. Und der war hier. Und als wir hier Sommerfest hatten, da kam er angefahren, halt mit dem Motorrad, April ja, aber er war auf einmal da. Und uneingeladen, aber so als Freund des Hauses hatte ich damit auch kein Problem. Ja und vor zwei Jahren fing der dann an, hat sich aus dieser $<<<$ Unternehmen anonymisiert $>>>$ in $<<<$ Ort anonymisiert $>>>$, die es in $<<<$ Ort anonymisiert $>>>$ und in $<<<$ Ort anonymisiert $>>>$ gab, die alte $<<<$ Unternehmen anonymisiert $>>>$ wieder herausgelöst. Und haben hier eine Niederlassung aufgemacht um die Ecke, 500 Meter. Und dieser jener, meine Freund, der da mit Skifahren war, ist hier Geschäftsführer. Und mein Vertriebsleiter, mit dem ich meine Probleme hatte, ist samt dem kompletten Vertrieb, und insgesamt waren es dann 30 Leute, da rübergegangen.

Und wenn halt mal der komplette Vertrieb von heute auf morgen weg ist, dann heißt das natürlich auch, in dem Geschäft haben Sie Vorlaufzeiten, die im Schnitt ja in einer 
Schwangerschaft, neun Monate, liegen, also zwischen / ja, es geht mei- / ja, es ist mal ein lucky punch, ja / Man hat vielleicht auch mal Glück, dann kriegt man nach 5 / 6 Monaten einen Auftrag, aber tendenziell ist es so fast ein Jahr bis sie von einem Erstkontakt / Es ist immer die Frage natürlich, wann Sie in so einen Akquiseprozess einsteigen. Aber sind Sie zu spät, kommen Sie gar nicht mehr rein. Sind Sie zu früh, können Sie auch zwei Jahre hinterherlaufen. Aber, ich sage mal, im Schnitt, ist ein Jahr sicherlich nicht so schlecht, dreiviertel Jahr / Jahr. Und wenn der komplette Vertrieb dann auf einmal wegbricht, dann haben Sie natürlich ihre Schwierigkeiten, überhaupt Aufträge zu bekommen. Sie sind dann so auch bestimmte Kosten los, aber wenn Sie eine schlechte Auslastung haben dann / Und die Fixkosten haben Sie ja nun mal an der Backe. Dann kommt dazu, dass die Axapta-Truppe gesagt hat, ok, wir brauchen mehr Platz usw. Dann haben wir noch kurz vorher einen Mietvertrag unterschrieben für so eine Etage für die nächsten 5 Jahre. Und danach haben die gekündigt alle. Also, das war sicherlich eine maßgebliche, schwierige Sache. Was einen natürlich auch persönlich trifft, wenn man mit Leuten in so einem kleinen Unternehmen 15 Jahre zusammenarbeitet, und dann auf einmal wechseln die alle zusammen das Lager.

Und ich konnte eben die beiden da nicht dazu bewegen, dass sie sich da auf meine Seite stellen, und man sich von dem Vertriebsleiter trennt. Was sicherlich dann ein Fehler war. Ich habe das dann halt immer mal thematisiert. Das nervt dann natürlich den einen oder anderen auch. Wäre wahrscheinlich gescheiter gewesen, ich hätte einfach für mich die Entscheidung getroffen. Jetzt gehe ich noch auf Ihren Fragebogen ein, da bin ich also nicht der Typ für. Ich bin also schon eher der, der den kooperativen Führungsstil pflegt. Ja, und wie gesagt, das war also schon mit ihm eine Anspannung. Er hat auch schon mal gesagt, dann geht er und kündigt oder so. Dann haben wir uns da beim Mr. Black im Café da getroffen, und hat er so Kärtchen vorbereitet gehabt und hat Besserung gelobt. Aber Fakt war auf jeden Fall, da sind in dem Zuge dann 30 Leute gegangen. Und das war schon ganz schwierig.

Das Schwierige an der ganzen Veranstaltung ist natürlich, dass die Leute alle Kundenkontakt haben. Die kennen alle Projekte, die kennen alle Kunden. Und was brauchen die natürlich als allererstes? Aufträge. Und da kann man natürlich bei Bestandskunden gut operieren. Und diesen Fall hatte ich dann jetzt zwei Jahre später nochmal mit einem Mitarbeiter. Der dann / zwei Wochen war er krank, dann war er 
fünf Wochen auf Kur, dann war er zwei Wochen im Urlaub, dann hat er hier angerufen bei meinem Controller, hat gesagt, er ist jetzt wieder gut hergestellt und fit. Und er hat viel Sport gemacht und hat abgenommen und hat das Malen angefangen. Und dann kam er zurück, hat sich bei mir zurückgemeldet, hat mir seine Bildchen gezeigt, hat gemeint, das soll ich auch mal machen. Das würde mir auch guttun. Und zwei Tage später hat er gesagt, er verlässt $<<<$ Unternehmen anonymisiert $>>>$. Er gründet eine $\mathrm{GmbH}$ mit einer Firma $<<<$ Unternehmen anonymisiert $>>>$ zusammen und die maßgeblichen Leute, das war dann der Nachfolger, der den Projektbereich Navision geleitet hat, gehen mit ihm. Und das war dann natürlich / Bei den komplexen Installationen, die wir hatten, waren das halt dann so ziemlich die ganzen erfahrenen Leute. Wir hatten vor ein paar Jahren die $<<<$ Unternehmen anonymisiert $>>>$-Gruppe als Kunden gewonnen. Das sind mehrere Unternehmen im Anlagenbau, es sind sechs an der Zahl. Und ich hatte da einen Mitarbeiter, noch gar nicht so lange vorher eingestellt, der hat fünf Jahre nichts anderes gemacht, wie in diesem Unternehmen unser $<<<$ Name anonymisiert $>>>$ einzuführen. Die hatten vorher in einem der Unternehmen $<<<$ Unternehmen anonymisiert $>>>$ mit $<<<$ Name anonymisiert $>>>$, das ist so eine Bertelsmann Tochter, und vorher $<<<$ Name anonymisiert $>>>$ und $<<<$ Name anonymisiert $>>>$, und $<<<$ Name anonymisiert $>>>$ versucht einzuführen, also neu zu entwickeln. Wir haben da, ich glaube, zwei Millionen bezahlt, und es hat nie funktioniert. Das haben wir dann mit unserem $<<<$ Name anonymisiert $>>>$ abgelöst. Aber der ist natürlich da auch mitgegangen, und damit sind natürlich alle Kunden weg. Die haben dann mit einem externen Berater, mit einem Herrn $<<<$ Name anonymisiert $\gg>>$ zusammen hat der zusammengearbeitet. Und wenn einer dann halt fünf Jahre da rumspringt, kennt er natürlich die Prozesse, kennt die Leute und und und. Der Kunde möchte natürlich nicht auf das Wissen, das dort dann sich aufgebaut hat, verzichten und jemandem Neuen die ganzen Dinge von Grund auf von vorne erklären usw. Und da sind Sie natürlich extrem anfällig, dass diese Kunden dann wechseln.

Dann kommt dazu, dass der Microsoft Werbung macht, Partnerwechsel per Mausklick so quasi. Das heißt, selbst wenn da vertragliche Beziehungen bestehen zwischen dem Endkunden und uns, Wartungsverträge, Serviceverträge, Updateverträge und so was, die noch zwei Jahre laufen, dann wechseln die einfach zu einem anderen Partner, zahlen das Geld an den anderen Partner, meinen halt, naja, das ist Microsoft halt. Und 
wir können dann gucken, wie wir zu unserem Geld kommen. Wir haben im Moment aktuell zahlreiche solche Fälle, die bei der Frau $<<<$ Name anonymisiert $>>>$ liegen, wo rein vom Vertrag her der Kunde zahlen muss, es aber nicht tut. Also, es ist halt auch ein schwieriges Geschäft, dieses Projektgeschäft. Es gibt sicherlich Unternehmen, die haben das einigermaßen gut im Griff, aber es gibt auch viele, die mit denselben Problemen kämpfen. Bei manchen funktioniert es halt wirtschaftlich, und bei manchen halt auch nicht.

Also, wir reden im Moment mit jemanden, der hier einsteigt und quasi die Rest$<<<$ Unternehmen anonymisiert $>>>$ übernimmt aus der Schweiz. Und der war hier und hat gesagt, Sie könnten unsere Chronik schreiben. „2008 waren wir auch quasi vor dem Aus." Und er hat da dann wohl / war jetzt nicht operativ tätig, sondern hat so eine Holding-Struktur und ein paar kleinere andere Firmen, aber die sind eher vernachlässigbar, hatte auch irgendwie so eine Navision-Firma. Und da sind auch Leute weggegangen, bei ihm sind die wohl $\mathrm{zu}<<<$ Unternehmen anonymisiert $>>>$ in der Schweiz gewechselt. Und dann waren die auch vor dem Aus, und der hat das dann wieder irgendwie in den Griff bekommen. Die waren halt zum Glück besser abgesichert als ich von der reinen juristischen Konstruktion. Das war eine Kapitalgesellschaft. Und der hat dann gesagt, ja, siebenstelligen Betrag, glaube ich, reingeschossen, den muss man halt auch erst mal reinschießen können. Und hat das Unternehmen dann irgendwie gerettet. Aber das sind jetzt 30 Navision Leute, aber die hatten mal 100 Millionen Umsatz gemacht. Also, und waren, glaube ich, sogar an der Börse. Also, das hat dann auch ganz ordentlich geknallt. Also, das gibt es woanders auch. Nur ist es bei ihm etwas besser ausgegangen.

I: Wo sehen Sie die Gründe dafür, dass es zur Insolvenz kam? Also, warum sind zweimal so viele Mitarbeiter weggegangen? Gab es da interne Probleme, hat sich das abgezeichnet? Ich meine, klar, die Antipathie mit dem Betriebsleiter, das hat ja wahrscheinlich schon ein bisschen gebrodelt, aber noch irgendetwas?

B: Ja, also, ich denke, das ist immer schwierig aus der eigenen Sicht zu sehen. Also, ich reflektiere das natürlich auch selbst, versuche das selbstkritisch zu sehen. Es gibt Dinge, die hätte ich anders entscheiden müssen. Ich hätte mir auch mehr die Zahlen unseres Servicegeschäfts anschauen müssen, also, die Verträge. Wir hatten Verträge 
geschlossen, mit den Kunden, wo wir früher gesagt hätten, ok, soundso viel Prozent zum Beispiel vom Lizenzumsatz für Hotline. Das praktizieren einige Unternehmen so. Bei Manchen ist das sehr profitabel, die halt kaum anfragen und einfach zahlen. Es hat sich aber da die Welt etwas verändert. Und es gab eben auch Unternehmen, die haben wenig bezahlt, das muss dann immer upgedated werden und und und. Dann hat der Microsoft natürlich immer wieder mal die Preise angehoben, und was man dann immer beim Kunden durchsetzen kann, ist halt endlich. Da ist man dann schon in so einer Sandwhichposition auch. Und wir hätten diese Verträge eher kündigen müssen, ändern müssen, so dass wir nach Aufwand abrechnen. Dazu hätte es eine klarere Disziplin, es ist immer schwierig, die Leute zu disziplinieren, im Customer Service bedurft, die wirklich alles, was sie für den Kunden leisten, auch sauber buchen. Da gibt es ja dann auch immer Fehler, der eine macht sie, der andere bügelt sie dann aus. Und der Kunde zahlt es nicht, solche Dinge. Also, da hätte man das sauberer strukturieren müssen. a) von der Vertragsgestaltung her, damit die Mitarbeiter nicht einfach alles auf Servicevertrag buchen, sondern das ist eben die Schwierigkeit bei der Vertragskonstruktion gewesen, zu differenzieren, was ist denn durch den Vertrag abgedeckt, und was müsste man separat fakturieren. Und wenn sie das dann tun, dann sind das oft junge Leute auch, die sich dann da auch nicht durchsetzen können, oder da führt es zum Konflikt halt beim Kunden. Und dem versuchen sie dann eher aus dem Weg zu gehen und buchen es halt dann irgendwie anders. Also, das waren so Dinge.

Und was sicherlich auch mit dazu beigetragen hat, das war als diese ganzen Leute da gegangen sind, hatten wir natürlich keinen Vertrieb. Und mein Vertriebsleiter war damals in der Akquise bei einer Brauerei auch im $<<<$ Ort anonymisiert $>>>$, und wir waren auch relativ zuversichtlich, dass wir den Auftrag bekommen. Es war dann aber nicht so. Ich war in der Akquise auch mit eingeschaltet, nicht bei dieser Brauerei, es gab eine zweite, das war die $<<<$ Unternehmen anonymisiert $>>>$ in $<<<$ Ort anonymisiert $>>>$. Und er sagte dann noch hier, er hätte gedacht, dass wir die im $<<<$ Ort anonymisiert $>>>$, ich überlege jetzt gerade, wie sie heißt, aber egal, dass wir das gewinnen und die wäre einfacher gewesen und die $<<<$ Unternehmen anonymisiert $\gg>>$ nicht. Da habe ich gesagt, nein, das sehe ich nicht unbedingt so. Wobei das war noch voll in der Akquise, Workshops sind da noch gelaufen, da hat es auch am Anfang gleich ziemlich geknallt. Aber das Ergebnis war, die 
$<<<$ Unternehmen anonymisiert $>>>$ haben wir gewonnen, und das war für Navision ein sehr großes Projekt mit drei Millionen etwa Dienstleistungsumsatz. Aber sehr, sehr, sehr, sehr, sehr komplex. Da hatten wir vorher die $<<<$ Unternehmen anonymisiert $>>>$ und $<<<$ Unternehmen anonymisiert $>>>$ gemacht, aber das war alles nicht vergleichbar in der Komplexität. Und wir hatten im Prinzip nicht die Anzahl an Berater, nicht die Qualität an Entwicklern, wahrscheinlich wurden auch die falschen Entwickler eingesetzt, weil andere halt gerade noch mit anderen Dingen beschäftigt waren, die auch whichtig waren und nicht frei waren für dieses Projekt. Und wenn Sie so komplexe Prozesse unterstützen müssen, spezifizieren müssen, programmieren müssen, die Programmierer kennen ja wiederum die Prozesse nicht, also brauche Sie im Prinzip Berater, die diese Dinge definieren. Weil ein Programmierer, der es programmiert, der Berater, der controlled und prüft, ob er auch das programmiert hat, was da gefordert ist, und dann bräuchten Sie noch einen Oberentwicklungsleiter quasi, der auch guckt, ob der Code was taugt, der da programmiert wird, ob das auch sauber dokumentiert ist und, und, und, und, und. Also, sprich, das Projekt hat uns massiv überfordert. Und der Kunde, das kommt auch noch dazu, war natürlich auch nicht einfach, und hat extrem viel gefordert. So dass wir da ich weiß nicht wie viele hundert Tage für lau gearbeitet haben, wo wir kein Geld mehr bekommen hatten, aber das Projekt halt abschließen wollten. Und, Ja, das war so ein Moloch, der halt auch vom Projektmanagement her kaum steuerbar war. Wenn ich da gefragt habe, wo stehen wir, und wie lange brauchen wir noch, und was kostet es noch, und wieviel Budget haben wir noch? und wie, ja / Wir haben dann vier Mal den Termin verschieben müssen. Und die Datenübernahme war komplex auch aufgrund der Datensituation auf der Kundenseite, die da auch überfordert waren. Also, das ist halt einfach sehr stark aus dem Ruder gelaufen, und wir haben das Projekt so nicht wirklich am Ende des Tages beherrscht. Aber uns halt sehr stark ins Zeug gelegt, um das umzusetzen, was natürlich auch dazu führt, dass Sie dann Mitarbeiter haben, die dann eineinhalb Jahre im Hotel $<<<$ Ort anonymisiert $>>>$ sitzen, und der Kunde prügelt auf die Leute ein. Die Externen sind natürlich immer schuld, da zahlt man viel Geld hin, und dort wird gefordert ohne Ende bis sie zusammenbrechen. Wir sollten dann samstags arbeiten und am Wochenende arbeiten und abends bis um acht, neun, zehn Uhr arbeiten. Und dann gibt es natürlich auch den einen oder anderen Mitarbeiter, der dann sieht, wo das hinläuft, und der dann in der Verantwortung vielleicht steht, der dann kündigt. Das hat 
man dann. Der erste war der Projektleiter, ein Herr $<<<$ Name anonymisiert $>>>$, der ist dann kurz nach Projektstart zu dieser $<<<$ Unternehmen anonymisiert $>>>$ gegangen. Dann musste ich den Geschäftsführer anrufen und ihm erklären, dass gerade mal sein Projektleiter nicht mehr zur Verfügung steht. Dann hatten wir einen Neuen, alles kein Problem, der hat dann gewechselt und ging $\mathrm{zu}<<<$ Unternehmen anonymisiert $>>>$. Weil dann fängt man halt früh um, keine Ahnung, halb neun an und ist um $17 \mathrm{Uhr} z u$ Hause, und ist nicht um $8 \mathrm{Uhr}$ am Freitagabend noch im Hotel $<<<$ Ort anonymisiert $>>>$ und fährt dann noch vier Stunden Auto oder drei.

Also, wie gesagt, es ist sicherlich nicht, wenn Sie nach der Insolvenz fragen, das ist sicherlich nicht auf einen Punkt zu reduzieren. Aber ich denke mal, wir hätten die Verträge eher anders gestalten müssen, die Leistung, die wir erbringen, sauber buchen und auch fakturieren. Das ist ein Ding. Da hätte ich mich mehr darum kümmern müssen. Und das habe ich deshalb eigentlich nicht getan, weil ich letztendlich geglaubt habe, dass die Leute in dem Projektbereich das gut machen. Und dadurch, dass wir immer eher Probleme im Vertrieb hatten, und ich da herkam, war mein Fokus mehr auf das Thema Vertrieb ausgerichtet. Weil wenn keine Aufträge reinkommen, ist das immer schwierig. Heute, im Nachhinein betrachtet, ist das falsch. Wenn wir die Bestandskunden sauber betreut hätten, und die entsprechende Leistung fakturiert hätten, und dafür auch die Rahmenbedingungen mit den Verträgen geschaffen hätten, hätte das Unternehmen alleine von den Bestandskunden, die waren nämlich sehr, sehr gut, und es waren auch ausreichend viele, hätte das Unternehmen alleine nur von den Bestandskunden gut leben können.

I: Der Moment, als Sie gemerkt haben, jetzt ist es soweit, jetzt muss ich Insolvenz anmelden, wann war das und was hat dazu geführt, dass Sie es quasi einsehen mussten oder eingesehen haben, dass es jetzt soweit ist?

B: Naja, gut, das ist natürlich schon so, dass man da nach dem Motto gerne verfährt: Die Hoffnung stirbt zuletzt. Ich habe ja gesagt, wie das anfing. Und, ich meine, da waren ja auch schöne Zeiten dabei, wo wir gemeinsam Erfolge gefeiert haben und Sommerfeste und Weihnachtsfeiern, und auch gute und nette Mitarbeiter hatten und engagierte, und wo die Stimmung gut war. Und man denkt dann halt: „Ok, jetzt machen wir das noch und das noch.“ Es wurden dann immer wieder Maßnahmen 
eingeleitet. Ja, der Controller hat dann versucht, Kosten runter zu fahren. Und man hat sich von Mitarbeitern getrennt, was dann auch immer in so einem kleinen

Unternehmen eine schwierige Geschichte ist. Aber hat dann mit der $<<<$ Unternehmen anonymisiert $\gg>>$ verhandelt, dass man vorvertraglich Fläche zurückgeben kann, die man nicht mehr braucht und hat Parkplätze gekündigt und Autos weggegeben und was auch immer.

Aber letztendlich gerade aufgrund der Situation mit $<<<$ Unternehmen anonymisiert $>>$. Und wir hatten dann auch einen Vertriebsmitarbeiter eingestellt. Der war viele Jahre bei $<<<$ Unternehmen anonymisiert $>>>$ im Vertrieb tätig, aber leider wohnte er in Norddeutschland, ich weiß gar nicht, irgendwo ganz oben. Habe ich gesagt, ok, wenn der so erfahren ist, und so lange das schon macht, dann kann man den auch an der langen Leine da oben laufen lassen. Und wir haben ja Projekte in ganz Deutschland und auch in Österreich und auch in der Schweiz. Dann soll der halt da oben akquirieren hauptsächlich, ja, Hauptsache wir kriegen da dann Aufträge rein, weil Leute zu finden, die da, sag ich mal, sofort loslegen können, ist halt sehr schwierig. Dann haben wir den eingekauft, aber der hat im Grunde genommen zwei Jahre lang keinen einzigen Auftrag geholt. Der kannte sich zwar und kennt sich im Bereich Navision und Lizenzierungen und auch mit dem Produkt ganz gut aus, aber verkaufen kann der nicht. Das ist meine persönliche Meinung. Und ich war ja auch mal mit oben, da hat er gesagt, ich soll mal mit hoch kommen in meiner Funktion halt als Eigentümer und Geschäftsführer, weil da geht es jetzt um die Unterschrift. Wir haben zwei Stunden geredet und dann war klar, dass die nichts kaufen werden. Und er war halt schon dreimal da mit einem Pre-Saler und einem Externen und, und, und, und, ja.

Das sind halt auch immer so Geschichten. nachdem der eine Vertriebsleiter weg war, haben wir dann einen eingestellt über einen Headhunter. Der hat gesagt, ja da haben sie einen high potential, der war Sales Direktor bei SAP. Das war eine Katastrophe. Und nach einem Jahr oder so haben wir ihm halt wieder gekündigt. Und, ja, gut, mein Mitarbeiter, der dann, nachdem die Leute alle weg waren, Vertrieb und so weiter, der dann den Operationsbereich geleitet hatte, den kompletten Navisionbereich, der war auch schon zehn Jahre bei mir, auch aus dem Osten, dann zwei Wochen krank und Kur und Urlaub. Der hat mir dann erklärt, ja, das Produkt hier, die ganzen Leute gehen ja zu ihm, und dann kann ich mit dem Produkt eh nichts mehr anfangen. Er möchte das 
Produkt umsonst haben für lau und die $<<<$ Name anonymisiert $>>>-K u n d e n$. Und er wird nur sich auf das Projektgeschäft konzentrieren, nur $<<<$ Name anonymisiert $>>>$ machen, und ich kann ja dann Handel machen oder Brauerei oder irgendwas. Da hatten wir aber gar kein Produkt. Und das Produkt war relativ gut ausgereift, vielleicht auch schon ein bisschen überaltert, aber im Prinzip war das schon noch einsetzbar. Ja und das war / das hat mich auch ziemlich zermürbt, muss ich sagen. Der war zehn Jahre da, hat ein gutes Geld verdient, wirklich ein gutes Geld verdient. Er hat mir auch immer erklärt, dass er noch seinen missratenen Schwiegersohn mit durchfüttern muss. (lacht) Ja, also ich denke, das bleibt, und dass er deswegen so viel Gehalt braucht. Und, ja, dann war ich auch so ein bisschen hin und her gerissen. Meine Controlling Leute waren komischerweise sehr auf ihn, haben ihn sehr geschätzt, ich weniger. Er hat also zwar viel Meetings gemacht und tausend OneNote-Protokolle geschrieben, aber Ergebnisse hat er im Prinzip keine abgeliefert. Er ist einmal zum Kunden gefahren, der eigentlich / wo wir an erster Stelle gesetzt waren, wo der Vertrag unterschrieben werden sollte, und den hat er kaputtverhandelt, der wollte halt noch ein bisschen Geschäftsführerrabatt haben, vielleicht noch eine Deckelung im Ding. Das hat er halt nicht gemacht. War das erste Mal da, hatte keinen Kontakt, keine Beziehung, ist mit dem Vertriebsmenschen hingefahren, der ihn natürlich auch nicht anständig gebrieft hat. Hätte ihn mal zur Seite genommen unter vier Augen, hat gesagt ... (unverständlich). Den Auftrag hätten wir auch dringend gebraucht, wäre eine halbe Million gewesen, wäre ein schöner Auftrag gewesen. Das heißt, in seiner Zeit haben wir da halt auch keine Aufträge generiert. Und das war so jemand, der konnte alles. Der konnte Projekt, und der konnte Vertrieb, und der konnte M\&A und / ja. Und jetzt sitzt er eine Etage hier oben und läuft jeden Tag vorbei, sagt Mahlzeit und strahlt über das ganze Gesicht und hat halt einen Gutteil der erfahrenen Leute, die zehn / fünfzehn Jahre hier waren.

I: Wann haben Sie dann Insolvenz angemeldet?

B: Hm, mit Datum habe ich es nicht so, so ungefähr vor einem Jahr.

I: Ungefähr vor einem Jahr. Wie war das für Sie? 
B: Ja, hm. (Pause)

I: War das ein bisschen eine Erleichterung so einen Schlussstrich zu ziehen, oder war es schrecklich, wie war die Stimmung?

B: Hm, also, sagen wir mal so, die Zeit vorher war schrecklicher. Also, da bin ich dann schon früh um vier / fünf aufgewacht und war völlig nass geschwitzt und konnte mein Shirt wechseln. Und das war schon nicht so leicht, ja. Es war ein Stück weit eine Erleichterung, aber das hört man wahrscheinlich allenthalben, das sagen wahrscheinlich alle. Weil halt dann irgendwie mal dieses Martyrium erst mal vorbei ist. Und man hat dann auch die Situation, dass irgendwie, dass dann Leute zur Seite stehen, um bestimmte Dinge einfach geregelt zu kriegen. Und vorher ist man da eher alleine. Also, ich will jetzt nicht sagen "alleine", natürlich gibt es Mitarbeiter, die da auch an diesem Thema mitdenken und auch arbeiten, und auch Entscheidungen vorbereiten oder, oder ja / da halt gegensteuern, sage ich mal, damit das eben nicht eintritt.

I: Wie war das Insolvenzverfahren bisher so für Sie? Also, gab es da größere Schwierigkeiten und Probleme oder würde Sie sagen, es war eher reibungslos?

B: Nein, reibungslos war es sicherlich nicht. Es gab sicherlich Schwierigkeiten, also es gab schon auch Kritik an die Insolvenzverwaltung an sich, also, selbst von Kunden, die gesagt haben, das hätte besser kommuniziert werden müssen. Aber das kann man sicherlich auch nicht wirklich richtigmachen, das muss man ja auch dazu sagen. Ja, es gab viele Dinge, wo auch Fehler passiert sind, wo Mitarbeiter geflucht haben, dass sie die Arbeit machen, aber der Insolvenzverwalter das Geld kassiert. Auch von deren Seite wurden viele Fehler gemacht. Da haben Einige geflucht und Dinge korrigiert. Aber ich will das jetzt nicht schlecht reden. Ich denke, ich hatte mit der Frau $<<<$ Name anonymisiert $>>>/$ Ich weiß nicht, wieviel Erfahrung sie in solchen Dingen hat. Ich glaube eher, nicht so sehr viel. Aber, ich glaube, sie hat das schon engagiert und auch gut gemacht, und auch, sage ich mal, verträglich und positiv für mich. Da gibt es ja auch Leute, ich habe da die Erfahrung zwar nicht selbst, aber was man so 
von Erzählungen hört, gibt es da ja auch sehr, sehr unangenehme Zeitgenossen, die da wirklich noch ihren Spaß daran haben, diese Leute an die Wand zu nageln.

I: Also, es war ein partnerschaftliches Verhältnis?

B: Ja. Auf jeden Fall. Das ja, aber gut, sie ist natürlich auch abhängig von der Zuarbeit von Leuten in der Kanzlei, die auch nicht immer optimal funktioniert haben. Aber gut, überall werden Fehler gemacht. Das ist / ja. Ich habe jetzt nur neulich mit meinem Steuerberater zufällig gesprochen in einer anderen Angelegenheit, und die machen ja jetzt die Buchhaltung. Die wurde ja ausgelagert. Die haben wir früher intern gehabt, die macht jetzt / gebucht wird beim Steuerberater. Der hat mir, ich kann nur zitieren, gesagt / Ich habe also mit der Dame, die das da macht, gesprochen, und die hatte gemeint, das was da also von der Insolvenzverwaltung abgeliefert wird, sei katastrophal. Ist nicht meine Meinung. Ich bin da auch in manchen Dingen gar nicht so nah dran, ich zitiere das nur.

I: Wie war jetzt das letzte Jahr für Sie? Wenn Sie das jetzt nochmal Revue passieren lassen, was genau ist da passiert, wie war so der Ablauf, was waren die größten Hürden, was waren Situationen, wo Sie neue Hoffnung geschöpft haben oder wo etwas sehr positiv gelaufen ist? Wenn Sie das Jahr mal durchgehen.

B: Also, ein Stück weit Hoffnung geschöpft hatte ich, als die Leute weggegangen sind $\mathrm{zu}<<<$ Unternehmen anonymisiert $>>>$. Da gab es Aussagen von Leuten, die gegangen sind, die zehn Jahr da waren, und wo ein sehr gutes Verhältnis war, der gesagt hat: ,$\ll<<$ Unternehmen anonymisiert $>>>$ wird es entweder nicht mehr geben oder halt mit irgendwie 20 Leuten." Und wir hatten damals gekämpft, wir hatten ja die Situation, dass ein Mitarbeiter, der einen guten Job früher hier gemacht hatte, und auch lange da war, Verantwortung trug im Navisionbereich, also der Leiter des Bereichs war, der hatte gekündigt. Und unser Problem war, die waren natürlich auch teilweise in Projekten, waren hier noch im Haus und hatten die Kündigungsfristen. Und dann waren wir halt mit der Situation konfrontiert, stellt man die frei? Das kann man natürlich machen, wenn man ein Konzern ist und ein paar Millionen im Kreuz hat. Aber wenn man auf das Know-how noch angewiesen ist. Und das nächste Problem ist, 
je eher man die frei lässt, desto mehr akquirieren die natürlich dann gegen einen, sprich, greifen die unsere Bestandskunden an unter der neuen Flagge. Also haben wir versucht, die möglichst lange hier zu binden. Das führt natürlich dazu, dass Sie eine große Unruhe im Unternehmen haben. Sprich, dann bekam ich ja immer wieder die Information, ja, wo er sich sonst nicht darum gekümmert hat, da hat er jetzt auf einmal Zeit, und die Tür ist offen, und er lädt die Leute ein und ist entspannt und freundlich, was natürlich Bindungsversuche sind, um bestimmte qualifizierte Mitarbeiter - er braucht ja dort auch eine Mannschaft, die funktioniert - mitzuziehen. Da haben Sie natürlich eine große Unruhe. Da gibt es Mitarbeiter, die haben mir da Mails geschrieben, also, stell den jetzt frei, schmeiß den raus, sonst verlieren wir noch mehr Leute. Dann sind sie da natürlich auch immer hin und hergerissen. Und irgendwann haben wir das dann gemacht und haben gesagt, jetzt, zack, Notebook her und raus. Dann habe ich eine Mail gekriegt, was war denn das, und er ist ja völlig entsetzt nach der langen Zeit und überhaupt. Ist auch nicht meine Art, aber ich selber musste es zum Glück nicht tun.

Dann haben wir den Notebook untersuchen lassen von jemandem, der bei der Kripo war, und solche Systeme, Festplatten, forensisch untersucht. Dann hat man festgestellt / dann hat man Informationen gekriegt, die man gar nicht wissen will, Skype Protokolle, und was da gesprochen und geschrieben wurde. Es wurde natürlich alles gelöscht und wieder sichtbar gemacht. Und dann wussten wir, dass da Arbeitsverträge rübergeschoben worden sind, so dass die wussten, was verdient der, den ich akquiriere, was hat der für einen Bonus, hat der ein Auto und, und, und. Und dann wurden halt von der anderen Seite mit denen wurden da Termine gemacht, zum Essen eingeladen und so weiter. Also, es war sehr unschön. Danach sind wir zum Anwalt gegangen, und dem haben wir das erzählt. Und der hat dann wie gesagt das Ganze sichtbar gemacht und hat das gerichtsverwertbar dokumentiert, kostet natürlich alles ein Schweinegeld. Und der Anwalt sagte dann: „Ja, da müssen wir jetzt dagegen vorgehen, ganz klar.“ Ich meine, das würde ich als Anwalt auch machen, schließlich lebe ich davon. Ergebnis war auf jeden Fall, dass der dann da aktiv geworden ist und hat gesagt: „Ok, da schalten wir erst einmal die Staatsanwaltschaft ein. Das ist ja, was da läuft, ist ja eine Sauerei. Und dann tun wir uns auch zivilrechtlich leichter, wenn die da erst mal durchmarschiert sind." Naja, war bei der Kripo, die haben da die Räume durchsucht und die Wohnungen und alles. Und dann ist irgendwie nichts mehr 
passiert. Also wir war'n der Auffassung natürlich, dass die Produkte mitgenommen haben und, und, und. Und warum haben die die ganzen Sachen gelöscht, und so weiter, ist ja alles nicht erlaubt, das ist ja Eigentum der Firma. Auf jeden Fall sind wir mit der Staatsanwaltschaft da nicht weitergekommen. Dann gab es noch eine Beschwerde bei dem Generalstaatsanwalt, und da ist auch nichts passiert. Und dann haben die es doch irgendwie and das Bayrische Justizministerium geschickt, und da liegt es heute noch und ist auch nichts passiert. Also, sprich, wir sind da nicht weitergekommen. Letztendlich ist es auch schwierig dann da Schäden nachzuweisen und Schadenersatz geltend zu machen. Und so, außer Spesen nichts gewesen. Das hat ein Schweinegeld gekostet, das Ganze gerichtsverwertbar zu dokumentieren, und die Platten zu untersuchen und das alles und der Anwalt und, und, und. Rausgekommen ist nichts.

Ja, das sind, ehrlich gesagt, das sind viele solcher Dinge. Wir hatten auch einmal eine Software gekauft aus Belgien, ein Belgisches Unternehmen Namens $<<<$ Unternehmen anonymisiert $>>>$, und das war eine Software für Brauereien. Und mit der wollten wir dann halt in den Markt gehen. Und dann haben wir das erste Projekt gemacht, dann haben meine Entwickler Jungs gesagt: „Ne, da stimmen irgendwie die Rundungsdifferenzen nicht." Und die waren nicht bereit, das zu ändern, und die konnten das nicht. Und dann haben wir das alles im Rahmen des Projekts $<<<$ Unternehmen anonymisiert $>>>$ in einer Nacht und Nebel Aktion alles selber programmiert. In dem Vertrag stand aber drin, dass wir nach Beendigung des Vertrages mit denen drei Jahre kein eigenes Produkt entwickeln dürfen. Das hatten wir dann aber. Das haben wir dann halt daran festgemacht, dass das fehlerhaft war und so nicht funktioniert hat, und die auch nicht die beseitigen wollten. Fakt war auf jeden Fall diese $<<<$ Unternehmen anonymisiert $>>>$ haben dann gegen uns geklagt. Zwischenzeitlich wurde $<<<$ Unternehmen anonymisiert $>>>$ von einer Firma $<<<$ Unternehmen anonymisiert $>>>$ gekauft. Die haben dann eine richtig teure Anwaltskanzlei eingeschaltet, und die haben dann richtig Druck gemacht, wollten dann irgendwie 160.000 Euro. Ich habe dann gesagt, nein, habe ich denen mal, ich weiß gar nicht mehr, 15.000 angeboten. Dann haben die halt laut gelacht. Und so ging das jetzt, ich glaube, zwei Jahre dahin. Wir hatten einen Korrespondenzanwalt, einen Herrn $<<<$ Name anonymisiert $>>>$ in Belgien, an den haben wir, schätze ich mal, auch 60 - 70.000 Euro bezahlt. Und da können Sie ja alleine gar nichts machen. Das ist 
dann irgendwie flämisch-belgisches Recht in flämischer Sprache, wo kein Mensch weiß. Wir haben eigentlich nur darüber diskutiert, welches Gericht zuständig ist, ob da deutsches Gericht oder belgisches Gericht oder EU-Recht oder keine Ahnung. Da sind Sie wirklich auf Gedeih und Verderb ausgeliefert. Ich habe dann immer mit meinem Anwalt, und der dann wieder mit dem belgischen, und so ging das also hin und her. Und irgendwie hat dann das Gericht entschieden, ja, dass irgendwie / Also, das ging schon mal los, dass die teure Anwaltskanzlei erst mal die $<<<$ Unternehmen anonymisiert $\gg>>\mathrm{GmbH}$ verklagt. Das ist eine $\mathrm{GmbH}$, die ruht, die auch $<<<$ Unternehmen anonymisiert $>>>$ heißt, die aber gar nicht aktiv ist. Die eigentliche $<<<$ Unternehmen anonymisiert $>>>$ ist ja, leider für mich jetzt, eine Einzelfirma, die eigentlich der Vertragspartner war. Aber die haben erst mal das falsche Unternehmen verklagt. Und dann musste das, musste ich irgendwie dem Verfahren beitreten, das geht irgendwo in Belgien. Und das Ergebnis war, dass dann das Gericht entschieden hat: „So, da machen wir nichts.“ Quasi hat dann $<<<$ Unternehmen anonymisiert $>>>$ so, wenn man so will, verloren. Und die haben dann geschrieben an meinen Anwalt, ich soll 1000 Euro zahlen, und dann lassen sie es auf sich beruhen. Und dann hat mein Anwalt gesagt: „Wieso, die haben doch nichts erreicht. Warum sollst du 1000 Euro zahlen, da zahlen wir gar nichts.“ Ok. Dann haben die also wieder weitergemacht. Und jetzt im Rahmen der Insolvenz haben die dann eben so einen übermotivierten Junganwalt aus $<<<$ Ort anonymisiert $>>>$ geschickt. Da waren dann die ganzen Leute, die da waren, es waren ja nicht viele, es war die Bank da und / zwei Bankvertreter und zwei Mitarbeiter und dieser Übermotivierte. Deshalb hat das vier Stunden gedauert. Und die Frau $<<<$ Name anonymisiert $>>>$, die hat gesagt, es wäre normalerweise in einer viertel Stunde erledigt gewesen, wenn der nicht da uns ewig genervt hätte, dass er irgendwelche Stimmrechte haben wollte oder was auch immer. Und die hatten dann eine Million Euro in der Insolvenztabelle angemeldet. Schon mal so ein bisschen viel. Und das ist da halt so in so einer Insolvenztabelle. Ich meine, als ich Insolvenz angemeldet hatte, hat der Anwalt gesagt, ja, wieso dass Sie schon da sind. Normalerweise haben die, wenn wir so Insolvenzfälle bekommen, dann haben die Leute schon irgendwie vier Monate / fünf Monate, keine Gehälter mehr gekriegt und so weiter. Es wurden alle Gehälter bezahlt, es waren quasi alle Sozialversicherungen bezahlt. Und wir haben im Prinzip zwei Hauptgläubiger, das war Microsoft. Der Microsoft hat zur Klage gar nichts angemeldet. Ich meine, das ist für die Pillepalle. 
Wir haben für die zehn Jahre lang ihre Lizenzen verkauft. Und die haben ja zwar einen Schaden, aber das ist ja jetzt nicht so ein materieller Schaden, wie jetzt, sagen wir mal, eine Baufirma, die jetzt ein Baugerät kauft, und danach ist das weg. Sondern die kopieren halt ihre Lizenzen, ja. Und der zweite war die $<<<$ Unternehmen anonymisiert $\gg>>$, unsere Vermieter hier, der ja selber kurz vor der Insolvenz steht. Ich meine, das war ja früher ein Staatsunternehmen, die wurden privatisiert, haben ein paar Milliarden mitgekriegt, und haben die jetzt halt durchgebracht. Die haben da dieses Square am Frankfurter Flughafen gebaut. Das kennen Sie wahrscheinlich, wo oben diese KPMG auch drauf ist. Da haben die ganz allein, glaube ich, eine Milliarde versenkt. Ja, und dann gab es halt so ein paar kleine Sachen. Aber es ist jetzt eigentlich niemand, der wirklich in / durch diese Insolvenz in / wirklich in Not gekommen ist, ja, oder in Schwierigkeiten. Das waren mehr so kleinere Geschichten. Und was dann halt der Fall ist, in so einer Situation werden natürlich die Forderungen von den Gläubigern alle auch aufgeblasen. Deswegen hat halt der $<<<$ Unternehmen anonymisiert $>>>$ dann eine Million daraus gemacht, und der $<<<$ Unternehmen anonymisiert $>>>$ hat gesagt, wir hätten ja eigentlich noch fünf Jahre umsonst arbeiten müssen, also melde ich das mal zur Klage an. Ja. Obwohl die mit ihrem Projekt live sind und auch damit arbeiten, und an sich kann man da erst mal sagen, das ist / haben wir uns sehr lang gemacht um denen, sag ich mal, das Projekt noch zum Abschluss zu bringen. Ja.

I: Wenn Sie zurückdenken, Sie haben schon gesagt Sie hätten sich / Wenn Sie nochmal könnten, würden Sie sich die Verträge genauer angucken. Gibt es noch was, wo Sie sagen, das würden Sie aus heutiger Sicht ganz anders machen?

B: Ja, ich hätte wahrscheinlich eher die Reißleine bei der Sleeq-Entwicklung ziehen sollen. Aber das ist halt immer so, wenn Sie da an etwas glauben, und sagen: „Mensch, das ist eigentlich toll, und der hängt sich dann auch rein.“ Dann hätte man das eher killen müssen. Da gab es natürlich schon immer mal auch die Anmerkung aus dem eigenen Haus vom Controlling. Das ist immer so ein bisschen eine schwierige Geschichte. Also, ich habe dann von den Leuten teilweise gehört, oder von einem, das kann man natürlich auch / habe ich auch eine spezielle Meinung zu, der dann sagt, ok, man sei beratungsresistent. Auf der anderen Seite stelle ich / habe ich auch immer wieder festgestellt, dass es natürlich auch ein Unterschied ist, wie jemand etwas zu 
einem sagt, also wie nachdrücklich, und wie dringlich er einen vor Gefahren man gewarnt wird. Wenn man das nur sagt, ja, ok, seh`ich schon, aber / Da muss man die Dinge vielleicht auch deutlicher gesagt bekommen. Ich meine, das habe ich auch immer den Mitarbeitern gesagt: „Ich brauche keine Ja-Sager. Denn ich brauche Leute, die mich auch vor Risiken schützen, weil ich vielleicht irgendwas übersehe oder nicht richtig beurteilen kann oder falsch beurteile, ja." Ich meine eigentlich nicht, dass ich so beratungsresistent bin, aber da hat man vielleicht auch ein verstelltes Bild, also, weiß ich nicht. Aber ich mache mich nicht frei von Schuld.

I: Gibt es auch etwas Positives an der ganzen Sache, wenn Sie zurückdenken?

B: Vielleicht ja. Also, der Stress. Ich habe eine Zeit gehabt, die ersten 15 / 20 Jahre, da haben wir super Projekte gemacht, da hat das alles ganz gut funktioniert, eine gute Truppe, Spaß gemacht mit den Leuten. Und am Schluss war es mir schon viel Belastung. Also, in dem Druck und in dem Stress, und dann ist man natürlich auch in der Kritik bei einigen Leuten, ob das der Vertriebsleiter war, der natürlich auch alle seine nicht gewonnenen Aufträge letztendlich mir zugeschoben hat, die Schuld, ja. Also, das ist weg.

Was natürlich etwas blöde ist, ich bin jetzt 56 in einem Alter, wo ich sage, so eine Insolvenz wäre mir natürlich mit 32 oder mit 28 lieber, da kann man nochmal irgendwie leichter durchstarten. Und wenn Sie quasi nie in einem Angestelltenverhältnis waren, und sie waren vom Studium an selbstständig und hatten dann ein Unternehmen mit 100 Leuten und über 10 Millionen Umsatz. Wir waren ja / In diesem Markt, sind wir ja schon wahrgenommen worden. Und den Namen kann man sich auch gut einprägen. Ich denke, wir hatten ein ganz gutes Marketing dann auch. Dann ist das natürlich nicht so prickelnd, wenn das weg ist. Aber die Belastung ist natürlich irgendwo weg. Ich muss jetzt halt irgendwo mich neu, völlig neu, sortieren und gucken, wie ich da wirtschaftlich überleben kann, ja. Da gibt es jetzt noch Dinge, zum Beispiel diese Immobilie in $<<<$ Ort anonymisiert $>>>$ umzufinanzieren, dass ich die behalten kann. Weil da ist noch so viel finanzielle Belastung drauf, dass sie für die Insolvenzverwaltung nichts bringt. Und wenn die Sparkasse wohlwollend ist, und mir die bei den jetzigen Zinsen neu finanziert, dann / Das sind neun Wohnungen und, keine Ahnung, drei Tiefgaragenplätze in einer 
zentralen Lage. Und wenn vielleicht noch ein bisschen die Inflation mithilft, dass die Mieten steigen, und die Verbindlichkeiten weniger werden. Also, nicht durch die Inflation weniger werden, sondern halt durch die Tilgung. Aber man kann natürlich leichter tilgen, wenn man die Preise erhöhen kann. Dann würde das ein bisschen helfen. Also, sagen wir mal, dann hätte ich damit eine gewisse Alterssicherung. Weil, das ist natürlich schon ein Problem. Ich habe da zwar schon vorgesorgt gehabt, aber halt in Form von Lebensversicherungen und solchen Dingen, und die sind natürlich / die hat die Frau $<<<$ Name anonymisiert $>>>$ natürlich liebend genommen.

I: Kam bei Ihnen eine Privatinsolvenz dazu zur Firmeninsolvenz?

B: Ja, im Prinzip ja, das ist ja eins bei einer Einzelfirma.

I: Was war das für eine Gesellschaftsform?

B: Einzelfirma.

I: Einzelfirma? Ist das dann ein eingetragener Kaufmann?

B: Ja, wenn Sie so wollen.

I: Ok.

B: Ja, es war keine Kapitalgesellschaft. Weil bei einer Kapitalgesellschaft haben Sie halt das Firmenkapital, und wenn das Ding den Bach runtergeht, ist das halt weg, aber ihr Privatbereich ist halt nicht tangiert. Den können Sie damit schützen, und das ist damit halt nicht möglich. Das geht dann nur über Beziehung, wie das halt bei Vielen ist, die dann irgendetwas auf den Namen der Frau betreiben oder dort noch irgendwo Vermögen haben können oder so.

I: Würden Sie sagen, dass die Insolvenz Sie verändert hat?

B: Ich hoffe nicht. 
I: Also, sind Sie der Gleiche geblieben?

B: Ich hoffe nicht. Ja, gut, ob man der Gleiche geblieben ist, ich denke mal, man wird im Laufe seines Lebens immer von bestimmten Dingen, Ereignissen ein Stück weit geprägt. Aber ich kann vielleicht jemanden zitieren, ich weiß / ich kenne den Namen nicht mehr, ich weiß nicht, wer das genau war, aber jemand, der erfolgreich war im Film- oder Musikgeschäft, war ein Interview halt im Radio. Und den hat man auch gefragt, ob er sich da verändert hat, und darauf hat er geantwortet, ich zitiere: "Entweder man ist vorher ein Arschloch (lacht) oder nicht, aber, dadurch ändert sich das nicht." (lacht) Und ich hoffe mal, dass es mich nicht zum Negativen verändert hat. Ich meine, das sind ja immer so Dinge auch im Unternehmen, wenn man Enttäuschungen erfährt von Mitarbeitern, die einem dann auf einmal sich auf die andere Seite stellen. Oder an die man geglaubt hat, und, oder ihnen Vertrauen gegeben hat. Ich meine, wenn jemand den kompletten Navisionbereich leitet, dann geben sie ihm viel Vertrauen. Ich habe mit ihm noch über variable Vergütung geredet. Also, wenn er erfolgreich ist, auch entsprechend mitverdient. Und wenn der natürlich dann zum Wettbewerber geht, und dann ihre eigenen Kunden angräbt, dann sind das schon Dinge, die weh tun. Und irgendwie, solche Enttäuschungen, auch mit dem Vertriebsleiter / Ich habe dann schon immer versucht, da dann nicht verbissen zu werden oder irgendwie verhärmt, sondern dann halt trotzdem zu sagen: „Na gut, ist halt so." Und, weil man neigt halt, oder die Gefahr besteht darin, wenn man ein paar Mal so Erfahrungen macht, dass man dann mit der ganzen Mitarbeiterschaft, mit der Führung und so sich verändert und ganz anders umgeht.

\section{I: Misstrauisch wird?}

B: Misstrauisch wird, ja, jeden und alles in Frage stellt, und das bringt natürlich auch nichts.

I: Wie hat Ihr Umfeld auf die Insolvenz reagiert?

B: Überrascht. 


\section{I: Haben Sie Familie?}

B: Überrascht, ja, weil die Firma, denke ich, einen ganz guten Ruf im Markt hatte, auch noch hat. Und wenn ein Unternehmen einen guten Ruf hat, und auf einmal hört man insolvent, ähm, wie? Die? Kann eigentlich gar nicht sein. Ja, also, das denke ich schon. War, denke ich, für Viele, die das mitbekommen haben, schon eher so aus dem heiteren Himmel.

I: Und wie war das für Ihre Familie? wie hat die reagiert?

B: Auch schwierig. Ja, also, meine Partnerin, die hat natürlich auch darunter gelitten, klar. Wenn ich entnervt heimkomme und abends schlecht drauf bin. Weil ich habe ja im Prinzip / das ist ja so ein Sterben in Raten. Und vor allen Dingen, was mich immer massiv belastet hat, ist, wenn Mitarbeiter gekündigt haben. Und Mitarbeiter haben ja oft / Das hat man ja oft so erlebt, dass man dann von anderen Mitarbeitern gehört hat: „Oh, der wackelt, oder ich glaube der, der verhält sich so komisch, mit dem solltest du mal reden, weil, oh, wenn der geht, ja." Und dann gab es auch Leute, die sind damit offen umgegangen, die haben dann gesagt: „Ja, ich bewerbe mich bei $<<<$ Unternehmen anonymisiert $>>>$, ich will es dir nur sagen. “Und überhaupt, mir hat es hier gut gefallen, alles ist prima, also, die Abschiedsmails, die sind alle toll, $<<<$ Unternehmen anonymisiert $>>>$ ist toll, und macht es gut, und ich werde die Zeit in guter Erinnerung behalten, und / Aber wenn Sie dann immer wieder diese Nackenschläge kriegen, weil dann ja doch der eine oder andere kündigt und so, dann ist das natürlich schon hart. Und da bin ich dann natürlich nicht entspannt und locker und freudestrahlend heimgekommen.

\section{I: Ja, klar}

B: Sondern ich bin dann heimgekommen: „Mann, Schieße, (haut auf Tisch) der Dominik hat gekündigt (haut auf Tisch) oder der (haut auf Tisch) Mann! Und ich habe noch angerufen, habe noch gehofft, hat aber nicht /“" Das ist natürlich schon frustrierend. 
I: Und so Ihr Umfeld ihr Freundeskreis, wie wurde es da aufgenommen? Hatten Sie da das Gefühl / Zum Beispiel ein Gesprächspartner meinte, dass es wie ein Makel ist, dass man sich vorkommt, als würde man scheitern. Oder dass Leute schadenfroh sind? Also, die verschiedensten Reaktionen sind ja denkbar, wie war das bei Ihnen?

B: Ja, das gibt es bestimmt, das gibt es bestimmt. Aber ich vermute halt, dass die das nicht mir erzählen, sondern eher (lacht) irgendjemand einem Dritten untereinander.

I: Also, Ihnen gegenüber haben Sie in der Richtung nichts erfahren.

B: Nein. Ich habe / Also, das gibt es bestimmt. Schadenfreude ist, glaube ich, etwas, was bei den Leuten in der breiten Bevölkerung sehr gut (lacht), sage ich mal, funktioniert. Und ich glaube, also wenn mich jemand als, als / wie hieß es da in Ihrem Fragebogen? Ähm, selbstherrlich stand, glaube ich, nicht drin, aber so ähnlich, gell so. (blättert)

\section{I: Wo meinen Sie?}

B: Ich weiß nicht, irgendwo war mal so eine Frage dabei. Selbstgefällig, selbstsüchtig. Wenn einer einen so einschätzt oder beurteilt, dann, glaube ich, ist das eine gute Basis für Schadenfreude. Aber ansonsten, nein, eigentlich nicht. Es gibt / ich habe eigentlich eher Leute, die sagen: „Komm, es gibt Schlimmeres.“ Man wird ja dann immer mit noch schlimmeren Katastrophen getröstet. Also, stell dir vor, du hättest Krebs oder, oder, oder keine Ahnung. Und irgendwie geht es weiter und keine Ahnung, ja. Mein Anwalt, der hatte dann Sorgen, dass ich suizidgefährdet bin. Und da habe ich gesagt: „Nein, mach dir mal keine Gedanken, ich werde mich nicht wie der Herr Merkle vor den Zug schmeißen. Und der hätte das ja nicht machen brauchen, der hat ja noch genug Millionen im Gegensatz zu mir.“ Aber er war halt dann in seinem Dings verletzt oder / (seufzt) Wie gesagt, da hat jede Persönlichkeit / Jeder geht da mit Sicherheit auch anders mit um, ich meine, ich hätte mir natürlich auch vorgestellt / Also, aus dem Business wollte ich. Ich habe schon vor langer Zeit mal versucht, raus zu kommen. Da waren wir noch gar nicht in den Räumen, und da sind wir jetzt 
bestimmt 16 Jahre. Und da hatte ich jemanden eingestellt, einen Informatiker aus $<<<$ Ort anonymisiert $>>>$. Und da habe ich gesagt, du, pass auf, bau ihn auf als Geschäftsführer, führ den Laden weiter, ich ziehe mich da zurück. Aber es hat nicht funktioniert. Und es wäre schön gewesen, ich hätte rechtzeitig jemanden gefunden, der das übernimmt. Weil wenn Sie das 35 Jahre machen und waren nie in einem anderen Unternehmen, dann sind Sie auch ein Stück weit betriebsblind. Es ist irgendwann auch / Möchten Sie dann mal absteigen, und die Verantwortung jemanden anderen übergeben, auch vielleicht was anderes machen oder mal eine Auszeit nehmen. Also, ich hatte hier Mitarbeiter, die gut hier gearbeitet haben, die sind beide miteinander privat befreundet. Die haben halt dann gesagt, wir machen jetzt mal Sabbatical und sind dann halt mal ein Jahr nach Italien, Verona, und italienisch gelernt. Und so etwas hätte ich schon auch mal gerne gemacht.

Ich meine, ich bin in den ersten 15 Jahren, da lief es gut, aber da habe ich halt auch kaum Urlaub gemacht, und dann die Aufbauarbeit geleistet. Da war es relativ stressfrei. Das war positiver Stress, man hat gearbeitet, den Vertrieb gemacht und Leute eingestellt, Personal, und ist durch die Gegend gefahren, Kunden besucht. Das war positiver Stress, aber es war weniger nervig. Also, heute sind die Kunden nerviger. Ich hatte, glaube ich, die ersten 15 Jahre gar keinen Anwalt gebraucht. Heute geht fast nichts mehr ohne Anwalt. Also, da hat sich die Welt auch verändert. Und es sind natürlich auch / Der Markt ist reifer geworden. Es sind mehr professionelle Unternehmen einfach da am Start. Auch ist es ein Markt, der sich zunehmend konsolidiert. Also, ich hatte zum Beispiel hier Besuch von jemanden, der hat gesagt, so, ich bin unterwegs für eine honorige Familie. Die möchten in den gehobenen Dienstleistungsmarkt einsteigen, und da haben sie sich gerade ERP ausgesucht. Und wie haben jetzt mal 500 Firmen gescannt, und die wollen so 50 kaufen. Und $<<<$ Unternehmen anonymisiert $>>>$ passt da in den Zielfokus, ins Beuteschema. Ob ich denn da verkaufen würde. Und da war ich halt schon in der Schieflage, wo das dann nicht wirklich Sinn gemacht hätte wahrscheinlich, oder vielleicht schon. Der war dann auch nochmal da mit einem Interessenten, der sich dann aber dagegen entschieden hatte, weil er sagte, er versteht zu wenig von diesem Geschäft hier. Und da, wie gesagt, vor ewiger Zeit hätte ich da schon mal den Versuch gemacht, und da hätte ich gerne jemanden gehabt, der sich da / der das Unternehmen weiterführt nach der Aufbauarbeit. 
Mein Manko ist sicherlich auch, dass ich kein Informatiker bin. Und das Geschäft ist sehr stark auch mittlerweile halt informatikgeprägt. Und das ist schon auch doof, wenn sie dann irgendwelche Dinge nicht beurteilen können, ja. Wie aufwendig ist es, so eine Schnittstelle zu programmieren, oder wie komplex ist die Datenübernahme oder, oder, oder. Sie sind da immer auf das Urteil von Leuten angewiesen, die dann, wenn es später nicht funktioniert hat, erklären, ja, das konnten wir nicht wissen und hä und ja. Auch Aufwände zum Beispiel zu kalkulieren, ja. Die Leute kalkulieren halt dann fünf Tage, und später haben wir dann pauschal irgendeinen Prozentsatz draufgeschlagen. Und dann haben sie es sich mal einen halben Tag angekuckt, haben festgestellt, oh, doch sieben. Aber jetzt habe ich dem Kunden schon fünf kommuniziert, ja. Und das gleiche können Sie natürlich auch mit 15 und 20 machen. Und dann kann ich es nicht mehr durchsetzen, dann ist Konflikt, dann ist Theater. Dann wird es halt gemacht, und Sie bleiben auf den Aufwänden dann sitzen. Also, das sind immer so Dinge, wo ich sagen muss, das ist mittlerweile alles sehr, sehr IT-komplex. Und, ich meine, zu meiner Zeit ist man ja mit dem Zeug überhaupt nicht aufgewachsen. Ich habe noch einen Rechenschieber in der Schule gehabt. Wenn ich jetzt Sie sehe / Also, ich habe einen Sohn, der ist 12 Jahre alt. Klar, also, die gehen mit einer Natürlichkeit mit ihren IPod und Wii und Playstation um. Und jetzt hat er recherchiert, was ist denn das beste Handy, und hat sich dann für dieses Nokia Experia blub blub blub entschieden. Ähm, ja. Insofern habe ich eine gewisse Aufbauarbeit gemacht, ich habe die Marke etabliert, habe Leute / habe ein gutes Händchen eigentlich gehabt für gute Leute. Da war ich lange bekannt für, dass ich immer gute Leute im Projektbereich hatte. Damals war es auch einfacher noch gute Leute zu kriegen als das heute ist. Und der Markt ist konsolidiert. Heute sind da / steigen da professionelle Leute ein. Dieses honorige Unternehmen / ich habe den Termin dann gemacht, um zu wissen, wer da dahintersteht. Das war dann eine Familie, denen $<<<$ Unternehmen anonymisiert $>>>$ gehört. Das ist ein riesengroßer Laden. Die nehmen halt mal 100 Millionen in die Hand, oder mehr, und kaufen sich halt mal in so einen Markt ein, kaufen sich extern die Geschäftsführer ein, die irgendwo schon einmal bewiesen haben, dass sie auch in der Lage sind so eine Dienstleistungsgesellschaft auch in der Lage sind zu steuern. Ja, und gegen die stehen sie dann einfach auch im Wettbewerb.

I: Hm. 
B: Wobei das jetzt nicht der Grund der Insolvenz war, ja, also, das sehe ich nicht. Aber wir waren früher mit Unternehmen auf Augenhöhe. Und zwar ein Unternehmen habe ich da jetzt im Kopf, mit dem war ich mal in Florida. Das war auch eine IncentiveGeschichte im ... (unverständlich). Da haben wir gewonnen gegen die, die sitzen da unten am Bodensee und haben an ... (unverständlich) die Hardware geliefert, waren stinkesauer, dass wir dann den großen Softwareauftrag dort bekommen haben, und auch $<<<$ Unternehmen anonymisiert $>>>$ den Auftrag bekommen haben. Die sitzen ja auch da unten. Aber heute sind die halt 280 Mann stark und wachsen und haben das irgendwie ganz gut im Griff.

Auch Produktentwicklung ist sicherlich auch ein Manko bei uns gewesen. Das ist halt immer so ein Problem. Wenn Sie die Aufträge vorne nicht reinkriegen und haben die Auslastung nicht und kämpfen da. Dann haben Sie wieder keine Resourcen frei für Produktentwicklung. Ja, da kommt die Kohle nicht rein, die Sie dann bräuchten, um die Produkte fit zu machen. Wenn Sie die fitten Produkte nicht haben, na / Dafür brauchen Sie auch wieder Leute, die Produktentwicklung machen können. Weil Produktentwicklung ist wieder ein völlig anderes, in Anführungszeichen, Geschäft, als ein Projekt abzuwickeln. Da brauchen Sie jemanden, der dann wirklich so ein Produkt entwirft, der das entsprechend parametrisierbar und skalierbar aufbaut, dass es halt wirklich für viele Varianten einsetzbar ist, unterschiedliche Unternehmen. Sie müssen dafür sorgen, dass der Vertrieb nicht jedem Kunden jedes rosa Schleifchen verkauft, sondern sagt, das ist der Standard, nimm es oder lass es, außer es ist irgendetwas, wo wir entscheiden, es kommt in das Produkt rein. Sonst haben Sie wieder 100.000 unterschiedliche Installationen im Markt, die Ihnen dann die Probleme machen bei Update, bei Support, Wartung und so weiter und so weiter, ja. Also, da brauchen Sie auch jemanden, der die harte Hand dann hat, und der weiß, was mach ich jetzt rein und was mache ich nicht rein, und diese Entscheidungen dann auch trifft. Also, es sind viele, viele Faktoren in dem Geschäft, wo ich mich auch nicht wirklich im Stande sehe, das alles zu handlen. So dass ich auf externe Leute angewiesen bin, die dann aber auch konsequent ihren Job machen müssen. Und die Leute sind auch selten. (lacht)

I: Und wie ist jetzt gerade im Moment der aktuelle Stand? 
B: Der aktuelle Stand ist, dass ich heute bis $14 \mathrm{Uhr}$ entscheiden muss, für wieviel Geld ich die Marke $<<<$ Name anonymisiert $>>>$ an einen Übernehmer verkaufe, weil die Marke $<<<$ Name anonymisiert $>>>$ ich mal irgendwann in die $\mathrm{GmbH}$ ausgeliefert habe, und damit ist sie dem Zugriff der Insolvenzverwaltung verwehrt. Und der die Marke $<<<$ Name anonymisiert $>>>$ halt haben möchte, weil da hängt natürlich auch Homepage und Einträge in hunderte von Datenbanken und, und, und dahinter, und möchte eben nicht mit seinem Namen aus der Schweiz hier in Deutschland antreten. Da haben wir heute früh noch hin und her gemailt, und er hat mir gestern eine Frist bis $16 \mathrm{Uhr}$ gesetzt. Und dann habe ich ihm geschrieben, dass ich das noch mit meinem Anwalt besprechen möchte, der hat aber keine Zeit. So ist das auch mit Anwälten. Da habe ich zehn Tage hinterher telefoniert bis ich ihn überhaupt gekriegt habe, und dann hat er gesagt, ja, er weiß erst seit einem Tag Bescheid, er hat erst mit der Frau $<<<$ Name anonymisiert $>>>$ gesprochen. (lacht) Und innerhalb von einem Tag, das geht ja gar nicht. Dass die schon zum zweiten Mal da sind und schon vor ein paar Wochen mal da waren, das hat er halt nicht mitgekriegt. Wenn ich ihn anrufe, ruft er nicht zurück. Hat er dann irgendwann mal ausrichten lassen durch sein Büro, dass er mich nicht vergessen hat, dass er sich die Woche noch meldet. Hat er natürlich auch nicht getan. Dann gestern habe ich ihn kurz erwischt, da hat er gesagt, er kann nicht. Da habe ich ihn gebeten, dass er da mal anruft von neutraler Seite in der Verhandlung. Da hat er gesagt, ja, das kann er erst am Montag machen, weil heute ist er den ganzen Tag in München. Dann habe ich ihm heute gerade eine SMS geschickt, dass der mir eine Frist bis 14 Uhr gesetzt hat. Und es wäre gut, wenn er dort sich einklinken könnte, oder ihn mal anrufen könnte. Daraufhin hat er gesagt, das kann er nicht, er ist in irgendwelchen / Das ist ein Thema. Wenn sie sich dann mal überlegen, dass er mal so locker 10.000 Euro am Anfang gekriegt hat, und für einen Insolvenzplan, der auf völlig falschen Zahlen aufgebaut war.

Es war ja ein Insolvenzplanverfahren angedacht, um das Unternehmen wieder aus eigener Kraft zu sanieren. Dann hätte es mir weiterhin gehört. Dann hätte ich über die Erträge die Gläubiger befriedigt in den nächsten Jahren, ja. So war das ursprünglich geplant. Dann sind uns halt immer mehr Kunden weggebrochen, und noch weitere Mitarbeiter weggebrochen, ja. Und dann hat er halt mal einen Insolvenzplan für wahrscheinlich 20.000 Euro gebastelt, der Jenseits von Gut und Böse war. Und es 
findet auch nicht statt. Und er wird auch nicht gebraucht. Also, ich wüsste schon Berufe, die ich (lacht) im neuen Leben (lacht)

I: Und warum kam es dann nicht zu der Planinsolvenz? Eben, weil die Mitarbeiterzahlen gesunken sind?

B: Ja, halt auch Kunden weggebrochen sind. Und auch Kunden vor allen Dingen nicht bezahlt haben. Wir haben ja 4 - 500.000 Euro draußen gehabt, aber die haben halt einfach nicht bezahlt, wo Sie Zahlungsverpflichtungen haben. Ja, da hat der Herr $<<<$ Name anonymisiert $>>>$, der dann mit dazu kam, um das hier nach vorne zu bringen, hat er mir neulich gesagt, er hat sich wohl auch mit der Frau $<<<$ Name anonymisiert $\gg>$ ein bisschen in die Haare gekriegt, weil er sagt, wir können hier nichts mehr machen. Ihr müsst jetzt von der Anwaltsseite her halt jetzt sagen (haut auf Tisch), so wir fahren jetzt mal den Drohdienst auf, damit ihr zahlt. Weil es gibt einen Vertrag und es steht da drin (haut auf Tisch). Es ist im Prinzip so, es gibt Kunden, die sagen halt, ja, wir haben jetzt gewechselt, warum sollen wir zahlen? Sage ich, ja, aber das geht doch nicht! Ich kann doch nicht sagen, ich lease jetzt auf drei Jahre einen BMW, und nach einem dreiviertel Jahr sage ich, ach, ich habe mich jetzt gerade für einen Mercedes entschieden, ich zahl jetzt die Leasingrate dahin und nicht mehr dahin (haut auf Tisch). Oder ich wechsel mal, wenn ich einen Dreijahresvertrag bei Vodafone unterschrieben habe, fällt mir nach dem dreiviertel Jahr oder einem Jahr ein, ach, O2 ist mir lieber (haut auf Tisch). Und dann zahle ich meine Dings jetzt nicht mehr an Vodafone, sondern an O2. Und genau so läuft das ab. (haut auf Tisch) In anderen Bereichen unvorstellbar.

I: Das Unternehmen an sich existiert aber ja noch. Es ist ja nicht nur die Marke, die noch existiert, Sie haben ja auch noch Mitarbeiter draußen.

B: Ja klar, das Unternehmen existiert, freilich, ist ja operativ tätig.

I: Würde dann jetzt das gesamte Unternehmen verkauft werden oder nur der Name? 
B: Es wäre ein Asset-Deal. Nein, nein, das gesamte Unternehmen, ein Asset-Deal. Ich meine, sie können ein komplettes Unternehmen verkaufen, mit allem, und Sie können / Ursprünglich war ja Eigensanierung, Insolvenzplanverfahren, und damit halt den Gläubigern eine höhere Quote quasi zusichern, als wenn sie das jetzt über die Tabelle bekämen. Muss halt entsprechend attraktiv sein und muss natürlich auch von der Wirtschaftskraft her leistbar sein vom Unternehmen. So. Und das war lange Zeit war das der Plan, und das hat auch mein Herr Anwalt propagiert, und das war auch, gibt es ja auch Berichte in den Medien von der Frau $<<<$ Name anonymisiert $>>>$. Und das war sicherlich die eherne Absicht, und mich hätte das natürlich auch gefreut, weil dann hätte ich das Unternehmen behalten können, hätte das irgendwie sanieren können und dann hätte ich es irgendwann veräußern können oder was auch immer damit tun. Dann hätte ich noch meinen Job, eine Einkommensquelle. Aber das ist dann irgendwann halt nicht mehr machbar gewesen, das ist dann wie gesagt / Die Kunden, Kunden sind weggebrochen, und das Problem ist natürlich auch, mit dem "I" am Namen, also wenn Sie noch in der Insolvenz sind, haben Sie so gut wie keine Chance Neugeschäfte zu generieren. Ich meine, was wir machen, ERP-Geschäft heißt ja, dass die Software alle Unternehmensprozesse durch das ganze Unternehmen unterstützt. Einkauf, Verkauf, Kostenrechnung, bla bla bla, Planung, was auch immer. Das ist im Prinzip der Nervenstrang, das Rückenmark des Unternehmens, das wir unterstützen. Anders als wenn wir jetzt meinetwegen nur eine CAD-Software oder so etwas anbieten würden, wo halt eine Konstruktionsabteilung vielleicht ein Produkt kriegt. Sondern das zieht sich ja durch alle Abteilungen, Versand, Lager, alles, ja, Einkauf, Vertrieb, alles was da an Unternehmensprozessen unterstützt wird. So eine Software ist eine extrem kritische Sache für so ein Unternehmen. Das ist ja schon im normalen Geschäft so, dass die sich genau angucken, mit wem habe ich es zu tun und ist das Unternehmen auch solvent und lebt das auch in fünf Jahren noch und, und, und, und, und, ja. Und wenn Sie da natürlich in der Insolvenz sind, dann sagt natürlich jeder / Wir haben präsentiert, und die haben das alles gut gefunden (haut auf Tisch) waren kurz vor der Entscheidung (haut auf Tisch) und dann haben die gesagt, hm, wenn ihr aus der Insolvenz draußen seid wieder, ja, gefällt uns, machen wir, aber jetzt "no". Das ist natürlich für Entscheider auch auf der Kundenseite, das können die intern natürlich auch schlecht vertreten und verkaufen, dass sie da bei einem Unternehmen, das in der 
Insolvenz ist, so eine unternehmenskritische Anwendung einkaufen. Das geht dann schief. Das ist ja für den Entscheider dann eine Katastrophe.

Und das bedeutet, ich meine unabhängig davon, dass wir im Moment natürlich keinen leistungsfähigen Vertriebsmitarbeiter haben, ich habe ja vorhin schon ein bisschen was dazu gesagt. Sie kriegen natürlich in dieser Situation a) (haut auf Tisch) keine, so gut wie keine kompetenten Mitarbeiter, b) (haut auf Tisch) müssen Sie sie bezahlen können, (haut auf Tisch) Sie kriegen kein Neugeschäft. Das ist zum Beispiel anders, ich habe mit einem Kunden von uns gesprochen, der sagt, ja, ja, ist kein Problem, wir haben auch immer wieder mal mit Lieferanten zu tun, die in der Insolvenz sind, wir haben deswegen bei denen weiterbezogen. Gut, wenn ich halt von irgendeinem irgendwelche Blechteile beziehe und baue die irgendwo ein, und es funktioniert, dann kann ich mit dem mal in der Insolvenz weitermachen und so weiter, ja. Aber bei so unternehmenskritischen Geschichten ist das natürlich nochmal anders.

Und dann sind natürlich die, die weggegangen sind, auch draußen und erzählen entsprechende Geschichten. Und das verunsichert natürlich auch wieder die Leute, da wird auch viel Unsinn erzählt. Aber Sie können das halt nicht wirklich verhindern. Also, Unsinn im Sinne / Unwahrheiten besser gesagt, ja, die die halt benutzen zum eigenen Vorteil.

I: Und was machen Sie jetzt? Was sind Ihre Pläne für die Zukunft?

B: (seufzt) Ich hoffe da auf ein paar gute Anregungen von Ihnen.

I: (lacht)

B: ein paar gute Ideen.

I: Das ist aber viel verlangt. (lacht)

B: Ich weiß es noch nicht. (Pause) Ich weiß es noch nicht.

I: Vielleicht kommen wir nochmal kurz zum Abschluss auf ihre Familie zurück. Wie haben Sie das empfunden, das auch ihrer Partnerin zu erzählen, gegenüber ihrem Kind, 
war das eher / war die Familie für Sie eher eine Stütze oder eine Zusatzbelastung, weil Sie gesagt haben, ich bin ja nicht alleine, ich muss ja meine Familie auch noch ernähren.

B: Ja, das kommt drauf an. Das ist mal so und mal so. In der schwierigen Zeit war es mal eine Stütze, es war aber auch mal eine Belastung. Will ich natürlich mit den ganzen Themen da immer schwanger gegangen bin und hab da / Das ist sicherlich Persönlichkeitsstruktur, habe da zur Verarbeitung jemanden gebraucht, mit dem ich das reflektieren und besprechen und diskutieren kann. Und wenn es natürlich über eineinhalb, zwei Jahre geht, dann sagt der andere natürlich mal: „Hey jetzt, ich kann es nicht mehr hören, lass mich in Ruhe, ja." Und flippt auch aus und so. Also, was dann schon zum Konflikt führt, wo ich sage, das brauche ich jetzt nicht. (lacht) Eigentlich bräuchte ich jetzt jemanden, der da eher mal die Dinge mit mir einfach verarbeitet. Aber Menschen verarbeiten unterschiedlich. Also, ich kenne Leute, die kriegen den Mund nicht auf in einer schwierigen Situation. Ich meine, das ist ja auch bei Krebspatienten so, manche gehen ganz offen damit um, und andere, die sagen über lange Zeit der eigenen Familie nichts davon, obwohl, ja / Gut, mein Sohnemann, der geht da relativ entspannt damit um, der sagt: „Na, jetzt weißt du es doch, jetzt hast du was gelernt, jetzt weißt du, wie du es nicht mehr machst.“ Punkt Ende. (lacht)

I: (lacht) Ja, hat er recht.

B: Sehr pragmatisch, ja. (lacht) Ja, ansonsten ist es natürlich schon eine Schwitze, ganz klar. Weil ich ja jetzt erst mal in eine gewisse wirtschaftliche schwierige Situation reinfalle. Was ich mache, das sagen Sie im Moment nicht weiter, ich deale im Moment mit Aktien (lacht). Das ist etwas, das kann ich zu Hause machen, das kann ich überall machen mit einem Tablet. Es macht mir Spaß. Und es ist halt sehr rechercheintensiv, weil man, wenn man es falsch macht, man auch schnell auf den Bauch fallen kann. Aber man kann es auch gut machen. Und man kann dabei auch brutal viel Geld verdienen. Und mittlerweile sage ich, warum brauche ich dieses ganze Affentheater über Mitarbeiter, über Kunden, die nicht zahlen, über Kunden, die nerven, über Kunden, die anrufen, dass dies und das und jenes nicht funktioniert, über Mitarbeiter, die draußen Scheiße bauen, dann ruft der Kunde an, ist sauer. und dann 
muss er wieder irgendwas geschenkt kriegen, weil er ja sonst / und, und, und, und, und. Wä, es nervt. Und das ist ja immer so, wenn Sie in dieser Funktion sind, dann sind Sie natürlich immer für Troubleshooting dann irgendwann zuständig. Sie kriegen immer den Mist auf den Tisch.

I: Ja.

B: Und da muss ich sagen, ja, man hat Fehler gemacht, man hätte den Laden straffer, anders führen müssen. Ich glaube, es wäre gut gewesen vor fünf, sechs Jahren nicht diesen Vertriebsleiter $<<<$ Name anonymisiert $>>>$ und später nicht den $<<<$ Name anonymisiert $\gg>>$ zu haben und andere Leute nicht zu haben. Es wäre gut gewesen, jemanden zu haben, wie den Herrn $<<<$ Name anonymisiert $>>>$, der macht das gut. Der ist zwar jetzt auch entnervt, weil er sieht, diese Kunden sind nervig und dies und das und jenes. Aber ich glaube, der macht das ganz gut, und der geht mit einer gewissen Energie und einer gewissen Power und auch mit einer guten Einstellung ganz locker da ran. Und hat auch die Akzeptanz der Mitarbeiter. Ich meine, mit den Mitarbeitern, mit vielen kam ich eigentlich gut aus und, und, und ja ich denke auch, dass ich da nicht so einen schlechten / Es gibt halt immer mal den einen oder anderen, gerade wenn man Fehlentscheidungen trifft, oder wenn Leute, wenn die Leistung nicht passt, dann kriege ich es hier erzählt oder was auch immer. Dann ist das nicht so gut. Es gibt auch Leute, die haben eine falsche Sicht auf manche Dinge gehabt, wo ich mich wundere, dass sich jemand so gut verkaufen konnte. Und diese Leute, die ich sehr schätze, die gut sind, der eine oder andere da trotzdem drauf reingefallen ist. Ja, das ist der / Den Steve Jobs haben sie mal gefragt, ist schon länger her, ich meine, mittlerweile lebt er ja nicht mehr, was denn sein größter Fehler war in seiner AppleZeit. Das war noch die Anfangszeit, da hat er gesagt: "I hired the wrong people."

I: (Lacht) Ja, das passiert schnell, könnte ich mir vorstellen.

B: Das ist halt nämlich schon einfach von vielen, ja. Aber klar, also am Ende des Tages muss ich sagen, ein erfahrener IT-Manager hätte da wahrscheinlich anders hingelangt, als ich das getan habe. Und der wäre wahrscheinlich erforderlich gewesen. Ja, also ich wehre mich dagegen, zu sagen, es war der schuld und der schuld und der 
schuld, und ich habe damit nichts zu tun. Ich stehe an der obersten Stelle und damit habe ich die Verantwortung. Punkt. Ende. So ist das nun mal.

Ja, ich hatte mal einen Disput mit der $<<<$ Unternehmen anonymisiert $>>>$ Bank. Und zwar wollte ich ein Haus bauen für mich, also für meine Eltern, die lebten damals noch, mein Vater war Parkinsonpatient, war auch schon älter, war schwierig. Wollte ich die mit dazu nehmen, hatte ich halt geplant ein Haus, wo die barrierefrei wohnen können, meine Mutter war da auch schon 78. Dass ich die halt dann rüber hole in dieses Haus rein, und ich das andere. Und dann kann man das später vielleicht, wenn sie mal nicht mehr leben sollten, zusammenlegen, als ein schönes Haus hier in $<<<$ Ort anonymisiert $\gg>>$. Und dann sind die verstorben, und eigentlich will ich gar kein solches Haus und Unkraut jäten will ich auch nicht, und das wäre dann schon auch ein Haus gewesen, ganz schick, geplant war, und dann halt doch in einem Gebiet, das ich ganz gut finde, aber das mehr so ländlich ist. Das heißt, dann wollen die Leute ja doch lieber nach $<<<$ Ort anonymisiert $>>>$, das ist hier das Nobelviertel. Wenn Sie dann in so eine Kategorie von Haus investieren, und Sie das irgendwann verkaufen wollen, darum ging es mir. Und dann kriege ich das möglicherweise das Geld nicht mehr, und habe mich dann dagegen entschieden. Und ich ging dann zur $<<<$ Unternehmen anonymisiert $\gg>$, habe gesagt: ,Also, passt mal auf, für diese, keine Ahnung, eine Million oder eineinhalb Millionen würde ich gerne umplanen und würde gerne sechs Wohnungen bauen.“ Ich hatte da schon Material, ich habe zwei Grundstücke gekauft damals, und das habe ich von einem Bauträger, und der Bauträger hat keine zweigeschossige Bebauung genehmigt bekommen. Die wollten halt keinen solchen Bauträgermist da in diesem Viertel haben. Und deshalb hat er die Grundstücke verkauft. Habe ich gesagt, mache ich, wenn ich beide krieg. Und bin dann, habe mir ein Modell bauen lassen, zur Baubehörde, zum Herrn $<<<$ Name anonymisiert $>>>$ da von der Stadt, und habe gesagt: „Passen Sie auf, ich möchte da zwei Gebäude hinbauen.“ Habe halt gesagt, ok, fränkische Dachneigung und fränkischer Stil modern interpretiert, damit das da in die Landschaft passt. "Ja, waren Sie da vorher schon mal bei mir?" Dachte ich: „Oh, das geht ja schon gut los.“ Und dann haben wir uns aber ganz gut verstanden, und am Schluss hat er gesagt, na, lassen Sie mir doch mal das Modell da. Es ist natürlich schwierig, wenn man dem einen das absagt und dem anderen genehmigt. Dem genehmigt man das nicht und dem genehmigt man das. Da ist dann auch ein wenig Politik im Spiel dann innerhalb der Behörde. Auf jeden Fall 
hat das ein Jahr gedauert, dann habe ich das durchgekriegt, dass ich da zweigeschossig hinbauen darf. So. Und dann habe ich mich umentschieden, bin zur $<<<$ Unternehmen anonymisiert $>>>$ gegangen, habe gesagt: „Pass mal auf, $<<<$ Name anonymisiert $>>>$, wie ist denn das, wenn ich das ändere." Da hatte ich die Finanzierung für das Grundstück und für das Haus. Wenn ich das ändere und mache eine / zweigeschossig und mache das jetzt so. Es wurden dann fünf Wohnungen. Aufgrund der Stellplätze konnte man fünf Wohnungen bauen. Dann wurde das umgeplant. Da werde ich auch finanzielle Mittel brauchen. Ja, da müssen wir halt dann die erste Finanzierung kündigen gegen eine kleine Vorfälligkeitsentschädigung. Das Bauvolumen war quasi identisch. Das eine war halt ein wenig eine noblere Einfamilienhütte, auch auf zwei Etagen, und das andere wäre halt einfach ein paar Wände dazwischen. Und dann habe ich vom Plan weg schon eine Wohnung verkauft an jemanden vom Finanzamt. Und eine zweite, das war so eine Firma, die machen so Fördertechnik, nicht $<<<$ Unternehmen anonymisiert $>>>$, egal, für deren, weiß ich nicht, Schwiegervater oder irgendwas. Und dann hat die $<<<$ Unternehmen anonymisiert $>>>$ mir die Finanzierung verweigert. Der Architekt, der hat gesagt, ja, das läuft schon, und hat der Baufirma gesagt, ihr könnt schon anfangen. Die haben dann, ich fahr da eines Tages hin, da war eine Grube da mit einer Bodenplatte drin, mit einer Betonplatte. Und die $<<<$ Unternehmen anonymisiert $>>>$ hat mir keine Finanzierung gegeben. Begründung: Der, der für die erste Finanzierung zuständig war, den haben sie versteckt, an den bin ich nicht mehr rangekommen. Der war nicht mehr erreichbar. Die Begründung war dann, sie finanzieren keine Bauträgergeschäfte mehr. Also, mehr als zwei Wohnungen ist angeblich Bauträger, und wird dann anders kalkuliert oder was auch immer. Ich bekam keine Finanzierung. Ich hatte noch dieses Projekt in $<<<$ Ort anonymisiert $>>>$ laufen mit den neun Wohnungen, die Sanierung, bei der Sparkasse. Da konnte ich auch nicht hin. Und wenn eine Bank das nicht finanziert, dann kriegen Sie auch keine andere, davon können Sie ausgehen. Dann musste ich mit 300.000 Verlust dieses Projekt an die Baufirma verkaufen. Ich war dann in $<<<$ Erlangen anonymisiert $>>>$, bei den $<<<$ Unternehmen anonymisiert $>>>$-Leuten, zwei Damen, das sind so die Leichenfledderer, die mir das da dann abgerungen haben. Ich musste da noch irgendwie was zahlen und so weiter. War echt heftig. Und keiner hat mir vorher ein Wort davon gesagt. Dass ich das nicht finanziert kriege. Da hätte ich lieber die Einfamilienhütte gebaut, vielleicht ein bisschen abgeschwächt und hätte die verkauft 
oder was. Kein Wort. Nach dem Motto, wie heißt es so schön, in dem Werbespruch von der $<<<$ Unternehmen anonymisiert $>>>$, wir kümmern uns, leben Sie, wir kümmern uns. Und der $<<<$ Unternehmen anonymisiert $>>>$-Banker hat dann gesagt, ja, kümmern Sie sich darum, dann lassen wir Sie am Leben. Ja, ich glaube, das trifft mehr zu.

Ja, das ist das, dann war ich hier bei den Kammergesprächen in der IHK mal, und da war $<<<$ Name anonymisiert $>>>$, Vorstandssprecher der $<<<$ Unternehmen anonymisiert $>>>$ eingeladen. Da sind immer mal irgendwelche Vorstände, Politiker, wer auch immer. Und der hat erzählt, wie mittelstandsorientiert, kundenorientiert und super sein Scheißladen ist. Ich hatte so einen Hals. Ich war dann, hatte versucht über alle möglichen Leute da eine Lösung zu finden. War dann hier neben der $<<<$ Ort anonymisiert $\gg>>$ in der Bank, da war dann eine Dame im netten Kostümchen und irgendwo ein Typ, der hat dauernd gefragt, ob er das Fenster auf- oder zumachen soll, oder die Heizung rauf oder runterregeln. Der war scheinbar fürs Raumklima zuständig, keine Ahnung. Und denen habe ich das erzählt, habe gesagt, das ist wirklich eine Sauerei, was ihr hier treibt. Nichts zu machen. Dann habe ich dem $<<<$ Name anonymisiert $>>>$ einen Brief geschrieben. Ich habe gestern da, oder die Tage, ihren Vortrag gehört im Rahmen der Kammergespräche der IHK $<<<$ Ort anonymisiert $>>>$. Da haben Sie erzählt, wie toll, prima und, und, und, und ich habe das so und so und so erlebt. Und ich kann da nichts erkennen von mittelstandsorientiert und kundenorientiert. Und ich nehme ihn beim Wort, der Schaden lässt sich beziffern, er soll ihn bitte regulieren, ersetzen. Naja, dann habe ich vier Wochen nichts gehört. Ich habe ja dann die Freunde in $<<<$ Ort anonymisiert $>>>$ angerufen. Ja, es gab eine Vorstandsbeschwerde und so weiter, und es wäre ja alles korrekt, und es wäre ja alles in Ordnung. Dann sage ich: ,Ja, wenn es formal nicht, rechtlich nicht korrekt wäre, dann hätte auch nicht ich angerufen, sondern mein Anwalt. Es geht mir hier um Geschäftsethik und Verhalten, Moral und so weiter, und es ist unter aller Kanone.“ Ja, dann ist eben wieder nichts passiert. Dann habe ich den nächsten Brief geschrieben, habe mich auf mein Schreiben bezogen, und wann ich denn mit einer Antwort rechnen kann. Habe so ein bisschen Druck aufgemacht. Dann klingelte mein Telefon. Dann war ein, ja, ich weiß nicht mehr wie der hieß, auf jeden Fall, habe ich gefragt, langsam, langsam, jetzt sagen Sie mal, wer Sie sind, Name, Funktion. Ja, Vorstand $<<<$ Unternehmen anonymisiert $>>>$, der Immobilienvorstand $<<<$ Unternehmen 
anonymisiert $>>>,<<<$ Name anonymisiert $>>>$, genau, $<<<$ Name anonymisiert $>>>$. $<<<$ Unternehmen anonymisiert $>>><<<$ Ort anonymisiert $>>>$. Es geht da um die Geschichte und so weiter, und dann sage ich, ja. Und dann meinte er, was ich mir denn vorstelle. Und dann sage ich, einen Schadenersatz, lässt sich beziffern, 300.000. Überweisen Sie und gut ist es. Ja, nein und hin und her. Dann hat er mir irgendwie, man sei da juristisch sauber. Ja, aber wir brauchen nicht darüber diskutieren, was da abgelaufen ist, ist eine Sauerei, und das hat mit sauberer Geschäftsgepflogenheit nichts zu tun. Dann meinte er, ja, dass das nicht so ganz reibungslos lief, das ginge ja aus den Unterlagen hervor. Dann sage ich, ja, dreimal dürfen Sie raten, wer daran schuld ist! Dann meinte er, dass der Herr $<<<$ Name anonymisiert $>>>$ da ja nichts dafürkönne, er hätte irgendwie 3.000 Mitarbeiter. Sage ich, aha, ab wie vielen Mitarbeitern hat man keine Verantwortung mehr für das, was passiert? Ab 10 oder 100 oder erst ab 3.000? Auf jeden Fall hat er mir dann irgendwie ein paar Euro angeboten. Da habe ich gesagt, ich will keine Almosen, ich will einen Schadenersatz haben. Und dann habe ich ihn hängen lassen. Habe mir gedacht, vergiss das, du kriegst da keinen Cent. Und ich sagte, denken Sie darüber nach, melden Sie sich wieder. Nein für den Ding nicht. Und dann hat er sich wieder gemeldet nach einer Woche. Und dann hat er, glaube ich, 50.000 Euro oder irgendwas angeboten. Ja, mehr kriegst du nicht. Dann hat er gemeint, ja, mehr kann er nicht, und mehr will er nicht. Und dann hat mir der $<<<$ Unternehmen anonymisiert $>>>-$ Vorstand gesagt, ja, sie scheinen mir jünger zu sein, bei ihm würde schon der Altersstarrsinn einsetzen, hat er mir gesagt. Habe ich gesagt, das weiß ich nicht, das kann sein. Und da war gerade / da lief gerade die Übernahme von den Italienern. Die haben die $<<<$ Unternehmen anonymisiert $>>>$ übernommen. Und da sagte er, ja, das ist ein ungünstiger Zeitpunkt. Vielleicht können wir im Frühjahr nochmal reden usw. Dann habe ich gesagt, ok, und Sie laden mich zum Essen ein. Machen wir die 50.000 erst mal, da müsst ich noch was zahlen, hat er mich gefragt, ob ich das kann. Habe ich gesagt, ja, und Sie laden mich zum Essen ein. Ok.

Dann hat das ewig nicht funktioniert. Und dann wollte er mich in die Allianzarena einladen auf so eine Kundenveranstaltung. Ich sage, ich will nicht mit den Kunden da sein, will ja mit Ihnen und so. Naja, ok. Hat er gesagt, ja, die Sekretärinnen kriegen das nicht hin, dann müssen wir das irgendwie direkt ausmachen. Also, haben wir einen Termin ausgemacht, dann bin ich nach $<<<$ Ort anonymisiert $>>>$ gefahren, kam eine 
halbe Stunde zu spät, und er stand da mit seinem Regenschirm vor seiner komischen $<<<$ Unternehmen anonymisiert $>>>$. Und dann bin ich in seinen S-Klasse-Benz eingestiegen. Und dann sind wir da nach $<<<$ Ort anonymisiert $>>>$ in irgendsoeinen Nobelschuppen / da gefällt es sogar der Isis Berben. Das ist mit geschnitztem Gemüse und so / essen gegangen. Und dann sind wir da hingefahren. Und dann hat er mir erzählt / gefragt, was ich so mache. Und dann hat er gesagt, ja dann sind sie ja Berater, wie wir. Nein, wirklich nicht. Dann habe ich erzählt, also der $<<<$ Name anonymisiert $>>>$ ist ja nicht verantwortlich mit den vielen Mitarbeitern. Sie sind ja kein Bauträger, das ist ja nicht Ihr Kerngeschäft. Sie haben ja nur mal ein Haus gebaut. Und wenn wir uns vorher gekannt hätten, wäre es gar nicht so weit gekommen. Und lauter solche Aussagen, wo ich denke: „Ey, du Idiot.“ Ja, so ist das halt.

I: Und wie ging es dann aus? Haben sie noch was rausgerückt?

B: Ja, ja, diese 50.000 oder was, die hat er dann noch bezahlt. Aber mehr halt nicht. 50 waren es dann, oder sollen es 45 gewesen sein, Ich weiß es gar nicht mehr genau. Ja. Unsäglich. Dann war ich hier im $<<<$ Ort anonymisiert $>>>$, da waren wir in der Alumni-Sommer-Dings-Veranstaltung, und da spricht mich einer an, den ich nicht kannte und sagt: "Wir kennen uns. Haben Sie bei der $<<<$ Unternehmen anonymisiert $>>>$ mal gearbeitet?" (schreit, lacht)

\section{I: (lacht)}

B: Und dann war die Pause zu Ende, und die Veranstaltung ging weiter, da sagte ich: „Da erzähl ich Ihnen nachher eine Geschichte.“ Dann habe ich dem das erzählt. Ein Herr $<<<$ Name anonymisiert $>>>$, der hat mir dann gesagt: „Ja, einen Tipp, aber sagen Sie nicht, dass das von mir ist, so Geld direkt ist schwierig, weil die Filialen, da werde die Grundstücke verwertet und so. Aber was sie schon mal machen können, ist irgendwie einen Kredit rausgeben mit ganz niedrigen Zinsen oder irgendsoetwas, das machen die schon mal." Und ich soll mich da an einen Herrn $<<<$ Name anonymisiert $\gg>>$ wenden, das wäre so ein Oberpfälzer Bauernbub, und mit dem kann man da reden, der ist bodenständig, und da soll ich das mal probieren. Ok. Da müsste ich mich aber beeilen, weil der geht bald in Rente. Also, habe ich den angerufen, 
passen sie auf, so und so, ich hätte gerne einen Termin. Um was geht es denn? Naja, also ich habe nicht ihn sondern eine Sekretärin dran gehabt, das würde ich ihm gerne selber sagen. Ja, dann haben sie wieder angerufen, was denn? Sag ich ja, ok, der Herr $<<<$ Name anonymisiert $>>>$ freut sich auf einen Termin mit Ihnen. Termin bestätigt, alles prima. Zwei Tage vorher angerufen, der Herr $<<<$ Name anonymisiert $>>>$ hat keine Zeit. Kein Termin. Ok.

Dann hatte ich eine Einladung von der $<<<$ Unternehmen anonymisiert $>>>$ in $<<<$ Ort anonymisiert $>>>$ im Hotel, Mittelstandsblubblubblub. War ich da, $<<<$ Name anonymisiert $>>>$ auch da, Keynote-Speaker war der $<<<$ Name anonymisiert $>>>$ dann am Abend. Da saßen wir dann. Ja, da gab es unterschiedliche Themenworkshops und so was. Und dann saßen wir abends in der Runde beim Essen, $<<<$ Name anonymisiert $>>>$ hat einen Vortrag gehalten, dann hat er sich verabschiedet, der Herr $<<<$ Name anonymisiert $>>>$, hat gesagt, ja, er geht jetzt, wir sollen noch sitzen bleiben, ist ja so ein schöner Abend und bla bla bla. Ich wollte dann auch gehen, bin gegangen, bin dann auf die Toilette. Treffe ich den Herrn $<<<$ Name anonymisiert $>>>$ am Waschbecken. Sage ich, Herr $<<<$ Name anonymisiert $>>>$, tolle Veranstaltung, Kompliment, prima! Der Herr Wöhrl hat auch gesprochen und die Banker, und partnerschaftlich und rauf und runter und zusammen und gemeinsam. Habe ich gesagt: „Aber das, was ich so erlebe, passt gar nicht zu dem allen, was da heute hier verkündet worden ist."

„Ja was denn?““

Sage ich, ich versuche seit Wochen einen Termin mit Ihnen zu kriegen und kriege keinen. Ja wie, was? was? was?

„Ja, ist abgesagt worden ein paar Tage vorher, ein Tag vorher, das war Freitag.“ „Ja, reicht Montag noch?“

Und dann habe ich am Montag einen Termin gekriegt, habe ihm das erzählt, wie das alles abgelaufen ist. Und da sagt er zu mir: „Ja, das glaube ich Ihnen, ich merke ja, wie das aus Ihnen herausbricht. Das kann ich Ihnen sagen, ich habe mich schon oft für diese Bank geschämt.“

Was habe ich gekriegt? Die liegen noch drüben auf meinem Schreibtisch. Zwei Eintrittskarten für das $<<<$ Unternehmen anonymisiert $>>>$-Museum in $<<<$ Ort anonymisiert $>>>$. Und der $<<<$ Name anonymisiert $>>>$ war noch dabei, ein früherer Mitarbeiter im Controlling, der hat einen Bildband "Moderne Kunst und nicht Picasso" 
oder umgekehrt gekriegt. Und das war es. Er kann da nichts mehr machen. Und die Unterlagen sind alle verräumt und blubb blub blub blub blub. Der war auf der Systems gewesen, auf der Messe, das war davor noch. da hat er auch eine Einladung von mir gekriegt, im Carlton hier, auch so ein Mittelstandsding, ... (unverständlich)

Nachfolgeregelung und bla bla bla. Da kamen sie alle mit ihren dunklen Anzügen zum Akquirieren, auf mich zu. Und da habe ich dem einen, $<<<$ Name anonymisiert $>>>$ hieß der, die Geschichte erzählt. Da hat er gesagt, ja, das regelt er, und das ist ja eine Sauerei hier, und wir sollen jetzt wieder akquirieren, und da verbrannte Erde. Und wir sollen dann wieder irgendwie Geschäft generieren. Und er kümmert sich darum, und das geht nicht. Und da können Sie nichts dafür. Wenn man da einmal Bauträger nur gesagt hat, hat es allen schon die Nackenhaare gestellt. Also da war die $<<<$ Unternehmen anonymisiert $>>>$ vor der Pleite. Da ist die Aktie von 60 Euro auf 6 Euro gefallen. Ich weiß aus berufenem Munde, dass die mit Kurier Geld in die Zentrale geschafft haben. Die haben Objekte, die 18 Millionen wert waren, für 10 Millionen verkauft, nur um irgendwie Geld zu schöpfen. Da ist das natürlich vorbei. Da haben die ihre eigene Haut gerettet, und da sind ja Viele hinten runtergefallen. Auch solvente Bauträger haben keine Kredite mehr gekriegt, sind umgefallen. Ein paar Leute haben sich umgebracht. Und der hat sich dann halt / hochmotiviert war der da, was für mich zu tun. Ja, das ist im Sande verlaufen. Wenn der oberste Vorstand den Deckel draufgemacht hat, dann läuft der gegen die Betonmauer. Ja.

I: Aber die Finanzierung für das Haus in $<<<$ Ort anonymisiert $>>>$ haben Sie bei einer anderen Bank, oder?

\section{B: Sparkasse.}

I: Bei der Sparkasse. Genau. Da sind Sie zufrieden?

B: Ja. Also, das hatte damals. Das darf man gar nicht laut sagen. Das hatte damals der Banker, der und hier als Firmenbetreuer war, hat uns da auch für diese Immobilie die Finanzierung gemacht. Da sind wir reingefahren und haben dem die Unterlagen sortiert. 
B: Der war völlig überfordert. Der hatte überhaupt keinen Plan, was so Objektbaufinanzierung betrifft. Also, das war nicht in der Bauabteilung. Also, mit dem habe ich telefoniert, wo es auch mal irgendwie schwierig war, dann fragt der mich. Also, das kann man sich gar nicht vorstellen. "Sagen Sie mal, was Sie so machen, was machen Sie eigentlich?" Der, der sie betreut und ihr Unternehmen finanziert! "Ist das auch so was wie Excel?"

I: (lacht)

B: Da stehen sie da mit offenem Mund und denken sich, der entscheidet über Kredite über dein ach und weh! Wir hatten 10 Millionen Umsatz gemacht, wir hatten gerade mal bei der Commerzbank 200.000 ... (unverständlich) und bei der Sparkasse 300.000. Das ist nichts! Und die Commerzbank hat mein Elternhaus komplett verpfändet für 200.000 ohne Risiko. Und jetzt hat mich da irgendsoeine Tante da aus Mannheim angerufen im Rahmen dieser Insolvenzgeschichte und hat da auf blöd gemacht. Am liebsten hätte ich ihr gesagt, ja wenn der Staat nicht 15 Millionen da reingeschossen hätte, dann hätte diese Tante schon lang keinen Job mehr.

I: Das Haus in $<<<$ Ort anonymisiert $>>>$ haben Sie ja gesagt, konnten Sie retten, indem Sie es /

B: Nein. Ich habe am 8., kommende Woche, einen Termin mit Frau $<<<$ Name anonymisiert $\gg>>$ und mit meinem Anwalt bei den / bei der Sparkasse, mit jemandem von der Sparkasse. Und also, der hat einen ganz guten Ruf. Ich habe auch mit meinem Steuerberater geredet, der kennt den auch. Der ist ein ganz Vernünftiger. Und ich hoffe, dass das funktioniert. Weil ich weiß ja auch nicht, ob eine Bank einen gekündigten Kredit dann wieder neu beleben darf. Oder ob es da auch irgendwelche Vorbehalte gibt oder gar rechtliche Einschränkungen.

I: Ok. Na, da wünsche ich Ihnen auf jeden Fall viel Glück und Erfolg. 
Nachtrag zum Interview:

Wird am Ende etwas sentimental. Sagt also, ja, er hat es aufgebaut. Und wenn er nun auf seinen Ruhestand und sein Lebenswerk guckt, dann ist nichts mehr übrig. "Wie gewonnen, so zerronnen." 
Appendix XI: Transcript of Interview 10

I: Zu Beginn würde ich gerne einfach mal so Ihren Werdegang hören, beruflich und privat. Dass Sie mir einfach mal so in groben Schritten Ihre Lebensgeschichte bis heute schildern, damit ich Sie ein bisschen kennenlerne.

B: Ja, ich könnte das Ihnen auch aus dem Buch jetzt "Menschen, von denen man spricht", oder so ähnlich, habe ich eines da, kann ich Ihnen fotokopieren. Dann hätten Sie es leichter.

I: (lacht)

B: (lacht) Aber ich kann Ihnen sagen, ich bin als einziges Kind von den Eltern, die ein kleines Baugeschäft gehabt haben, in $<<<$ Ort anonymisiert $>>>$ geboren worden von $<<<$ Name anonymisiert $>>>$ und $<<<$ Name anonymisiert $>>>$. Mein Vater war ja lange im Krieg, und meine Mutter hat mich dann aufgezogen, und das größte Erlebnis war, wie ich mit fünf Jahren das erste Mal meinen Vater richtig gesehen habe in der Türe, wie er vom Krieg zurückgekommen ist. War einer meiner schönsten Tage oder Momente im Leben. Und dann bin ich halt hier im Kindergarten in $<<<$ Ort anonymisiert $\gg>>$ und dann in der Volksschule aufgewachsen bis zur vierten Klasse. In $<<<$ Ort anonymisiert $>>>$ war ich dann im Gymnasium. Habe bei Hausleuten gewohnt. Und danach habe ich ein Praktikum gemacht und bin nach $<<<$ Ort anonymisiert $>>>$ in die Fachhochschule, damals Staatsbauschule, und habe dann Architektur studiert. Habe dann noch ein zweites Studium. Ich bin 61 fertig geworden, also mit 21 Jahren. Habe dann noch Ingenieurbau studiert. Nach dem Ingenieurbau bin ich dann / wolle ich an und für sich nochmal / habe Verträge gehabt in der Welt / wollte ich nochmal durchforsten und wollte größere Bauvorhaben mitmachen und gestalten. Aber da ist dann leider meine Mutter mit 56 Jahren gestorben. Und da musste ich dann daheimbleiben, weil mein Vater alleine war mit dem Geschäft. Mein Vater war davor auch / da habe ich während der Schulzeit mal ein bisschen Sorgen gehabt, weil er mit Magenkrebs lange krank war. Und ich musste dann nebenbei zu meinem Studium auch das Geschäft etwas mitführen. Also, da musste ich dann also auch einsteigen. 
Und habe dann, muss ich sagen, sehr früh geheiratet mit 25. Habe heute, da bin ich stolz drauf, zwei hervorragende Buben, die ins Geschäft eingestiegen sind, die Geschäftsführer sind und Management führen. Und ich bin rechtzeitig zurückgetreten als Geschäftsführer und bin heute Prokurist. Habe das denen alles übergeben mit 59 Jahren, vorm 60. Habe davor allerdings, ein Jahr davor, ein Dilemma gehabt. Weil wir haben 1800 Leute beschäftigt gehabt. Ein ziemlich großes Bauunternehmen aufgebaut, von 18 Leuten auf 1800. Habe in Polen und Deutschland überall Fertigteilwerke große, z.B. den Reichstag geführt, das Objekt, und also sehr große Bauvorhaben. Da kann ich Ihnen dann mal einen Prospekt mitgeben. Können Sie mal sehen, was wir alles so geleistet haben. Und haben wir dann Konkurs gemacht, weil ich 276 Millionen bei Kunden mit meiner Gutmütigkeit verloren habe, wo ich auch gebürgt habe, z.B. in $<<<$ Ort anonymisiert $>>>$ alleine 138 Millionen verloren, weil der Bauträger Konkurs gegangen ist, und ich habe für ihn gebürgt. Und habe da in $<<<$ Ort anonymisiert $>>>$ das Werk da unten aufgebaut, $<<<$ Ort anonymisiert $>>>$, wo heute der $<<<$ Name anonymisiert $>>>$ ist, mit Bürogebäuden und Fertigteilwerken, auch Fertigteilwerk in $<<<$ Ort anonymisiert $>>>$. Und habe also etliche, auch in $<<<$ Ort anonymisiert $>>>$ Etliches aufgebaut. Und habe dann mal einen Tiefschlag. Habe dann wieder 2000 mit meinen Söhnen, wo ich das alles übergeben habe, angefangen. Und heute, glaube ich, haben wir noch eines der renommiertesten Bauunternehmen, vielleicht nach $<<<$ Unternehmen anonymisiert $>>>$ in $<<<$ Ort anonymisiert $>>>$ sicher eines der größten, die auch mit dem bayrischen Innovationspreis, mit dem oberfränkischen und hessischen Holzbaupreis usw. etliche. Haben jetzt in $<<<$ Ort anonymisiert $>>>$ wieder gebaut oder jetzt z.B. in $<<<$ Ort anonymisiert $>>>$ die Baumeisterhäuser, die der Gauck jetzt eingeweiht hat, oder eben die Frau Merkel die Grundsteinlegung in $<<<$ Ort anonymisiert $>>>$ mit einem großen $<<<$ Unternehmen anonymisiert $>>>$-Werk usw. Also wir haben doch Objekte durchgeführt, die schon wieder aufhorchen ließen, und wir haben heute wieder 450, also zurzeit fast 500, eigene Leute und vielleicht 800 , die für uns arbeiten. Mit meinen Söhnen und mit jungen Leuten und jetzt das Büro, werden Sie ja gesehen haben drüben, angebaut. Und läuft an und für sich jetzt, muss ich sagen, gut.

Meine Söhne sind besser wie ich, und zwar deshalb besser, weil ich habe sehr viele Nebenjobs gehabt, Kreisrat, Stadtrat, Obermeister der Bauinnung, Präsident des Fußballclubs, die ja bis in die Regionalliga gespielt haben. Ich habe in vielen 
Ausschüssen natürlich vom Arbeitsamt in dem Verwaltungsausschuss bis zum LVA bis zu allen Posten. Irgendwo hat man halt gedacht, der $<<<$ Name anonymisiert $>>>$ hat nie "nein" gesagt, und hat deswegen eben alles mitgemacht, was er machen sollte. Und hat eben, aber auch da möchte ich sagen, viele nicht gute Sachen erlebt. Denn ich muss sagen: "Tue manchmal nicht niemandem etwas Gutes, damit dir nichts Schlechtes widerfährt". Ich habe bei vielen guten Taten viele negative Erfahrungen gemacht, aber auch positive. Ich möchte also nicht die negativen überziehen, sondern ich möchte sagen, dass gute Taten auch belohnt werden. Weil ich habe viele Freunde. Und die Freunde haben mir damals gleich nach dieser Insolvenz, 2000, geholfen, mit nicht unerheblichen Beträgen. Und haben mich also sofort wieder / Weil sie gesagt haben, du musst weiter am Bau bleiben. Und ich meine, man kann im Ring hinfallen, man muss aber gleich wieder aufstehen. Man muss wieder weiterkämpfen. Und das ist, glaube ich, das Entscheidende im Leben, und das habe ich praktiziert. Mit 74, fühle mich heute mit 74 noch so wohl, dass ich jeden Tag meine 12-16 Stunden arbeite oft. Und auch wenn es sein muss Samstag, Sonntag, meistens sogar. Und Arbeit macht mir ja Spaß mit den jungen Leuten. Muss ich sagen, macht mir großen Spaß. Weil die sehr gut mitziehen. Und ich habe noch eine Tochter, die Regisseurin ist, die mit / Ich habe jetzt acht Enkel. Sie hat drei Mädchen. Und die anderen haben / ich habe allerdings sieben Mädchen und einen Buben als Enkel. Und fühle mich dadurch, ich habe sehr viel meiner Frau zu verdanken, die sehr viel Rücksicht genommen hat auf meine Tätigkeit und sehr viel Verständnis dafür. Das ist auch von ihrem Vater, dem Bein und Arm amputiert waren, Baugeschäft aufgebaut hat, das gelernt, und hat das miterlebt. Und deswegen hat sie also da auch sehr viel Rücksicht genommen und nimmt auch jetzt noch Rücksicht. Und so, muss ich sagen, führe ich an und für sich ein glückliches Leben und bete jeden Tag und bedanke mich beim lieben Gott, wenn ich Fahrrad fahre, früh eine Stunde, von halb fünf bis halb sechs, ich meine mal 10 Minuten rauf oder runter, und bete dort diese Stunde natürlich auch für meine Vorfahren, von den Eltern bis zu den Großeltern und Ureltern, und natürlich die im Geschäft auch nicht mehr da sind, die mir sehr viel geholfen haben. Und finde, mit diesem Grundriss fühle ich mich an und für sich ausgeglichen und muss sagen, was der Heinz Rühmann mal gesagt hat, den ich auch sehr als großen Schauspieler verehre, der gesagt hat, wie er mit 85 noch mit dem Flugzeug geflogen ist und Schauspieler gemacht hat, haben sie ihn gefragt, wie er sich da noch fühlt. Und 
da hat er gesagt: „Ich bin an und für sich zufrieden mit meiner Familie und mit dem Umfeld, mit Deutschland, mit allem, dass ich hier leben darf, und aus dieser Zufriedenheit fühle ich mich wohl." Und das muss ich auch sagen.

Ich habe vor drei Wochen das gesehen in Sizilien, wie die syrischen Asylanten ankommen, und da bin ich froh, dass ich hier gegen den Widerstand der $<<<$ Ort anonymisiert $>>>$ er mit da oben, diesem Asylheim, 160 Asylanten, überwiegend aus Syrien ein Heim gegeben habe. Wie ich das gesehen habe. Und habe dort denen einen Bolzplatz gebaut. Habe denen einen Spielplatz gebaut. Habe sie unterstützt. Meine Tochter mit Frauen gibt denen Deutschunterricht und so, und dass sie sich hier wohl fühlen. Und in den zwei Jahren, wo sie da sind, war nicht eine negative Erfahrung. Da können sich manche Deutsche eine Scheibe abschneiden. Es sind ja auch sehr intelligente Leute dort. Es ist ein Augenarzt dort, ist ein Vermessungsingenieur dort usw. Es sind also Leute dort, die wirklich auch was auf dem Kasten haben. Und man sieht, wie die aus diesem, möchte ich sagen, in diesem Verfolgungswahn dann hier von ihrer Heimat / Keiner geht gern von seiner Heimat weg. Und da kann ich mich auch fühlen. Ich meine, da war ich noch zu jung, um das richtig zu fühlen, wie unsere deutsche Landsleute vom Osten vertrieben worden sind. Und ich glaube, das sollte man heute nicht vergessen, und das vergessen viele. Ich glaube, man sollte wieder versuchen, mehr Menschlichkeit in unser Leben zu bringen, auch mehr Vertrauen und mehr Ehrlichkeit zueinander, mehr Offenheit und weniger Egoismus. So, jetzt habe ich ihnen, glaube ich, genug von meinen Einstellungen so ein bisschen gesagt, aber da habe ich so viel zu erzählen, das wäre sicher eine Nacht. Ich mache zurzeit die Biografie, macht mir eine Frau mit. Da habe ich ein paar Ordner gesammelt. Und die kann aber nur einen Teil von dem bringen, was wirklich abgelaufen ist. Ich bin z. B. von hier nach Rom gewandert. Bin mit dem Fahrrad von hier bis Sizilien gefahren. Bin nach Santiago de Compostela gefahren. Bin nach, wo ich ein Fertigteilwerk gehabt habe oder drei, zwei Fertigteilwerke, nach $<<<$ Ort anonymisiert $>>>$ gefahren. War in Marseille. Bin von Flensburg nach Marseille gefahren. Bin durch ganz Frankreich, Rhône, Loire, usw. Paris und das Ganze, durchgefahren ... (unverständlich) mit dem Fahrrad. Habe also sehr viel / bin ich jetzt wieder durch Polen gefahren. Jetzt wieder mal im September von Cádiz wieder rauf nach Rostock gefahren an der Neiße entlang usw. Also, ich versuche da mit Fahrrad oder mit Wandern Europa kennenzulernen in vielen Sachen. Und ich mache das jetzt, meine 
Frau kann das nicht so machen, und da fahr ich immer noch mal dazwischen mit der Aida, die ja diese Kreuzfahrten macht, wo sie dann jeden Tag an einem anderen Ort sind, den kennenlernen. Und da habe ich das eben in Sizilien gesehen, in Palermo unten, mit diesen Flüchtlingen. Ich bin da extra mal rausgefahren, habe mich vom Taxi rausfahren lassen. Und ich muss Ihnen sagen, das ist schon erschütternd. Wir dürfen alle froh sein, dass wir in Deutschland geboren sind. Dankbar sein, dass wir das Glück haben, hier leben zu dürfen.

I: Ja. Habe ich das richtig verstanden, Ihr Vater hat das Unternehmen gegründet?

B: Nein, mein Ur-Ur-Großvater.

I: Ach so.

B: Ja, schon 1881

I: Aha. Und wurde dann immer weitergeführt.

B: Ja. Immer weitergeführt bis zu diesem Crash. Aber da sind wir wieder aufgestanden mit meinen Söhnen, und innerhalb von einem Jahr waren wir wieder voll top da.

I: Aha. Was waren damals die Gründe für die Schieflage? Sie haben ja gesagt, Sie haben damals gebürgt für Bauträger.

B: Wir haben 272 Millionen durch Bauträger, konkurse Bauträger usw., verloren, weil wir Gelder nicht bekommen haben. 68 Millionen allein am Reichstag, den ich geführt hab, haben die uns nicht gezahlt. Aber dann, wie wir Konkurs waren, sind die ausgezahlt worden, aber dann hat sie der Insolvenzverwalter bekommen, und die haben natürlich alles zunichtegemacht.

I: Wenn Sie jetzt zurückdenken an die Insolvenz, was würden Sie heute anders machen? 
B: Ich weiß nicht, ob ich das anders machen würde, weil ich habe die Gutmütigkeit gezeigt, dass ich jemandem geholfen habe, mit dem ich gute Geschäfte gemacht habe, und der dann sich übernommen hat in Leipzig, und ich habe für ihn gebürgt. Aber ich würden nie mehr bürgen.

I: Also das war das Ausschlaggebende, was dann zur Insolvenz geführt hat?

B: Das war mit das Ausschlaggebende. Da habe ich allein, wissen Sie, 140 / Und musste das dann übernehmen, das Ganze. Und musste / habe dort / das hat uns fast eine Million jeden Monat gekostet. Und wenn Sie dann mal / wir haben auch enorm hier investiert gehabt / Und wenn Sie mal in diesem Schlingelkurs drin sind, dann kommen Sie nicht mehr raus, weil die Banken, die $<<<$ Unternehmen anonymisiert $>>>$, hat ja Ihres dazu getan. Da bin ich ein bisschen vielleicht ein Mollath-Geschädigter. Denn die wollten, wie ich mit der Bank mich angelegt habe, und ich denen ihre Fehler aufgezeigt habe, die sie bei mir gemacht haben. Davor haben sie Millionen verdient. Die haben ein Konto mit zehn Millionen nicht mehr gefunden, ein Festgeldkonto, plötzlich, und lauter so Sachen gemacht. Und haben mich da versucht in die Enge zu treiben, weil die Direktoren, die waren bei den großen Baufirmen, wie $<<<$ Unternehmen anonymisiert $>>>,<<<$ Unternehmen anonymisiert $>>>$, waren die in den Aufsichtsräten. Und die haben versucht dann das Unternehmen $<<<$ Unternehmen anonymisiert $>>>$, ist vielleicht ein bisschen zu frech geworden, wieder nieder zu machen. Und wie ich das klar gestellt habe bei denen, was sie für Fehler machen, das ist ja dann um 20 Millionen gegangen bei einem Vermögen von 680 Millionen, das ist ja kein Riesenbetrag. Aber die haben mich versucht, klein zu machen. Haben da auch noch jemanden eingesetzt. Und das würde ich nie mehr machen. Ich würde also nie mehr eine Bank in das Unternehmen reinlassen. Ich habe gesagt: „Das können Sie auch weiterführen, aber Sie sind unfähig.“ Und die wollten mich dann auch wie den Mollath, in eine Psychiatrie bringen.

I: Aha.

B: Ja, und haben versucht bei meinem Sohn Peter, weil ich denen die Meinung gesagt habe, und ist ja klar, ich bin ein bisschen ein forscher Mensch, der sagt, was er sich 
denkt, haben sie gesagt: „Ihr Vater, der müsste in die Psychiatrie. Wir kennen Ärzte. Den können wir in kurzer Zeit reinbringen." Weil ich Ihnen ein bisschen auf den Zahn gefühlt habe. Und genauso der Mollath, der gesagt hat mit dem Schwarzgeld, so habe ich das halt in die andere Richtung gesagt. Und dann haben sie versucht meinen Peter zu überzeugen, haben gesagt: „Peter, mit dem Vater werden Sie nie vorne dran an die Firma kommen, der lässt ja keinen anderen hochkommen." Es war aber gerade das Gegenteil. Verstehen Sie, von dem. Mein Sohn Peter hat das natürlich glatt abgelehnt. „Unterschreiben Sie das mal, Ihr Vater hat Ihnen doch sicher mal ein paar Ohrfeigen gegeben, oder ist ein bisschen gewalttätig geworden bei Ihnen, hat Sie mal richtig verdroschen oder wie irgendwo." Hat er gesagt: „Das hat er nicht gemacht. Deswegen brauch ich es auch nicht unterschreiben. Ich mache das nicht." "Na komm, das können Sie doch. und dann innerhalb von ein, zwei Tagen ist der in der Psychiatrie." Und dann sind sie zu meiner Frau, wie sie es beim Peter nicht fertiggebracht haben, und haben zu meiner Frau gesagt, sie geben ihr 9.500 DM Rente bis zu ihrem Lebensende, das waren damals DM, bis zu ihrem Lebensende, wenn sie das unterschreibt, dass ich mal bei ihr vielleicht auch mal ein bisschen gewalttätig war, oder sie vielleicht /

I: Was die Bank war das?

B: Ja, ja, die Bank.

I: Das ist ja Wahnsinn.

B: Der Herr $<<<$ Name anonymisiert $>>>$, hat er geheißen, kann ich ihnen sagen. Aber Gott sei Dank, stellen Sie sich mal vor, ich hätte mit meiner Frau ein schlechtes Verhältnis gehabt, ich hätte irgendeine Freundin gehabt oder irgendwas. Und sie hätte gesagt: „Na, dann haben wir den Alten weg, ich habe mich gesichert." Na, dann ist der weg. So war des mit dem Mollath. Genauso. Genau dasselbe. Tendenz. Und sie hat auch nein gesagt, klar, Gott sei Dank, weil wir uns ja verstehen. „Kommt gar nicht in Frage. Da können Sie mir Geld geben und anbieten wie sie wollen, mach ich nicht mit." Und dann, da bin ich damals nach Nepal, habe da eine vierwöchige Trekkingtour in den Himalaya gemacht. Und davor, da haben sie mir das natürlich erzählt, da bin ich natürlich erst mal ein bisschen "dieser Gauner, dieser Verbrecher!" Verstehen Sie, 
wie ich es erfahre. Und wie ich früh, da bin ich gejoggt, jetzt fahre ich Fahrrad, weil ich mich mit dem Knie ein bisschen mit dem Fahrrad fahren leichter tue, und dann habe ich mir natürlich überlegt, das musst du anders machen: „Sehr geehrter Herr Direktor $<<<$ Name anonymisiert $>>>$, ich habe nie gewusst, dass Sie sich so viel Sorgen um meine Gesundheit machen. Aber da Sie ja festgestellt haben, dass ich geistig nicht mehr normal bin, denn jeder glaubt ja geistig normal zu sein, werde ich jetzt vier Wochen in Nepal / bin ich im Zelt von einem Professor, Dr., mit dem war ich damals im Zelt mit, der wird mich genau beobachten und wird mich genau ärztlich beurteilen, ob ich geisteskrank bin oder nicht. Aber da Sie es festgestellt haben, erwarte ich, ich verweise auf das Bürgerliche Gesetzbuch, Wenn Sie mit einem Geisteskranken oder einem Betrunkenen ein Geschäft machen, oder einen Vertrag, ist der nichtig. Deshalb sind alle Verträge, die sie mit einem geisteskranken $<<<$ Name anonymisiert $>>>$, mit mir, gemacht haben, sind damit nichtig. Und bitte ich zu meiner Entlastung meinen Söhnen zurückzugeben. Mit vorzüglicher Hochachtung, Ihr dankbarer $<<<$ Name anonymisiert $>>>$. “

I: (lacht)

B: Dann sind sie gerannt am nächsten Tag, da war ich aber dann schon im Flugzeug nach Nepal. Da lachen sie heute noch über den Brief. Und haben das nicht fertiggebracht, verstehen Sie. Da haben sie sich verarscht gefühlt von mir, ist ja klar. Ich habe da wirklich das umgedreht, Gott sei Dank, habe ich auch daraus gelernt, dass man auf solche Sachen nicht / Verstehen Sie, wenn ich jetzt runter wäre und hätte mich da aufgeführt, dann hätten sie nichts Einfacheres gehabt zu sagen: "Schauen Sie mal, wie der sich benimmt. Ja, es führt jetzt / Der Mann, der ist so weit. Denn bringen wir so weit, oder haben wir so weit gebracht." Verstehen Sie?

I: Ja.

B: Weil ich war ihnen ein Dorn im Auge. Und ich muss Ihnen offen sagen, wenn jetzt Direktoren von einer Bank freigesprochen werden, wie jetzt in Hamburg, die Milliarden vertan haben. Wenn ich das als Unternehmer gemacht hätte. Es war ja bei mir eine saubere Insolvenz. Das hat ja der Staatsanwalt gesagt, so eine saubere hat er 
noch nie erlebt, mit allem. Die Firma war top, in einem top Zustand, und das hätte es nie gebraucht. Wenn sie da mit dazu gehalten hätten, wäre die Firma ja weiter in der Form gehalten, verstehen Sie. Und wenn diese Leute, die wirklich mit solchen Methoden versuchen, Menschen nieder zu machen. Und nicht sich duellieren mit ihnen auf der Ebene der Fairness, dann muss man sagen, und dass die dann frei, und spricht die frei, Also echt. Ja, wissen Sie warum? Das kann ich Ihnen / ich habe das ja alles schon nachrecherchiert, wie das ist. 70 - 75 \% der Parteigelder sind Bankgelder. Und die wiederum, die Partei mit der Regierung hat das Justizministerium. Und die Richter werden vom Justizministerium befördert, sind abhängig. Also, jetzt brauche ich Ihnen nicht mehr viel erzählen, wie die ganze Sache abläuft, die Soße. Ich habe damals auch versucht, diese zehn Millionen zu bekommen. Das Gericht ist überhaupt nicht drauf eingegangen. Das hat sich hinter die Bank gestellt. Verstehen Sie? Da kannst du nichts machen. Der Richter, der ist dann befördert worden nach Karlsruhe in den Bundesgerichtshof. Der Richter, der uns dann abgeurteilt hat, negativ. Also, wissen Sie, da verlieren sie den Glauben an eine faire, demokratische Behandlung.

I: Ja.

B: Daraus habe ich auch viel gelernt. Ich habe auch wieder kürzlich gelernt mit dieser Kommunalwahl, wo so viele Unwahrheiten verbreitet worden sind. Ich habe ganz bestimmt genug Leuten geholfen in meinem Leben, ich will das jetzt nicht aufzählen, was da alles / Ich versuche, jedem zu helfen. In jedem Verein, ich bin allein in 108 Vereinen. Da können Sie sich also vorstellen, was ich da bis jetzt / und bin mindestens gerade bei 60 Vereinen Ehrenmitglied.

I: Aha.

B: Ja, da können Sie sich schon vorstellen, dass ich da Einiges gemacht habe, vereinsmäßig oder auch sonst, weil ich die Leute, die in Vereinen sind und Vereine führen mit Kindern und mit Jugendlichen, ob das Sportverein ist oder ob das Schachclub ist oder ob das Rotkreuz ist, wo ich da auch schon 160 Mal Blut gespendet habe. Oder sonst was. Verstehen Sie? Diese Leute muss man unterstützen, die solche ehrenamtliche Tätigkeiten machen. Und da sollen sich dann Abgeordnete, und da bin 
ich auch mit dem Stadtrat angeeckt, weil wir haben immer 15 Euro, das war maximal, Sitzungsgeld, und die haben sie jetzt erhöht auf fast 200 Euro im Monat. Und ich sage jetzt, so viele Vereinsvorsitzende machen das ehrenamtlich, unentgeltlich, dann muss man von einem ehrenamtlichen Stadtrat verlangen, dass er es normal auch unentgeltlich macht. Denn ich kann dann gleich in die Stadtratssitzung, kann dann mein Kuvert aufmachen, und dann sagen, schnell abstimmen, schnell, ich muss wieder heim. Verstehen Sie? Und kassiere mein Sitzungsgeld. Das kann der Vorstand, der einen Turnverein oder so was führt, der kann das nicht machen. Der muss sich echt hinsetzen und muss arbeiten. Verstehen Sie, das ist das, was ich verurteile, dass viele Menschen nicht mehr diese ehrenamtliche Tätigkeit richtig würdigen, richtig unterstützen. Und deswegen kommen auch so viele Vereine in die Schieflage. Ich könnte da auch wieder ein paar Sachen erzählen, die so unfair laufen. Ja, ich habe da draußen ein Stadion gebaut von meiner Lebensversicherung, muss ich sagen, von dem Geld habe ich ein Stadion gebaut mit 20000 ... (unverständlich). Ich weiß nicht, ob Sie es schon gesehen haben, da draußen steht das. Da oben, kann man von da auch sehen.

I: Aha.

B: Da ganz oben am Wald. Da wo die Masten sind.

I: Ah, ja.

B: Das ist ja nicht $<<<$ Ort anonymisiert $>>>,<<<$ Ort anonymisiert $>>>$ spielt in $<<<$ Ort anonymisiert $>>>$ Fußball.

I: Aha.

B: Auch jetzt spielt $<<<$ Ort anonymisiert $>>>,<<<$ Ort anonymisiert $>>>$ gegen $<<<$ Ort anonymisiert $\gg>$ am 19. Juli in dem Stadion.

I: Aha. Schön. 
B: Aber solche Sachen, oder wie Stadthalle usw. Aber das ist alles, wissen Sie, man nimmt ja nichts mit, mit 80, da nimmt man nichts mit. Wie hat ein alter Politiker immer gesagt: „Junger, ich habe noch nie einen Leichenwagen mit einem Anhänger gesehen."

I: (lacht)

B: Und darüber muss man, verstehen Sie, da muss man realistisch darüber nachdenken. Deswegen tut mir das auch nicht weh, wenn man da was verloren hat oder sonst was. Man hat es wieder neu aufgebaut, aus.

I: Hm. Und nochmal zur Insolvenz an sich. Was war so der Punkt, wo Sie gedacht haben, jetzt ist es soweit, jetzt muss ich Insolvenz anmelden? Wann haben Sie das so richtig realisiert?

B: Da war ich nicht da. Da war ich in Nepal.

I: Ach das war da. Ok. Hm.

B: Und das musste mein Sohn machen, weil ich war ja draußen. Ich bin ja dort frühzeitig rausgegangen. Ich war ein Jahr im Geschäft nicht mehr drin. Weil sie mich ja nicht mehr wollten, die Banken.

I: Ok. Also, es hat sich praktisch im Vorfeld schon weng so zugespitzt.

B: ... (unverständlich) Wir haben vielleicht 300 Millionen Aufträge gehabt. Wie ich ein halbes Jahr draußen war, haben sie bloß noch 20 Millionen Aufträge gehabt. Verstehen Sie, ich hab ja so viele Beziehungen, Verbindungen gehabt, dass ich die Aufträge immer geholt habe. Aber die wollten ja nicht mehr. Ich war ja denen ihr Feind, weil ich die Banken, die dann die Macht übernommen haben, wie sie reingekommen sind, 50\% haben denen ja dann vom Betrieb gehört.

I: Wieso kam es da überhaupt dazu? 
B: Na weil die 20 Millionen, die ich gebraucht / Wissen Sie, ich habe / Die Bauträger haben kein Geld mehr bezahlt. Die sind Konkurs gegangen. Und ich habe jeden Tag eine Million gebraucht. Und wenn sie jetzt mal 20 Tage kein Geld bekommen, dann sind sie gleich 20 Millionen hinter. Da haben mir die Banken gesagt, nein nix, geht nicht, kriegst nix.

I: Das war praktisch so der Anfang von der Schieflage, und die wollten das ausnutzen.

B: Die haben das ausgenutzt.

I: Hm.

B: Und haben versucht, mich da wegzukriegen, weil ich gesagt habe, wie ihr das macht, macht ihr das Unternehmen $<<<$ Unternehmen anonymisiert $>>>$, das wirklich top war / Sie können sich ja vorstellen, wenn wir den Reichstag gebaut haben und solche Sachen. Das war in einem Topzustand. Da können sie sich ja vorstellen, dass man da / ja, wir haben solche Objekte gebaut, wir haben zum Beispiel in Erfurt die einzige Radrennbahn der Welt in Beton gebaut. Wir haben das Polizeipräsidium in Frankfurt gebaut. Wir haben überall, verstehen Sie, haben wir neue Fertigungen und gebaut mit der Gutenberggalerie in Leipzig mit dem geschliffenen Beton ... (unverständlich) auch jetzt noch. Sonst würden wir auch jetzt nicht wieder Preise bekommen. Wir haben den Löwen, zweimal als einziges Bauunternehmen zweimal den Bayrischen Löwen jetzt bekommen als einer der besten, also fifty, the fifty best of Bayern, wo wir als einziges Bauunternehmen drin waren.

I: Aha.

B: Ich meine, das hat ja Gründe. Geht ja nicht von alleine.

I: Ja. Und wie war das dann. Sie waren in Nepal, und was ist dann genau passiert?

B: Ja, dann hat mein Sohn mit der Bank Konkurs angemeldet. Weil das Geld / 
I: Wussten Sie das?

B: Ich habe es erfahren im Flugzeug heimwärts.

I: Ok.

B: Dann bin ich heim, und da haben mich meine Söhne in Frankfurt abgeholt und haben gedacht, ich dreh da durch, oder irgendwas. Habe ich gesagt: „Jungs, das ist einfach, wir setzen uns in zweieinhalb Stunden, sitzen wir in $<<<$ Ort anonymisiert $>>>$ an einem Tisch und dann überlegen wir das, was wir da draus am besten machen. Dann geht's weiter.“

I: Aha. Und wie ging es dann weiter?

B: Sofort. Sofort haben wir gegründet wieder neue Firma, und haben sofort weitergemacht.

I: Was war das für eine Firma dann? Sie hatten ja keine Privatinsolvenz, oder? Das war eine reine Firmeninsolvenz.

B: Jawohl.

I: Und dann haben Sie eine neue Firma gegründet zu dritt /

B: Und habe sehr viel, muss ich sagen, von Bauherrn, die wieder mit mir weiterbauen wollten, Geld im Voraus bekommen.

I: Aha. Die haben Sie unterstützt.

B: Das habe ich alles wieder zurückbezahlt, und die haben wir / Sie brauchen ja da flüssige Mittel, sonst bekommen Sie ja kein Material und nichts. 
I: Ja.

B: Und da habe ich mit einem Kern unserer Leute weitergebaut. Die waren sofort dabei.

I: Aha, Schön.

B: Und das war innerhalb von einer Woche, ist das Geschäft schon wieder voll gelaufen. Weil ich ja Beziehungen gehabt habe, und das haben die nicht gedacht.

I: Ja.

B: Ich habe ja da in $<<<$ Ort anonymisiert $>>>$ damals, wie sie mir mit den Banken / ich war ja mit der $<<<$ Unternehmen anonymisiert $>>>$, wie sie da / Da habe ich gesagt: „Ja, pass auf, führt ihr das Unternehmen $<<<$ Unternehmen anonymisiert $>>>$ weiter, und ich fange vollkommen eine neue Firma an. Wenn ihr sagt, ich bin nicht fähig das Unternehmen zu führen.“ Ja, da haben sich die aufgeführt. Der $<<<$ Name anonymisiert $>>>$ ist da um den Tisch gerannt und hat gesagt, ich mache das Bauunternehmen $<<<$ Unternehmen anonymisiert $>>>$ kaputt. Dann sage ich: „Ihr müsst doch froh sein, wenn ihr sagt, ich kann es nicht führen, und ich gehe raus freiwillig, und sage, ich fange ein neues Geschäft an, und ihr wisst, ich kann es nicht, dann kann doch das euch nicht irgendwie stören." Aber anscheinend haben sie gemerkt, dass sie es eben nicht können.

I: Ja.

B: Wissen Sie, es gehört im Leben auch ein bisschen mehr dazu, wie nur sachlich und fachliches Können. Es gehört auch Menschlichkeit dazu. Und das glaube ich, wird heute im Leben auch etwas vergessen. Wissen Sie, wo ich das, ich meine, das ist zwar jetzt ein weiter Bogen, aber ich habe den Kohl ja kennengelernt am Reichstag. Und ich habe gewusst, was für ein großartiger Mensch der Helmut Kohl ist. Der mit dem Gorbatschow die deutsche Wiedervereinigung / Zwei Männerfreunde. Und ich weiß, was heute Männerfreundschaft bedeutet. Die zwei Männerfreunde, die haben die 
deutsche Wiedervereinigung begründet. Was hat der Gorbatschow für einen Dank bekommen? Der hat nicht mal ein Prozent der Wähler bekommen von Russland damals als Ministerpräsident. Und der Gorbatschow hat Großartiges für Russland geleistet. Und deswegen wollte ich sagen, was ein Mann, oder was irgendein Mensch leisten kann oder bewegen kann, wenn er Leute um sich herumhat, die ihn unterstützen.

I: Hm.

B: Den Gorbatschow habe ich damals gehört, da war ich ja in $<<<$ Ort anonymisiert $\gg>$ öfters, und ich habe da Vorträge gehört, der hat gesagt, er ist in den Kreml rein, und er hat gesagt: „Wir wollen die deutsche Wiedervereinigung, wir wollen die Deutschen wieder ein Volk lassen.“ Da haben die gesagt: „Was? Michael, überleg dir das. Jetzt hast du die Möglichkeiten, die Deutschen platt zu machen. Mach sie platt!“ Sie müssen ja überlegen, in $<<<$ Ort anonymisiert $>>>$, wo wir ... (unverständlich) gebaut haben ... (unverständlich) da waren 120 oder 125 Flugzeuge in Betonshets gestanden mit Atomraketen, Kampfflugzeuge. Wenn der die 120 oder 125 nach Deutschland, da hätte kein Mensch aufgehalten. Rübergeschickt, wenn er hätte die Atomraketen losgelassen, da wäre Deutschland heute kein Deutschland mehr. Das müssen Sie sich mal vorstellen, wie nahe das war. Und jetzt müssen sie das mal überlegen, was Männer, was Menschen an und für sich bewegen können, wenn sie entweder positiv denken, positiv handeln oder negativ handeln. Sie sehen es ja jetzt in Palästina, Sie sehen es jetzt in Syrien. Verstehen Sie, sie sehen ja jetzt was Menschen / Ich halte ja auch von Putin etwas mehr, als wie es dargestellt wird. Der Putin, die Russen haben ja viel verloren. Sie müssen ja mal überlegen, das ganze Russische Reich, das war ein riesen Reich. Es hat ja alles zu Russland gehört, ob die Ukraine ob Weißrussland usw. und Lettland, Estland, Litauen und und und, hat ja alles zu einem Reich gehört. Und das hat ja der Gorbatschow zerschlagen. Der Gorbatschow hat gesagt, das geht nicht mehr so weiter. Wir müssen das aufgeben. Wir müssen die Leute einzeln wieder bestimmen lassen. Wir müssen sie einzeln entwickeln lassen. Das ist ja eine riesen demokratische Leitung gewesen, politische, mit einem Mann. 
I: Und haben Sie sich auch immer unterstützt gefühlt in ihrem Leben durch ihre Familie oder durch ihre Freunde?

B: Erstens natürlich durch meine Familie, meine Frau, meine Familie. Ja und ich habe mich unterstützt gefühlt mit vielen Freunden. Ich habe Freunde gehabt, die haben sich abgesondert.

I: Als das mit der Insolvenz war?

B: Ja. Aber sehr viele Freunde habe ich auch weiter gehabt. Denen ich früher viel geholfen habe. Aber ich habe auch Leuten geholfen, die sich dann abgewendet haben.

I: Wegen der Insolvenz dann?

B: Ja.

I: Wie erklären Sie sich das?

B: Dass die Menschen/ Ich habe hier einen, dem habe ich so viel geholfen, der so viel hochgekommen ist. Den habe ich unterstützt und Sachen abgenommen, und die Grundstücke versorgt und so weiter. Der hat sich total danebenbenommen. Auch mein Nachbar hat sich danebenbenommen, schwer danebenbenommen. Heute spielt er wieder den Freund. Aber ich weiß genau, was dahintersteckt. Es gibt eben Menschen, die Egoisten sind, und es gibt Menschen, die wissen, wen sie auch ihre Dankbarkeit zeigen müssen.

I: Und inwiefern hatten Sie das Gefühl, dass sich der Umgang mit Ihnen verändert hat durch die Insolvenz oder während der Insolvenz? Sind die Leute anders mit Ihnen umgegangen in der Zeit?

B: Manche. Ein Teil.

I: Inwiefern? 
B: Ein Teil, dass sie sich also distanziert haben, und dass sie einfach / Also, ich möchte sagen, vielleicht zwei Drittel hat sich auf meine Seite gestellt und ein Drittel hat sich abgewandt.

I: Und wie haben Sie die Zeit persönlich empfunden?

B: Ich muss Ihnen offen sagen, ich habe zu meiner Frau gesagt: „Das ist wie ein Baum, der sehr groß war, der sehr viele faule Äste gehabt hat, sehr viele neue Äste, der Betrieb. Die sind jetzt abgesägt. Und die frischen Äste, die wir dazu erhalten, die bilden wieder einen neuen Baum. Und deswegen sei froh“" - das versteht sie immer nicht - „Sei froh, dass es so gekommen ist.“ Wissen Sie warum? Ich muss Ihnen offen sagen, ich war ja tagtäglich bis in die Nacht rein immer unterwegs mit dem Konferenzbus und so weiter. Ich weiß nicht, ob ich heute noch leben würde, wenn ich nicht insolvent gegangen wäre. Also, es hat auch eine gute Seite. Verstehen Sie. Ich habe ja gesagt, wie der Baum. Es gibt Bäume, die verfaulen, wenn man sie nicht der morschen Äste entledigt. Und das ist halt da passiert. Es war sehr viel /

Ich habe einen riesen Fehler gemacht, dass ich vielleicht versucht habe, so ein Unternehmen obwohl ich ... (unverständlich) meine Söhne, allein zu führen. Heute weiß ich, dass im Betrieb auch der Peter, dass er sehr viel verteilt, sehr viel Verantwortung verteilt. Und dadurch läuft der Betrieb besser. Verstehen Sie. Nicht dass man versucht, dass vielleicht alles zu organisieren und zu machen und jawohl, jawohl, jawohl. Sondern sagen, so, komm, das ist deine Aufgabe, das erledige du jetzt und zeige es mir, wenn du es fertig hast.

I: Also, wenn ich Sie richtig verstehe, hat jetzt im Nachhinein betrachtet die Insolvenz durchaus auch ihr Gutes für Sie gehabt.

B: Natürlich, immer. Man muss immer das Gute daran sehen. Natürlich. Ich finde, der Besitz / Wir haben ja so viel besessen / das ist ja wurscht. Aber mit dem kannst du ja nichts anfangen. Verstehen Sie. Man muss ja immer, wie ich gesagt habe, das Menschliche / Wir waren so groß, dass man vielleicht / Ich mein, da war ja damals die Baukrise / dass man einfach mit Gewalt irgendwas nicht aufhalten kann, was man 
nicht verändern kann. Man soll also nicht irgendwas mit Gewalt versuchen zu verändern, was nicht veränderbar ist. Und das war so. Verstehen Sie. Mit diesen vielen Baustellen. Wir haben Baustellen gehabt eben, wo kein Geld eingegangen ist, wo dann dieser Bauträger Konkurs gemacht hat, wo die anderen / Verstehen Sie. Und das kannst du nicht überbrücken.

I: Und hat sich jetzt Ihr Leben durch die Insolvenz verändert, wenn man jetzt mal das Unternehmen ausblendet?

B: Ja.

I: Inwiefern?

B: Dass ich mehr zu mir selber gefunden habe. Dass ich noch mehr zur Familie gestanden bin. Und, ähm, ich feiere nächstes Jahr goldene Hochzeit. Dass es alles gefestigt hat. Und dass ich an und für sich auch mehr den Menschen zuhöre, mehr Zeit mir für andere Menschen nehme, die ich früher nicht gehabt habe. Ich finde das positiv.

I: Schön. ja. Ähm, und nochmal zurück zum Ende der ersten Firma quasi. Was war denn an der Abwicklung der Insolvenz die größten Probleme oder Hürden oder Schwierigkeiten? Gab es da irgendetwas, wo Sie sagen, das hat viel Zeit gekostet, das hat viel Nerven oder Mühe gekostet?

B: Ja, die größte Mühe, die größte Zeit an und für sich, waren das Misstrauen der Banken. Und, die also kein Vertrauen dazu gehabt haben. Und von Menschen, die sehr gut verdient haben, und plötzlich der Firma den Rücken gedreht haben. Das waren an und für sich meine Enttäuschungen. Aber mit denen habe ich mich an und für sich nicht so befasst. Sondern ich habe gesagt, lern daraus und arbeite mit den Leuten zusammen, die halt zu dir halten.

I: Und wie whichtig war aus Ihrer Sicht in dieser Phase der Insolvenzverwalter, die Rolle und die Person des Insolvenzverwalters? 
B: Ich muss Ihnen sagen (seufzt, kurze Pause), der hat kein Vertrauen gehabt zur Betriebsleitung und zu mir. Und da sind einige hundert Millionen verblasen worden. Zum Beispiel das in $<<<$ Ort anonymisiert $>>>$. Da haben wir eine Kiesgrube habe ich da gekauft. damals sehr günstig gleich nach der Wende. Das war mindestens ein Wert von 110 Millionen. Die habe ich vielleicht gekauft für 300.000. Riesenkies. Das ist an der $<<<$ Ort anonymisiert $>>>$. Da kann man Kies 27 Meter hoch abbauen. Ohne / Also riesen/ das wird ja heute noch/ Das machen sie ja heute noch oben. Die sagen ja immer noch Chef zu mir. Ich wenn alle Jahre oder was mal rauf komme, die rollen fast den roten Teppich aus. Und die rufen mich auch immer an, könnten wir / wie sollen wir so machen, wie sollen wir das machen? Ich wollte nur sagen, das sind riesen Vermögen. Und der Insolvenzverwalter, der hat das verkauft um 50.000 oder was. Auch die zwei Werke. Der war froh, dass er sie losgehabt hatte. Bloß schnell ein Geld. Der hat also nicht das Vertrauen gehabt, dass er gewusst hat, wo unwahrscheinliche Reserven des Betriebes liegen.

I: Also, er hat sich da auch nicht mit Ihnen abgestimmt?

B: Ich war Feind. Ich war für ihn ein Feind. $<<<$ Name anonymisiert $>>>$. Verstehen Sie, und das war falsch. Ich wollte ja nur helfen. Aber, da war öffentlich einmal in der Zeitung gestanden: , $<<<$ Name anonymisiert $>>>$ bietet sich als Hilfe an". Ja, war groß drin, aber, weil er's nicht so gemacht hat, aber er hat es nicht gebraucht. Verstehen Sie, die haben alle gedacht, sie sind intelligenter, können es besser machen. Und heute sind sie neidisch, weil es wieder läuft. Aber ist ja gut so. Da hat mich natürlich auch der Ehrgeiz gepackt, zu zeigen, dass es ja wir wirklich können. Und das ist das Gute. Verstehen Sie, es kommt immer nach einer Niederlage kommt / kann immer auch wieder mal ein Erfolg kommen. Und das ist auch gut so. Und man muss halt wieder aufstehen. Man muss wieder kämpfen. Man muss halt / man kann nicht irgendwas regeln mit Nikotin und mit Alkohol oder sonst was, sondern man muss es halt mit harter Arbeit regeln.

I: Und Konkurs angemeldet haben Sie, haben Sie ja gesagt 2000. 
B: Ja.

I: Wie lange hat sich das dann hingezogen?

B: Bis heute noch.

I: Das läuft heute noch?

B: Ja, freilich.

I: Ach so.

B: Ja, freilich. Der Insolvenzverwalter, der hat ja noch viel Geld. Der hat ja noch viel Geld von der Firma $<<<$ Unternehmen anonymisiert $>>>$. Heute noch, nach 14 Jahren noch. Nach 14 Jahren hat der noch Leute beschäftigt und verwaltet das Vermögen der insolventen Firma $<<<$ Unternehmen anonymisiert $>>>$. Und schreibt jedes Monat Rechnungen, und zieht von dem Vermögen das Geld raus. Und das macht er so lange, bis nichts mehr da ist.

I: Aha.

B: Ja, das macht der noch 20, 30 Jahre.

I: Aber das Unternehmen wurde ja nicht mehr weitergeführt.

B: Nein.

I: Nur das Vermögen wird verwaltet.

B: Freilich.

I: Ich dachte, das wird alles verkauft um die Gläubiger zu bedienen. 
B: Ja, der hat verkauft und das Geld angelegt. Und von dem Geld lebt er. Insolvenzverwalter sind die größten Haie.

I: Und die ganzen Leute, die noch Ansprüche hatten, die sind wohl alle bedient?

B: Eben nicht. Das wird ja eliminiert. Der zahlt ja nichts aus. Der macht so lange bis halt eines Tages kein Geld mehr da ist. Dann sagt er, meine Herren, ich habe kein Geld mehr. Ich kann euch nichts mehr geben. Schön, oder? Das ist eine feine Sache.

I: (lacht) Jetzt bin ich baff.

B: Das ist wirklich so. Der Richter, bei dem ich mal beim Geburtstagsessen dabei war, der hat gesagt, Herr $<<<$ Name anonymisiert $>>>$, wie ich ihm das geschildert habe, ja Mensch, wären Sie doch zu mir gekommen, ich hätte das nie unterschrieben. Der muss ja das immer unterschreiben bei einer Insolvenz. Der legt den Bericht vor, und der unterschreibt. Dann hab ich ihm das mal erklärt. Dann war er ganz außer sich, und er hat gesagt, ich bin jetzt pensioniert. Ja, sagte ich, wenn ich da damals gekommen wäre, hätte Sie mir das geglaubt? Hätten Sie dem Insolvenzverwalter geglaubt, oder hätten Sie dem $<<<$ Name anonymisiert $>>>$ geglaubt?

I: Und was hat er gesagt?

B: Ja, so wie ich Sie kennengelernt habe, hätte ich wahrscheinlich Ihnen geglaubt. Ja, sagte er. Aber, weißt du nicht. Nicht? Das ist halt immer eine Frage, nicht? Bitte. Der wird halt / Aber wissen Sie, da wird der Insolvenzverwalter / Der hat ja schon / Ein halbes Jahr davor habe ich einmal die Papiere drüben durchgeschaut, und da war bei dem, der von der Bank, der drin war, war dringestanden: Firma $<<<$ Unternehmen anonymisiert $>>>$ zerschlagen. Und Insolvenzverwalter wäre der $<<<$ Name anonymisiert $>>>$ in $<<<$ Ort anonymisiert $>>>$. Da haben schon ein halbes, dreiviertel Jahr die Banken das vorbereitet. Ist immer darauf hingetrieben worden. Da wie ich zu dem Bank/ zu dem $<<<$ Name anonymisiert $>>>$ gesagt habe: „Schauen Sie mal, Herr $<<<$ Name anonymisiert $>>>$, schauen Sie mal raus. Ich habe da 160 Millionen investiert, neue Einrichtungen, neues Fertigteilwerk, Designbeton und und und." 
Da hat er gesagt: „Herr $<<<$ Name anonymisiert $>>>$, das ist 0 Mark wert, wenn Sie morgen nicht mehr da sind."

„Danke", habe ich gesagt. „Deswegen habe ich ein Unternehmen aufgebaut und beschäftige 1800 Leute, damit ich von Ihnen so eine Antwort bekomme." Verstehen Sie / ist das nicht traurig? Von der Seite haben Sie es noch nicht angeschaut, oder?

I: Ja. Sie haben vorhin gesagt, dass sich ihr Leben und auch teilweise die Beziehung zu anderen Leuten verändert hat durch die Insolvenz. Hat / Würden Sie auch sagen, dass sich ihre Persönlichkeit verändert hat?

B: Das kann man natürlich / man kann ja selbst sich nicht beurteilen. Beurteilt wird man immer von anderen. Das ist ja / man kann ja selbst nicht wissen wie man ist. Ich meine, meine Sekretärin sagt, die hat mich ja schon früher gekannt, wie sie als junges Mädchen da war / jetzt weiß ich es / die hat gesagt: „Sie haben sich unwahrscheinlich positiv verändert. Sie sind viel ruhiger, menschlicher, sachlicher geworden." Ich glaub das ihr auch. Habe ich schon gesagt, wie ist das, wie fühlst du dich? Sagt sie: „Blendend, mit dir zu arbeiten ist für mich ein Gedicht. Ist wirklich ein Lebensgedicht" ...(unverständlich) das muss man ihr sagen. Sie ist ein paar vierzig Jahre alt. Hat als junges Mädchen hier gelernt. Und haben sie mir zugeleitet, muss ich sagen ist ein Glücksfall. Die kann es am besten beurteilen. Die kann am besten sagen, wie ich früher war, und wie ich jetzt bin. Also, ich glaube aber persönlich, dass ich ruhiger geworden bin, nicht mehr so hektisch. Dass ich abgeklärter, dass ich auch zum Teil menschlicher geworden bin. Dass ich mehr, immer mehr die Arbeit meiner Mitarbeiter, mehr anerkenne, wie vielleicht früher. Weil ich zu viel drüber wegmusste. Weil ich zu viel, zu viel zu entscheiden gehabt habe, in Sekundenschnelle. Weil ich jetzt das mit dem Mitarbeiter besser besprechen kann, Entscheidungen. Nicht? Das kann ich an und für sich / ich kann mit meinen Söhnen über Entscheidungen sprechen / ich kann mit anderen / kann aber meine Meinung auch / ändere auch meine Meinung. Adenauer, der mir ein großes Vorbild ist, der hat immer gesagt: „Was interessiert mich mein Geschwätz von gestern? - Wenn ich heute anderer Meinung bin?" Also wenn ich überzeugt werde von Leuten. „Pass mal auf du warst auf dem falschen Weg." Nicht? Dann muss man das auch akzeptieren und muss dankbar sein. Kritik um sich herum, oder als Chef / oder als mein Peter oder Thomas, immer wieder Kritik um euch herum, 
das sind die Besten Miterbeiter. Nicht die, die das sagen, was ihr gern hören möchtet, sondern die das sagen, was sie erkennen, und manchmal, wenn es euch auch mal nicht passt. Und das ist an und für sich das, was ich auch dadurch eher gelernt hab. Also deswegen durch die / ich sage die Insolvenz birgt auch sehr viele positive Seiten. Nicht? In Amerika sagt man immer: „Ein guter Unternehmer muss ein oder zwei Mal in die Insolvenz gehen, um ein guter Unternehmer zu werden." Man muss auch selbst einmal, ab und zu einmal eine Backpfeife bekommen. Ich meine mit Backpfeife mein ich eben, dass es nicht so geht wie man denkt. Nicht? Um vielleicht zu erkennen, dass man sich auch selbst anders verhalten muss.

I: Würden Sie sagen, dass das Deutschland und Amerika unterscheidet in der Sichtweise, oder dass man das in Deutschland auch so sieht?

B: Ich meine Amerika / sind ja immerhin, ich glaube ja 30 oder $35 \%$ Deutsche Nachkommen. Muss man immer wieder sagen. War ja ziemlich deutlich, sie wissen ja, damals die, die Abstimmung mit der deutschen und englischen Sprache war ja ganz eng. Deutsch / Amerika hat den Vorteil, dass der Bürokratismus und die Gesetze viel lockerer sind wie in Deutschland. Und dadurch, können sie es sich ja mal überlegen, ist in Amerika / Wenn sie sagen / die haben ja in den fün- / 1850, glaub ich, 1860 war doch der Bürgerkrieg oder? Nicht? Waren doch die Bürgerkriege? In hundert Jahren hat ja Amerika die Entwicklung durchgemacht, die in Deutschland fast 2000 Jahre gebraucht hat, und Europa. Bis zur Demokratie. Und zur Entwicklung. Und wenn Sie mal überlegen, was da in Amerika an Leistung / ob das alles richtig war oder nicht, ist eine zweite Frage / was hier alles an Infrastruktur, also ich meine jetzt Straßen, Kanäle, Brücken und und und / und Gebäude und so weiter gebaut worden ist, in hundert Jahren. Nicht? Ist ja nur da möglich gewesen / ich sage immer ob es gut ist oder nicht / da steht eine gotische Kirche neben einem Hochhaus und sonst / weil die Freiheit des Menschen, die ihm gegeben worden ist, sich zu entwickeln, viel größer war wie in Deutschland. In Deutschland durch die Demokratie, durch das eingeengte rechts/ möchte ich sagen / von Beamten, durch diese Einschnürung / ist vielleicht einmal gut, aber was ich jetzt merke bei Bauherren. Es wird vielen Bauherren auch wieder der Mut genommen, was zu unternehmen oder zu bauen. Durch diese Überbürokratie. Wenn ich heute in Amerika baue, dann kann ich natürlich mit einem 
Architekten mit irgendeinem Bauvorhaben. Dann werden die Beteiligten eingeladen in einen Saal. Dann wird das Bauvorhaben vorgestellt. Dann kann ein jeder seinen Kommentar dazu sagen. Wird in der Aktennotiz verfasst, jeder, der will das, der will das. Dann wird darüber diskutiert, und nach fünf, sechs Stunden wird das unterschrieben, und er kann morgen das bauen anfangen. Das ist in Deutschland überhaupt nicht möglich. Das gibt es Bauvorhaben, die laufen drei, vier, fünf Jahre bis zur Genehmigung. Verstehen sie? Und da vergeht der Mut und der Wille des Bauherrn. Letztendlich ist ja jedes Bauobjekt auch von dem Mut und dem Willen des Bauherrn abhängig. Wenn der sagt: „Ich mag nicht mehr, steigt mir doch dem Buckel rauf. Die verlangen ja von mir so viel und so viel Unterlagen und so viel Belastungen und so viel Abfindungen und, und, und. Die können mich doch. Ich nehm mein Geld und tu es in die Schweiz." Verstehen sie? Das ist das was, was Deutschland auch in Zukunft wirtschaftlich, irgendwann zu schaffen machen wird. Diese Entwicklung, die Erneuerung / Das wird dann alles in Gesetze, weißt, da gibt's die DIN-Normen. Und du musst dich genau nach den DIN-Normen verhalten, sonst darfst du nicht so bauen oder so Maschinen konstruieren und so weiter. Das ist aber Krampf. Verstehen Sie? Eine Entwicklung von einem Volk geht ja mit Erneuerungen. Und Erneuerungen kannst du ja nur, wenn du die vorhandenen Vorschriften auch mal überschreitest oder änderst. Sonst kannst es ja gar nicht experimentieren. Ob das anders, besser läuft.

I: Ja.

B: Das wird einfach hier / wird man einfach in ein Korsett gesteckt, wo der Einzelne in seiner Entwicklung, in seiner Erfindung, mit seinem technischen Knowhow und, und / einfach eingeengt wird. Wenn er sich anders verhält, dann bekommt er gleich einer „Du hast da verstoßen, du hast dort verstoßen“ - Bumm, einer auf den Dötz. Da sagt er: „Soll ich das noch? Oder steig ich aus?" Wie viele steigen aus in Betrieben? Das ist besorgniserregend. Da kommen dann Aus- / schauen sie die Ausländer kaufen zurzeit die deutsche Wirtschaft auf. Im großen Stil. Ich bin ja in ganz Deutschland unterwegs. Ich seh das. Das ist nicht positiv für uns. Warum, weil die dann auch in der Entwicklung eben eingeengt werden. 
I: Ein Gesprächspartner hat zu mir einmal gesagt, als er über seine Insolvenz gesprochen hat: „In Deutschland gibt es keine Kultur des Scheiterns." Das es also da eher da als Makel gesehen wird, sowas. Das wäre / läuft ja eigentlich in diese Richtung. Dass man praktisch / das das der große Unterschied wäre.

B: Natürlich. Weil es immer wieder / Hört man immer wieder. Der Bürgermeister, wie ich im Stadtrat war, weil ich war 40 Jahre im Stadtrat. Also nicht öffentlich, und ich habe ihn angegriffen. Habe gesagt: „Das machst du verkehrt oder das." Hat er gesagt: „Du Insolvenzler, du Konkursmacher, sei ruhig." Habe ich gesagt: „Du bist doch mehr in Insolvenz, du hast ja mehr Schulden wie Vermögen. Du kannst dich ja bloß deswegen aufrechterhalten, weil die Bürger ja für die Stadt bürgen." Die bürgen für die Stadt. Verstehen Sie, deswegen kann die Stadt gar nicht Konkurs machen. Aber nominell hast du ja mehr Schulden wie Vermögen. Da sei doch ruhig!

I: Was hat er dann gesagt?

B: Naja, dann hat es halt eine Debatte gegeben. Aber ist doch so. Verstehen Sie, als Politiker, wenn ich mehr Schulden habe wie Vermögen, dann bin ich ja insolvent. Na, sobald ich an diese Grenze komme, mehr Schulden zu haben wie Vermögen, muss ich als Geschäftsführer Insolvenz anmelden. Sonst mache ich einen betrügerischen Bankrott. Da wenn Sie jetzt hergehen und bestellen bei mir meinetwegen ein Hochhaus da draußen so für fünf Millionen und sagen: „Bau einmal, ich gebe dir einen Auftrag". Dann müssen Sie ja wissen, wie das finanziert ist. Wenn Sie das aus blauem Dunst sagen: „Naja, da mach ich halt mal was. Wie das finanziert ist, interessiert mich momentan nicht.", machen Sie sich des betrügerischen Bankrotts / sind Sie im Gefängnis. Der Politiker, der Stadtrat, der Bürgermeister in $<<<$ Ort anonymisiert $>>>$, der vergibt jetzt Millionenaufträge, hat noch gar keinen Haushalt. Verstehen Sie, hat gar keine Deckung, interessiert den gar nicht wie das ist. Verstehen Sie, das ist doch unmöglich! Oder?

I: Ja. 
B: Und da muss ich sagen / Des hat jetzt eine Frau, die Bürgermeisterin, die Frau $<<<$ Name anonymisiert $>>>$, die ich auch sehr schätze, die hat gesagt, heute steht es in der Zeitung: „Ich kann nicht mehr ausgeben, wie ich einnehme. Ich kann mit meinem Haushalt, mit meinem Privathaushalt nicht Geld ausgeben, wenn ich das nicht weiß, dass ich das einnehme oder verdiene. Aber den Bürgermeister vor mir, den hat das anscheinend gar nicht interessiert." Ich ziehe jetzt / Da sage ich: „Respekt vor der Frau." Das ist eine Lehrerin. Respekt vor der Frau, die da klaren Mut zeigt und sagt: „Leute, ich kann es nicht. Ich kann euch das jetzt nicht machen, weil halt das Geld nicht da ist." Finden Sie nicht auch, da muss ich / Ja, unsere Merkel hat es auch nicht interessiert. Die hat ja auch den Griechen Milliarden gegeben und hat nicht gewusst, wie es finanziert wird. Oder den Banken. Wie vielen Banken hat sie geholfen! Das ist dasselbe. Und da müssen Sie sich vorstellen, da sind sie auf die Idee gekommen, eine Bad Bank / Haben Sie das richtig mitgekriegt?

\section{I: Nein.}

B: Ich tue die Schulden der Commerzbank, gründe eine Bad Commerzbank, also eine schlechte Commerzbank, und gebe da die Schulden rüber, und fahre mit der anderen Bank gesund weiter.

I: Das habe ich nicht mitbekommen.

B: Haben Sie nicht? Das haben die gemacht. Das ist ja für mich ein Betrug am Bürger. Das ist ja Betrug! Also, Sie haben Schulden. Sie sagen jetzt, Sie machen eine Bad Person. Und dann fahren Sie mit der anderen Person himmeljauchzend weiter. Stellen Sie sich mal vor. Da haben sie so viele bad Banks gemacht. Das ist doch nicht zu glauben, wie die mit unserem Geld spielen. Die Deutschen merken das gar nicht. Also die Merkel, also ich meine, ich bin an und für sich / nicht dass ich jetzt Frauen / Ich sage, wie die $<<<$ Name anonymisiert $>>>$ da als Bürgermeisterin, Respekt. Nicht aber unsere Merkel. Der Herr Gutenberg, der kommt außerdem in 14 Tagen zu mir. Der Gutenberg da, der Theodor. Oder ein März oder ein Koch oder ein Biegenkopf oder ein Späth und so weiter, was die für Leute, die wirklich gute Politiker sind, was die verheizt hat und weggedrückt hat. Verstehen Sie, sie sind ja nur so gut wie die Leute, 
die um Sie herum sind. Ich könnte jetzt mit Ihnen nicht beruhigt diskutieren, wenn ich weiß, dass bei mir oder bei uns so viel schiefgeht, und dass meine Söhne das nicht machen und andere Mitarbeiter. Da könnte ich ja gar nicht mit Ruhe diskutieren. Da wäre ich ja schon wieder in Aufregung. Machen die das richtig oder so. Die muss doch froh sein, wenn sie solche Leute hat. Die auch kritisch zu ihr sind. Ich weiß es von Guttenberg.

I: Ja das wissen viele nicht zu schätzen.

B: Kritische Leute um sich zu haben. Die sind nur so gut / und der Kritiker ist ja der Gute. Der merkt das ja. Der merkt, was der Fehler ist. Ich habe vorhin wieder einen auf die Schulter geklopft, hab gesagt: „Mensch das hast du prima gemacht. Hervorragend gemacht." Nicht? Weil er auch kritisch war.

Hat gesagt: „Chef, das kann man doch nicht so machen. Ich wüsste eine bessere Lösung."

„Prima," habe ich gesagt, „Mach das so, sehr gute Idee". Da mach ich mir doch nichts $\mathrm{ab} /$ da brech ich mir doch kein Zahn ab, wenn ich sage: „Ich habe davor eine schlechtere Idee gehabt". Oder? Bin ich deswegen ein schlechter Seniorchef? So Prokura unter meinen Söhnen. Habe ich gesagt / Bin ich deswegen schlechter? Wenn ich einmal sage, ich habe keine so gute Idee gehabt wie der Mitarbeiter?

I: Ja, da haben sie recht.

B: ... (unverständlich) Ich habe mit der Jungen Union diskutiert / vom $<<<$ Ort anonymisiert $>>>$ einmal. Hat angefangen um 19 Uhr, habe ich einen Vortrag gehabt, war das Fernsehen mit dort. Und wissen Sie, wann wir das diskutieren aufgehört haben? Nachts um halb zwölf. (lacht) Da ist keiner fort.

\section{I: Schön}

B: Und da war draufgestanden in der Zeitung ganz groß: ,, $<<<$ Name anonymisiert $>>>$ auf der Achterbahn". Weil ich auch gesagt habe, was ich für Fehler gemacht habe, die sie nicht machen sollen. Und was ich gut gemacht habe ...(unverständlich), und so 
weiter, verstehen Sie. Wie ich schon gesagt habe „Achterbahn". Man ist ja auch im Leben auf einer Achterbahn. Das Leben ist eine Achterbahn. Oder wie der Bürgermeister sagt, er warnt die meisten meiner Bevölkerung von den guten Taten eines $<<<$ Name anonymisiert $>>>$, damit sie von ihm nicht abhängig werden. Müssen sie sich mal vorstellen. Nicht? Und da sage ich, abhängig sind wir alle voneinander. Wir brauchen einen Arzt, wir brauchen einen Mechaniker, wir brauchen einen Metzger, wir brauchen einen Bäcker, wir brauchen einen Textiler. Nicht? Wir brauchen / Wir sind alle voneinander abhängig. Wenn die alle nicht mehr wollen, sind wir arme Menschen. Sie gehn jetzt raus oder was und brechen sich ein Bein, brauchen sofort Hilfe, brauchen sofort einen Rotkreuzler oder irgendwas. Nicht? Wir sind abhängig. Wir sind abhängig, dass wir richtig im Krankenhaus behandelt werden. Vom Arzt, von der Versorgung von allem. Sind vielleicht Schwestern verantwortlich, ...(unverständlich) dass die die richtige Arznei hergibt und so weiter. Sind ja alle abhängig. Wir sind alle voneinander abhängig. Und da manche Egoisten sagen: „Ach, ich brauch doch keinen anderen, ich bin doch der." Das ist falsch. Wir sind von jedem anderen Menschen abhängig. Weißt, in der Familie abhängig auch. Sind von ihren Eltern abhängig, dass die sie richtig behandelt haben. Dass sie sagen / ich weiß ja nicht ob sie schon verheiratet sind oder irgendwas.

I: Am 23. August ist es soweit.

B: Sehen sie, ja da sind sie von ihrem Mann abhängig. Sind sie ganz bestimmt abhängig.

I: Ja.

B: Wenn der sie schlecht behandelt, nicht? Ich sag ja bloß, sie sind von ihrem Mann abhängig dann. Sehen sie? Sehr schön find ich das. Wenn Sie Kinder haben, dann sind Sie für die Kinder verantwortlich. Die Kinder aber auch wieder von der Mutter abhängig und von den Eltern.

I: Ja, hängt alles zusammen. 
B: Verstehen Sie. Wir sind voneinander abhängig. Also, so ein Quatsch, was der da erzählt. Also, ich mein, der fliegt halt bei mir jetzt raus, nicht? Der kommt nicht mehr rein, wenn der solche Aussagen macht. Und sagt, er warnt die Leute. Von den guten Taten ...(unverständlich). Das zeugt ja nur von Dummheit. Hat 30 Semester und hat nicht fertig studiert, hat keinen Abschluss. Das sagt doch alles, oder? Sagt doch alles. Mit 42 Jahren keinen Abschluss. Naja, haben wir diskutiert. Haben Sie noch Fragen?

I: Gut. Ich bin durch mit meinen Fragen.

B: Habe ich alles beantwortet?

I: Möchten Sie noch etwas loswerden?

B: Nein, ich wollte nur sagen, dass ich Menschen, die sich für irgendeine Allgemeinheit sich opfern wie zum Beispiel in Nepal / Ich bin auch bei der Nepalhilfe aktiv. Wie gesagt, ich bin über hundertacht, glaube ich, Vereine sind es. Da gehört auch die Nepalhilfe dazu. Menschen, die zum Beispiel Jahresurlaube nehmen und nach Nepal gehen und im Lepra-Krankenhaus arbeiten unentgeltlich. Ich finde so viele Deutsche / ist ja nicht nur / das sehen Sie ja bei den Spenden immer, die sehr hohe Spendenquoten haben / dass es sehr viele Deutsche gibt, die ehrenamtlich sich opfern und Zeit opfern / sich menschlich / sich einfach für andere Menschen einsetzen, finde ich großartig. Und sehr viele, die auch in Nepal / gerade in Nepal kennengelernt / viele, oder auch in der Türkei, Laos / und würde es für gut halten, wenn sich viele Menschen das überlegen würden, auch auf diese Pfade der Nächstenliebe, der Unterstützung, der Arbeit für andere sich auch zu opfern und die Zeit zu opfern. Sie bekommen es absolut wieder zurück. Ich sage nur beim Blutspenden, wo ich öfters einmal reden musste. Ich habe gesagt: „Wer auf dem Krankenbett liegt und braucht zur Erhaltung seiner Gesundheit fremdes Blut, der könnte kein fremdes Blut bekommen, wenn es nicht Blutspender geben würde, die für andere bereit sind Blut zu spenden." Oder auch bereit sind, auch ehrenamtlich die vielen Bergwachtler, wie jetzt dieser Höhlenforscher gerettet worden ist. Großartig, großartige Menschen, wie ein Böttrich, der wie heißt der mit Vornamen schnell wieder? Der sich da mit unten / Tag und Nacht mit unten war, als Arzt und hat da mitgeholfen. Wenn es jetzt nicht solche 
Menschen geben würde, stellen sie sich mal vor die wären / Wenn du jetzt in so eine Notlage kommst wie diese Höhlenforscher, wärst du verlassen.

I: Ja, das stimmt.

B: Und da drüber sollte an und für sich jeder drüber nachdenken, sollte auch Menschen gerade wie jetzt zum Beispiel die syrischen Asylanten unterstützen. Was ich da erlebt habe. Ich bin des Lebens bedroht worden, wegen des Asylheimes da oben, gleich da neben dem Stadion.

I: Weil Sie das gebaut haben sind die bedroht worden?

B: Weil ich es zur Verfügung gestellt habe. Bedroht worden.

I: Aha.

B: Hat eine Frau gesagt: „Jetzt müssen wir unsere Garage zusperren." Habe ich gesagt: „Du, sei ruhig, denk einmal über dein Leben nach." Die hat nämlich LidlVerbot bekommen. Edeka-Verbot, weil sie gestohlen hat. Und dann muss sie zu anderen sagen, sie muss jetzt die Garage zusperren. „Du, sei ruhig!" 
Appendix XII: Transcript of Interview 11

I: Mir wäre es am liebsten, wenn Sie einfach mal damit anfangen, ihren Werdegang zu schildern von Geburt bis heute in groben Zügen beruflich und privat.

B: Das ist aber eine ganz schön lange Zeit, nicht?

I: Macht nichts.

B: Wie viele Stunden haben Sie denn mitgebracht?

I: Ich habe heute nichts anderes vor. (lacht)

B: (lacht) Naja, gut. Wie gesagt, ich habe Schulausbildung das Abitur. Danach bin ich nach $<<<$ Ort anonymisiert $>>>$ gegangen und habe dort Forstwirtschaft studiert und habe nach einer Unterbrechung bei der Bundeswehr dann letztendlich auch abgeschlossen. Bin dann weitergegangen und habe dann die große forstliche Staatsprüfung abgelegt bei der Staatsforstverwaltung und bin dann schließend 10 Jahre beim Staat gewesen als Forstbeamter des höheren Dienstes, oder Beamter des höheren Forstdienstes heißt das ja.

Zwischenzeitlich habe ich dann kurz nach dem Staatsexamen geheiratet. Habe dann in der Zeit dieser 10 Jahre zwei Kinder bekommen. Und das ging eigentlich alles ganz gut los, bis ich dann /

Ich habe mich aber nie so richtig wohlgefühlt beim Staat. Das war nicht meine Welt. Das war alles zu eingeengt mit viel zu vielen Vorschriften ausgestattet, mit vielen Vorschriften, die auch unsinnig sind nach meinem Dafürhalten, viel zu umständlich. Und man hat, wenn man frei arbeiten will und sich eigene Gedanken macht, hat man viel zu wenig Freiheit. Das ist so mein Eindruck gewesen. Vielleicht ist es speziell da der Fall, aber ich sehe das heute in anderen Verwaltungen ähnlich. $\mathrm{Na}$, jedenfalls habe ich immer nach Möglichkeiten gesucht, mich selbstständig zu machen, auszusteigen. Und das war dann so. Da war ich dann 38. Hab bei dem damaligen riesen Windwurf in 1990, Wiebke war das damals mit 60 Millionen 
Festmeter über ganz Deutschland verteilt, was umgefallen ist, Einblicke erhalten in die Verträge, die es da gegeben hat mit den Unternehmen, die vor allem aus Skandinavien geholt worden sind mit den Maschinen, die bei uns da noch nicht eingeführt waren und auch abgelehnt worden sind durch die Bank, weil es auch bei uns falsche Maschinen gegeben hat. Habe mich dann, ja, informiert. Und habe dann gesehen, dass es eigentlich, wenn überhaupt, jetzt der richtige Zeitpunkt ist, abzuspringen. Weil es ist jede Menge Auftragspotential dagewesen. Ich habe so ein bisschen Insiderkenntnisse gehabt über die Verträge, über die Preise. Ja, gut, dann habe ich halt geschaut, ob ich a) Verträge kriege und b) ob ich die Investitionen irgendwie regeln kann. Und das war damals eine Million Mark netto, also ohne Mehrwertsteuer. Und das war schon ein Batzen und auch ein heftiger Schritt von der sicheren Beamtenstelle - ich war ja schon Lebenszeitbeamter gewesen - raus in die freie Wirtschaft. Aber ich habe es einfach nicht mehr ausgehalten. Ich habe da in diesen 10 Jahren / Drei mal bin ich versetzt worden, immer an Stellen, die, ich sage mal, wohl etwas hervorgehoben waren. Aber trotzdem, ich wollte ja nicht. Ich wollte raus sein. Ich wollte eigentlich was machen. Ich wollte irgendwo ein Forstamt leiten und führen. Und da hätte ich, ich sage mal, was bewirken können, ja? Da hätte ich gesehen, was ich tue. Aber das kann man ja in Stellen wie in der Forstschule oder in der Waldarbeitsschule oder, ja, auch vielleicht in einer Zentralenstelle nicht. Da hat man halt Papierkram und fertig, ja? Das war nicht mein Ziel, und deswegen bin ich auch weg. Das war auch einer der Gründe. Ja gut, und dann ging das halt los. Und dann habe ich über all die Jahre, insgesamt 23 Jahre, habe ich die Firma aufgebaut. Wir haben zum Teil mit Subunternehmen bis zu 50 Leute beschäftigt gehabt. Wir haben, ja, bis zu 7 - 8 Millionen Mark Jahresumsatz gehabt mit einer relativ kleinen Besetzung. Also, es ging ganz gut eine Zeit lang.

I: Ok. Und was genau hat die Firma gemacht?

B: Wir haben Holzeinschläge in Dienstleistung gemacht, haben dann auch Holzgroßhandel gemacht. Das heißt, was die Waldbesitzer zu veräußern gehabt haben, das haben wir angekauft und weitergegeben an unsere Großkunden. Also, Holzindustrie, Sägewerke, Papierindustrie, Spanplattenwerke, ja? Und das war nicht nur in Deutschland, das war auch international, Österreich, das war Tschechei. Ich war 
auch in Frankreich, ich war in Schweden. Also, ich bin ein bisschen rumgekommen dadurch. Und es hat, ich sage mal, meinen Blick schon etwas geweitet. Das war ganz gut. War ich auch sehr zufrieden. Aber es war natürlich mit Arbeit, mit Stress, mit zeitlichem Einsatz und manchmal auch mit großer Anspannung verbunden, weil es halt auch um einen Haufen Geld ging, ja? Und das Unangenehme ist bei dem Ganzen a) man halt also immer mit großen Summen zu tun, aber die Margen sind zum Teil so klein, dass man aufpassen muss, trotzdem was übrig zu haben, ja? Das ist das Eine. Das Zweite ist, sie haben in dem Geschäft nie eine konstante Auslastung. Das heißt also, sie hangeln sich von Auftrag zu Auftrag. Und leider Gottes ist über die Jahre das so dann gewesen, dass die Aufträge immer kleiner geworden sind, die Konkurrenz immer größer, die Preise immer kleiner geworden sind, ja? Und, ich sage mal, an Stelle dessen, dass die Auftraggeber irgendwann einmal gesagt haben: „Oh, der ist gut, und den nehmen wir, und da müssen wir gar nicht groß rumschauen", ist es also so gewesen, dass die Ausschreibungen immer mehr Firmen zugelassen haben, um ja korrekt zu sein, ja? Aber nicht beachten, dass es ja so ist, dass trotzdem alle Unternehmen irgendwo was kriegen. Und dann hat es den sogenannten Unternehmertourismus gegeben. Da fahren die Bayern nach Nordrhein-Westfalen, die Nordrhein-Westfalen nach Sachsen, die Sachsen dann nach Hessen oder sonst wohin. Also, es ist völlig widersinnig, ja. Verursacht nur Kosten und letztendlich hat das die ganze Branche in den Ruin getrieben. Wir haben also gerade in dieser Branche, die ich dann mit vertreten habe, fast kaum eine Firma, die gesund ist. Ja. Das ist so geblieben.

I: Und war Ihnen das, dass es so schwierig ist in der Branche, schon bevor Sie sich selbstständig gemacht haben, bewusst? Oder mussten Sie das dann erst feststellen und lernen?

B: Mir war da gar nichts bewusst, ja? Auch wenn ich ein Beamter war, der recht gut beurteilt war, dann muss ich sagen, war ich in einer anderen Welt. Als Beamter ist man in einer anderen Welt. Von der freien Wirtschaft keine Ahnung, ja? Und vor allem es waren viele einfache Dinge des täglichen Wirtschaftens, des täglichen, ja, was man zu tun hat auch. Die ganz normalen praktischen Dinge draußen, die waren mir nicht bekannt, obwohl ich sie natürlich hätte wissen müssen. Aber so etwas kriegt man beim Staat nicht mitgeteilt. Kriegt man auch nicht rüber, weil wie gesagt, sie leben - 
zumindest bei dieser Verwaltung - in einer Welt für sich, die auch heute noch meint, sie ist was ganz Besonderes. Das ist sie auch, aber nicht in dem Sinn, wie sie es meinen. (lacht)

I: (lacht)

B: Ja. Als, ich war da / Das schwierigste Jahr war das erste Jahr, muss ich sagen, wo ich niemanden hatte, wenn ich jetzt nicht wusste, ob es jetzt richtig ist, oder nicht, wo ich nachfragen konnte. Beim Staat, da können sie dann bei der vorgesetzten Dienststelle anrufen oder bei irgendeinem Sachbearbeiter. Die wissen das dann schon oder vielleicht auch nicht. Dann fragen sie halt weiter, ja? Und so ist es, jedenfalls kann man die Verantwortung weiterschieben. Das können sie als Selbstständiger nicht. Da sind sie für alles verantwortlich. Und wenn sie es nicht wissen und trotzdem falsch machen, ist es ihr Pech. Und wenn sie es nicht wissen, und sie verstoßen gegen irgendwelche fiskalischen oder sonstigen Vorschriften, dann haben sie zwei Mal Pech, weil dann kriegen sie auch noch was auf den Deckel, ja? Und das ist, ja, das hat sicherlich zu meiner Fortbildung als Mensch insgesamt beigetragen, aber es war schmerzlich. Und wenn ich gewusst hätte, welche Schwierigkeiten auf mich zukommen, weiß ich nicht, ob ich gegangen wäre. Ja, ich glaube eher nicht. Weil das war eine sehr harte Lehrzeit. Und wir hatten da im ersten halben Jahr zwei/ drei massive Maschinenschäden mit entsprechenden Standzeiten und Folgekosten. Also, da schlafen sie dann erst mal eine Zeit lang nicht so gut. Außerdem, ich meine, diese Maschinen sind ja bei uns völlig neues Neuland gewesen. Also, sie kriegen da auch nicht einen Fahrer irgendwo vom Supermarkt, der das wunderbar kann, sondern wir haben da / Ich habe mir halt da Leute gesucht, wo ich gedacht habe: „Naja, mit denen kannst du was anfangen:" Und dann haben wir zu viert, ich inklusive, angefangen zu versuchen, diese Maschinen zu bewegen. Dass da erst einmal keine große Leistung da ist, ist selbstverständlich. Aber die Kosten sind trotzdem da. Also, das war am Anfang schon eine relativ schwierige Kiste. Das hat sich nach einem halben/ dreiviertel Jahr ein wenig beruhigt. Ja, und dann ging das halt los. Am Anfang hatte ich reine Dienstleistung. Und dann ging das los, dass abzusehen war, nur mit Dienstleistung wird das auf Dauer nichts, weil bei diesen Mengen, die am Boden gelegen sind, war irgendwann einmal der Ofen aus für den Waldbesitzer, wenn er sein Holz nicht 
verkaufen kann. Weil er muss ja die Arbeit zahlen. Und von was soll er es zahlen, wenn das Holz nicht verkauft werden kann? So. Also musste ich zwangsläufig in den Holzhandel einsteigen, was letztendlich nicht schlecht war. Hat natürlich auch da über die Zeit Ups und Downs gegeben, ist klar. Wie es halt im Weltmarkt so ist. Und Holzmarkt ist Weltmarkt. Und, aber ok. Das war Teil des Ganzen. Und naja, so hat sich das halt entwickelt. Es kam die eine Krise auch in dieser Wirtschaft, in diesem Wirtschaftssegment. Und es hat immer wieder mal Windwürfe gegeben mit Preiseinbrüchen und immer wieder Turbulenzen. Das ist so. Das ist wie an der Börse im Holz. Und deswegen ist es nicht absehbar, was im nächsten Jahr passiert oder auch im nächsten halben, ja? Es war schon ein Wunder, dass ich relativ lange ausgehalten habe. Vor allem kleine Firmen, wenn sie selber fahren, wenn sie also keine angestellten Fahrer haben, dann sparen sie sich schon mal 4-5 tausend Euro im Monat, vielleicht auch sogar 6 oder 7, die Lohnnebenkosten mit eingerechnet. Und wenn sie angestellte Fahrer haben, muss das erst einmal im Monat übrigbleiben. Dass das überhaupt bezahlt wird. Und dann haben sie noch keinen Gewinn, nicht? Naja, jedenfalls, es hat Ups und Downs gegeben. Ich habe sehr gute Jahre gehabt. Ich habe zwischendurch immer wieder schlechte Jahre gehabt. Naja.

I: Wie lange hatten Sie die Firma dann insgesamt?

B: 23 Jahre.

I: Aha.

B: Also, es war / In diesem unruhigen Wasser war das schon relativ lang. Und ich hätte es auch weitergemacht, weil wenn sie mal drin sind, dann machen sie weiter, wenn es weitergeht, ja? Und, es hat sich also dann letztendlich / Diese Möglichkeiten für Unternehmer sind immer weiter reduziert worden ausgehend von den Staatsbehörden, die gemeint haben, den Handel ausschließen zu müssen. Weil den Euro, den der Handel da verliert pro Einheit, den können sie dann auch noch Gewinn machen, ja? Dann haben sie Ausschreibungen großgemacht und viele Leute dazu genommen, mit dem Ergebnis, dass also heutzutage die Preise beim Staat nicht mehr 
auskömmlich sind. Man zahlt also drauf, ja? Und das ist also so die permanente Entwicklung gewesen.

Zudem ist es so, dass sie mehr und mehr Einfluss genommen haben auf die Körperschaftswälder, also nicht nur Staatswald an sich, sondern auch die anderen Bereiche sind da stark beeinflusst worden. Zumindest in Bayern. Also, es ist, ich sage mal unattraktiv geworden das Ganze, nicht? Und, was das Schwierigste ist, sie konnten sich keine Rücklagen bilden, ja? Und dann kam noch eins hinzu, und das ist der fiskalische Aspekt. Wenn sie gute Jahre hatten, ich sage mal, es sind 500.000 Euro übriggeblieben, dann haben sie allein 250 oder mehr an Steuern zu zahlen gehabt, ja? Bleiben also noch 250. Dann haben sie ihre Tilgungen. Weil sie müssen ja investieren. Ich sage mal, von den 500 haben sie im Jahr bestimmt, wenn sie solche Maschinen haben, zwischen 80 und 120.000 Euro Tilgungen, Zinsen dazu, ja? Und dann haben sie ihre Lohnkosten was auch immer, gut, die sind in dem Gewinn schon weg, aber die Tilgungen müssen sie dann abschreiben. Und dann haben sie vielleicht Ansparabschreibungen für später. Also, da bleibt nicht viel übrig, um Schulden, die sie haben, runterzufahren, ja? Und wenn sie dann ins nächste Jahr kommen, und sie haben da Verluste, dann kriegen sie das aber nicht zurück von der Steuer, sondern das sind Verluste. Punkt. Ja. Was ich damit sagen will: In unserem System ist es so, wenn sie Geld verdienen, dürfen sie zahlen, und wenn sie verlieren, wird es über den Zeitfaktor, zwei, drei, fünf, oder wieviel Jahre aus / kann das nicht ausgeglichen werden. Ja, also, es wird meiner Ansicht nach mit den Firmen, mit den kleinen Mittelständlern, schlecht umgegangen von fiskalischer Seite aus. Sie kriegen keine Luft, ja? Immer wenn sie investieren, hangeln sie sich von einem, ich sage mal, von einem Investment zum anderen. Wenn sie dann wirklich was übrighaben, und sie müssen einen Haufen Steuern zahlen, überlegen sie sich, soll ich mir jetzt was anschaffen? Dann spare ich steuern, und ich habe wieder was, ja?

I: Ja.

B: Oder soll ich Steuern zahlen, und ich hab das Bisschen, was da ist, übrig, ja?

$\mathrm{I}: \mathrm{Hm}$. 
B: Ja? Aber ist in Deutschland, zumindest in dem Bereich, den ich miterlebt habe, und ich spreche da davon, dass wir eigentlich häufig zwischen 150 und 300.000 Euro übriggehabt haben, ja. Also, es war nicht jedes Jahr so, aber das war so der Level, der durchaus realistisch gewesen wäre, bei normalem Verlauf und bei seriöser Abwicklung der Geschäfte, Das kommt noch dazu, muss ich sagen. Aber davon konnten sie keine Rücklagen bilden.

I: Ja.

B: Ja. Und was noch dazu kam über all die Jahre, das war einfach, dass die Vertragspartner, egal ob es Auftragsgeber oder Auftragsnehmer waren, zunehmend unseriös geworden sind. Und sich zunehmend nicht an Absprachen gehalten haben. bei Margen ja, aber die Abrechnung nicht. Das heißt, es ist von Auftraggeberseite aus dann öfter versucht worden dann im nachhinein, Mängel geltend zu machen, um die Preise zu reduzieren. Und der Käufer hat das gleiche versucht, um weniger zahlen zu müssen. Und da können sie einfach nicht mehr kalkulieren, nicht mehr seriös, ja. Auch wenn sie gute Arbeit leisten, dann war da immer was im Busch. Und Holz hat tausend Gesichter, also wenn sie wollen, können sie immer was reklamieren. $\mathrm{Na}$, und das war schon immer so, wenn Holz gebraucht worden ist, dann sind die Fehler toleriert worden, und wenn zu viel da war, dann hat es überall einen Mangel gehabt. Ja, also, das ist eine der Unwägbarkeiten, die dieses Geschäft hat, vielleicht andere auch. Aber das hat die ganze Sache zusätzlich erschwert, ja. Naja, jedenfalls ich 2005 war ich in Schweden ein halbes Jahr. Ich hatte eigentlich einen sehr guten Vertrag mit guten Preisen, große Mengen. Und dann hat mein Stammfahrer, der mich bis dahin begleitet hat - das waren immerhin 15 Jahre - der hat sich verabschiedet, weil er wohl in Deutschland bleiben wollte. Obwohl er vorher mit mir droben war und sich das angeschaut hat. Ist dann zu meinem stärksten Konkurrenten in meinem Gebiet. (lacht) $\mathrm{Na}$, aber ich war dann oben mit den Maschinen. Er ist noch die Kündigungszeit bei mir geblieben, hat gearbeitet, also ganz ohne Tadel in diesem Zusammenhang, aber dann war er weg. Und dann hatte ich einen riesen Auftrag. Und wenn sie so eine Situation haben wie einen riesen Windwurf in Südschweden, das waren damals um die 700.000 Festmeter, dann kriegen sie keinen guten Fahrer. Die guten Fahrer sind alle untergebracht auch in Notzeiten, ja? 
I: Ja.

B: Aber in Notzeiten haben sie noch eher mal die Chance vielleicht irgendjemanden zu kriegen. Aber in solchen Zeiten kriegen sie eigentlich nur das, was übrigbleibt. Und das war dann auch das Ergebnis, was ich da oben hatte, ja. Also, ich habe trotz gutem Auftrag Glück gehabt, dass ich in etwa Null für Null rausgekommen bin. Ja. Naja, das war dann die Situation, Dann habe ich da halt weitergeschaut, und weitergeschaut, dass ich gescheite Fahrer kriege. Das war wieder so eine ganz ungünstige Geschichte. Ich meine, bei diesen hochkomplizierten Maschinen, wenn sie da nicht einen Fahrer haben, der wirklich passt, der muss sich auskennen mit Maschinen, weil er immer wieder reparieren muss. Das ist am besten so ein Landmaschinenmechaniker, nicht? Der muss auch ein bisschen schweißen können. Der muss ein bisschen was von Elektrik, von Hydraulik verstehen, ja. Aber er muss auch fit in der Birne sein, weil ich kann ihm nicht vorschreiben Baum für Baum, was er zu tun hat. Der hat eine komplexe Aufgabe, das heißt hier sind 10 ha Wald, was raus muss, wird in der Regel ausgezeichnet, sprich markiert. Er kriegt eine Einweisung in das Gelände, dass er weiß, wie er fahren kann oder muss, ja? Und wie er es dann macht, ist seine Aufgabe. Also, er braucht eine Flächenorganisation, er braucht eine Arbeitsorganisation vom Zeitablauf von allem Möglichen. Er muss auch seinen Diesel selbst bestellen, weil ich weiß ja nicht, wann er es braucht oder nicht braucht, das muss er alles selber machen. Er muss schauen, dass die Ersatzteile da sind und und und. Also, das ist eine hochkomplexe Tätigkeit. Und er muss natürlich auch die Möglichkeit haben über die Fingerfertigkeit, wie diese Kids mit ihren Joysticks da zu arbeiten. Weil das ist / Ein guter Fahrer, der darf gar nicht hinschauen. Das muss in Fleisch und Blut übergehen, sonst geht das nicht. Sonst ist man auch von der Leistung her nicht in dem Level, der dann rentabel ist. Ja. Und das alles zusammen, und natürlich auch eine Arbeit, die a) qualitativ gut ist, hochwertig und auch die Maschine schont, das alles zusammen. Also, Sie sehen schon, es ist ein hochkomplexes Thema. Und da können sie nicht einen jeden brauchen. Und da gibt es 100.000 Bezahlfahrer, die sich anpreisen, die aber nichts können, die sich draufsetzten und die Maschine mal eben bewegen, ja? Und dann ist das von Haus aus ein Verlustgeschäft. Ja, in der Potenz sogar. Naja, jedenfalls ich habe da rumgesucht zwei Jahre, und just in diesen Ablauf ist dann ein 
riesen Windwurf im Sauerland in Nordrhein-Westfahlen gekommen. Kyrill war das damals. Und da bin ich angerufen worden von einem Förster, der mich schon gekannt hat, ich soll doch mal schauen, da oben in seinem Heimatbereich, da liegt ein Haufen. Ich bin da hoch, habe einen riesen Auftrag machen können zu sehr guten Preisen und habe aber keine Maschinen gehabt. Nur eine, und keinen gescheiten Fahrer. Naja, und dann habe ich, ich habe aber Zusagen gehabt, weil ich das damals so organisiert hatte, dass andere Unternehmer mit mir zusammenarbeiten, wenn ich Arbeit hätte.

I: Ok.

B: Ja. So, und jetzt war es dann so weit. Deswegen konnte ich auch diesen Auftrag annehmen auf diese Zusagen hin, nur die sind nicht gekommen. Die sind bei sich zu Hause geblieben, weil die ganzen Leute um sie rum: „Ja, wir haben auch was. Und du kriegst auch später wieder was. Wenn du jetzt abhaust, kriegst nie mehr was." So ungefähr. Weil sie alle Panik hatten völlig unbegründet. Sind alle nicht gekommen, haben sich hier abgekaspert mit schlechten Aufträgen. Bei mir hätten sie wirklich gutes Geld verdient, weil ich perfekte Verhältnisse hatte. und konnte auch einen guten Preis anbieten. Jedenfalls das ist sehr zäh losgegangen mit dem Ergebnis, dass ich etwa ein Fünftel der Auftragssumme abgeben musste, weil es nicht richtig losging. Das war schon mal ein riesen Verlust von vielleicht 500.000 Euro. Und dann habe ich alle möglichen Leute versucht zu akquirieren. Ich musste auf Ausländer zurückgreifen, ja. Das hat dann sogar einigermaßen geklappt. Ich war eigentlich fast ständig da oben. Und, ja. Ich hatte da zwei sehr gute Jahre dann letztendlich trotzdem, wo ich dann / wo mein Kontostand plötzlich im Plus war, ja? Ich war draußen, ja? Es hätte nur noch ein Jahr dauern müssen. Ich habe also prognostiziert, dass da oben dann auch noch Käferholz kommt in großen Mengen, dass es weitergeht. Wir waren eigentlich gut eingefahren, Arbeit ist gelaufen. Ja, bloß ist kein Käferholz gekommen. Und gleichzeitig ist die Finanzkrise gekommen.

Ich weiß nicht, ob Ihnen das bewusst ist, 2008/ 2009 weltweite Finanzkrise mit dem Börsencrash erst in New York und dann überall mit dem Ergebnis, dass Holzhandel, Holzgeschäft wie gesagt die Börse und ein Weltmarkt zusammengebrochen ist. Es ging also plötzlich nichts mehr. Und ich hatte im Jahr 2007, wo ich so große Aufträge hatte, hatte ich noch einmal insgesamt drei neue Maschinen gekauft. Das war ein 
Volumen von über eine Million Euro. Das war durchkalkuliert, das hätte 100\%ig geklappt, ja. Ich war voll in der Tilgung drin mit einer relativ großen Tilgung. Wir haben, glaub ich, monatlich 70.000 Euro getilgt. Also, es ist voll gerannt, ja. Und, wie gesagt, dann ist diese Finanzkrise gekommen mit dem Absturz, ja. Ich habe dann nur noch 5-10 \% Auftrag gehabt. Nicht minus, sondern insgesamt 5-10\%. Und habe die Maschinen gehabt, die ich nicht verkaufen konnte natürlich. Ich meine, da hat keiner Aufträge gehabt, da hat keiner Maschinen gebraucht. Ja, ich war dann mit riesen Verpflichtungen da und habe nicht gewusst, wie ich sie leisten soll, ja? Und keiner hat natürlich auch sagen können, wie lange es dauert. ich meine, dass irgendwann einmal das Holzgeschäft wieder anspringt, davon ist jeder ausgegangen. Aber wann, konnte keiner sagen. Und es ging auch sehr zögerlich los irgendwann dann 2010 so einigermaßen, ja. Das war so ein ganz vorsichtiges Hineintasten in den Markt wieder. Was natürlich auch nicht bewirkt hat, dass man dann sofort wieder sprunghaft losgelegt hat. Und zum anderen, die Fahrer, die ich vorher hatte, und wo alles funktioniert hat, die waren natürlich weg, ja? Wenn ich keine Aufträge habe, die haben sich halt was anderes suchen müssen. Zum Teil auch in anderen Branchen, ja? So, und das dann wieder so zu starten ist einfach bei solchen komplexen, komplizierten Maschinen nicht möglich. Naja. Ich bin dann Mitte-Ende 2010, Anfang 2011, nach Südwestfrankreich. Da hat es zwischen Bordeaux und Bayonne, also an der spanischen Grenze, ja, auch um die 65 Millionen geschmissen auf einer relativ zusammenhängenden Fläche. Kiefer, genauso Bäume wie bei uns. Man glaubt es nicht, aber es ist so. Mittlerweile weiß ich das. Und nach einiger Wartezeit, wo die Franzosen dann versucht haben, das alles selbst hinzukriegen, sind dann die Ausländer reingelassen worden. Und ich bin dann natürlich auch unten gewesen mit meiner ganzen Flotte, was natürlich auch Geld kostet. Habe zwischenzeitlich eine lettische Gruppe gefunden, das heißt einer, der verschiedene Fahrer gesucht, angeworben hat, und die unter seiner Regie dann gelaufen sind. Er musste die führen und installieren und anweisen. Ich habe die Maschinen gehabt, und ich war halt auch unten, um das Ganze zu führen, zu leiten, zu regeln, zu korrigieren und Aufträge zu holen, abzurechnen und das Ganze. Und wir waren dann nach einem halben Jahr so weit, dass es richtig gelaufen ist. Ja, und zwei Monate später hat Frankreich die Klappe runtergelassen. Das heißt, also, die haben / Die Werke waren voll. Der Käfer hat zwar zwischenzeitlich ziemlich gewütet. Der ist da unten auch in der Kiefer, in der 
Seekiefer ist der dann wirklich massiv tätig gewesen. Aber die Werke waren nicht mehr aufnahmefähig, die es da unten gibt. Der Waldbesitzer, oder wer auch immer das zu zahlen gehabt hätte, war nicht mehr zahlungswillig und zahlungsfähig, weil wenn sie Hunderttausende von Festmetern hinlegen und sollen das zahlen, und es geht nicht weiter, ja. Das geht nicht. Also haben sie wahrscheinlich, das kann ich mir nicht anders vorstellen, in Zusammenarbeit aller Betroffenen, das waren die Behörden, die Waldbesitzer, ja, und auch die Werke, die Sägewerke, haben sie wohl beschlossen, in einer Nacht- und Nebelsituation dieses ganze Gebiet zu überfliegen und zu begiften. Ja, und das in einem ausgesprochenen Erholungs- und Naturschutzbereich. Ja, das ist in Frankreich schon möglich so was. Weil ansonsten wäre das nicht möglich gewesen, dass der Käfer mitten im Sommer, und zwar wo es am heißesten ist, wo er sich am wohlsten fühlt, ja, plötzlich aufhört weiter zu befallen. Das kann anders nicht sein. ja. Jedenfalls von heute auf morgen sind dann alle Ausländer abgewürgt worden. Ich war dann unten mit meiner Flotte. Keine Arbeit mehr. Habe unterstellt, dass es dann nach der Sommerpause - das war Ende Juli. Im August machen die in der Regel komplett zu in ganz Frankreich, das beginnt aber schon zwei Wochen vorher und dauert zwei Wochen danach auch noch an. Also, die sind / Ganz Frankreich ist da komplett zwei Monate außer Gefecht - habe ich gedacht, naja, danach geht es wieder los. Aber es ist nicht mehr losgegangen. Na, dann musste ich zurück. Dann hat es hier keine Aufträge so schnell gegeben. Ja, das war bei uns auch nicht so am Laufen. Ich habe dann leider Gottes als Subunternehmer arbeiten müssen. Leider Gottes deswegen, weil da halt, da musst du nehmen, was übrigbleibt. Und in der Regel wird man da auch noch falsch abgerechnet. Das ist mir mehrfach passiert dann. Aber es war nicht zu belegen, weil ich keine Unterlagen gekriegt habe. Ja, also, ich habe da wirklich einen Griff ins Klo nach dem anderen gehabt dann nach diesen Phasen. Das war nicht mehr aufzuhalten. Und dann war ich also schon wirklich hart an der Grenze abzunippeln.

Und dann war es so, ich hatte noch drei Maschinen. Zwei sind mittlerweile abgebrannt. Das war pervers. Aber eine in Frankreich, eine hier in Deutschland, des gleichen Typs mit unterschiedlichen Fahrern. Und das war natürlich irgendwo im Raum gestanden, ist das Absicht gewesen oder nicht, ja? Aber das war für uns / Ich habe in Frankreich in einem sehr großen Auftrag den Schaden gehabt. Das hätte keinen Sinn gemacht, und in Deutschland genauso. Ja, bei $<<<$ Ort anonymisiert $>>>$ da oben, haben wir einen großen Auftrag bekommen, in der Zeit. Das hätte keinen, 
keinen Sinn gemacht. Na, jedenfalls, die waren weg. Und dann waren noch drei Maschinen, drei Harvester, da, die wollte ich dann abgeben, ältere Modelle, und einen Neuen kaufen. Habe aber diesen Deal mit dem Forstmaschinenhändler nicht zuwege gebracht, weil es sich halt zu wenig versprochen hat davon, ja? Ich habe mir von dieser Vorgehensweise versprochen, dann halt nicht mehr drei Fahrer haben zu müssen, sondern einen. Und eine leistungsstarke Maschine, die halt überall eingesetzt werden kann. Also, das hätte wohl nochmal funktionieren können, aber es hat nicht funktioniert. Da waren meine Zahlen schon zu schlecht, um das finanziert zu kriegen. Na gut.

I: Wann war das dann?

B: Das war in 2012. War das. Und, ja, dann kam noch hinzu, dass, glaube ich, ab 2011 Betriebsprüfung nochmal kam und zwar für diese Jahre, die so gut waren in Kyrill im Sauerland da oben, mit letztendlich einer Forderung von Finanzamt und Körperschaften, also sprich Gemeinde $<<<$ Ort anonymisiert $>>>$, von rund 200.000 Euro kamen. Und das war es dann. Das konnte ich nicht mehr stemmen. Ja. Also, es war, es war, ich sage mal, immer mehr oder minder stressige Zeit mit sehr viel zeitlichem Einsatz, mit sehr viel Ups und Downs. Hat irgendwo Spaß gemacht, aber letztendlich war zu viel Hektik dabei. Und es ist unterm Strich viel zu wenig übriggeblieben. Ja?

I: Und, ich meine, es lief ja viele Jahre lang gut, obwohl es so ein unwägbares Umfeld ist. Was waren jetzt für Sie im Nachhinein wirklich die Hauptgründe, warum es dann letztendlich doch zur Insolvenz kam?

B: Naja, das ist eine langfristige Entwicklung gewesen. Das ist wie eine Krankheit, die sich langsam aufbaut.

I: Ok.

B: Es war einmal so, dass die Dienstleistungspreise immer schwächer geworden sind. Also, letztendlich immer weniger übriggeblieben ist. Das heißt, die Möglichkeiten, 
sich ein Polster aufzubauen, sind immer kleiner geworden. Die Konkurrenz ist größer geworden, die Aufträge sind kleiner geworden. Es ist immer schwieriger geworden, die Maschinen auszulasten. Das ist der eine Punkt gewesen. Der zweite Punkt der letztendlich, ich sage mal, der Anfang vom Ende letztendlich war, das war letztendlich der Verlust von dem langjährigen Fahrer. Das war eine Art Vorarbeiter draußen. Den habe ich irgendwie, egal welcher Auftrag das war, den habe ich einfach hinsetzen können, ein paar, ich sage mal, Kernaussagen, und dann ist das gelaufen. Da habe ich mich gar nicht groß kümmern müssen. Oder ganz im Gegenteil, das war einfach besser, wenn der draußen war, weil der konnte auf Augenhöhe mit den Leuten draußen sprechen. Und da ist der Chef nicht dagewesen, sondern das war halt dann so. Und das war gut so. Also, mit dem Weggang von dem langjährigen Mitarbeiter ist es deutlich nach unten gegangen. Ich meine, das habe ich ja gesehen, in Schweden ist nichts mehr hängen geblieben. In den zwei Folgejahren hatte ich nur Schwierigkeiten, weil ich, weil ich keine gescheiten Fahrer hatte, ja? Ich habe in der Folgezeit schon ansatzweise gute Aufträge, hätte ich haben können. Aber das ist nicht gelaufen, weil da die Fahrer nicht gepasst haben, ja?

$\mathrm{I}: \mathrm{Hm}$.

B: Und wenn sie keine guten Ergebnisse haben, dann sind sie gleich abserviert. Das ist so. Das muss ich auch so anerkennen. Und wie gesagt der, letztendlich der Neckbreaker war die Finanzkrise 2008/2009, wo ich einfach aus dem vollen Einsatz auf nahe Null runtergefahren wurde. Und zwar für fast ein Jahr. Ja, und das ist / das können sie normal nicht aushalten. Diese Finanzgeschichte da, Finanzamtsgeschichte, am Schluss, das war eigentlich nur der letzte Tropfen auf dem angespannten Wasserspiegel. Ich hätte mit dem Finanzamt sogar noch einen Deal vereinbaren können. Also, die waren dann, als sie gemerkt haben, dass es wirklich eng ist, überraschend kulant, was sie vorher hätten sein sollen, dann wäre es gar nicht so weit gekommen. (lacht) Ja. Aber, das war eigentlich nur noch der letzte Tropfen auf dem Topf, der am überlaufen war. Ja, das waren die Gründe letztendlich.

I: Und wenn Sie jetzt zurückdenken - Wann war der Punkt für Sie erreicht, wo Sie realisiert haben, jetzt, jetzt geht es nicht mehr? 
B: Naja, sagen wir es mal so: Ich habe ja schon auch Jahre vorher immer Schwierigkeiten gehabt und habe eine Zeit lang nicht gewusst, wie ich das packe und habe gedacht: „Naja, du bist da immer wieder rausgekommen. Das wird auch jetzt wieder so sein." Eben aus der Überzeugung heraus oder aus der Erfahrung heraus, dass sich immer wieder was auftut, womit man gar nicht gerechnet hat, oder was man gar nicht vorhersehen konnte. Das war tatsächlich so. Und es war aber so, ich sage mal, wie das dann in Frankreich so plötzlich aus dem Ruder gelaufen ist. Und wie ich dann so in Deutschland das Folgejahr hatte mit wirklich nur noch Negativerfahrungen und abschlüssen. Da habe ich schon mir gedacht, naja, jetzt wird es schwierig werden, ja? Und ich habe ja eigentlich bis zum Schluss immer wieder Planungen gemacht, immer wieder Überlegungen, wie ich da rauskomme. Aber das hat alles nicht mehr hingehauen. Und letztendlich habe ja nicht ich die Insolvenz angemeldet, sondern das Finanzamt. Wobei wir sprechen ja / Ich weiß nicht, sprechen Sie von der GmbH, oder von was sprechen Sie? Ich habe ja drei Firmen, die insolvent sind, nicht?

I: Ach so, ok. Das wusste ich nicht.

B: Ich habe zwei GmbHs gehabt und ein Einzelunternehmen. Und ich habe mit der ersten $\mathrm{GmbH}$ angefangen. Ich glaube, davon wissen Sie nichts, aber von der zweiten. Bei der zweiten $\mathrm{GmbH}$ da habe ich den Herrn $<<<$ Name anonymisiert $>>>$ kennengelernt, und über den, glaube ich, sind Sie auf mich gekommen, nicht?

I: Ja.

B: So, und diese zweite Firma, die musste ich anmelden, weil halt da nichts mehr gelaufen ist, ja? Da gibt es ja gewisse Vorschriften, wann sie als Geschäftsführer eine $\mathrm{GmbH}$ anmelden müssen. Das habe ich schon im Auge gehabt. Und das war auch nicht einmal so, ich sage mal, der Knackpunkt für mich.

I: Aber diese drei Firmen waren eigentlich im Grunde immer die gleiche Tätigkeit und die gleiche Firma oder? Es hat sich halt im Zeitablauf / 
B: Nein, nein, die sind parallel gelaufen.

I: Ach, parallel, ok.

B: Ja, ja, es war eigentlich ursprünglich so gedacht, dass die $\mathrm{GmbH}$, die ich ja über den Herrn $<<<$ Name anonymisiert $>>>$ dann insolvent gemeldet habe, die war ja im Osten erst angesiedelt. Ich habe nach der Wende drüben eine Firma aufgemacht, um auch eine Ostfirma zu haben, um dort Leute einstellen zu können, die es dann plötzlich zuhauf gegeben hat. Das war meine Intention, dass es da auch ein paar arbeitswillige und arbeitskräftige Leute geben müsste, ja? War schwierig trotzdem. Und es waren noch ein paar andere Aspekte, die ich nutzen wollte, sprich Fördergelder und dergleichen hat es ja gegeben, war ganz legitim. Gut, diese Firma haben wir dann zurückgeholt nach Deutschland, wie es dann drüben nicht mehr interessant war. Und dann halt eine dritte noch aufgemacht 2008. Wo ich da im Sauerland relativ große Umsätze gemacht habe, die sollte sich ausschließlich mit Handel beschäftigen.

I: Aha.

B: Das war da oben in dem Bereich. Na gut.

I: Haben Sie dann zusätzlich zu den Unternehmensinsolvenzen auch eine Privatinsolvenz gehabt?

B: Ja, ja.

I: Ja.

B: Ich habe erst diese GmbHs da insolvent gemeldet oder melden müssen aufgrund der Ergebnisse und musste ja auch den Zeitrahmen im Auge behalten. Also, das habe ich schon sehr genau beachtet, dass ich da nicht straffällig werde, ja?

I: Hm. 
B: Das Einzelunternehmen wollte ich eigentlich nicht abmelden, aber das hat dann das Finanzamt gemacht, weil ich halt nichts zahlen konnte, ja? Und im Nachhinein muss ich sagen - ich habe dann auch private Insolvenz anmelden müssen, weil wenn sie ein Einzelunternehmen anmelden, dann müssen sie das auch machen, dass sie halt die Restschuldbefreiung bekommen. Ich habe ja haften müssen für das Ganze. So.

I: Wie lange haben Sie jetzt dann noch? Wann war das?

B: Das war jetzt in `13, im September `13.

I: Ah, ja, ok.

B: Ich glaube, die Regelinsolvenz ist sechs Jahre oder?

I: Sieben, glaube ich. Sechs oder sieben.

B: Erschrecken Sie mich nicht.

I: (lacht)

B: (lacht) Normal sechs, glaube ich. Aber wie auch immer, ich werde es sehen. Ja, dann habe ich das anmelden müssen, damit ich halt die Restschuldbefreiung erreiche. Und, ja, und das war halt alles dann in 2013, wo das dann gelaufen ist. Ja. Erst die GmbHs und dann das Einzelunternehmen.

I: Wie haben Sie sich da gefühlt in dieser Insolvenzphase persönlich?

B: Ich sage mal, in der Entstehungsphase war ich natürlich schon / ja, da sind sie erst einmal, sind sie erst einmal müde, runtergefahren, Stecker gezogen, solche Dinge, enttäuscht. Kommen auch so Dinge wie, ja, Versager, oder: „,hast du es doch nicht geschafft." Ja? Solche Dinge, oder "ich bin schuld", das Ganze ja, solche Szenarien. Aber mit fortschreitender Dauer, vor allem auch mit dem Wissen, dass es ja Unmengen von Insolvenzen gibt, zum einen, also ich bin da nicht alleine. Was mich 
natürlich nicht besonders tröstet, aber es ist halt so. Und zum anderen, viele meiner Freunde, die doch durchaus Persönlichkeiten sind, die haben mich darauf hingewiesen, dass es ja nicht unbedingt meine Schuld war. Ja. Sondern, dass ich in diesem unruhigen Fahrwasser doch relativ lange ausgehalten habe. Und dass ich Vieles versucht habe, um das noch hinzukriegen, aber dass es halt, dass es halt wohl nicht möglich war, ja?

I: Also, Ihr Umfeld war eher unterstützend für Sie?

B: Ja.

I: Ja, auch Familie?

B: Gut, meine Frau ist natürlich schon auch ein wenig, ja, wie soll man sagen, ich weiß es nicht, natürlich ernüchtert. Das kann man alles nicht sagen, weil sie war ja in der Buchhaltung bei mir. Sie wusste ja, was auf uns zukommt.

I: $\mathrm{Hm}$.

B: Sie hat erstaunlicherweise zu mir gesagt: „Naja, das ist alles ein wenig zu spät gekommen." (lacht) Ja. Ja, natürlich, das ist wie beim Geländewagen, der gut motorisiert ist, und der gut ausgestattet ist. Mit dem fahren sie auch viel weiter in den Dreck wie mit einem anderen, aber dann, wenn es passiert, kommen sie gar nicht mehr raus, ja? Und so war es halt da auch. Und, ja, ich muss sagen, mir haben eigentlich alle Leute, auf deren Meinung ich ein wenig was gebe, weil sie halt schon auch selbst was im Kopf haben, und weil sie auch was darstellen in ihrem Beruf oder auch sonst was oder auch eine eigene Meinung haben, ja, bin ich eigentlich eher unterstützt worden und darauf hingewiesen worden, dass das jetzt keine Schande ist, oder dass das jetzt nicht unbedingt ein Negativmerkmal wäre, gerade im persönlichen Bereich, ja. Sondern dass es halt jetzt einmal so ist mit der Chance, was Neues zu machen, ja, die Schulden endlich mal weg zu haben, die ich 23 Jahre abbauen wollte, von der Erstinvestition, ja? Und, ja, bin da eigentlich in die Richtung dann gekommen, dass ich sage: „Ich habe alles versucht, aber es war wohl nicht mein Weg." War wohl der 
falsche Weg, den ich gegangen bin. Und die Branche, wie sie sich entwickelt hat, hat nicht mehr die Chance, gesund zu werden, so wie sie im Moment ist, ja?

Also, ist es besser, ich bin heute überzeugt davon, dass es mich erwischt hat. Heute bin ich auch der Auffassung, dass es eigentlich 10 Jahre zu spät war, wäre ich schon längst durch und hätte was Anderes aufgebaut, ja? Aber besser jetzt als nie. Jedenfalls, mir geht es heute im Vergleich erheblich besser. Ich habe den Stress nicht. Mir geht es auch im Prinzip, auch wenn sich das lustig anhört, finanziell besser, weil ich habe keinen Verlust mehr jeden Monat, ja? Ich habe auch den Druck nicht mehr, ständig viel Geld verdienen zu müssen. Ich habe den Druck nicht mehr, dass ich immer wieder Anrufe bekomme, wann ich denn überweisen möcht oder so, ja? Oder ich müsste selbst nachstoßen, wann denn endlich jetzt das Geld kommt oder so, ja? Das waren ja alltägliche Geschichten. Ja, gerade in der heutigen Zeit ist die Zahlungsmoral nicht unbedingt toll, und das ist auch ein Grund für Insolvenzen.

I: Ja.

B: Ja. Und gerade, wenn es Staatsbehörden sind, dann müssen sie sich wundern, warum die das machen. Es ist nicht ihr Geld. Aber häufig kriegt man vom Staat besonders spät sein Geld. Ich verstehe das nicht, warum das so ist. Ja. Naja, ok, jedenfalls ich bin heute eigentlich in einer Situation, die sehr viel besser ist. Und die Insolvenz hat mir auch die Möglichkeit gegeben, vielleicht über andere Wege nachzudenken. Ja. und ich bin, ich bin deswegen ganz zuversichtlich, dass mir da was gelingt, habe da auch schon Ideen. Aber man wird sehen. Ja.

I: Und Phase der Insolvenz, das waren ja drei Firmen, Privatinsolvenz, wie haben Sie diese Phase an sich erlebt, das Zusammenspiel mit den Behörden, die ganze Abwicklung an sich?

B: Also, ich war ja da, wie es dann klar war, dass es losging, war ich natürlich, ja, a) unsicher, weil ich war ja Neuling - Wollen Sie noch ein Wasser?

I: Nein, danke. 
B: Und zum anderen war ich natürlich auch, ja, wie soll ich denn sagen, ängstlich nicht, aber ich war dann schon sehr bemüht, alles zu hinterfragen, um halt a) keine Fehler zu machen und b) einfach um zu wissen, was auf mich zukommt, nicht? Und ich bin da zu einem Tennisfreund gegangen, der auch Insolvenzrechtsanwalt ist, und habe halt ihn einfach gebeten, mich ein bisschen zu informieren und mir Tipps zu geben und was auch immer. Und das hat mir dann schon mal am Anfang ziemlich geholfen. Und ich muss sagen, der Umgang mit den, mit den Insolvenzfirmen, so kann man es ja wohl sagen, der $<<<$ Name anonymisiert $>>>$ ist ja da in einer von diesen, der war für mich eigentlich immer sehr überraschend angenehm, sage ich mal so. Ja? Ich habe die Auskünfte gekriegt, die ich gebraucht habe, ich habe da auch jetzt nicht die Ablehnung, also die persönliche Ablehnung, erfahren, die man vielleicht unterstellt, wenn man neu ist in dem Geschäft, ja? Also, insofern hat das alles zu meiner Beruhigung beigetragen. Und je mehr ich eigentlich von der ganzen Sache dann in Erfahrung bringen konnte, desto mehr ist es eigentlich Business as usual gewesen. Also, man schaut sich die Sachen an, man überlegt, man tut, was zu tun ist, ja? Man stößt auch nach, wenn was vielleicht nicht in Ordnung sein kann. Also, wie ein ganz normales Geschäftsgebaren habe ich das festgestellt. Ja.

Und bis es halt dann so weit war, war ich natürlich in einer, ja, ich war schon ein Jahr, eineinhalb, fast zwei Jahre war ich eigentlich nicht in der Lage, über was Neues nachzudenken, ja? Ich war auch, ich war einfach so leer. Weil wenn sie über 20 Jahre wirklich nur Gas geben, und am Schluss kommt nichts raus dabei. Das ist schon ein wenig enttäuschend oder frustrierend. Aber es gibt andere Schwerpunkte im Leben oder Tätigkeiten. Es ist ganz gut, dass man dann eigentlich mit Gewalt da hingeführt wird, ja? Und auf dem Weg bin ich gerade. Und wenn ich das so denken kann und irgendwann einmal wieder ein bisschen Geld verdiene, dann ist es ja ganz ok. Was ich leider über all die Jahre versäumt habe, ist genügend Zeit für meine Familie und für meine Kinder zu haben. Und das hat auch zu einer gewissen Entfremdung geführt, ganz einfach, weil ich nicht präsent genug war, weil ich auch andere Dinge immer für whichtiger genommen habe. Und das ist eigentlich schade, aber ich kann es nicht zurückdrehen, nicht?

I: Ja. 
B: Ich habe dann auch in dieser Phase, das war, man kann sagen, 12/ 13 Jahre vor der Insolvenz, bin ich dann / haben wir uns getrennt, meine Frau und ich. Und vor zwei Jahren haben wir uns dann scheiden lassen. Ich habe dann gesagt: „Ja, also, entweder gehen wir wieder zusammen, oder wir lassen uns scheiden, weil das ist kein Zustand, da getrennt zu leben und diesen nicht geordneten Zustand zu haben." Das ist für sie nicht gut und für mich nicht, ja? Also, haben wir uns dann scheiden lassen, und wir verstehen uns heute ganz gut. Aber es war auch ganz gut, dass wir jetzt auseinander sind. Das ist, das ist die bessere Entscheidung gewesen. Ja, gut, das ist halt das, so wie es gelaufen ist. Und ich sehe das so, dass ein neuer Abschnitt begonnen hat Gott sei Dank. Und ich denke mal, dass es ein einfacherer Weg wird. Ja, das ist, das ist ganz gut so.

I: Wenn Sie zurückdenken, gibt es irgendwas, wo Sie sagen, das würde ich heute ganz anders machen?

B: Ja.

I: Was denn?

B: Ich habe immer wieder Entscheidungen mit relativ großer Tragweite oder auch mit großem finanziellem Engagement viel zu schnell entschieden, also viel zu, ja, wie soll ich denn das sagen? Zu wenig wohlüberlegt, ja, zu wenig hinterfragt auch zu wenig kritisch den anderen gegenüber. Oder mit einem anderen Wort: zu blauäugig bin ich in viele Sachen hineingestolpert. Das hat auch richtig Geld gekostet zum Teil, nicht?

I: Aha.

B: Die Grundüberlegungen waren immer aus der heutigen Sicht nicht verkehrt, aber die Entscheidungen waren meistens zu schnell und deswegen auch manchmal falsch. Ja, manche Investitionen oder manche Zusammenarbeit hätte nicht sein sollen. Aber das kam aus dem Zwang heraus. Habe ich mich treiben lassen einfach aus dem Zwang heraus möglichst schnell diese Investition runterzufahren, die ich gemacht habe, die Schulden weg zu haben. Und da war ich einfach, ja, zu schnell entschlossen und 
deswegen nicht durchdacht genug gewesen. Also, das stimmt, das würde ich heutzutage wohl anders machen.

I: Würden Sie sagen, die Insolvenz hat Sie verändert?

B: Ja.

I: Inwiefern?

B: Ich bin mir wieder mehr ich geworden. Ja. Und ich lasse mir für viele kleine Sachen des täglichen Lebens viel mehr Zeit, genieße es mehr. Und ich muss auch sagen, ich habe auch festgestellt mit wie wenig Geld man ganz gut auskommt. Und das ist auch meiner Ansicht nach eine ganz whichtige Erkenntnis. Ich brauche nicht unbedingt viel Geld um glücklich zu sein. Das ist / Es macht halt ruhig, ja? Das ist aber auch alles. Und andere Dinge sind meiner Ansicht nach whichtiger. Also ich denke schon, dass ich anders geworden bin, ja. Ich bin nicht mehr der, ja, der Stressmacher von früher, so kann man das schon sagen, ja. Ich habe mich und andere unter Stress gesetzt, weil ich halt ständig angeschoben habe, und das war auch nicht richtig. War aber aus der Situation im Nachhinein nachvollziehbar, wenn es auch nicht richtig war.

I: $\mathrm{Hm}$.

B: Heutzutage würde ich manche Dinge wohl anders machen, ja.

I: Sie haben ja vorher sehr viel gearbeitet, jetzt haben Sie wesentlich mehr Zeit. Wie nutzen Sie die, was ist Ihr Ausgleich so?

B: Basteln. Handwerkeln.

I: Aha. 
B: Also, ich habe hier dieses Haus bezogen vor etwa zweieinhalb Jahren, das in einem ziemlich spartanischen Zustand war. Habe dann erst einmal ein Jahr gebraucht um aufzuwachen. Das war ja alles mit dieser Insolvenz in Verbindung gewesen, weil hier muss ich keine Miete zahlen. Und, naja, habe dann angefangen das Eine oder das Andere vielleicht einmal ein bisschen anders zu machen und habe dann festgestellt, dass ich das eigentlich gar nicht so schlechtmache.

I: Ist das ihr Elternhaus?

B: Ja, ja.

I: Ja.

B: Und das ging halt so weiter, und jetzt bin ich halt wirklich am Handwerken und habe schon Einiges gemacht. Das ist das Eine. Das Andere ist, ich habe beschlossen, meinen Körper wieder fit zu kriegen oder fitter als früher, einfach um / Wenn der Körper fit ist, bleibt der Geist auch fit. Außerdem tut mir das gut. Und dann habe ich, verwende ich relativ viel Zeit mit Selbstfindung. Das hört sich blöd an, ist aber so. Also, drüber nachzudenken, was für mich whichtig ist, was ich möchte, wo ich eigentlich Fehler im Umgang mit mir oder mit anderen oder Schwierigkeiten mit mir oder im Umgang mit anderen sehe, warum das so ist. Und was es für Hintergründe gibt dafür, weil wenn ich das weiß, dann kann ich es auch abstellen. Also, damit verbringe ich auch Einiges an Zeit. Und dann verbringe ich Einiges an Zeit, um meine alten Baustellen so Zug um Zug aufzuräumen, die es immer noch gibt.

Und damit habe ich leider Gottes immer wieder Arbeit und Ärger auch heute noch. Wobei mich das heute bei weitem weniger ärgert als früher, sondern einfach manchmal nur noch wundert. Und das Letzte ist, dass ich Projekte habe, die ich angehe, also so zukunftsorientiert. Gedanken, Ideen, die ich versuche umzusetzen oder zumindest zu konstruieren, um dann halt irgendwann wieder, ja, in die Richtung zu kommen, dass ich wieder produktiv werde und halt auch mein / ich muss ja fürs Alter noch ein bisschen was anschaffen. Das ist ja alles weg. Nicht? Aber das schreckt mich nicht. Irgendwie kriege ich das schon hin. Und wenn ich sehe, mit wie wenig Geld 
man zurechtkommt, dann hat das alles für mich keinen Schrecken mehr. Nicht? Na, so ist es halt im Moment.

I: Sie haben gesagt, Sie haben sich ein bisschen verändert durch die Insolvenz. Haben sie auch das Gefühl, dass andere Leute anders mit Ihnen umgehen jetzt heute als früher?

B: Ja.

I: Wie hat sich das verändert?

B: Ich werde mehr akzeptiert, mehr angenommen. Die Leute gehen auf mich zu.

I: Aha. Also zum Positiven.

B: Ja, ja. Ja, ja. Das merke ich immer wieder bei kleinen Gelegenheiten immer wieder ganz überraschend, dass die Leute, egal ob das jetzt an einer Kasse ist oder sonst wo, ja, habe ich immer wieder ganz nette Erlebnisse. Das hatte ich früher in der Form nicht.

I: Aha. Vielleicht auch früher gar nicht so wahrgenommen.

B: Nein, ich habe mich anders verhalten.

I: Ok.

B: Bin auch anders rübergekommen, denke ich mal. Ich meine, wenn sie eine stressige Aura haben, dann geht niemand mit ihnen gerne um. Und ich denke, dass ich das ablegen konnte.

I: Also, im Großen und Ganzen hat es durchaus auch positive Effekte für Sie gehabt. 
B: Letztendlich sage ich Ihnen ganz offen und ganz pauschal raus: Es ist schade, dass es nicht früher passiert ist. Ja? Es ist wirklich schade. Hätte ich zehn Jahre mehr von dem anderen Leben gehabt.

I: $\mathrm{Hm}$.

B: Aber auf der anderen Seite, es passiert alles zu seiner Zeit. Ich heule dem nicht nach. Das war alles, was zu meinem Leben gehören sollte und musste. Und das ist so, ich nehme das als Erfahrungswerte mit und werde da halt weiter schauen, dass ich da in die Richtung gehe, die mir guttut. Ja, von dem her, wenn einer auf mich zukommt, mich stressen will, dann blocke ich das, mache ich nicht mit. (lacht) 
Appendix XIII: Transcript of Interview 12

I: Mir wäre es am liebsten, wenn Sie einfach mal so frei von der Seele weg Ihren Werdegang erzählen von Kind bis heute, beruflich, privat, wie sich alles so zusammengefügt hat und ergeben hat. Bis jetzt eben.

B: Ok. Gut, also 61 bin ich geboren in Eisenach, also ehemalige DDR. Schulabschluss hatte ich dann Mittlere Reife. Dann musste ich Schlosser lernen.

I: Sie mussten?

B: Ich musste, weil es damals auch nichts anderes gab. War eine ähnliche Situation wie heute. Gut, heute sucht man wieder Lehrlinge oder Auszubildende. Damals gab es halt nichts. Habe Schlosser gelernt. Bin dann nach der Lehre / In einem privaten Betrieb habe ich gelernt. Das war auch selten. Bin dann zu einer Großbäckerei gewechselt, das nannte sich damals $<<<$ Unternehmen anonymisiert $>>>$. Habe dort als Schlosser gearbeitet, 1985 einen schweren Arbeitsunfall erlitten. 1987 noch einen, und war eigentlich dann bis zur Wende damals arbeitsmäßig außer Gefecht.

Nach der Wende wurden wir von der Firma $<<<$ Unternehmen anonymisiert $>>>$ übernommen aus $<<<$ Ort anonymisiert $>>>$. Da bin ich dann zum Verkaufsleiter aufgestiegen und viele, viele Jahre geblieben bis die Firma aus persönlichen Gründen der Familie, der Inhaberfamilie, verkauft wurde an die $<<<$ Unternehmen anonymisiert $>>>-$-Gruppe, die es heute noch gibt. Und war die ganze Zeit als Verkaufsleiter tätig hauptsächlich in $<<<$ Ort anonymisiert $>>>$ und in $<<<$ Ort anonymisiert $>>>$.

1985 habe ich geheiratet. Das war auch das Jahr, wo ich den ersten Arbeitsunfall hatte. 1993 kam dann unser Sohn zur Welt. Und gut, dann habe ich mich verändert beruflicherseits, das heißt wie das so nach so Übernahmen ist: Man soll dann eigentlich nicht mehr das machen, was man mal gemacht hat. Die Firmen sagen: „Na, wir haben unsere eigenen Mitarbeiter, die das machen." Na, das war dann ein Key Account Manager. Ich habe mich dann umgeschaut, ich habe, ja, mit einer Abfindung den Betrieb verlassen. 
I: Wieso, war das nicht mehr zu Ihrer Zufriedenheit nach der /

B: Nein, ich habe $<<<$ Produkt anonymisiert $>>>$ europaweit verkauft, und habe auch die ganzen Handelsketten wie Kaufland, damals gab es noch Spar, Netto war erst im Kommen, Edeka, all diese Zentralen betreut. Die Firma $<<<$ Unternehmen anonymisiert $>>>$ hat dann gesagt, wir haben unseren eigenen Manager, die kommen aus den alten Bundesländern, und die kennen die Leute schon viele Jahre. Dann brauchen wir die aus den neuen Bundesländern halt nicht.

Ich meine, die sind preisgünstiger als die, aber ist egal. (lacht) Und dann hatte ich ein Angebot bekommen von der Firma $<<<$ Unternehmen anonymisiert $>>>$ in $<<<$ Ort anonymisiert $>>>$. Das war ebenfalls eine $<<<$ Produkt anonymisiert $>>>$-firma. Dort bin ich ein bisschen - ja wie soll ich sagen? - ausgetrickst worden. Man hatte mir also eine Stelle zugesagt als Betriebsleiter, Produktionsleiter und eben Verkauf von $<<<$ Produkt anonymisiert $>>>$. Das Ganze war aber getarnt, da war nur jemand - was heißt nur, das „Nur“" muss man auch in Anführungszeichen setzen - zu einer Herzoperation angemeldet. Und als der wiederkam, habe ich halt gekündigt, nicht?

I: Aha, ok, das wäre dann vorrübergehend nur gewesen.

B: Genau, nicht? Das war also wirklich unehrlich. Dann bin ich aber gleich zur nächsten $<<<$ Produkt anonymisiert $>>>$-firma gewechselt in $<<<$ Ort anonymisiert $>>>$

I: Wie viele gibt es denn da?

B: Ach, da gibt es ein ganzes ... (unverständlich), aber große nur drei.

Ja, vier, vier. (lacht) heute gibt es nur noch drei. Und da bin ich gewechselt zu der Firma $<<<$ Unternehmen anonymisiert $>>>$ in $<<<$ Ort anonymisiert $>>>$. Dann hatte ich einen Autounfall unverschuldet. Da war Verdacht auf Riss des Halswirbels, das waren diese beiden Wirbel hier oben. Und da hat man halt auch gesagt, ich war immer noch in der Probezeit nach einem dreiviertel Jahr, ehe der so lange krank wird. Dann haben die mich halt entsorgt. Dann habe ich mich sehr ... (unverständlich) gemacht, bin zur Firma $<<<$ Unternehmen anonymisiert $>>>$ gegangen. $<<<$ Unternehmen 
anonymisiert $\gg>>$ sagt vielleicht noch was, Lexikothek früher. Ich war aber im Bereich Faksimile tätig, also alte Bibeln, alte Atlanten.

I: Und was genau haben Sie da gemacht?

B: Privatkunden praktisch angerufen, Termine gemacht und denen, ja, recht teure Bücher vorgestellt.

I: Aha. Sie waren da aber nicht Angestellter.

B: Nein, ich war da selbstständig. Das lief auch recht gut, muss ich sagen, bis dann die ganze Rentengeschichte in der Bundesrepublik anfing, dass die Rentner weniger Rente haben sollten und Besteuerung und Krankenkasse, und was da so alles reinlief. Und da hat keiner mehr Geld ausgegeben für eine Bibel, die 2600 Mark damals noch, später dann 2100 Euro gekostet hat. (lacht) Und da war ich eine Weile arbeitslos, also ich habe gesagt: „Bringt nichts mehr." Wenn Sie nur Kosten haben, wenn Sie nur / Sie verfahren das Benzin, und es kommt nichts mehr rum. Und dann sah ich eine Annonce in der Zeitung, und jetzt kommen wir schon langsam zur Insolvenz. Da war mal eine Annonce in der Zeitung, und da stand drin $<<<$ Unternehmen anonymisiert $>>>$ in $<<<$ Ort anonymisiert $>>>$, das ist ein Handelsunternehmen in $<<<$ Ort anonymisiert $>>>$. Ich weiß nicht, ob es Ihnen was sagt. In $<<<$ Ort anonymisiert $>>>$ gibt es zum Beispiel auch einen $<<<$ Unternehmen anonymisiert $>>>$. Sucht Filialleiter auf selbstständiger Basis. Ich wohnte damals noch in $<<<$ Ort anonymisiert $>>>$ und bin dann auch hingefahren nach $<<<$ Ort anonymisiert $>>>$ und habe mir das angehört. Da ging es um einen Markt in $<<<$ Ort anonymisiert $>>>, 1200$ qm Verkaufsfläche. Dann hat man mir ja die Zahlen zur Verfügung gestellt, was an Umsatz möglich ist. Und dann habe ich persönlich einen Fehler gemacht. Ich habe einen guten, oder zur damaligen Zeit noch guten Freund als Steuerberater genommen. Der hat gesagt: „Sieht doch alles fantastisch aus." Ich bin mit der Firma $<<<$ Unternehmen anonymisiert $>>>$ einen Vertrag eingegangen. Und wo ich dann so ein paar Monate schon dabei war, das lief auch anfangs recht gut, hörte ich dann: „Oh, genau 100 Meter daneben wird ein $<<<$ Unternehmen anonymisiert $>>>$ gebaut." Und, ja gut, dieser $<<<$ Unternehmen anonymisiert $>>>$ hat uns dann das Genick gebrochen nach drei Jahren. Der 
$<<<$ Unternehmen anonymisiert $>>>$ hat also dann uns die Kunden weggeschnappt, das ist ganz klar. Die haben so aggressive Werbung gefahren. $<<<$ Unternehmen anonymisiert $\gg>>$ ist ja mehr im hochpreisigen Segment ansässig. Mittlerweile waren schon etliche meiner Kollegen in die Insolvenz gegangen.

Und mein Steuerberater hat auch ein paar Fehler gemacht mit zum Beispiel. Ich habe ihm das alles vollkommen überlassen. Der hat also auch die Löhne überwiesen und alles. Also, wie man es halt erwartet. Tja, aber er hat zum Beispiel drei Jahre lang keine Krankenkasse für mich bezahlt.

I: Oh, ok.

B: Bei der Krankenkasse ist das aber auch nicht aufgefallen. Die hatten genauso /

I: Hat er das böswillig gemacht oder/

B: Angeblich hat er es irgendwie nicht bemerkt. Ich weiß es nicht.

I: Sind Sie noch befreundet?

B: Nein. Wir sind also ganz böse auseinandergegangen. Ja, und dann habe ich eines Tages dann ein Gespräch gehabt, das war 2006 im Dezember. Und ich sagte: „Ich kann nicht mehr und ihr müsst mir die Miete erlassen, dass ich überleben kann. Ansonsten kann ich nicht mehr." Hatte natürlich Sicherheiten bei der Sparkasse hinterlegen müssen. Ja, also die Firma $<<<$ Unternehmen anonymisiert $>>>$ hat damals drauf bestanden 30.000 - das waren dann schon Euro, oder? - ja, 30.000 Euro an Sicherheiten. 15.000 hatte ich so als Sicherheit hinterlegt, und 15.000 hatte ich mir eine Bürgschaft geholt von der Bank, von der Sparkasse. Ja, und dann kam das alles so ein bisschen zusammen, muss ich sagen. Also, die sagten, die können mir die Miete nicht nachlassen. Also, ich musste eine sehr hohe Miete bezahlen für den Markt. Dann kam diesen Monat dann die Krankenkasse. (lacht) Das kam dann alles zusammen. Wollten - jetzt müsste ich lügen - 9000 Euro oder so was haben. Tja, und der Steuerberater hat dann auch plötzlich gesagt: „Ich habe so viel für dich gemacht. Was wir vorher vereinbart haben, das gilt alles nicht mehr." Der wollte dann auch bald viel 
mehr Geld. Tja, und dann hat die Sparkasse Mitte Dezember 2006 die Bürgschaft, das Geld dafür, haben wollen, weil sie gesagt haben, das rechnet sich nicht mehr. Ich musste ihr die Zahlen vorlegen. Dazu muss ich auch sagen, war zeitgleich in $<<<$ Ort anonymisiert $>>>$ noch ein Kollege, der dasselbe Problem hatte. Der war auch bei der Sparkasse. Der war beim selben Berater.

Dann war Schluss. Dann bin ich erst einmal eigentlich mit der Firma $<<<$ Unternehmen anonymisiert $>>>$ so übereingekommen, dass ich gesagt habe: „Ok, ich versuche das irgendwie zurückzuzahlen." Ich wusste aber noch nicht, wieviel es ist. Das ging auch eine ganze Weile gut. Das ging dann Richtung Vergleich. Dann hatten wir schon das Jahr / ja, am 31.12.2006 habe ich aufgehört. Dann war ich arbeitslos, bekam natürlich auch kein Arbeitslosengeld, weil ich ja über zwei Jahre selbstständig war, dann ist das ja weg. Tja, dann blieb mir eigentlich nur der Gang zu Hartz 4.

I: Was für eine Gesellschaftsform war dieser Markt? War das dann eine Privatinsolvenz für Sie?

B: Das war als Handelsvertretung geführt. Das war ganz geschickt gemacht von $<<<$ Unternehmen anonymisiert $>>>$. Wir haben praktisch Handelsvertretergeld bekommen für den Umsatz. Hm. Ja, und dann bot sich an, dann habe ich noch Zeitung gelesen, eine Firma $<<<$ Unternehmen anonymisiert $>>>$ sucht für $<<<$ Ort anonymisiert $\gg>>$ Filialleiter. Da mein Sohn - wie alt war der damals? 93, 14 Jahre auch kaum Aussicht auf eine Lehrstelle hatte in $\langle<<$ Ort anonymisiert $>>>$, hatten wir dann damals gesagt: „Mensch, vielleicht klappt es, dann ziehen wir halt nach $<<<$ Ort anonymisiert $>>>$." Und die Sparkasse ließ mich zu dem Zeitpunkt noch in Ruhe. An das Finanzamt habe ich regelmäßig was zurückgezahlt, dann auch an die anderen Firmen was zurückgezahlt, so was ging. Ja, und mit der Sparkasse wurde ich dann auch einig, und ging auch relativ problemlos erst mal. Allerdings dadurch, dass ich noch einen Kredit bei der Sparda Bank hatte, im Endeffekt haben wir Löcher zugeschoben. Wenn man es heute so sieht. Dann war ich im Sommer 2007 in $<<<$ Ort anonymisiert $\gg>$ zum Vorstellungsgespräch, bin auch genommen worden und bin dann Filialleiter geworden bei der $<<<$ Unternehmen anonymisiert $>>>$ mit einer Festanstellung. Die $<<<$ Unternehmen anonymisiert $>>>$, ist eine 100\%ige Tochter der 
$<<<$ Unternehmen anonymisiert $>>>$ und hat, ja, über 200 Tankstellen weggenommen. Also, die gutgehenden Tankstellen hat man praktisch den Pächtern genommen und hat wieder ein Filialsystem draus gemacht. Dort bin ich reingekommen und habe für die $<<<$ Unternehmen anonymisiert $>>>$ Tankstellen übernommen. Das heißt also, der Pächter wurde entlassen, gekündigt, und ich habe dann die Tankstellen als Filialleiter übernommen. Habe das Personal ausgebildet, das heißt das wird ja meistens übernommen. Aber nach den neuen Richtwerten. Habe dann alles aufgebaut. Und immer, wenn es aufgebaut war, dann bin ich wieder in den nächsten Ort gewechselt.

I: Aha.

B: Na, das heißt also, ich war in $<<<$ Ort anonymisiert $>>>$ und $<<<$ Ort anonymisiert $>>>$ bin ich ausgebildet worden. Ich habe dann nochmal fast 6 Monate Ausbildung gemacht. Und wir sind dann / haben dann den Umzug geplant. Es war auch alles friedlich. Mit der Firma $<<<$ Unternehmen anonymisiert $>>>$ ging es eigentlich immer noch wegen der Einigung irgendwie. Dann sind wir - puh, jetzt muss ich überlegen - 2008 nach $<<<$ Ort anonymisiert $>>>$ gezogen.

I: Aber das heißt in der ganzen Zeit war von Insolvenz eigentlich nie die Rede.

B: Nein. Nein. Ich wollte das immer verhindern eigentlich, abwenden, sag ich jetzt mal so. Kurz bevor wir hier runter gezogen sind nach $<<<$ Ort anonymisiert $>>>-$ ich habe hier damals die Tankstelle in der Hindenburgstraße hier drüben bekommen spielte dann das Finanzamt in $<<<$ Ort anonymisiert $>>>$ verrückt. Das heißt, das Finanzamt hat mich dargestellt wie einen Steuerflüchtling. Ja? Weil praktisch /

I: Wegen des Umzugs oder warum?

B: Wegen des Umzugs. Also, das war schon unterste Schublade, was da so gelaufen ist. Auf jeden Fall kamen dann plötzlich Pfändungsbeschlüsse vom Finanzamt. Dann wechselte leider der Mann bei $<<<$ Unternehmen anonymisiert $>>>$ in $<<<$ Ort anonymisiert $>>>$, der immer mir noch Hoffnungen gemacht hat, wir finden irgendwo eine Einigung. Dann stellten die auch Forderungen. Dann sind wir erst mal 
hierhergezogen. Das hat noch alles funktioniert. Tja, und dann kamen die Briefe immer böser, das war einfach so. Na, also, vom Finanzamt habe ich ja fast täglich einen Brief bekommen. Na, also. Obwohl die jeden Monat von mir Geld bekommen haben. Na, also das, was möglich war, haben die von mir bekommen. Ich müsste jetzt aber lügen, ich glaube 150 oder 200 haben die im Monat von mir bekommen. Mehr ging halt nicht. Ja, dann haben die mir versucht einen Gerichtsvollzieher auf den Hals zu schicken das Finanzamt $<<<$ Ort anonymisiert $>>>$. Und dann habe ich mich einfach umgehört hier. Und dann bin ich zu - wie die Frau hieß, weiß ich auch nicht mehr, in der Friedrichstraße war das. Die Dame kümmerte sich so um Insolvenzen. Diese Voranmeldungen erst machen und das alles. Und die hat gesagt, es bleibt mir kein Weg. Und da meine Frau überall unterschriftsberechtigt war, musste sie auch mit rein. Und da sind wir dann, ja, in die Insolvenz gegangen.

I: Wann war das dann? 2007?

B: 2009 erst.

I: 9 , ach so.

B: Jetzt bin ich fertig im Sommer. (lacht)

I: Aha, herzlichen Glückwunsch.

B: (lacht) Ja, danke schön. Ja, so hat sich das Ganze / Also, mit meiner Frau bin ich immer noch zusammen seit 1985, also / (lacht) So hat sich das Ganze entwickelt.

I: Aha. Und der Ablauf der Insolvenz an sich - kam da dann noch so viel, oder war das dann / Also, ich meine der größte Teil der Geschichte ist ja eigentlich bevor Sie Insolvenz angemeldet haben. Was genau kam dann noch, als Sie dann wirklich den Schritt gegangen sind und angemeldet haben?

B: Dann kam eine ganze Menge. Dann wollte die Firma $<<<$ Unternehmen anonymisiert $>>>$ sehr viel Geld haben. 
I: War Ihnen das vorher schon bewusst, wieviel da noch auf Sie zukommt?

B: Ja. Also, ich hatte eine angebliche Inventurdifferenz damals von 75 oder 77 Tausend Euro. Da hätte ich zwei LKWs mit nach Hause nehmen müssen. (lacht) Gut, (seufzt) heute sage ich mir, ich hätte das damals irgendwie anfechten sollen. Habe ich halt nicht gemacht. Ja, die $<<<$ Unternehmen anonymisiert $>>>$ hat dann also ruckzuck geklagt, und mit jeder Klageschrift wurde das teurer. Na, so dass dann bei $<<<$ Unternehmen anonymisiert $>>>$, die erscheinen zweimal, einmal 48112 Euro und einmal 1369 Euro. Dann war da noch das Finanzamt 14.000 Euro, Sparda Bank 26, fast 27.000. Dann hat das Finanzamt $<<<$ Ort anonymisiert $>>>$ umgebucht auf das Finanzamt $<<<$ Ort anonymisiert $>>>$, dass ich da auch noch ein paar Schulden habe. Das waren dann auch nochmal 6.700. und die $<<<$ Unternehmen anonymisiert $>>>$, die Krankenkasse, hatte ich dann schon abbezahlt bis auf 1222 Euro. Aber mit denen war ich sofort clean, die hätten / die waren mit kleinen Raten dann auch noch zufrieden. Im Endeffekt war es, muss ich sagen, ja, $<<<$ Unternehmen anonymisiert $>>>$, aber ausschlaggebend / mit $<<<$ Unternehmen anonymisiert $>>>$ hätte man vielleicht noch einen Vergleich hinbekommen auf eine gewisse Summe. Aber mit dem Finanzamt war nichts mehr zu spaßen. Na, so dass sich die Summe insgesamt belaufen hat auf 102209 Euro.

I: Und Sie haben ja gesagt, Sie wollten es erst nicht wahrhaben und abwenden.

B: Ja.

I: Was ist passiert oder wann war so der Augenblick, wo Sie gesagt haben: „Jetzt geht es halt nicht anders, jetzt muss ich in den sauren Apfel beißen."

B: Als das Finanzamt anfing. Ja. Also, das war ja wirklich massiv. Also, das war, ja, kann man sich kaum vorstellen. Also, die wollten ja zigtausende Euro von jetzt auf nachher haben. Die haben versucht die Konten zu sperren und alles, also, obwohl ja nichts drauf war. (lacht) Hm, und, tja. Das Finanzamt, würde ich sagen, war dann / Und dann der Wechsel bei $<<<$ Unternehmen anonymisiert $>>>$. Ja, das war so ein 
erfahrener Mann, der da dran war, und der ist halt gewechselt. Warum weiß ich heute auch, weil die sind ja dann auch ziemlich den Bach runter gegangen. Die sind ja auch übernommen worden, $<<<$ Unternehmen anonymisiert $>>>$. Tja, und viele meiner Kollegen, die selbstständig waren, die sind ja alle denselben Weg gegangen. Na, also, ich muss ganz ehrlich sagen, meine persönliche Meinung ist, die haben ihr System darauf aufgebaut. Na, die Läden, die nicht mehr gelaufen sind, da haben sie die Leute fast alle in den Ruin getrieben. Und wenn einer weg war, kann ich Ihnen sagen, so wie es ist, vier Wochen später war der Nächste da. Und der hat im Endeffekt dasselbe Leid dann in Anführungszeichen ertragen. Übrigens den Markt hat man geschlossen, wo ich mal war, wegen Unwirtschaftlichkeit.

I: Und neben dem Geschäftsgebaren von $<<<$ Unternehmen anonymisiert $>>>$, wo sehen Sie noch Hauptgründe dafür, dass es schiefgelaufen ist?

B: Ja, gut, der $<<<$ Unternehmen anonymisiert $>>>$ daneben hat schon massiven Umsatzeinbruch gebracht. Ja, der hat, also ich sage mal, ich habe sehr gute Umsätze gemacht im Weihnachtsgeschäft. Und da hat man halt eine örtliche Reklame gefahren. Man hat also wirklich Flugblätter überall noch mit in die normalen Werbeblätter eingelegt, wo nochmal soundso viel Prozent drauf waren, dass der Kunde eigentlich gar nicht anders konnte. Der ist einfach nicht mehr gekommen. Also, mir ist ab Oktober in diesem Jahr 2006 ist mir alles weggebrochen vom Umsatz. Im Endeffekt habe ich von dem, was noch war, noch die Löhne bezahlt und die Energie, und rausgekommen ist gar nichts mehr. Die haben im September aufgemacht, ich weiß nicht mehr, 5. oder 10. September haben die aufgemacht und haben dann aggressiv gefahren. Also, es war schon eine Ausrichtung darauf: „Den $<<<$ Unternehmen anonymisiert $\gg>>$ kriegen wir klein!" Na, das war in anderen Nachbarorten dasselbe. $\mathrm{Na}$, wo dann Märkte gebaut wurden, die wurden so aggressiv noch mit Zusatzwerbung bepflastert, sage ich mal, dass dann keine Chance war. Ja, und was auch noch ein Grund war natürlich, wir haben anfangs / Das waren die Personalkosten. Wir haben anfangs ja nur bis 14 Uhr zum Beispiel offen gehabt am Samstag. Und man hat uns kleine Leute dann halt auch gezwungen bis 20 Uhr zu öffnen, obwohl halt von 14 bis 20 Uhr in so einem kleinen Dorf nichts mehr los ist. Die Leute gehen auf den Fußballplatz oder fahren in die Stadt, aber gehen dann nicht unbedingt einkaufen. 
I: Und das Personal muss bezahlt werden.

B: Und das Personal muss bezahlt werden. Und wenn Sie davon ausgehen, dass das ein 1200 qm Markt war, dann können sie auch nicht nur einen oder zwei Mann dahaben, weil dann hätte man noch mehr geklaut, als man so schon geklaut hat. Weil dann hat man einfach, ja, sehen müssen, dass auch genügend Leute da waren. Also, ich war zum Beispiel so ein Dummer, ich war immer von früh um 6 bis abends um 9 da, um die Personalkosten zu senken.

I: Wie haben Sie die Insolvenz an sich erlebt? Also, wie war jetzt das Zusammenspiel mit dieser Dame, die Sie da beraten hat oder dann auch mit den Anwälten, mit dem Verwalter? War das auf Augenhöhe, oder hatten Sie das Gefühl, Sie haben jetzt eigentlich nichts mehr zu sagen und haben sich ausgeliefert gefühlt, oder wie haben Sie das empfunden?

B: Gut, das war schon ein sehr hässlicher Gang. Ich bin damals zu der Dame, ich weiß wirklich nicht mehr, wie die hieß, und da hat man meine Frau noch außenvorgelassen, weil sie sagte, vielleicht kommen wir da drum rum. Ja, aber das ging halt nicht. Das Finanzamt hat auch da dann bei meiner Frau noch das Konto gesperrt und und und oder versucht, sage ich jetzt mal. Wir haben es auch ein bisschen ausgetrickst, aber ging nicht anders. Und ich habe dann die Frau $<<<$ Name anonymisiert $>>>$ bekommen als Insolvenzanwalt. Und da muss ich sagen, das ist sehr ordentlich, ja, sehr ordentlich gelaufen. Also, es hat nie die Firma mitgeteilt bekommen von mir, dass ich in einer Insolvenz bin. Das weiß also niemand. Und ich habe immer die Lohnscheine geschickt die ganze Zeit. Und sie hat mir zurückgeschickt die Rechnungen, und ich habe es halt bezahlt. Ja, man muss sich schon umstellen, das ist klar. Ich sage mal von der Sache ist es noch fast ein Glück, dass mein Sohn noch lernt. Also, er wird jetzt fertig. Und dadurch hat man ja doch ein bisschen mehr Geld zur Verfügung, als ohne. Aber ich muss sagen, eine ganz faire Behandlung von, wie heißt es, Treuhand. Ja. Sie hat keine Konten gesperrt zum damaligen Zeitpunkt, gar nichts. Also, ja. Und meine Sorge war ja auch, an einer Tankstelle, ich sage, man hat da Umgang mit Geld und allem und Tresor leermachen und was so alles so dazu gehörte, nicht? Ich sage, na, nicht dass da 
dann irgendwas kommt in der Richtung. Und das war von Anfang an klar. Na, ich bezahle meine pfändbaren Anteile so wie ich mein Geld kriege und dann passt das.

I: Sie haben dann aber bis zu dem Zeitpunkt, wo das mit ihrer Schulter war, durchgearbeitet, nicht?

B: Ja.

I: Ja, und jetzt sind Sie krankgeschrieben. Und was würden Sie heute anders machen, wenn Sie so auf diese Geschichte zurückblicken?

B: Ich würde mich nie wieder selbstständig machen. (lacht)

I: (lacht)

B: Ja, ich würde heute, wenn ich mich nochmal selbstständig / ich bin jetzt 54 mit kaputter Schulter und kaputtem Arm, also geht nicht mehr. Aber ich würde mich besser erkundigen.

I: Aha.

B: Ja, ich würde auch nie mehr einen persönlichen Freund als Steuerberater nehmen, sondern würde da immer jemand Fremdes nehmen, wo ich auch vorher wirklich Informationen mir einhole: Ist der auch was, oder ist der auch nichts? Weil, na, dieser Herr hat doch sehr viel auch zum Schaden beigetragen, muss ich einfach sagen. Ansonsten, man kann die Selbstständigkeit nicht beurteilen, das kann man nicht. Das ist einerseits schön. Ich kenne es mein Leben lang nicht anders, ich habe immer von früh bis abends gearbeitet, bei mir war Wochenende immer Arbeitszeit. Also, pff. Eigentlich würde ich es wieder machen, aber wie gesagt, dann vielleicht mit $<<<$ Unternehmen anonymisiert $>>>$ oder $<<<$ Unternehmen anonymisiert $>>>$ und nicht mit $<<<$ Unternehmen anonymisiert $>>>$. 
I: Ja, ok. Und Sie haben gesagt, das weiß niemand. Das heißt, Sie können jetzt auch nicht beurteilen, wie ihr Umfeld darauf reagiert hat. Sie haben das geheim gehalten.

B: Das weiß niemand.

I: Wieso haben Sie das geheim gehalten?

B: Ich wollte es nicht, dass es jemand weiß. Ansichtssache einfach. Wir waren uns von Anfang an einig, also meine Eltern leben nicht mehr aber meine Schwiegereltern leben noch. Die wissen das auch nicht.

I: Aha. War das jetzt aus Schamgefühl?

B: Nö, wir wollten das einfach nicht. Wir haben gesagt, wenn es so geht, geht es so. Und jetzt die letzten zwei Monate auch nicht mehr. (lacht)

I: Ja. und wie war es für die Familie? Das sind ja eigentlich die Einzigen, die es wissen.

B: Ja. Tja, man hat eigentlich gelernt, damit umzugehen. Es ist einfach so.

I: Es war jetzt dann also weniger schlimm, als erwartet am Anfang, oder?

B: Ja. Ja.

I: Gibt es jetzt im Nachhinein, wenn Sie zurückblicken, auch irgendwas Positives, das sie da rausziehen, dass Sie sagen, durch die Erfahrung hat sich irgendwas Positives ergeben?

B: Ja, gut, Positives vielleicht das, dass man sagt, eigentlich ist es eine sehr schöne in Anführungszeichen gesagt - eine sehr schöne Sache, wenn man so halt unverschuldet reingerät, dass man die Schulden dann zum Großteil erlassen kriegt, sage ich jetzt mal. Wobei ich es nie bei solchen Menschen verstehen könnte, die es ja 
auch genug gibt, die es aus Konsumrausch dahin schaffen. Ja, nur ich sage es mal, soll mal einer so dumm sein wie ich und 6 Tage die Woche mindestens 12 Stunden am Tag arbeiten, um dafür im Endeffekt dann, ja, Vieles zu verlieren. (lacht)

I: Ja, aber jetzt haben Sie es dann, wann? Nächstes Jahr haben Sie es geschafft?

B: Dieses Jahr.

I: Dieses Jahr schon.

B: Ja.

I: Na super.

B: Juli.

I: Und haben Sie da dann irgendwelche Pläne, was dann als nächstes kommt? Weil Sie ja dann wieder flexibler sind vielleicht.

B: Ich weiß es noch nicht. Ich muss erst mal sehen, wie das mit der Schulter nachher ausgeht.

I: Ja, erst mal überraschen lassen.

B: Ja.

I: Na gut. Das war es auch schon.

B: Ok.

I: Ich bin schon durch mit meinen Fragen. Haben Sie noch irgendwas, was Sie loswerden möchten, irgendwas, was Sie ergänzen möchten? 
B: Eigentlich alles gesagt. Wie gesagt, mit der Frau $<<<$ Name anonymisiert $>>>$ läuft es. ich kann mich da wirklich nicht beschweren.

I: Hm, schön.

B: Ich hatte auch mittendrin dann mal eine größere Reparatur mit dem Auto, das ist ganz klar. Wenn man nicht so viel zur Verfügung hat. Ja, der Unterhalt ist auch relativ teuer, sage ich jetzt mal. Aber da ging es auch mal zu schieben. Dann hat sie halt mal einen Monat nicht gekriegt und den Monat zweimal. Finde ich ganz toll, muss ich ehrlich sagen.

I: Schön. Jetzt war mir gerade noch etwas eingefallen, jetzt habe ich es aber schon wieder vergessen. (Pause) Was wollte ich denn jetzt noch? Ach so, Sie haben gesagt, es war ein schwerer Gang zu ihr zu gehen, weil ja dann /

B: Na, ich war erst nicht, ich war ja / Frau $<<<$ Ort anonymisiert $>>>$ habe ich ja zugeteilt bekommen.

I: Ja, ich meine zur Beraterin zu gehen.

B: zur Beraterin das war ein schwerer Gang, ja.

I: Wie genau haben Sie sich da gefühlt?

B: Besch... bescheiden. (lacht) Ja gut, es gab keinen anderen Weg, ich weiß es nicht. Irgendwie hatte ich das Gefühl zum damaligen Zeitpunkt, man ist dann abgestempelt oder so in der Richtung sage ich jetzt mal.

I: Also, so wie die anderen Leute auch reagieren könnten?

B: Ja. Aber, ich weiß auch wirklich nicht mehr wie die Frau hieß, jedenfalls in der Friedrichstraße war sie. Der ihr Mann war Richter, das weiß ich auch noch oder Lebensgefährte. Aber, pff, ja, die Frau hat mir die Angst eigentlich auch genommen. 
Die hat auch / Das Positive bei dem Besuch damals, muss ich sagen, ich war bei dieser Dame, und die hat sofort alle angeschrieben, und ich habe ab drei, vier Tage später von keinem mehr Post bekommen. Na, auch das Finanzamt konnte mich mal gerne haben. (lacht)

I: (lacht) Na gut.

B: Ja. und trotzdem muss man sagen, sechs Jahre sind eine lange Zeit.

I: Das glaube ich, ja. Das ist sehr lang.

B: Ja. Ich finde das schon - wie gesagt für Leute, die wirklich nichts dafürkönnen, wo ich mich jetzt wirklich dazu zähle, Sie haben es ja auch gehört - da könnte es etwas kürzer sein. Aber nicht bei denen, die es / Ich kenne da auch jemanden, naja (lacht) schnell noch ein paar große Reisen gemacht hat bevor es dann soweit war.

I: Haben Sie eigentlich mal darüber nachgedacht ins Ausland zu gehen. Das haben nämlich auch Einige gesagt, dass in Frankreich oder England oder so die Insolvenzdauer ja kürzer ist.

B: Ja, in Frankreich ist sie, glaube ich, nur drei Jahre.

I: Das man da sich vielleicht ein bisschen rausmogeln kann.

B: Das war nie ein Thema.

I: Wäre das nicht in Frage gekommen?

B: Nein.

I: Wieso nicht? 
B: Bin ich zu ehrlich dafür. Ich habe, obwohl ich schon damals nicht mehr so jung war, ich sage halt, ich war so dumm und habe den Fehler gemacht. Hätte es vielleicht eher sehen sollen. Hätte vielleicht auch durch den Steuerberater eher den Hinweis kriegen sollen: „Du, pass auf, wo es hingeht." Ja, und nein. Wäre nie ein Thema gewesen. 
Nachtrag:

Auf die Frage, ob ihn die Insolvenz seiner Meinung nach verändert habe, antwortet er mit „nein“. Dazugelernt habe er sicherlich, er würde dieselben Fehler nicht wieder machen, hofft er (lacht), aber verändert habe er sich dadurch nicht wirklich. 